\title{
EIELSON AIR FORCE BASE OPERABLE UNIT 2 BASELINE RISK ASSESSMENT
}

\author{
R. E. Lewis \\ T.T. Jarvis \\ M.R. Jarvis \\ G. Whelan
}

October 1994

Prepared for

the U.S. Department of Energy

under Contract DE-AC06-76RLO 1830

Pacific Northwest Laboratory

Richland, Washington 99352

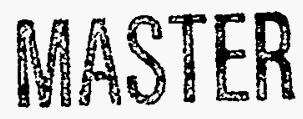




\section{.}




\section{DISCLAIMER}

This report was prepared as an account of work sponsored by an agency of the United States Government. Neither the United States Government nor any agency thereof, nor any of their employees, make any warranty, express or implied, or assumes any legal liability or responsibility for the accuracy, completeness, or usefulness of any information, apparatus, product, or process disclosed, or represents that its use would not infringe privately owned rights. Reference herein to any specific commercial product, process, or service by trade name, trademark, manufacturer, or otherwise does not necessarily constitute or imply its endorsement, recommendation, or favoring by the United States Government or any agency thereof. The views and opinions of authors expressed herein do not necessarily state or reflect those of the United States Government or any agency thereof. 


\section{DISCLAIMER}

Portions of this document may be illegible in electronic image products. Images are produced from the best available original document. 


\section{EXECUTIVE SUMMARY}

Operable Unit 2 at Eielson Air Force Base (AFB) near Fairbanks, Alaska, is one of several operable units characterized by petroleum, oil, and lubricant contamination, and by the presence of organic products floating at the water table, as a result of Air Force operations since the 1940s. The base is approximately 19,270 acres in size, and comprises the areas for military operations and a residential neighborhood for military dependents. Within Operable Unit 2, there are seven source areas (ST10, ST11, ST13, SS14, ST18, ST19, and DP26). These source areas were grouped together primarily because of the contaminants released [diesel fuel, jet fuel (JP-4), and motor gasoline], and hence are not necessarily in geographical proximity. Source area ST10 includes a surface water body (Hardfill Lake) next to a fuel spill area. The primary constituents of concem for human health include benzene, toluene, ethylbenzene, and xylenes (BTEX). Monitored data showed these volatile constituents to be present in groundwater wells. The data also showed an elevated level of trace metals in groundwater.

Sites ST10 and ST14 were grouped together as one site in this assessment. They are contiguous are share the same sources of contamination. Sites ST13 and DP26 were also grouped together for the same reasons.

Field studies were conducted by firms under contract to the Air Force in 1986, 1987, 1988,1991 , and 1992 to determine the nature and extent of contamination at the site. The field work included gathering information about the extent of contamination of soil, groundwater, surface water, sediment, and soil air pores at the site. The resulting data form the basis for the baseline risk assessment presented in this report.

Both a cancer risk and a Hazard Index were calculated for each site or group of sites using a variety of exposure scenarios. Three land use scenarios were used: current industrial, future industrial, and future residential. Each land use scenario had two exposure scenarios, average exposure and reasonable maximum exposure. In addition, risk values were reported both with and without contributions from metals in soil and groundwater that are believed to be site background and are not believed to have resulted from base activities.

The following two tables summarize the total pathway cancer risk and Hazard Index for each site. The first table uses a current industrial land use scenario; the second uses the more conservative future residential land use scenario. The contributions from site background metals have been subtracted from these totals.

\begin{tabular}{||l|c|c||}
\hline \hline \multicolumn{3}{||l|}{ TABLEA_. Total Pathway Risk Values for Operable Unit 2, Current Industrial Land Use } \\
\hline \hline Site & $\begin{array}{c}\text { Reasonable Maximum } \\
\text { Total Cancer Risk }\end{array}$ & $\begin{array}{c}\text { Total Exposure Hazenario } \\
\text { Tord Index }\end{array}$ \\
\hline \hline ST10/SS14 & $1 \mathrm{E}-03$ & $2 \mathrm{E}+00$ \\
\hline ST11 & $<1 \mathrm{E}-07$ & $<1 \mathrm{E}-02$ \\
\hline ST13/DP26 & $1 \mathrm{E}-05$ & $1 \mathrm{E}-02$ \\
\hline ST18 & $1 \mathrm{E}-06$ & $<1 \mathrm{E}-02$ \\
\hline ST19 & $<1 \mathrm{E}-07$ & $<1 \mathrm{E}-02$ \\
\hline
\end{tabular}




\begin{tabular}{||l|c|c||}
\hline \multicolumn{2}{||c|}{$\begin{array}{c}\text { IABLE B } \\
\text { Sotal Pathway Risk Values for Operable Unit 2 , Future Residential Land } \\
\text { Use }\end{array}$} \\
\hline \hline Site & $\begin{array}{c}\text { Reasonable Maximum Exposure Scenario } \\
\text { Total Cancer Risk }\end{array}$ & \begin{tabular}{c} 
Total Exposure Hazard Index \\
\hline ST10/SS14
\end{tabular} \\
\hline ST11 & $2 \mathrm{E}-03$ & $4.00 \mathrm{E}+00$ \\
\hline ST13/DP26 & $2 \mathrm{E}-06$ & $<1 \mathrm{E}-02$ \\
\hline ST18 & $6 \mathrm{E}-04$ & $3 \mathrm{E}+00$ \\
\hline ST19 & $3 \mathrm{E}-05$ & $1 \mathrm{E}-02$ \\
\hline
\end{tabular}




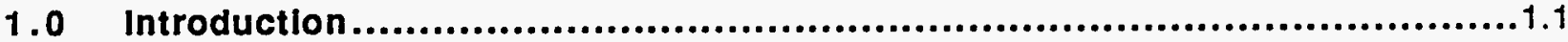

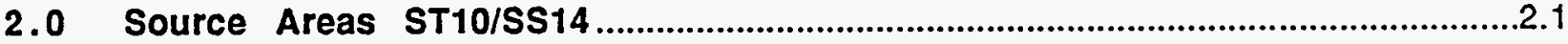

2.1 Conceptual Site Model ...........................................................................................2.1

$2.2 \quad$ Exposure Assessment.........................................................................................2.3

2.2.1 Land-Use Assumptions for ST10/SS14 ………...........................................2.3

2.2.2 Theoretical Exposure Pathways ..................................................................2.3

2.2.3 Current Exposure Pathways, Industrial Land Use: Rationale for Elimination from Further Consideration............................................................................2.3

2.2.4 Identification of Current (Industrial) Exposure Pathways ...................................2.5

2.2.5 Future Exposure Pathways: Residential Land Use ........................................2.5

2.2.6 Future Exposure Pathways, Industrial Land Use: Rationale for Elimination from Further Consideration............................................................................2.6

2.2.7 Future Exposure Pathways: Industrial Land Use..............................................

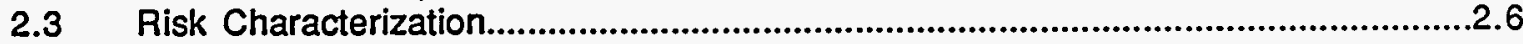

2.4 Site-Specific Uncertainties and Considerations............................................................

2.4.1 Exposure Uncertainties...................................................................................

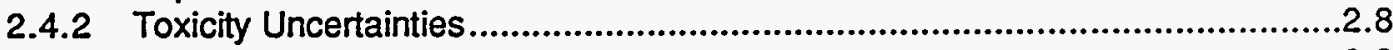

2.4.3 General Site Uncertainties .........................................................................2.8

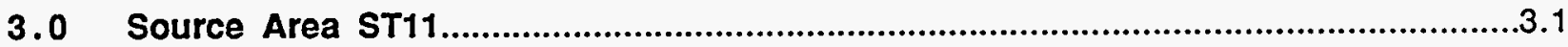

3.1 Conceptual Site Model............................................................................................

3.2 Exposure Assessment...........................................................................................

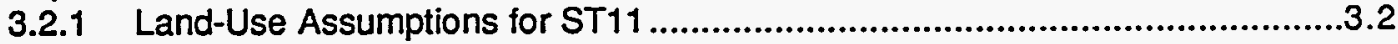

3.2.2 Theoretical Exposure Pathways.....................................................................

3.2.3 Current Exposure Pathways, Industrial Land Use: Rationale for Elimination from Further Consideration...........................................................................3.2

3.2.4 Identification of Current (Industrial) Exposure Pathways........................................

3.2.5 Future Exposure Pathways: Residential Land Use ............................................

3.2.6 Future Exposure Pathways, Industrial Land Use: Rationale for Elimination from Further Consideration...........................................................................3.5

3.2.7 Future Exposure Pathways: Industrial Land Use.............................................

3.3 Risk Characterization.............................................................................................

3.4 Site-Specific Uncertainties and Considerations...........................................................

3.4.1 Exposure Uncertainties..................................................................................

3.4.2 Toxicity Uncertainties......................................................................................

3.4.3 General Site Considerations ...........................................................................

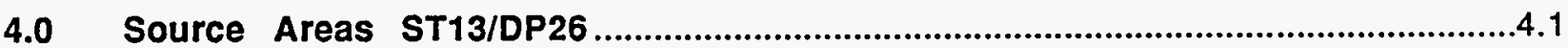

4.1 Conceptual Site Model.............................................................................................4.1

4.2 Exposure Assessment...........................................................................................

4.2.1 Land-Use Assumptions for ST 13/DP26 ........................................................4.2

4.2.2 Theoretical Exposure Pathways...................................................................4.2

4.2.3 Current Exposure Pathways, Industrial Land Use: Rationale for Elimination 
from Further Consideration...........................................................................4.3

4.2.4 Identification of Current (Industrial) Exposure Pathways ...............................4.3

4.2.5 Future Exposure Pathways: Residential Land Use .......................................4.3

4.2.6 Future Exposure Pathways, Industrial Land Use: Rationale for Elimination from Further Consideration........................................................................4.5

4.2.7 Future Exposure Pathways: Industrial Land Use..........................................

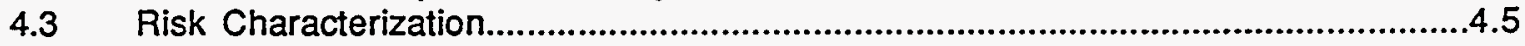

4.4 Site-Specific Uncertainties and Considerations............................................................6

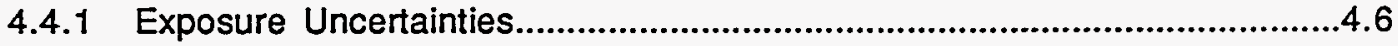

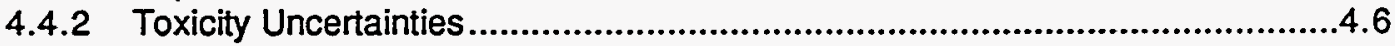

4.4.3 General Site Considerations..................................................................4.7

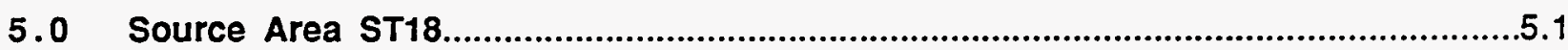

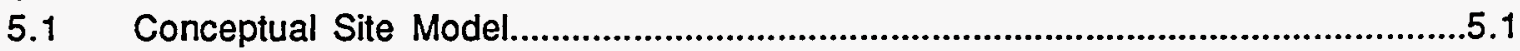

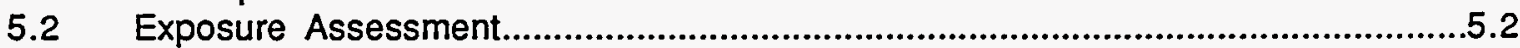

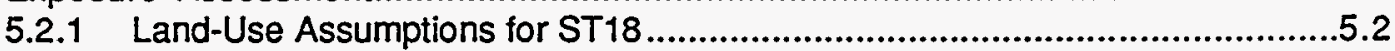

5.2.2 Theoretical Exposure Pathways...........................................................5.2

5.2.3 Current Exposure Pathways, Industrial Land Use: Rationale for Elimination from Further Consideration.......................................................................5.2

5.2.4 Identification of Current (Industrial) Exposure Pathways...................................5.3

5.2.5 Future Exposure Pathways: Residential Land Use .......................................5.3

5.2.6 Future Exposure Pathways, Industrial Land Use: Rationale for Elimination from Further Consideration..........................................................................5.5

5.2.7 Future Exposure Pathways: Industrial Land Use.......................................5.5

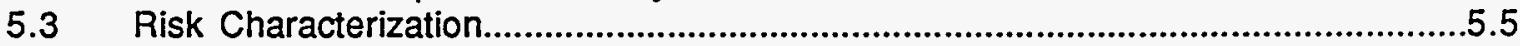

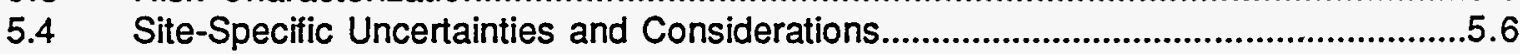

5.4.1 Exposure Uncertainties............................................................................

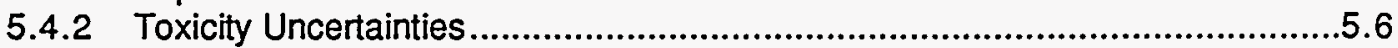

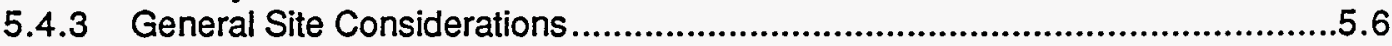

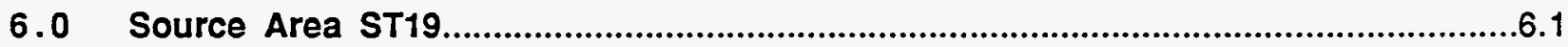

6.1 Conceptual Site Model...............................................................................................6.1

$6.2 \quad$ Exposure Assessment.............................................................................................

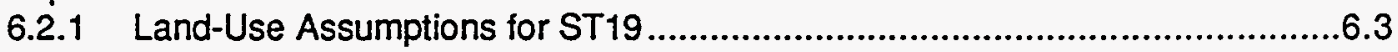

6.2.2 Theoretical Exposure Pathways....................................................................6.3

6.2.3 Current Exposure Pathways, Industrial Land Use: Rationale for Elimination from Further Consideration.....................................................................6.3

6.2.4 Identification of Current (Industrial) Exposure Pathways.....................................6.4

6.2.5 Future Exposure Pathways: Residential Land Use ...................................6.4

6.2.6 Future Exposure Pathways, Industrial Land Use: Rationale for Elimination from Further Consideration........................................................................6.4

6.2.7 Future Exposure Pathways: Industrial Land Use....................................6.4

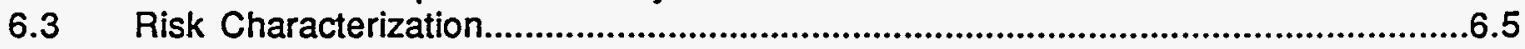

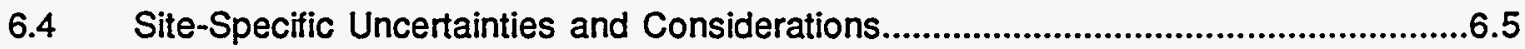

6.4.1 Exposure Uncertainties............................................................................6.6

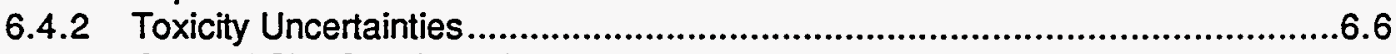

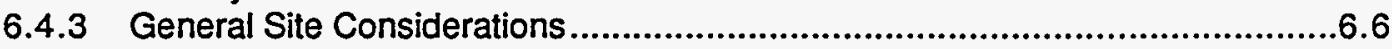

7.0 Identification of Chemicals of Potential Concern............................................... 7.1

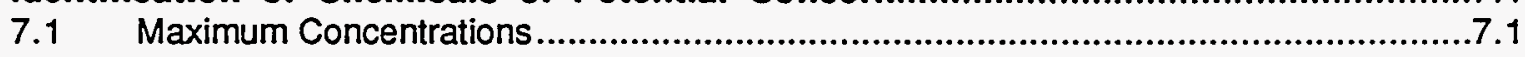




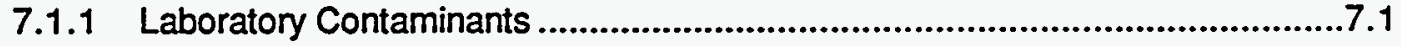

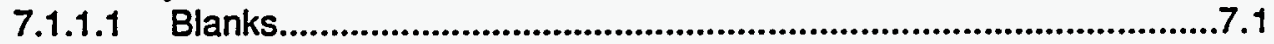

7.1.1.2 Suspected Laboratory Contaminants..............................................7.2

7.2 Comparison of Maximum Concentrations to Risk-Based Screening Concentrations .....7.3

7.2.1 Calculation of Risk-Based Screening Concentrations .....................................7.3

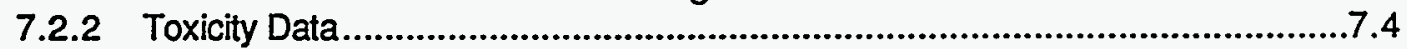

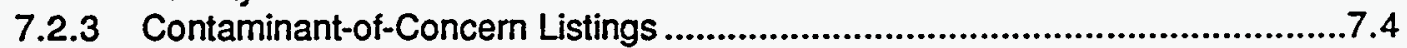

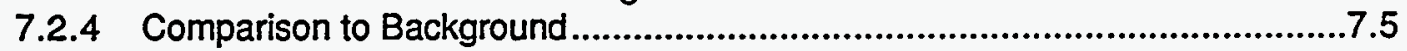

8.0 Exposure Point Concentrations and Modeling Results........................................8.1

8.1 Conversions to Concentrations in Air or Dust...........................................................8.1

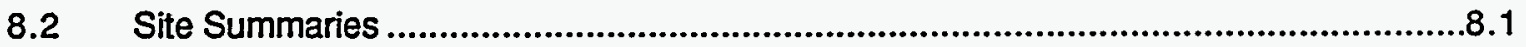

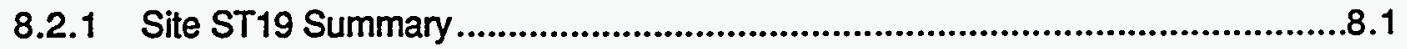

8.2.1.1 Approach......................................................................................8.1

8.2.1.2 Constituent Data at Monitoring Well..................................................8.3

8.2.1.3 Site Data Utilized for the Transport and Fate Assessment ...................8.4

8.2.1.4 Application Results and Discussion..................................................8.5

8.2.1.5 BTEX Concentration Input for Future Land Use ............................8.10

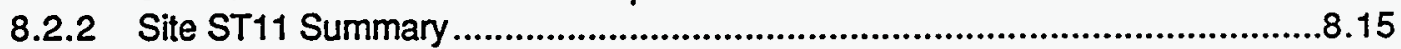

8.2.2.1 Approach...........................................................................8.15

8.2.2.2 Site Data Utilized for the Transport and Fate Assessment ................8.17

8.2.2.3 Application Results and Discussion...............................................8.17

8.2.3 Site ST18 Summary .................................................................................21

8.2.3.1 Approach.................................................................................22

8.2.3.2 Site Data Utilized for the Transport and Fate Assessment .................8.22

8.2.3.3 Application Results and Discussion...............................................8.23

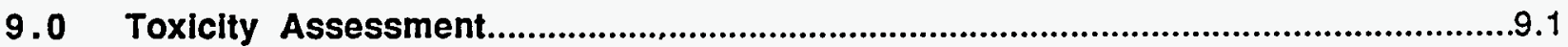

9.1 Toxicity Information for Noncarcinogenic Effects .....................................................

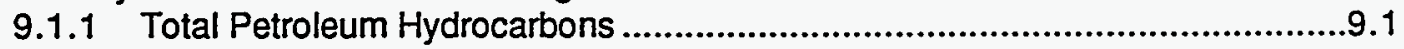

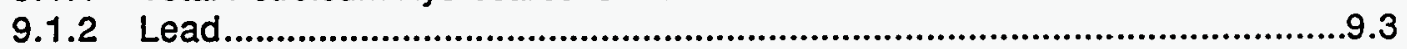

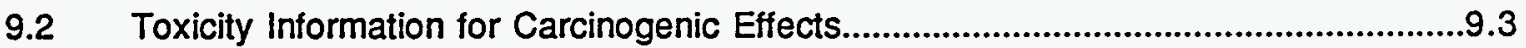

9.2.1 Polycyclic Aromatic Hydrocarbons.......................................................................

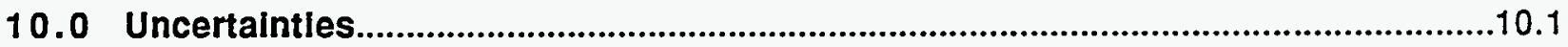

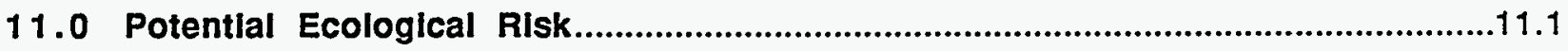

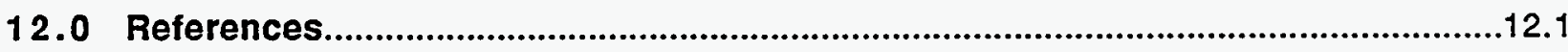

APPENDICES

Appendix A: Risk Calculation Formulas

Appendix B: Exposure Factors

Appendix C: Fate and Transport Models

Appendix D: Chemical Concentrations and Monitoring Data

Appendix E: Determination of Background Metal Concentrations

Appendix F: Contaminant Concentration Inputs

Appendix G: Chemical Parameters

Appendix H: Biotransfer Parameters

Appendix I: Method for Estimating Exposure to Contaminants in Aqueous Phase Due to Dermal Contact 
Appendix J: Skin Permeability and Absorption Parameters

Appendix K: Risk Output Tables

Appendix L: Demographic Information

Appendix M: Model Used for Outdoor Volatilization

\section{TABLES}

2.1 Summary of Human Exposure Pathways for Source Areas ST10/SS14

2.2 Source Areas ST10/SS14; Summary of Cancer Risk and Hazard Index: Average Exposure

Case: Current Exposure Pathways/Industrial Land-Use Assumption........................................2.9

2.3 Source Areas ST10/SS14; Summary of Cancer Risk and Hazard Index: Reasonable

Maximum Exposure Case: Current Exposure Pathways/Industrial Land-Use Assumption.......2.11

2.4 Source Areas ST10/SS14; Summary of Cancer Risk and Hazard Index: Average Exposure

Case: Future Exposure Pathways/Residential Land-Use Assumption...................................2.13

2.5 Source Areas ST10/SS14; Summary of Cancer Risk and Hazard Index: Reasonable

Maximum Exposure Case: Future Exposure Pathways/Residential Land-Use Assumption.....2.15

2.6 Source Areas ST10/SS14; Summary of Cancer Risk and Hazard Index: Average Exposure

Case: Future Exposure Pathways/Industrial Land-Use Assumption .......................................2.17

2.7 Source Areas ST10/SS14; Summary of Cancer Risk and Hazard Index: Reasonable

Maximum Exposure Case: Future Exposure Pathways/Industrial Land-Use Assumption ........2.19

2.8 Exposure Factors Used for Dermal Contact with and Incidental Ingestion of Soils plus

Inhalation of Resuspended Particulates Pathways ..............................................................2.21

2.9 Magnitude of Effect of Uncertainties on Risk Estimates for Sites ST10/SS14 ........................2.22

3.1 Summary of Human Exposure Pathways for Source Area ST11 .........................................3.3

3.2 Source Area ST11; Summary of Cancer Risk and Hazard Index: Average Exposure Case:

Current Exposure Pathways/Industrial Land-Use Assumption................................................3.7

3.3 Source Area ST11; Summary of Cancer Risk and Hazard Index: Reasonable Maximum Exposure Case: Current Exposure Pathways/Industrial Land-Use Assumption .......................3.8

3.4 Source Area ST11; Summary of Cancer Risk and Hazard Index: Average Exposure Case:

Future Exposure Pathways/Residential Land-Use Assumption...............................................3.9

3.5 Source Area ST11; Summary of Cancer Risk and Hazard Index: Reasonable Maximum

Exposure Case: Future Exposure Pathways/Residential Land-Use Assumption ..................3.10

3.6 Source Area ST11; Summary of Cancer Risk and Hazard Index: Average Exposure Case:

Future Exposure Pathways/Industrial Land-Use Assumption................................................3.11

3.7 Source Area ST11; Summary of Cancer Risk and Hazard Index: Reasonable Maximum

Exposure Case: Future Exposure Pathways/Industrial Land-Use Assumption........................3.12

3.8 Magnitude of Effect of Uncertainties on Risk Estimates for Site ST11 ....................................13

4.1 Summary of Human Exposure Pathways for Source Areas ST13/DP26..................................4.4

4.2 Source Areas ST13/DP26; Summary of Cancer Risk and Hazard Index: Average

Exposure Case: Current Exposure Pathways/Industrial Land-Use Assumption .

4.3 Source Areas ST13/DP26; Summary of Cancer Risk and Hazard Index: Reasonable

Maximum Exposure Case: Current Exposure Pathways/Industrial Land-Use Assumption

4.4 Source Areas ST13/DP26; Summary of Cancer Risk and Hazard Index: Average Exposure

Case: Future Exposure Pathways/Residential Land-Use Assumption.

4.5 Source Areas ST13/DP26; Summary of Cancer Risk and Hazard Index: Reasonable

Maximum Exposure Case: Future Exposure Pathways/Residential Land-Use Assumption.....4.11

4.6 Source Areas ST13/DP26; Summary of Cancer Risk and Hazard Index: Average Exposure

Case: Future Exposure Pathways/lndustrial Land-Use Assumption.

4.7 Source Areas ST13/DP26; Summary of Cancer Risk and Hazard Index: Reasonable

Maximum Exposure Case: Future Exposure Pathways/Industrial Land-Use Assumption........4.13

4.8 Magnitude of Effect of Uncertainties on Risk Estimates for Sites ST13/DP26.........................4.14

5.1 Summary of Human Exposure Pathways for Source Area ST18 ..........................................5.4

5.2 Source Area ST18; Summary of Cancer Risk and Hazard Index: Average Exposure Case:

Current Exposure Pathways/Industrial Land-Use Assumption.................................................5.7

5.3 Source Area ST18; Summary of Cancer Risk and Hazard Index: Reasonable Maximum 
Exposure Case: Current Exposure Pathways/Industrial Land-Use Assumption

5.4 Source Area ST18; Summary of Cancer Risk and Hazard Index: Average Exposure Case:

Future Exposure Pathways/Residential Land-Use Assumption.

5.5 Source Area ST18; Summary of Cancer Risk and Hazard Index: Reasonable Maximum Exposure Case: Future Exposure Pathways/Residential Land-Use Assumption

5.6 Source Area ST18; Summary of Cancer Risk and Hazard Index: Average Exposure Case:

Future Exposure Pathways/Industrial Land-Use Assumption.

5.7 Source Area ST18; Summary of Cancer Risk and Hazard Index: Reasonable Maximum Exposure Case: Future Exposure Pathways/Industrial Land-Use Assumption.

6.2 Source Area ST19; Summary of Cancer Risk and Hazard Index: Average Exposure Case:

Current Exposure Pathways/Industrial Land-Use Assumption.

6.3 Source Area ST19; Summary of Cancer Risk and Hazard Index: Reasonable Maximum Exposure Case: Current Exposure Pathways/Industrial Land-Use Assumption

6.5 Source Area ST19; Summary of Cancer Risk and Hazard Index: Reasonable Maximum Exposure Case: Future Exposure Pathways/Residential Land-Use Assumption Source Area ST19; Summary of Cancer Risk and Hazard Index: Average Exposure Case:

6.7 Source Area ST19; Summary of Cancer Risk and Hazard Index: Reasonable Maximum Exposure Case: Future Exposure Pathways/Industrial Land-Use Assumption.................................. Field and Equipment Blank Detections from Operable Unit 21991 Field Sampling Event Groundwater Detections of Bis(2-ethylhexyl)Phthalate from Operable Unit 21991 Field Sampling Event that Exceed Ten Times the Maximum Blank Value Groundwater Detections of Methylene Chloride from Operable Unit 21991 Field Sampling Event that Did Not Have a "U" Qualifier

Risk-Based Contaminant of Concern Cutoff Concentrations.................................................. Contaminants of Concern for Source Areas ST10/SS14

Contaminants of Concern for Source Areas ST13/DP26 .......................................................15

Contaminants of Concern for Source Area ST18.....................................................................18

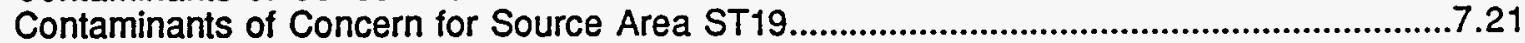

BTEX and Naphthalene Composition in Various Fuels................................................................8.3

BTEX Analyses from Monitoring Well 19-02A.......................................................................8.3

Maximum Soil Concentrations for BTEX Constituents at Site ST19...........................................

Site Data Utilized for the Fate and Transport Assessment at Site ST19 .................................8.4

Constituent Information Employed in Modeling Site ST19 ......................................................8.5

Future Benzene Concentrations Calculated by MEPAS .......................................................8.11

Future Toluene Concentrations Calculated by MEPAS .......................................................12

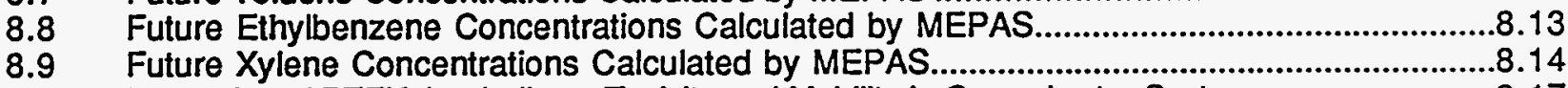

8.10 Properties of BTEX that Indicate Toxicity and Mobility in Groundwater Systems........................8.17

8.11 Site Data Utilized for the Fate and Transport Assessment at Site ST11 ...............................8.18

8.12 Preliminary Assessment Results at BSW A Associated with ST1 .......................................8.19

8.13 Site Data Utilized for the Fate and Transport Assessment at Site ST18 ..............................8.23

8.14 Preliminary Assessment Results for Xylene and Benzene, Based on Xylene Calibration at Well GW-18MW03 for Site ST18.

8.15 Preliminary Assessment Results for Benzene at Site ST18 Well D for an Assumed

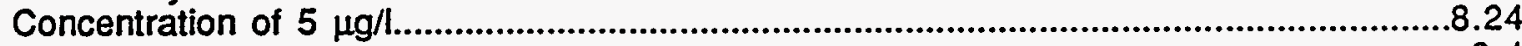

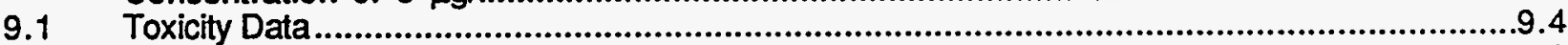

9.2 Relative Cancer Potency Estimates for Polycyclic Aromatic Hydrocarbons ..............................9.10 
11.1 Metal Concentrations in Hardfill Lake Sediments 11.1

11.2 Arsenic Surface Water and Groundwater Concentrations from ST10/SS14.

\section{FIGURES}

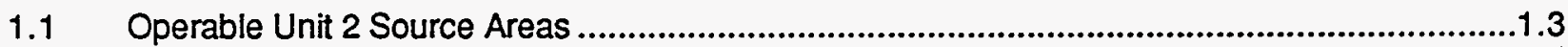

2.1 ST10 and SS14 Subsurface Soil and Sediment TPH Concentrations, September, 1991 .........2.25

2.2 ST10/SS14 Approximate Extent of Floating Fuel...................................................................2.2.

2.3 ST10 and SS14 TPH Concentration in Soils, Cross Section A-A' ......................................2.2.29

2.4 ST10 and SS14 Groundwater and Surface Water Toluene Concentrations..............................2.31

2.5 ST10 and SS14 Groundwater TPH Concentrations............................................................33

2.6 ST10 and SS14 Groundwater Lead Concentrations, September 1991 .............................2.35

2.7 ST10, Benzene Concentration in Groundwater, Cross Section B-B'........................................2.37

2.8 ST10, Benzene Concentration in Groundwater, Cross Section C-C'......................................2.39

3.1 ST11 Subsurface Soil TPH Concentrations, September 1991.................................................16

3.2 ST11, TPH Concentrations in Soils, Cross Section D-D' ....................................................17

4.1 ST13 and DP26 Benzene Concentrations in Groundwater, 1988 .........................................4.17

4.2 ST13 and DP26 Benzene Concentrations in Groundwater, 1991 .....................................4.19

4.3 ST13 and DP26 Groundwater Toluene Concentrations......................................................4.21

$4.4 \quad$ ST13 and DP26 Groundwater Lead Concentrations............................................................4.23

4.5 ST13 and DP26 Subsurface Soil TPH Concentrations, September 1991 ............................4.25

4.6 ST13 TPH Concentration in Soils, Cross Section E-E' ......................................................4.27

5.1 ST18 Subsurface Soil TPH Concentrations ................................................................16

5.2 ST18, TPH Concentrations in Soils, Cross Section H-H' ...................................................17

6.1 ST19 Groundwater Benzene Concentrations ..................................................................6.16

6.2 ST19 Groundwater Toluene Concentrations ........................................................................17

6.3 ST19Subsurface Soil TPH Concentrations, 1991 and 1992 .................................................19

6.4 ST19, TPH Concentrations in Soils, Cross Section I-1' and J-J'............................................6.21

8.1 Temporally Varying Benzene Concentrations at ST19 Monitoring Well GW-19MW02A............8.6

8.2 Temporally Varying Toluene Concentrations at ST19 Monitoring Well GW-19MW02A ..............8.7

8.3 Temporally Varying Ethylbenzene Concentrations at ST19 Monitoring Well GW-19MW02A......8.8

8.4 Temporally Varying Xylene Concentrations at ST19 Monitoring Well GW-19MWO2A.................8.9 


\subsection{INTRODUCTION}

Operable Unit 2 at Eielson Air Force Base (AFB) near Fairbanks, Alaska, is one of severai operable units characterized by petroleum, oil, and lubricant contamination, and by the presence of organic products floating at the water table, as a result of Air Force operations since the 1940s. The base is approximately 19,270 acres in size, and comprises the areas for military operations and a residential neighborhood for military dependents. Within Operable Unit 2, there are seven source areas: ST10, ST11, ST13, SS14, ST18, ST19, and DP26. The source areas are shown in Figure 1.1. These source areas were grouped together primarily because of the contaminants released [diesel fuel, jet fuel (JP4), and motor gasoline], and hence are not necessarily in geographical proximity. Source areas ST10 and SS14 are contiguous and share the same contaminant sources. As such, they were treated as one composite unit in this assessment. Source areas $\mathrm{ST} 13$ and DP26 were also grouped together for the same reasons. DP26 was added to Operable Unit 2 during the summer of 1992, after an initial baseline risk assessment for Operable Unit 2 was completed. This additional site was added because it was the source for most of the groundwater contamination at ST13, and it was believed to be the source of an actively growing benzene groundwater plume. Subsequent work suggests that the benzene plume is dispersing. Source area ST10 includes a surface water body (Hardfill Lake) adjacent to a fuel spill area. Source area ST11 is next to a small stream (Garrison Slough)

The primary constituents of concern for human health include benzene, toluene, ethylbenzene, and xylenes (BTEX). Monitored data showed these volatile constituents to be present in groundwater wells. The data also showed an elevated level of trace metals in groundwater. In addition, naphthalenes and polycyclic aromatic hydrocarbons (PAHs) were also present at most of the sites; naphthalenes in groundwater and soils, PAHs primarily in surface soils and sediments. High levels of total petroleum hydrocarbons (TPH) were detected in the subsurface soils at all of the sites. Lesser amounts were present in the groundwater at several of the sites.

Field studies were conducted by firms under contract to the Air Force in 1986,1987 , 1988, 1991, and 1992 to determine the nature and extent of contamination at the site. The field work included gathering information about the extent of contamination of soil, groundwater, surface water, sediment, and soil air pores at the site. The resulting data form the basis for the baseline risk assessment presented in this report.

A baseline risk assessment is intended to provide an understanding of chemical releases from the site in the absence of cleanup action, pathways of human exposure, and degree to which exposure to the chemical releases will result in adverse health effects to affected populations.

The initial step of the baseline risk assessment involved extensive reviews and validation of the data, consultation with the U.S. Environmental Protection Agency (EPA) and its contractor, and characterization of the site. On the basis of this initial effort, the procedure for the baseline risk assessment was agreed upon by the parties involved.

The nature and extent of contamination at Operable Unit 2 have been characterized, and the results are presented in tabular and graphical forms in Section 5 of the Draft Remedial Investigation Report (U.S. Air Force 1993c), where qualitative assessment of site contamination is presented. Sections 2 through 6 of this report presents conceptual site models based on these data. In addition, these sections present exposure assessments that define completed exposure pathways for three different land-use scenarios (current industrial, future industrial, and future residential), a discussion of the risk characterization, 
plus a discussion of site-specific uncertainties and considerations. Each section has tables that list the exposure pathways used and summary risk calculations for the different land-use and exposure scenarios used.

Section 7 of this assessment identifies the chemicals of potential concern that were examined through the risk assessment process. The chemicals were selected following the procedures recommended by EPA Region X (1991a). In the chemical selection process, toxicological effects of chemicals in the form of lifetime cancer effects or chronic non-cancer effects are a major consideration.

Elevated levels of total petroleum hydrocarbons (TPH) in subsurface soils were encountered at all of the sites. A fate and transport modeling effort was performed to quantify the amount of leachate that could migrate to groundwater and adjacent water supply wells at the three sites that presented the least risk to human health and the environment: ST11, ST18, and ST19. A description of the models and results is in Section 8.

Section 9 presents toxicological data needed to score chemicals detected at the site and to identify chemicals of potential concern based on their toxic effects. A discussion of the toxicity of TPH, lead and polycyclic aromatic hydrocarbons (PAHs) is also included. These contaminants of concern do not have EPA-approved toxicity data.

Section 10 discusses general uncertainties in the risk assessment, both exposure and toxicological, that should be considered when interpreting the data.

Ecological risk at Eielson AFB is being addressed with a phased approach. Section 11 of this report evaluates if sources within Operable Unit 2 are acting as a continuing source of contamination with potential impact to ecological receptors. A Sitewide ecological risk assessment, that is currently under development, will assess these impacts from multiple source areas to determine the need for additional remediation of secondary pathways.

Many calculations were performed in order to determine the risks reported in this assessment. The appendixes list all of the equations, data, and models used for the risk calculations in this assessment. 


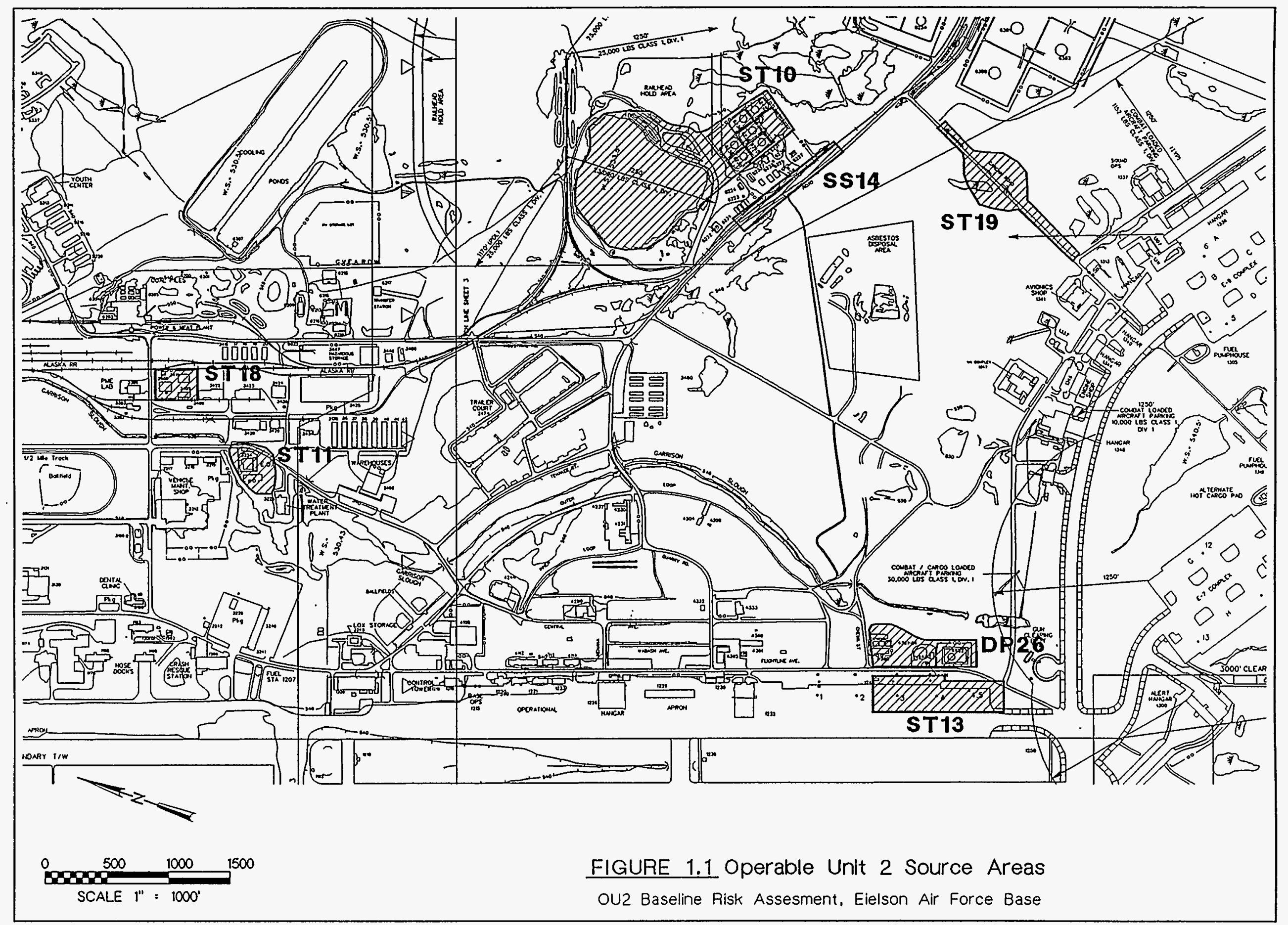

I:AEIELSON^MST.UNIT2SC.DGN 


\subsection{SOURCE AREAS ST10/SS14}

\subsection{CONCEPTUAL SITE MODEL}

This section examines site-specific information on waste sources, release mechanisms, receiving media, and routes of contaminant migration at the site to develop a conceptual understanding of the site. This conceptual site model is needed to evaluate potential risks to human health and the environment.

The contamination at this site is of four types: 1) petroleum hydrocarbons in the subsoil and groundwater, 2) lead in the surface soils and groundwater, 3) surface soil contamination by polynuclear aromatic hydrocarbons (PAHs), and 4) surface soil contamination by chlorinated hydrocarbon insecticides [DDT, DDD, and DDE] adjacent to Hardfill Lake. The hydrocarbon contamination is believed to have originated from leaks in the underground storage tanks of the area and/or spillage from fuel-bladder filling operations (U.S. Air Force 1993a, Section 5.4). The surface soil contamination is of two types (DDT and PAHs). The DDT, DDD, and DDE contamination is concentrated along Hardfill Lake and may be the residues of past pesticide applications of DDT. The PAHs most likely originated either from diesel exhaust deposition on the soil surface or from spills and leaks of fuels.

The petroleum hydrocarbons at source areas ST10/SS14 are believed to have originated from two separate fuel-spill sources (Figure 2.1): 1) leaks from fuel storage tanks (ST10) and 2) fuel spillage during railroad and truck loading dock operations and/or fuel leaks from subsurface pipes (SS14). Initially, ST10 and SS14 (although close in location) appeared to be distinct source areas. However, groundwater investigations have revealed that their groundwater plumes have commingled. Similarly, subsurface soil investigations show the presence of a contiguous layer of high-molecular-weight hydrocarbon contaminants in the subsurface soils under both ST10 and SS14. Thus the two source areas are now considered as one site for evaluation purposes.

Existing information indicates that both JP-4 fuel (jet propulsion fuel number four) and leaded fuels were spilled into the soil at both source area ST10 and source area SS14. [JP-4 fuel contains a lower percentage of benzene (approximately 2 to 3 weight percent) than contemporary automotive gasoline (approximately 4 to 5 weight percent benzene [Table 8.1]); JP-4 fuel does not contain lead as an additive.] The presence of lead in the groundwater suggests that earlier spills of MOGAS and AVGAS occurred. MOGAS is contemporary leaded military automotive gasoline, generally containing 2 weight percent benzene. MOGAS used prior to 1974 was leaded. AVGAS is leaded fuel used for piston aircraft, containing approximately 3 to 4 weight percent benzene.

The working hypothesis is that repeated spills or continuous spills of fuel infiltrated into the soil and migrated downward to the water table [located at a minimum depth of $\sim 2.1$ meters ( 7 feet) below the ground surface level], where the fuel initially spread laterally on top of the groundwater. The residual evidence of this process is the "floating product," "floating fuel," or "free product" which is found in Monitoring Wells 10-1 and 10-8 and the product probes (Figure 2.2).

The water-soluble chemical components of the floating product (which tend to be the lower-molecular-weight petroleum constituents such as benzene, toluene, ethylbenzene, and xylene) preferentially volatilized or dissolved into the groundwater and migrated with the groundwater. The less water-soluble components, composed of higher-molecular-weight hydrocarbons, preferentially remained in the subsurface soils above the groundwater level. The higher-molecular-weight hydrocarbon accumulation in 
the subsurface soil likely varied in depth in accordance with fluctuations in the groundwater elevation. Their presence in soil samples is inferred by measuring TPH. TPH analyses measure all organic contaminants as a single value and does not discriminate between the constituent hydrocarbons. The resulting layer of TPH-rich hydrocarbons underlies much of the tank farm area at ST10 and extend downgradient toward Hardfill Lake (Figures 2.1 and 2.3).

The water-soluble contaminants that dissolve into the groundwater are carried with the groundwater downgradient toward Hardfill Lake (Figure 2.4). Each contaminant moves at a unique chemical-specific rate in the groundwater; benzene moves faster than toluene, toluene moves faster than the other soluble organic constituents, and soluble lead moves at the slowest rate (Figures 2.4, 2.5, and 2.6). Because of the relatively high rate of horizontal groundwater flow [approximately 0.6 meter/day ( 2 feet/day)], and the slow vertical mixing of the groundwater, the soluble contaminants move directly toward Hardfill Lake and discharge into the lake. Once in the lake, the contaminants with high vapor pressures (benzene, toluene, xylene, and ethylbenzene) are assumed to have been released to the atmosphere, and secondarily were attached to lake sediments and/or remained dissolved in the surface water column. It is likely that the contaminants with low vapor pressures predominantly settled out of solution and combined with the sediments of the lake (Figure 2.1).

The other influence of the site's rapid horizontal groundwater movement is that groundwater contaminants are confined near the top of the upper groundwater level. Therefore, near the top of the aquifer (within the contamination plume), the concentration of benzene in groundwater is at its highest. As water is sampled from successively deeper levels in the aquifer, the concentration of benzene drops sharply (Figures 2.7 and 2.8). The phenomena account for the lack of detectable groundwater contamination in the water supply well at source area ST10 (BSW-14). BSW-14 is screened from 86 to 96 feet bgs. Water from this well was sampled in 1991 as part of the Operable Unit 2 field season; no organic contaminants were detected. Water from this well is analyzed for benzene and other organics quarterly as part of the U.S. Air Force Bioenvironmental public health sampling of all drinking water wells; no organic contaminants have been detected. Two monitoring wells at ST10 are completed at intermediate depths: 10-06 is screened from 30.4 to 50.4 feet bgs and $10 \mathrm{MWO} 0 \mathrm{l}$ is screened from 33.7 to 53.7 feet bgs. Benzene was detected in well $10 \mathrm{MWO} 8 \mathrm{l}$ at a concentration of $2 \mathrm{~J} \mu \mathrm{g} / \mathrm{L}$. No organic contamination was detected in Well 10-06.

In summary, the groundwater plumes of soluble contaminants, as well as the subsurface layer of high-molecular-weight hydrocarbon contaminants originating from the ST10 tank farm leaks, have become mixed with their counterparts from SS14. The source of the contamination for SS14 was fuel spillage from railroad and truck loading dock operations, and/or subsurface pipe leaks. The fate of the contaminants described above for ST10 was similar for SS14. The discharge point for the commingled contaminant plumes is Hardfill Lake.

The surface soils of the site contain lead in concentrations above typical naturalbackground levels. Its presence is likely attributable to surface spills of leaded fuels from the above ground tanks; it may also be due to the disposal of tank siudge and the sandblasting and repainting of storage tanks. 


\subsection{EXPOSURE ASSESSMENT}

The "Exposure Assessment" section examines land use, exposure time frame, exposure setting, and exposure pathways. Table 2.1 summarizes the results of the exposure assessment. A list of chemicals of potential concem, fate and transport modeling results, exposure point concentrations, intake variables and/or exposure factors, toxicological values, and risk calculations are presented elsewhere in this report.

Exposure is defined as the contact of an organism with a chemical or physical agent. The overall objective of the exposure assessment is to estimate the types and magnitude of exposures to chemicals of potential concern that are present at, or migrating from, the site. The results of the exposure assessment are combined with chemical-specific toxicity and dose-response information and to characterize potential risks (EPA 1989a).

\subsubsection{Land-Use Assumptions for ST10/SS14}

Health risk will be quantified for three land-use assumptions. The risk from current land use is industrial in nature. Two different land-use assumptions are considered for evaluation of the future risk: 1) residential housing and 2) military/industrial land use. All of the assumptions assume that no mitigation or corrective action is undertaken. The difference between current and future industrial land-use assumptions is that the contaminants are expected to migrate and change in concentration over time.

Long-range land-use plans (Eielson Air Force Base 1992) indicate that sites ST10/SS14 will remain industrial sites for the foreseeable future. Several of the storage tanks at ST10 are recently undergone conversion from diesel to JP-8 storage. The associated underground piping has not been upgraded.

\subsubsection{Theoretical Exposure Pathways}

The plausible (current and future) theoretical human exposure pathways from ST10/SS14 contaminants are

- ingestion of groundwater used as potable water supply

- inhalation of and dermal contact with contaminants during groundwater use

- incidental ingestion of surface water (Hardfill Lake)

- dermal contact with surface water (Hardfill Lake)

- ingestion of fish from Hardfill Lake

- incidental ingestion of surface soils

- dermal contact with surface soils

- incidental ingestion of sediments

- dermal contact with sediments

- ingestion of plants grown in contaminated soils (future only)

- incidental ingestion of the subsurface soils

- dermal contact with subsurface soils

- inhalation of volatile contaminants released from the soil into the ambient air

- inhalation of resuspended particulates.

\subsubsection{Current Exposure Pathways, Industrial Land Use: Rationale for Elimination from Further Consideration}

This subsection explains why one theoretical exposure pathway, postulated to occur given existing land-use conditions, is not examined in the quantitative risk 
TABLE 2.1. SUMMARY OF HUMAN EXPOSURE PATHWAYS FOR SOURCE AREAS ST10/SS14

\section{IHEORETICAL PATHWAYS}

CURRENT LAND USE (INDUSTRIAL)

RESIDENTIAL

-EUTURE L.AND USE--

INDUSTRIAL

- ingestion of groundwater used as potable water supply....................

$\mathrm{X}$

$x$

- inhalation of and dermal contact with contaminants during groundwater use....

- incidental ingestion of surface water...

- dermal contact with surface water...

- ingestion of fish from Hardfill Lake....

- incidental ingestion of surface soils...

- dermal contact with surface soils...

$\times$

$x$

- ingestion of plants grown in contaminated soils..

- incidental ingestion of subsurface soils.

- dermal contact with subsurface soils...

- inhalation of volatile contaminants released from the soil into the ambient air.

- inhalation of resuspended particulates 
calculations to follow. The eliminated pathway is identified, and the rationale for elimination is noted.

Eliminated Pathway: ingestion of plants grown in contaminated soils.

Rationale: The area's current land use is a military/industrial complex. No crops are grown on the site soils. Therefore, the theoretical exposure pathway involving plant ingestion is incomplete and will not be evaluated quantitatively.

\subsubsection{Identification of Current (Industrial) Exposure Pathways}

The current land use of ST10/SS14 is for industrial fuel storage and railroad/ truck docking operations. For the current time frame risk calculations, the following pathways are complete and reasonable for further analysis:

- ingestion of groundwater from base supply well (BSW-14) used for production of potable water

- inhalation of and dermal contact with contaminants during water use at work (e.g., showering; an on-site shower facility is available to workers)

- incidental ingestion of surface water (Hardfill Lake)

- dermal contact with surface water (Hardfill Lake)

- ingestion of fish from Hardfill Lake

- incidental ingestion of surface soils

- dermal contact with surface soils

- incidental ingestion of sediments

- dermal contact with sediments

- incidental ingestion of subsurface soils

- dermal contact with subsurface soils

- inhalation of volatile contaminants released from the soil into the ambient air

- inhalation of resuspended particulates.

A detailed explanation of these exposure pathways, and exposure factors/parameters may be found in Appendix B, Exposure Factors.

BSW-14 supplies groundwater to Building 6224 only (see Figure 2.1 for location of the building). This water is currently only used for an emergency shower and bathroom. Nevertheless, the ingestion pathway is retained to be conservative.

\subsubsection{Euture Exposure Pathways: Residentlal Land Use}

Assuming a residential housing land use as a future exposure assumption, the following pathways are considered to be complete and reasonable for analysis:

- ingestion of groundwater used as potable water supply

- inhalation of and dermal contact with contaminants during groundwater use

- incidental ingestion of surface water (Hardfill Lake)

- dermal contact with surface water (Hardfill Lake)

- ingestion of fish from Hardfill Lake

- incidental ingestion of surface soils

- dermal contact with surface soils

- incidental ingestion of sediments

- dermal contact with sediments

- ingestion of plants grown in contaminated soils,

- incidental ingestion of subsurface soils 
- dermal contact with subsurface soils

- inhalation of volatile contaminants released from the soil into the ambient air

- inhalation of resuspended particulates.

Future residences are assumed to utilize groundwater for potable supply and to have garden plots associated with the homes. All exposure pathways postulated (and listed above) will be examined in subsequent risk calculations.

\subsubsection{Future Exposure Pathways, Industrial Land Use: Rationale for Elimination from Further Consideration}

This section explains why one theoretical exposure pathway is not examined in the quantitative risk calculations to follow. The eliminated pathway is identified and the rationale for elimination is noted.

Eliminated Pathway: ingestion of plants grown in contaminated soils.

Rationale: The area's future land use is assumed to be industrial. The assumption, therefore, is that no crops will be grown on contaminated soils, and thus the exposure pathway involving plant ingestion is incomplete and will not be evaluated further.

\subsubsection{Future Pathways of Exposure: Industrlal Land Use}

Assuming an industrial land use as a future exposure assumption, the following pathways are considered to be complete and reasonable for analysis:

- ingestion of groundwater used as potable water supply

- inhalation of and dermal contact with contaminants during groundwater use

- incidental ingestion of surface water (Hardfill Lake)

- dermal contact with surface water (Hardfill Lake)

- ingestion of fish from Hardfill Lake

- incidental ingestion of surface soils

- dermal contact with surface soils

- incidental ingestion of sediments

- dermal contact with sediments

- incidental ingestion of subsurface soils

- dermal contact with subsurface soils

- inhalation of volatile contaminants released from the soil to the ambient air

- inhalation of resuspended particulates.

Future industrial activities are assumed to be similar to current activities.

\subsection{RISK CHARACTERIZATION}

This section presents, in table format, the excess cancer risk and the Hazard Index for source area ST10/SS14 by exposure pathway. The cancer risk and Hazard Index are presented for both the "Average Exposure Case" and the "Reasonable Maximum Exposure Case." Tables 2.2 and 2.3 present risk values for the current land use (industrial), Tables 2.4 and 2.5 present the future residential land-use values, and Tables 2.6 and 2.7 present the future industrial land-use values.

Each table presents the cancer risk and the Hazard Index for each exposure pathway individually. A total cancer risk value and a total Hazard Index are presented that add all of 
the exposure pathway risks together. Values are presented for cancer risk and Hazard Index in two ways. The first column includes the contribution of metals in the groundwater that are suspected to be attributable to site background and therefore likely not related to past site activities. The second column excludes the contribution from potential background metals. The potential background metals are antimony, arsenic, barium, beryllium, cadmium, manganese, and thallium.

The calculation of the cancer risk and Hazard Index requires the use of information and data input from many sources, which are presented elsewhere in this report. For ease of reference, the information used to perform the risk calculations is cross referenced below.

Identification of Chemicals of Potential Concern

Exposure Point Concentrations and Modeling Results

Toxicity Assessment

Risk Calculation Formulas

Exposure Factors

Fate and Transport Models

Contaminant Concentration Inputs
Section 7.0

Section 8.0

Section 9.0

Appendix A

Appendix B

Appendix $\mathrm{C}$

Appendix $F$

More detailed risk output tables are in Appendix K (Table K.1 through K.12). These tables include all the data in Tables 2.2 through 2.7 plus the cancer risks and Hazard Quotients for the individual compounds that drive the risk (cancer risk $>10^{-7}$ and Hazard Quotient > 10-2).

\subsection{SITE-SPECIFIC UNCERTAINTIES AND CONSIDERATIONS}

This section presents key information bearing on the level of confidence in the quantitative risk estimates for a site. The risk estimates are conditional given a considerable number of assumptions about site characterization, exposure, and toxicity. Two major categories of uncertainty are discussed in the following subsections. Table 2.10 lists the major sources of uncertainty that affect this assessment and their possible magnitude of effect on the risk estimates.

\subsubsection{Exposure Uncertainties}

Some of the exposure frequencies used in this assessment differ from default values provided by EPA Region X (EPA 1991a) for the following exposure pathways: dermal contact with surface and subsurface soils, incidental ingestion of surface and subsurface soils, and inhalation of resuspended particulates. These differences are delineated in Table 2.8. Different exposure factors were used because of the subarctic climate at Eielson AFB, which is atypical of most EPA Region X sites. 146 days per year is the mean number of days at Fairbanks without snow cover (Battelle 1992b). Table 2.9 lists the magnitude of effect for this assumption.

The ingestion of animals raised on contaminated feed was not included in the primary risk calculations due to the sub-arctic climate at Eielson. Table 2.9 presents the magnitude of effect caused by exclusion of this exposure pathway. The risk was calculated using exposure factors presented in EPA (1991e) for consumption of animal products. Subsistence fishing was also not included in the primary risk calculations due to the apparent lack of fish at Hardfill Lake. Table 2.9 presents the magnitude of effect caused by exclusion of this exposure pathway. The risk was calculated using exposure factors presented in EPA (1991e) for subsistence fishing. 


\subsubsection{Toxiclty Uncertainties}

There are no approved EPA toxicity values for two of the principal contaminants at Operable Unit 2 sites: total petroleum hydrocarbons (TPH) and lead. These compounds were not included in the primary risk calculations. However, surrogate toxicity values were introduced in Section 9 of this assessment. The magnitude of effect on the risk calculations due to the inclusion of these compounds is presented in Table 2.9.

There were several detections of bis (2-ethylhexyl) phthalate in groundwater and soils at sites ST10/SS14 that were not included in the risk assessment. These detections were believed to be laboratory contamination. Section 7.0 describes the evidence. The magnitude of effect on the risk calculations due to the inclusion of these compounds is presented in Table 2.9.

\subsubsection{General Site Uncertainties}

Section 10 of this assessment discusses the effects of uncertainties that affect all of the Operable Unit 2 sites. Table 2.9 estimates their magnitude of effect. 
TABLE 2.2. SOURCE AREAS ST10/SS14; SUMMARY OF CANCER RISK AND HAZARD INDEX Average Exposure Case: Current Exposure Pathways / Industrial Land-Use Assumption

EXPOSUREPATHWAYS

- ingestion of groundwater (BSW-14)

cancer risk.

Suspected Background Metals

Hazard Index

Included Not Included

inhalation of and dermal contact with contaminants during groundwater use at work

cancer risk.

$.1 E-04$

2E-05

.2E+01

1E-01

Hazard Index

.3E-04

3E-04

$2 \mathrm{E}+00$

$2 \mathrm{E}+00$

- incidental ingestion of surface water

cancer risk.

$<1 E-07$

<1E-07

Hazard Index

- dermal contact with surface water

cancer risk

$<1 E-07$

$<1 E-07$

Hazard Index

$<1 E-02$

$<1 E-02$

- ingestion of fish in Hardfill Lake

cancer risk.

1E-05

$3 E+01$

<1E-07

Hazard Index

cancer risk..

cancer risk..

4E-02 02

- incidental ingestion of sediments

cancer risk.

Hazard Index

- dermal contact with sediments

cancer risk.

Hazard Index 
TABLE 2.2. SOURCE AREAS ST10/SS14; SUMMARY OF CANCER RISK AND HAZARD INDEX Average Exposure Case: Current Exposure Pathways / Industrial Land-Use Assumption (Continued)

\section{EXPOSUREPATHWAYS}

- incidental ingestion of subsurface soils

cancer risk

Hazard Index

Suspected Background Metals

Included Not lncluded

dermal contact with subsurface soils

cancer risk

Hazard Index

$<1 \mathrm{E}-02$

- inhalation of volatile contaminants released from the soil to the ambient air

cancer risk.

4E- 07

Hazard Index.

$<1 \mathrm{E}-02$

$4 \mathrm{E}-07$

- inhalation of resuspended particulates

cancer risk

1E-06

Hazard Index.

3E-01

$<1 E-07$

SUMMATION ACROSS ALL EXPOSURE PATHWAYS FOR SOURCE AREA

Total cancer risk

4E-04

Total Hazard Index

$.5 \mathrm{E}+01$

3E-04

$2 \mathrm{E}+00$ 


\section{TABLE 2.3. SOURCE AREAS ST10/SS14; SUMMARY OF CANCER RISK AND HAZARD INDEX}

Reasonable Maximum Exposure Case: Current Exposure Pathways / Industrial Land-Use Assumption

\section{EXPOSUREPATHWAYS}

- ingestion of groundwater (BSW-14)

cancer risk

Suspected Background Metals

Hazard Index

lation of and dermal contact with contaminants during groundwater use at work

cancer risk.

Hazard Index...

1E-01

- incidental ingestion of surface water

cancer risk.

al contact with surface water

cancer risk

Hazard Index

- ingestion of fish in Hardfill Lake

cancer risk

Hazard Index

- incidental ingestion of surface soils

cancer risk.

Hazard Index

- dermal contact with surface soils

cancer risk. $6 \mathrm{E}-07$

Hazard Index.

- incidental ingestion of sediments

cancer risk.

Hazard Index.

- dermal contact with sediments

cancer risk. 
TABLE 2.3. SOURCE AREAS ST10/SS14; SUMMARY OF CANCER RISK AND HAZARD INDEX Reasonable Maximum Exposure Case: Current Exposure Pathways / Industrial Land-Use Assumption (Continued)

\section{EXPOSUREPATHWAYS}

- incidental ingestion of subsurface soils

cancer risk

Hazard Index

Suspected Background Metals

Included Not Included

dermal contact with subsurface soils

cancer risk

$<1 E-02$

Hazard Index

.1E-06

$<1 \mathrm{E}-07$

$.5 \mathrm{E}-02$

$<1 E-02$

- inhalation of volatile contaminants released from the soil to the ambient air

cancer risk.

1E-06

Hazard Index

$<1 E-02$

1E-06

- inhalation of resuspended particulates

cancer risk

6E-06

Hazard Index

3E-01

$<1 E-07$

SUMMATION ACROSS ALL EXPOSURE PATHWAYS FOR SOURCE AREA

Total cancer risk

.1E-03

Total Hazard Index

$.5 \mathrm{E}+01$

1E-03

$2 \mathrm{E}+00$ 
TABLE 2.4. SOURCE AREAS ST10/SS14; SUMMARY OF CANCER RISK AND HAZARD INDEX Average Exposure Case: Future Exposure Pathways / Residential Housing Land-Use Assumption

\section{EXPOSUREPATHWAYS}

- ingestion of groundwater used as potable water supply

cancer risk.

Hazard Index

Suspected Background Metals Included Not Included

halation of and dermal contact with contaminants during groundwater use

cancer risk.

2E-04

3E-05

$3 \mathrm{E}+01$

2E-01

Hazard Index

4E-04

4E-04

.2E+00

2E-00

- incidental ingestion of surface water

cancer risk

$<1 E-07$

$<1 E-07$

Hazard Index $<1 E-02$

$<1 E-02$

- dermal contact with surface water

cancer risk

Hazard Index

- ingestion of fish in Hardfill Lake

cancer risk

$1 E-05$

Hazard Index

- incidental ingestion of surface soils

cancer risk.

Hazard Indox

- dermal contact with surface soils

cancer risk

Hazard Index

- ingestion of plants grown in contaminated soils

cancer risk.

Hazard Index

- incidental ingestion of sediments 
TABLE 2.4. SOURCE AREAS ST10/SS14; SUMMARY OF CANCER RISK AND HAZARD INDEX

Average Exposure Case: Future Exposure Pathways / Residential Housing Land-Use Assumption

(Continued)

\section{EXPOSUREPATHWAYS}

- dermal contact with sediments

cancer risk......

Hazard Index.

Suspected Background Metals Included Not Included

- incidental ingestion of subsurface soils

cancer risk

Hazard Index

$<1 \mathrm{E}-07$

$<1 \mathrm{E}-02$

$<1 \mathrm{E}-07$

$4 \mathrm{E}-02$

dermal contact with subsurface soils

cancer risk

Hazard Index

1E-06

$<1 \mathrm{E}-07$

1E-01

$<1 \mathrm{E}-02$

inhalation of volatile contaminants released from the soil to the ambient air

cancer risk.

Hazard Index

inhalation of resuspended particulates

cancer risk..

Hazard Index

$.4 \mathrm{E}-07$

$<1 E-02$

4E-07

$<1 E-02$

SUMMATION ACROSS ALL EXPOSURE PATHWAYS FOR SOURCE AREA

Total cancer risk.....

$.1 \mathrm{E}-06$

$<1 \mathrm{E}-07$

4E-01

$<1 \mathrm{E}-02$

Total Hazard Index... 
TABLE 2.5. SOURCE AREAS ST10/SS14; SUMMARY OF CANCER RISK AND HAZARD INDEX

Reasonable Maximum Exposure Case: Future Exposure Pathways / Residential Housing Land-Use Assumption

\section{EXPOSUREPATHWAYS}

Suspected Background Metals

- ingestion of groundwater used as potable water supply

cancer risk.

Included Not Included

Hazard Index

$.9 E-04$

2E-04

- inhalation of and dermal contact with contaminants during groundwater use

cancer risk.

$.5 \mathrm{E}+01$

4E-01

Hazard Index

idental ingestion of surface water

cancer risk

$3 E+00$

Hazard Index

mal contact with surface water

cancer risk.

Hazard Index

- ingestion of fish in Hardfill Lake

cancer risk

Hazard Index

- incidental ingestion of surface soils

- dermal contact with surface soils

- incidental ingestion of sediments

- dermal contact with sediments 
TABLE 2.5. SOURCE AREAS ST10/SS14; SUMMARY OF CANCER RISK AND HAZARD INDEX

Reasonable Maximum Exposure Case: Future Exposure Pathways / Residential Housing Land-Use Assumption (Continued)

\section{EXPOSUREPATHWAYS}

- ingestion of plants grown in contaminated soils

cancer risk

Hazard Index

Suspected Background Metals

Included

Not Included

incidental ingestion of subsurface soils

cancer risk

$.2 \mathrm{E}-05$

8E-06

Hazard Index

9E-06

3E-07

mal contact with subsurface soils

cancer risk

3E-07

Hazard Index

1E-02

$<1 E-07$

alation of volatile contaminants released from the soil to the ambient air

cancer risk

.1E-06

Hazard Index

$<1 E-02$

1E-06

alation of resuspended particulates

cancer risk.

3E-06

Hazard Index

3E-01

$<1 E-07$

SUMMATION ACROSS ALL EXPOSURE PATHWAYS FOR SOURCE AREA

Total cancer risk.

3E-03

Total Hazard Index

TE+02

2E-03

$4 E+00$ 


\section{EXPOSUREPATHWAYS}

- ingestion of groundwater used as potable water supply

cancer risk.

Hazard Index.
Suspected Background Metals Included Not Included

1E-04

2E-05

.2E+01

1E-01

3E-04

$2 E+00 \quad 2 E+00$

cancer risk.

$2 \mathrm{E}+00$

$2 E+00$

- incidental ingestion of surface water

cancer risk.

$<1 \mathrm{E}-07$

$<1 E-07$

Hazard Index.

3E-02

$<1 E-02$

- ingestion of fish in Hardfill Lake

cancer risk.

1E-05

$<1 \mathrm{E}-07$

Hazard Index

$3 \mathrm{E}+01$

$<1 \mathrm{E}-02$

- incidental ingestion of surface soils

cancer risk

8E-07

$.9 E-02$

2E-07

Hazard Index

cancer risk.

Hazard Index. 
TABLE 2.6. SOURCE AREAS ST10/SS14; SUMMARY OF CANCER RISK AND HAZARD INDEX

Average Exposure Case: Future Exposure Pathways / Industrial Land-Use Assumption

(Continued)

\section{EXPOSUREPATHWAYS}

- dermal contact with subsurface soils

cancer risk.

Hazard Index

Continued)

Suspected Background Metals

Included Not Included

- inhalation of volatile contaminants released from the soil to the ambient air

cancer risk.

Hazard Index.

$<1 E-07$

$<1 \mathrm{E}-02$

$<1 E-07$

$<1 E-02$

4E-07

4E-07

$<1 E-02$

$<1 E-02$

- inhalation of resuspended particulates

cancer risk.

..1E-06

Hazard Index

3E-01

$<1 \mathrm{E}-07$

$<1 \mathrm{E}-02$

\section{SUMMATION ACROSS ALL EXPOSURE PATHWAYS FOR SOURCE AREA}

Total cancer risk

4E-04

Total Hazard Index

$.5 E+01$

3E-04

$2 E+00$ 
TABLE 2.7. SOURCE AREAS ST10/SS14; SUMMARY OF CANCER RISK AND HAZARD INDEX Reasonable Maximum Exposure Case: Future Exposure Pathways / Industrial Land-Use Assumption

\section{EXPOSUREPATHWAYS}

- ingestion of groundwater used as potable water supply

cancer risk..

Suspected Background Metals

Hazard Index. Not Included

- inhalation of and dermal contact with contaminants during groundwater use

cancer risk..

Hazard Index.

.3E-04

$2 E+01$

6E-05

1E-01

- incidental ingestion of surface water

cancer risk..

Hazard Index.

- ingestion of fish in Hardfill Lake

cancer risk.

Hazard Index

- incidental ingestion of surface soils

Hazard Index.

- dermal contact with surface soils

cancer risk. .6E-07

Hazard Index.

- incidental ingestion of sediments

cancer risk..

Hazard Index.

- dermal contact with sediments

- incidental ingestion of subsurface soils 
TABLE 2.7 SOURCE AREAS ST10/SS14; SUMMARY OF CANCER RISK AND HAZARD INDEX Reasonable Maximum Exposure Case: Future Exposure Pathways / Industrial Land-Use Assumption (Continued)

\section{EXPOSUREPATHWAYS}

- dermal contact with subsurface soils

cancer risk.

Suspected Background Metals

Hazard Index

1E-02

halation of volatile contaminants released from the soil to the ambient air

cancer risk.

Hazard Index.

$<1 \mathrm{E}-02$

$1 \mathrm{E}-06$

alation of resuspended particulates

cancer risk

3E-01

$<1 \mathrm{E}-07$

Hazard Index....

$<1 \mathrm{E}-02$

SUMMATION ACROSS ALL EXPOSURE PATHWAYS FOR SOURCE AREA

Total cancer risk

1E-03

$1 \mathrm{E}-03$

Total Hazard Index

$.5 \mathrm{E}+01$

$2 \mathrm{E}+00$ 


\begin{tabular}{|c|c|c|}
\hline \multicolumn{3}{|c|}{$\begin{array}{c}\text { TABLE 2.8, Exposure Factors Used for Dermal Contact with and } \\
\text { Incidental Ingestion of Surface and Subsurface Soil plus Inhalation } \\
\text { of Resuspended Particulates Pathways } \\
\text { (Values are in days per year) }\end{array}$} \\
\hline Exposure Scenario & $\begin{array}{c}\text { This } \\
\text { Assessment } \\
\end{array}$ & $\begin{array}{c}\text { Region X } \\
\text { Guidance (1) } \\
\end{array}$ \\
\hline AE INDUSTRIAL CANCER & 146 & 250 \\
\hline AE INDUSTRIAL NON-CANCER & 146 & 250 \\
\hline RME INDUSTRIAL CANCER & 180 & 250 \\
\hline $\begin{array}{l}\text { RME INDUSTRIAL NON- } \\
\text { CANCER }\end{array}$ & 180 & 250 \\
\hline AE RESIDENTIAL CANCER & 180 & 275 \\
\hline $\begin{array}{l}\text { AE RESIDENTIAL NON- } \\
\text { CANCER }\end{array}$ & 180 & 275 \\
\hline RME RESIDENTIAL CANCER & 180 & 350 \\
\hline $\begin{array}{l}\text { RME RESIDENTIAL NON- } \\
\text { CANCER }\end{array}$ & 180 & 350 \\
\hline \multicolumn{3}{|c|}{$\begin{array}{l}\text { (1) EPA 1991a } \\
\text { AE Average Exposure Scenario } \\
\text { RME Reasonable Maximum Exposure Scenario }\end{array}$} \\
\hline
\end{tabular}


IABLE 2.9. The Magnitude of Effect of Uncertainties on Risk Estimates for Sites ST10/SS14

\begin{tabular}{|c|c|c|c|}
\hline \multirow{2}{*}{ Source of Uncertainty } & \multicolumn{3}{|c|}{ Potential Magnitude of Effect on Risk Estimate } \\
\hline & Underestimating Risk & $\begin{array}{c}\text { Underestimating or } \\
\text { Overestimating Risk }\end{array}$ & Overestimating Risk \\
\hline $\begin{array}{l}\text { Assumption that concentrations } \\
\text { of metals in environmental } \\
\text { media represent background } \\
\text { contamination }\end{array}$ & $\begin{array}{l}\text { High. Calculations show risk } \\
\text { estimates generally increased by two } \\
\text { orders of magnitude when exposure } \\
\text { to metals was included }\end{array}$ & & \\
\hline $\begin{array}{l}\text { Use of exposure factors other } \\
\text { than default values provided in } \\
\text { Region } 10 \text { guidance (e.g., } \\
\text { frequency of exposure to } \\
\text { contaminated soil) }\end{array}$ & $\begin{array}{l}\text { Very low. Calculations show that } \\
\text { risk estimates did not increase when } \\
\text { Region } 10 \text { default values were used. }\end{array}$ & & \\
\hline $\begin{array}{l}\text { Assumption that subsistence } \\
\text { fishing subpopulation will not } \\
\text { exist }\end{array}$ & $\begin{array}{l}\text { Very low. Calculations show that } \\
\text { risk estimates did not increase if this } \\
\text { pathway was included. }\end{array}$ & & \\
\hline $\begin{array}{l}\text { Assumption that ingestion of } \\
\text { animals fed contaminated plants } \\
\text { is not a complete pathway }\end{array}$ & $\begin{array}{l}\text { Very low. Calculations show that } \\
\text { risk estimates did not increase if this } \\
\text { pathway was included. }\end{array}$ & & \\
\hline $\begin{array}{l}\text { Effect of not including surface } \\
\text { water runoff pathway }\end{array}$ & $\begin{array}{l}\text { Unknown. The surface soil } \\
\text { contamination is mainly PAHs and } \\
\text { DDT, neither is very mobile. }\end{array}$ & & \\
\hline $\begin{array}{l}\text { Use of EPA Region } 10 \text { default } \\
\text { exposure factors }\end{array}$ & & & $\begin{array}{l}\text { Low to Moderate. Risk estimates for } \\
\text { the "average" individual are } \\
\text { approximately one order of } \\
\text { magnitude lower than those of the } \\
\text { "RME" individual for the residential } \\
\text { scenarios; the difference is less than } \\
\text { one order of magninde for the } \\
\text { industrial scenarios. }\end{array}$ \\
\hline $\begin{array}{l}\text { Method used to sum risk across } \\
\text { multiple substances and } \\
\text { pathways }\end{array}$ & & $\begin{array}{l}\text { Unknown. Summing effects across } \\
\text { multiple contaminants assumes their } \\
\text { effects are additive. Risk may be } \\
\text { underestimated if two or more } \\
\text { chemicals act synergistically and } \\
\text { overestimated if two or more } \\
\text { chemicals act antagonistically. The } \\
\text { approach also assumes that target } \\
\text { organs and toxicity mechanisms are } \\
\text { identical, an assumption that should } \\
\text { overestimate risk. }\end{array}$ & $\mathrm{C}_{\mathrm{C}}$ \\
\hline
\end{tabular}


IABLE 2.9. The Magnitude of Effect of Uncertainties on Risk Estimates for Sites ST10/SS14

\begin{tabular}{|c|c|c|c|}
\hline $\begin{array}{l}\text { Use of arithmetic average and } \\
\text { upper UCL concentrations to } \\
\text { describe contact rate }\end{array}$ & & $\begin{array}{l}\text { Unknown, because the overlap } \\
\text { between distribution of } \\
\text { environmental contamination and } \\
\text { distribution of worker/resident } \\
\text { activity is unknown. Approach will } \\
\text { over-estimate risk if "hot spots" are } \\
\text { located in areas rarely used and will } \\
\text { underestimate risk if "hot spots" are } \\
\text { located in areas commonly used. }\end{array}$ & \\
\hline $\begin{array}{l}\text { Effect of assuming normality in } \\
\text { chemical datasets on } \\
\text { comparisons to background and } \\
\text { use of UCL }\end{array}$ & & $\begin{array}{l}\text { Unknown. It may effect the UCL } \\
\text { concentration values input into the } \\
\text { risk calculations. Reduces the power } \\
\text { of the t-tests. }\end{array}$ & \\
\hline $\begin{array}{l}\text { Analytical chemistry methods } \\
\text { resulting in quantitation limits } \\
\text { for many substances being } \\
\text { above "risk-based screening } \\
\text { concentrations" }\end{array}$ & $\begin{array}{l}\text { Low to Moderate. There are no } \\
\text { records of most of these substances } \\
\text { ever being present at Eielson AFB. } \\
\text { However, some pesticides and other } \\
\text { organic chemicals (PAHs) could be } \\
\text { present in groundwater. }\end{array}$ & & \\
\hline $\begin{array}{l}\text { Assuming concentrations of bis } \\
\text { (2-ethylhexyl) phthalate are due } \\
\text { to laboratory contamination }\end{array}$ & $\begin{array}{l}\text { High. Calculations show that } \\
\text { including bis ( } 2 \text {-ethylhexyl) } \\
\text { phthalate increases the risk estimate } \\
\text { by approximately two orders of } \\
\text { magnitude. }\end{array}$ & & \\
\hline $\begin{array}{l}\text { Use of current contamination to } \\
\text { estimate future risk }\end{array}$ & & $\begin{array}{l}\text { Unknown. Most substances are } \\
\text { likely to degrade over time, and } \\
\text { current waste management practices } \\
\text { are likely to reduce or prevent future } \\
\text { releases. However, degradation } \\
\text { products could be more toxic than } \\
\text { parent compounds and their } \\
\text { constituents which were evaluated in } \\
\text { this assessment. }\end{array}$ & \\
\hline $\begin{array}{l}\text { Use of average time in a } \\
\text { residence as average time in a } \\
\text { workplace }\end{array}$ & $\begin{array}{l}\text { Low. Increasing average time in the } \\
\text { workplace from } 9 \text { to } 27 \text { years would } \\
\text { increase overall risk estimates by } \\
\text { less than a factor of } 3 \text {. }\end{array}$ & & \\
\hline $\begin{array}{l}\text { Use of aquifer as sole source of } \\
\text { drinking water supply }\end{array}$ & & & $\begin{array}{l}\text { Low to Moderate. The water well at } \\
\text { site is not used for drinking water. It } \\
\text { is completed below measurable } \\
\text { contamination. }\end{array}$ \\
\hline
\end{tabular}


TABLE 2.9. The Magnitude of Effect of Uncertainties on Risk Estimates for Sites ST10/SS14

\begin{tabular}{|c|c|c|c|}
\hline $\begin{array}{l}\text { Use of "generic" } \\
\text { bioconcentration factors }\end{array}$ & & $\begin{array}{l}\text { Unknown. Site-specific } \\
\text { bioaccumulation factors could be } \\
\text { lower or higher than the } \\
\text { bioconcentration factors used in the } \\
\text { analysis by one or two orders of } \\
\text { magnitude. However, food chain } \\
\text { risks generally are expected to be } \\
\text { overestimated because the surface } \\
\text { waters are not very attractive to } \\
\text { fishermen (e.g., fish consumption } \\
\text { rates are higher than expected). }\end{array}$ & \\
\hline $\begin{array}{l}\text { Effect of sub-arctic climate on } \\
\text { temperature-specific chemical } \\
\text { parameters (e.g.. Henry's Law } \\
\text { Constant and diffusivity) }\end{array}$ & & & $\begin{array}{l}\text { Unknown. These values are used to } \\
\text { determine volatilization from soil, } \\
\text { an exposure pathway that contributed } \\
\text { little to the total risk. Volatilization } \\
\text { efficiencies should decrease with sub- } \\
\text { arctic temperatures. }\end{array}$ \\
\hline $\begin{array}{l}\text { Failure to evaluate risk from TPH } \\
\text { because no toxicity values are in } \\
\text { IRIS or HEAST }\end{array}$ & $\begin{array}{l}\text { Moderate. Calculations show that } \\
\text { including TPH increases the risk } \\
\text { estimates by one order of magnitude. }\end{array}$ & & \\
\hline $\begin{array}{l}\text { Failure to evaluate risk from lead } \\
\text { because no toxicity values are in } \\
\text { IRIS or HEAST for the inorganic } \\
\text { form }\end{array}$ & $\begin{array}{l}\text { Low to High. Calculations show that } \\
\text { inorganic lead toxicity increased risk } \\
\text { by factor of five, tetraethyl lead } \\
\text { increased risk by three orders of } \\
\text { magnitude. }\end{array}$ & & \\
\hline $\begin{array}{l}\text { Effect of using toxicity ratios } \\
\text { for PAHs }\end{array}$ & $\begin{array}{l}\text { Moderate. If benzo(a)pyrene } \\
\text { toxicity was used for all PAHs the } \\
\text { risk estimate increased by factor of } 4\end{array}$ & & \\
\hline $\begin{array}{l}\text { Use of EPA toxicity values } \\
\text { (slope factors and RfDs) to } \\
\text { estimate toxicity and dose- } \\
\text { response }\end{array}$ & & & $\begin{array}{l}\text { Unknown. EPA's methods for } \\
\text { deriving toxicity values are intended } \\
\text { to be conservative (i.e., health- } \\
\text { protective). An uncertainty analysis } \\
\text { for these parameters was beyond the } \\
\text { scope of this analysis. }\end{array}$ \\
\hline
\end{tabular}




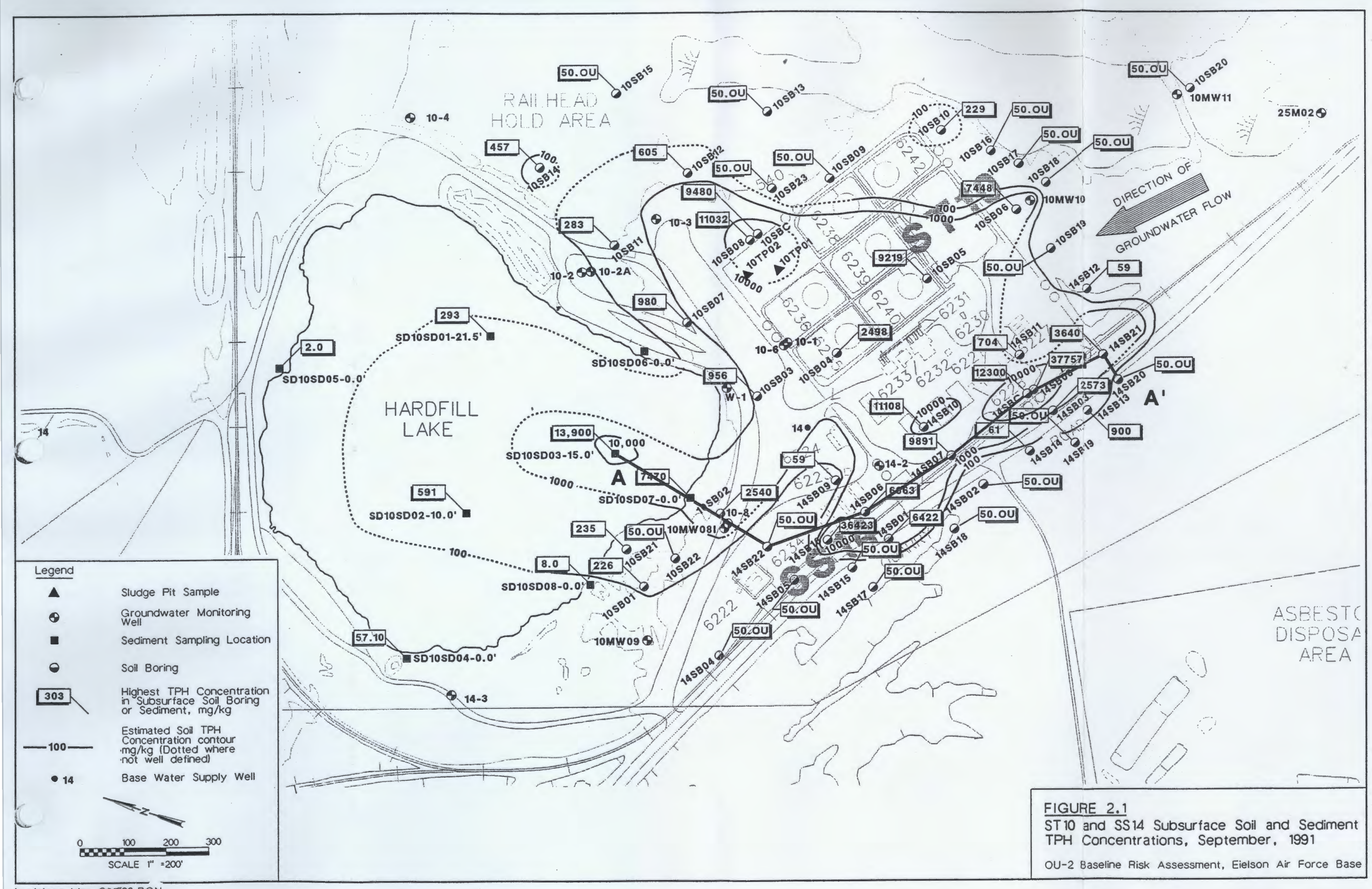




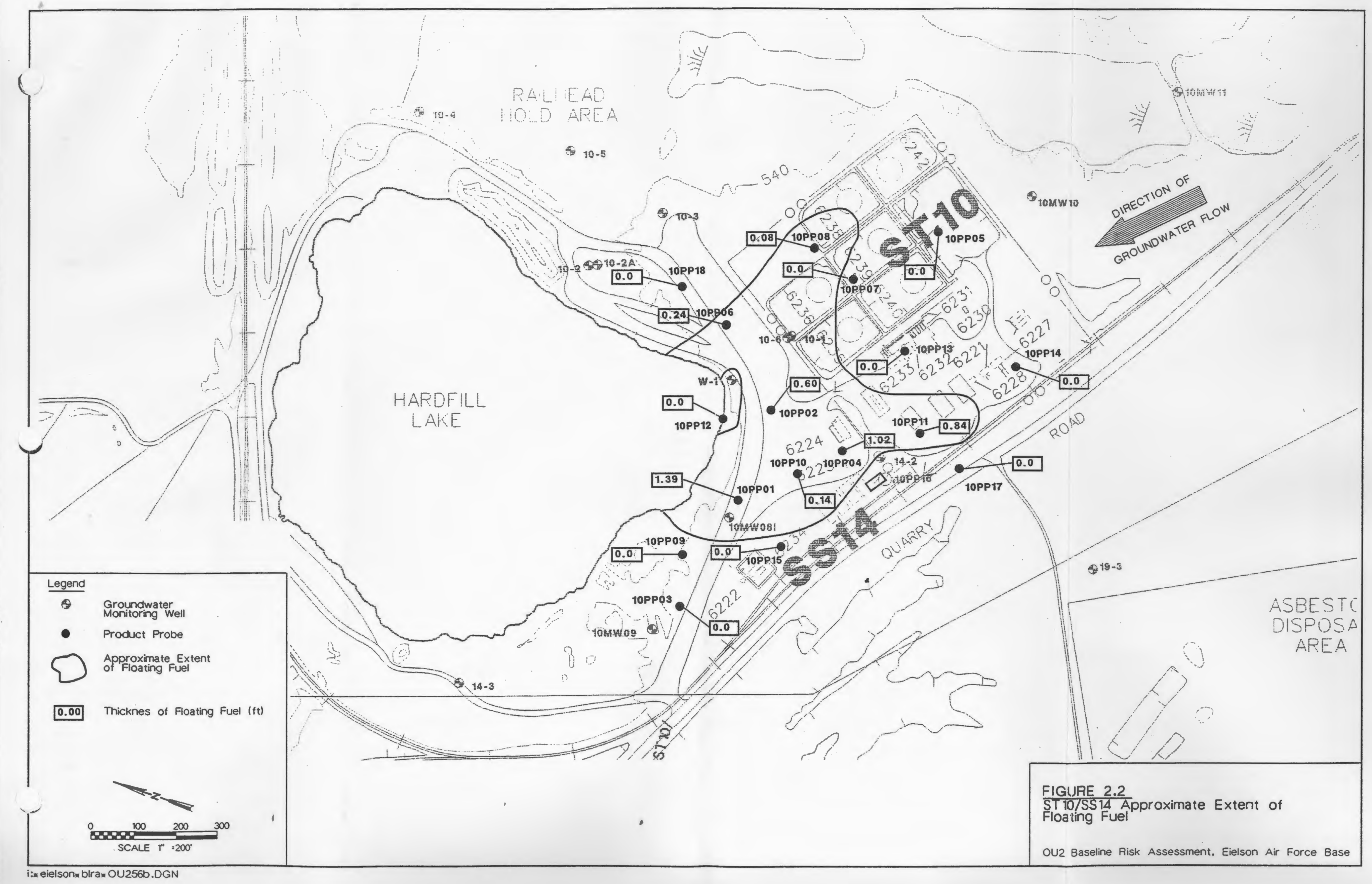




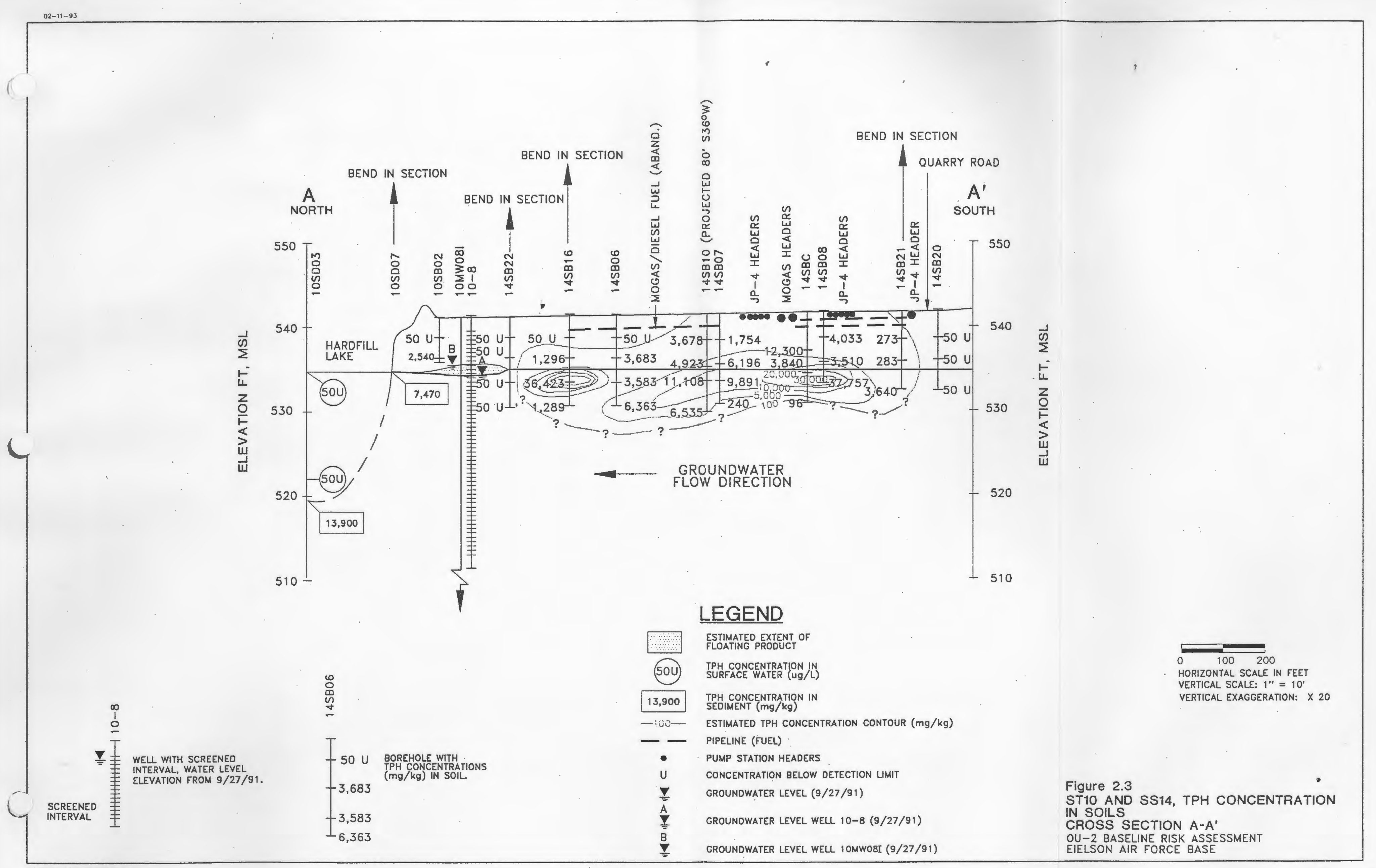




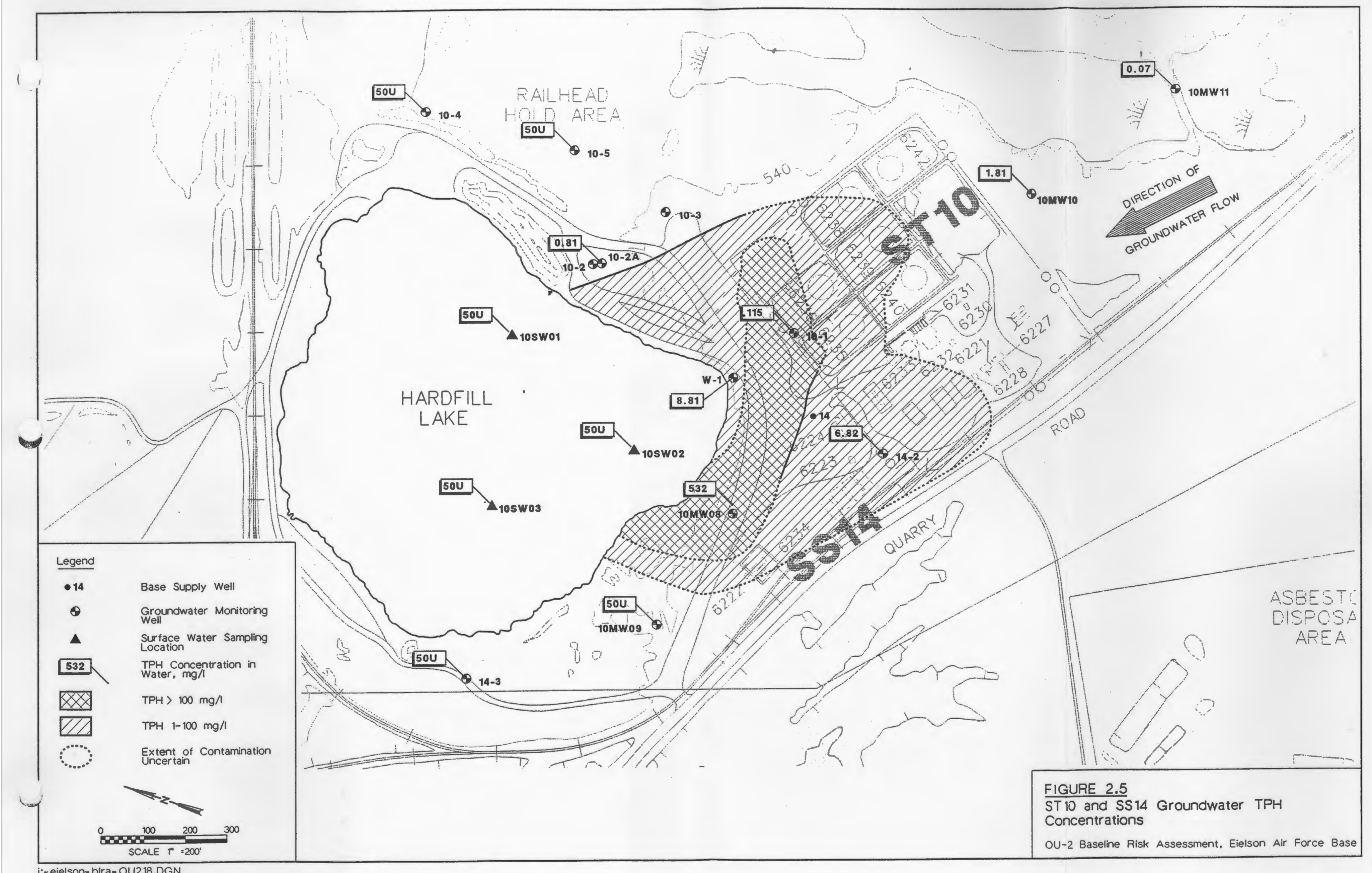




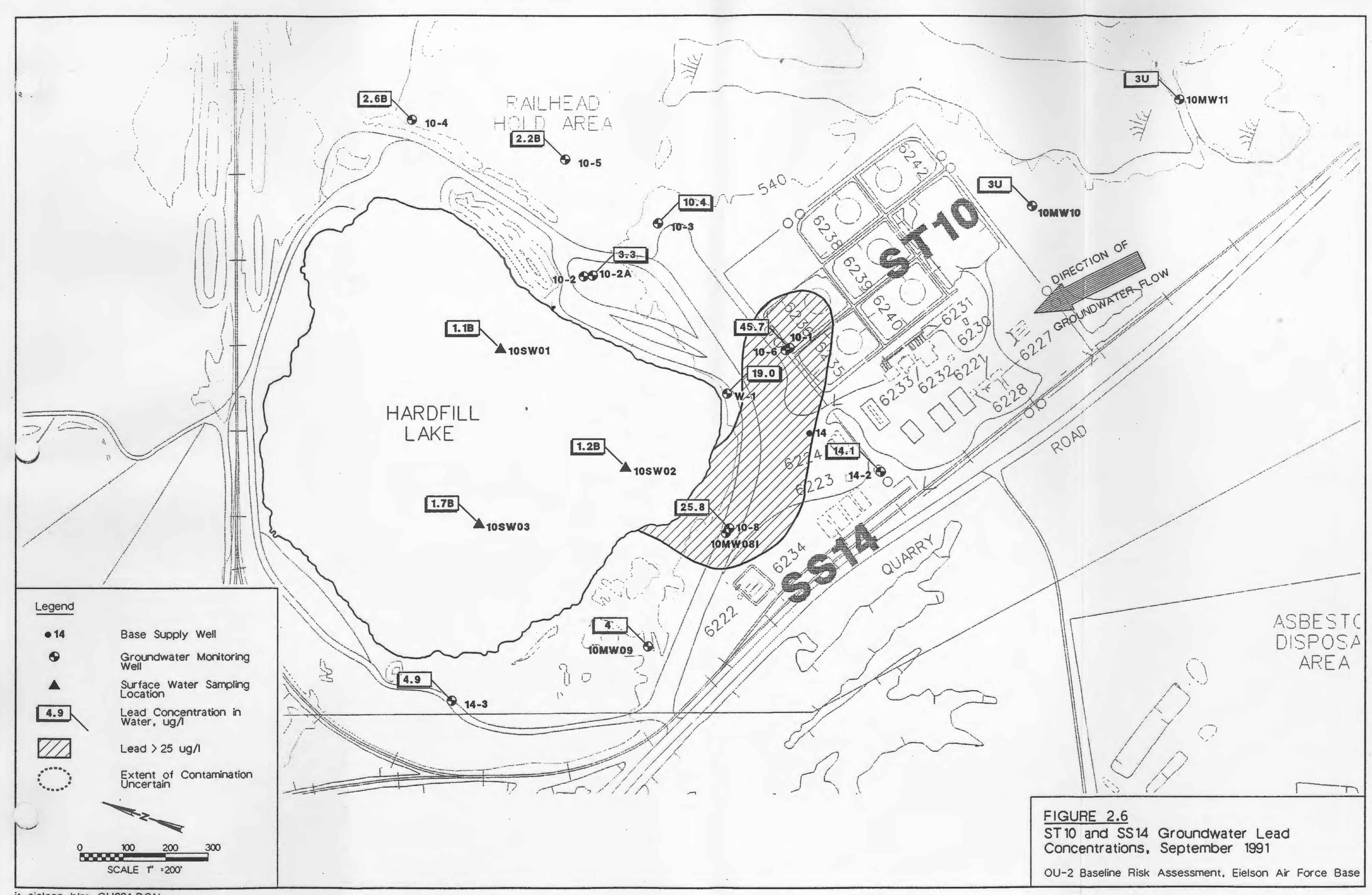




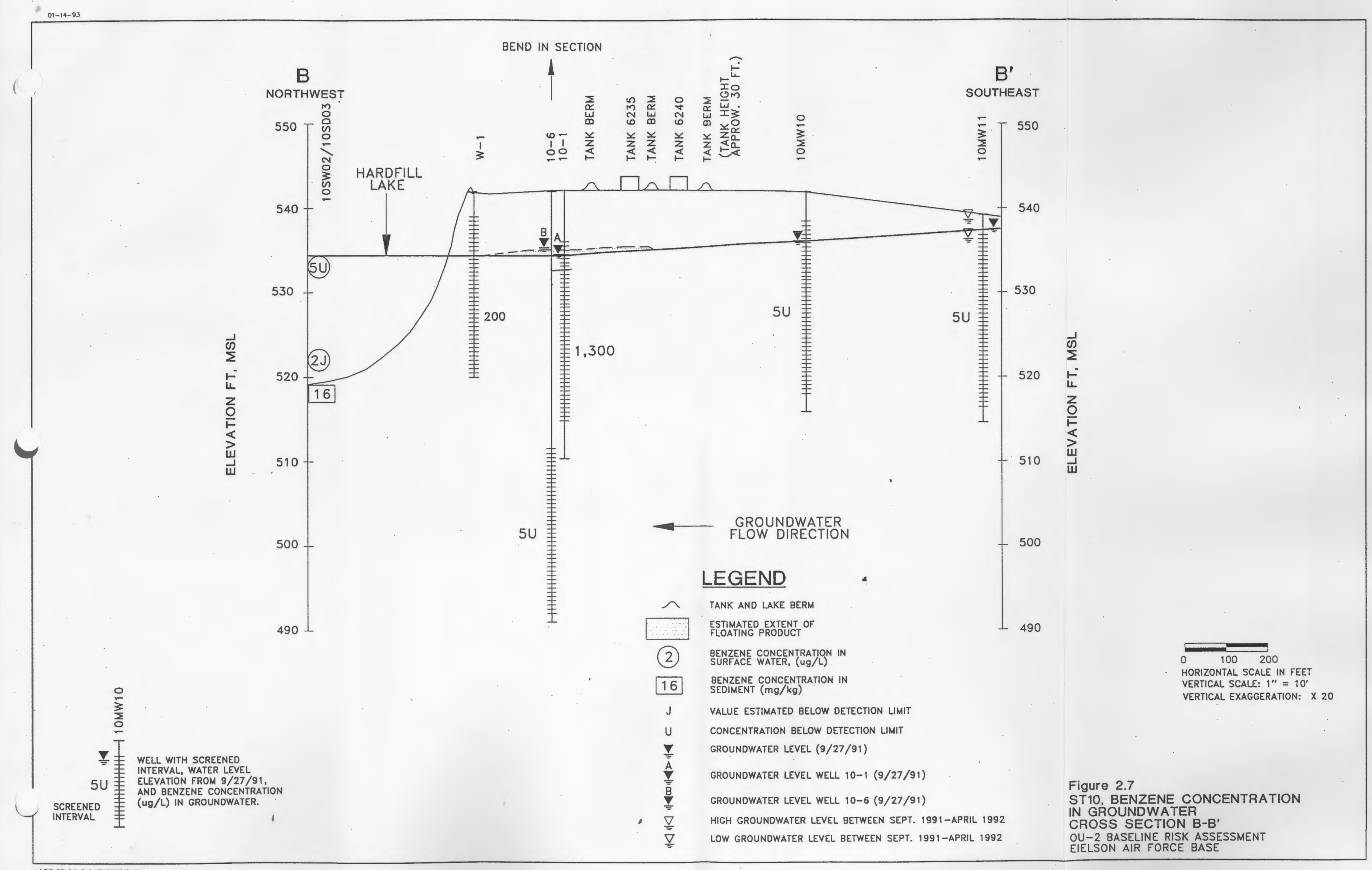




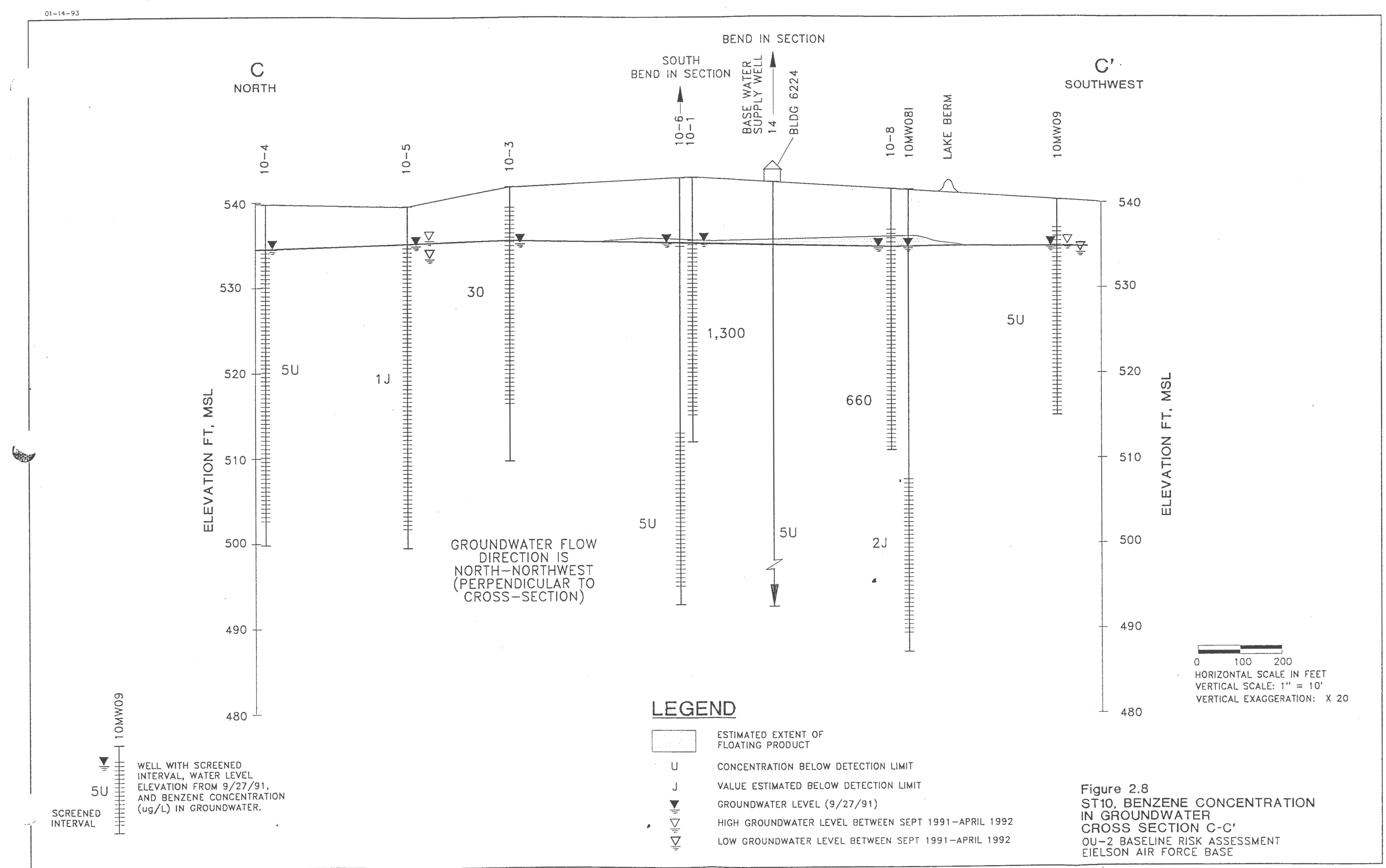




\subsection{SOURCE AREA ST11}

\subsection{CONCEPTUAL SITE MODEL}

This section examines site-specific information on waste sources, release mechanisms, receiving media, and routes of contaminant migration at the site to develop a conceptual understanding of the site. This conceptual site model is needed to evaluate potential risks to human health and the environment.

The contamination at this site is believed to have originated from a long-term (approximately 20 years in duration) subsurface leak of diesel fuel (U.S. Air Force 1993c, Section 5.3) from a buried piping that fired the base bakery ovens. The pipeline was removed in 1977. The location of the former contamination source is believed to be near the highest concentration of total petroleum hydrocarbons (TPH) in the subsurface soils. The surface soils of the site contain inorganic lead in concentrations above typical naturalbackground levels. The presence of lead is likely attributable to automobile and truck exhaust from nearby Central Avenue.

The underground release of diesel fuel initially caused the formation of floating product on top of the groundwater. The water-soluble chemical components of the floating product are assumed to have dissolved into the groundwater and migrated in the direction of the prevailing groundwater flow. Contamination at this site was discovered when an organic sheen migrated onto the waters of Garrison Slough. The water-soluble contaminants (which tend to be the lower-molecular-weight petroleum constituents such as benzene, toluene, ethylbenzene, and xylene) dissolved and volatilized. The less water-soluble constituents of the fuel, presumably composed of higher-molecular-weight hydrocarbons, remained and accumulated in the subsurface soils above the groundwater level. The higher-molecular-weight hydrocarbon accumulation in the subsurface soil likely varied in depth in accordance with fluctuations in the groundwater elevation. Their presence in soil samples is identified by measuring TPH. This TPH-rich layer (ranging in soil TPH concentration from 100 to $>10,000 \mathrm{ppm}$ ) of contaminants underlies an area approximately 140 by 50 meters ( 450 feet by 150 feet) on the northeast side of Garrison Slough (Figure 3.1).

The spill occurred between approximately 1956 through 1977 . Due to the age of the spill, the water-soluble contaminants have not been detected. Groundwater has likely moved through contaminated soil, picking up water-soluble contaminants in the process. The remaining contamination consists of high-molecular-weight hydrocarbons that form a TPH-rich layer found between 2.7 and 4.0 meters ( 9 and 13 feet) below ground surface level (Figures 3.1 and 3.2).

The slow vertical mixing of the aquifer has caused soluble contaminants to concentrate at or near the groundwater level. There is a direct connection between the aquifer and Garrison Slough at this site. Garrison Slough discharges into the aquifer for the majority of the year, augmenting both the dilution of contaminants and the groundwater horizontal flow velocity. Recharge of the aquifer into the slough occurs only during the spring thaw, late April through early June (U.S. Air Force 1993c)

\subsection{EXPOSURE ASSESSMENT}

The "Exposure Assessment" section examines land use, exposure timeframe, exposure setting, and exposure pathways. Table 3.1 summarizes the results of the exposure assessment. A list of contaminants of concern, fate and transport modeling results, 
exposure point concentrations, intake variables and/or exposure factors, toxicological values, and risk calculations are presented elsewhere in this report.

Exposure is defined as the contact of an organism with a chemical or physical agent. The overall objective of the exposure assessment is to estimate the types and magnitude of exposures to chemicals of potential concern that are present at, or migrating from, the site. The results of the exposure assessment are combined with chemical-specific toxicity information to characterize potential risks (EPA 1989a).

\subsubsection{Land-Use Assumptions for ST11}

Health risk will be quantified for three land-use assumptions. The risk from current land use is industrial in nature. Two different land-use assumptions are considered for evaluation of the future risk: 1) residential housing and 2) military/industrial land use. All of the land-use assumptions assume that no mitigation or corrective action is undertaken. The difference between the current and future industrial land-use assumptions is that the contaminants are expected to migrate and change in concentration over time.

Long-range land-use plans (Eielson Air Force Base 1992) indicate that site ST11 will remain an industrial site for the foreseeable future. The site is presently used as a kennel.

\subsubsection{Theoretical Exposure Pathways}

The plausible (current and future) theoretical human exposure pathways from ST11 contaminants are

- ingestion of groundwater used as potable water supply (future only)

- inhalation of and dermal contact with contaminants during groundwater use

(future only)

- incidental ingestion of surface water (Garrison Slough)

- ingestion of fish from Garrison Slough

- incidental ingestion of surface soils

- dermal contact with surface soils

- ingestion of plants grown in contaminated soils (future only)

- incidental ingestion of subsurface soils

- dermal contact with subsurface soils

- inhalation of volatile contaminants released from the soil into the ambient air

- inhalation of resuspended particulates.

\subsubsection{Current Exposure Pathways, Industrial Land Use: Rationale for Elimination from Further Consideration}

This subsection explains why two theoretical exposure pathways, postulated to occur given existing land-use conditions, are not examined in the quantitative risk calculations to follow. Each eliminated pathway is identified, and the rationale for elimination is noted.

Eliminated Pathway: ingestion of groundwater used as potable water supply.

Rationale: Groundwater in the vicinity of ST11 contains detectable concentrations of benzene, chlorinated solvents and metals (U.S. Air Force 1993c, subsection 5.3.2). However, this groundwater is currently not the source of potable water for the base. 
TABLE 3.1. SUMMARY OF HUMAN EXPOSURE PATHWAYS FOR SOURCE AREA ST11

RESIDENTIAL

- ingestion of groundwater used as potable water supply.

$x$

$x$

- inhalation of and dermal contact with contaminants during groundwater use.....

$\mathrm{x}$

$x$

- incidental ingestion of surface water...

- ingestion of fish from Garrison Slough..

- incidental ingestion of surface soils...

- dermal contact with surface soils...

- ingestion of plants grown in contaminated soils.

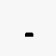

$x$

- incidental ingestion of subsurface soils.

- dermal contact with subsurface soils...

- inhalation of volatile contaminants released from the soil into the ambient air.

$X=$ Pathway retained for quantitative risk evaluation

- = Pathway eliminated, see text for elimination rationale 
Base water supply well (BSW) A is $160 \mathrm{~m}$ (525 ft) downgradient of ST11 (U.S. Air Force 1993c, Figure 4.21). Fate and transport modeling was performed to determine the effect of any contamination at ST11 upon this drinking water well. The results (Section 8.2.2.3 of this report) suggest that contamination at ST11 presents little potential for adversely affecting the water quality at BSW A, currently or in the future. Thus, this pathway was eliminated from this part of the assessment.

Eliminated Pathways: ingestion of plants grown in contaminated soils.

Rationale: The area's current land use is a military complex with industrial processes. No crops are grown on contaminated soils. Therefore, the pathway involving plant ingestion is considered incomplete and will not be evaluated.

\subsubsection{Identification of Current (Industrial) Exposure Pathways}

The current land use of ST11 is industrial operations. For the current risk calculations, the following pathways are complete and reasonable for further analysis:

- incidental ingestion of surface water (Garrison Slough), (This water body requires various routine maintenance activities such as weed control, sampling, inspection, and cleaning/clearing of discharge structures.)

- ingestion of fish from Garrison Slough

- incidental ingestion of surface soils

- dermal contact with surface soils

- incidental ingestion of subsurface soils

- dermal contact with subsurface soils

- inhalation of volatile contaminants released from the soil into the ambient air

- inhalation of resuspended particulates.

A detailed explanation of these exposure pathways, and exposure factors/parameters may be found in Appendix B, Exposure Factors.

\subsubsection{Euture Exposure Pathways: Residential Land Use}

Assuming a residential housing land use as a future exposure assumption, the following pathways are considered to be complete and reasonable for analysis:

- ingestion of groundwater used as potable water supply

- inhalation of and dermal contact with contaminants during groundwater use

- incidental ingestion of surface water (Garrison Slough)

- ingestion of fish from Garrison Slough

- incidental ingestion of surface soils

- dermal contact with surface soils

- ingestion of plants grown in contaminated soils

- incidental ingestion of subsurface soils

- dermal contact with subsurface soils

- inhalation of volatile contaminants released from the soil into ambient air

- inhalation of resuspended particulates.

Future residences are assumed to utilize groundwater for potable supply and to have garden plots associated with the homes. All theoretical exposure pathways postulated (and listed above) will be examined in subsequent risk calculations for the future exposure residential assumption. 


\subsubsection{Future Exposure Pathways: Industrial Land Use: Rationale for Elimination from Further Consideration}

This subsection explains why one theoretical exposure pathway is not examined in the quantitative risk calculations to follow. The eliminated pathway is re-stated and the rationale for elimination is noted.

Eliminated Pathways: ingestion of plants grown in contaminated soils.

Rationale: The area's future land use is assumed to be industrial. Therefore, no crops will be grown on contaminated soils and thus the exposure pathway involving plant ingestion is incomplete and will not be evaluated further.

\subsubsection{Future Exposure Pathways: Industrial Land Use}

Assuming industrial activities as the future land use, the following pathways are considered to be complete and reasonable for analysis:

- ingestion of groundwater used as potable water supply,

- inhalation of and dermal contact with contaminants during groundwater use

- incidental ingestion of surface water (Garrison Slough)

- ingestion of fish from Garrison Slough

- incidental ingestion of surface soils

- dermal contact with surface soils

- incidental ingestion of subsurface soils

- dermal contact with subsurface soils

- inhalation of volatile contaminants released from the soil into the ambient air

- inhalation of resuspended particulates.

Future industrial activities are assumed to be similar to current activities.

\subsection{RISK CHARACTERIZATION}

This section presents, in table format, the excess cancer risk and the Hazard Index for source area ST11 by exposure pathway. The cancer risk and Hazard Index are presented for both the "Average Exposure Case" and the "Reasonable Maximum Exposure Case." Tables 3.2 and 3.3 present risk values for the current land use (industrial), Tables 3.4 and 3.5 present the future residential land-use values, and Tables 3.6 and 3.7 present the future industrial land-use values.

Each table presents the cancer risk and the Hazard Index for each exposure pathway individually. A total cancer risk value and a total Hazard Index are presented that add all of the exposure pathway risks together. Values are presented for cancer risk and Hazard Index in two ways. The first column includes the contribution of metals in the groundwater that are suspected to be attributable to site background and therefore likely not related to past site activities. The second column excludes the contribution from potential background metals. The potential background metals are arsenic, barium, beryllium, manganese, and thallium.

The calculation of the cancer risk and Hazard Index necessitates the use of information and data input from many sources which are presented elsewhere in this report. For ease of reference, the information used to perform the risk calculations is cross referenced below. 
More detailed risk output tables are in Appendix K (Table K.13 through K.24). These tables include all of the data in Tables 3.2 through 3.7 plus the cancer risks and Hazard Quotients for the individual compounds that drive the risk (cancer risk $>10^{-7}$ and Hazard Quotient $>10^{-2}$ ).

\subsection{SITE-SPECIFIC UNCERTAINTIES AND CONSIDERATIONS}

This section presents key information bearing on the level of confidence in the quantitative risk estimates for a site. The risk estimates are conditional given a considerable number of assumptions about site characterization, exposure, and toxicity. Two major categories of uncertainty are discussed in the following subsections. Table 2.10 lists the major sources of uncertainty that affect this assessment and their possible magnitude of effect on the risk estimates.

\subsubsection{Exposure Uncertainties}

Some of the exposure frequencies used in this assessment differ from default values provided by EPA Region X (EPA 1991a) for the following exposure pathways: dermal contact with surface and subsurface soils, incidental ingestion of surface and subsurface soils, and inhalation of resuspended particulates. These differences are delineated in Table 2.8. Different exposure factors were used because of the subarctic climate at Eielson AFB, which is atypical of most EPA Region $X$ sites. 146 days per year is the mean number of days at Fairbanks without snow cover (Battelle 1992b). Table 3.8 lists the magnitude of effect for this assumption.

The ingestion of animals raised on contaminated feed was not included in the primary risk calculations due to the sub-arctic climate at Eielson. Table 3.8 presents the magnitude of effect caused by exclusion of this exposure pathway. The risk was calculated using exposure factors presented in EPA (1991e) for consumption of animal products. Subsistence fishing was also not included in the primary risk calculations due to limited size of Garrison Slough. Table 3.8 presents the magnitude of effect caused by exclusion of this exposure pathway. The risk was calculated using exposure factors presented in EPA (1991e) for subsistence fishing.

\subsubsection{Toxicity Uncertainties}

There are no approved EPA toxicity values for total petroleum hydrocarbons. It was not included in the primary risk calculations. However, a surrogate toxicity value was introduced in Section 9. of this assessment. The magnitude of effect on the risk calculations due to the inclusion of this compound is presented in Table 3.8.

\subsubsection{General Site Considerations}

Section 10 of this assessment discusses the effects of uncertainties that affect all of the Operable Unit 2 sites. Table 3.8 estimates their magnitude of effect. 


\section{TABLE 3.2. SOURCE AREA ST11; SUMMARY OF CANCER RISK AND HAZARD INDEX}

Average Exposure Case: Current Exposure Pathways / Industrial Land-Use Assumption

\section{EXPOSUREPATHWAYS}

- incidental ingestion of surface water (Garrison Slough)

cancer risk.

Hazard Index.

Suspected Background Metals Included Not Included

1E-07

$<1 E-02$

$<1 \mathrm{E}-07$

$<1 \mathrm{E}-02$

- ingestion of fish from Garrison Slough

cancer risk.

$<1 E-07$

$<1 E-07$

Hazard Index.

$<1 E-02$

$<1 \mathrm{E}-02$

- incidental ingestion of surface soils

cancer risk.

1E-06

$2 E-01$

$<1 \mathrm{E}-07$

Hazard Index.

$<1 \mathrm{E}-02$

- dermal contact with surface soils

cancer risk.

Hazard Index.

$<1 E-02$

$<1 \mathrm{E}-07$

$<1 \mathrm{E}-02$

- incidental ingestion of subsurface soils

cancer risk.

$9 \mathrm{E}-07$

$1 E-01$

$<1 \mathrm{E}-07$

Hazard Index

- inhalation of volatile contaminants released from the soil to the ambient air

cancer risk.

Hazard Index

- inhalation of resuspended particulates

cancer risk.

Hazard Index.

SUMMATION ACROSS ALL EXPOSURE PATHWAYS FOR SOURCE AREA 
TABLE 3.3. SOURCE AREA ST11; SUMMARY OF CANCER RISK AND HAZARD INDEX Reasonable Maximum Exposure Case: Current Exposure Pathways / Industrial Land-Use Assumption

\section{EXPOSUREPATHWAYS}

- incidental ingestion of surface water (Garrison Slough)

cancer risk..

Hazard Index.

Suspected Background Metals

Included Nol lncluded

ingestion of fish from Garrison Slough

cancer risk.

$<1 E-07$

$<1 E-07$

Hazard Index

$<1 E-07$

$<1 E-02$

$<1 \mathrm{E}-07$

$<1 \mathrm{E}-02$

- incidental ingestion of surface soils

cancer risk.

.4E-06

Hazard Index.

.2E-01

$<1 \mathrm{E}-07$

$<1 E-02$

- dermal contact with surface soils

cancer risk..

.4E-07

Hazard Index.

.2E-02

$<1 E-07$

$<1 E-02$

- incidental ingestion of subsurface soils

cancer risk

.3E-06

Hazard Index

- dermal contact with subsurface soils

cancer risk.

Hazard Index

- inhalation of volatile contaminants released from the soil to the ambient air

cancer risk...

$<1 \mathrm{E}-07$

$<1 \mathrm{E}-07$

Hazard Index.

$<1 E-02$

- inhalation of resuspended particulates

cancer risk

$<1 \mathrm{E}-07$

$<1 \mathrm{E}-07$

Hazard Index.

$<1 E-02$

$<1 \mathrm{E}-02$

SUMMATION ACROSS ALL EXPOSURE PATHWAYS FOR SOURCE AREA

Total cancer risk.

.7E-06

Total Hazard Index

3E-0 


\section{TABLE 3.4. SOURCE AREA ST11; SUMMARY OF CANCER RISK AND HAZARD INDEX}

Average Exposure Case: Future Exposure Pathways / Residential Housing Land-Use Assumption

\section{EXPOSUREPATHWAYS}

- ingestion of groundwater used as potable water supply

cancer

Hazard Index.

Included Not Included

kground Metals

halation of and dermal contact with contaminants during groundwater use

cancer risk.

Hazard Index.

idental ingestion of surface water (Garrison Slough)

cancer risk.

Hazard Index.

.1E-04

$2 E+01$

$<1 \mathrm{E}-07$

estion of fish from Garrison Slough

cancer risk.

$.6 \mathrm{E}-07$

4E-02

$<1 E-02$

Hazard Index.

$<1 E-07$

3E-07

dental ingestion of surface soils

cancer risk

$<1 E-02$

$<1 E-02$

Hazard Index.

$<1 E-07$

$<1 E-02$

$<$ IE-07

$<1 E-02$

rmal contact with surface soils

.3E-06

2E-01

cancer risk.

$<1 E-07$

$<1 E-02$

$<1 E-07$

$<1 E-02$

Hazard Index.

.6E-06

cancer risk...

$2 \mathrm{E}+01$

Hazard Index.

2E-06

3E-01

cancer risk.

Hazard Index

$<1 \mathrm{E}-07$

$<1 E-02$

$<1 E-07$

$<1 E-02$

$<1 \mathrm{E}-07$

$<1 E-02$

$<1 E-07$

$<1 E-02$

$<1 \mathrm{E}-07$

$<1 \mathrm{E}-02$

$<1 E-07$

$<1 E-02$

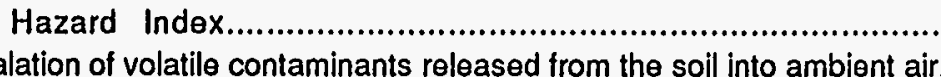

cancer risk...

Hazard Index.

$<1 \mathrm{E}-07$

$<1 \mathrm{E}-02$

$<1 \mathrm{E}-07$

$<$ SE-02

- inhalation of resuspended particulates

cancer risk.

2E-04

MMATION ACROSS ALL EXPOSURE PATHWAYS FOR SOURCE AREA

Total cancer risk

Total Hazard Index 
TABLE 3.5. SOURCE AREA ST11; SUMMARY OF CANCER RISK AND HAZARD INDEX Reasonable Maximum Exposure Case: Future Exposure Pathways / Residential Housing Land-Use Assumption

\section{EXPOSUREPATHWAYS}

- ingestion of groundwater used as potable water supply

cancer risk.

Hazard Index.

Included

alation of and dermal contact with contaminants during groundwater use

cancer risk...

.7E-02

.9E-04

.4E+01

Hazard Index.

$3 E-06$

cidental ingestion of surface water (Garrison Slough)

cancer risk.

.<1E-07

Hazard Index.

$<1 E-02$

- ingestion of fish from Garrison Slough

cancer risk

$<1 \mathrm{E}-07$

Hazard Index.

$<1 \mathrm{E}-02$

3E-05

$1 \mathrm{E}+00$

cancer risk..

$1 E+00$

Hazard Index

$8 \mathrm{E}-07$

cancer risk

$3 E-02$

Hazard Index.

2E-05

cancer risk

$2 E+01$

Hazard Index.

2E-05

$8 \mathrm{E}-01$

cancer risk..

6E-07

mal contact with subsurface soils

cancer risk.

Hazard Index.

$<1 E-07$

$<1 E-02$

cancer risk.

$<1 E-07$

alation of resuspended particulates

cancer risk..

$<1 E-02$

MMATION ACROSS ALL EXPOSURE PATHWAYS FOR SOURCE AREA

Total cancer risk

$.9 E-04$

Total Hazard Index

$6 \mathrm{E}+01$

$<1 \mathrm{E}-07$

$<1 E-02$

1E-06

$<1 E-02$

$<1 \mathrm{E}-07$

$<1 \mathrm{E}-02$

$<1 \mathrm{E}-07$

$<1 E-02$

$<1 \mathrm{E}-07$

$<1 E-02$

<1E-07

$<$ IE-02

1E-07

$<1 E-02$

$<1 E-07$

$<1 E-02$

$<1 E-07$

$<1 E-02$

$<1 E-07$

$<1 E-02$

$<1 E-07$

$<1 E-02$

2E-06

<1E-02 
TABLE 3.6. SOURCE AREA ST11; SUMMARY OF CANCER RISK AND HAZARD INDEX Average Exposure Case: Future Exposure Pathways / Industrial Land-Use Assumption

\section{EXPOSUREPATHWAYS}

- ingestion of groundwater used as potable water supply

cancer risk

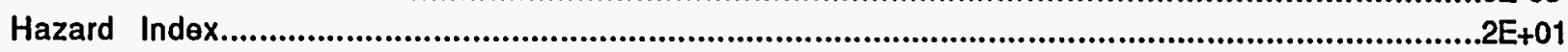

Suspected Background Metals

Included Not Included

- inhalation of and dermal contact with contaminants during groundwater use

cancer risk...

$2 \mathrm{E}+01$

$<$ IE-07

Hazard Index.

$.5 \mathrm{E}-07$

$4 \mathrm{E}-02$

$<1 \mathrm{E}-02$

- incidental ingestion of surface water (Garrison Slough)

cancer risk.

Hazard Index.

$<1 \mathrm{E}-07$

$<1 \mathrm{E}-02$

3E-07

$<1 \mathrm{E}-02$

- ingestion of fish from Garrison Slough

cancer risk..

$<1 \mathrm{E}-07$

Hazard Index.

$<1 \mathrm{E}-02$

- incidental ingestion of surface soils

cancer risk

1E-06

Hazard Index.

.2E-01

$<1 \mathrm{E}-07$

$<1 E-02$

- dermal contact with surface soils

cancer risk..

$<1 E-07$

Hazard Index.

$<1 \mathrm{E}-02$

- incidental ingestion of subsurface soils

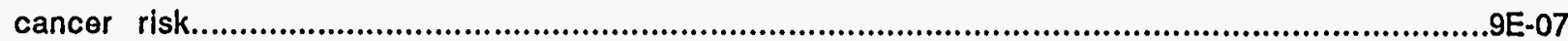

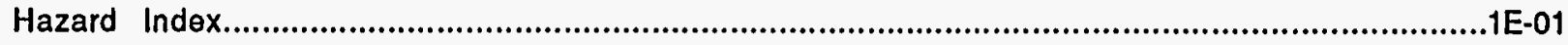

- dermal contact with subsurface soils

cancer risk.

$<1 \mathrm{E}-07$

Hazard Index.

$<1 E-02$

$<1 \mathrm{E}-07$

$<1 \mathrm{E}-02$

$<1 \mathrm{E}-07$

$<1 \mathrm{E}-02$

inhalation of volatile contaminants released from the soil into ambient air.

cancer risk.

$<1 \mathrm{E}-07$

$<1 E-02$

$<1 \mathrm{E}-07$

$<1 E-02$

Hazard Index.

$<1 E-07$

cancer risk..

$<1 \mathrm{E}-02$

$<1 E-07$

$<1 E-02$

Hazard Index

$.1 \mathrm{E}-04$

Total cancer risk

$2 E+01$

$<1 \mathrm{E}-07$

$<1 \mathrm{E}-02$

$<1 \mathrm{E}-07$

$<1 E-02$

$<1 \mathrm{E}-07$

$<1 E-02$

Total Hazard Index 
TABLE 3.7. SOURCE AREA ST11; SUMMARY OF CANCER RISK AND HAZARD INDEX

Reasonable Maximum Exposure Case: Future Exposure Pathways / Industrial Land-Use Assumption

\section{EXPOSUREPATHWAYS}

- ingestion of groundwater used as potable water supply

cancer risk.

Hazard Index.

Suspected Background Metals

Included Not lncluded

- inhalation of and dermal contact with contaminants during groundwater use

cancer risk.....

$.3 E-04$

$.2 E+01$

$<1 E-07$

Hazard Index

\section{$5 E-02$}

9E-07

- incidental ingestion of surface water (Garrison Slough)

cancer risk

$<1 \mathrm{E}-07$

Hazard Index.

$<1 \mathrm{E}-02$

$<1 \mathrm{E}-02$

- ingestion of fish from Garrison Slough

cancer risk.

$<1 \mathrm{E}-07$

$<1 E-02$

Hazard Index.

- incidental ingestion of surface soils

cancer risk

4E-06

Hazard Index.

2E-01

dermal contact with surface soils

cancer risk..

4E-07

Hazard Index.

2E-02

- incidental ingestion of subsurface soils

cancer risk.

3E-06

Hazard Index.

1E-01

dermal contact with subsurface soils

cancer risk...

$3 \mathrm{E}-07$

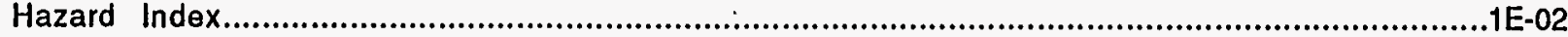

- inhalation of volatile contaminants released from the soil into ambient air.

cancer risk.

$<1 \mathrm{E}-07$

Hazard Index.

$<1 \mathrm{E}-02$

- inhalation of resuspended particulates

cancer risk..

$<1 E-07$

Hazard Index.

$<1 E-02$

SUMMATION ACROSS ALL EXPOSURE PATHWAYS FOR SOURCE AREA

Total cancer risk

3E-04

Total Hazard Index

$2 E+01$

$<1 \mathrm{E}-07$

$<1 E-02$

$<1 \mathrm{E}-07$

$<1 E-02$

$<1 \mathrm{E}-07$

$<1 E-02$

$<1 E-07$

$<1 E-02$

$<1 E-07$

$<1 E-02$

$<1 E-07$

$<1 E-02$

$<1 E-07$

$<1 E-02$

$<1 E-07$

$<1 E-02$

IE-06

$<1 E-02$ 
IABLE 3.8. The Magnitude of Effect of Uncertainties on Risk Estimates for Site ST11

\begin{tabular}{|c|c|c|c|}
\hline \multirow{2}{*}{ Source of Uncertainty } & \multicolumn{3}{|c|}{ Potential Magnitude of Effect on Risk Estimate } \\
\hline & Underestimating Risk & $\begin{array}{l}\text { Underestimating or } \\
\text { Overestimating Risk }\end{array}$ & Overestimating Risk \\
\hline $\begin{array}{l}\text { Assumption that concentrations } \\
\text { of metals in environmental media } \\
\text { represent background } \\
\text { contamination }\end{array}$ & $\begin{array}{l}\text { Very high. Calculations show that } \\
\text { risk estimates generally increased by } \\
\text { two to three orders of magnitude when } \\
\text { exposure to metals was included }\end{array}$ & & \\
\hline $\begin{array}{l}\text { Use of exposure factors other than } \\
\text { default values provided in Region } \\
10 \text { guidance (e.g., frequency of } \\
\text { exposure to contaminated soil) }\end{array}$ & $\begin{array}{l}\text { Very low. Calculations show that risk } \\
\text { estimates did not increase when } \\
\text { Region } 10 \text { default values were used. }\end{array}$ & & \\
\hline $\begin{array}{l}\text { Assumption that subsistence } \\
\text { fishing subpopulation will not } \\
\text { exist }\end{array}$ & $\begin{array}{l}\text { Very low. Calculations show that risk } \\
\text { estimates did not increase if this } \\
\text { pathway was included. }\end{array}$ & & \\
\hline $\begin{array}{l}\text { Assumption that ingestion of } \\
\text { animals fed contaminated plants } \\
\text { is not a complete pathway }\end{array}$ & $\begin{array}{l}\text { Low. Calculations show that risk } \\
\text { estimates would increase by about } 1 / 2 \\
\text { is this pathway was included. }\end{array}$ & & \\
\hline $\begin{array}{l}\text { Effect of not including surface } \\
\text { water runoff pathway }\end{array}$ & $\begin{array}{l}\text { Unknown. The surface soil } \\
\text { contamination is DDT, which is not } \\
\text { very mobile. }\end{array}$ & & \\
\hline $\begin{array}{l}\text { Use of EPA Region } 10 \text { default } \\
\text { exposure factors }\end{array}$ & & & $\begin{array}{l}\text { Low to Moderate. Risk estimates for } \\
\text { the "average" individual are } \\
\text { approximately one order of magnitude } \\
\text { lower than those of the "RME" } \\
\text { individual for the residential } \\
\text { scenarios; the difference is less than } \\
\text { one order of magnitude for the } \\
\text { industrial scenarios. }\end{array}$ \\
\hline $\begin{array}{l}\text { Method used to sum risk across } \\
\text { multiple substances and pathways }\end{array}$ & & $\begin{array}{l}\text { Unknown. Summing effects across } \\
\text { multiple contaminants assumes their } \\
\text { effects are additive. Risk may be } \\
\text { underestimated if two or more } \\
\text { chemicals act synergistically and } \\
\text { overestimated if two or more } \\
\text { chemicals act antagonistically. The } \\
\text { approach also assumes that target } \\
\text { organs and toxicity mechanisms are } \\
\text { identical, an assumption that should } \\
\text { overestimate risk. }\end{array}$ & \\
\hline
\end{tabular}


IABLE 3.8. The Magnitude of Effect of Uncertainties on Risk Estimates for Site ST11

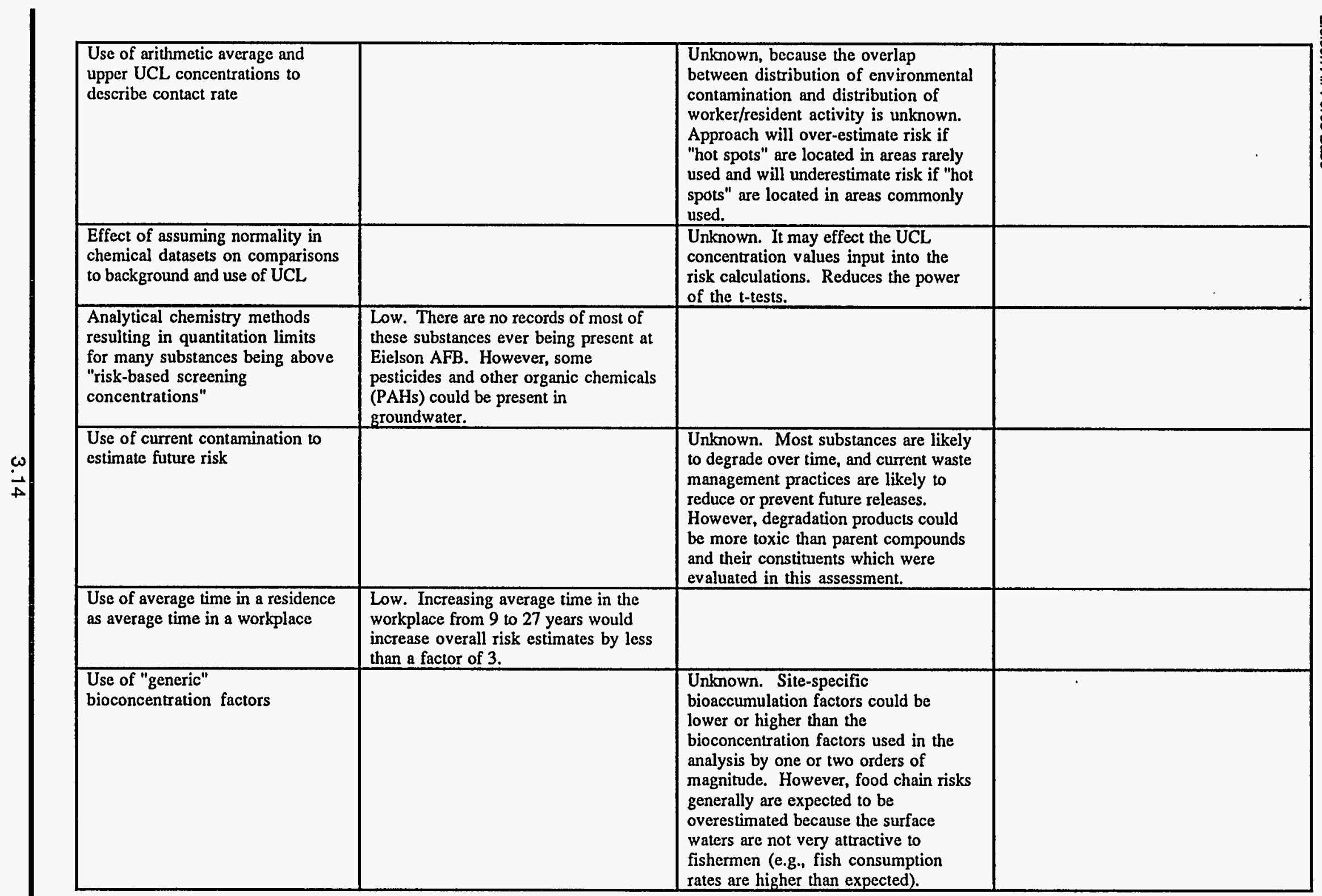


IABLE 3.8. The Magnitude of Effect of Uncertainties on Risk Estimates for Site ST11

\begin{tabular}{|l|l|l|l|}
\hline $\begin{array}{l}\text { Effect of sub-arctic climate on } \\
\text { temperature-specific chemical } \\
\text { parameters (e.g., Henry's Law } \\
\text { Constant and diffusivity) }\end{array}$ & & $\begin{array}{l}\text { Unknown. These values are used to } \\
\text { determine volatilization from soil, an } \\
\text { exposure pathway that contributed } \\
\text { little to the total risk. Volatilization } \\
\text { efficiencies should decrease with sub- } \\
\text { arctic temperatures. }\end{array}$ \\
\hline $\begin{array}{l}\text { Failure to evaluate risk from TPH } \\
\text { because no toxicity values are in } \\
\text { IRS or HEAST }\end{array}$ & $\begin{array}{l}\text { High. Calculations show that } \\
\text { including TPH increases the risk } \\
\text { estimates by two order of magnitude. }\end{array}$ & & \\
\hline $\begin{array}{l}\text { Failure to evaluate risk from lead } \\
\text { because no toxicity values are in } \\
\text { IRIS or HEAST for the inorganic } \\
\text { form }\end{array}$ & $\begin{array}{l}\text { No effect. Lead was not detected in } \\
\text { concentrations greater than natural } \\
\text { background.. }\end{array}$ & & \\
\hline $\begin{array}{l}\text { Effect of using toxicity ratios for } \\
\text { PAHs }\end{array}$ & $\begin{array}{l}\text { No effect. PAHS were not detected at } \\
\text { this site. }\end{array}$ & & \\
\hline $\begin{array}{l}\text { Use of EPA toxicity values (slope } \\
\text { factors and RfDs) to estimate } \\
\text { toxicity and dose-response }\end{array}$ & & & $\begin{array}{l}\text { Unknown. EPA's methods for } \\
\text { deriving toxicity values are intended } \\
\text { to be conservative (i.e., health- } \\
\text { protective). An uncertainty analysis } \\
\text { for these parameters was beyond the } \\
\text { scope of this analysis. }\end{array}$ \\
\hline
\end{tabular}




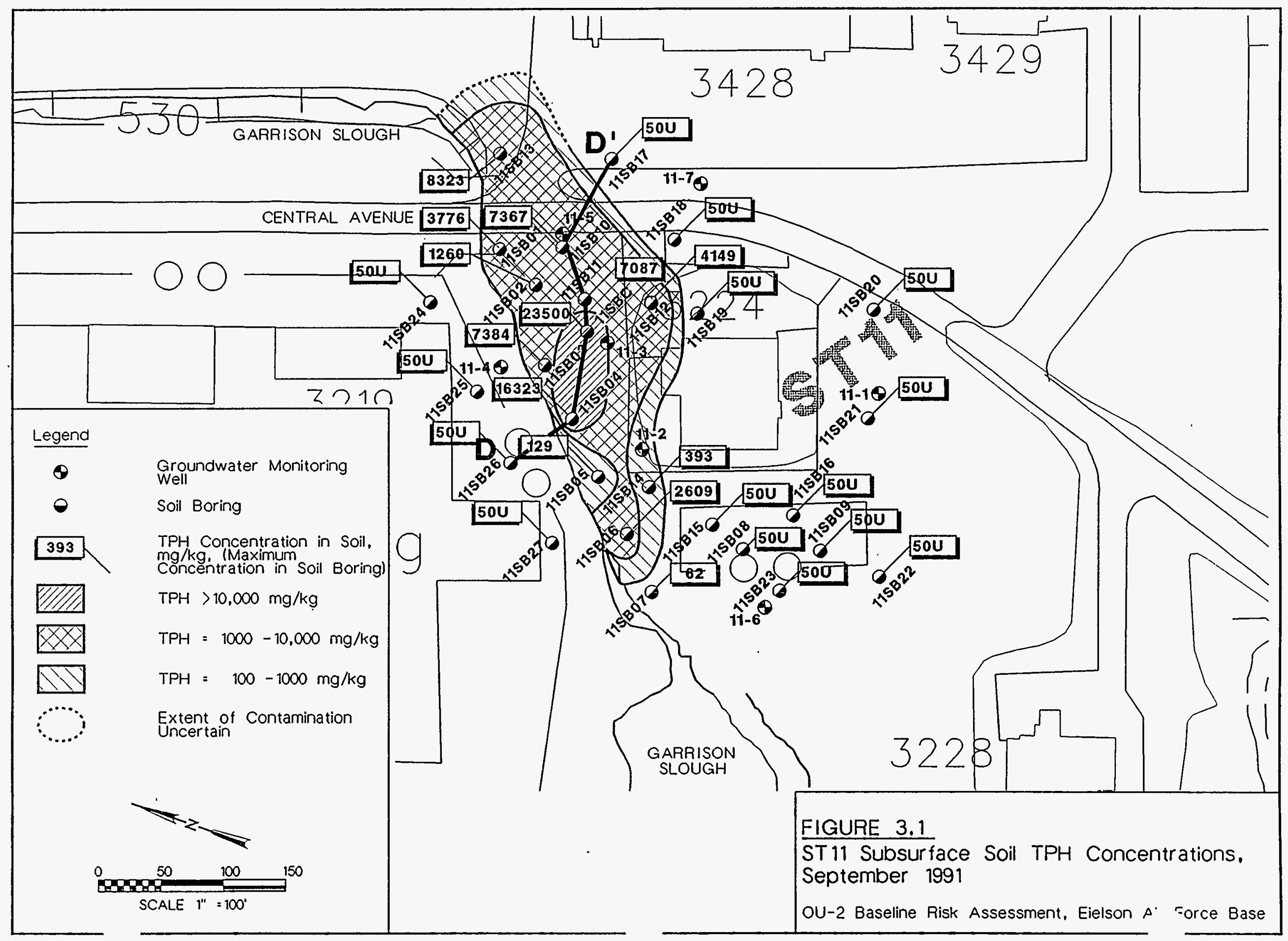

1:+ eielson* bira * UU227.DGN 


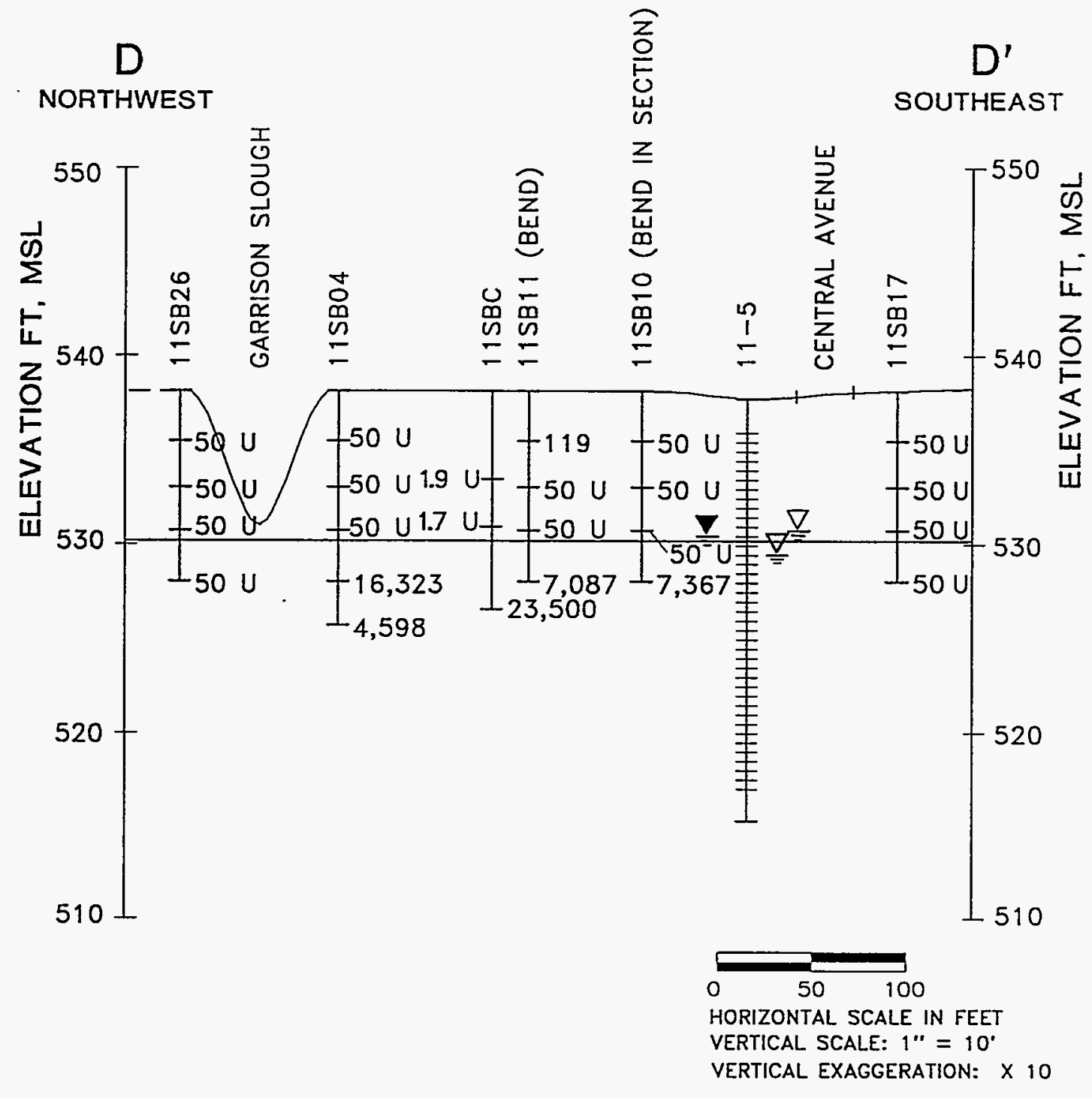

\section{LEGEND}

U CONCENTRATION BELOW DETECTION LIMIT

$\stackrel{\nabla}{=} \quad$ GROUNDWATER LEVEL $(9 / 27 / 91)$

$\stackrel{\nabla}{=} \quad$ HIGH GROUNDWATER LEVEL BETWEEN SEPT. 1991-APRIL 1992

$\stackrel{\nabla}{\bar{\nabla}} \quad$ LOW GROUNDWATER LEVEL BETWEEN SEPT. 1991-APRIL 1992

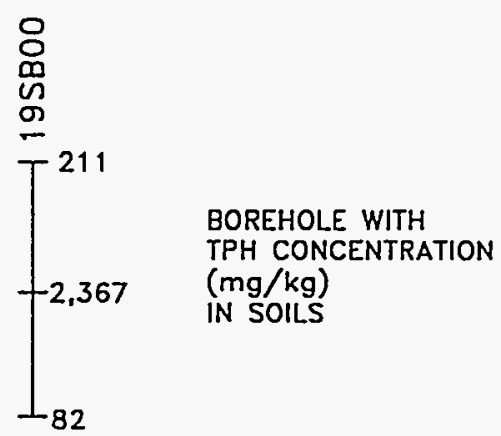

Figure 3.2

ST11, TPH CONCENTRATIONS

IN SOILS 


\subsection{SOURCE AREAS ST13/DP26}

\subsection{CONCEPTUAL SITE MODEL}

This section examines site-specific information on waste sources, release mechanisms, receiving media, and routes of contaminant migration at the site to develop a conceptual understanding of the site. This conceptual site model is needed to evaluate potential risks to human health and the environment.

The contamination at this site is of three types: 1) petroleum hydrocarbons in the subsoil and groundwater, 2) surface and subsurface soil contamination by polynuclear aromatic hydrocarbons (PAHs), and 3) surface soil contamination by chlorinated hydrocarbon insecticides [DDT, DDD, and DDE] along Flightline Avenue. The hydrocarbon contamination is believed to have originated from leaks in storage tanks in the area and/or spillage from fuel-bladder filling operations (U.S. Air Force 1993c, Section 5.4). There is evidence to suggest some of the groundwater contamination may have other sources, presenting the potential of co-mingled plumes. This data is discussed in an Appendix to the Operable Unit 2 Feasibility Study (U.S. Air Force 1993d). The surface soil contamination is of two types (DDT and PAHs). The DDT, DDD, and DDE contamination is along Flightline Avenue and may be the residues of past pesticide applications of DDT. The PAHs most likely originated either from diesel exhaust deposition on the soil surface or the spills and leaks of fuels.

The hypothesized fate and transport mechanism for the hydrocarbon contamination (believed to be mainly JP-4 and diesel fuel) is that spilled fuel infiltrated into the soil and migrated downward to the water table where it initially spread laterally on top of the groundwater. The residual evidence of this process is the "floating product," "floating fuel," or "free product" found at the site.

The water-soluble chemical components of the floating product (which tend to be the lower-molecular-weight petroleum constituents such as benzene, toluene, ethylbenzene, and xylene) preferentially volatilized or dissolved into the groundwater and migrated with the groundwater. The dissolved contaminants migrate at unique chemicalspecific rates in the groundwater; benzene moves faster than toluene, toluene moves faster than the other soluble organic constituents, and soluble lead moves at the slowest rate. The plume of benzene moved fastest (Figures 4.1 and 4.2 ) in a north by northwest direction between 1988 and 1992 [extending 150 meters (500 feet) downgradient] but apparently diminished in size between 1991 and 1992. The toluene plume is moving slower than the benzene plume but in the same basic direction (Figure 4.3). A plume of soluble lead (an additive in the fuel) also exists at the site but is slower moving than the toluene plume (Figure 4.4). The soluble lead in the groundwater is most likely evidence of old spills of MOGAS or AVGAS because lead is not an additive to JP-4.

The aquifer has a relatively high rate of horizontal groundwater flow [approximately 0.6 meter/day ( 2 feet/day)] and a slow vertical rate of mixing. The rapid horizontal groundwater velocity serves to confine groundwater contaminants near the top of the upper groundwater level.

The less water-soluble components, composed primarily of higher-molecular-weight hydrocarbons, preferentially remained in the subsurface soils above the groundwater level. The higher-molecular-weight hydrocarbon accumulation in the subsurface soil likely varied in depth in accordance with fluctuations in the groundwater elevation. Their presence in soil samples is inferred by measuring TPH. TPH analyses measure all organic contaminants as a single value and does not discriminate between the constituent 
hydrocarbons. The resulting layer of TPH-rich hydrocarbons underlies much of the original source area at depths of approximately 2.1 to 3.0 meters (7 to 10 feet) (Figures 4.5 and 4.6). This layer still retains measurable amounts of petroleum light ends (benzene and toluene) which will eventually find their way to the groundwater or to the soil surface and volatilize.

In summary, ST13/DP26 is characterized by groundwater plumes of soluble contaminants and a subsurface layer of high-molecular-weight hydrocarbon contaminants. Two areas of surface soil contamination have been located; one is contaminated with PAHs and the other with DDT, DDE, and DDD.

\subsection{EXPOSURE ASSESSMENT}

The "Exposure Assessment" section characterizes land use, exposure time frame, exposure setting, and exposure pathways. Table 4.1 summarizes the results of the exposure assessment. A list of chemicals of potential concem, fate and transport modeling results, exposure point concentrations, intake variables and/or exposure factors, toxicological values, and risk calculations are presented elsewhere in this report.

Exposure is defined as the contact of an organism with a chemical or physical agent. The overall objective of the exposure assessment is to estimate the types and magnitude of exposures to chemicals of potential concern that are present at, or migrating from, the site. The results of the exposure assessment are combined with chemical-specific toxicity information to characterize potential risks (EPA 1989a).

\subsubsection{Land-Use Assumptions for ST13/DP26}

Health risk will be quantified for three land-use assumptions. The risk from current land use is industrial in nature. Two different land-use assumptions are considered for evaluation of the future risk: 1) residential housing and 2) military/industrial land use. All of the assumptions assume that no mitigation or corrective action is undertaken. The difference between the current and future industrial land-use assumptions is that the contaminants are expected to migrate and change in concentration over time.

Long-range land-use plans (Eielson Air Force Base 1992) indicate that sites ST13/DP26 will remain industrial sites for the foreseeable future. The sites are adjacent to an active runway precluding residential development while air activities continue.

\subsubsection{Theoretical Exposure Pathways}

The plausible (current and future) theoretical human exposure pathways from ST13/DP26 contaminants are:

- ingestion of groundwater (future only)

- inhalation of and dermal contact with contaminants during groundwater use

(future only)

- incidental ingestion of surface soils

- dermal contact with surface soils

- ingestion of plants grown in contaminated soils (future only)

- incidental ingestion of subsurface soils

- dermal contact with subsurface soils

- inhalation of volatile contaminants released from the soil into the ambient air 
- inhalation of resuspended particulates.

\subsubsection{Current Exposure Pathways, Industrlal Land Use: Rationale for Elimination from Further Consideration}

This subsection explains why four theoretical exposure pathways, postulated to occur given existing land-use conditions, are not examined in the quantitative risk calculations to follow. Each eliminated pathway is identified, and the rationale for elimination is noted.

Eliminated Pathways: ingestion of groundwater, and inhalation of and dermal contact with contaminants during groundwater use.

Rationale: There are no production water wells within the identified groundwater plumes at this site, and the nearest drinking water well is approximately 210 meters (700 feet) downgradient. Therefore, there is no complete pathway for exposure to the contaminated groundwater and the pathways involving groundwater exposure will not be evaluated.

There are several abandoned base water supply wells in the vicinity of ST13/DP26 (Figure 4.1). The purpose of the wells, when they were abandoned, and the reason for their abandonment is unknown.

Eliminated Pathways: ingestion of plants grown in contaminated soils.

Rationale: The area's current land use is a military complex with industrial processes. No crops are grown on contaminated soils. Therefore, the pathway involving plant ingestion is considered incomplete and will not be evaluated.

\subsubsection{Identiflcation of Current (Industrial) Exposure Pathways}

The current land use of ST13/DP26 is industrial operations. For the current risk calculations, the following pathways are complete and reasonable for analysis:

- incidental ingestion of surface soils

- dermal contact with surface soils

- incidental ingestion of subsurface soils

- dermal contact with subsurface soils

- inhalation of volatile contaminants released from the soil into the ambient air.

- inhalation of resuspended particulates.

A detailed explanation of these exposure pathways, and exposure factors/parameters may be found in Appendix B.

\subsubsection{Future Exposure Pathways: Besidential Land Use}

Assuming residential housing as the future land use, the following pathways are considered to be complete and reasonable for analysis:

- ingestion of groundwater used as potable water supply

- inhalation of and dermal contact with contaminants during groundwater use

- incidental ingestion of surface soils

- dermal contact with surface soils

- ingestion of plants grown in contaminated soils 
TABLE 4.1 SUMMARY OF HUMAN EXPOSURE PATHWAYS FOR SOURCE AREAS ST13/DP26

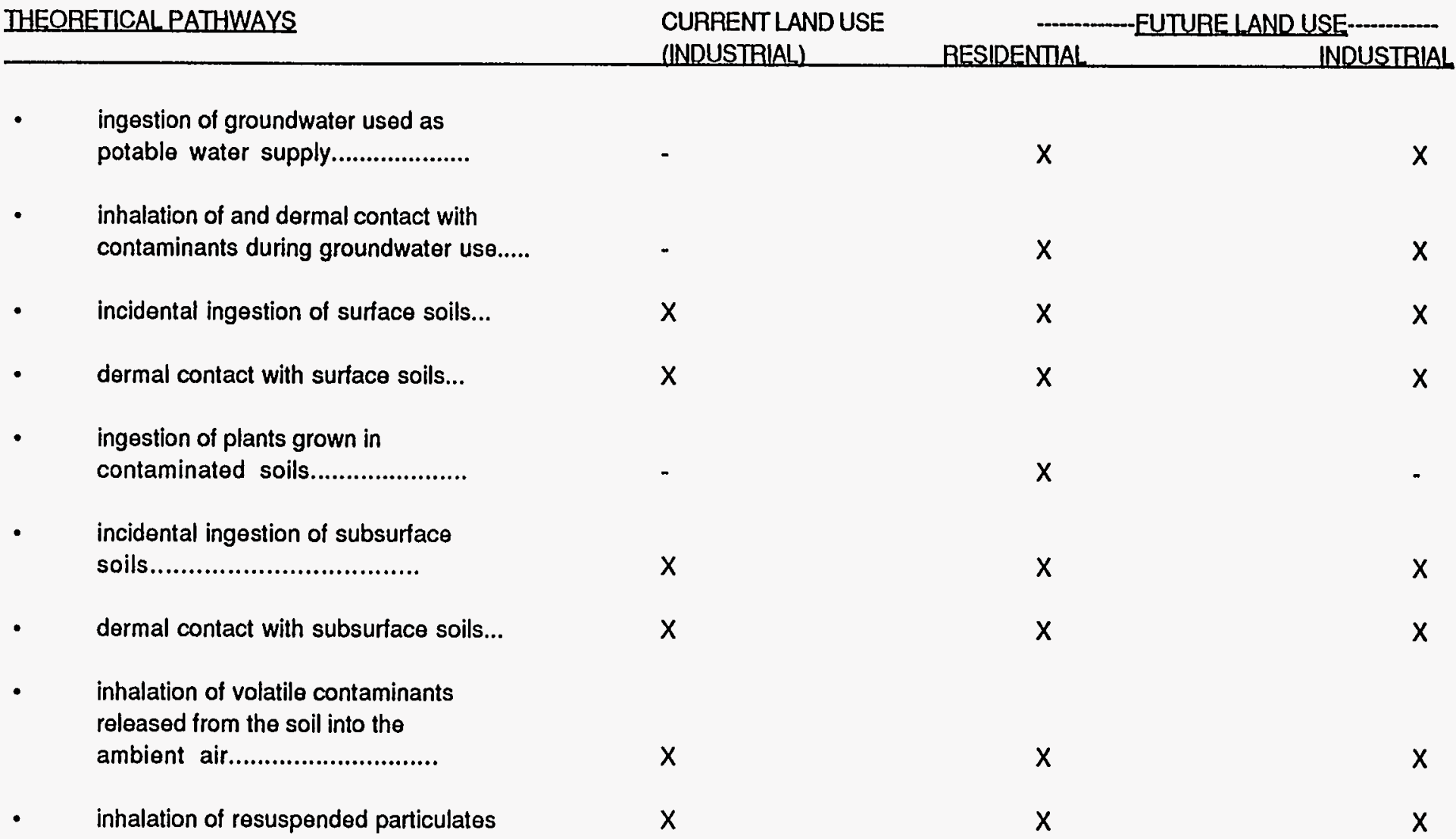

\footnotetext{
$\mathrm{X}=\mathrm{Pathway}$ retained for quantitative risk evaluation

- = Pathway eliminated, see text for elimination rationale
} 
- incidental ingestion of subsurface soils

- dermal contact with subsurface soils

- inhalation of volatile contaminants released from the soil into the ambient air

- inhalation of resuspended particulates.

Future residences are assumed to utilize groundwater for potable supply and to have garden plots associated with the homes. All theoretical exposure pathways postulated (and listed above) will be examined in subsequent risk calculations for the future exposure residential assumption.

\subsubsection{Future Exposure Pathways, Industrial Land Use: Rational for Elimination from Further Consideration}

This subsection explains why on theoretical exposure pathway, postulated to occur given existing land use conditions, is not examined in the quantitative risk calculations to follow. The eliminated pathway is stated, and the rationale for elimination is noted.

Eliminated Pathways: ingestion of plants grown in contaminated soils.

Rationale: The area's current land use is a military complex, with industrial processes. No crops are grown on the contaminated soils. Therefore, the pathway involving plant ingestion is considered incomplete and will not be evaluated.

\subsubsection{Future Exposure Pathways: Industrial Land Use}

Assuming industrial activities as the future land use, the following pathways are considered to be complete and reasonable for analysis:

- ingestion of groundwater used as potable water supply

- inhalation of and dermal contact with contaminants during groundwater use

- incidental ingestion of surface soils

- dermal contact with surface soils

- incidental ingestion of subsurface soils

- dermal contact with subsurface soils

- inhalation of volatile contaminants released from the soil into the ambient air

- inhalation of resuspended particulates.

Future industrial activities are assumed to be similar to current activities.

\subsection{RISK CHARACTERIZATION}

This section presents, in table format, the excess cancer risk and the Hazard Index for source area ST13/DP26 by exposure pathway. The cancer risk and Hazard Index are presented for both the "Average Exposure Case" and the "Reasonable Maximum Exposure Case." Tables 4.2 and 4.3 present risk values for the current land use (industrial), Tables 4.4 and 4.5 present the future residential land-use values, and Tables 4.6 and 4.7 present the future industrial land-use values.

Each table presents the cancer risk and the Hazard Index for each exposure pathway individually. A total cancer risk value and a total Hazard Index are presented that add all of the exposure pathway risks together. Values are presented for cancer risk and Hazard Index in two ways. The first column includes the contribution of metals in the groundwater that are suspected to be attributable to site background and therefore likely not related to past site activities. The second column excludes the contribution from potential 
background metals. The potential background metals are antimony, arsenic, barium, beryllium, cadmium, manganese, and thallium.

The calculation of the cancer risk and Hazard Index necessitates the use of information and data input from many sources which are presented elsewhere in this report. For ease of reference, the information used to perform the risk calculations is cross referenced.

Identification of Chemicals of Potential Concern

Exposure Point Concentrations and Modeling Results

Toxicity Assessment

Risk Calculation Formulas

Exposure Factors

Fate and Transport Models

Contaminant Concentration Inputs
Section 7.0

Section 8.0

Section 9.0

Appendix A

Appendix B

Appendix $\mathrm{C}$

Appendix $F$

More detailed risk output tables are in Appendix K (Tables K.25 through K.36). These tables include all of the data in Tables 4.2 through 4.7 plus the cancer risks and Hazard Quotients for the individual compounds that drive the risk (cancer risk $>10^{-7}$ and Hazard Quotient $>10^{-2}$ ).

\subsection{SITE-SPECIFIC UNCERTAINTIES AND CONSIDERATIONS}

This section presents key information bearing on the level of confidence in the quantitative risk estimates for a site. The risk estimates are conditional given a considerable number of assumptions about site characterization, exposure, and toxicity. Two major categories of uncertainty are discussed in the following subsections. Table 4.8 lists the major sources of uncertainty that affect this assessment and their possible magnitude of effect on the risk estimates.

\subsubsection{Exposure Uncertaintles}

Some of the exposure frequencies used in this assessment differ from default values provided by EPA Region X (EPA 1991a) for the following exposure pathways: dermal contact with surface and subsurface soils, incidental ingestion of surface and subsurface soils, and inhalation of resuspended particulates. These differences are delineated in Table 2.8. Different exposure factors were used because of the subarctic climate at Eielson AFB, which is atypical of most EPA Region X sites. 146 days per year is the mean number of days at Fairbanks without snow cover (Battelle 1992b). Table 4.8 lists the magnitude of effect for this assumption.

The ingestion of animals raised on contaminated feed was not included in the primary risk calculations due to the sub-arctic climate at Eielson. Table 4.8 presents the magnitude of effect caused by exclusion of this exposure pathway. The risk was calculated using exposure factors presented in EPA (1991e) for consumption of animal products.

\subsubsection{Toxicity Uncertainties}

There are no approved EPA toxicity values for two of the principal contaminants at Operable Unit 2 sites: total petroleum hydrocarbons (TPH) and lead. These compounds were not included in the primary risk calculations. However, surrogate toxicity values were introduced in Section 9 of this assessment. The magnitude of effect on the risk calculations due to the inclusion of these compounds is presented in Table 4.8 . 
There were several detections of bis (2-ethylhexyl) phthalate in groundwater and soils at sites ST10/SS14 that were not included in the risk assessment. These detections were believed to be laboratory contamination. Section 7.0 describes the evidence. The magnitude of effect on the risk calculations due to the inclusion of these compounds is presented in Table 4.8.

There were several detections of methylene chloride in groundwater at sites ST13/DP26 that were not included in the risk assessment. These detections were believed to be laboratory contamination. Section 7.0 describes the evidence. The magnitude of effect on the risk calculations due to the inclusion of these compounds is presented in Table 4.8.

\subsubsection{General Site Considerations}

Section 10 of this assessment discusses the effects of uncertainties that affect all of the Operable Unit 2 sites. Table 4.8 estimates their magnitude of effect. 
TABLE 4.2. SOURCE AREAS ST13/DP26; SUMMARY OF CANCER RISK AND HAZARD INDEX Average Exposure Case: Current Exposure Pathways / Industrial Land-Use Assumption

EXPOSUREPATHWAYS

- incidental ingestion of surface soils

cancer risk.

Suspected Background Metals Included Not Included

Hazard Index

1E-06

7E-07

$. .8 \mathrm{E}-02$

$<1 E-02$

- dermal contact with surface soils

cancer risk

2E-07

2E-07

Hazard Index

- incidental ingestion of subsurface soils

cancer risk

7E-07

$<1 E-07$

Hazard Index

$<1 E-02$

- dermal contact with subsurface soils

cancer risk

$<1 E-07$

Hazard Index

$<1 E-02$

$<1 \mathrm{E}-07$

$<1 E-02$

- inhalation of volatile contaminants released from the soil into ambient air.

cancer risk..

2E-06

Hazard Index

- inhalation of resuspended particulates

cancer risk.

$<1 E-07$

$<1 \mathrm{E}-02$

Hazard Index

SUMMATION ACROSS ALL EXPOSURE PATHWAYS FOR SOURCE AREA

Total cancer risk.

Total Hazard Index 
TABLE 4.3. SOURCE AREAS ST13/DP26; SUMMARY OF CANCER RISK AND HAZARD INDEX Reasonable Maximum Exposure Case: Current Exposure Pathways / Industrial Land-Use Assumption

\section{EXPOSUREPATHWAYS}

- incidental ingestion of surface soils

cancer risk.

Suspected Background Metals

Hazard Index

- dermal contact with surface soils

cancer risk.

Hazard Index.

incidental ingestion of subsurface soils

cancer risk..

Hazard Index

- dermal contact with subsurface soils

cancer risk.

Hazard Index

- inhalation of volatile contaminants released from the soil into ambient air.

cancer risk..

Hazard Index.

- inhalation of resuspended particulates

cancer risk..

Hazard Index

1E-02

$<1 \mathrm{E}-02$

SUMMATION ACROSS ALL EXPOSURE PATHWAYS FOR SOURCE AREA

Total cancer risk

$1 E-05$

Total Hazard Index 
TABLE 4.4. SOURCE AREAS ST13/DP26; SUMMARY OF CANCER RISK AND HAZARD INDEX Average Exposure Case: Future Exposure Pathways / Residential Housing Land-Use Assumption

\section{EXPOSUREPATHWAYS}

- ingestion of groundwater used as potable water supply

cancer risk.

Hazard Index.

Suspected Background Metals Included Not Included

- inhalation of and dermal contact with contaminants during groundwater use

cancer risk.

Hazard Index.

- incidental ingestion of surface soils

cancer risk.

Hazard Index

$1 \mathrm{E}-04$

$6 \mathrm{E}+01$

2E-05

$1 \mathrm{E}-01$

$1 \mathrm{E}-04$

$1 \mathrm{E}-04$

$2 E+00$

mal contact with surface soils

cancer risk.

$3 E+00$

2E-06

$1 \mathrm{E}-01$

$<1 \mathrm{E}-02$

Hazard Index

2E- 07

$<1 \mathrm{E}-02$

$2 \mathrm{E}-07$

$<1 \mathrm{E}-02$

- ingestion of plants grown in contaminated soils

cancer risk.

$1 E-05$

Hazard Index.

$8 \mathrm{E}+00$

$8 \mathrm{E}-06$

$2 \mathrm{E}-02$

- incidental ingestion of subsurface soils

cancer risk.

2E-06

Hazard Index.

3E-01

$1 \mathrm{E}-07$

$<1 \mathrm{E}-02$

- dermal contact with subsurface soils

cancer risk.

$<1 \mathrm{E}-07$

Hazard Index....

$<1 E-02$

$<1 \mathrm{E}-07$

$<1 \mathrm{E}-02$

- inhalation of volatile contaminants released from the soil into ambient air.

cancer risk.

$5 \mathrm{E}-07$

Hazard Index.

$<1 \mathrm{E}-02$

5E-07

$<1 \mathrm{E}-02$

- inhalation of resuspended particulates

cancer risk.

$<1 \mathrm{E}-07$

Hazard Index.

$1 \mathrm{E}-02$

$<1 \mathrm{E} \cdot 07$

$<1 E-02$

SUMMATION ACROSS ALL EXPOSURE PATHWAYS FOR SOURCE AREA

Total cancer risk

2E-04

Total Hazard Index 
TABLE 4.5. SOURCE AREAS ST13/DP26; SUMMARY OF CANCER RISK AND HAZARD INDEX Reasonable Maximum Exposure Case: Future Exposure Pathways / Residential Housing Land-Use Assumption

\section{EXPOSUREPATHWAYS}

- ingestion of groundwater used as potable water supply

cancer risk

Hazard Index.

Suspected Background Metals

Included Not included

- inhalation of and dermal contact with contaminants during groundwater use

cancer risk.

Hazard Index.

$1 E+02$

1E-04

$4 E-04$

$3 E+00$

4E-04

- incidental ingestion of surface soils

cancer risk.

3E-05

Hazard Index

$.5 E-01$

$3 E+00$

- dermal contact with surface soils

cancer risk.

$.5 E-06$

Hazard Index..

2E-02

ingestion of plants grown in contaminated soils

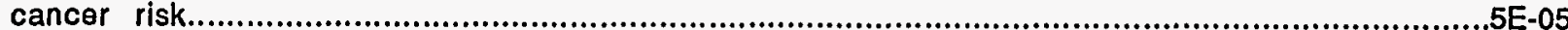

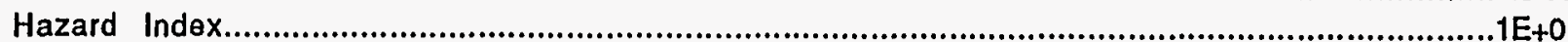

- incidental ingestion of subsurface soils

cancer risk.

IE-05

Hazard Index.

- dermal contact with subsurface soils

cancer risk..........................

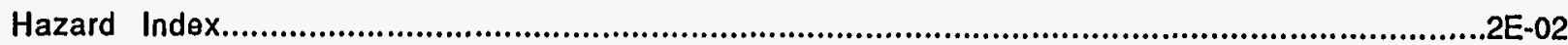

- inhalation of volatile contaminants released from the soil into ambient air.

cancer risk.

.2E-06

Hazard Index.

$<1 \mathrm{E}-02$

- inhalation of resuspended particulates

cancer risk.

2E-07

Hazard Index.

SUMMATION ACROSS ALL EXPOSURE PATHWAYS FOR SOURCE AREA

Total cancer risk

5E-06

$<1 E-02$

3E-05

3E-02

1E-06

$<1 E-02$

3E-07

$<1 \mathrm{E}-02$

2E-06

$<1 E-02$

$<1 E-07$

$<1 \mathrm{E}-02$ 


\section{TABLE 4.6. SOURCE AREAS ST13/DP26; SUMMARY OF CANCER RISK AND HAZARD INDEX}

Average Exposure Case: Future Exposure Pathways / Industrial Land-Use Assumption

\section{EXPOSUREPATHWAYS}

- ingestion of groundwater used as potable water supply

cancer risk.

Hazard Index.

Suspected Background Metals

Included Not Included

- inhalation of and dermal contact with contaminants during groundwater use

cancer risk.

$4 \mathrm{E}+01$

$1 E-05$

Hazard Index

9E-02

- incidental ingestion of surface soils

cancer risk...

$1 \mathrm{E}-06$

Hazard Index

- dermal contact with surface soils

cancer risk.

Hazard Index

- incidental ingestion of subsurface soils

cancer risk.

Hazard Index.

- dermal contact with subsurface soils

cancer risk

<1E-07

Hazard Index.

- inhalation of volatile contaminants released from the soil into ambient air.

cancer risk..

2E-06

Hazard Index.

- inhalation of resuspended particulates

cancer risk.

$<1 E-07$

Hazard Index.

SUMMATION ACROSS ALL EXPOSURE PATHWAYS FOR SOURCE AREA

Total cancer risk

Total Hazard Index. 
TABLE 4.7. SOURCE AREAS ST13/DP26; SUMMARY OF CANCER RISK AND HAZARD INDEX Reasonable Maximum Exposure Case: Future Exposure Pathways / Industrial Land-Use Assumption

EXPOSUREPATHWAYS

- ingestion of groundwater used as potable water supply

cancer risk.

Suspected Background Metals

Hazard Index...

2E-04

3E-05

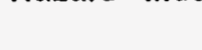

alation of and dermal contact with contaminants during groundwater use cancer risk.

Hazard Index.

dex...................

dental ingestion of surface soils

cancer risk.

Hazard Index.

- dermal contact with surface soils

cancer risk..

Hazard Index.

- incidental ingestion of subsurface soils

$$
\text { cancer risk. }
$$

- dermal contact with subsurface soils

$$
\text { cancer risk. }
$$

- inhalation of volatile contaminants released from the soil into ambient air.

- inhalation of resuspended particulates 
IABLE 4.8. The Magnitude of Effect of Uncertainties on Risk Estimates for Sites ST13/DP26

\begin{tabular}{|c|c|c|c|}
\hline \multirow{2}{*}{ Source of Uncertainty } & \multicolumn{3}{|c|}{ Potential Magnitude of Effect on Risk Estimate } \\
\hline & Underestimating Risk & $\begin{array}{l}\text { Underestimating or } \\
\text { Overestimating Risk }\end{array}$ & Overestimating Risk \\
\hline $\begin{array}{l}\text { Assumption that concentrations } \\
\text { of metals in environmental media } \\
\text { represent background } \\
\text { contamination }\end{array}$ & $\begin{array}{l}\text { Moderate. Calculations show that risk } \\
\text { estimates generally by one order of } \\
\text { magnitude when exposure to metals } \\
\text { was included }\end{array}$ & & \\
\hline $\begin{array}{l}\text { Use of exposure factors other than } \\
\text { default values provided in Region } \\
10 \text { guidance (e.g., frequency of } \\
\text { exposure to contaminated soil) }\end{array}$ & $\begin{array}{l}\text { Very low. Calculations show that risk } \\
\text { estimates did not increase when } \\
\text { Region } 10 \text { default values were used. }\end{array}$ & & \\
\hline $\begin{array}{l}\text { Assumption that ingestion of } \\
\text { animals fed contaminated plants } \\
\text { is not a complete pathway }\end{array}$ & $\begin{array}{l}\text { Very low. Calculations show that risk } \\
\text { estimates did not increase if this } \\
\text { pathway was included. }\end{array}$ & & \\
\hline $\begin{array}{l}\text { Effect of not including surface } \\
\text { water runoff pathway }\end{array}$ & $\begin{array}{l}\text { Unknown. The surface soil } \\
\text { contamination is mainly PAHs and } \\
\text { DDT, neither is very mobile. }\end{array}$ & & \\
\hline $\begin{array}{l}\text { Use of EPA Region } 10 \text { default } \\
\text { exposure factors }\end{array}$ & & & $\begin{array}{l}\text { Low to Moderate. Risk estimates for } \\
\text { the "average" individual are } \\
\text { approximately one order of magnitude } \\
\text { lower than those of the "RME" } \\
\text { individual for the residential } \\
\text { scenarios; the difference is less than } \\
\text { one order of magnitude for the } \\
\text { industrial scenarios. }\end{array}$ \\
\hline $\begin{array}{l}\text { Method used to sum risk across } \\
\text { multiple substances and pathways }\end{array}$ & & $\begin{array}{l}\text { Unknown. Summing effects across } \\
\text { multiple contaminants assumes their } \\
\text { effects are additive. Risk may be } \\
\text { underestimated if two or more } \\
\text { chemicals act synergistically and } \\
\text { overestimated if two or more } \\
\text { chemicals act antagonistically. The } \\
\text { approach also assumes that target } \\
\text { organs and toxicity mechanisms are } \\
\text { identical, an assumption that should } \\
\text { overestimate risk. }\end{array}$ & \\
\hline
\end{tabular}




\begin{tabular}{|c|c|c|c|}
\hline $\begin{array}{l}\text { Use of arithmetic average and } \\
\text { upper UCL concentrations to } \\
\text { describe contact rate }\end{array}$ & & $\begin{array}{l}\text { Unknown, because the overlap } \\
\text { between distribution of environmental } \\
\text { contamination and distribution of } \\
\text { worker/resident activity is unknown. } \\
\text { Approach will over-estimate risk if } \\
\text { "hot spots" are located in areas rarely } \\
\text { used and will underestimate risk if "hot } \\
\text { spots" are located in areas commonly } \\
\text { used. }\end{array}$ & \\
\hline $\begin{array}{l}\text { Effect of assuming normality in } \\
\text { chemical datasets on comparisons } \\
\text { to background and use of UCL }\end{array}$ & & $\begin{array}{l}\text { Unknown. It may effect the UCL } \\
\text { concentration values input into the } \\
\text { risk calculations. Reduces the power } \\
\text { of the t-tests. }\end{array}$ & \\
\hline $\begin{array}{l}\text { Analytical chemistry methods } \\
\text { resulting in quantitation limits } \\
\text { for many substances being above } \\
\text { "risk-based screening } \\
\text { concentrations" }\end{array}$ & $\begin{array}{l}\text { Low. There are no records of most of } \\
\text { these substances ever being present at } \\
\text { Eielson AFB. However, some } \\
\text { pesticides and other organic chemicals } \\
\text { (PAHs) could be present in } \\
\text { groundwater. }\end{array}$ & & \\
\hline $\begin{array}{l}\text { Assuming concentrations of bis } \\
\text { (2-ethylhexyl) phthalate are due } \\
\text { to laboratory contamination }\end{array}$ & $\begin{array}{l}\text { High. Calculations show that } \\
\text { including bis ( } 2 \text {-ethylhexyl) phthalate } \\
\text { increases the risk estimate by } \\
\text { approximately two orders of } \\
\text { magnimude. }\end{array}$ & & \\
\hline $\begin{array}{l}\text { Assuming concentrations of } \\
\text { methylene chloride are due to } \\
\text { laboratory contamination }\end{array}$ & $\begin{array}{l}\text { Low. There was no effect on the risk } \\
\text { estimates. }\end{array}$ & & \\
\hline $\begin{array}{l}\text { Use of current contamination to } \\
\text { estimate future risk }\end{array}$ & & $\begin{array}{l}\text { Unknown. Most substances are likely } \\
\text { to degrade over time, and current waste } \\
\text { management practices are likely to } \\
\text { reduce or prevent future releases. } \\
\text { However, degradation products could } \\
\text { be more toxic than parent compounds } \\
\text { and their constituents which were } \\
\text { evaluated in this assessment. }\end{array}$ & \\
\hline $\begin{array}{l}\text { Use of average time in a residence } \\
\text { as average time in a workplace }\end{array}$ & $\begin{array}{l}\text { Low. Increasing average time in the } \\
\text { workplace from } 9 \text { to } 27 \text { years would } \\
\text { increase overall risk estimates by less } \\
\text { than a factor of } 3 \text {. }\end{array}$ & & \\
\hline $\begin{array}{l}\text { Use of aquifer as sole source of } \\
\text { drinking water supply }\end{array}$ & & & $\begin{array}{l}\text { Low to Moderate. The water well at } \\
\text { site is not used for drinking water. It } \\
\text { is completed below measurable } \\
\text { contamination. }\end{array}$ \\
\hline
\end{tabular}


IABLE 4.8. The Magnitude of Effect of Uncertainties on Risk Estimates for Sites ST13/DP26

\begin{tabular}{|c|c|c|c|}
\hline $\begin{array}{l}\text { Use of "generic" } \\
\text { bioconcentration factors }\end{array}$ & & $\begin{array}{l}\text { Unknown. Site-specific } \\
\text { bioaccumulation factors could be } \\
\text { lower or higher than the } \\
\text { bioconcentration factors used in the } \\
\text { analysis by one or two orders of } \\
\text { magnitude. However, food chain risks } \\
\text { generally are expected to be } \\
\text { overestimated because the surface } \\
\text { waters are not very attractive to } \\
\text { fishermen (e.g., fish consumption } \\
\text { rates are higher than expected). }\end{array}$ & \\
\hline $\begin{array}{l}\text { Effect of sub-arctic climate on } \\
\text { temperature-specific chemical } \\
\text { parameters (e.g., Henry's Law } \\
\text { Constant and diffusivity) }\end{array}$ & & & $\begin{array}{l}\text { Unknown. These values are used to } \\
\text { determine volatilization from soil, an } \\
\text { exposure pathway that contributed } \\
\text { little to the total risk. Volatilization } \\
\text { efficiencies should decrease with sub- } \\
\text { arctic temperatures. }\end{array}$ \\
\hline $\begin{array}{l}\text { Failure to evaluate risk from TPH } \\
\text { because no toxicity values are in } \\
\text { IRIS or HEAST }\end{array}$ & $\begin{array}{l}\text { Moderate. Calculations show that } \\
\text { including TPH quadrupled the risk } \\
\text { estimates. }\end{array}$ & & \\
\hline $\begin{array}{l}\text { Failure to evaluate risk from lead } \\
\text { because no toxicity values are in } \\
\text { IRIS or HEAST for the inorganic } \\
\text { form }\end{array}$ & $\begin{array}{l}\text { Very high. Calculations show that } \\
\text { inorganic lead toxicity increased risk } \\
\text { by factor of five, tetraethyl lead } \\
\text { increased risk by four orders of } \\
\text { magnitude. }\end{array}$ & & \\
\hline $\begin{array}{l}\text { Effect of using toxicity ratios for } \\
\text { PAHs }\end{array}$ & $\begin{array}{l}\text { Moderate. If benzo(a)pyrene toxicity } \\
\text { was used for all PAHs the risk estimate } \\
\text { increased by factor of } 30 \%\end{array}$ & & \\
\hline $\begin{array}{l}\text { Use of EPA toxicity values (slope } \\
\text { factors and RfDs) to estimate } \\
\text { toxicity and dose-response }\end{array}$ & & & $\begin{array}{l}\text { Unknown. EPA's methods for } \\
\text { deriving toxicity values are intended } \\
\text { to be conservative (i.e., health- } \\
\text { protective). An uncertainty analysis } \\
\text { for these parameters was beyond the } \\
\text { scope of this analysis. }\end{array}$ \\
\hline
\end{tabular}




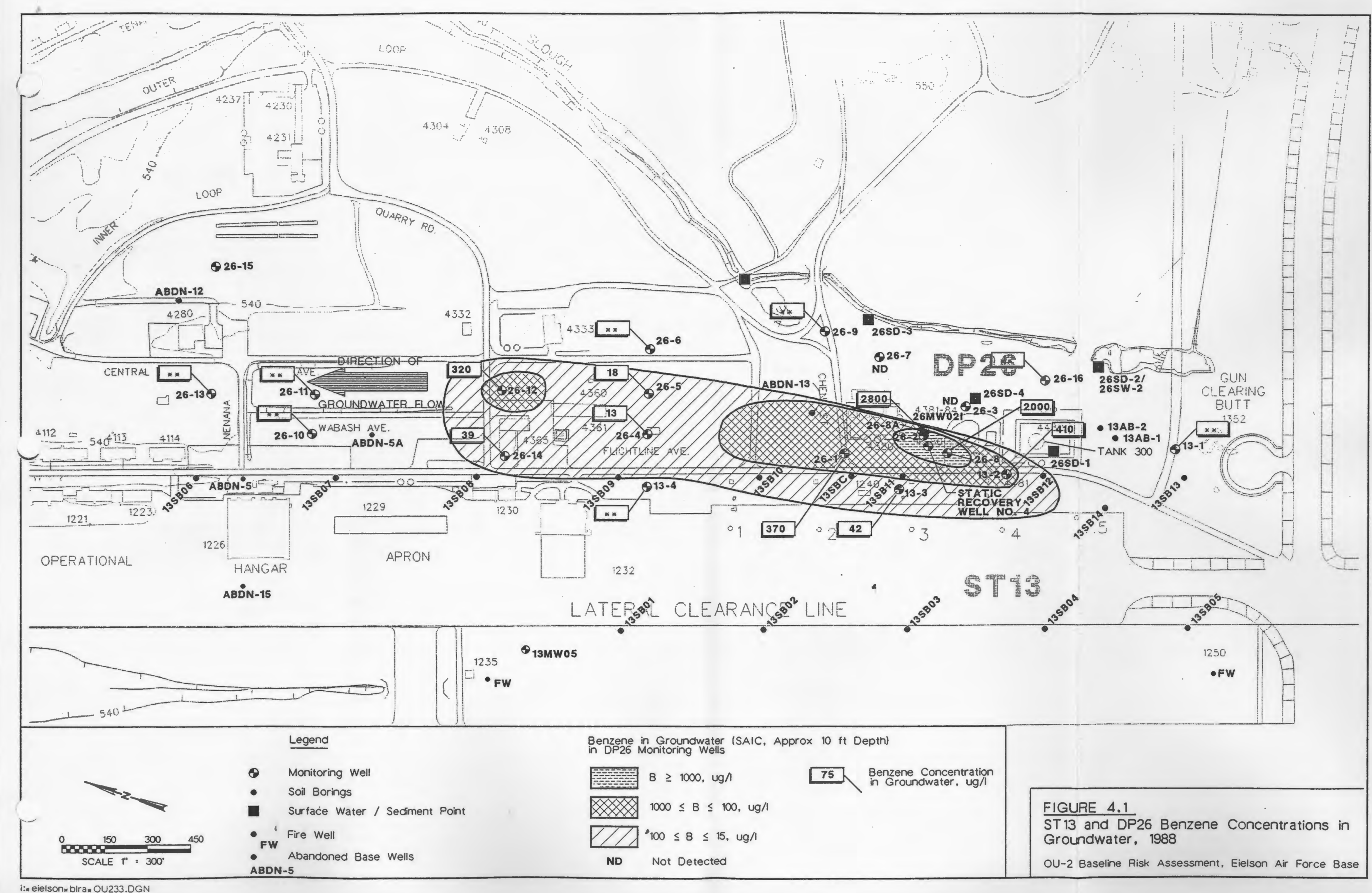




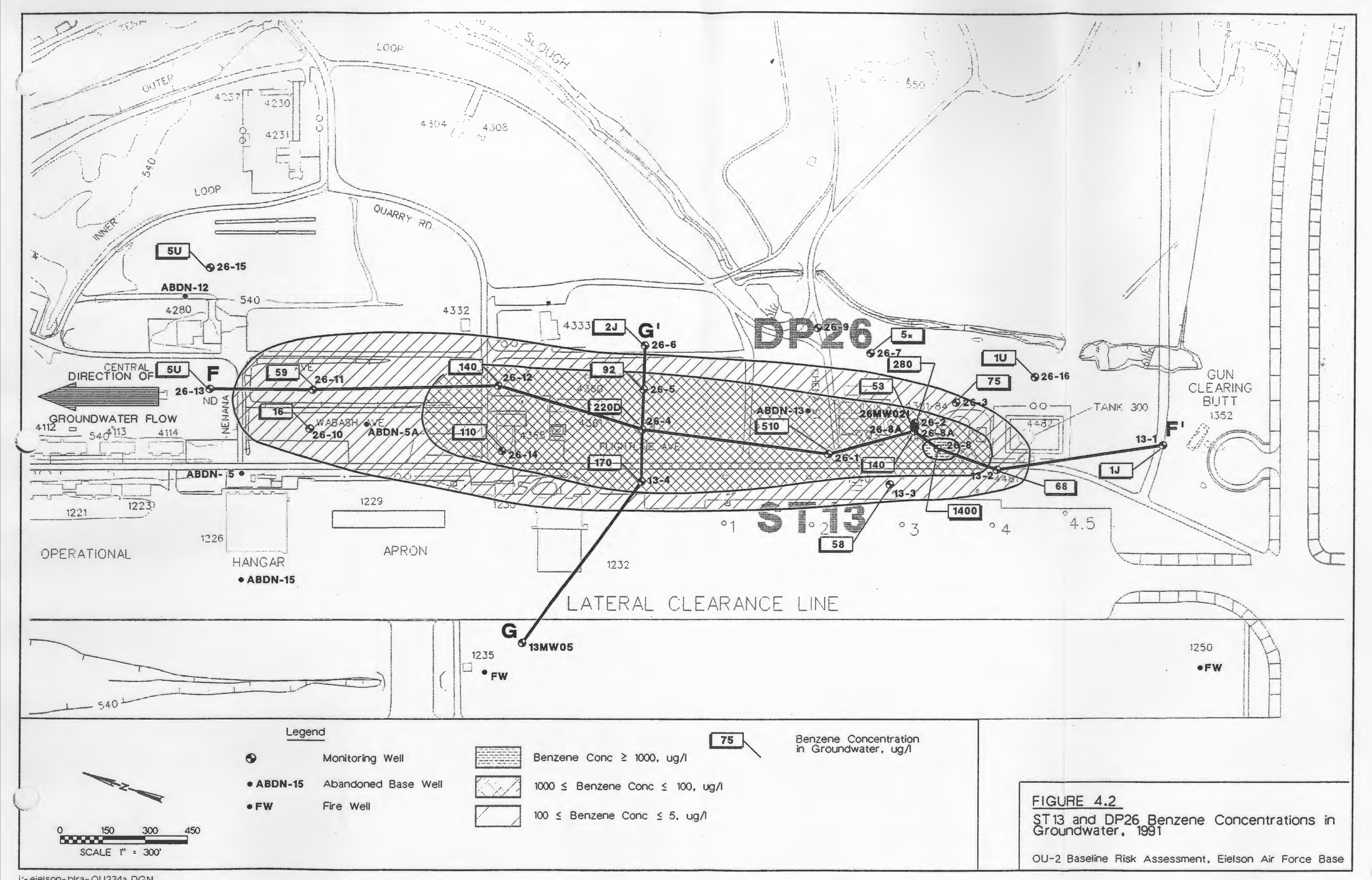




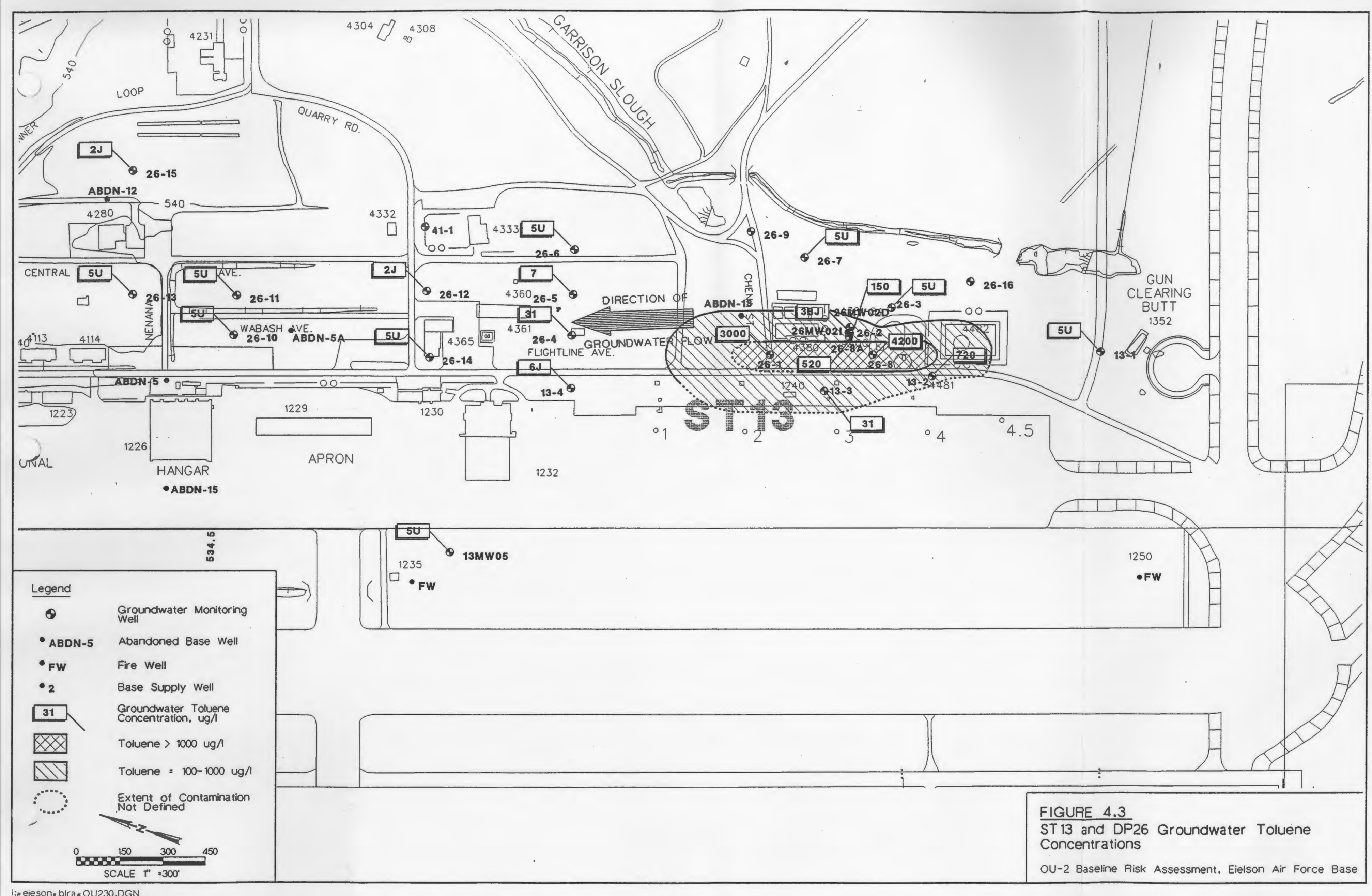




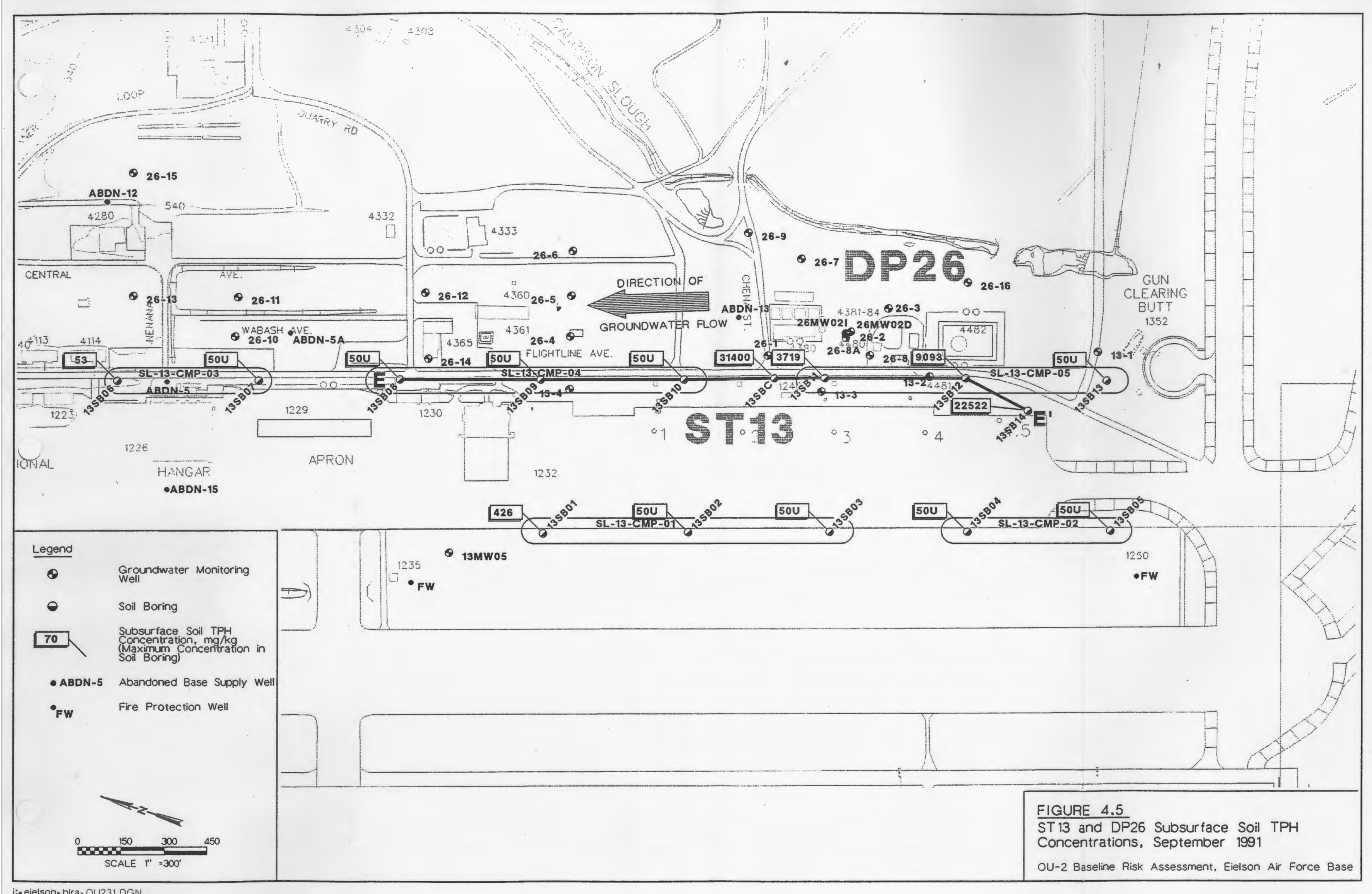




\subsection{SOURCE AREA ST18}

\subsection{CONCEPTUAL SITE MODEL}

This section examines site-specific information on waste sources, release mechanisms, receiving media, and routes of contaminant migration at the site to develop a conceptual understanding of the site. This conceptual site model is needed to evaluate potential risks to human health and the environment.

The contamination at this site is of two types: petroleum hydrocarbons in the subsoil and groundwater, and surface soil contamination by polynuclear aromatic hydrocarbons (PAHs). The petroleum hydrocarbon contamination is believed to have originated from leaks in two 95,000-liter (25,000-gallon) underground diesel storage tanks (U.S. Air Force 1993c, Section 5.5).

The hydrocarbons originally leaked from the tanks into the soil matrix at a depth of approximately 3 meters ( 10 feet) below the soil surface. The leaked fuel infiltrated into the soil and migrated to the water table, where it initially spread laterally on top of the groundwater. The residual evidence of this process is the "floating product," "floating fuel," or "free product" found at the site. The free product consists of two physically distinct phases, a water-soluble phase and a relatively non-water-soluble phase.

The water-soluble contaminants then started to dissolve into the groundwater or volatilize to the atmosphere, while the higher-molecular-weight hydrocarbon contaminants (which are less water soluble) accumulated at the groundwater interface. As the groundwater fluctuated downward the higher-molecular-weight hydrocarbon contaminants were assumed to have been carried deeper into the soil profile, where they remained when the groundwater fluctuated upward again. These higher-molecular-weight hydrocarbons, and longer-chain contaminants are measured on site as total petroleum hydrocarbons (TPH).

The water-soluble contaminants that dissolve into the groundwater are carried with the groundwater downgradient. Each contaminant moves at a unique rate in the groundwater; benzene moves faster than toluene, toluene moves faster than the other soluble organic constituents, and soluble lead moves at the slowest rate. The aquifer has a relatively high rate of horizontal groundwater flow [approximately 0.6 meter/day (2 feet/day)] and the slow vertical mixing of the groundwater. The rapid horizontal groundwater movement probably serves to confine groundwater contaminants near the top of the upper groundwater level. This assumption is confirmed by the lack of groundwater contamination in a well at site ST18 completed at an intermediate depth..

As the water-soluble contaminants (which tend to be the lighter petroleum constituents such as benzene, toluene, ethylbenzene, and xylene) are carried away, the highermolecular-weight hydrocarbon contaminants become less mobile in the soil matrix, because of increased viscosity, until eventually movement virtually stops and a highly viscous layer forms in the soil. This viscous layer of contaminants underlies an area that extends north and east of the underground diesel storage tanks, to a depth of approximately 1.5 to 4.6 meters ( 5 to 15 feet). However, the contamination appears to be concentrated at depths of 2.7 to 3.2 meters (9 to 10.5 feet) (Figures 5.1 and 5.2).

The surface soil PAH contamination is probably unrelated to the subsurface hydrocarton contamination. The PAHs occur along a railroad track that is upgradient from the subsurface hydrocarbon contamination. The PAHs most likely originated from the 
deposition (on the surface soil) of diesel exhaust while mechanics were tuning diesel engines in the nearby locomotive repair shop.

\subsection{EXPOSURE ASSESSMENT}

The "Exposure Assessment" section examines land use, exposure time frame, exposure setting, and exposure pathways. Table 5.1 summarizes the results of the exposure assessment. A list of chemicals of potential concem, fate and transport modeling results, exposure point concentrations, intake variables and/or exposure factors, toxicological values, and risk calculations are presented elsewhere in this report.

Exposure is defined as the contact of an organism with a chemical or physical agent. The overall objective of the exposure assessment is to estimate the types and magnitude of exposures to chemicals of potential concern that are present at, or migrating from, the site. The results of the exposure assessment are combined with chemical-specific toxicity information to characterize potential risks (EPA 1989a).

\subsubsection{Land-Use Assumptions for ST18}

Health risk will be quantified for three land-use assumptions. One is the risk from current land use, which is industrial in nature. Two different land-use assumptions are considered for evaluation of the future risk: 1) residential housing and 2) military/industrial land use. All of the assumptions assume that no mitigation is undertaken. The difference between the current and future industrial use assumptions is that the contaminants are expected to migrate and change in concentration over time.

Long-range land-use plans (Eielson Air Force Base 1992) indicate that site ST18 will remain an industrial site for the foreseeable future. The two 25,000 gallon underground diesel storage and associated piping are scheduled to be tested in summer 1993.

\subsubsection{Theoretical Exposure Pathways}

The plausible (current and future) theoretical human exposure pathways from ST18 contaminants are

- ingestion of groundwater (future only)

- inhalation of and dermal contact with contaminants during groundwater use

(future only)

- incidental ingestion of the surface soils

- dermal contact with surface soils

- ingestion of plants grown in contaminated soils (future only)

- incidental ingestion of the subsurface soils

- dermal contact with subsurface soils

- inhalation of volatile contaminants released from the soil into the ambient air

- inhalation of resuspended particulates.

\subsubsection{Current Exposure Pathways, Industrial Land Use: Ratlonale for Elimination from Further Consideration}

This subsection explains why four theoretical exposure pathways, postulated to occur given existing land-use conditions, are not examined in the quantitative risk 
calculations to follow. Each eliminated pathway is identified, and the rationale for elimination is noted.

Eliminated Pathways: ingestion of groundwater, and inhalation of and dermal contact with contaminants during groundwater use.

Rationale: There are no production water wells within the identified groundwater plumes at this site. The nearest drinking water well is approximately 210 meters $(700$ feet) downgradient. Fate and transport modeling indicates that contamination at ST18 will be have no measurable effect now or in the future on the water quality at the base supply well (Section 8.2.3.3).

An abandoned base well is within ST18 (Figure 5.1). There is no record of the use of the well, why it was abandoned, or when it was abandoned. There is no surface expression of the well today. Therefore, there is no complete pathway for exposure to the contaminated groundwater, and the pathways involving groundwater exposure will not be evaluated.

An abandoned well is sited within the TPH-contaminated part of ST18 (Figure 5.1).

Eliminated Pathways: ingestion of plants grown in contaminated soils.

Rationale: The area's current land use is for a military complex, with industrial processes. No crops are grown on the contaminated soils. Therefore, the pathway involving plant ingestion is considered incomplete and will not be evaluated.

\subsubsection{Identification of Current (Industrial) Exposure Pathways}

For the current risk calculations, the following pathways are considered to be complete and reasonable for further analysis:

- incidental ingestion of surface soils

- dermal contact with surface soils

- incidental ingestion of the subsurface soils

- dermal contact with subsurface soils

- inhalation of volatile contaminants released from the soil into the ambient air

- inhalation of resuspended particulates.

\subsubsection{Euture Exposure Pathways: Resldentlal Land Use}

Assuming a residential housing land use as a future exposure assumption, the following pathways are considered to be complete and reasonable for analysis:

- ingestion of groundwater used as potable water supply

- inhalation of and dermal contact with contaminants during groundwater use

- incidental ingestion of surface soils

- dermal contact with surface soils

- ingestion of plants grown in contaminated soils

- incidental ingestion of subsurface soils

- dermal contact with subsurface soils

- inhalation of volatile contaminants released from the soil into the ambient air

- inhalation of resuspended particulates. 
IABLE_5.1. SUMMARY OF HUMAN EXPOSURE PATHWAYS FOR SOURCE AREA ST18

\section{IHEORETICALPATHWAYS}

ingestion of groundwater used as

potable water supply.

CURRENT LAND USE

(INDUSTBIAL)

inhalation of and dermal contact with

contaminants during groundwater use.....

- incidental ingestion of surface soils...

- dermal contact with surface soils...

- ingestion of plants grown in

contaminated soils.

- incidental ingestion of subsurface

soils.

- dermal contact with subsurface soils.

- inhalation of volatile contaminants

released from the soil into the

ambient air....

- inhalation of resuspended particulates $x$

$x$

$x$

$x$

$x$

$x$

$x$

$x$

$x$

$x$ $x$

$x$

$x$

$x$

$x$

$X=$ Pathway retained for quantitative risk evaluation

- = Pathway eliminated, see text for elimination rationale 
Future residences are assumed to utilize groundwater for potable supply and to have garden plots associated with the homes. All theoretical exposure pathways postulated (and listed above) will be examined in subsequent risk calculations for the future exposure residential assumption.

\subsubsection{Euture Exposure Pathways, Industrlal Land Use: Rationale for Elimination from Further Consideration}

This subsection explains why one theoretical exposure pathway, postulated to occur given existing land-use conditions, is not examined in the quantitative risk calculations to follow. The eliminated pathway is stated and the rationale for elimination is noted.

Eliminated Pathways: ingestion of plants grown in contaminated soils.

Rationale: The area's current land use is a military/industrial complex. No crops are grown on the site soils. Therefore, the theoretical exposure pathway involving plant ingestion is incomplete and will not be evaluated quantitatively.

\subsubsection{Euture Exposure Pathways: Industrial Land Use}

Assuming industrial activities as the future land use, the following pathways are considered to be complete and reasonable for analysis:

- ingestion of groundwater used as potable water supply

- inhalation and dermal contact with contaminants during groundwater use

- incidental ingestion of surface soils

- dermal contact with surface soils

- incidental ingestion of subsurface soils

- dermal contact with subsurface soils

- inhalation of volatile contaminants released from the soil into the ambient air

- inhalation of resuspended particulates.

Future industrial activities are assumed to be similar to current activities.

\subsection{RISK CHARACTERIZATION}

This section presents, in table format, the excess cancer risk and the Hazard Index for source area ST18 by exposure pathway. The cancer risk and Hazard Index are presented for both the "Average Exposure Case" and the "Reasonable Maximum Exposure Case." Tables 5.2 and 5.3 present risk values for the current land use (industrial), Tables 5.4 and 5.5 present the future residential land-use values, and Tables 5.6 and 5.7 present the future industrial land-use values.

Each table presents the cancer risk and the Hazard Index for each exposure pathway individually. A total cancer risk value and a total Hazard Index are presented which add all of the exposure pathway risks together. Values are presented for cancer risk and Hazard Index in two ways. The first column includes the contribution of metals in the groundwater that are suspected to be attributable to site background and therefore likely not related to past site activities. The second column excludes the contribution from potential background metals. The potential background metals are arsenic, berylium, cadmium, manganese, and thallium. 
The calculation of the cancer risk and Hazard Index necessitates the use of information and data input from many sources which are presented elsewhere in this report. For ease of reference, the information used to perform the risk calculations is cross referenced.

Identification of Chemicals of Potential Concern

Section 7.0

Exposure Point Concentrations and Modeling Results

Section 8.0

Toxicity Assessment

Risk Calculation Formulas

Exposure Factors

Section 9.0

Fate and Transport Models

Appendix A

Contaminant Concentration Inputs

Appendix B

Appendix $C$

Appendix F

More detailed risk output tables are in Appendix K (Tables K.37 through K.48). These tables include all of the data in Tables 5.2 through 5.7 plus the cancer risks and Hazard Quotients for the individual compounds that drive the risk (cancer risk $>10^{-7}$ and Hazard Quotient $>10^{-2}$ ).

\subsection{SITE-SPECIFIC UNCERTAINTIES AND CONSIDERATIONS}

This section presents key information bearing on the level of confidence in the quantitative risk estimates for a site. The risk estimates are conditional given a considerable number of assumptions about site characterization, exposure, and toxicity.

Two major categories of uncertainty are discussed in the following subsections. Table 5.8 lists the major sources of uncertainty that affect this assessment and their possible magnitude of effect on the risk estimates.

\subsubsection{Exposure Uncertainties}

Some of the exposure frequencies used in this assessment differ from default values provided by EPA Region X (EPA 1991a) for the following exposure pathways: dermal contact with surface and subsurface soils, incidental ingestion of surface and subsurface soils, and inhalation of resuspended particulates. These differences are delineated in Table 2.8. Different exposure factors were used because of the subarctic climate at Eielson AFB, which is atypical of most EPA Region X sites. 146 days per year is the mean number of days at Fairbanks without snow cover (Battelle 1992b). Table 5.8 lists the magnitude of effect for this assumption.

The ingestion of animals raised on contaminated feed was not included in the primary risk calculations due to the sub-arctic climate at Eielson. Table 5.8 presents the magnitude of effect caused by exclusion of this exposure pathway. The risk was calculated using exposure factors presented in EPA (1991e) for consumption of animal products.

\subsubsection{Toxicity Uncertainties}

There are no approved EPA toxicity values for total petroleum hydrocarbons. It was not included in the primary risk calculations. However, a surrogate toxicity value was introduced in Section 9 of this assessment. The magnitude of effect on the risk calculations due to the inclusion of this compound is presented in Table 5.8.

\subsubsection{General Site Considerations}

Section 10 of this assessment discusses the effects of uncertainties that affect all of the Operable Unit 2 sites. Table 5.8 estimates their magnitude of effect. 


\section{TABLE 5.2, SOURCE AREA ST18; SUMMARY OF CANCER RISK AND HAZARD INDEX}

Average Exposure Case: Current Exposure Pathways / Industrial Land-Use Assumption

\section{EXPOSUREPATHWAYS}

- incidental ingestion of surface soils

cancer risk.

Hazard Index Not Included

rmal contact with surface soils

cancer risk.

Hazard Index

$<1 E-07$

$<1 E-02$

2E-07

E-01

$<1 E-02$

- incidental ingestion of subsurface soils

cancer risk.

Hazard Index

- inhalation of volatile contaminants released from the soil into ambient air.

cancer risk.

Hazard Index

- inhalation of resuspended particulates

cancer risk.

Hazard Index

SUMMATION ACROSS ALL EXPOSURE PATHWAYS FOR SOURCE AREA

Total cancer risk

Total Hazard Index 
TABLE 5.3. SOURCE AREA ST18; SUMMARY OF CANCER RISK AND HAZARD INDEX Reasonable Maximum Exposure Case: Current Exposure Pathways / Industrial Land-Use Assumption

\section{EXPOSUREPATHWAYS}

- incidental ingestion of surface soils

cancer risk

Hazard Index

Suspected Background Metals Included Not Included

dermal contact with surface soils

cancer risk.

Hazard Index

3E-06

7E-07

IE-01

$<1 E-02$

- incidental ingestion of subsurface soils

cancer risk

7E-07

$7 \mathrm{E}-02$

$<1 E-07$

Hazard Index

cancer risk

cancer risk.. 
TABLE 5.4. SOURCE AREA ST18; SUMMARY OF CANCER RISK AND HAZARD INDEX Average Exposure Case: Future Exposure Pathways / Residential Housing Land-Use Assumption

\section{EXPOSUREPATHNAYS}

Suspected Background Metals

- ingestion of groundwater used as potable water supply

cancer risk.

Included Not Included

Hazard Index

$.1 E-04$

$<1 \mathrm{E}-07$

- inhalation of and dermal contact with contaminants during groundwater use

cancer risk.

$2 \mathrm{E}+01$

$<1 \mathrm{E}-02$

Hazard Index.

$.2 \mathrm{E}-06$

2E-06

- incidental ingestion of surface soils

cancer risk.

$. .4 \mathrm{E}-02$

$<1 E-02$

Hazard Index

$.3 E-06$

$6 \mathrm{E}-07$

- dermal contact with surface soils

1E-01

$<1 E-02$

cancer risk.

$<1 E-07$

$<1 \mathrm{E}-07$

Hazard Index.

$<1 \mathrm{E}-02$

$<1 E-02$

- ingestion of plants grown in contaminated soils

cancer risk..

6E-06

Hazard Index

$1 E+01$

3E-06

- incidental ingestion of subsurface soils

cancer risk.

$6 \mathrm{E}-07$

Hazard Index.

2E-01

$<1 E-02$

- dermal contact with subsurface soils

cancer risk.

$<1 \mathrm{E}-07$

$<1 E-02$

$<1 \mathrm{E}-07$

Hazard Index

$<1 \mathrm{E}-07$

$<1 E-02$

$<1 E-02$

- inhalation of volatile contaminants released from the soil into ambient air.

cancer risk.

$<1 \mathrm{E}-07$

alation of resuspended particulates

cancer risk.

$<1 E-02$

$<1 \mathrm{E}-07$

$<1 \mathrm{E}-02$

Hazard Index

$<1 \mathrm{E}-07$

$<$ TE-02

SUMMATION ACROSS ALL EXPOSURE PATHWAYS FOR SOURCE AREA

Total cancer risk.

Total Hazard Index 
TABLE 5.5, SOURCE AREA ST18; SUMMARY OF CANCER RISK AND HAZARD INDEX Reasonable Maximum Exposure Case: Future Exposure Pathways / Residential Housing Land-Use Assumption

\section{EXPOSUREPATHWAYS}

- ingestion of groundwater used as potable water supply

cancer risk.

Hazard Index.

- inhalation of and dermal contact with contaminants during groundwater use

cancer risk.

Hazard Index.

- incidental ingestion of surface soils

cancer risk.

Hazard Index.

Suspected Background Metals

Included Not Included

rmal contact with surface soils

cancer risk.

$.9 E-04$

$.4 E+01$

6E-07

Hazard Index

1E-05

.7E-02

$<1 E-02$

9E-06

$<1 E-02$

$.2 E-05$

8E-01

5E-06

$<1 E-02$

in contaminated solls

cancer risk ...........3E-05

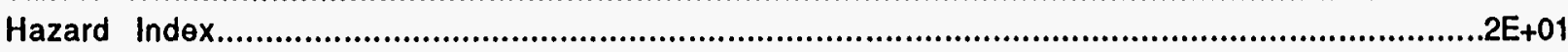

.2E-06

2E-06

$<1 \mathrm{E}-02$

dental ingestion of subsurface soils

cancer risk.

$.5 \mathrm{E}-06$

Hazard Index.................5E-01

- dermal contact with subsurface soils

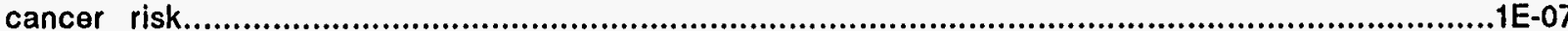

Hazard Index......................................................................................................1E-02

- inhalation of volatile contaminants released from the soil into ambient air.

cancer risk.

.<1E-07

Hazard Index.

$<1 \mathrm{E}-02$

- inhalation of resuspended particulates

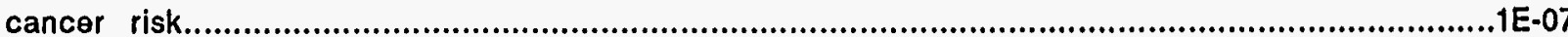

Hazard Index

SUMMATION ACROSS ALL EXPOSURE PATHWAYS FOR SOURCE AREA

Total cancer risk

Total Hazard Index. 
IABLE 5.6, SOURCE AREA ST18; SUMMARY OF CANCER RISK AND HAZARD INDEX Average Exposure Case: Future Exposure Pathways / Industrial Land-Use Assumption

\section{EXPOSUBEPATHWAYS}

- ingestion of groundwater used as potable water supply

cancer risk

Hazard Index.

- inhalation of and dermal contact with contaminants during groundwater use

cancer risk.

Hazard Index.

Suspected Background Metals

Included

Notlncluded

incidental ingestion of surface soils

cancer risk...

9E-05

$<1 E-07$

Hazard Index

1E+01

$<$ IE-02

dermal contact with surface soils

cancer risk

2E-06

3E-02

2E-06

$<1 E-02$

Hazard Index.

1E-06

1E-01

2E-07

<1E-02

$<1 E-02$

$<1 E-07$

$<1 E-02$

- incidental ingestion of subsurface soils

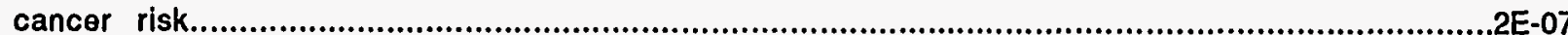

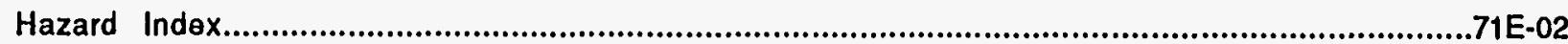

$<1 \mathrm{E}-07$

$<1 E-02$

- dermal contact with subsurface soils

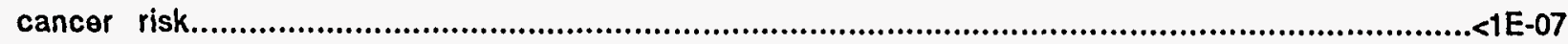

Hazard Index.

$<1 E-02$

$<1 \mathrm{E}-07$

$<1 E-02$

- inhalation of volatile contaminants released from the soil into ambient air.

cancer risk.

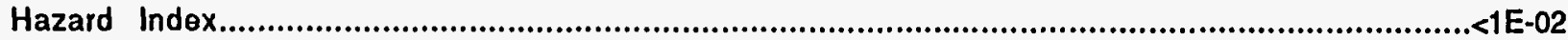

$<$ IE-07

$<1 E-02$

- inhalation of resuspended particulates

cancer risk.

.<1E-07

Hazard Index.

$<1 E-02$

$<1 E-07$

$<1 E-02$

SUMMATIN ACROSS ALL EXPOSURE PATHWAYS FOR SOURCE AREA

Total cancer risk

1E-04

2E-06

Total Hazard Index

$1 E+01$

$<1 E-02$ 
TABLE 5.7. SOURCE AREA ST18; SUMMARY OF CANCER RISK AND HAZARD INDEX Reasonable Maximum Exposure Case: Future Exposure Pathways / Industrial Land-Use Assumption

\section{EXPOSUREPATHWAYS}

- ingestion of groundwater used as potable water supply

cancer risk.

Hazard Index.

Suspected Background Metals Included Not Included

- inhalation of and dermal contact with contaminants during groundwater use

cancer risk

2E-07

Hazard Index.

$.5 \mathrm{E}-02$

$<1 E-02$

- incidental ingestion of surface soils

cancer risk.

Hazard Index.

1E-01

6E-06

$<1 \mathrm{E}-02$

mal contact with surface soils

cancer risk.

9E-07

Hazard Index...

.1E-02

7E-07

$<1 E-02$

- incidental ingestion of subsurface soils

cancer risk

7E-07

Hazard Index.

7E-07

<1E-02

- dermal contact with subsurface soils

cancer risk.

$<1 E-07$

Hazard Index

$<1 E-02$

$<1 E-07$

$<1 E-02$

- inhalation of volatile contaminants released from the soil into ambient air.

cancer risk

$<1 E-07$

Hazard Index.

$<1 E-02$

$<1 E-07$

$<1 E-02$

- inhalation of resuspended particulates

cancer risk.

1E-07

Hazard Index

$<1 E-02$

$<1 E-07$

$<1 \mathrm{E}-02$

SUMMATION ACROSS ALL EXPOSURE PATHWAYS FOR SOURCE AREA

Total cancer risk

Total Hazard Index 
IABLE 5.8. The Magnitude of Effect of Uncertainties on Risk Estimates for Site ST18

\begin{tabular}{|c|c|c|c|}
\hline \multirow{2}{*}{ Source of Uncertainty } & \multicolumn{3}{|c|}{ Potential Magnitude of Effect on Risk Estimate } \\
\hline & Underestimating Risk & $\begin{array}{l}\text { Underestimating or } \\
\text { Overestimating Risk }\end{array}$ & Overestimating Risk \\
\hline $\begin{array}{l}\text { Assumption that concentrations } \\
\text { of metals in environmental media } \\
\text { represent background } \\
\text { contamination }\end{array}$ & $\begin{array}{l}\text { High. Calculations show that risk } \\
\text { estimates generally increased by two } \\
\text { to four orders of magnitude when } \\
\text { exposure to metals was included }\end{array}$ & & \\
\hline $\begin{array}{l}\text { Use of exposure factors other than } \\
\text { default values provided in Region } \\
10 \text { guidance (e.g., frequency of } \\
\text { exposure to contaminated soil) }\end{array}$ & $\begin{array}{l}\text { Very low. Calculations show that risk } \\
\text { estimates did not increase when } \\
\text { Region } 10 \text { default values were used. }\end{array}$ & & \\
\hline $\begin{array}{l}\text { Assumption that ingestion of } \\
\text { animals fed contaminated plants } \\
\text { is not a complete pathway }\end{array}$ & $\begin{array}{l}\text { Moderate. Calculations show that risk } \\
\text { estimates would double if this pathway } \\
\text { was included. }\end{array}$ & & \\
\hline $\begin{array}{l}\text { Effect of not including surface } \\
\text { water runoff pathway }\end{array}$ & $\begin{array}{l}\text { Unknown. The surface soil } \\
\text { contamination is PAH, which is not } \\
\text { very mobile and there are no surface } \\
\text { water bodies nearby. }\end{array}$ & & \\
\hline $\begin{array}{l}\text { Use of EPA Region } 10 \text { default } \\
\text { exposure factors }\end{array}$ & & & $\begin{array}{l}\text { Low to Moderate. Risk estimates for } \\
\text { the "average" individual are } \\
\text { approximately one order of magnitude } \\
\text { lower than those of the "RME" } \\
\text { individual for the residential } \\
\text { scenarios; the difference is less than } \\
\text { one order of magnitude for the } \\
\text { industrial scenarios. }\end{array}$ \\
\hline $\begin{array}{l}\text { Method used to sum risk across } \\
\text { multiple substances and pathways }\end{array}$ & & $\begin{array}{l}\text { Unknown. Summing effects across } \\
\text { multiple contaminants assumes their } \\
\text { effects are additive. Risk may be } \\
\text { underestimated if two or more } \\
\text { chemicals act synergistically and } \\
\text { overestimated if two or more } \\
\text { chemicals act antagonistically. The } \\
\text { approach also assumes that target } \\
\text { organs and toxicity mechanisms are } \\
\text { identical, an assumption that should } \\
\text { overestimate risk. }\end{array}$ & \\
\hline
\end{tabular}


IABLE 5.8. The Magnitude of Effect of Uncertainties on Risk Estimates for Site ST18

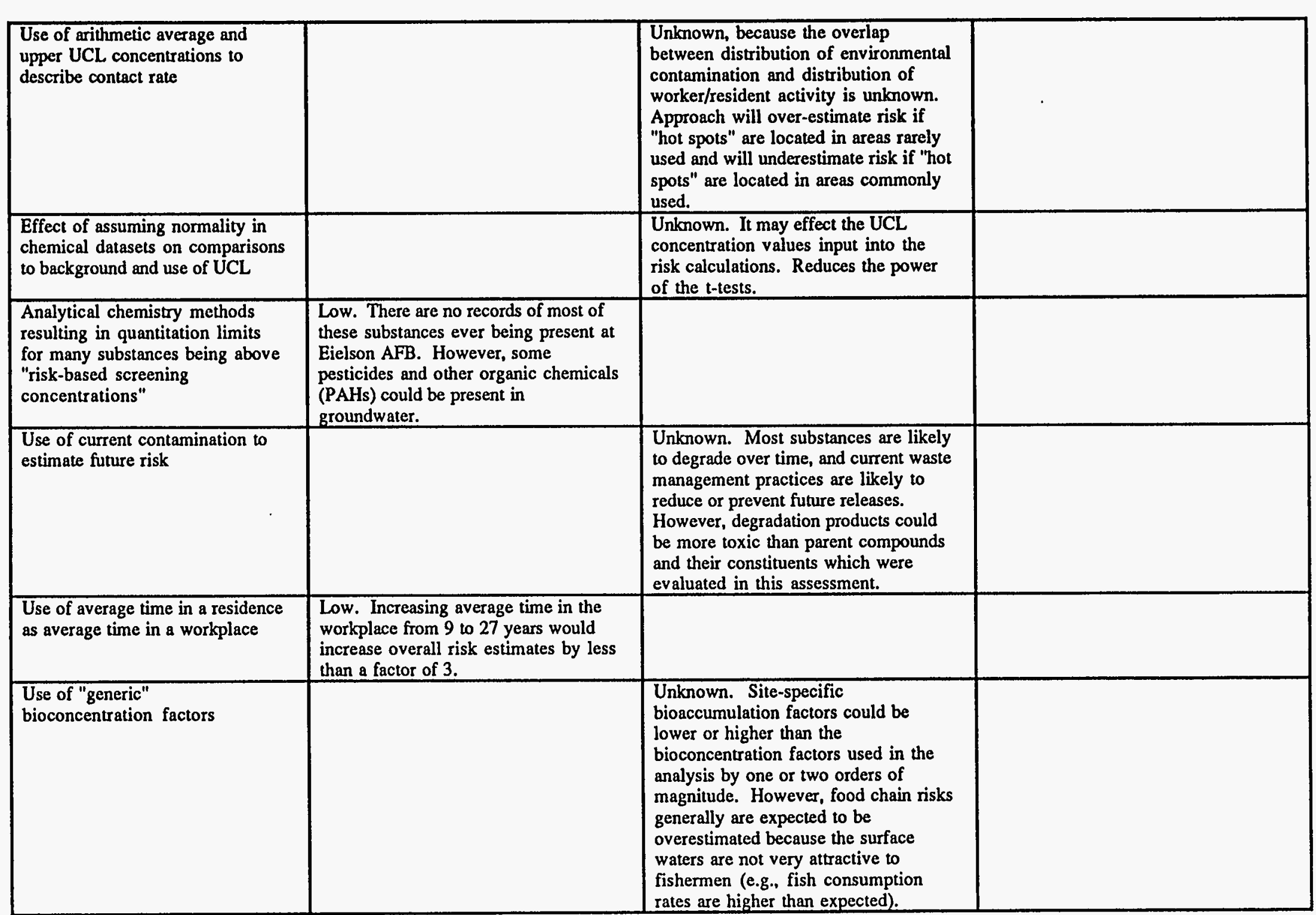


IABLE 5.8. The Magnitude of Effect of Uncertainties on Risk Estimates for Site ST18

\begin{tabular}{|c|c|c|}
\hline $\begin{array}{l}\text { Effect of sub-arctic climate on } \\
\text { temperature-specific chemical } \\
\text { parameters (e.g., Henry's Law } \\
\text { Constant and diffusivity) }\end{array}$ & & $\begin{array}{l}\text { Unkonown. These values are used to } \\
\text { determine volatilization from soil, an } \\
\text { exposure pathway that contributed } \\
\text { little to the total risk. Volatilization } \\
\text { efficiencies should decrease with sub- } \\
\text { arctic temperatures. }\end{array}$ \\
\hline $\begin{array}{l}\text { Failure to evaluate risk from TPH } \\
\text { because no toxicity values are in } \\
\text { IRIS or HEAST }\end{array}$ & $\begin{array}{l}\text { High. Calculations show that } \\
\text { including TPH increases the risk } \\
\text { estimates by two order of magnitude. }\end{array}$ & \\
\hline $\begin{array}{l}\text { Failure to evaluate risk from lead } \\
\text { because no toxicity values are in } \\
\text { IRIS or HEAST for the inorganic } \\
\text { form }\end{array}$ & $\begin{array}{l}\text { No effect. Lead was not detected in } \\
\text { concentrations greater than natural } \\
\text { background.. }\end{array}$ & \\
\hline $\begin{array}{l}\text { Effect of using toxicity ratios for } \\
\text { PAHs }\end{array}$ & $\begin{array}{l}\text { Moderate. Risk estimates doubled if } \\
\text { toxicity of benzo(a)pyrene is used for } \\
\text { all PAHs. }\end{array}$ & \\
\hline $\begin{array}{l}\text { Use of EPA toxicity values (slope } \\
\text { factors and RfDs) to estimate } \\
\text { toxicity and dose-response }\end{array}$ & & $\begin{array}{l}\text { Unknown. EPA's methods for } \\
\text { deriving toxicity values are intended } \\
\text { to be conservative (i.e., health- } \\
\text { protective). An uncertainty analysis } \\
\text { for these parameters was beyond the } \\
\text { scope of this analysis. }\end{array}$ \\
\hline
\end{tabular}




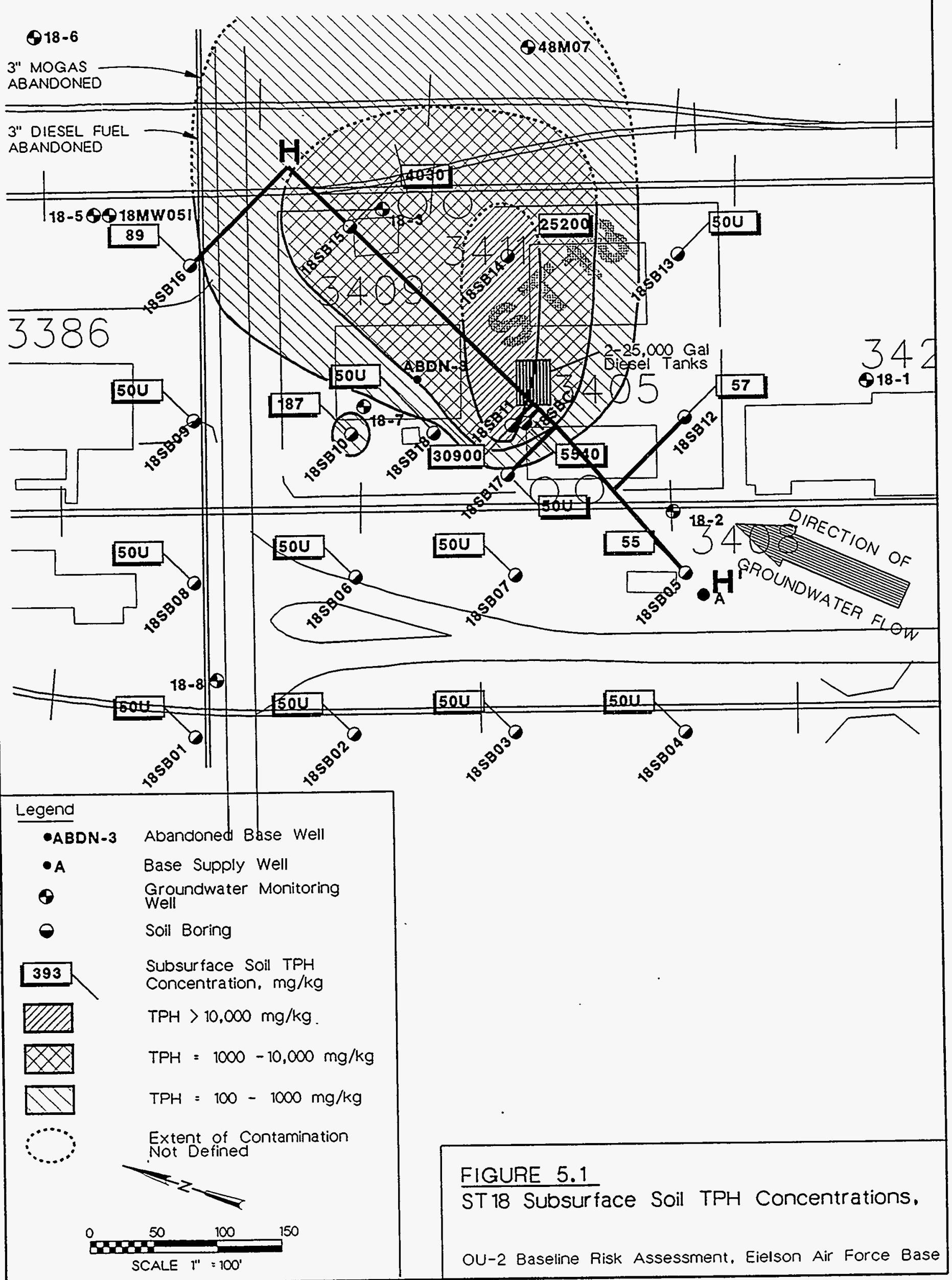




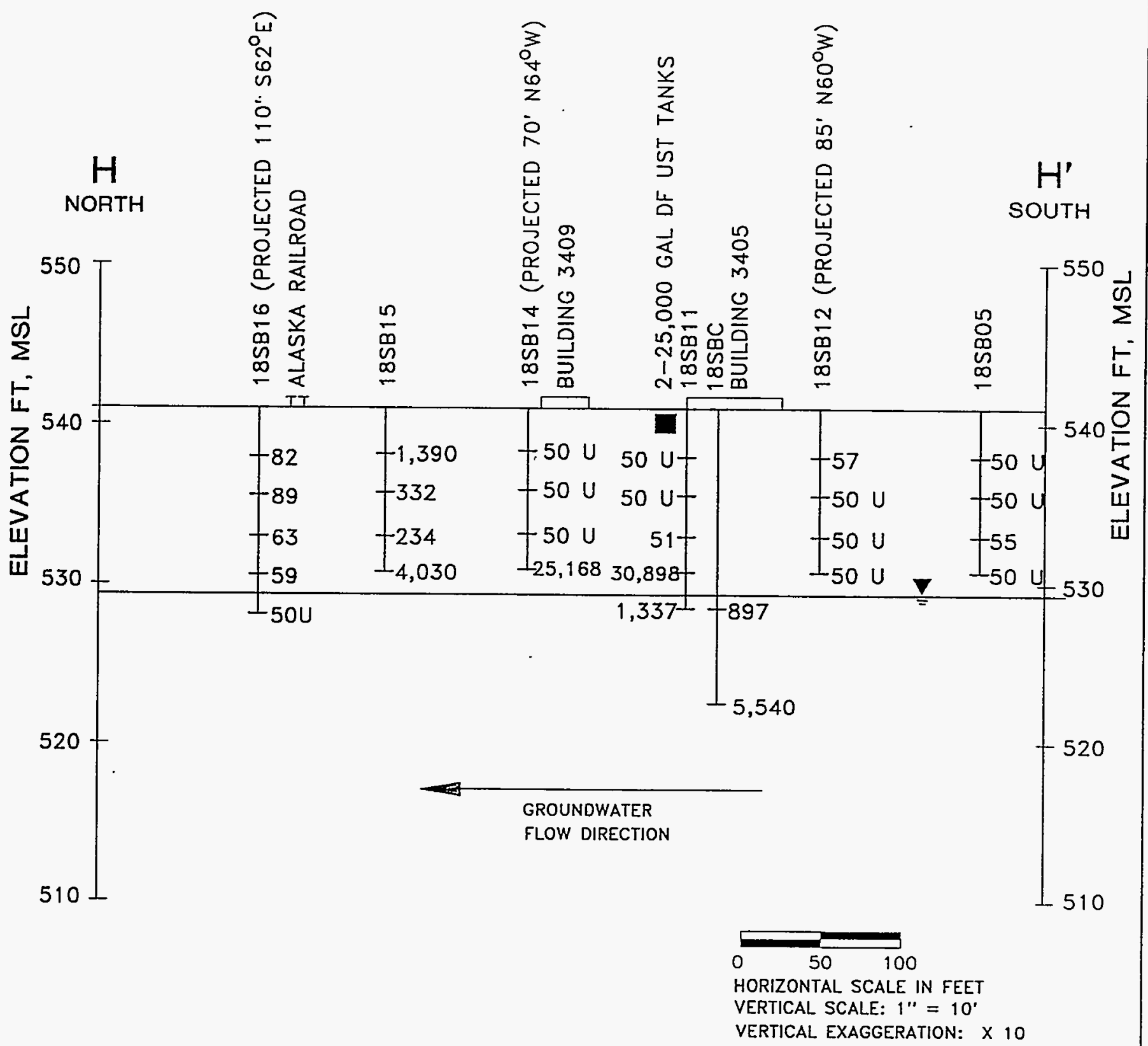

\section{LEGEND}

$\begin{array}{ll}\text { U } & \text { CONCENTRATION BELOW DETECTION LIMIT } \\ \searrow & \text { GROUNOWATER LEVEL }(9 / 27 / 91) \text { PROJECTED } \\ \cong & \text { FROM WELLS } 18-2 \text { AND } 18-3\end{array}$

U UNDERGROUND STORAGE TANK

O DF=DIESEL FUEL

VERTICAL SCALE: $1^{\prime \prime}=10^{\circ}$

VERTICAL EXAGGERATION: $\times 10$

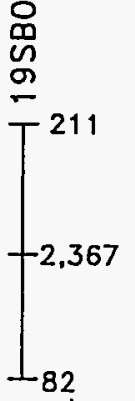

Figure 5.2

BOREHOLE WITH

TPH CONCENTRATION

ST18, TPH CONCENTRATIONS

iN SOILS

IN SOILS 


\subsection{SOURCE AREA ST19}

\subsection{CONCEPTUAL SITE MODEL}

This section examines site-specific information on waste sources, release mechanisms, receiving media, and routes of contaminant migration at the site to develop a conceptual understanding of the site. This conceptual site model is needed to evaluate potential risks to human health and the environment.

ST19 is located along a road next to a buried, concrete-lined utilidor that contains two jet fuel pipelines. A snowplow broke a flow control valve in the late 1950s, and approximately 200,000 gallons of JP-4 were spilled onto the surface soils along the right-of-way. The site is located in a remote wooded area of the base. The working hypothesis is that spilled JP-4 formed a small reservoir along the pipeline and surrounding depressions (U.S. Air Force 1993c, Section 5.6). It is believed that the lighter contaminants (benzene, toluene, ethylbenzene, and xylene) volatilized from the surface of the small JP-4 reservoir.

The JP-4 infiltrated into the soil, where some separation of chemical components is assumed to have occurred. The lighter petroleum components (benzene, toluene, ethylbenzene, and xylene), being relatively water soluble, were carried down to the water table, where they probably moved horizontally with the groundwater flow. The highermolecular-weight hydrocarbon contaminants migrated slowly into the soil profile. As the lighter petroleum components were separated from the fuel, the remaining highermolecular-weight hydrocarbon contaminants became more viscous. Therefore, their rate of movement in the soil slowed. The soluble components appear to still be actively leaching downward to the water table, where they dissolve in the groundwater (Figures 6.1 and 6.2).

The water-soluble contaminants that dissolve into the groundwater are carried downgradient with the groundwater. Each contaminant moves at a unique chemicalspecific rate in the groundwater: benzene moves faster than toluene, toluene moves faster than the other soluble organic constituents, and soluble lead moves at the slowest rate. The rapid horizontal groundwater movement serves to confine groundwater contaminants near the top of the upper groundwater level.

This subsurface soil hydrocarbon contamination covers an oblong area that runs approximately 610 meters ( 2000 feet) along the pipeline route and is approximately 180 meters (600 feet) wide (Figure 6.3). The subsurface soil contamination is at higher concentrations near the location of the original pipeline rupture and is found between 0.9 and 1.5 meters ( 3 to 5 feet) below ground surface (Figure 6.4).

\subsection{EXPOSURE ASSESSMENT}

This section examines land use, exposure timeframe, exposure setting, and exposure pathways. Table 6.1 summarizes the results of the exposure assessment. A list of chemicals of potential concern, fate and transport modeling results, exposure point concentrations, intake variables and/or exposure factors, toxicological values, and risk calculations are presented elsewhere in this report.

Exposure is defined as the contact of an organism with a chemical or physical agent. The overall objective of the exposure assessment is to estimate the types and magnitude of exposures to chemicals of potential concern that are present at, or migrating from, the site. The results of the exposure assessment are combined with chemical-specific toxicity information to characterize potential risks (EPA 1989a). 
TABLE 6.1. SUMMARY OF HUMAN EXPOSURE PATHWAYS FOR SOURCE AREA ST19

\section{THEORETICALPATHWAYS}

CURRENT LAND USE (INDUSTRIAL)

BESIDENMIAL.

FUTUAE LAND USE

INDUSTRIAL.

- ingestion of groundwater used as

potable water supply.

$X$

$X$

- inhalation of and dermal contact with

contaminants during groundwater use.....

$x$

$X$

$X$

$x$

$x$

$x$

$\mathrm{X}$

$x$

$x$

- inhalation of volatile contaminants

released from the soil into the

ambient air.

- inhalation of resuspended particulates

$X=$ Pathway retained for quantitative risk evaluation

- = Pathway eliminated, see text for elimination rationale 


\subsubsection{Land-Use Assumptions for ST19}

Health risk will be quantified for three land-use assumptions. The risk from current land use is industrial in nature. Two different land-use assumptions are considered for evaluation of the future risk: 1) residential housing and 2) military/industrial land use. All of the land-use assumptions assume that no mitigation or corrective action is undertaken. The difference between the current and future industrial use assumptions is that the contaminants are expected to migrate and change in concentration over time.

Long-range land-use plans (Eielson Air Force Base 1992) indicate that site ST19 will remain an industrial site for the foreseeable future. The site is within a designated wetland in a remote part of the base; future development, therefore, is unlikely.

\subsubsection{Theoretical Exposure Pathways}

The plausible (current and future) theoretical human exposure pathways from ST19 contaminants are

- ingestion of groundwater used as potable water supply (future only)

- inhalation of and dermal contact with contaminants during groundwater use

(future only)

- incidental ingestion of surface soils

- dermal contact with surface soils

- ingestion of plants grown in contaminated soils (future only)

- incidental ingestion of the subsurface soils

- dermal contact with subsurface soils

- inhalation of volatile contaminants released from the soil into the ambient air

- inhalation of resuspended particulates.

\subsubsection{Current Exposure Pathways, Industrial Land Use: Rationale for Elimination from Further Consideration}

This subsection explains why three theoretical exposure pathways, postulated given existing land-use conditions, are not examined in the quantitative risk calculations to follow. Each eliminated pathway is identified, and the rationale for elimination is noted.

Eliminated Pathways: ingestion of groundwater, and inhalation of and dermal contact with contaminants during groundwater use.

Rationale: There are no production water wells within the identified groundwater plumes at this site and the nearest drinking water well is approximately 1.6 kilometer (one mile) away. Therefore, there is no complete pathway for exposure to the contaminated groundwater and the pathways involving groundwater exposure will not be evaluated.

Eliminated Pathways: ingestion of plants grown in contaminated soils.

Rationale: The area's current land use is a military complex, with industrial processes. No crops are grown on the contaminated soils. Therefore, the pathways involving plant ingestion and animal matter ingestion are considered incomplete and will not be evaluated. 


\subsubsection{Identiflcation of Current (Industrial) Exposure Pathways}

The current land use of ST19 is undeveloped wetlands. For the current risk calculations, the following pathways are complete and reasonable for further analysis:

- incidental ingestion of surface soils

- dermal contact with surface soils

- incidental ingestion of the subsurface soils

- dermal contact with subsurface soils

- inhalation of volatile contaminants released from the soil into the ambient air

- inhalation of resuspended particulates.

A detailed explanation of these exposure pathways and exposure factors/parameters may be found in Appendix $B$.

\subsubsection{Euture Exposure Pathways: Residential Land Use}

Assuming residential housing as the future land use, the following pathways are considered to be complete and reasonable for analysis:

- ingestion of groundwater used as potable water supply, (including the future addition of chemical leachate from subsurface soil contamination to grounowwater)

- inhalation of and dermal contact with contaminants during groundwater use

- incidental ingestion of surface soils

- dermal contact with surface soils

- ingestion of plants grown in contaminated soils

- incidental ingestion of subsurface soils

- dermal contact with subsurface soils

- inhalation of volatile contaminants released from the soil into the ambient air

- inhalation of resuspended particulates.

Future residences are assumed to utilize groundwater for potable supply and to have garden plots associated with the homes. All theoretical exposure pathways postulated (and listed above) will be examined in subsequent risk calculations of the future exposure residential assumption.

\subsubsection{Future Exposure Pathways, Industrial Land Use: Rationale for Elimination from Further Consideration}

This subsection explains why one theoretical exposure pathway, postulated to occur given existing land use conditions, is not examined in the quantitative risk calculations to follow. The eliminated pathway is stated, and the rationale for elimination is noted.

Eliminated Pathways: ingestion of plants grown in contaminated soils.

Rationale: The area's future land use is assumed to be a military complex, with industrial processes. It is assumed that no crops will be grown on the contaminated soils. Therefore, the pathway involving plant ingestion is considered incomplete and will not be evaluated.

\subsubsection{Future Exposure Pathways: Industrial Land Use}

Assuming industrial activities as the future land use, the following pathways are considered to be complete and reasonable for analysis: 
- ingestion of groundwater used as potable water supply (including the future addition of chemical leachate from subsurface soil contamination to groundwater)

- inhalation and dermal contact with contaminants during groundwater use

- incidental ingestion of surface soils

- dermal contact with surface soils

- incidental ingestion of subsurface soils

- dermal contact with subsurface soils

- inhalation of volatile contaminants released from the soil into the ambient air

- inhalation of resuspended particulates.

Future industrial activities are assumed to be similar to current activities.

\subsection{RISK CHARACTERIZATION}

This section presents, in table format, the excess cancer risk and the Hazard Index for source area ST19 by exposure pathway. The cancer risk and Hazard Index are presented for both the "Average Exposure Case" and the "Reasonable Maximum Exposure Case." Tables 6.2 and 6.3 present risk values for the current land use (industrial), Tables 6.4 and 6.5 present the future residential land-use values, and Tables 6.6 and 6.7 present the future industrial land-use values.

Each table presents the cancer risk and the Hazard Index for each exposure pathway individually. A total cancer risk value and a total Hazard Index are presented that add all of the exposure pathway risks together. Values are presented for cancer risk and Hazard Index in two ways. The first column includes the contribution of metals in the groundwater that are suspected to be attributable to site background and therefore likely not related to past site activities. The second column excludes the contribution from potential background metals. The potential background metals are antimony, arsenic, barium, beryllium, cadmium, manganese, and thallium.

The calculation of the cancer risk and Hazard Index necessitates the use of information and data input from many sources, which are presented elsewhere in this report. For ease of reference, the information used to perform the risk calculations is cross referenced.

Identification of Chemicals of Potential Concern

Exposure Point Concentrations and Modeling Results

Toxicity Assessment

Risk Calculation Formulas

Exposure Factors

Fate and Transport Models

Contaminant Concentration Inputs

Section 7.0

Section 8.0

Section 9.0

Appendix A

Appendix B

Appendix C

Appendix $F$

More detailed risk output tables are in Appendix K (Tables K.49 through K.60). These tables include all of the data in Tables 6.2 through 6.7 plus the cancer risks and Hazard Quotients for the individual compounds that drive the risk (cancer risk $>10^{-7}$ and Hazard Quotient $>10^{-2}$ ).

\subsection{SITE-SPECIFIC UNCERTAINTIES AND CONSIDERATIONS}

This section presents key information bearing on the level of confidence in the quantitative risk estimates for a site. The risk estimates are conditional given a considerable number of assumptions about site characterization, exposure, and toxicity. 
Two major categories of uncertainty are discussed in the following subsections. Table 6.8 lists the major sources of uncertainty that affect this assessment and their possible magnitude of effect on the risk estimates.

\subsubsection{Exposure Uncertaintles}

Some of the exposure frequencies used in this assessment differ from default values provided by EPA Region X (EPA 1991a) for the following exposure pathways: dermal contact with surface and subsurface soils, incidental ingestion of surface and subsurface soils, and inhalation of resuspended particulates. These differences are delineated in Table 2.8. Different exposure factors were used because of the subarctic climate at Eielson AFB, which is atypical of most EPA Region X sites. 146 days per year is the mean number of days at Fairbanks without snow cover (Battelle 1992b). Table 6.8 lists the magnitude of effect for this assumption.

The ingestion of animals raised on contaminated feed was not included in the primary risk calculations due to the sub-arctic climate at Eielson. Table 6.8 presents the magnitude of effect caused by exclusion of this exposure pathway. The risk was calculated using exposure factors presented in EPA (1991e) for consumption of animal products.

The groundwater concentrations for BTEX that were input into the future land use risk estimates are based on fate and transport modeling (Section 8). The concentrations are averages integrated over the future 30 years. Table 6.8 discusses the effect of using these concentrations in contrast to using the present BTEX groundwater concentrations.

\subsubsection{Toxicity Uncertainties}

There are no approved EPA toxicity values for total petroleum hydrocarbons. It was not included in the primary risk calculations. However, a surrogate toxicity value was introduced in Section 9 of this assessment. The magnitude of effect on the risk calculations due to the inclusion of this compound is presented in Table 6.8.

\subsubsection{General Site Considerations}

Section 10 of this assessment discusses the effects of uncertainties that affect all of the Operable Unit 2 sites. Table 6.8 estimates their magnitude of effect. 


\section{IABLE 6.2. SOURCE AREA ST19; SUMMARY OF CANCER RISK AND HAZARD INDEX}

Average Exposure Case: Current Exposure Pathways / Industrial Land-Use Assumption

\section{EXPQSUREPATHMAYS}

- incidental ingestion of surface soils

cancer risk.

Hazard Index.

mal contact with surface soils

cancer risk

Hazard Index

- incidental ingestion of subsurface soils

cancer risk

Hazard Index

mal contact with subsurface soils

cancer risk

Hazard Index

- inhalation of volatile contaminants released from the soil into ambient air.

cancer risk.

Hazard Index.

- inhalation of resuspended particulates

cancer risk...

Hazard Index.

\section{SUMMATION ACROSS ALL EXPOSURE PATHWAYS FOR SOURCE AREA}

Total cancer risk. 
IABLE 6.3. SOURCE AREA ST19; SUMMARY OF CANCER RISK AND HAZARD INDEX Reasonable Maximum Exposure Case: Current Exposure Pathways / Industrial Land-Use Assumption

\section{EXPOSUREPATHWAYS}

- incidental ingestion of surface soils

cancer risk.

Hazard Index

Included

eckround Metals

mal contact with surface soils

cancer risk.

Hazard Index.

2E-02

$<1 \mathrm{E}-02$

- incidental ingestion of subsurface soils

cancer risk.

Hazard Index

- dermal contact with subsurface soils

cancer risk 1E-07

$<1 E-07$

Hazard Index

$<1 E-02$

$<1 E-02$

- inhalation of volatile contaminants released from the soil into ambient air.

cancer risk.

$<1 E-07$

$<1 \mathrm{E}-07$

Hazard Index...

$<1 E-02$

$<1 \mathrm{E}-02$

- inhalation of resuspended particulates

cancer risk......

2E-07

Hazard Index...

$<1 E-02$

$<1 \mathrm{E}-07$

$<$ IE-02

SUMMATION ACROSS ALL EXPOSURE PATHWAYS FOR SOURCE AREA

Total cancer risk

5E-06

Total Hazard Index 
IABLE 6.4. SOURCE AREA ST19; SUMMARY OF CANCER RISK AND HAZARD INDEX Average Exposure Case: Future Exposure Pathways / Residential Housing Land-Use Assumption

\section{EXPOSUREPATHWAYS}

- ingestion of groundwater used as potable water supply (including the future

Suspected Background Metals addition of chemical leachate from subsurface soil contamination to groundwater)

cancer risk.

$8 \mathrm{E}+01$

5E-07

Hazard Index Included Not Included

- inhalation of and dermal contact with contaminants during groundwater use

cancer risk.

3E-06

Hazard Index

$6 \mathrm{E}+00$

- incidental ingestion of surface soils

cancer risk.

3E-06

Hazard Index

2E-01

- dermal contact with surface soils

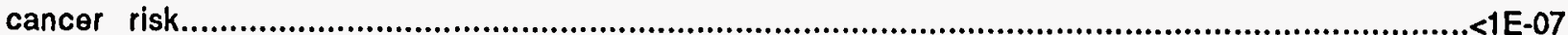

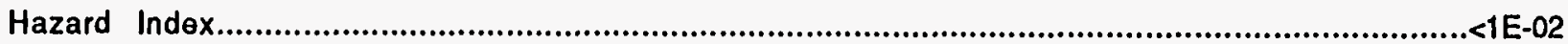

- ingestion of plants grown in contaminated soils

cancer risk.

Hazard Index.

$6 \mathrm{E}-06$

$2 \mathrm{E}+01$

- incidental ingestion of subsurface soils

cancer risk.

7E-07

Hazard Index

$1 E-01$

- dermal contact with subsurface soils

cancer risk.

$<1 E-07$

Hazard Indox

$<1 E-02$

$<1 E-07$

$<1 E-02$

cancer risk.

Hazard Index.

$<1 E-07$

cancer risk.

$<1 E-02$

5E-01

3E-06

$6 \mathrm{E}+00$

$<1 E-07$

$<1 E-02$

Hazard Index.

Total cancer risk 
TABLE 6.5. SOURCE AREA ST19; SUMMARY OF CANCER RISK AND HAZARD INDEX Reasonable Maximum Exposure Case: Future Exposure Pathways / Residential Housing Land-Use Assumption

\section{EXPOSUREPATHWAYS}

Suspected Background Metals

ingestion of groundwater used as potable water supply (including the future

addition of chemical leachate from subsurface soil contamination to groundwater)

cancer risk...

Hazard Index

Included Notincluded

inhalation of and dermal contact with contaminants during groundwater use

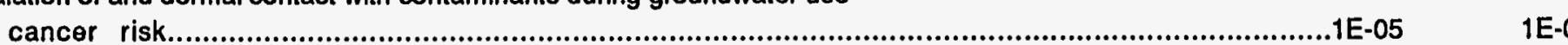

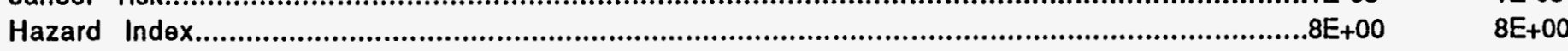

- incidental ingestion of surface soils

cancer risk.

$.3 E-05$

Hazard Index.

- dermal contact with surface soils

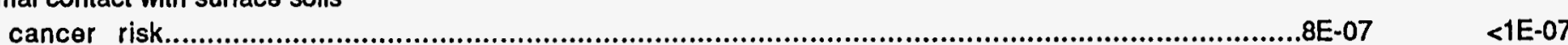

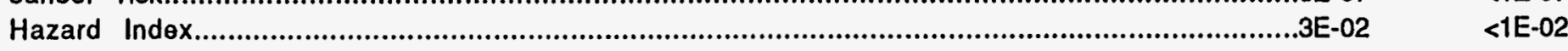

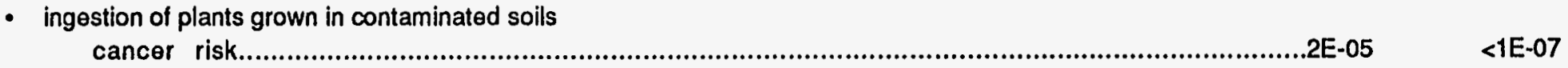

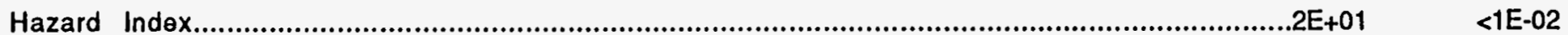

- incidental ingestion of subsurface soils

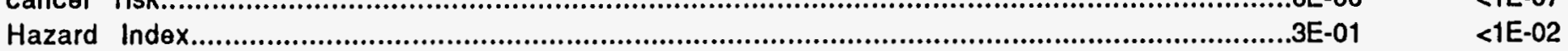

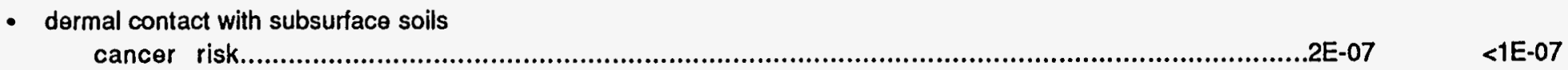

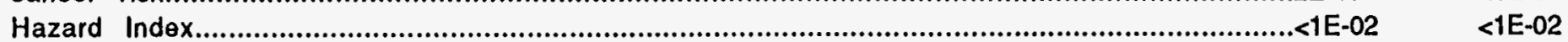

- inhalation of volatile contaminants released from the soil into ambient air.

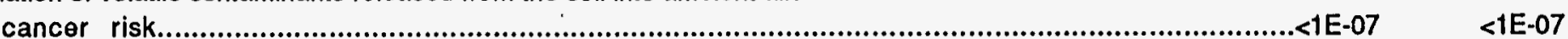

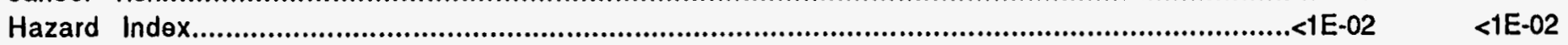

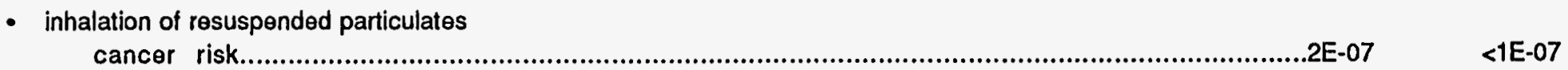

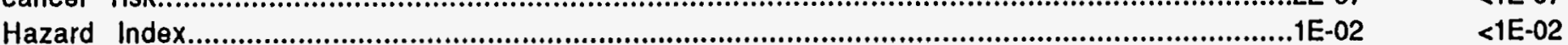

SUMMATION ACROSS ALL EXPOSURE PATHWAYS FOR SOURCE AREA

Total cancer risk .................................................................................................9E-04

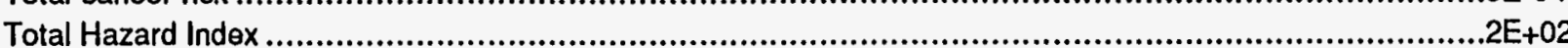




\section{TABLE 6.6. SOURCE AREA ST19; SUMMARY OF CANCER RISK AND HAZARD INDEX Average Exposure Case: Future Exposure Pathways / Industrial Land-Use Assumption}

\section{EXPOSUREPATHWAYS}

- ingestion of groundwater used as potable water supply (including the future addition of chemical leachate from subsurface soil contamination to groundwater)

cancer risk

Hazard Index

Suspected Background Metals Included Not Included

inhalation of and dermal contact with contaminants during groundwater use

cancer risk.

$5 \mathrm{E}+01$

Hazard Index

.3E-06

$.5 \mathrm{E}+00$

- incidental ingestion of surface soils

cancer risk.

1E-06

Hazard Index

2E-01

- dermal contact with surface soils

cancer risk.

$<1 E-07$

Hazard Index

$<1 E-02$

incidental ingestion of subsurface soils

cancer risk.

3E-07

Hazard Index

.4E-02

- dermal contact with subsurface soils

cancer risk.

$<1 E-07$

Hazard Index

$<1 E-02$

- inhalation of volatile contaminants released from the soil into ambient air.

cancer risk.

$<1 E-07$

Hazard Index

$<1 E-02$

- inhalation of resuspended particulates

cancer risk.

$<1 E-07$

Hazard Index

2E-01

3E-06

$5 E+00$

$<1 E-07$

<1E-02

UMMATION ACROSS ALL EXPOSURE PATHWAYS FOR SOURCE AREA

Total cancer risk.

Total Hazard Index 
IABLE_6.7 SOURCE AREA ST19; SUMMARY OF CANCER RISK AND HAZARD INDEX

Reasonable Maximum Exposure Case: Future Exposure Pathways / Industrial Land-Use Assumption

\section{EXPOSUREPATHWAYS}

- ingestion of groundwater used as potable water supply (including the future addition of chemical leachate from subsurface soil contamination to groundwater)

cancer risk.

Hazard Index

- inhalation of and dermal contact with contaminants during groundwater use

cancer risk.

Hazard Index.

- incidental ingestion of surface soils

cancer risk.

Hazard Index

- dermal contact with surface soils

cancer risk.

Hazard Index

- incidental ingestion of subsurface soils

cancer risk.

Hazard Index

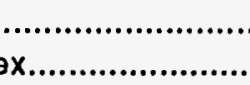

Suspected Background Metals

Included Notuncluded

- dermal contact with subsurface soils

cancer risk

Hazard Index.

1E-07

alation of volatile contaminants released from the soil into ambient air.

cancer risk...

Hazard Index

$<$ IE-07

$<1 \mathrm{E}-02$

- inhalation of resuspended particulates

cancer risk.

2E-07

Hazard Index.

$<1 E-02$

9E-07

2E-01

$8 \mathrm{E}-06$

$7 E+00$

$<1 E-07$

$<1 \mathrm{E}-02$

$<1 E-07$

$<1 E-02$

$<1 \mathrm{E}-07$

$<1 \mathrm{E}-02$

$<1 \mathrm{E}-07$

$<1 E-02$

$<1 E-07$

$<1 E-02$

$<1 E-07$

$<1 E-02$

\section{SUMMATION ACROSS ALL EXPOSURE PATHWAYS FOR SOURCE AREA}

Total cancer risk

Total Hazard Index 
IABLE 6.8. The Magnitude of Effect of Uncertainties on Risk Estimates for Site ST19

\begin{tabular}{|c|c|c|c|}
\hline \multirow{2}{*}{ Source of Uncertainty } & \multicolumn{3}{|c|}{ Potential Magnitude of Effect on Risk Estimate } \\
\hline & Underestimating Risk & $\begin{array}{c}\text { Underestimating or } \\
\text { Overestimating Risk }\end{array}$ & Overestimating Risk \\
\hline $\begin{array}{l}\text { Assumption that concentrations } \\
\text { of metals in environmental media } \\
\text { represent background } \\
\text { contamination }\end{array}$ & $\begin{array}{l}\text { High. Calculations show that risk } \\
\text { estimates generally increased by one } \\
\text { to two orders of magnitude when } \\
\text { exposure to metals was included }\end{array}$ & & \\
\hline $\begin{array}{l}\text { Use of exposure factors other than } \\
\text { default values provided in Region } \\
10 \text { guidance (e.g., frequency of } \\
\text { exposure to contaminated soil) }\end{array}$ & $\begin{array}{l}\text { Very low. Calculations show that risk } \\
\text { estimates did not increase when } \\
\text { Region } 10 \text { default values were used. }\end{array}$ & & \\
\hline $\begin{array}{l}\text { Assumption that ingestion of } \\
\text { animals fed contaminated plants } \\
\text { is not a complete pathway }\end{array}$ & $\begin{array}{l}\text { Very low. Calculations show that risk } \\
\text { estimates would not change if this } \\
\text { pathway was included. }\end{array}$ & & \\
\hline $\begin{array}{l}\text { Effect of not including surface } \\
\text { water runoff pathway }\end{array}$ & $\begin{array}{l}\text { Unknown. No appreciable surface soil } \\
\text { contamination. }\end{array}$ & & \\
\hline $\begin{array}{l}\text { Use of EPA Region } 10 \text { default } \\
\text { exposure factors }\end{array}$ & & & $\begin{array}{l}\text { Low to Moderate. Risk estimates for } \\
\text { the "average" individual are } \\
\text { approximately one order of magnitude } \\
\text { lower than those of the "RME" } \\
\text { individual for the residential } \\
\text { scenarios; the difference is less than } \\
\text { one order of magnitude for the } \\
\text { industrial scenarios. }\end{array}$ \\
\hline $\begin{array}{l}\text { Method used to sum risk across } \\
\text { multiple substances and pathways }\end{array}$ & & $\begin{array}{l}\text { Undonown. Summing effects across } \\
\text { multiple contaminants assumes their } \\
\text { effects are additive. Risk may be } \\
\text { underestimated if two or more } \\
\text { chemicals act synergistically and } \\
\text { overestimated if two or more } \\
\text { chemicals act antagonistically. The } \\
\text { approach also assumes that target } \\
\text { organs and toxicity mechanisms are } \\
\text { identical, an assumption that should } \\
\text { overestimate risk. }\end{array}$ & \\
\hline
\end{tabular}


IABLE 6.8. The Magnitude of Effect of Uncertainties on Risk Estimates for Site ST19

\begin{tabular}{|c|c|c|c|}
\hline $\begin{array}{l}\text { Use of arithmetic average and } \\
\text { upper UCL concentrations to } \\
\text { describe contact rate }\end{array}$ & & $\begin{array}{l}\text { Unknown, because the overlap } \\
\text { between distribution of environmental } \\
\text { contamination and distribution of } \\
\text { worker/resident activity is unknown. } \\
\text { Approach will over-estimate } m \text { areas } \\
\text { rarely used and will underestimate risk } \\
\text { if "hot spots" are located in areas } \\
\text { commonly used. }\end{array}$ & \\
\hline $\begin{array}{l}\text { Effect of assuming normality in } \\
\text { chemical datasets on comparisons } \\
\text { to background and use of UCL }\end{array}$ & & $\begin{array}{l}\text { Unknown. It may effect the UCL } \\
\text { concentration values input into the } \\
\text { risk calculations. Reduces the power } \\
\text { of the t-tests. }\end{array}$ & \\
\hline $\begin{array}{l}\text { Analytical chemistry methods } \\
\text { resulting in quantitation limits } \\
\text { for many substances being above } \\
\text { "risk-based screening } \\
\text { concentrations" }\end{array}$ & $\begin{array}{l}\text { Low. There are no records of most of } \\
\text { these substances ever being present at } \\
\text { Eielson AFB. However, some } \\
\text { pesticides and other organic chemicals } \\
\text { (PAHs) could be present in } \\
\text { groundwater. }\end{array}$ & & \\
\hline $\begin{array}{l}\text { Use of current contamination to } \\
\text { estimate future risk }\end{array}$ & & $\begin{array}{l}\text { Unknown. Most substances are likely } \\
\text { to degrade over time, and current waste } \\
\text { management practices are likely to } \\
\text { reduce or prevent future releases. } \\
\text { However, degradation products could } \\
\text { be more toxic than parent compounds } \\
\text { and their constituents which were } \\
\text { evaluated in this assessment. }\end{array}$ & \\
\hline $\begin{array}{l}\text { Use of modeling for BTEX } \\
\text { groundwater concentrations for } \\
\text { future land use scenarios }\end{array}$ & & & $\begin{array}{l}\text { Very low. The estimated risk } \\
\text { decreased by about } 50 \% \text { if the current } \\
\text { groundwater concentrations were input } \\
\text { into the calculations. }\end{array}$ \\
\hline $\begin{array}{l}\text { Use of average time in a residence } \\
\text { as average time in a workplace }\end{array}$ & $\begin{array}{l}\text { Low. Increasing average time in the } \\
\text { workplace from } 9 \text { to } 27 \text { years would } \\
\text { increase overall risk estimates by less } \\
\text { than a factor of } 3 \text {. }\end{array}$ & & \\
\hline
\end{tabular}


IABLE 6,8. The Magnitude of Effect of Uncertainties on Risk Estimates for Site ST19

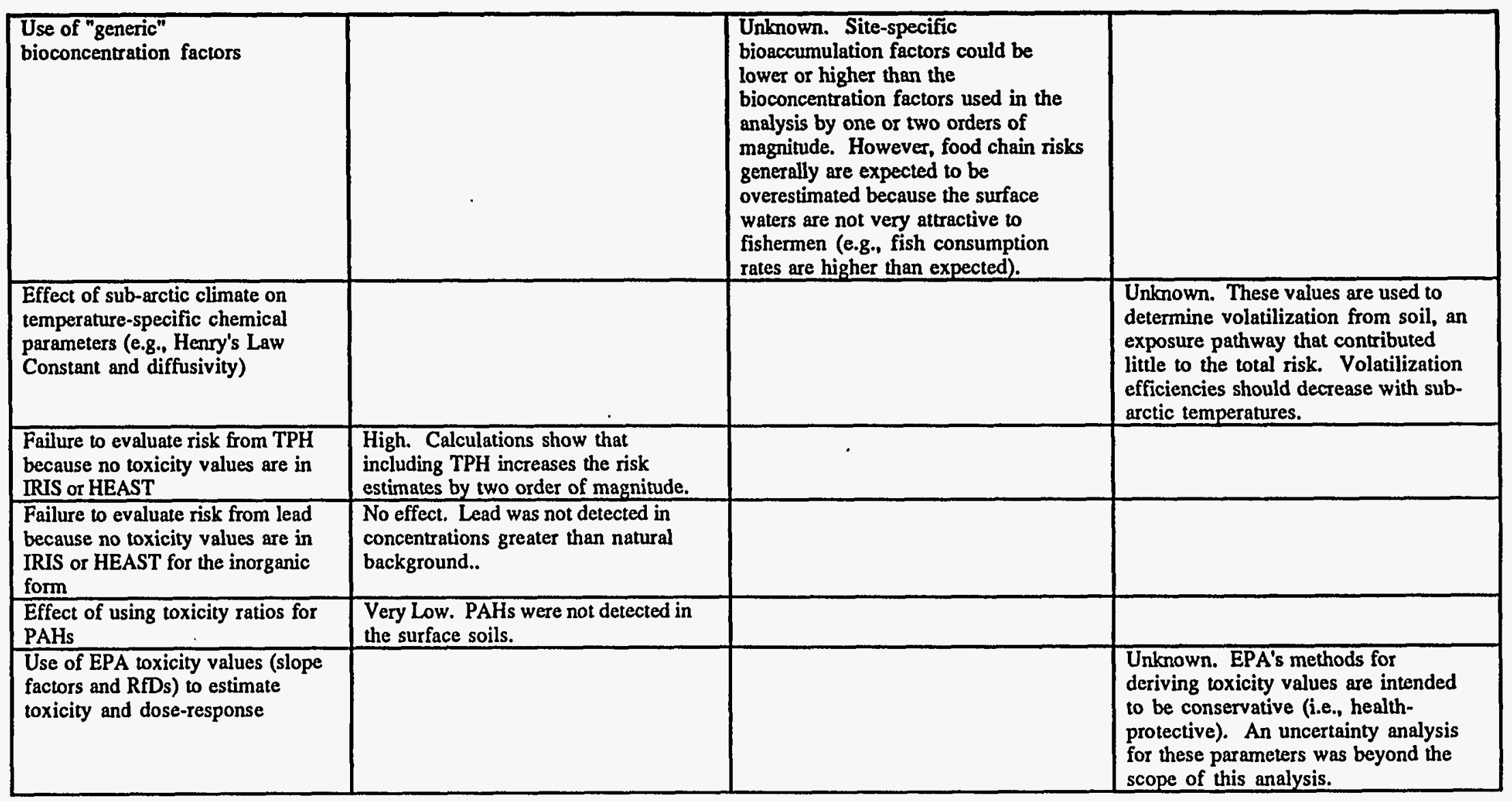




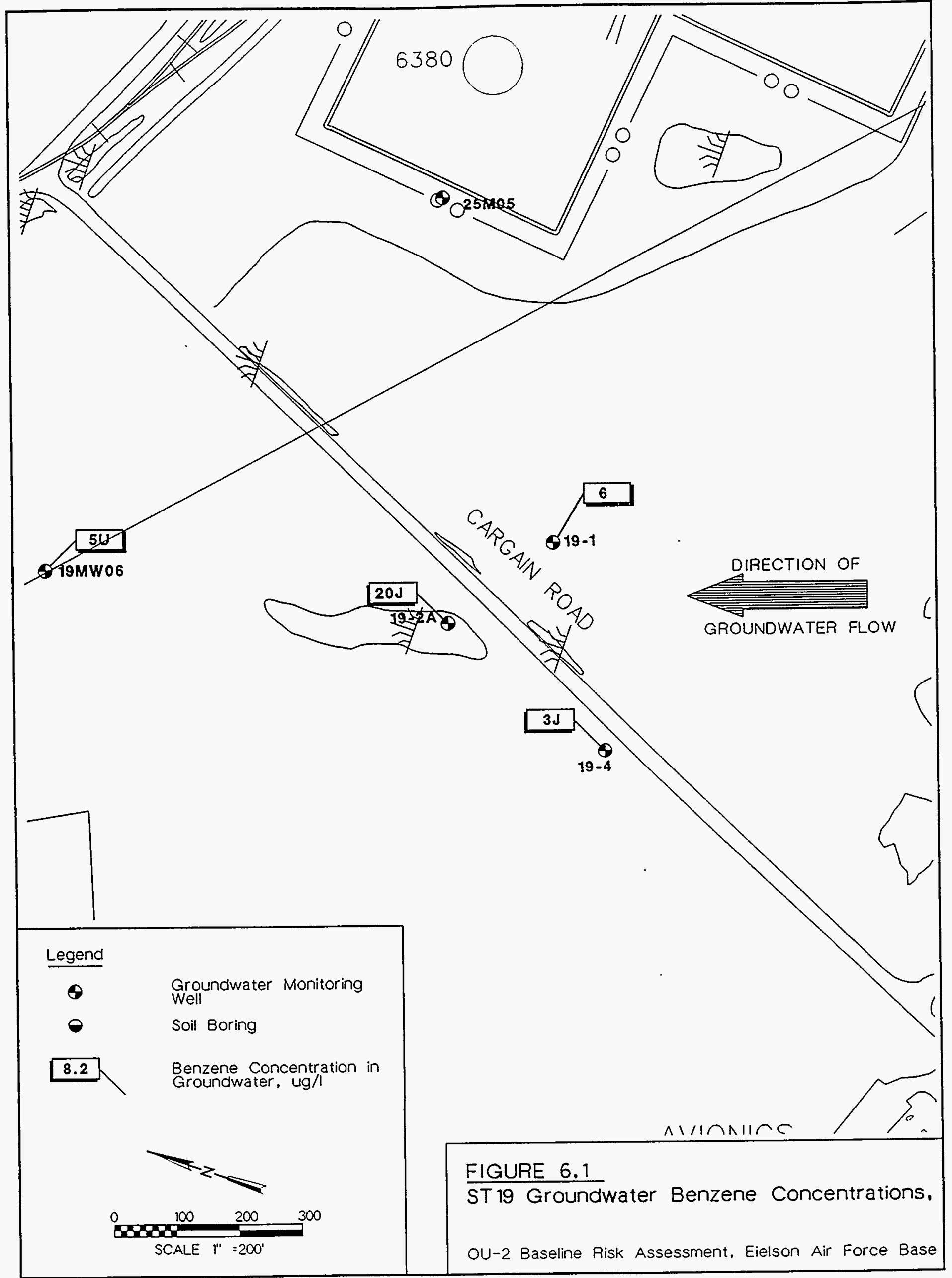




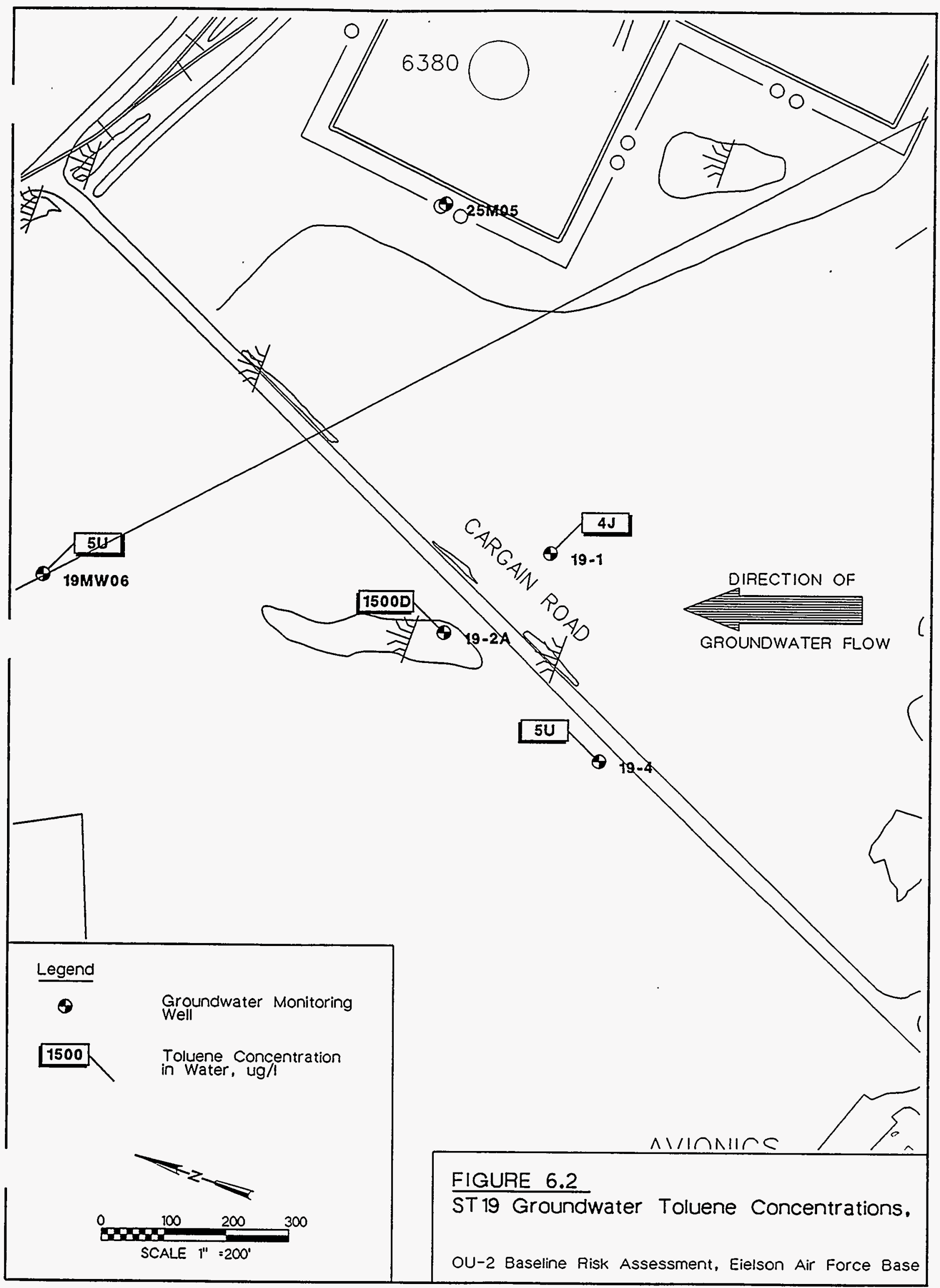




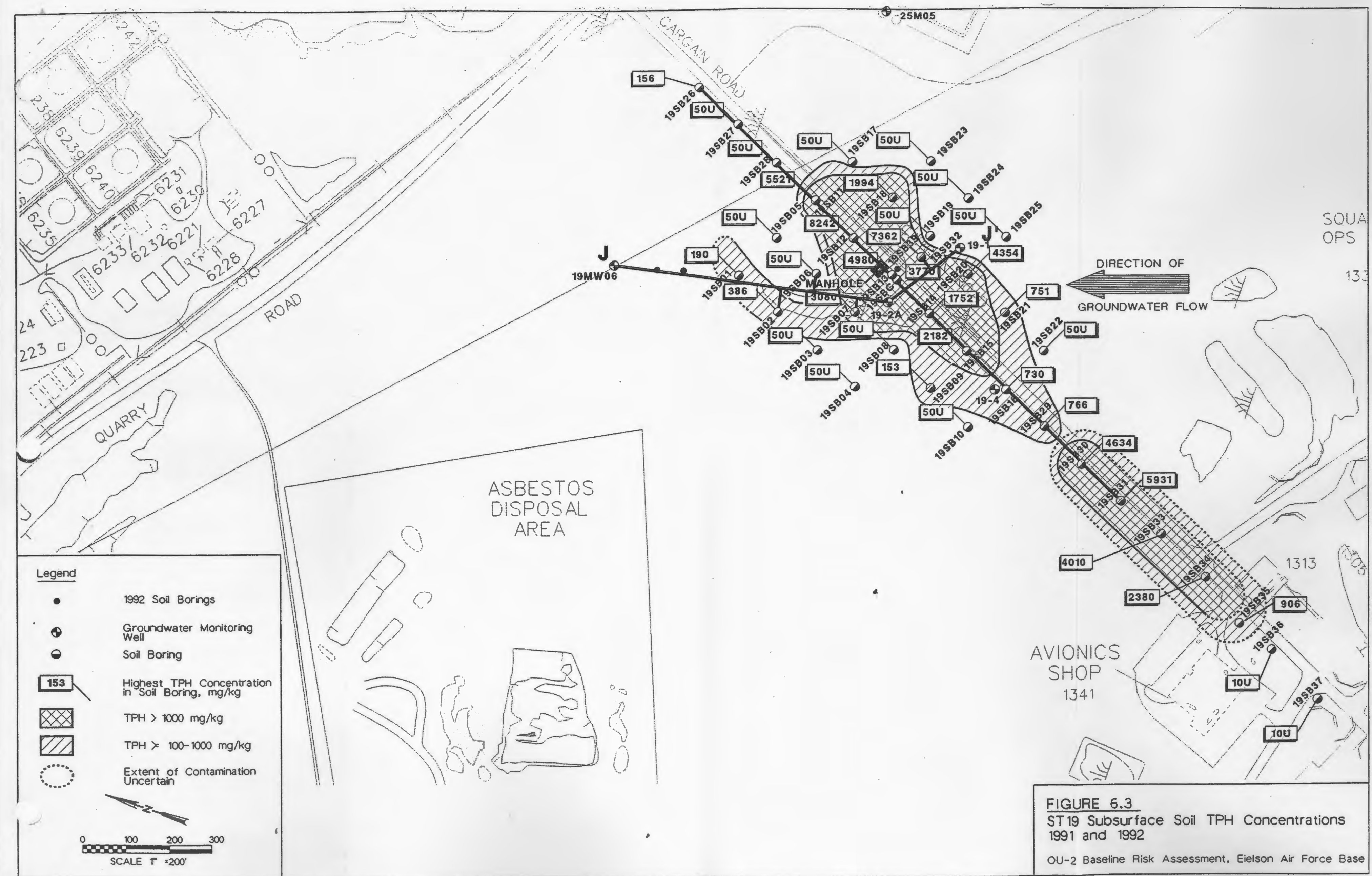




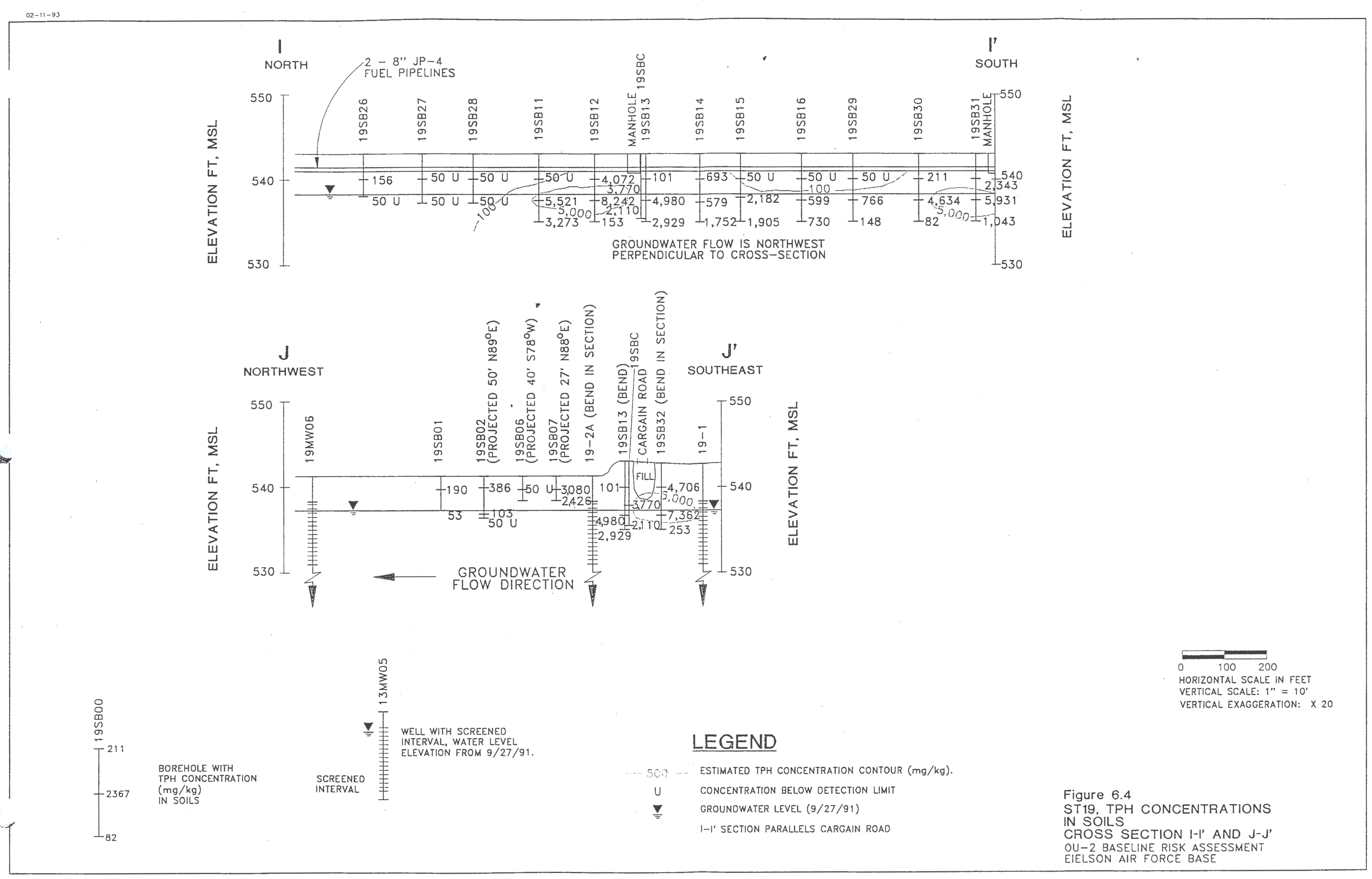




\subsection{IDENTIFICATION OF CHEMICALS OF POTENTIAL CONCERN}

Contaminants of potential concern were identified based on the screening method suggested in the Supplemental guidance for Superfund Risk Assessments in U. S. EPA Region 10 (EPA 1991). This method called the "risk-based screening approach" compares the maximum concentration levels detected at each site to a risk-based screening concentration. The methods used to calculate these concentrations are described in Section 7.2.1. The criteria for the screening, as given in the Region 10 supplemental guidance, are

1) list maximum concentration of each chemical in each medium for each site

2) compare to risk-based screening concentration

3) eliminate chemicals if

maximum detection for water $\leq 10^{-6}$ cancer risk screening value

maximum detection for soil $\leq 10^{-7}$ cancer risk screening value

$\leq 0.1$ Hazard Quotient screening value

4) carry remaining chemicals through baseline risk assessment.

\subsection{MAXIMUM CONCENTRATIONS}

Tables D.1 through D.5 list the maximum concentrations for each analyte in each medium for the Operable Unit 2 sites. The data are primarily from the 1991 sampling effort. Details on the sources for the values are given in Appendix $D$.

\subsubsection{Laboratory Contaminants}

\subsubsection{Blanks}

The analytical laboratories used trip and equipment blanks as specified in the respective Sampling and Analysis Plans (SAIC 1988; Battelle 1991). A "B" qualifier was used where an analyte was detected in the associated blank as well as the sample. The use of these qualifiers was validated for the 1986 to 1988 data (SAIC 1989) and 1991 and 1992 data (U.S. Air Force 1993d).

As specified in EPA guidances (EPA 1989a), the analyte values for common laboratory contaminants from the 1991 field sampling event with "B" qualifiers were compared to 10 times the maximum amount detected in any blank (Table 7.1) for groundwater samples. Only on value exceeds this level. Monitoring well 26-08 had an acetone concentration of $580 \mathrm{~B} \mu \mathrm{g} / \mathrm{L}$. However, this sample was measured with a 40:1 dilution, and EPA guidance (EPA 1991f) recommends adjusting the action level by the inverse of the dilution ratio. This raises the $10 x$ value for this sample to $35 \times 10 \times 40=14,000 \mu \mathrm{g} / \mathrm{L}$, which is much greater than $580 \mu \mathrm{g} / \mathrm{L}$. Therefore, all groundwater samples that had " $\mathrm{B}$ " qualifiers were removed from the remainder of this risk assessment.

The blanks for soil samples were measured in water and are reported in $\mu g / L$. "Ottowa sand" or a similar material was not used as a blank for soil analyses. Thus, before comparing soil samples with "B" qualifiers to 10 times the maximum detected in any blank (Table 7.1), the blank results were adjusted with the extraction ratio, which is approximately $38: 1$, and any relevant dilution ratios. All 
soil analyses with " $B$ " qualifiers passed this criteria, and they were not continued through the risk assessment.

\begin{tabular}{||l|c|c|c||}
\hline \hline BABLE 7.1 Field and Equipment & \multicolumn{3}{c||}{$\begin{array}{c}\text { Blank Detections from Operable Unit } 21991 \text { Field } \\
\text { Sampling Event }\end{array}$} \\
\hline \hline Blank Contaminant & $\begin{array}{c}\text { Maximum } \\
\text { Concentration } \\
(\mu \mathrm{g} / \mathrm{L})\end{array}$ & $\begin{array}{c}\text { Number of } \\
\text { Blank } \\
\text { Detections }\end{array}$ & $\begin{array}{c}\text { Number of } \\
\text { Blanks } \\
\text { Measured }\end{array}$ \\
\hline \hline ACETONE & 35 & 45 & 52 \\
\hline METHYLENE CHLORIDE & 51 & 51 & 52 \\
\hline 2-BUTANONE & 8 & 1 & 52 \\
\hline BROMODICHLOROMETHANE & 1 & 1 & 52 \\
\hline CARBON DISULFIDE & 5 & 2 & 52 \\
\hline CHLOROFORM & 8 & 7 & 52 \\
\hline BIS(2-ETHYLHEXYL)PHTHALATE & 22 & 4 & 8 \\
\hline DI-N-BUTYLPHTHALATE & 2 & 1 & 8 \\
\hline \hline
\end{tabular}

\subsubsection{Suspected Laboratory Contaminants}

Detections of bis (2-ethylhexyl) phthalate with no "B" qualifier were reported for 58 samples analyzed from the 1991 field season. Thirty-eight are groundwater analyses. There are no known sources for bis (2-ethylhexyl) phthalate contamination at Operable Unit 2.

Bis (2-ethylhexyl) phthalate is considered a common laboratory contaminant (EPA 1991) and as such, it may be removed from inclusion in the risk assessment if the measured concentration is less than 10 times the maximum amount detected in any blank (EPA 1989a). The 1991 Data Validation Report (U.S. Air Force 1993b) for OU-2 data reports that bis (2-ethylhexyl) phthalate was detected in the majority of the method blanks analyzed at concentrations less than the CRDL. The maximum blank detection was $22 \mu \mathrm{g} / \mathrm{L}$ for equipment blank EB-17. If all groundwater analyses of bis (2-ethylhexyl) phthalate with concentrations of 220 $\mu \mathrm{g} / \mathrm{L}$ or less are removed, then only five analyses remain (Table 7.2). Unlike the rest of the semi-volatile organic analyses, these five have a dilution factor greater than one.

\begin{tabular}{|c|c|c|c|c|}
\hline Sample & Bis(2-Ethylhexyl)Phthalate & Qualifier & UNITS & $\begin{array}{c}\text { Dilution } \\
\text { Factor }\end{array}$ \\
\hline GW-10MW01 & 11000 & $\mathrm{D}$ & $\mathrm{ug} / \mathrm{L}$ & 100 \\
\hline GW-10MW08 & 2700 & $\bar{D}$ & $\mathrm{ug} / \mathrm{L}$ & 25 \\
\hline GW-26MW02 & 870 & & $\mathrm{ug} / \mathrm{L}$ & 4 \\
\hline GW-26MW08 & 350 & & $\mathrm{ug} / \mathrm{L}$ & 2 \\
\hline GW-26MW08A & 3200 & & $\mathrm{ug} / \mathrm{L}$ & 10 \\
\hline
\end{tabular}


If these remaining analyses are corrected by multiplication of the inverse of their dilution factor, as recommended in EPA (1991f) guidance, then only sample GW26MW08A qualifies to be carried through the risk assessment. More discussion on the value input into the risk assessment is in Appendix F.

20 soil analyses at Operable Unit 2 detected bis (2-ethylhexyl) phthalate without a "B" qualifier. These values were compared to 10 times the maximum blank concentration of $22 \mu \mathrm{g} / \mathrm{L}$ for this analyte after adjustment for the extraction ratio of 38:1. The resulting screening concentration is $8,360 \mu \mathrm{g} / \mathrm{L}$. No soil values of bis (2-ethylhexyl) phthalate exceed this value, and they were not continued in the risk assessment.

Methylene chloride is also a common laboratory contaminant (EPA 1991). 51 of 52 equipment and travel blanks analyzed had methylene chloride contamination (Table 7.1). Nevertheless, detection of this chemical listed without a " $B$ " qualifier were reported for a few groundwater samples at Operable Unit 2. The analyses and their dilution factors are reported in Table 7.3. All have concentrations less than 10 times the maximum reported blank value of $51 \mu \mathrm{g} / \mathrm{L}$. Thus, all groundwater analyses of methylene chloride will be removed from the risk assessment.

\begin{tabular}{|c|c|c|c|c|}
\hline \multicolumn{5}{|c|}{$\begin{array}{c}\text { IABLE 7.3. Groundwater Detections of Methylene Chloride from Operable } \\
\text { Unit } 21991 \text { Field Sampling Event that Did Not Have a "U" Qualifier }\end{array}$} \\
\hline$\overline{\text { Sample }}$ & Methylene Chloride & Qualifier & Units & $\begin{array}{l}\text { Dilution } \\
\text { Factor }\end{array}$ \\
\hline GW-13MW01 & 3 & J & $u g / L$ & 1 \\
\hline GW-13MW02 & 57 & $\mathrm{~J}$ & $\mathrm{ug} / \mathrm{L}$ & 15 \\
\hline GW-13MW03 & 5 & & $u g / L$ & 1 \\
\hline GW-13MW04 & 4 & $\bar{J}$ & $u g / L$ & 1.5 \\
\hline GW-26MW02 & 3 & $J$ & $\mathrm{ug} / \mathrm{L}$ & 1 \\
\hline GW-26MW08 & 49 & $J$ & $u g / L$ & 40 \\
\hline GW-26MW08A & 8 & $\mathrm{~J}$ & $u g / L$ & 5 \\
\hline
\end{tabular}

\subsection{COMPARISON OF MAXIMUM CONCENTRATIONS TO RISK-BASED SCREENING CONCENTRATIONS}

Risk-based screening concentrations were calculated for all analytes sampled at Operable Unit 2 in 1991 and 1992. The results are compiled in Table 7.4.

\subsubsection{Calculation of Risk-Based Screening Concentrations}

Risk-based screening concentrations for each analyte were calculated with equations provided in EPA Region 10 guidance (EPA 1991). The exposure assumptions used in the back-calculations of the risk-based screening concentrations are the same as those corresponding to the residential land use scenario (Appendix B). Table 7.4 provides the risk-based screening concentration levels corresponding to $10^{-7}$ and 
$10^{-6}$ cancer risk for soil and water, respectively, and 0.1 Hazard Quotient for both soil and water.

The values in Table 7.4 were calculated using the equations in Appendix I of EPA (1991a). Risk-based screening concentrations for the drinking water ingestion of non-volatile chemicals (Henry's constant [unitless] $\leq 10^{-4}$ and molecular weight $\geq 200$ ) were calculated with equations 6 and 10 for cancer risk and Hazard Quotient, respectively. A Hazard Quotient of 0.1 was substituted for 1 in equation 10 . Riskbased screening concentrations for the ingestion and inhalation of volatile chemicals from drinking water were calculated with equations 8 and 12 of Appendix I. A Hazard Quotient of 0.1 was substituted for 1 in equation 12.

Equations 14 and 16 of Appendix I of EPA (1991a) were used to calculate the riskbased screening concentrations for soil ingestion. A target risk of $10^{-7}$ was substituted for $10^{-6}$ in equation 14. A Hazard Quotient of 0.1 was substituted for 1.0 in equation 16.

\subsubsection{Toxicity Data}

Table 9.1 lists the toxicity input for these equations, both slope factors and reference dosages. More detailed information on the toxicity data is in Section 9 of this assessment.

Analytes for which no toxicity data was found in either IRIS or HEAST were left blank and, in general, not continued through this screening process. Those analytes detected that have no toxicity data include: TPH, aluminum, calcium, cobalt, magnesium, iron, and lead. They were all detected at all Operable Unit 2 sites.

Aluminum, calcium, magnesium, and iron were not continued through the screening process because they are not associated with toxicity to humans under normal circumstances (EPA 1991a). Cobalt was included to this list of metals due to its low apparent toxicity (personal communication, T.T. Jarvis 1993).

The toxicity of TPH and lead are discussed in Section 9.

An order-of-magnitude contribution to total risk from the analytes listed above is discussed in the Magnitude of Effect of Uncertainties on Risk Estimates tables for each site.

The risk-based screening concentrations listed for PAHs in EPA Region $X$ guidance (EPA 1991) are smaller than those calculated in this assessment. In order to keep the contaminant-of-concern process conservative, the values listed in the EPA guidance were used; $1.17 \times 10 \mu \mathrm{g} / \mathrm{L}$ for groundwater and $8.75 \mu \mathrm{g} / \mathrm{kg}$.

\subsubsection{Contaminant-of-Concern Listings}

Table 7.4 lists the calculated risk-based screening concentrations. These concentrations were compared to the site maximum values for each medium. The cell for any analyte that exceeded the risk-based screening concentrations was marked with an " $X$ " as shown in Tables 7.5 through 7.9. If the maximum concentration of a contaminant was less than the risk cutoff, it was marked with a "\#." If all detections of a contaminant were also measured in a corresponding blank, it was marked with a "B." 
If the contaminant was not detected, but one-half of the contract required quantitation limit (CRQL) was greater than the risk cutoff, it was marked with an "A." There are two different causes for this situation: 1) the analytical methods used were not sensitive enough to detect risk-based screening concentrations, or 2) elevated levels of one contaminant led to the use of a high dilution factor.

The detection limits used by $\mathrm{CH} 2 \mathrm{M}$ Hill for the 1991 sampling effort are discussed in Section 4.2 of the Quality Assurance Project Plan in the Operable Unit 2

Management Plan (Battelle 1991). They recognized that the detection limits for their sampling effort were constrained by cost and analytical methods. The detection limits for all soil samples met the $10^{-4}$ cancer risk. They did not necessarily meet the $10^{-7}$ cancer risk. The detection limits for groundwater samples, except for polycyclic aromatic hydrocarbons (PAHs) and PCBs, met the 10-4 cancer risk. PAHis and PCBs analyses were unable to meet this risk-based level due to analytical limits. The high detection limit for PAHs is of particular concern because they are minor constituents of diesel fuels (Neff 1979). The uncertainty in risk calculations are described in the Magnitude of Effect of Uncertainties tables for each site.

$\mathrm{CH} 2 \mathrm{M}$ Hill typically only performed one analysis of a sample. If the sample had an elevated concentration of a contaminant (e.g., xylenes), then the sample was run with a dilution factor greater than 1 . If one increases the dilution factor, then the detection limit is also increased. This relationship led to some very high detection limits, primarily for volatiles, at sites ST10/SS14, ST13/DP26, and ST19.

None of the contaminants listed with an " $\mathrm{A}$ " in Tables 7.5 through 7.9 were included in the final risk calculations (Appendix F). There were no known sources for any of the volatiles and semi-volatiles at the Operable Unit 2 sites. The effects of the high detection limits are discussed in the appropriate uncertainty sections of this assessment.

\subsubsection{Comparison to Site Background}

Analytical results for metals listed in Tables 7.5 through 7.9 were statistically compared to site background values measured during the 1991 and 1992 field sampling events. Those samples whose mean value was statistically indistinguishable from site background or below the background mean were highlighted in Tables 7.5 through 7.9. Greater detail on the determination of site background metal concentrations is in Appendix $E$.

Several of the site background groundwater metals were not detected at CRQLs that were significantly greater than their respective risk-based screening concentration: antimony, beryllium, and cadmium. For site metal concentrations greater than the risk threshold yet less than one-half background CRQL, the corresponding cell was highlighted in Tables 7.5 through 7.9 .

In addition, Appendix E provides evidence that the concentrations of several of the metals that were statistically greater than background are probably not related to base activities. These metals are also highlighted in the tables.

In this assessment, all organic compounds were considered anthropogenic and were not compared to background. 
IABLE 7.4. Risk-Based Contaminant of Concern Cutoff Concentrations

\begin{tabular}{|c|c|c|c|c|c|}
\hline ANALYTE & CAS & $\begin{array}{c}\text { Conc. Corresp. } \\
\text { to } 1 \text { E-6 Risk } \\
\text { Water } \\
(\mu g / L)\end{array}$ & $\begin{array}{c}\text { to } 1 \mathrm{E}-7 \text { Risk } \\
\text { Soil } \\
(\mu \mathrm{g} / \mathrm{kg})\end{array}$ & $\begin{array}{c}\text { Conc. Corresp. } \\
\text { to } H Q=0.1 \\
\text { Water } \\
(\mu \mathrm{g} / \mathrm{L})\end{array}$ & $\begin{array}{c}\text { Soil } \\
(\mu \mathrm{g} / \mathrm{kg})\end{array}$ \\
\hline \multicolumn{6}{|l|}{ VOLATILES } \\
\hline 1,1,1-TRICHLOROETHANE & 71556 & $1.49 \mathrm{E}+00$ & $1.11 \mathrm{E}+03$ & $3.29 E+02$ & $2.46 E+06$ \\
\hline $1,1,2,2$-TETRACHLOROETHANE & 79345 & 8.96E-02 & $3.19 E+02$ & & \\
\hline 1,1,2-TRICHLOROETHANE & 79005 & $3.15 E-01$ & $1.12 E+03$ & $1.46 E+01$ & $1.10 E+05$ \\
\hline 1,1-DICHLOROETHANE & 75343 & & & $7.68 E+01$ & $2.74 E+06$ \\
\hline 1,1-DICHLOROETHENE & 75354 & $6.68 \mathrm{E}-02$ & $1.06 E+02$ & $3.29 E+01$ & $2.46 \mathrm{E}+05$ \\
\hline 1,2-DICHLOROETHANE & 107062 & 1.97E-01 & $7.02 E+02$ & & \\
\hline 1,2-DICHLOROETHENE (TOTAL) & 156605 & & & $7.30 \mathrm{E}+01$ & $5.48 E+05$ \\
\hline 1,2-DICHLOROPROPANE & 78875 & 2.64E-01 & $9.39 E+02$ & $1.07 E+00$ & \\
\hline 2-BUTANONE & 78933 & & & $5.92 E+01$ & 1.37E+06 \\
\hline 2-HEXANONE & 591786 & & & & \\
\hline \multicolumn{6}{|l|}{ 4-METHYL-2-PENTANONE } \\
\hline ACETONE & 67641 & & & $3.65 E+02$ & $2.74 E+06$ \\
\hline $\begin{array}{l}\text { BENZENE } \\
\text { BENZYL ALCOHOL }\end{array}$ & 71432 & $6.18 \mathrm{E}-01$ & $2.20 E+03$ & & \\
\hline BROMODICHLOROMETHANE & 75274 & 6.55E-01 & $4.91 E+02$ & $7.30 E+01$ & $5.48 E+05$ \\
\hline BROMOFORM & 75252 & $3.78 E+00$ & $8.09 E+03$ & $7.30 E+01$ & $5.48 E+05$ \\
\hline BROMOMETHANE & 74839 & & & $2.49 E+00$ & $3.83 E+04$ \\
\hline CARBON DISULFIDE & 75150 & & & $2.71 E+00$ & $2.74 E+06$ \\
\hline CARBON TETRACHLORIDE & 56235 & $2.59 \mathrm{E}-01$ & $4.91 E+02$ & $2.56 \mathrm{E}+00$ & $1.92 E+04$ \\
\hline CHLOROBENZENE & 108907 & & & $5.16 E+00$ & $5.48 E+05$ \\
\hline CHLOROETHANE & 75003 & & & $7.68 E+03$ & $2.74 E+08$ \\
\hline CHLOROFORM & 67663 & $2.75 \mathrm{E}-01$ & $1.05 E+04$ & $3.65 E+01$ & $2.74 E+05$ \\
\hline CHLOROMETHANE & 74873 & $2.33 E+00$ & $4.91 E+03$ & $1.97 E+03$ & $1.48 \mathrm{E}+07$ \\
\hline CIS-1,3-DICHLOROPROPENE & 542756 & $3.66 \mathrm{E}-01$ & $3.55 E+02$ & 9.15E-01 & $8.21 E+03$ \\
\hline DIBROMOCHLOROMETHANE & 124481 & $1.01 E+00$ & $7.60 \mathrm{E}+02$ & $7.30 \mathrm{E}+01$ & $5.48 E+05$ \\
\hline ETHYLBENZENE & 100414 & & & $1.59 E+02$ & $2.74 E+06$ \\
\hline METHYLENE CHLORIDE & 75092 & $6.31 E+00$ & $8.52 E+03$ & 2.19E+02 & $1.64 E+06$ \\
\hline STYRENE & 100425 & 2.27E+00 & $2.13 E+03$ & $2.04 E+02$ & $5.48 E+06$ \\
\hline TETRACHLOROETHENE & 127184 & $1.47 E+00$ & $1.25 E+03$ & $3.65 E+01$ & $2.74 E+05$ \\
\hline TOLUENE & 108883 & & & $3.15 E+02$ & $5.48 E+06$ \\
\hline TRANS-1,3-DICHLOROPROPENE & 10061026 & & & $1.10 \mathrm{E}+00$ & $8.21 E+03$ \\
\hline TRICHLOROETHENE & 79016 & $1.14 \mathrm{E}+00$ & $5.81 E+03$ & & \\
\hline VINYL ACETATE & 108054 & & & $4.38 E+01$ & $1.56 E+06$ \\
\hline VINYL CHLORIDE & 75014 & 2.85E-02 & $3.36 \mathrm{E}+01$ & & \\
\hline XYLENES (TOTAL) & 1330207 & & & $8.28 E+01$ & $5.48 \mathrm{E}+07$ \\
\hline \multicolumn{6}{|l|}{ SEMI-VOLATILES } \\
\hline 1,2,4-TRICHLOROBENZENE & 120821 & & & $3.65 E+01$ & $2.74 E+05$ \\
\hline 1,2-DICHLOROBENZENE & 95501 & & & $3.29 E+02$ & $2.46 E+06$ \\
\hline 1,2-DIPHENYLHYDRAZINE & 122667 & 1.06E-01 & $7.98 \mathrm{E}+01$ & & \\
\hline 1,3-DICHLOROBENZENE & 541731 & & & $3.29 E+02$ & $2.46 E+06$ \\
\hline 1,4-DICHLOROBENZENE & 106467 & 7.47E-01 & $2.66 E+03$ & $1.93 E+02$ & $1.56 \mathrm{E}+08$ \\
\hline 2,4,5-TRICHLOROPHENOL & 95954 & & & $3.65 E+02$ & $2.74 E+06$ \\
\hline 2,4,6-TRICHLOROPHENOL & 88062 & $1.63 E+00$ & $5.81 E+03$ & & \\
\hline 2,4-DICHLOROPHENOL & 94757 & & & 3.65E+01 & $2.74 E+05$ \\
\hline 2,4-DIMETHYLPHENOL & 105679 & & & $7.30 E+01$ & $5.48 E+05$ \\
\hline 2,4-DINITROPHENOL & 51285 & & & $7.30 E+00$ & $5.48 E+04$ \\
\hline 2,4-DINITROTOLUENE & 121142 & 1.25E-01 & $9.39 E+01$ & & \\
\hline \multicolumn{6}{|l|}{ 2,6-DINITROTOLUENE } \\
\hline 2-CHLORONAPHTHALENE & 91578 & & & $2.92 E+02$ & $2.19 E+06$ \\
\hline
\end{tabular}




\begin{tabular}{|c|c|c|c|c|c|}
\hline ANALYTE & CAS & $\begin{array}{c}\text { Conc. Corresp. } \\
\text { to } 1 \mathrm{E}-6 \text { Risk } \\
\text { Water } \\
(\mu g / \mathrm{L}) \\
\end{array}$ & $\begin{array}{c}\text { to } 1 \text { E-7 Risk } \\
\text { Soil } \\
(\mu \mathrm{g} / \mathrm{kg})\end{array}$ & $\begin{array}{c}\text { Conc. Corresp. } \\
\text { to } H Q=0.1 \\
\text { Water } \\
(\mu g / L)\end{array}$ & $\begin{array}{c}\text { Soil } \\
(\mu g / \mathrm{kg})\end{array}$ \\
\hline 2-CHLOROPHENOL & 95578 & & & $1.83 E+01$ & $1.37 \mathrm{E}+05$ \\
\hline 2-METHYLNAPHTHALENE & 91576 & & & 2.19E+02 & $1.64 E+06$ \\
\hline 2-METHYLPHENOL & 95487 & & & $1.83 E+02$ & 1.37E+06 \\
\hline 4-METHYLPHENOL & 106445 & & & $6.35 E+01$ & 1.37E+06 \\
\hline 2-NITROANILINE & 88747 & & & $2.19 E-01$ & $1.64 \mathrm{E}+03$ \\
\hline \multicolumn{6}{|l|}{ 2-NITROPHENOL } \\
\hline $\begin{array}{l}\text { 3,3'-DICHLOROBENZIDINE } \\
\text { 3-NITROANILINE }\end{array}$ & 91941 & $1.89 E-01$ & $1.42 E+02$ & $3.29 E+02$ & $2.46 \mathrm{E}+06$ \\
\hline $\begin{array}{l}\text { 4,6-DINITRO-2-METHYLPHENOL } \\
\text { 4-BROMOPHENYL-PHENYLETHER } \\
\text { 4-CHOLOR-3-METHYLPHENOL }\end{array}$ & 534521 & & & $3.65 E+00$ & $2.74 E+04$ \\
\hline 4-CHLOROANILINE & 106478 & & & $1.46 \mathrm{E}+01$ & $1.10 E+05$ \\
\hline 4-CHLOROPHENYL-PHENYLETHER & 7005723 & & & & \\
\hline 4-NITROANILINE & 100016 & & & $3.65 E+03$ & $2.74 \mathrm{E}+07$ \\
\hline 4-NITROPHENOL & 100027 & & & $2.74 \mathrm{E}+02$ & $2.05 E+06$ \\
\hline ACENAPHTHENE & 83329 & & & 2.19E+02 & $1.64 \mathrm{E}+06$ \\
\hline ACENAPHTHYLENE & 208968 & & & & \\
\hline ANTHRACENE & 120127 & $1.15 \mathrm{E}-02$ & $6.25 E+02$ & $1.10 E+03$ & $8.21 E+06$ \\
\hline BENZO(A)ANTHRACENE & 56553 & 8.05E-02 & $6.03 E+01$ & & \\
\hline BENZO(A)PYRENE & 50328 & 1.17E-02 & $8.75 E+00$ & & \\
\hline BENZO(B & 205992 & 8.33E-02 & $E+01$ & & \\
\hline BENZO( & & $5.30 E-01$ & $3.98 \mathrm{E}+02$ & & \\
\hline FLUOORANTHENE & 207089 & $1.77 E-01$ & $1.33 E+02$ & & \\
\hline BENZOIC ACID & 65850 & & & $1.46 \mathrm{E}+04$ & $1.10 E+08$ \\
\hline \multicolumn{6}{|l|}{ BIS(2-CHLOROETHOXY)METHANE } \\
\hline BIS(2-CHLOROETHYL)ETHER & 111444 & $1.63 \mathrm{E}-02$ & $5.81 E+01$ & & \\
\hline BIS(2-CHLOROISOPROPYL)ETHER & 39638329 & 4.23E-01 & $9.13 E+02$ & $1.46 \mathrm{E}+02$ & $1.10 E+06$ \\
\hline $\begin{array}{l}\text { BIS(2-ETHYLHEXYL)PHTHALATE } \\
\text { BUTYLBENZYLPHTHALATE }\end{array}$ & 117817 & $6.08 \mathrm{E}+00$ & $4.56 \mathrm{E}+03$ & $\begin{array}{l}7.30 \mathrm{E}+01 \\
7.30 \mathrm{E}+02\end{array}$ & $\begin{array}{l}5.48 E+05 \\
5.48 E+06\end{array}$ \\
\hline ENE & 218019 & $2.65 E+00$ & $1.99 E+03$ & & \\
\hline PHTHALATE & 84742 & & & $3.65 E+02$ & $2.74 E+06$ \\
\hline DI-N-OCTYLPHT & 117840 & $6.08 \mathrm{E}+00$ & $4.56 \mathrm{E}+03$ & $7.30 \mathrm{E}+01$ & $5.48 E+05$ \\
\hline HRACENE & 53703 & $1.05 \mathrm{E}-02$ & $7.88 E+00$ & & \\
\hline DIBENZOFURAN & & & & $1.46 E+04$ & $1.10 E+08$ \\
\hline DIETHYLPHTHALATE & 84662 & & & $2.92 E+03$ & $2.19 \mathrm{E}+07$ \\
\hline DIMETHYLPHTHALATE & 131113 & 8.52E-02 & $6.39 E+01$ & $3.65 E+04$ & $2.74 E+08$ \\
\hline FLUORANTHENE & 206440 & & & $1.46 E+02$ & $1.10 E+06$ \\
\hline FLUORENE & 86737 & & & $1.46 \mathrm{E}+02$ & $1.10 E+06$ \\
\hline HEXACHLOROBENZENE & 118741 & $5.32 E-02$ & $3.99 \mathrm{E}+01$ & $2.92 E+00$ & $2.19 \mathrm{E}+04$ \\
\hline HEXACHLOROBUTADIENE & 87683 & $1.09 E+00$ & $8.19 E+02$ & $7.30 E+00$ & $5.48 E+04$ \\
\hline HEXACHLOROCYCLOPENTADIENE & 77474 & & & $2.56 E+01$ & $1.92 E+05$ \\
\hline HEXACHLOROETHANE & 67721 & $6.08 \mathrm{E}+00$ & $4.56 \mathrm{E}+03$ & $3.65 E+00$ & $2.74 E+04$ \\
\hline INDENO(1,2,3-CD)PYRENE & 193395 & 5.03E-02 & 3.77E+01 & & \\
\hline ISOPHORONE & 78591 & $8.96 E+01$ & $6.72 E+04$ & $7.30 \mathrm{E}+02$ & $5.48 \mathrm{E}+06$ \\
\hline N-NITROSO-DI-N-PROPYLAMINE & 621647 & $1.22 \mathrm{E}-02$ & $9.13 E+00$ & & \\
\hline N-NITROSODIPHENYLAMINE (1) & 86306 & $1.74 E+01$ & $1.30 E+04$ & & \\
\hline NAPHTHANLENE & 91203 & & & $1.46 E+02$ & $1.10 E+06$ \\
\hline NITROBENZENE & 98953 & & & 3.70E-01 & $1.37 E+04$ \\
\hline PENTACHLOROPHENOL & 87865 & 7.10E-01 & $5.32 E+02$ & $1.10 E+02$ & $8.21 E+05$ \\
\hline PHENANTHRENE & 85018 & & & $3.07 E+01$ & $1.10 E+06$ \\
\hline PHENOL & 108952 & & & $2.19 E+03$ & $1.64 E+07$ \\
\hline
\end{tabular}


IABLE 7.4. Risk-Based Contaminant of Concern Cutoff Concentrations

\begin{tabular}{|c|c|c|c|c|c|}
\hline ANALYTE & CAS & $\begin{array}{c}\text { Conc. Corresp. } \\
\text { to } 1 E-6 \text { Risk } \\
\text { Water } \\
(\mu g / L)\end{array}$ & $\begin{array}{c}\text { to } 1 \text { E-7 Risk } \\
\text { Soil } \\
(\mu \mathrm{g} / \mathrm{kg})\end{array}$ & $\begin{array}{c}\text { Conc. Corresp. } \\
\text { to } H Q=0.1 \\
\text { Water } \\
(\mu g / L)\end{array}$ & $\begin{array}{c}\text { Soil } \\
(\mu \mathrm{g} / \mathrm{kg})\end{array}$ \\
\hline PYRENE & 129000 & $1.44 \mathrm{E}-01$ & $1.08 \mathrm{E}+02$ & $1.10 \mathrm{E}+02$ & $8.21 E+05$ \\
\hline \multicolumn{6}{|c|}{ TPH } \\
\hline \multicolumn{6}{|l|}{ PCB } \\
\hline AROCLOR-1016 & 12674112 & 1.11E-02 & $8.30 \mathrm{E}+00$ & & \\
\hline AROCLOR-1221 & 1104282 & 1.11E-02 & $8.30 \mathrm{E}+00$ & & \\
\hline AROCLOR-1232 & 11141165 & $1.11 E-02$ & $8.30 E+00$ & & \\
\hline AROCLOR-1242 & 53469219 & $1.11 E-02$ & $8.30 E+00$ & & \\
\hline AROCLOR-1248 & 12672296 & 1.11E-02 & $8.30 E+00$ & & \\
\hline AROCLOR-1254 & 11091691 & 1.11E-02 & $8.30 E+00$ & & \\
\hline AROCLOR-1260 & 11096825 & $1.11 E-02$ & $8.30 E+00$ & & \\
\hline \multicolumn{6}{|l|}{ PESTICIDES } \\
\hline 4,4'-DDD & 72548 & 3.55E-01 & $2.66 \mathrm{E}+02$ & & \\
\hline 4,4'-DDE & 72559 & $2.50 E-01$ & $1.88 E+02$ & & \\
\hline 4,4'-DDT & 50293 & $2.50 E-01$ & $1.88 \mathrm{E}+02$ & $1.83 E+00$ & $1.37 E+04$ \\
\hline ALDRIN & 309002 & $5.01 E-03$ & $3.76 \mathrm{E}+00$ & $1.10 E-01$ & $8.21 E+02$ \\
\hline ALPHA-BHC & 319846 & 1.35E-02 & $1.01 \mathrm{E}+01$ & & \\
\hline ALPHA-CHLORDANE & 57749 & $6.55 E-02$ & $4.91 E+01$ & 2.19E-01 & $1.64 E+03$ \\
\hline BETA-BHC & 319857 & 4.73E-02 & $3.55 E+01$ & $1.10 E+00$ & $8.21 E+03$ \\
\hline DELTA-BHC & 319868 & & & $7.30 \mathrm{E}+00$ & $5.48 E+04$ \\
\hline DIELDRIN & 60571 & 5.32E-03 & $3.99 E+00$ & 1.83E-01 & $1.37 E+03$ \\
\hline ENDOSULFAN I & & & & 1.83E-01 & $1.37 E+03$ \\
\hline ENDOSULFAN II & & & & 1.83E-01 & $1.37 E+03$ \\
\hline \multicolumn{6}{|l|}{ ENDOSULFAN SULFATE } \\
\hline ENDRIN & 72208 & & & $1.10 E+00$ & $8.21 E+03$ \\
\hline \multicolumn{6}{|l|}{ ENDRIN KETONE } \\
\hline GAMMA-BHC (LINDANE) & 58899 & & & $1.10 E+00$ & $8.21 E+03$ \\
\hline GAMMA-CHLORDANE & 57749 & 6.55E-02 & $4.91 E+01$ & 2.19E-01 & $1.64 E+03$ \\
\hline HEPTACHLOR & 76448 & $1.89 \mathrm{E}-02$ & $1.42 E+01$ & $1.83 E+00$ & $1.37 E+04$ \\
\hline HEPTACHLOR EPOXIDE & 1024573 & $9.36 \mathrm{E}-03$ & $7.02 E+00$ & $3.65 E-02$ & $2.74 E+02$ \\
\hline METHOXYCHLOR & 72435 & & & $1.83 E+01$ & $1.37 E+05$ \\
\hline TOXAPHENE & 8001352 & 7.74E-02 & $5.81 E+01$ & & \\
\hline \multicolumn{6}{|l|}{ METALS } \\
\hline ALUMINUM & 7429905 & & & & \\
\hline ANTIMONY & 7440360 & & & $1.46 \mathrm{E}+00$ & $1.10 E+04$ \\
\hline ARSENIC & 7440382 & 4.87E-02 & $3.65 E+01$ & $1.10 E+00$ & $8.21 E+03$ \\
\hline BARIUM & 7440393 & & & $2.56 E+02$ & $1.92 E+06$ \\
\hline BERYLLIUM & 7440417 & 1.98E-02 & $1.49 E+01$ & $1.83 E+01$ & $1.37 E+05$ \\
\hline CADMIUM & 7440439 & & & $1.83 E+00$ & $1.37 E+04$ \\
\hline \multicolumn{6}{|l|}{ CALCIUM } \\
\hline CHROMIUM VI & 7440473 & & & $1.83 E+01$ & $1.37 E+05$ \\
\hline COBALT & 7440484 & & & & \\
\hline COPPER & 7440508 & & & $1.35 \mathrm{E}+02$ & $1.01 E+06$ \\
\hline IRON & 15438310 & & & & \\
\hline LEAD & 7439921 & & & & \\
\hline MAGNESIUM & 7786303 & & & & \\
\hline MANGANESE & 7439965 & & & $1.83 E+01$ & $3.83 E+04$ \\
\hline
\end{tabular}


IABLE 7.4. Risk-Based Contaminant of Concern Cutoff Concentrations

\begin{tabular}{lccccc}
\multicolumn{1}{c}{ ANALYTE } & CAS $\begin{array}{c}\text { Conc. Corresp. } \\
\text { to } \begin{array}{c}\text { 1E-6 Risk } \\
\text { Water } \\
(\mu \mathrm{g} / \mathrm{L})\end{array}\end{array}$ & $\begin{array}{c}\text { Conc. Corresp. } \\
\text { to } \begin{array}{c}\text { SE-7 Risk } \\
(\mu \mathrm{g} / \mathrm{kg})\end{array}\end{array}$ & $\begin{array}{c}\text { to } \\
\text { to } \mathrm{Hater} \\
(\mu \mathrm{g} / \mathrm{L})\end{array}$ & $\begin{array}{c}\text { Soil } \\
(\mu \mathrm{g} / \mathrm{kg})\end{array}$ \\
\hline MERCURY & & & $1.10 \mathrm{E}+00$ & $8.21 \mathrm{E}+03$ \\
NICKEL & 7439976 & & $7.30 \mathrm{E}+01$ & $5.48 \mathrm{E}+05$ \\
POTASSIUM ION & 7440020 & & & \\
SELENIUM & 7447407 & & $1.83 \mathrm{E}+01$ & $1.37 \mathrm{E}+05$ \\
SILVER & 7782492 & & $2.92 \mathrm{E}+01$ & $2.19 \mathrm{E}+05$ \\
SODIUM & 7440224 & & $1.10 \mathrm{E}+06$ & $8.21 \mathrm{E}+09$ \\
THALLIUM & 7647145 & & $2.92 \mathrm{E}-01$ & $2.19 \mathrm{E}+03$ \\
VANADIUM & 7440280 & & $3.29 \mathrm{E}+01$ & $2.46 \mathrm{E}+05$ \\
ZINC COMPOUNDS & 7440622 & & $7.30 \mathrm{E}+02$ & $5.48 \mathrm{E}+06$ \\
\hline
\end{tabular}


IABLE 7.5. Contaminants of Concern for Source Areas ST10/SS14

\begin{tabular}{|c|c|c|c|c|c|}
\hline ANALYTES & $\begin{array}{c}\text { SURFACE } \\
\text { SOILS }\end{array}$ & $\begin{array}{c}\text { SUBSURFACE } \\
\text { SOILS }\end{array}$ & SEDIMENTS & $\begin{array}{l}\text { GROUND } \\
\text { WATER }\end{array}$ & $\begin{array}{l}\text { SURFACE } \\
\text { WATERS }\end{array}$ \\
\hline \multicolumn{6}{|l|}{ VOLATILES } \\
\hline 1,1,1-TRICHLOROETHANE & & & & A & A \\
\hline 1,1,2,2-TETRACHLOROETHANE & & & & A & $A$ \\
\hline 1,1,2-TRICHLOROETHANE & & & & A & A \\
\hline 1,1-DICHLOROETHENE & & & & A & A \\
\hline 1,2-DICHLOROETHANE & & & & A & A \\
\hline TRANS-1,2-DICHLOROETHENE & & & & $\#$ & \\
\hline 1,2-DICHLOROPROPANE & & & & A & A \\
\hline 2-BUTANONE & & $\#$ & \# & \# & \\
\hline ACETONE & & $\#$ & B & B & B \\
\hline BENZENE & & $x$ & \# & $\mathbf{x}$ & $\mathbf{x}$ \\
\hline BROMODICHLOROMETHANE & & & & A & A \\
\hline BROMOFORM & & & & A & \\
\hline BROMOMETHANE & & & & A & A \\
\hline CARBON TETRACHLORIDE & & & & A & A \\
\hline CHLOROFORM & & $\#$ & & \# & \\
\hline CHLOROMETHANE & & & & A & \\
\hline CIS-1,3-DICHLOROPROPENE & & & & A & A \\
\hline DIBROMOCHLOROMETHANE & & & & A & A \\
\hline ETHYLBENZENE & & \# & & $\mathbf{x}$ & \\
\hline METHYLENE CHLORIDE & & $\#$ & B & $\#$ & B \\
\hline STYRENE & & & & A & \\
\hline TETRACHLOROETHENE & & & & A & \\
\hline TOLUENE & & $\#$ & $\#$ & $x$ & \\
\hline TRANS-1,3-DICHLOROPROPENE & & & & A & A \\
\hline TRICHLOROETHENE & & & & $\#$ & \\
\hline VINYL CHLORIDE & & A & & A & A \\
\hline XYLENES (TOTAL) & & $\#$ & $\#$ & $\mathbf{x}$ & \\
\hline \multicolumn{6}{|l|}{ SEMI-VOLATILES } \\
\hline 1,2-DIPHENYLHYDRAZINE & & A & & & \\
\hline 1,4-DICHLOROBENZENE & & & & A & A \\
\hline 2,4-DINITROPHENOL & & A & A & A & A \\
\hline 2,4-DINITROTOLUENE & & A & A & A & A \\
\hline 2,6-DINITROTOLUENE & & A & $A$ & A & $A$ \\
\hline 2-NITROANILINE & A & A & A & A & A \\
\hline 2-METHYLNAPHTHALENE & $\#$ & $\#$ & $\#$ & $\mathbf{x}$ & \\
\hline 3,3'-DICHLOROBENZIDINE & & A & A & A & A \\
\hline ACENAPHTHENE & & $\#$ & & & \\
\hline ANTHRACENE & \# & $\#$ & $\#$ & $\mathbf{x}$ & \\
\hline BENZO(A)ANTHRACENE & $x$ & $\mathbf{x}$ & $x$ & A & A \\
\hline BENZO(A)PYRENE & $\mathbf{x}$ & A & $\mathbf{x}$ & A & A \\
\hline BENZO(B)FLUORANTHENE & $\mathbf{x}$ & A & $\mathbf{x}$ & A & A \\
\hline BENZO(K)FLUORANTHENE & $x$ & $\mathbf{x}$ & $\mathbf{x}$ & A & A \\
\hline BENZOIC ACID & A & & & $\#$ & \\
\hline BIS(2-CHLOROETHYL)ETHER & & A & A & A & \\
\hline BIS(2-CHLOROISOPROPYL)ETHER & & & & A & A \\
\hline BIS(2-ETHYLHEXYL)PHTHALATE & $\#$ & $\#$ & B & $\mathbf{x}$ & \\
\hline BUTYLBENZYLPHTHALATE & $\#$ & & $\#$ & \# & \\
\hline CHRYSENE & $x$ & $\mathbf{x}$ & $x$ & A & A \\
\hline DI-N-BUTYLPHTHALATE & & B & & & \\
\hline DI-N-OCTYLPHTHALATE & \# & & & & \\
\hline DIBENZ(A,H)ANTHRACENE & $\mathbf{x}$ & A & A & A & A \\
\hline
\end{tabular}


IABLE 7.5. Contaminants of Concern for Source Areas ST10/SS14

\begin{tabular}{|c|c|c|c|c|c|}
\hline ANALYTES & $\begin{array}{c}\text { SURFACE } \\
\text { SOILS } \\
\end{array}$ & $\begin{array}{c}\text { SUBSURFACE } \\
\text { SOILS }\end{array}$ & SEDIMENTS & $\begin{array}{c}\text { GROUND } \\
\text { WATER }\end{array}$ & $\begin{array}{l}\text { SURFACE } \\
\text { WATERS } \\
\end{array}$ \\
\hline DIETHYLPHTHALATE & & $B$ & & & \\
\hline FLUORANTHENE & $\#$ & $\#$ & $\#$ & $\#$ & \\
\hline FLUORENE & $\#$ & $\#$ & & $\#$ & \\
\hline HEXACHLOROBENZENE & & A & A & A & A \\
\hline HEXACHLOROBUTADIENE & & & & A & A \\
\hline HEXACHLOROETHANE & & & & A & A \\
\hline INDENO(1,2,3-CD)PYRENE & $\mathbf{x}$ & A & $\mathbf{x}$ & A & A \\
\hline N-NITROSO-DI-N-PROPYLAMINE & $\#$ & A & A & A & A \\
\hline N-NITROSODIPHENYLAMINE (1) & $\#$ & & $\#$ & A & \\
\hline NAPHTHALENE & & \# & & $\mathbf{x}$ & \\
\hline NITROBENZENE & & & A & A & A \\
\hline PENTACHLOROPHENOL & & A & A & A & A \\
\hline PYRENE & $\#$ & $\#$ & $\#$ & $\#$ & \\
\hline \multicolumn{6}{|l|}{ РСВ } \\
\hline AROCLOR-1016 & A & & A & A & \\
\hline AROCLOR-1221 & A & A & A & A & \\
\hline AROCLOR-1232 & A & A & A & A & \\
\hline AROCLOR-1242 & A & & A & A & \\
\hline AROCLOR-1248 & A & & A & A & \\
\hline AROCLOR-1254 & & & A & A & \\
\hline AROCLOR-1260 & & & $\mathbf{x}$ & A & A \\
\hline \multicolumn{6}{|l|}{ PESTICIDES } \\
\hline $4,4^{\prime}-\mathrm{DDD}$ & $\#$ & $\#$ & $x$ & A & \\
\hline 4,4'-DDE & $\#$ & $\#$ & \# & & \\
\hline $4,4^{\prime}-\mathrm{DDT}$ & $\mathbf{x}$ & $\#$ & $\#$ & A & \\
\hline ALDRIN & $x$ & & & A & \\
\hline ALPHA-BHC & & & & A & A \\
\hline ALPHA-CHLORDANE & & & & A & \\
\hline BETA-BHC & & & & A & \\
\hline DIELDRIN & & & & A & A \\
\hline ENDOSULFAN I & & & & A & \\
\hline GAMMA-BHC (LINDANE) & & & & A & \\
\hline GAMMA-CHLORDANE & & & & A & A \\
\hline HEPTACHLOR & & & & A & \\
\hline HEPTACHLOR EPOXIDE & & & & A & A \\
\hline TOXAPHENE & & & & A & A \\
\hline \multicolumn{6}{|l|}{ METALS } \\
\hline ANTIMONY & \# & A & $\#$ & 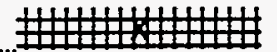 & A \\
\hline ARSENIC & $\mathrm{x}$ & 2. & (3. & $\mathrm{x}$ & $x$ \\
\hline BARIUM & $\#$ & 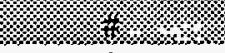 & ix & $x$ & $\#$ \\
\hline BERYLLIUM & . & A & i. & \#\#\#弗 & A \\
\hline CADMIUM & $\#$ & 柇 & : & 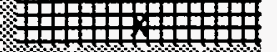 & $\#$ \\
\hline CHROMIUM & :- & $\#$ & \# & 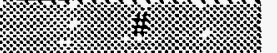 & \\
\hline COPPER & $\#$ & \%? & (2) & i & \\
\hline MANGANESE & $\%$ & *i: & (x) & 1) & $x$ \\
\hline MERCURY & $\#$ & & $=$ & & \\
\hline NICKEL & $\#$ & (1) & 2. & $=$ & $\#$ \\
\hline SELENIUM & & & & $\#$ & $\#$ \\
\hline SILVER & 4 & & & & \\
\hline THALLIUM & tit: & A & & $\mathrm{x}$ & A \\
\hline
\end{tabular}


IABLE 7.5. Contaminants of Concern for Source Areas ST10/SS14

\begin{tabular}{|c|c|c|c|c|c|}
\hline ANALYTES & $\begin{array}{l}\text { SURFACE } \\
\text { SOILS }\end{array}$ & $\begin{array}{c}\text { SUBSURFACE } \\
\text { SOILS }\end{array}$ & SEDIMENTS & $\begin{array}{l}\text { GROUND } \\
\text { WATER }\end{array}$ & $\begin{array}{l}\text { SURFACE } \\
\text { WATERS }\end{array}$ \\
\hline VANADIUM & 然 & 14 & 聯 & xy & $\#$ \\
\hline ZINC & \# & 8 & 梦 & $\#$ & \# \\
\hline
\end{tabular}

$\begin{array}{ll}\# & \text { Present at concentration < risk } \\ \text { Present at cocentration }>=\text { risk or ARAR } \\ \text { Not detected. However, (CRQL2) }>=\text { risk or ARAR value } \\ \text { Analyte found in associated blank as well as sample. } \\ \text { Analyte Detected. Sample mean }=<\text { Background Mean. } \\ \text { Background meaurements are nondetect with } \\ \text { CRQL }>\text { risk or ARAR values. }\end{array}$

There are no background measurements for Surface Waters. There are no background water measurements for Selenium or Thallium. 
IABLE 7.6. Contaminants of Concern for Source Area ST11

\begin{tabular}{|c|c|c|c|c|c|}
\hline ANALYTES & $\begin{array}{c}\text { SURFACE } \\
\text { SOILS }\end{array}$ & $\begin{array}{c}\text { SUBSURFACE } \\
\text { SOILS }\end{array}$ & SEDIMENTS & $\begin{array}{l}\text { GROUND } \\
\text { WATER }\end{array}$ & $\begin{array}{l}\text { SURFACE } \\
\text { WATERS }\end{array}$ \\
\hline \multicolumn{6}{|l|}{ VOLATILES } \\
\hline 1,1,1-TRICHLOROETHANE & & & & A & \\
\hline 1,1,2,2-TETRACHLOROETHANE & & & & A & A \\
\hline 1,1,2-TRICHLOROETHANE & & & & A & \\
\hline 1,1-DICHLOROETHENE & & & & A & A \\
\hline 1,2-DICHLOROETHANE & & & & A & \\
\hline 1,2-DICHLOROETHENE (TOTAL) & & & & $\#$ & \\
\hline ACETONE & & $\#$ & & B & \\
\hline BENZENE & & A & & $\mathbf{x}$ & \\
\hline BROMODICHLOROMETHANE & & & & A & \\
\hline $\begin{array}{l}\text { BROMOMETHANE } \\
\text { BRO }\end{array}$ & & & & A & \\
\hline CARBON TETRACHLORIDE & & & & A & A \\
\hline CHLOROFORM & & \# & & & \\
\hline CIS-1,3-DICHLOROPROPENE & & & & A & A \\
\hline DIBROMOCHLOROMETHANE & & & & A & \\
\hline METHYLENE CHLORIDE & & B & & B & \\
\hline TETRACHLOROETHENE & & $\#$ & & & \\
\hline TOLUENE & & $\#$ & & & \\
\hline TRANS-1,3-DICHLOROPROPENE & & & & A & \\
\hline VINYL CHLORIDE & & A & & A & A \\
\hline XYLENES (TOTAL) & & \# & & & \\
\hline \multicolumn{6}{|l|}{ SEMI-VOLATILES } \\
\hline 1,2,4-TRICHLOROBENZENE & & & & A & A \\
\hline 1,4-DICHLOROBENZENE & & & & A & A \\
\hline \multicolumn{6}{|l|}{ 2,4,6-TRICHLOROPHENOL } \\
\hline 2,4-DINITROPHENOL & & & & & \\
\hline 2,4-DINITROTOLUENE & & & & A & A \\
\hline 2,6-DINITROTOLUENE & & & & A & A \\
\hline 2-NITROANILINE & A & A & & A & A \\
\hline 3,3'-DICHLOROBENZIDINE & & & & A & A \\
\hline BENZO(A)ANTHRACENE & A & A & A & A & A \\
\hline BENZO(A)PYRENE & A & A & A & A & A \\
\hline $\begin{array}{l}\text { BENZO(B)FLUORANTHENE } \\
\text { B. }\end{array}$ & A & A & A & A & A \\
\hline BENZO(K)FLUORANTHENE & A & A & A & A & A \\
\hline BIS(2-CHLOROISOPROPYL)ETHER & & & A & A & A \\
\hline $\begin{array}{l}\text { BIS(2-ETHYLHEXYL)PHTHALATE } \\
\text { D. }\end{array}$ & $\#$ & \# & & $\#$ & $\#$ \\
\hline CHRYSENE & A & A & A & A & A \\
\hline DI-N-BUTYLPHTHALATE & & B & \# & & \\
\hline DIBENZ(A,H)ANTHRACENE & A & A & A & A & A \\
\hline FLUORANTHENE & $\#$ & & $\#$ & & \\
\hline HEXACHLOROBENZENE & & & A & A & A \\
\hline HEXACHLOROBUTADIENE & & & & A & A \\
\hline HEXACHLOROETHANE & & & & A & A \\
\hline INDENO(1,2,3-CD)PYRENE & A & A & A & A & A \\
\hline N-NITROSO-DI-N-PROPYLAMINE & A & A & A & A & A \\
\hline NITROBENZENE & & & A & A & A \\
\hline PENTACHLOROPHENOL & & & & A & A \\
\hline PYRENE & $\#$ & & & & \\
\hline
\end{tabular}


IABLE 7.6. Contaminants of Concern for Source Area ST11

\begin{tabular}{|c|c|c|c|c|c|}
\hline ANALYTES & $\begin{array}{l}\text { SURFACE } \\
\text { SOILS }\end{array}$ & $\begin{array}{l}\text { SUBSURFACE } \\
\text { SOILS }\end{array}$ & SEDIMENTS & $\begin{array}{l}\text { GROUND } \\
\text { WATER }\end{array}$ & $\begin{array}{l}\text { SURFACE } \\
\text { WATERS }\end{array}$ \\
\hline \multicolumn{6}{|l|}{ PCB } \\
\hline AROCLOR-1016 & A & & & & \\
\hline AROCLOR-1221 & A & A & & & \\
\hline AROCLOR-1232 & A & A & & & \\
\hline AROCLOR-1242 & $A$ & & & & \\
\hline AROCLOR-1248 & A & & & & \\
\hline AROCLOR-1260 & & & & A & \\
\hline \multicolumn{6}{|l|}{ PESTICIDES } \\
\hline 4,4'-DDD & $\#$ & & & & \\
\hline 4,4'-DDE & \# & & & & \\
\hline 4,4'-DDT & $x$ & $\#$ & & & \\
\hline ALDRIN & & & & A & \\
\hline ALPHA-BHC & & & & A & \\
\hline DIELDRIN & & & & A & \\
\hline HEPTACHLOR EPOXIDE & & & & A & \\
\hline TOXAPHENE & & & & A & \\
\hline \multicolumn{6}{|l|}{ METALS } \\
\hline ANTIMONY & 鑃 & 殮 & & A & \\
\hline ARSENIC & \% & $x$ & $\#$ & $\mathbf{x}$ & \\
\hline BARIUM & 辣 & 采 & & $\#$ & \\
\hline BERYLLIUM & 委 & 浑 & & $A$ & \\
\hline CADMIUM & 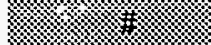 & & & 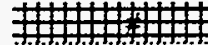 & \\
\hline CHROMIUM & 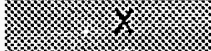 & 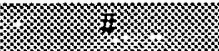 & & 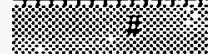 & \\
\hline COPPER & s. & 欉 & & 縍 & \\
\hline MANGANESE & $\%$ & 㛗 & & $\%$ & \\
\hline NICKEL & 显 & 紋 & & 然 & \\
\hline SELENIUM & & & & $\#$ & \\
\hline SILVER & 維 & & & & \\
\hline THALLIUM & 事 & 誃 & & $x$ & \\
\hline VANADIUM & 然 & 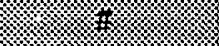 & & 栱 & \\
\hline ZINC & 楼 & 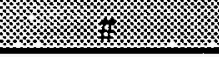 & & 样 & \\
\hline \# & \multicolumn{5}{|c|}{ Present at concentration $<$ risk } \\
\hline $\mathbf{x}$ & \multicolumn{5}{|c|}{ Present at cocentration $>=$ risk or ARAR } \\
\hline A & \multicolumn{5}{|c|}{ Not detected. However, (CRQL/2)>=risk or ARAR value } \\
\hline B & \multirow{2}{*}{\multicolumn{5}{|c|}{$\begin{array}{l}\text { Analyte found in associated blank as well as sample. } \\
\text { Samole Mean }=<\text { Backaround Mean (Alpha }>=0.05 \text { ) }\end{array}$}} \\
\hline W & & & & & \\
\hline H\#\#+\#\#\#\#\#\#+ & \multirow{2}{*}{\multicolumn{5}{|c|}{$\begin{array}{l}\text { Background meaurements are nondetect with CRQL }>\text { risk or ARAR values. } \\
\text { There are no backaround measurements for Surface Waters }\end{array}$}} \\
\hline & & & & & \\
\hline & \multicolumn{5}{|c|}{$\begin{array}{l}\text { There are no background water measurements for Selenium or Thallium. } \\
\text { Sediments and surface waters measured by U.S. Air Force (1992) }\end{array}$} \\
\hline
\end{tabular}


IABLE 7.7. Contaminants of Concern for Source Areas ST13/DP26

\begin{tabular}{|c|c|c|c|}
\hline ANALYTES & $\begin{array}{l}\text { SURFACE } \\
\text { SOILS }\end{array}$ & $\begin{array}{c}\text { SUBSURFACE } \\
\text { SOILS }\end{array}$ & $\begin{array}{l}\text { GROUND } \\
\text { WATER }\end{array}$ \\
\hline \multicolumn{4}{|l|}{ VOLATILES } \\
\hline $1,1,1$-TRICHLOROETHANE & $\#$ & & A \\
\hline 1,1,2,2-TETRACHLOROETHANE & & & A \\
\hline 1,1,2-TRICHLOROETHANE & & & A \\
\hline 1,1-DICHLOROETHENE & & A & A \\
\hline 1,2-DICHLOROETHANE & & & A \\
\hline 1,2-DICHLOROETHENE (TOTAL) & & & A \\
\hline 1,2-DICHLOROPROPANE & & & A \\
\hline 2-BUTANONE & & $\#$ & A \\
\hline ACETONE & & $\#$ & B \\
\hline BENZENE & & $\mathbf{x}$ & $\mathbf{x}$ \\
\hline BROMODICHLOROMETHANE & & & A \\
\hline BROMOFORM & & & A \\
\hline BROMOMETHANE & & & A \\
\hline CARBON DISULFIDE & & & $\#$ \\
\hline CARBON TETRACHLORIDE & & & A \\
\hline CHLOROBENZENE & & & A \\
\hline CHLOROFORM & $\#$ & B & $\mathrm{x}$ \\
\hline CHLOROMETHANE & & & $x$ \\
\hline CIS-1,3-DICHLOROPROPENE & & A & A \\
\hline DIBROMOCHLOROMETHANE & & & A \\
\hline ETHYLBENZENE & & $\mathbf{x}$ & $\mathbf{x}$ \\
\hline METHYLENE CHLORIDE & & B & $x$ \\
\hline STYRENE & & & A \\
\hline TETRACHLOROETHENE & & & A \\
\hline TOLUENE & $\#$ & $\mathbf{x}$ & $x$ \\
\hline TRANS-1,3-DICHLOROPROPENE & & A & A \\
\hline TRICHLOROETHENE & & & A \\
\hline VINYL CHLORIDE & & A & A \\
\hline XYLENES (TOTAL) & & $\#$ & $\mathbf{x}$ \\
\hline \multicolumn{4}{|l|}{ SEMI-VOLATILES } \\
\hline 1,2,4-TRICHLOROBENZENE & & & A \\
\hline 1,2-DIPHENYLHYDRAZINE & & A & \\
\hline 1,4-DICHLOROBENZENE & & & A \\
\hline 2-METHYLNAPHTHALENE & & $\#$ & $x$ \\
\hline 2,4-DICHLOROPHENOL & & & A \\
\hline 2,4-DINITROPHENOL. & & A & A \\
\hline 2,4-DINITROTOLUENE & & A & A \\
\hline 2,6-DINITROTOLUENE & & A & A \\
\hline 2-CHLOROPHENOL & & & A \\
\hline 2-NITROANILINE & & & A \\
\hline 3,3'-DICHLOROBENZIDINE & & A & A \\
\hline 4-CHLOROANILINE & & & A \\
\hline ACENAPHTHENE & \# & $\#$ & \\
\hline ANTHRACENE & \# & $\#$ & \\
\hline BENZO(A)ANTHRACENE & $\mathbf{x}$ & $\mathbf{x}$ & A \\
\hline BENZO(A)PYRENE & $\mathbf{x}$ & $\mathbf{x}$ & A \\
\hline $\begin{array}{l}\text { BENZO(B)FLUORANTHENE } \\
\text { B. }\end{array}$ & 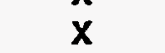 & $\mathrm{x}$ & A \\
\hline $\operatorname{BENZO(G,H,l)PERYLENE}$ & $\mathbf{x}$ & & \\
\hline BENZO(K)FLUORANTHENE & $\mathbf{x}$ & $x$ & A \\
\hline BIS(2-CHLOROETHYL)ETHER & & A & A \\
\hline BIS(2-CHLOROISOPROPYL)ETHER & & & A \\
\hline
\end{tabular}


IABLE 77. Contaminants of Concern for Source Areas ST13/DP26

\begin{tabular}{|c|c|c|c|}
\hline ANALYTES & $\begin{array}{l}\text { SURFACE } \\
\text { SOILS }\end{array}$ & $\begin{array}{c}\text { SUBSURFACE } \\
\text { SOILS }\end{array}$ & $\begin{array}{l}\text { GROUND } \\
\text { WATER }\end{array}$ \\
\hline BIS(2-ETHYLHEXYL)PHTHALATE & $\#$ & $\#$ & $x$ \\
\hline $\begin{array}{l}\text { CHRYSENE } \\
\text { CHS }\end{array}$ & $x$ & $x$ & A \\
\hline DI-N-BUTYLPHTHALATE & & B & $\#$ \\
\hline DIBENZ(A,H)ANTHRACENE & $\mathbf{x}$ & A & A \\
\hline FLUORANTHENE & $\#$ & \# & \\
\hline FLUORENE & $\#$ & \# & $\#$ \\
\hline HEXACHLOROBENZENE & & A & A \\
\hline HEXACHLOROBUTADIENE & & & A \\
\hline HEXACHLOROCYCLOPENTADIENE & & & A \\
\hline HEXACHLOROETHANE & & & A \\
\hline INDENO(1,2,3-CD)PYRENE & $x$ & $\mathbf{x}$ & A \\
\hline ISOPHORONE & & & A \\
\hline N-NITROSO-DI-N-PROPYLAMINE & A & A & A \\
\hline N-NITROSODIPHENYLAMINE (1) & & & A \\
\hline NAPHTHALENE & & $\#$ & $x$ \\
\hline NITROBENZENE & & A & A \\
\hline PENTACHLOROPHENOL & & A & A \\
\hline PHENOL & & & $\#$ \\
\hline PYRENE & $x$ & $x$ & \\
\hline \multicolumn{4}{|l|}{ PCB } \\
\hline AROCLOR-1016 & A & & \\
\hline AROCLOR-1221 & A & A & \\
\hline AROCLOR-1232 & A & A & \\
\hline AROCLOR-1242 & A & & \\
\hline AROCLOR-1248 & A & & \\
\hline AROCLOR-1254 & A & & \\
\hline AROCLOR-1260 & A & & A \\
\hline \multicolumn{4}{|l|}{ PESTICIDES } \\
\hline 4,4-DDD & $x$ & \# & \\
\hline 4,4-DDE & $\mathrm{x}$ & $\#$ & \\
\hline 4,4-DDT & $\mathrm{x}$ & \# & $\#$ \\
\hline ALDRIN & A & & A \\
\hline ALPHA-BHC & & & A \\
\hline ALPHA-CHLORDANE & & & A \\
\hline BETA-BHC & & & A \\
\hline DIELDRIN & A & & A \\
\hline GAMMA-CHLORDANE & & & A \\
\hline HEPTACHLOR & & & A \\
\hline HEPTACHLOR EPOXIDE & A & & A \\
\hline METHOXYCHLOR & \# & & \\
\hline TOXAPHENE & A & & A \\
\hline \multicolumn{4}{|l|}{ METALS } \\
\hline ANTIMONY & \% & A & 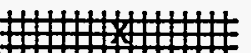 \\
\hline ARSENIC & . & 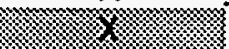 & $x$ \\
\hline BARIUM & (3t) & & $\ddot{x}$ \\
\hline BERYLLIUM & & & 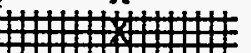 \\
\hline CADMIUM & 将 & & \#\#地 \\
\hline CHROMIUM & \# & \& & 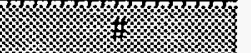 \\
\hline COPPER & \# & ; & (t) \\
\hline MANGANESE & & x. & $x$ \\
\hline
\end{tabular}


IABLE 7.7 Contaminants of Concern for Source Areas ST13/DP26

\begin{tabular}{|c|c|c|c|}
\hline ANALYTES & $\begin{array}{c}\text { SURFACE } \\
\text { SOILS }\end{array}$ & $\begin{array}{c}\text { SUBSURFACE } \\
\text { SOILS }\end{array}$ & $\begin{array}{l}\text { GROUND } \\
\text { WATER }\end{array}$ \\
\hline $\begin{array}{l}\text { MERCURY } \\
\text { NICKEL } \\
\text { SELENIUM } \\
\text { THALLIUM } \\
\text { VANADIUM } \\
\text { ZINC } \\
\end{array}$ & א. & 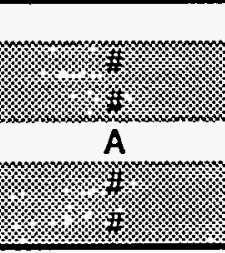 & 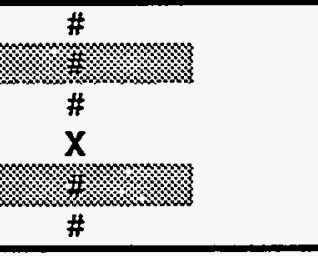 \\
\hline 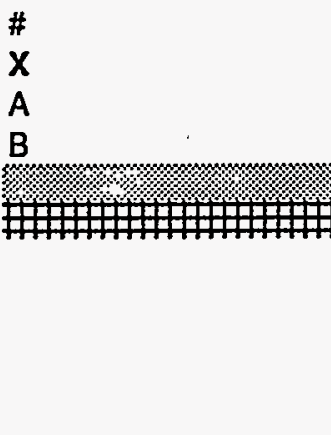 & $\begin{array}{l}\text { Present at conc } \\
\text { Present at coce } \\
\text { Not detected. } \\
\text { Analyte found ir } \\
\text { Sample Mean = } \\
\text { Analyte Detecte } \\
\\
\text { There are no be } \\
\text { There are no be } \\
\text { Selenium or Th }\end{array}$ & $\begin{array}{l}\text { tration < risk } \\
\text { ation >= risk or AF } \\
\text { vever, (CRQL2)> } \\
\text { ssociated blank as } \\
\text { Background Mean } \\
\text { Sample mean =< } \\
\text { Background meal } \\
\text { CRQL >risk or AR } \\
\text { ground measurem } \\
\text { ground water mea } \\
\text { um. }\end{array}$ & $\begin{array}{l}\text { k or ARAR value } \\
\text { il as sample. } \\
\text { pha }>=0.05 \text { ). } \\
\text { ckground Mean. } \\
\text { nents are nondetect with } \\
\text { values. } \\
\text { s for Surface Waters. } \\
\text { ements for Mercury, }\end{array}$ \\
\hline
\end{tabular}


TABLE 7.8. Contaminants of Concern for Source Area ST18

\begin{tabular}{|c|c|c|c|}
\hline ANALYTES & $\begin{array}{l}\text { SURFACE } \\
\text { SOILS }\end{array}$ & $\begin{array}{l}\text { SUBSURFACE } \\
\text { SOILS }\end{array}$ & $\begin{array}{l}\text { GROUND } \\
\text { WATER }\end{array}$ \\
\hline \multicolumn{4}{|l|}{ VOLATILES } \\
\hline 1,1,1-TRICHLOROETHANE & & & A \\
\hline 1,1,2,2-TETRACHLOROETHANE & & & A \\
\hline 1,1,2-TRICHLOROETHANE & & & A \\
\hline 1,1-DICHLOROETHENE & & & A \\
\hline 1,2-DICHLOROETHANE & & & A \\
\hline 1,2-DICHLOROETHENE (TOTAL) & & & $\#$ \\
\hline 1,2-DICHLOROPROPANE & & & A \\
\hline ACETONE & & $\#$ & B \\
\hline BENZENE & & A & \\
\hline BROMODICHLOROMETHANE & & & A \\
\hline BROMOMETHANE & & & A \\
\hline CARBON TETRACHLORIDE & & & A \\
\hline CHLOROFORM & & $\#$ & $\mathbf{x}$ \\
\hline CIS-1,3-DICHLOROPROPENE & & & A \\
\hline DIBROMOCHLOROMETHANE & & & A \\
\hline ETHYLBENZENE & & & $\#$ \\
\hline METHYLENE CHLORIDE & & $\#$ & B \\
\hline TETRACHLOROETHENE & & $\#$ & \\
\hline TRANS-1,3-DICHLOROPROPENE & & & A \\
\hline TRICHLOROETHENE & & & $x$ \\
\hline VINYL CHLORIDE & & A & A \\
\hline XYLENES (TOTAL) & & \# & \# \\
\hline \multicolumn{4}{|l|}{ SEMI-VOLATILES } \\
\hline 1,4-DICHLOROBENZENE & & & A \\
\hline 2-METHYLNAPHTHALENE & & & \# \\
\hline 2,4-DINITROPHENOL & & & A \\
\hline 2,4-DINITROTOLUENE & & & A \\
\hline 2,6-DINITROTOLUENE & & & A \\
\hline 2-NITROANILINE & A & A & A \\
\hline 3,3'-DICHLOROBENZIDINE & & & A \\
\hline ANTHRACENE & \# & & \\
\hline BENZO(A)ANTHRACENE & $x$ & A & A \\
\hline BENZO(A)PYRENE & $\mathrm{x}$ & A & A \\
\hline BENZO(B)FLUORANTHENE & $\mathbf{x}$ & A & A \\
\hline BENZO(G,H,I)PERYLENE & $x$ & & \\
\hline BENZO(K)FLUORANTHENE & $\mathbf{x}$ & A & A \\
\hline BENZOIC ACID & A & & \\
\hline BIS(2-CHLOROISOPROPYL)ETHER & & & A \\
\hline BIS(2-ETHYLHEXYL)PHTHALATE & \# & B & $\mathrm{x}$ \\
\hline BUTYLBENZYLPHTHALATE & \# & & \\
\hline CHRYSENE & $x$ & A & A \\
\hline DI-N-BUTYLPHTHALATE & & B & $x$ \\
\hline \multicolumn{4}{|l|}{ DI-N-OCTYLPHTHALATE } \\
\hline DIBENZ(A,H)ANTHRACENE & $x$ & A & A \\
\hline DIETHYLPHTHALATE & & B & \\
\hline FLUORANTHENE & $\#$ & & \\
\hline HEXACHLOROBENZENE & & & A \\
\hline HEXACHLOROBUTADIENE & & & A \\
\hline HEXACHLOROETHANE & & & A \\
\hline INDENO(1,2,3-CD)PYRENE & $x$ & A & A \\
\hline N-NITROSO-DI-N-PROPYLAMINE & A & A & A \\
\hline
\end{tabular}




\begin{tabular}{|c|c|c|c|}
\hline ANALYTES & $\begin{array}{c}\text { SURFACE } \\
\text { SOILS }\end{array}$ & $\begin{array}{c}\text { SUBSURFACE } \\
\text { SOILS }\end{array}$ & $\begin{array}{l}\text { GROUND } \\
\text { WATER }\end{array}$ \\
\hline N-NITROSODIPHENYLAMINE (1) & $\#$ & & $\mathrm{X}$ \\
\hline NITROBENZENE & & & A \\
\hline PENTACHLOROPHENOL & & & A \\
\hline PYRENE & $\mathbf{X}$ & & \\
\hline \multicolumn{4}{|l|}{ PCB } \\
\hline AROCLOR-1016 & A & & A \\
\hline AROCLOR-1221 & A & & A \\
\hline AROCLOR-1232 & A & & A \\
\hline AROCLOR-1242 & A & & A \\
\hline AROCLOR-1248 & A & & A \\
\hline AROCLOR-1254 & & & A \\
\hline AROCLOR-1260 & & & A \\
\hline \multicolumn{4}{|l|}{ PESTICIDES } \\
\hline 4,4'-DDE & \# & & \\
\hline 4,4'-DDT & \# & & A \\
\hline ALDRIN & & & A \\
\hline ALPHA-BHC & & & A \\
\hline ALPHA-CHLORDANE & & & A \\
\hline BETA-BHC & & & A \\
\hline DIELDRIN & & & A \\
\hline GAMMA-CHLORDANE & & & A \\
\hline HEPTACHLOR & & & A \\
\hline HEPTACHLOR EPOXIDE & & & A \\
\hline TOXAPHENE & & & A \\
\hline \multicolumn{4}{|l|}{ METALS } \\
\hline ANTIMONY & $x$ & $A$ & A \\
\hline ARSENIC & 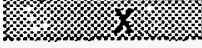 & 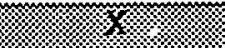 & $\mathbf{x}$ \\
\hline BARIUM & $\#$ & 耧 & $\#$ \\
\hline BERYLLIUM & 檾 & 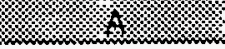 & A \\
\hline CADMIUM & 縞 & & प12 \\
\hline CHROMIUM & 采临 & 簑 & 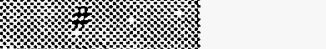 \\
\hline COPPER & 經慈 & 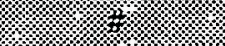 & 然 \\
\hline MANGANESE & $\mathbf{X}$ & 器 & \% \\
\hline MERCURY & 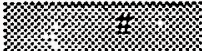 & & $\#$ \\
\hline NICKEL & 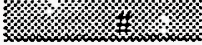 & 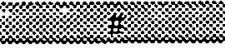 & 楼 \\
\hline SELENIUM & & & \# \\
\hline SILVER & 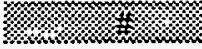 & & \\
\hline THALLIUM & & A & $\mathbf{X}$ \\
\hline VANADIUM & 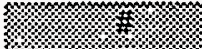 & 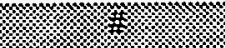 & 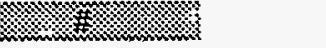 \\
\hline ZINC & 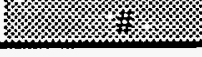 & 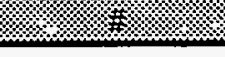 & $\#$ \\
\hline \# & \multicolumn{3}{|c|}{ Present at concentration < risk } \\
\hline$x$ & \multicolumn{3}{|c|}{ Present at cocentration $>=$ risk or ARAR } \\
\hline A & \multicolumn{3}{|c|}{ Not detected. However, (CRQL2)>=risk or ARAR value } \\
\hline B & \\
\hline H: & \multicolumn{3}{|c|}{ Sample Mean $=<$ Background Mean (Alpha $>=0.05$ ). } \\
\hline & \multicolumn{3}{|c|}{ Background meaurements are nondetect with } \\
\hline & \multicolumn{3}{|c|}{$\begin{array}{l}\text { CRQL }>\text { risk or ARAR values. } \\
\text { There are no background measurements for Surface Waters. }\end{array}$} \\
\hline
\end{tabular}




\section{IABLE 7.8. Contaminants of Concern for Source Area ST18}

ANALYTES

SURFACE

SUBSURFACE

GROUND SOILS SOILS

WATER

There are no background water measurements for Mercury, Selenium or Thallium. 
IABLE 7.9. Contaminants of Concern for Source Area ST19

\begin{tabular}{|c|c|c|c|}
\hline $\begin{array}{l}\text { CONTAMINANT } \\
\text { OF CONCERN }\end{array}$ & $\begin{array}{l}\text { SURFACE } \\
\text { SOILS }\end{array}$ & $\begin{array}{c}\text { SUBSURFACE } \\
\text { SOILS }\end{array}$ & $\begin{array}{l}\text { GROUND } \\
\text { WATER }\end{array}$ \\
\hline \multicolumn{4}{|l|}{ VOLATILES } \\
\hline 1,1,1-TRICHLOROETHANE & & A & A \\
\hline 1,1,2,2-TETRACHLOROETHANE & & $A$ & A \\
\hline 1,1,2-TRICHLOROETHANE & & A & A \\
\hline 1,1-DICHLOROETHENE & & A & A \\
\hline 1,2-DICHLOROETHANE & & A & A \\
\hline 1,2-DICHLOROPROPANE & & A & A \\
\hline 2-BUTANONE & & & $\#$ \\
\hline ACETONE & & B & B \\
\hline BENZENE & & $\#$ & $x$ \\
\hline BROMODICHLOROMETHANE & & A & A \\
\hline BROMOMETHANE & & A & A \\
\hline CARBON TETRACHLORIDE & & A & A \\
\hline CHLOROFORM & & B & \\
\hline CHLOROMETHANE & & & A \\
\hline CIS-1,3-DICHLOROPROPENE & & A & A \\
\hline DIBROMOCHLOROMETHANE & & A & A \\
\hline ETHYLBENZENE & & $\#$ & $x$ \\
\hline METHYLENE CHLORIDE & & B & B \\
\hline STYRENE & & & A \\
\hline TETRACHLOROETHENE & & & A \\
\hline TOLUENE & & \# & $\mathbf{x}$ \\
\hline TRANS-1,3-DICHLOROPROPENE & & A & A \\
\hline TRICHLOROETHENE & & & A \\
\hline VINYL CHLORIDE & & A & A \\
\hline XYLENES (TOTAL) & & $\#$ & $x$ \\
\hline \multicolumn{4}{|l|}{ SEMI-VOLATILES } \\
\hline 1,2,4-TRICHLOROBENZENE & & $\#$ & \\
\hline 1,2-DIPHENYLHYDRAZINE & & A & A \\
\hline 1,4-DICHLOROBENZENE & & $\#$ & A \\
\hline 2,4-DINITROPHENOL & & & $A$ \\
\hline 2,4-DINITROTOLUENE & & A & A \\
\hline 2,6-DINITROTOLUENE & & A & A \\
\hline 2-METHYLNAPHTHLENE & & $\#$ & $\#$ \\
\hline 2-NITROANILINE & A & A & A \\
\hline 3,3'-DICHLOROBENZIDINE & & A & A \\
\hline BENZO(A)ANTHRACENE & A & $\mathbf{x}$ & A \\
\hline BENZO(A)PYRENE & A & A & A \\
\hline BENZO(B)FLUORANTHENE & A & A & A \\
\hline BENZO(K)FLUORANTHENE & A & A & A \\
\hline BENZOIC ACID & & & \# \\
\hline BIS(2-CHLOROETHYL)ETHER & & A & A \\
\hline BIS(2-CHLOROISOPROPYL)ETHER & & & A \\
\hline BIS(2-ETHYLHEXYL)PHTHALATE & \# & B & $\mathbf{x}$ \\
\hline CHRYSENE & A & $\mathbf{x}$ & A \\
\hline DI-N-BUTYLPHTHALATE & & $\#$ & \\
\hline DIBENZ(A,H)ANTHRACENE & A & A & $A$ \\
\hline FLUORANTHENE & & $\#$ & \\
\hline FLUORENE & & $\#$ & \\
\hline HEXACHLOROBENZENE & A & A & A \\
\hline HEXACHLOROBUTADIENE & & & A \\
\hline HEXACHLOROETHANE & & & A \\
\hline
\end{tabular}


IABLE 72. Contaminants of Concern for Source Area ST19

\begin{tabular}{|c|c|c|c|}
\hline $\begin{array}{l}\text { CONTAMINANT } \\
\text { OF CONCERN }\end{array}$ & $\begin{array}{l}\text { SURFACE } \\
\text { SOILS }\end{array}$ & $\begin{array}{c}\text { SUBSURFACE } \\
\text { SOILS }\end{array}$ & $\begin{array}{l}\text { GROUND } \\
\text { WATER }\end{array}$ \\
\hline INDENO $(1,2,3-C D)$ PYRENE & $A$ & $A$ & $A$ \\
\hline N-NITROSO-DI-N-PROPYLAMINE & A & A & A \\
\hline NAPHTHALENE & & $\#$ & \# \\
\hline NITROBENZENE & & & A \\
\hline PENTACHLOROPHENOL & & & A \\
\hline PHENOL & & $\mathrm{x}$ & \\
\hline PYRENE & & $\mathbf{x}$ & \\
\hline \multicolumn{4}{|l|}{ РСB } \\
\hline AROCLOR-1016 & & & A \\
\hline AROCLOR-1221 & & & A \\
\hline AROCLOR-1232 & & & A \\
\hline AROCLOR-1242 & & & A \\
\hline AROCLOR-1248 & & & A \\
\hline AROCLOR-1254 & & & A \\
\hline AROCLOR-1260 & & & $\ddot{A}$ \\
\hline \multicolumn{4}{|l|}{ PESTICIDES } \\
\hline 4,4'-DDT & $\#$ & & A \\
\hline ALDRIN & & & A \\
\hline ALPHA-BHC & & & A \\
\hline ALPHA-CHLORDANE & & & A \\
\hline BETA-BHC & & & A \\
\hline DIELDRIN & & & A \\
\hline GAMMA-CHLORDANE & & & A \\
\hline HEPTACHLOR & & & A \\
\hline HEPTACHLOR EPOXIDE & & & A \\
\hline TOXAPHENE & & & A \\
\hline
\end{tabular}

METALS

ANTIMONY

ARSENIC

BARIUM

BERYLLIUM

CADMIUM

CHROMIUM

COPPER

MANGANESE

MERCURY

NICKEL

SELENIUM

THALLIUM

VANADIUM

ZINC

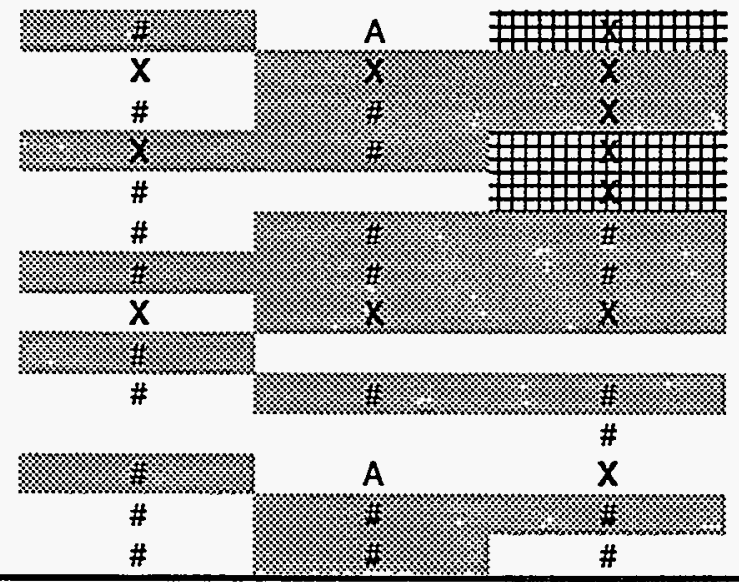

$\begin{array}{ll}\# & \text { Present at concentration }<\text { risk } \\ \mathrm{X} & \text { Present at cocentration }>=\text { risk or ARAR } \\ \mathrm{A} & \text { Not detected. However, (CRQL2) }>=\text { risk or ARAR value } \\ \mathrm{B} & \text { Analyte found in associated blank as well as sample. } \\ \text { Analyte Detected. Sample mean }=<\text { Background Mean. }\end{array}$

Background meaurements are nondetect with CRQL>risk or ARAR values. 
IABLE 7.9. Contaminants of Concern for Source Area ST19

CONTAMINANT

OF CONCERN

$\begin{array}{ccc}\text { SURFACE } & \text { SUBSURFACE } & \text { GROUND } \\ \text { SOILS } & \text { SOILS } & \text { WATER }\end{array}$

There are no background water measurements for Mercury,

Selenium or Thallium. 


\subsection{EXPOSURE POINT CONCENTRATIONS AND MODELING RESULTS}

\subsection{CONVERSIONS TO CONCENTRATIONS IN AIR OR DUST}

The concentrations of contaminants in air from volatilization and resuspension were calculated with the models outlined in EPA (1991b). The Andelman (1990) volatilization factor was used to calculate the volatilization of contaminants from groundwater during domestic use. The Hwang and Falco (1986) model was used to calculate the soil-to-air volatilization factor; the factor necessary to calculate the volatilization of contaminants from soils and sediments. Site-specific particulate emission factors (Table M.2) were used to calculate the resuspension of contaminants from surface soils and sediments. Greater detail on the latter two models are presented in Appendix $M$ of this assessment.

\subsection{SITE SUMMARIES}

Fate and transport modeling using the Multimedia Environmental Pollutant Assessment System (MEPAS) was performed for Operable Unit 2 sites ST11, ST18, and ST19. The primary focus was to model future concentrations of contaminants in groundwater (benzene, toluene, ethylbenzene, and xylenes) that would be transported through the leachate pathway from soil contamination present today, principally total petroleum hydrocarbons (TPH).

No modeling was performed for sites ST10/SS14 and ST13/DP26. Initial screening risk assessments indicated that contamination at these sites presented a significant current public health concern; modeling for future contaminant concentrations was deemed unnecessary.

The summary of the methods and results of the MEPAS modeling for sites ST19, ST11, and ST18 are presented below. Greater detail is presented in the Operable Unit 2 Draft Remedial Investigation (U.S. Air Force 1993c) and Appendix J of the Remedial Investigation (U.S. Air Force 1993d). A general description of MEPAS is in Appendix C of this report.

\subsubsection{Slte ST19 Summary}

Based on the description of the site in the Operable Unit 2 Remedial Investigation (U.S. Air Force 1993c), the events surrounding the contamination were modeled using the following assumptions:

- The initial fuel line break resulted in contamination moving directly through the partially saturated zone and into the saturated zone. The initial contamination into the saturated zone is assumed to occur prior to the formation of the weathered residual contamination present today and over a region smaller than the current vadose-zone soil area identified as being contaminated.

- The temporal distribution of leaching contamination was such that the environment experienced an immediate and noticeable degree of contamination to both the vadose and saturated zones, followed by a smaller, continuous contaminant flow from the site.

\subsubsection{Approach}

Although the modeling exercise represents a simplification of real-world phenomena, its intent is to describe the events surrounding the release of contaminants into the environment their transport and fate such that the essence 
of the problem is captured by the assessment. A multistep approach is, therefore, utilized in an effort to recreate the events of the contamination from the perspective of the environment. The first step is to develop a conceptual model of the problem. The second step is to define the constraints associated with the contamination at the site. The next step is to clearly define the problem and identify an appropriate solution. Fourth, important parameters are determined and values assigned. These values must make physical sense and represent the site. Finally, the transport and fate modeling is performed; modifications are made where appropriate and within reasonable bounds.

Assumptions associated with the assessment exercise are as follow:

- The BTEX composition associated with the fuel contamination at site ST19 is similar to the typical composition of BTEX in fuels outlined in Table 8.1.

- Parameters that are typically used in calibrating models with the same level of detail as MEPAS include distribution coefficients, pore-water velocities, and mass-flux rates from the source. These parameters are generally not well known and can be modified to ensure that the model can predict the arrival of a contaminant at a monitoring well at a given concentration level. Although different combinations of the parameters result in similar consequences, many of those combinations result in unrealistic values for some of the parameters. By using realistic values for these parameters, the calibration process at least ensures that the concentrations predicted by the model are at the right order of magnitude and representative of the problem at hand.

- Each component in the BTEX waste can be modeled as a separate and independent constituent.

- Contaminant-soil interactions can be adequately described by a distribution coefficient $\left(K_{d}\right)$, in which the $K_{d}$ represents a calibration parameter. $K_{d}$ is defined as

$$
\frac{d \mathrm{~S}}{d \mathrm{C}}=\mathrm{K}_{d}
$$

where $S$ is the mass of the solute species absorbed or precipitated on the solids per unit bulk dry mass of the porous medium, and $C$ is the solute concentration.

- The assessment of the site does not violate the mathematical suppositions associated with the analytical equations forming the bases of the modeling exercise. For example, solutions to the advective-dispersive equation are applicable with constant pore-water velocities in time and space, and homogeneous, anisotropic dispersivities.

- In many of the simulations, the zone of mixing is assumed to be $3.04 \mathrm{~m}$ (10 ft). Limiting the depth over which the mixing occurs attempts to account for the lower densities $\left(\approx 0.88 \mathrm{~g} / \mathrm{cm}^{3}\right)$ associated with the light nonaqueous phase liquids (LNAPLs) in the BTEX constituents.

- Monitored data containing time-varying, groundwater concentrations were available at ST19. This information was utilized to calibrate the model used in the preliminary transport and fate analysis for recreating the initial contamination of groundwater at the site. 


\begin{tabular}{|c|c|c|c|c|c|}
\hline \multicolumn{6}{|c|}{$\begin{array}{c}\text { TABLE 8.1. BTEX and Naphthalene Composition in Various Fuels } \\
\text { (U.S. Air Force 1993c) }\end{array}$} \\
\hline & $\begin{array}{c}\text { Benzene } \\
\text { (wt\%) }\end{array}$ & \begin{tabular}{c|c|} 
Toluene \\
(wt\%)
\end{tabular} & $\begin{array}{l}\text { Ethylbenzene } \\
\text { (wt\%) }\end{array}$ & $\begin{array}{l}\text { Total Xylene } \\
\text { (wt\%) }\end{array}$ & $\begin{array}{l}\text { Naphthalene } \\
\text { (wt\%) }\end{array}$ \\
\hline Diesel \#1 \& \#2 & 0.004 & 0.14 & 0.03 & $\begin{array}{r}0.20 \\
\end{array}$ & 0.20 \\
\hline Arctic Diesel & 0.22 & 0.23 & - & 1.23 & 0.29 \\
\hline $\mathrm{JP}-4$ & 2.46 & 5.68 & 0.76 & 3.17 & 0.50 \\
\hline Premium Unleaded & 4.59 & 18.93 & 3.06 & 16.61 & 0.22 \\
\hline
\end{tabular}

\subsubsection{Constituent Data at Monitoring Well}

The MEPAS transport and fate analysis utilized groundwater concentrations of constituents recorded at nearby monitoring wells and soil concentrations at the waste site itself to help calibrate the transport model. The peak concentrations (above detection limits) in groundwater were monitored at well 19-02A, located $45.7 \mathrm{~m}$ (150 ft) downgradient of the center of the source, and are in Table 8.2. Table 8.3 lists the maximum soil concentrations monitored for each BTEX constituent at the waste site. The soil levels were used to help estimate the mass of contamination remaining at the site.

\begin{tabular}{||l|r|r|r|r|r|r|r|r|r|r||}
\hline \hline \multicolumn{7}{||c|}{ IABLE 8.2. BTEX Analyses from Monitoring Well 19-02A. Values in $\mu \mathrm{g} / \mathrm{L}$} \\
(U.S. Air Force 1993c) \\
\hline \hline DATE & 1986 & 1987 & 1988 & & $1988 \mathrm{r}$ & 1991 & 1992 & $\mathrm{MCL}$ \\
\hline \hline Benzene & 71 & & 35 & & & 20 & $\mathrm{~J}$ & 11 & 5 \\
\hline Toluene & 1500 & 3600 & 6800 & $\mathrm{D}$ & 4100 & & 1500 & 1900 & 1000 \\
\hline Ethylbenzene & & 240 & 140 & & 86 & $\mathrm{~J}$ & 390 & 610 & 700 \\
\hline Total Xylenes & 1100 & 2500 & 3200 & $\mathrm{D}$ & 2800 & & 2300 & 4000 & 10,000 \\
\hline \hline VENDOR & SAIC & SAIC & SAIC & & SAIC & & CH2M HILL & DATACHEM & \\
\hline \hline
\end{tabular}

\begin{tabular}{||l|r|r|}
\hline \hline IABLE 8.3. Maximum Soil Concentrations for BTEX \\
Constituents at Site ST19 \\
(U.S. Air Force 1993c)
\end{tabular}




\subsubsection{Site Data Utilized for the Transport and Fate Assessment}

The groundwater model associated with the MEPAS methodology was utilized to model the transport of BTEX constituents at site ST19. Table 8.4 presents the parameters, values for each parameter, and references associated with each value that was used in the assessment. The data are divided into three categories: source-term information, partially saturated zone, and saturated zone.

\begin{tabular}{|c|c|c|}
\hline \multicolumn{2}{|c|}{ SOURCE-TERM INFORMATION } & \multirow{2}{*}{$\begin{array}{r}\text { Reference } \\
(1) \\
(1) \\
(1) \\
\end{array}$} \\
\hline $\begin{array}{l}\text { - Source-Term Length } \\
\text { - Source-Term Width } \\
\text { - Distance to Monitoring Well }\end{array}$ & $\begin{array}{c}2.4 \mathrm{~m} \\
122.0 \mathrm{~m} \\
45.7 \mathrm{~m}\end{array}$ & \\
\hline \multicolumn{3}{|c|}{ PARTIALLY SATURATED ZONE } \\
\hline $\begin{array}{l}\text { - Thickness } \\
\text { - Porosity } \\
\text { - Field Capacity } \\
\text { - Infiltration Leaching Rate } \\
\text { - z-Dispersivity } \\
\text { - Bulk Density }\end{array}$ & $\begin{array}{c}2.01 \mathrm{~m} \\
43.7 \% \\
12.0 \% \\
0.01 \mathrm{~cm} / \mathrm{d} \\
2.01 \mathrm{~cm} \\
1.50 \mathrm{~g} / \mathrm{cm}^{3}\end{array}$ & $\begin{array}{c}(1,4) \\
(4) \\
(3,4) \\
\text { MEPAS modeling } \\
(3) \\
(4)\end{array}$ \\
\hline \multicolumn{3}{|c|}{ SATURATED ZONE } \\
\hline $\begin{array}{l}\text { - Thickness of Contamination } \\
\text { - Aquifer Thickness } \\
\text { - Pore-Water Velocity } \\
\text { - x-Dispersivity } \\
\text { - y-Dispersivity } \\
\text { - z-Dispersivity } \\
\text { - Total Porosity } \\
\text { - Effective Porosity } \\
\text { - Bulk Density }\end{array}$ & $\begin{array}{c}3.05 \mathrm{~m} \\
91.4 \mathrm{~m} \\
3.05 \mathrm{~m} / \mathrm{d} \\
0.1 \mathrm{x} \\
0.02 \mathrm{x} \\
2\left(\mathrm{~h}_{\mathrm{m}}\right)^{2 / \mathrm{x}} \\
43.7 \% \\
25 \% \\
1.60 \mathrm{~g} / \mathrm{cm}^{3} \\
\end{array}$ & $\begin{array}{c}\text { assumed } \\
(5) \\
(1,2,4,6) \\
(3,7,8) \\
(3,7,8) \\
(3,9) \\
(3) \\
(3,6) \\
(4) \\
\end{array}$ \\
\hline \multicolumn{3}{|c|}{$\begin{array}{l}\text { References for Table: } \\
\text { 1. U.S. Air Force } 1993 \mathrm{c} \\
\text { 2. Raw Data for Calculations of Darcian Flow Velocities at the Eielson AFB supplied by Mr. T. } \\
\text { Gilmore of Battelle, Pacific Northwest Laboratories, Richland, Washington. } \\
\text { 3. Droppo et al. 1989 } \\
\text { 4. Hwang, S. T. 1992. "Results for Groundwater Fate and Transport Analysis for BTEX Found in } \\
\text { ST19 of Eielson Air Force Base." Letter Report. Prepared by Battelle, Pacific Northwest } \\
\text { Laboratories, Richland, Washington. September 24, 1992. (Draft). } \\
\text { 5. CH2M Hill } 1982 \\
\text { 6. SAlC } 1989 \\
\text { 7. EPA } 1985 \\
\text { 8. Gelhar et al. } 1985 \\
\text { 9. Whelan et al. } 1987\end{array}$} \\
\hline
\end{tabular}

Table 8.5 presents constituent information employed in the modeling exercise. The second column reports the mass for each BTEX constituent that would be associated with 200,000 gallons of JP-4 fuel. The third column presents an estimate of the amount of mass still remaining at the site. A simple mass 
calculation was performed (e.g., concentration times volume) based on monitored peak concentrations at the site as reported in Tables 8.2 and 8.3. If the sample calculation was greater than the mass documented in column 2, the mass remaining at the site was assumed to equal the mass of the BTEX constituent contained in the 200,000 gal (i.e., column 2). The values for mass presented in column 3 were utilized in the modeling assessment but do not have a direct affect on the concentrations reported by the modeling assessment. The mass column 3 is used to determine how long the site will be releasing contaminants into the environment.

\begin{tabular}{|c|c|c|c|c|c|}
\hline \multicolumn{6}{|c|}{ IABLE 8.5. Constituent Information Employed in Modeling Site ST19 } \\
\hline Constituent & $\begin{array}{l}\text { Mass based } \\
\text { on } \\
200,000-\mathrm{gal} \\
\text { spill (kg) }\end{array}$ & $\begin{array}{l}\text { Mass based on } \\
\text { soil contam- } \\
\text { ination }(\mathrm{kg})\end{array}$ & $\begin{array}{l}\text { Distribution } \\
\text { Coefficients } \\
\left(K_{d}\right)(\mathrm{ml} / \mathrm{g})\end{array}$ & $\begin{array}{l}\text { z-Dispersiv- } \\
\text { ity based on } \\
45.7 \mathrm{~m}(\mathrm{~m})\end{array}$ & $\begin{array}{c}\text { Contaminant mass } \\
\text { flux }(\mathrm{g} / \mathrm{yr}) \\
\text { Peak Baseline }\end{array}$ \\
\hline $\begin{array}{l}\text { Benzene } \\
\text { (Table 1) }\end{array}$ & $\begin{array}{c}16,660 \\
(2.5 \% \mathrm{JP}-4)\end{array}$ & $\begin{array}{l}19 \\
(2)\end{array}$ & $\begin{array}{c}0.10 \\
\text { (calibrated) }\end{array}$ & $\begin{array}{c}0.41 \\
\text { (calibrated) }\end{array}$ & $\begin{array}{c}4,200 \quad 10 \\
\text { (calibrated) }\end{array}$ \\
\hline $\begin{array}{l}\text { Toluene } \\
\text { (Table 1) }\end{array}$ & $\begin{array}{c}37,850 \\
(5.7 \% \text { JP-4) }\end{array}$ & $\begin{array}{l}16,750 \\
\text { (2) }\end{array}$ & $\begin{array}{c}0.25 \\
\text { (calibrated) }\end{array}$ & $\begin{array}{c}0.41 \\
\text { (calibrated) }\end{array}$ & $\begin{array}{c}148,000 \quad 958 \\
\text { (calibrated) }\end{array}$ \\
\hline $\begin{array}{c}\text { Ethylbenzene } \\
\text { (Table 1) }\end{array}$ & $\begin{array}{c}5064 \\
(0.76 \% \text { JP-4) }\end{array}$ & $\begin{array}{c}5064 \\
(2)\end{array}$ & $\begin{array}{c}0.45 \\
\text { (calibrated) }\end{array}$ & $\begin{array}{c}0.41 \\
\text { (calibrated) }\end{array}$ & $\begin{array}{l}44,000 \quad 275 \\
\text { (calibrated) }\end{array}$ \\
\hline $\begin{array}{c}\text { Xylene } \\
\text { (Table 1) }\end{array}$ & $\begin{array}{c}21,120 \\
(3.2 \% \mathrm{JP}-4)\end{array}$ & $\begin{array}{c}21,120 \\
\text { (2) }\end{array}$ & $\begin{array}{c}0.41 \\
\text { (calibrated) }\end{array}$ & $\begin{array}{c}0.41 \\
\text { (calibrated) }\end{array}$ & $\begin{array}{c}273,000 \\
\text { (calibrated) }\end{array}$ \\
\hline
\end{tabular}

\subsubsection{Application Results and Discussion}

Results associated with the modeling exercise are presented in Table 8.5 and Figures 8.1 through 8.4. Table 8.4 also presents constituent information employed in the modeling exercise. Columns 4 and 5 in Table 8.4 present the distribution coefficients and contaminant mass fluxes for each BTEX constituent in the modeling exercise. The values in each of these columns were the result of a calibration exercise.

The calibrated distribution coefficients in column 4 are within approximately one order of magnitude of $\mathrm{K}_{\mathrm{d}}$ values based on $\mathrm{K}_{\mathrm{oc}}$ and the percent organic content of $0.5 \%$. The $K_{0 c}$ values for benzene, toluene, ethylbenzene, and $x y l e n e$ are $83,1100,300$, and $240 \mathrm{mi} / \mathrm{g}$, respectively (Strenge and Peterson 1989) resulting in estimated distribution coefficients of $0.4,5.5,1.5$, and $1.2 \mathrm{ml} / \mathrm{g}$, respectively. Column 5 presents both the peak and baseline contaminant mass fluxes determined from the calibration exercise.

The results of the initial calibrations for benzene, toluene, ethylbenzene, and xylene are presented in Figures 8.1 through 8.4., respectively. These concentration hydrographs are associated with calibration runs to groundwater well 19-02A, which is $45.7 \mathrm{~m}$ (150 ft) from the source.

The benzene fate and transport evaluation presented in Figure 8.1 represents an order-of-magnitude analysis and, as such, is a preliminary assessment. Because data do not exist that describe the actual peak benzene concentration, the peak concentration of $200 \mu \mathrm{g} / \mathrm{L}$ at year 17 (i.e., 1975) does not necessarily represent the actual maximum contaminant level of benzene at monitoring well 19-02A. 


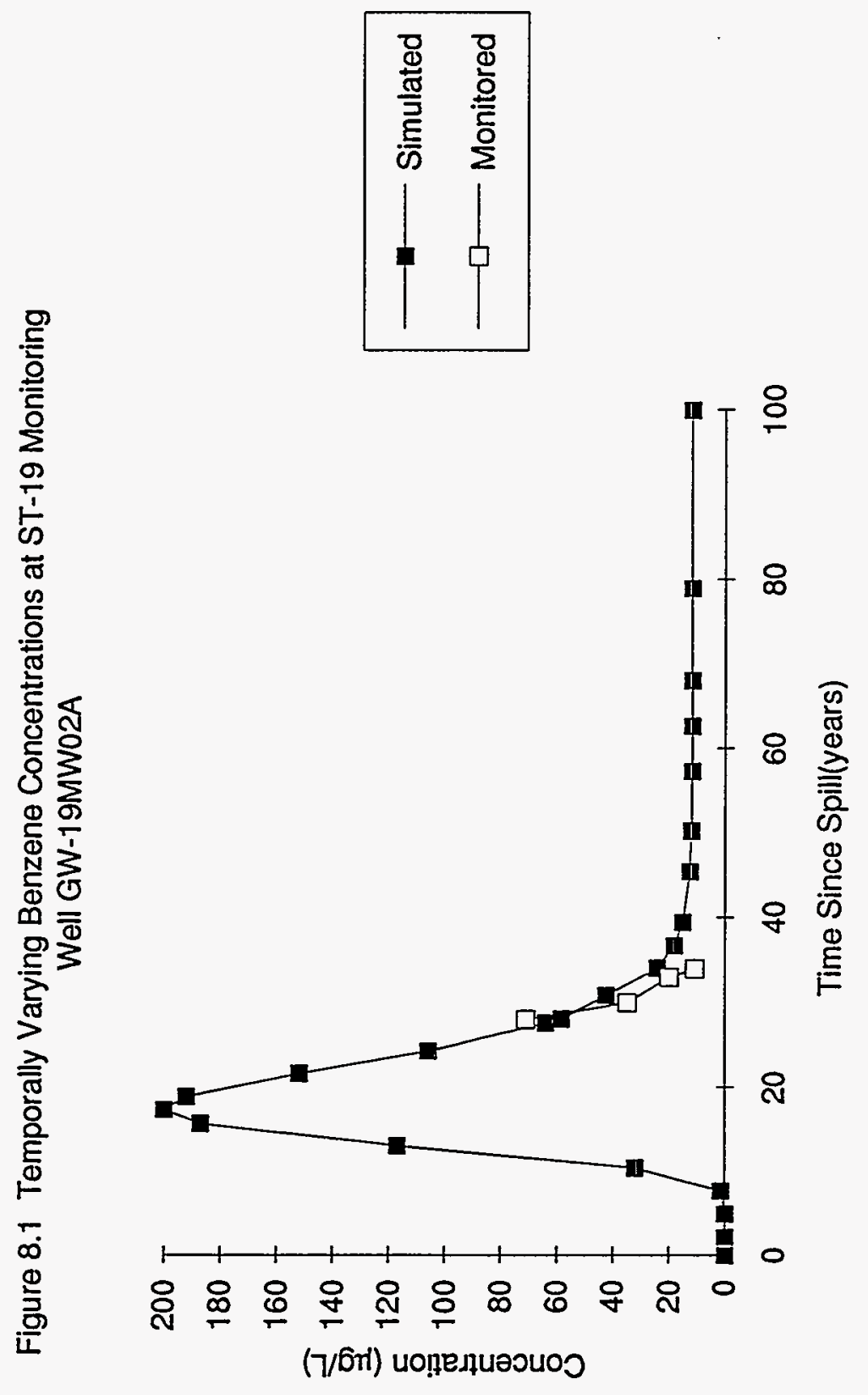


Figure 8.2 Temporally Varying Toluene Concentrations at ST-19 Monitoring Well GW-19MW02A

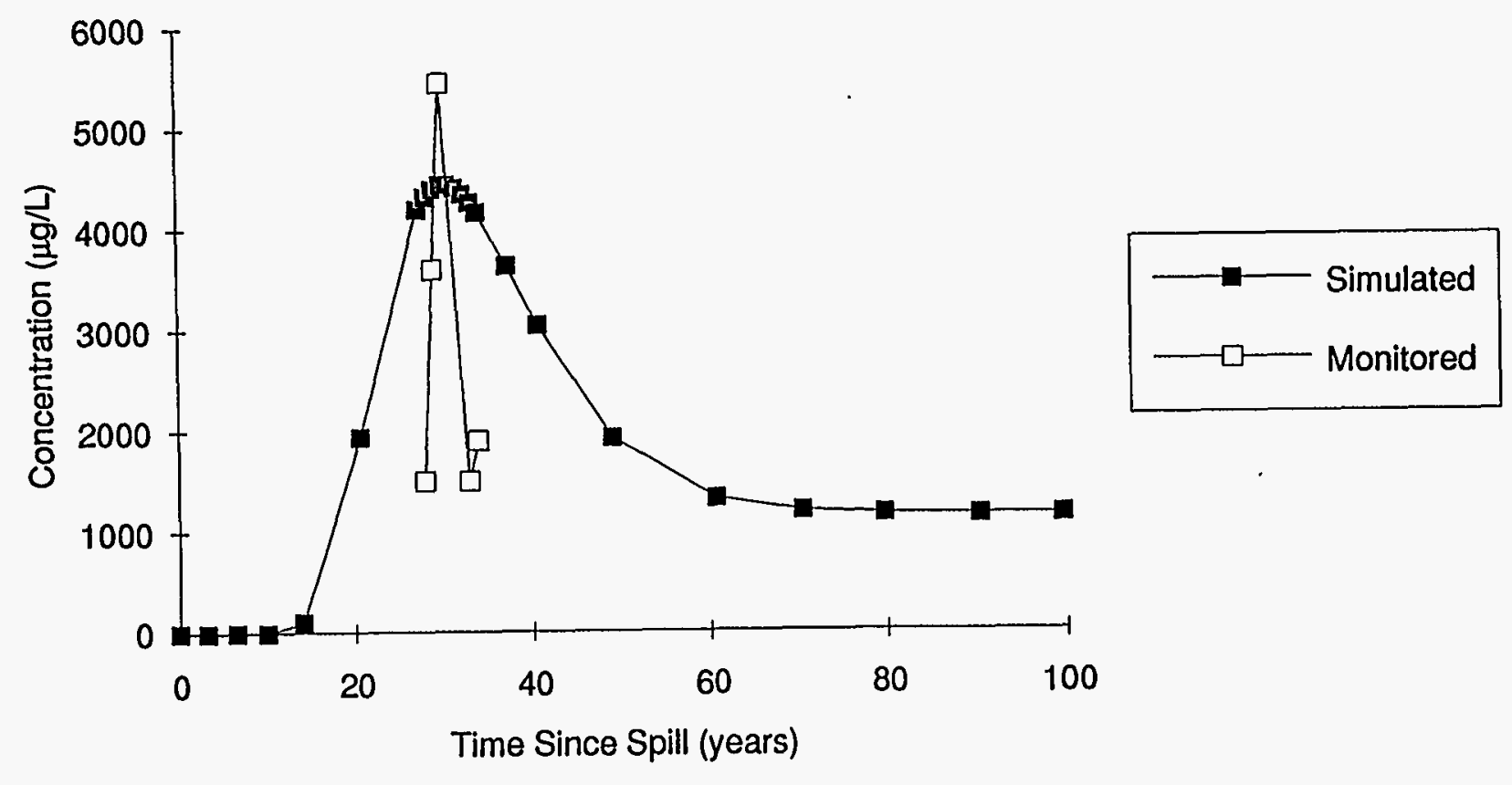




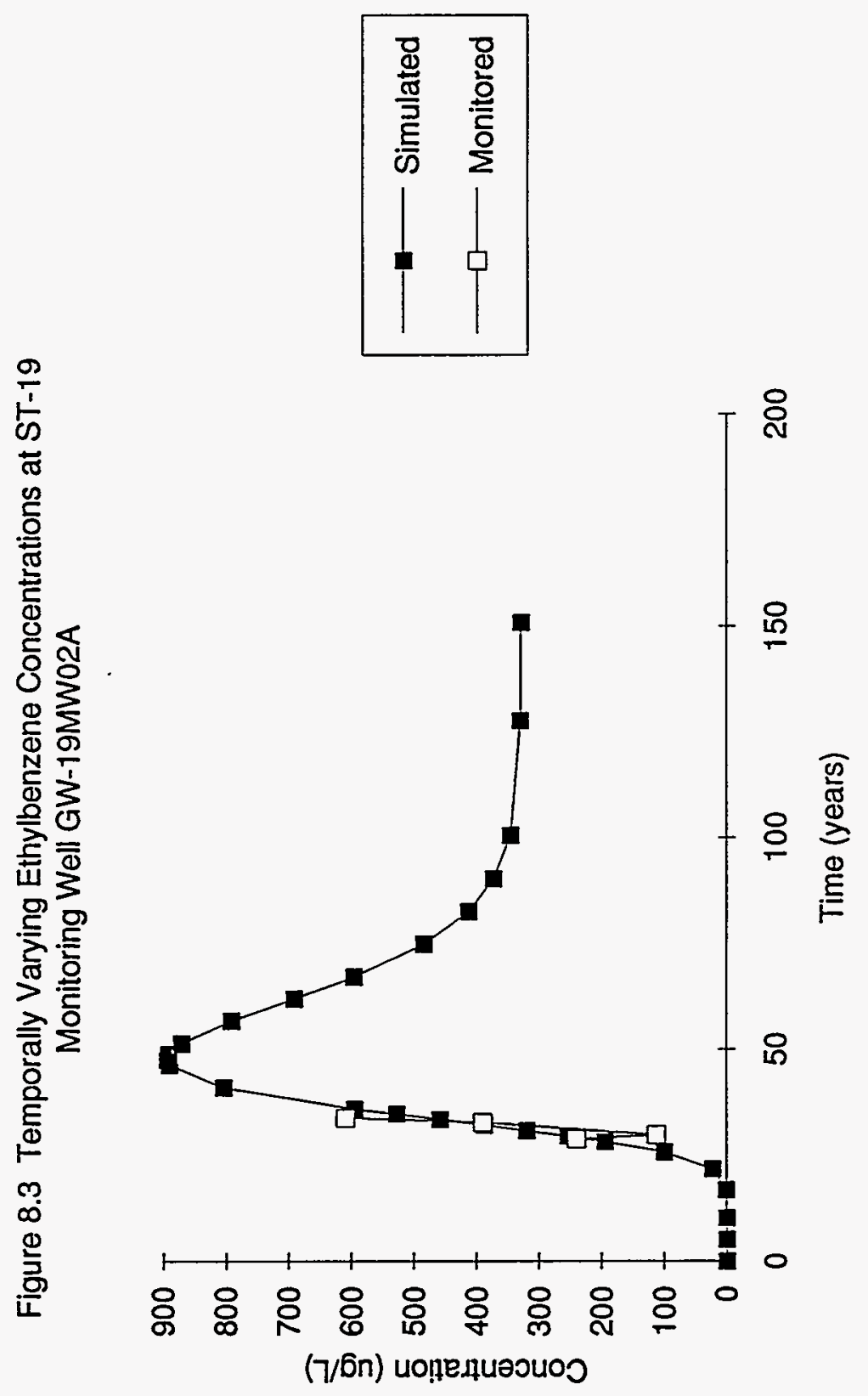


Figure 8.4 Temporally Varying Xylene Concentrations at ST-19 Monitoring Well

GW-19MW02A

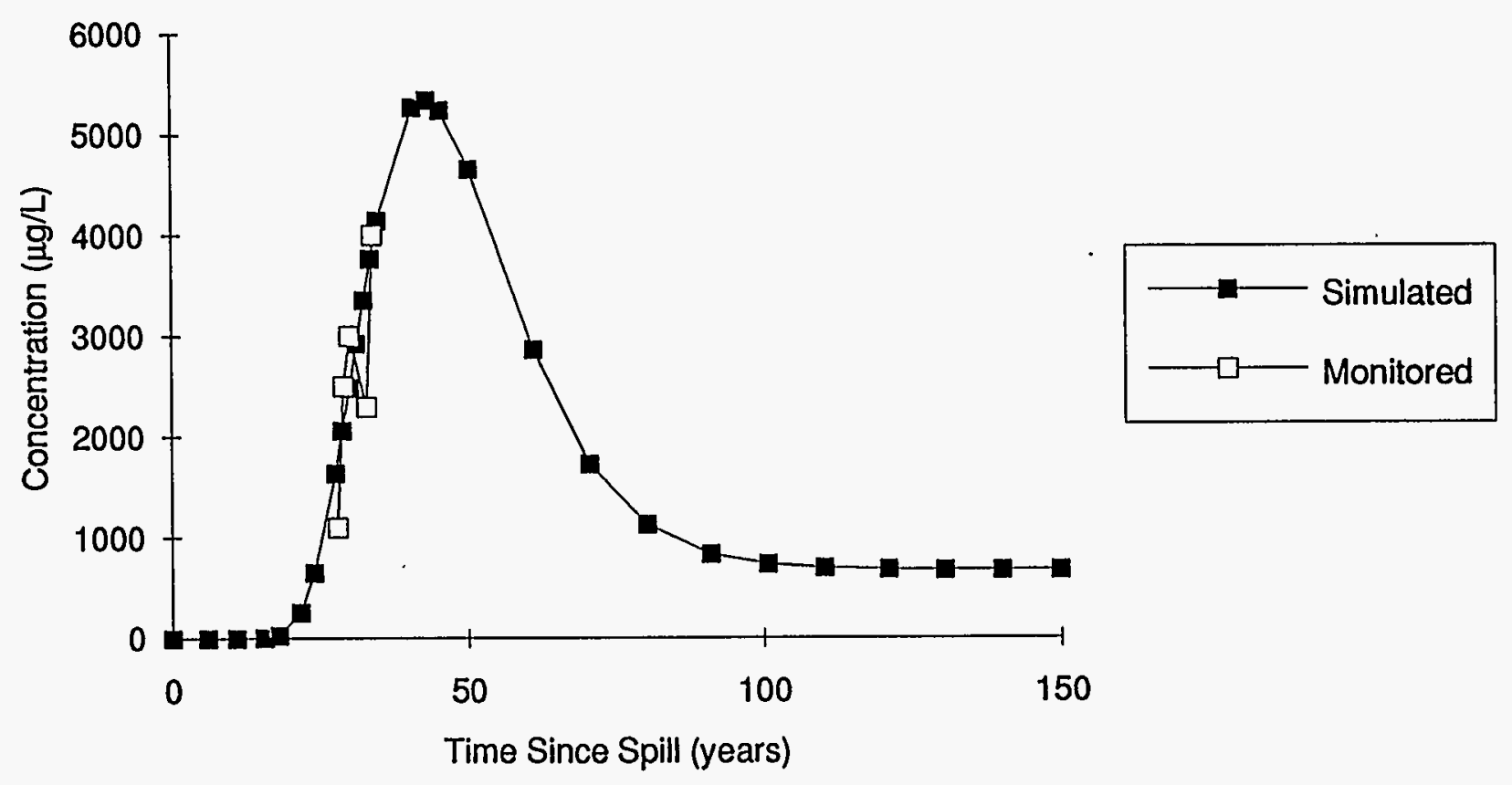


Although the steady-state groundwater concentration for benzene at the monitoring well is modeled to be approximately $12 \mu \mathrm{g} / \mathrm{L}$, these results do not suggest that the concentrations will exceed the MCL of $5 \mu \mathrm{g} / \mathrm{L}$. Because no long-term information is available on concentration levels after 1992 (i.e., year 34 in Figures 8.1 through 8.4.), the long-term modeling results represent only an order-of-magnitude analysis. The concentrations over time could and may decrease below the MCL especially given that the area of the original source used in the modeling exercise is significantly smaller than the actual area of contamination. Because the same mass of contamination was distributed over a larger area, the groundwater concentrations at the monitoring well should be lower than those predicted by the modeling exercise.

Because the monitoring well data associated with benzene occurred on the falling limb (that part of the curve where contaminant concentrations decrease with increasing time) of the concentration hydrograph, they provide information on both the peak concentration and the potential long-term concentration resulting from infiltration due to precipitation (i.e., rainfall and snowmelt). On the other hand, monitored concentrations for ethylbenzene and xylene, as illustrated in Figures 8.3 and 8.4 , occurred on the rising limbs of the concentration hydrographs. As such, they provide information only on the possible peak concentration and not on the long-term concentrations that may be expected from the site. Likewise, the peak of the toluene concentration hydrograph, as illustrated in Figure 8.2, appears to be associated with the peak concentration of the monitored data, thereby providing information for that region of the hydrograph only. It should be noted that the model simulation of toluene is not very good. Although the modeling results associated with all of the BTEX chemicals except xylene (which is well below its maximum contamination limit [MCL]) indicate that their long-term concentrations are around the MCL (see Table 8.2), the data are not available to confirm or dispute this conclusion.

\subsubsection{BTEX Concentration Input for Future Land Use at Monitoring Well 19-02}

A primary objective for performing fate and transport calculations at ST19 was to calculate the risk presented from future groundwater contaminants concentrations. Future BTEX concentration values at monitoring well 19-02, that is within the source area, were input into the two future land use scenarios (residential and industrial) for Site ST19 in this assessment. The input concentrations were time integrated from the present ( 34 years after the spill) till 30 years in the future ( 64 years after the spili).

The integrated input concentrations are $13 \mu \mathrm{g} / \mathrm{L}$ for benzene, $1800 \mu \mathrm{g} / \mathrm{L}$ for toluene, $760 \mu \mathrm{g} / \mathrm{L}$ for ethylbenzene, and $3540 \mu \mathrm{g} / \mathrm{L}$ for xylenes. Tables 8.6 through 8.9 present the MEPAS concentrations output that were integrated to determine the input concentrations. 


\begin{tabular}{|c|c|}
\hline $\begin{array}{l}\text { TABLE } 8.6 \\
\text { Concentrat } \\
\text { Well 19-02 C }\end{array}$ & $\begin{array}{l}\text { Iture Benzene } \\
\text { at Monitoring } \\
\text { lated by MEPAS }\end{array}$ \\
\hline $\begin{array}{c}\text { Time } \\
(y r)\end{array}$ & $\begin{array}{c}\text { Concentration } \\
\text { Calculated } \\
(\mu \mathrm{g} / \mathrm{L})\end{array}$ \\
\hline 0 & 0 \\
\hline 2.16 & 0 \\
\hline 4.9 & 0 \\
\hline 7.6 & 1.5 \\
\hline 10.3 & 32.2 \\
\hline 13 & 117 \\
\hline 15.67 & 187 \\
\hline 17.29 & 200 \\
\hline 18.91 & 192 \\
\hline 21.62 & 152 \\
\hline 24.32 & 106 \\
\hline 27.56 & 63.9 \\
\hline 28.1 & 58.5 \\
\hline 30.8 & 42.5 \\
\hline 34.04 & 24.2 \\
\hline 36.75 & 18.3 \\
\hline 39.45 & 15.2 \\
\hline 45.39 & 12.6 \\
\hline 50.26 & 12.1 \\
\hline 57.28 & 12 \\
\hline 62.69 & 12 \\
\hline 68.09 & 12 \\
\hline 78.90 & 12 \\
\hline 100.00 & 12 \\
\hline
\end{tabular}




\begin{tabular}{|c|c|}
\hline \multicolumn{2}{|c|}{$\begin{array}{l}\text { TABLE 8.7. Future Toluene } \\
\text { Concentrations at Monitoring } \\
\text { Well 19-02 Calculated by MEPAS }\end{array}$} \\
\hline $\begin{array}{c}\text { Time } \\
(\mathrm{yr})\end{array}$ & $\begin{array}{c}\text { Concentration } \\
\text { Calculated } \\
(\mu \mathrm{g} / \mathrm{L})\end{array}$ \\
\hline 0.00 & 0 \\
\hline 3.30 & 0 \\
\hline 6.60 & 0 \\
\hline 10.00 & 1 \\
\hline 14.10 & 106 \\
\hline 20.70 & 1940 \\
\hline 27.40 & 4200 \\
\hline 28.20 & 4320 \\
\hline 29.00 & 4400 \\
\hline 29.90 & 4440 \\
\hline 30.70 & 4440 \\
\hline 31.50 & 4410 \\
\hline 32.40 & 4350 \\
\hline 33.20 & 4270 \\
\hline 34.00 & 4170 \\
\hline 37.30 & 3640 \\
\hline 40.70 & 3050 \\
\hline 49.00 & 1930 \\
\hline 60.60 & 1320 \\
\hline 70.50 & 1190 \\
\hline 79.70 & 1160 \\
\hline 90.40 & 1150 \\
\hline 99.60 & 1150 \\
\hline
\end{tabular}




\begin{tabular}{|c|c|}
\hline \multicolumn{2}{|c|}{$\begin{array}{l}\text { TABLE } 8.8 \text {. Future } \\
\text { Ethylbenzene Concentrations at } \\
\text { Monitoring Well 19-02 Calculated } \\
\text { by MEPAS }\end{array}$} \\
\hline $\begin{array}{c}\text { Time } \\
\text { (yr) }\end{array}$ & $\begin{array}{c}\text { Calculated } \\
(\mu \mathrm{g} / \mathrm{L})\end{array}$ \\
\hline 0 & 0 \\
\hline 5 & $\overline{0}$ \\
\hline 10 & 0 \\
\hline 17 & 1 \\
\hline 22 & 22.8 \\
\hline 26 & 99.9 \\
\hline 28 & 195 \\
\hline 30 & 254 \\
\hline$\overline{31}$ & 320 \\
\hline 32 & 388 \\
\hline 34 & 459 \\
\hline 35 & 528 \\
\hline 36 & 595 \\
\hline 41 & 804 \\
\hline 47 & 891 \\
\hline 48 & 894 \\
\hline 49 & 892 \\
\hline 52 & 871 \\
\hline 57 & 792 \\
\hline 62 & 691 \\
\hline 67 & 596 \\
\hline 75 & 484 \\
\hline 83 & 413 \\
\hline 90 & 373 \\
\hline 101 & 346 \\
\hline 128 & 330 \\
\hline 151 & 329 \\
\hline
\end{tabular}




\begin{tabular}{|c|c|}
\hline \multicolumn{2}{|c|}{$\begin{array}{c}\text { TABLE 8.9. Future Xylenes } \\
\text { Concentrations at Monitoring } \\
\text { Well 19-02 Calculated by MEPAS }\end{array}$} \\
\hline $\begin{array}{c}\text { Time } \\
\text { (yr) }\end{array}$ & $\begin{array}{c}\text { Calculated } \\
(\mu \mathrm{g} / \mathrm{L})\end{array}$ \\
\hline$\overline{0}$ & 0 \\
\hline 6 & 0 \\
\hline 11 & 0 \\
\hline 16 & 5 \\
\hline 18 & 35 \\
\hline 22 & 262 \\
\hline 24 & 648 \\
\hline 28 & 1640 \\
\hline 29 & 2060 \\
\hline 30 & 2490 \\
\hline 31 & 2930 \\
\hline 32 & 3360 \\
\hline 34 & 3770 \\
\hline 35 & 4150 \\
\hline 41 & 5270 \\
\hline 43 & 5340 \\
\hline 46 & 5240 \\
\hline 50 & 4660 \\
\hline 61 & 2870 \\
\hline 71 & 1730 \\
\hline 80 & 1130 \\
\hline 91 & 835 \\
\hline 101 & 735 \\
\hline 110 & 697 \\
\hline 121 & 682 \\
\hline 131 & 677 \\
\hline 140 & 676 \\
\hline 150 & 675 \\
\hline
\end{tabular}




\subsubsection{Site ST11 Summary}

Analyses (U.S. Air Force 1993c) were conducted at ST11 for organic and inorganic contamination. The results of these analyses indicated that little or no BTEX could be measured, although high concentrations of TPH was found at the source. If BTEX contamination is being released at levels of concern from the source, contaminants would be found in one of the wells or soil cores, unless the plume moved under the zone of influence of the near-field wells and core-sampling areas and above the zone of influence of BSW A, which would appear to be unlikely. If no BTEX contamination can be monitored, then BTEX wastes do not appear to be of major concern.

Although BTEX may be eliminated from further analysis, weathered TPH residual still remains and might result in releases that could cause concern, unless shown othenwise. It should be noted that not all possible constituents were monitored for when soil core and water samples were analyzed, although the major constituents of concern were addressed. To investigate the possibility of an unknown constituent being released from the weathered residual, benzene is utilized as a surrogate, and a transport and fate simulation is performed to assess the possibility of benzene migration to BSW A to a concentration of $5 \mu \mathrm{g} / \mathrm{L}$ (i.e., $\mathrm{MCL}$ ). Benzene was chosen because of its relatively high toxicity and mobility with a low MCL. Although the following discussion addresses benzene by name, it only represents a surrogate as it was not found at the source or in the environment.

\subsubsection{Approach}

Based on the description of the site given in Section 3.1 of the assessment and U.S. Air Force (1993c), ST11 was modeled using the following assumptions:

- Monitored groundwater concentrations were not available at levels exceeding the detection limits of BTEX constituents, especially benzene, at groundwater monitoring wells surrounding this site. A conservative assessment was performed by back-calculating a set of conditions that would have to exist at the source for the site to be of concern. These source-term conditions were then analyzed to determine if they were unrealistic. Benzene was used as the indicator chemical because it is the most mobile and toxic constituent of all of the BTEX components.

- Little information exists at site ST11 from which the model can be calibrated; therefore, an indicator chemical is utilized in this assessment to help determine the impacts associated with the contamination at site ST11. As illustrated in Table 8.10 , benzene has

a) greatest mobility in the groundwater system, as indicated by the largest water solubility and smallest distribution coefficients (both octanol-water and carbon matter), and

b) poses the highest toxicity to humans, based on cancer potency factors (inhalation and ingestion).

Therefore, benzene is the primary focus of this study and is used as the indicator compound.

- The BTEX composition associated with the fuel contamination at site ST11 is similar to the typical composition of BTEX in fuels outlined in Table 8.1.

- Because BSW A is in the direction of the groundwater flow from Site ST11, an analysis is performed from the waste site to BSW A, which is $160 \mathrm{~m}(525 \mathrm{ft}$ ) from the center of the contaminated ST11 area.

- The Darcian flow velocity has been estimated to vary at the site from $0.76 \mathrm{~m} / \mathrm{d}$ $(2.5 \mathrm{ft} / \mathrm{d})$ to $6.4 \mathrm{~m} / \mathrm{d}(21 \mathrm{ft} / \mathrm{d})$ (SAlC 1989; personal communication, Tyler Gilmore 1992). The pore-water velocity, assuming an effective porosity of 
$25 \%$ (Droppo et al. 1989), would range from $3.0 \mathrm{~m} / \mathrm{d}(10 \mathrm{ft} / \mathrm{d})$ to $25.6 \mathrm{~m} / \mathrm{d}$ (84 $\mathrm{ft} / \mathrm{d}$ ). The faster the pore-water velocity, the lower the contaminant concentrations due to dilution. Given the speed at which the pore water moves, a conservative assessment would utilize a slower pore-water velocity, thereby ensuring a higher contaminant concentration at any receptor location. The Darcian and pore-water velocities assumed for site ST11 are $76.3 \mathrm{~cm} / \mathrm{d}(2.50 \mathrm{ft} / \mathrm{d})$ and $305 \mathrm{~cm} / \mathrm{d}(10.0 \mathrm{ft} / \mathrm{d})$, respectively.

- Contaminant-soil interactions can be adequately described by a distribution coefficient $\left(K_{d}\right)$, in which the $K_{d}$ represents a calibration parameter. Because no information exists for ST11 from which a benzene distribution coefficient $\left(K_{d}\right)$ can be estimated, the $K_{d}$ value from the site ST19 assessment (i.e., 0.1 $\mathrm{ml} / \mathrm{g}$ ) will be used.

- The assessment of the site does not violate the mathematical suppositions associated with the analytical equations (Appendix $\mathrm{C}$ ) forming the basis of the modeling exercise. For example, solutions to the advective-dispersive equation are applicable with constant pore-water velocities in time and space and homogeneous, anisotropic dispersivities.

- With a pore-water velocity of $305 \mathrm{~cm} / \mathrm{d}(10.0 \mathrm{ft} / \mathrm{d})$ (personal communication, Tyler Gilmore 1992), a bulk density of $1.6 \mathrm{~g} / \mathrm{cm}$ (personal communication,

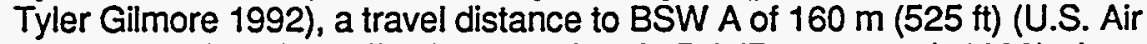
Force 1993c) and an effective porosity of $25 \%$ (Droppo et al. 1989), the travel time associated with benzene can be estimated as 0.24 year, using the following equation:

$$
t=x R_{f} / u
$$

$$
\begin{aligned}
& \text { Where } \\
& \qquad \begin{array}{l}
t=\text { time }(\mathrm{sec}) \\
\mathrm{x}=\text { travel distance }(\mathrm{cm}) \\
\mathrm{R}_{f}=\text { retardation factor (dimensionless) } \\
u=\text { pore water velocity }(\mathrm{cm} / \mathrm{s})
\end{array}
\end{aligned}
$$

Based on this travel time, any excess initial mass of contamination entering the groundwater aquifer would have passed BSW A. Because at least 17 years have passed since the discovery of the spill, the current contamination emanating from the site can be assumed to be constantly seeping from the weathered residual fuel due as a result of rainfall and snowmelt recharge.

- Because the concern associated with this site is the constant contaminant seepage from the weathered residual fuel, the assessment addresses contaminant movement from the waste site, through the saturated zone, to BSW A.

- Although contamination was noted in Garrison Slough in 1975, a modeling simulation was not performed in the slough because 1) no pertinent monitored information above detectable limits on the BTEX constituents were found in the surface water samples (HLA 1991, U.S. Air Force 1992), no pertinent monitored information above detectable limits were found in the groundwater, and 3) no pertinent monitored constituent or hydraulic information was documented in Garrison Slough. 


\begin{tabular}{||c|c|c|c|c||}
\hline \multicolumn{4}{|c|}{ TABLE8.10 Properties of BTEX That indicate Toxicity and Mobility in Groundwater Systems } \\
\hline \hline (from Strenge and Peterson 1989)
\end{tabular}

\subsubsection{Site Data Utillized for the Transport and Fate Assessment}

The groundwater model associated with MEPAS was utilized to model the transport of benzene at site ST11. The hydrogeologic data utilized in the ST11 study are presented in Table 25 . The $80 \mathrm{~kg}$ of mass of benzene reported in Table 8.11 was estimated from the 1) TPH-concentration isopleths with concentrations greater than $100 \mathrm{mg} / \mathrm{kg}$ (Figure 3.1) and 2) benzene content in arctic diesel fuel (Table 8.1), assuming there are no other sources and sinks. It was also assumed that the benzene content in arctic diesel fuel is representative of the benzene content in TPH.

\subsubsection{Application Results and Discussion}

With minor exceptions, monitored groundwater concentrations were not available at levels exceeding the detection limits of BTEX constituents at groundwater monitoring wells surrounding site ST11. As such, a conservative assessment was performed by back-calculating to find source-term conditions that would have to exist at the ST11 source for the contaminant levels at BSW A to equal the MCL of $5 \mu \mathrm{g} / \mathrm{L}$. These source-term conditions were then analyzed to determine if they were unrealistic.

Three scenarios were addressed in this assessment, with each scenario being represented by a different mixing depth: $3.05 \mathrm{~m}$ (10 ft), $29.0 \mathrm{~m}$ (95 ft), and 91.4 $\mathrm{m}(300 \mathrm{ft})$. For each depth it was assumed that the contaminant is fully (i.e., uniformiy) mixed over the region; as such, to maintain a concentration of $5 \mu \mathrm{g} / \mathrm{L}$ at BSW A, the flux rate of benzene from the source in $\mathrm{g} / \mathrm{yr}$ would have to increase as the depth increases because of dilution. The $3.05 \mathrm{~m}$ (10-ft) depth assumes that the LNAPL is limited to the top $3.05 \mathrm{~m}$ (10 ft) of the aquifer. The $29 \mathrm{~m}$ (95-ft) depth corresponds to the bottom-screen depth in BSW A, and the $91.4 \mathrm{~m}$ (300$\mathrm{ft}$ ) depth corresponds to the depth of the aquifer (CH2M Hill 1982).

The assessment focused on calculating the rate at which benzene would have to be released from the waste site to obtain the MCL concentration of $5 \mu \mathrm{g} / \mathrm{L}$ at BSW A, $160 \mathrm{~m}(525 \mathrm{ft})$ downgradient of the source. Based on this release rate, 1) a source concentration, 2) benzene mass at the source, and 3) a time for the entire 
source to be depleted of benzene can be estimated. These values can then be evaluated with respect to their reasonableness.

\begin{tabular}{|c|c|c|}
\hline \multicolumn{3}{|c|}{ TABLE 8.11. Site Data Utilized for the Fate and Transport Assessment at Site ST11 } \\
\hline \multicolumn{2}{|c|}{ SOURCE-TERM INFORMATION } & \multirow{2}{*}{$\begin{array}{r}\text { Reference } \\
(1) \\
(1) \\
(1) \\
(1)\end{array}$} \\
\hline $\begin{array}{l}\text { - Source-Term Length } \\
\text { - Source-Term Width } \\
\text { - Distance to BSW A } \\
\text { - Benzene Mass based on Soil Contamination }\end{array}$ & $\begin{array}{c}121.9 \mathrm{~m} \\
36.6 \mathrm{~m} \\
160 \mathrm{~m} \\
80 \mathrm{~kg}\end{array}$ & \\
\hline \multicolumn{3}{|c|}{ SATURATED ZONE } \\
\hline $\begin{array}{l}\text { - Aquifer Thickness } \\
\text { - Pore-Water Velocity } \\
\text { - x-Dispersivity } \\
\text { - y-Dispersivity } \\
\text { - z-Dispersivity } \\
\text { - Total Porosity } \\
\text { - Effective Porosity } \\
\text { - Bulk Density }\end{array}$ & $\begin{array}{c}3.05 \mathrm{~m} \\
29.0 \mathrm{~m} \\
91.4 \\
91.4 \mathrm{~m} \\
3.05 \mathrm{~m} / \mathrm{d} \\
0.1 \mathrm{x} \\
0.02 \mathrm{x} \\
2\left(\mathrm{~h}_{\mathrm{m}}\right)^{2} / \mathrm{x} \\
43.7 \% \\
25 \% \\
1.60 \mathrm{~g} / \mathrm{cm}^{3}\end{array}$ & $\begin{array}{c}\text { assumed } \\
\text { assumed } \\
(5) \\
(5) \\
(1,2,4,6) \\
(3,7,8) \\
(3,7,8) \\
(3,9) \\
(3) \\
(3,6) \\
(4)\end{array}$ \\
\hline \multicolumn{3}{|c|}{$\begin{array}{l}\text { References for Table: } \\
\text { 1. U.S. Air Force 1993c } \\
\text { 2. Raw Data for Calculations of Darcian Flow Velocities at the Eielson AFB supplied by Mr. T. } \\
\text { Gilmore of Battelle, Pacific Northwest Laboratories, Richland, Washington. } \\
\text { 3. Droppo et al. } 1989 \\
\text { 4. Hwang, S. T. 1992. "Results for Groundwater Fate and Transport Analysis for BTEX Found in } \\
\text { ST19 of Eielson Air Force Base." Letter Report. Prepared by Battelle, Pacific Northwest } \\
\text { Laboratories, Richland, Washington. September 24, 1992. (Draft). } \\
\text { 5. CH2M Hill } 1982 \\
\text { 6. SAIC } 1989 \\
\text { 7. EPA } 1985 \\
\text { 8. Gelhar et al. } 1985 \\
\text { 9. Whelan et al. } 1987\end{array}$} \\
\hline
\end{tabular}

The results at ST11 associated with the three depths are summarized in Table 8.12. Column 1 identifies the mixing depths that were utilized in the assessment. Column 2 presents the rate of release of benzene that would have to continuously emanate from the site to produce a concentration at BSW A of 5 $\mu \mathrm{g} / \mathrm{L}$, the concentration presented in column 3 .

The dissolved and particulate-soil benzene concentrations at the source, which are presented in columns 4 and 5 , were estimated utilizing the following expressions:

in which

$$
\begin{aligned}
& C_{d}=Q_{c} / Q_{S} \\
& C_{p}=K_{d} C_{d}
\end{aligned}
$$

$$
Q_{S}=i L W
$$




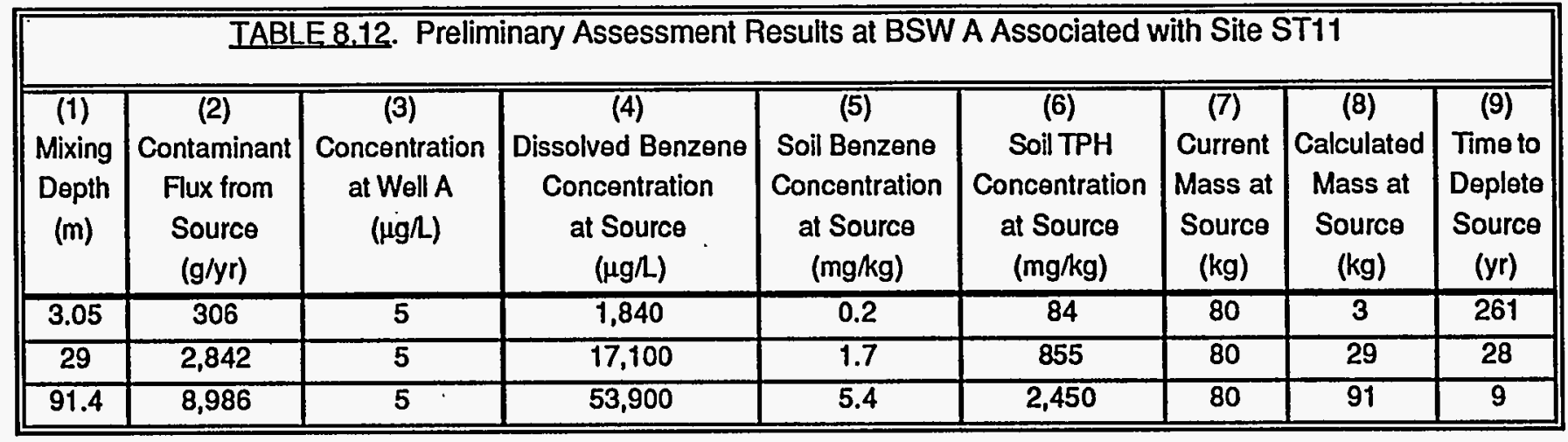


where $C_{d}$ is the dissolved concentration at the source, $Q_{s}$ is the volumetric leaching rate of water through the partially saturated zone, $Q_{c}$ is the contaminant flux from the source (i.e., column 2 in Table 8.12), $C_{p}$ is the particulate-soil concentration, $\mathrm{i}$ is the Darcian-flow velocity in the partially saturated zone (assumed as $0.01 \mathrm{~cm} / \mathrm{d}$; see Table 8.11), and $L$ and $W$ are the length and width of the waste site, respectively. Based on the calculated particulate-soil concentration for benzene in column 5, a corresponding TPH particulate-soil concentration can be estimated by assuming that $0.22 \%$ of the TPH is benzene; these results are presented in column 6.

The $80 \mathrm{~kg}$ of benzene mass that was initially estimated at site ST11 using TPH isopleths (see Table 8.11), are recorded in column 7 of Table 8.12. Based on the dissolved and particulate-soil concentrations in columns 4 and 5 , respectively, a corresponding benzene mass can be calculated at the source (see column 8), assuming a bulk density of $1.5 \mathrm{~g} / \mathrm{cm}^{3}$, moisture content of $16 \%$, soil density of $2.65 \mathrm{~g} / \mathrm{cm}^{3}$, porosity of $43.7 \%$, and a $K_{d}$ for benzene of $0.1 \mathrm{ml} / \mathrm{g}$ (see Table 8.11).

The length of time to deplete the source of its contamination is presented in column 9 and is calculated by dividing the current benzene mass at the source (i.e., column 7, Table 8.12 ) by the benzene flux rate from the source (i.e., column 2). Using a depth of $91.4 \mathrm{~m}$ ( $300 \mathrm{ft}$ ) as an example, the source will be totally depleted of its contamination after 9 years, if it has a total mass of $80 \mathrm{~kg}$ with a exiting flux rate of $8986 \mathrm{~g} / \mathrm{yr}$.

For any of the scenarios to be considered possible, all of the columns in Table 8.12 would have to represent a reasonable scenario. When reviewing the reasonableness of each scenario, the following limitations must be considered:

- The MEPAS analysis is a preliminary, order-of-magnitude analysis.

- Losses and diversions to Garrison Slough are not considered. If diversion of contamination has occurred or does occur, the concentrations at BSW A would be lower than that suggested by the current modeling scenario. Sampling in Garrison Slough was performed in July 1992, and all samples were below a detection limit of $1 \mu \mathrm{g} / \mathrm{L}$ (U.S. Air Force 1992).

- Only centerline concentrations are addressed in the assessment. If offcenterline calculations were performed, the concentrations at well $A$ would be lower than that suggested by the current modeling scenario.

- The mass flux from the source is considered to be constant. Generally speaking, a reduction in source term would also represent a reduction in the mass flux rate, resulting in lower concentrations at BSW A than that suggested by the current modeling scenario.

- A low groundwater velocity was assumed to minimize dilution and maximize the contaminant concentrations at BSW A. A faster velocity would have resulted in lower concentrations at BSW A than that suggested by the current modeling scenario.

- Dilution due to the screen interval is not accounted for. Dilution from uncontaminated portions of the aquifer would have resulted in lower concentrations at BSW A than that suggested by the current modeling scenario.

The 91.4-m (300-ft) mixing-depth scenario appears to be impossible. This scenario indicates that the source would be totally depleted of its TPH contamination in 9 years (using benzene as the surrogate chemical, as the mass 
and concentration estimates of benzene at the site are based on TPH), but TPH contamination at the site currently exists.

The 29-m (95-ft) assessment scenario appears to be improbable because the time for the source to be devoid of all contamination (i.e., 28 years, which makes it sometime around 1992) is unlikely. Thus, this scenario suggests that the contaminant mass flux rate from the source is too high. Lowering the mass flux rate will lower the simulated concentration at BSW A to below the MCL and provide a more reasonable time to deplete the source. If this scenario were reasonable, concentrations above detectable limits should have materialized at BSW A well before 1992.

The third scenario [i.e., 3.05-m (10-ft) depth] is possible only if the contamination is truly confined to the top $3.04 \mathrm{~m}(10-\mathrm{ft})$ of the aquifer. If this is the case, then little contamination would be monitored at BSW A, especially if the screen interval begins at a depth below $3.04 \mathrm{~m}$ (10 ft). If this scenario does occur, dissolved concentrations above detectable limits should have been recorded at locations closer to the waste site. Full EPA Level ill analyses were performed on ten ST11 soil samples. The soil boring from the most contaminated soils at SL11SBC-12.0 (highest TPH soil concentration of $23,500 \mathrm{mg} / \mathrm{kg}$ ), as suggested by the CSL analysis, reported no benzene above the maximum CRQL of $5 \mu \mathrm{g} / \mathrm{kg}$. EPA Methods 8240 and 8270 were used in the analysis. Methods 8240 and 8270 use methanol and methylene chloride as extraction agents, both of which are more efficient than water. With conservatism built into this assessment, a sampling program downgradient of the site may not find any contamination above MCLs or detectable limits for any constituents.

\subsubsection{Site ST18 Summary}

Analyses (U.S. Air Force 1993c) were conducted at ST18 for organic and inorganic contamination. The results of these analyses indicated that little or no BTEX could be measured, although high concentrations of TPH was found at the source. If BTEX contamination is being released at levels of concern from the source, contaminants would be found in one of the wells or soil cores, unless the plume moved under the zone of influence of the near-field well and core-sampling areas and above the zone of influence of BSW D, which would appear to be unlikely. If no BTEX contamination can be monitored, then BTEX wastes do not appear to be of major concern.

Although BTEX may be eliminated from further analysis, weathered TPH residual still remains and might result in releases that could cause concern, unless shown othenwise. It should be noted that it was not possible to determine the composition of the TPH, although the major constituents of concern were addressed with 8240 and 8270 analyses. To investigate the possibility of an unknown constituent being released from the weathered residual, xylene is calibrated at the site based on $8 \mu \mathrm{g} / \mathrm{L}$ recorded in the monitoring well. The xylene calibration was used to estimate the migration and fate of a surrogate chemical, which is more toxic and mobile with a lower MCL then xylene. Benzene is utilized as the surrogate chemical, and a transport and fate simulation is performed to assess the possibility of benzene migration to Wells GW18MW03 and D to a concentration of $5 \mu \mathrm{g} / \mathrm{L}$ (i.e., MCL). Benzene was chosen because of its relatively high toxicity and mobility with a low $\mathrm{MCL}$. Although the following discussion addresses benzene by name, it only represents a surrogate, as it was not found at the source or in the environment. 


\subsubsection{Approach}

Based on the description of the site in Section 5.1, ST18 was modeled using the following assumptions:

- Total xylene was monitored at 18-03 in September 1991 (U.S. Air Force 1993c). Only one concentration above detectable limits was recorded, that value being $8 \mu \mathrm{g} / \mathrm{L}$. This single concentration will by utilized to help calibrate the model for xylene.

- Because of its mobility and toxicity, benzene is used as the primary indicator compound. For more detail, refer to the assumptions associated with Site ST11 above.

- Because benzene concentrations were not found to be significantly above the detectable limit of $5 \mu \mathrm{g} / \mathrm{L}$ at monitoring well 18-03, the benzene assessment will be based on the xylene calibration.

- Because no information is available for the determination of the contaminant $K_{d}$ values for the site ST18, the $K_{d}$ values estimated from the site ST19 assessment will be used (i.e., 0.10 and $0.41 \mathrm{ml} / \mathrm{g}$ for benzene and xylene, respectively).

- The receptor well of concern is the BSW D which is located approximately $293 \mathrm{~m}$ (960 ft) downgradient of the suspected source area for ST18.

- The groundwater velocity and flow direction at site ST18 appear to vary seasonally. The Darcian velocities at Eielson range from 0.76 to $6.3 \mathrm{~m} / \mathrm{d} / 2.5$ to $20.6 \mathrm{ft} / \mathrm{d}$ ) (U.S. Air Force 1993, SAIC 1989, personal communication, Tyler Gilmore 1992). As noted earlier, the faster the pore-water velocity, the lower the contaminant concentration as a result of dilution. For a conservative analysis, the Darcian and pore-water velocities of 76 and $305 \mathrm{~cm} / \mathrm{d}(2.5$ and $10 \mathrm{ft} / \mathrm{d})$, respectively, were assumed. These values are also consistent with the assumptions in the assessments for sites ST11 and ST19.

- With a pore-water velocity of $305 \mathrm{~cm} / \mathrm{d}(10.0 \mathrm{ft} / \mathrm{d})$ (personal communication, Tyler Gilmore 1992), a bulk density of $1.6 \mathrm{~g} / \mathrm{cm}^{3}$, a travel distance to BSW D of $293 \mathrm{~m}$ (960 ft) (U.S. Air Force 1992), and an effective porosity of $25 \%$ (Droppo et al. 1989), the travel time associated with benzene can be estimated as 1.7 years, using equation (1). Based on this travel time, any excess initial mass of contamination entering the groundwater aquifer would have passed BSW D. Because at least 17 years have passed since the spill occurred, the current contamination emanating from the site can be assumed to be constantly seeping from the weathered residual fuel as a result of rainfall and snowmelt recharge.

- Because the concern associated with this site is the constant contaminant seepage from the weathered residual product, the assessment addresses contaminant movement from the waste site, through the saturated zone, to BSW D.

\subsubsection{SIte Data Utllized for the Transport and Fate Assessment}

The hydrogeologic parameters and their values utilized in the ST18 study are presented in Table 8.13 . The 458 and $82 \mathrm{~kg}$ of mass of xylene and benzene, respectively, reported in Table 8.14 were estimated from the 1) TPHconcentration isopleths with concentrations greater than $100 \mathrm{mg} / \mathrm{kg}$ (U.S. Air Force 1993c) and 2) xylene and benzene content in arctic diesel fuel (Table 8.1), assuming there are no other sources and sinks. It was also assumed that the xylene and benzene contents in arctic diesel fuel are representative of the xylene and benzene contents in TPH. 


\begin{tabular}{|c|c|c|}
\hline \multicolumn{3}{|c|}{ IABLE 8.13. Site Data Utilized for the Fate and Transport Assessment at Site ST18 } \\
\hline \multicolumn{2}{|c|}{ SOURCE-TERM INFORMATION } & \multirow[b]{2}{*}{$\begin{array}{r}\text { Reference } \\
(1) \\
(1) \\
(1) \\
(1) \\
(1)\end{array}$} \\
\hline $\begin{array}{l}\text { - Source-Term Length } \\
\text { - Source-Term Width } \\
\text { - Distance to BSW A } \\
\text { - Xylene Mass based on Soil Contamination } \\
\text { - Benzene Mass based on Soil Contamination }\end{array}$ & $\begin{array}{l}121.9 \mathrm{~m} \\
109.7 \mathrm{~m} \\
61 \mathrm{~m} \\
458 \mathrm{~kg} \\
82 \mathrm{~kg}\end{array}$ & \\
\hline \multicolumn{3}{|c|}{ SATURATED ZONE } \\
\hline $\begin{array}{l}\text { - Aquifer Thickness } \\
\text { - Pore-Water Velocity } \\
\text { - x-Dispersivity } \\
\text { - y-Dispersivity } \\
\text { - z-Dispersivity } \\
\text { - Total Porosity } \\
\text { - Effective Porosity } \\
\text { - Bulk Density }\end{array}$ & $\begin{array}{c}3.05 \mathrm{~m} \\
29.0 \mathrm{~m} \\
91.4 \\
91.4 \mathrm{~m} \\
3.05 \mathrm{~m} / \mathrm{d} \\
0.1 \mathrm{x} \\
0.02 \mathrm{x} \\
2\left(\mathrm{~h}_{\mathrm{m}}\right)^{2 / \mathrm{x}} \\
43.7 \% \\
25 \% \\
1.60 \mathrm{~g} / \mathrm{cm}^{3}\end{array}$ & $\begin{array}{c}\text { assumed } \\
\text { assumed } \\
(5) \\
(5) \\
(1,2,4,6) \\
(3,7,8) \\
(3,7,8) \\
(3,9) \\
(3) \\
(3,6) \\
(4)\end{array}$ \\
\hline \multicolumn{3}{|c|}{$\begin{array}{l}\text { References for Table: } \\
\text { 1. U.S. Air Force 1993c } \\
\text { 2. Raw Data for Calculations of Darcian Flow Velocities at the Eielson AFB supplied by Mr. T. } \\
\text { Gilmore of Battelle, Pacific Northwest Laboratories, Richland, Washington. } \\
\text { 3. Droppo et al. } 1989 \\
\text { 4. Hwang, S. T. 1992. "Results for Groundwater Fate and Transport Analysis for BTEX Found in } \\
\text { ST19 of Eielson Air Force Base." Letter Report. Prepared by Battelle, Pacific Northwest } \\
\text { Laboratories, Richland, Washington. September 24, 1992. (Draft). } \\
\text { 5. CH2M Hill } 1982 \\
\text { 6. SAIC } 1989 \\
\text { 7. EPA } 1985 \\
\text { 8. Gelhar et al. } 1985 \\
\text { 9. Whelan et al. } 1987\end{array}$} \\
\hline
\end{tabular}

\subsubsection{Application Results and Discussion}

Three separate assessments were performed at site ST18, each addressing either xylene or benzene. Xylene is included in the analysis because a monitored concentration of $8 \mu \mathrm{g} / \mathrm{L}$ was recorded in the downgradient well 18-03. Benzene is included because it is the indicator chemical. Each assessment is evaluated with respect to its reasonableness.

An initial analysis using xylene was performed to help calibrate the groundwater model with respect to the xylene flux rates from the contaminated source (i.e., utilizing a back calculation). This calibration exercise assumes that the LNAPL xylene is confined to the top $3.05 \mathrm{~m}$ ( $10 \mathrm{ft}$ ) of the aquifer. The results of the xylene calibration were then utilized to simulate the potential xylene concentrations at BSW D. 


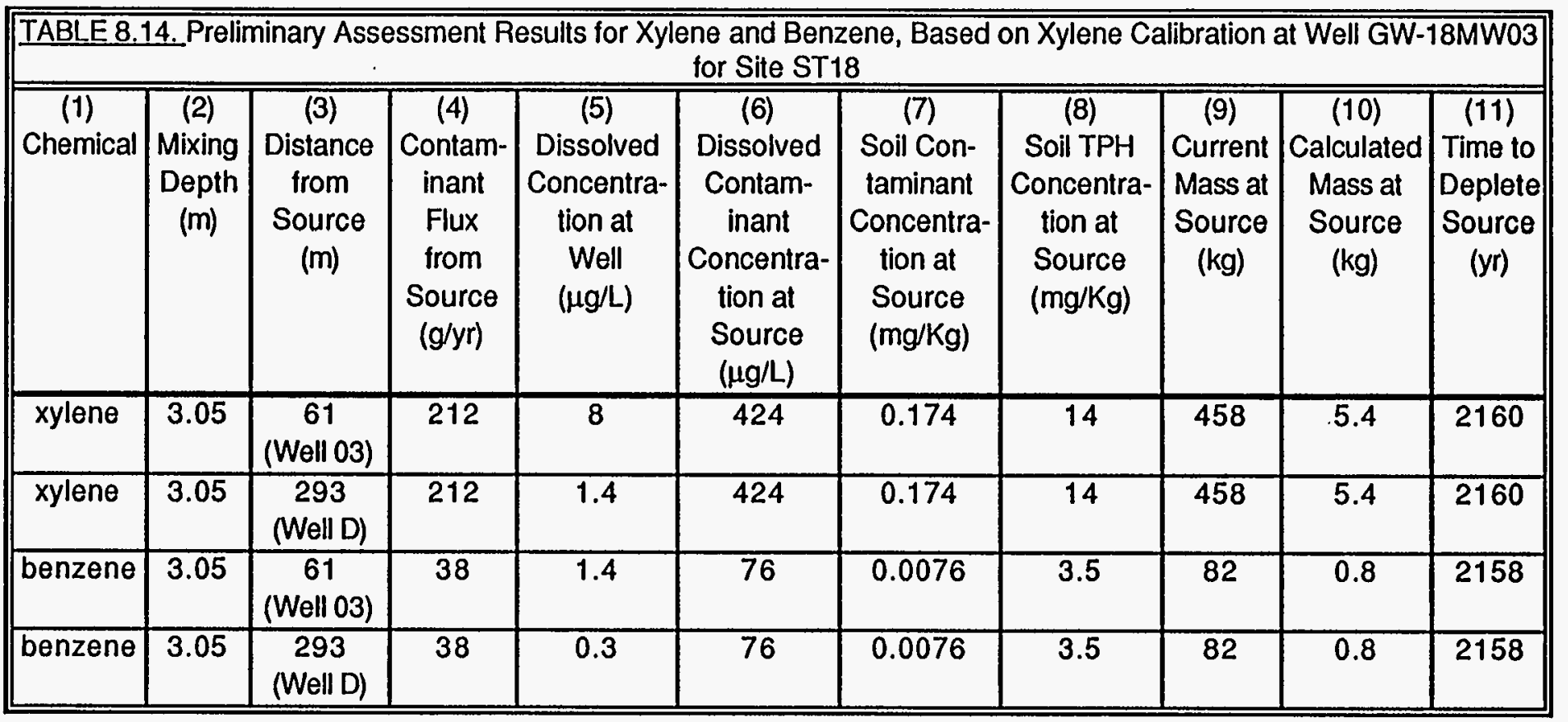

\begin{tabular}{||c|c|c|c|c|c|c|c|c||}
\hline \hline \multicolumn{7}{|c||}{ IABLE 8.15 Preliminary Assessment Results for Benzene at Site ST18 Well D for an } \\
Assumed Concentration of $5 \mu / \mathrm{L}$
\end{tabular}


The results of the xylene calibration were then used to develop an assessment of the migration and fate of benzene (i.e., the indicator chemical) in the saturated zone to both the monitoring well $18-03$ and BSW D. This modeling exercise also assumes that the LNAPL benzene is confined to the top $3.05 \mathrm{~m}$ (10 ft) of the aquifer.

Finally, a preliminary assessment was performed on benzene migrating to BSW D at an assumed concentration of $5 \mu \mathrm{g} / \mathrm{L}$ (i.e., the $\mathrm{MCL}$ of benzene). Three scenarios were addressed in this assessment, with each scenario being represented by a different mixing depth: $3.05 \mathrm{~m}(10 \mathrm{ft}), 29.0 \mathrm{~m}(95 \mathrm{ft})$, and 91.4 $\mathrm{m}(300 \mathrm{ft})$. The case for each depth assumes that the contaminant is fully (i.e., uniformly) mixed over the region; to maintain a concentration of $5 \mu \mathrm{g} / \mathrm{L}$ at BSW D, the flux rate of benzene from the source would have to increase as the depth increases, because of dilution. The case for the 3.05-m (10-ft) depth assumes that the LNAPL is limited to the top $3.05 \mathrm{~m}$ (10 ft) of the aquifer. The 29-m (95- $\mathrm{ft})$ depth represents the bottom-screen depth in BSW A, and the $160-\mathrm{m}(300-\mathrm{ft})$ depth represents the depth of the aquifer (CH2M Hill 1982).

Groundwater Calibration using Xylene--The xylene calibration consisted of simulating the release of xylene from the ST18 source at a flux rate that would re-create a monitored concentration of $8 \mu \mathrm{g} / \mathrm{L}$ at well $18-03[61 \mathrm{~m}(200 \mathrm{ft})$ downgradient of the source (location of buried tanks as depicted in Figure 5.1 )]. The values assigned to the modeling parameters are presented in Table 8.13. The results of the groundwater calibration using xylene are presented in the first two rows of Table 8.14. The first row presents the results of the calibration exercise from the source to monitoring well $18-03$, while the second column presents the xylene simulation results to BSW D.

Column 2 of Table 8.14 identifies the assumed thickness of the mixing zone as $3.05 \mathrm{~m}(10 \mathrm{ft})$ in all cases. Column 3 identifies the distance to the appropriate well (i.e., either $18-03$ or BSW D) that was used in the modeling exercise. Column 4, row 1 identifies the flux rate of xylene from the source in $\mathrm{g} / \mathrm{yr}$ that would have to continuously emanate from the site to produce a concentration of $8 \mu \mathrm{g} / \mathrm{L}$ at 18-03 (i.e., column 5, row 1). The flux rate of $212 \mathrm{~g} / \mathrm{yr}$ (column 4, rows 1 and 2 ) was also used in simulating the xylene concentration that could potentially appear at BSW $\mathrm{D}$ (column 5 , row 2 ).

The dissolved and particulate-soil xylene concentrations at the source, which are presented in columns 6 and 7 and rows 1 and 2, were estimated using Equations (2) through (4). Based on the calculated particulate-soil concentration for xylene in column 7, a corresponding TPH particulate-soil concentration can be estimated assuming that $1.23 \%$ of the TPH is xylene; these results are presented in column 8 [e.g., $14.1=(0.174) /(0.0123)]$.

The $458 \mathrm{~kg}$ of xylene mass, which was initially estimated at site ST18 using TPH isopleths (see Table 8.13), is recorded in column 9 of Table 8.14. Based on the dissolved and particulate-soil concentrations in columns 6 and 7 , respectively, a corresponding xylene mass can be calculated at the source (see column 10), assuming a bulk density of $1.5 \mathrm{~g} / \mathrm{cm}^{3}$, moisture content of $16 \%$, soil density of $2.65 \mathrm{~g} /$ cubic $\mathrm{cm}$, porosity of $43.7 \%$, and a $\mathrm{K}_{\mathrm{d}}$ for xylene of $0.41 \mathrm{mVg}$ (see Table 8.5).

The "current mass versus calculated mass at the source" was presented to determine if the scenario physically makes sense, given the assumptions of the 
modeling exercise. Because the "calculated mass at source" (see Column 10) is less than the "current mass at source" ([see Column 9] which is calculated from the TPH, so this mass may not actually be at the source), then the assumptions of the scenario are not invalid. If the calculated inventories were larger than the "current" inventories, then more mass than that which exists at the site would be required; this requirement would indicate that the scenario is impossible.

The xylene results indicate that the values assigned to the modeling parameters physically make sense. Although the "current (xylene) mass at source" is estimated at $458 \mathrm{~kg}$ (based on TPH isopleths), little xylene has actually been found at the site; therefore, the values calculated using TPH isopleths do represent conservative estimates. In addition, the xylene assessment indicates that the scenario is plausible, resulting in contaminant levels that are 1250 times lower than the MCL (i.e., 10,000/8).

Because the xylene calculation at the source is estimated from the TPH, the 'time to deplete source" (see Column 11 of Table 8.14) calculation indicate that depletion of the entire TPH source would not occur before 1993; as such, TPH should still remain at the source. Monitoring information confirms that TPH still exists at the source. Because the assessment has been designated as being possible, the assessment does not indicate that xylene is a problem; on the contrary, it indicates that TPH should still remain at the waste site, as it does.

The time to deplete the source of its contamination is presented in column 11 and is calculated by dividing the current xylene mass at the source (i.e., column 9 , Table 8.14) by the xylene flux rate from the source (i.e., column 4). Using a mixing depth of $3.05 \mathrm{~m}$ ( $10 \mathrm{ft}$ ) as an example, the source will be totally depleted of its contamination after 2160 years, if it has a total mass of $458 \mathrm{~kg}$ with an exiting flux rate of $212 \mathrm{~g} / \mathrm{yr}$.

For the scenario to be considered possible, all of the columns in Table 8.14 must have values that are reasonable. Although this assessment is an order-ofmagnitude analysis, the values presented in Table 8.14 for xylene appear to be very reasonable when compared to monitored soil and water concentrations. This conclusion is expected, given that the results are based on a calibration exercise using monitored data. The flux rates have values (i.e., $212 \mathrm{~g} / \mathrm{yr}$ ) that would not deplete the source prior to 1992 (i.e., within $17 \mathrm{yr}$ ). The soil-particulate concentrations in column 7 (i.e., $0.174 \mathrm{mg} / \mathrm{kg}$ ), which represent average values at the source, are well within the range of the monitored data from below detectable to $960 \mathrm{mg} / \mathrm{kg}$ xylene with most samples below detectable (i.e., $5 \mu \mathrm{g} / \mathrm{kg}$ ) (U.S. Air Force 1993c). Likewise, the simulated TPH-soil concentrations in column 8 (i.e., $5.4 \mathrm{mg} / \mathrm{kg}$ ) are not unreasonable; the monitored TPH concentrations vary from below detectable to $11,000 \mathrm{mg} / \mathrm{kg}$ with many sample concentrations of 20 to 60 $\mathrm{mg} / \mathrm{kg}$ (U.S. Air Force 1993c). Finally, the simulated xylene concentration at BSW $D$ (i.e., $1.4 \mu \mathrm{g} / \mathrm{L}$ ) is below the detectable limit of $2 \mu \mathrm{g} / \mathrm{L}$ (U.S. Air Force 1993c); these results correspond to monitored data that indicate that any xylene concentrations at BSW D are below detectable limits.

\section{Preliminary assessment of benzene at site ST18}

Utilizing the results from the xylene calibration presented in the preceding section, the migration of benzene to both well 18-03 and BSW D and its fate were simulated. The results of this assessment are presented in rows 3 and 4 of Table 8.14. The definition of the headings in Table 8.14 for benzene are the same as those for xylene. Like xylene, the benzene assessment assumes that the 
benzene contents in arctic diesel fuel are representative of the benzene contents in TPH. Therefore, the xylene flux rate can be modified for benzene by using the ratio of the fractional content of benzene and xylene in arctic diesel (e.g., $38=0.22 \% / 1.23 \%$ ). Column 4 , rows 3 and 4 of Table 8.14 present the assumed flux rate of benzene from the source, based on the calibration results of xylene. Because the migration and fate simulation is Gaussian and, therefore, linear in the saturated zone, the simulation results for benzene also differ from those of xylene by a factor of 0.179 (i.e., $0.179=0.22 \% / 1.23 \%$ ). Because the results in columns 7 and 8 are based on $K_{d}$ values, the ratio of 0.179 between benzene and xylene is not valid.

As with the xylene case, the values presented in Table 8.14 for benzene appear to be reasonable within an order of magnitude. For example, the simulated benzene concentrations at BSW D (i.e., $0.3 \mu \mathrm{g} / \mathrm{L}$, column 5, row 4) are well within the monitored concentrations at BSW D, which ranged from nondetectible to 1.4 $\mu \mathrm{g} / \mathrm{L}$, with many monitored values around $0.3 \mu \mathrm{g} / \mathrm{L}$ (Table 2 ). These results suggest that benzene concentrations significantly above $0.3 \mu \mathrm{g} / \mathrm{L}$ may not occur, assuming that the source of this contamination is in reality site ST18. If the surrogate chemical benzene does not appear to exceed the MCL at BSW D, then other less mobile and toxic minor products should also not exceed their respective MCLs at BSW D.

Although the analyses presented in Table 8.14 are for a mixing depth of $3.05 \mathrm{~m}$ $(10 \mathrm{ft})$, modifications to the depth of the aquifer will not result in any change to the conclusions in the analysis. If the depth was increased by a factor of 9.5 to $29 \mathrm{~m}$ ( $95 \mathrm{ft}$ ), the source-term mass flux for xylene would have to be increased by the same factor to maintain a concentration of $8 \mu \mathrm{g} / \mathrm{L}$. Xylene would increase from 212 to $2014 \mathrm{~g} / \mathrm{yr}$. An increase in the mass flux would lower the "time to deplete source" by the same factor from 2160 to $227 \mathrm{yr}$. Because benzene is intimately tied to the xylene calibration, its concentration would likewise remain unchanged.

Preliminary assessment of benzene at BSW D

With minor exceptions, monitored groundwater concentrations were not available at levels exceeding the detection limits of BTEX constituents at BSW D. A conservative assessment was performed by back-calculating source-term conditions that would have to exist at the ST18 source for the contaminant levels to equal the MCL of $5 \mu \mathrm{g} / \mathrm{L}$ at BSW D. These source-term conditions were then analyzed to determine whether they were unrealistic.

As with site ST11, three scenarios were addressed in this assessment, with each scenario being represented by a different mixing depth: $3.05 \mathrm{~m}$ (10 ft), $29.0 \mathrm{~m}$ $(95 \mathrm{ft})$, and $91.4 \mathrm{~m}(300 \mathrm{ft})$. Each case assumes that the contaminant is fully (i.e., uniformly) mixed over the region; to maintain a concentration of $5 \mu \mathrm{g} / \mathrm{L}$ at BSW D, the flux rate of benzene from the source would have to increase as the depth increases, because of dilution. The case for the $3.05-\mathrm{m}$ (10-ft) depth assumes that the LNAPL is limited to the top $3.05 \mathrm{~m}$ (10 ft) of the aquifer. The $29-\mathrm{m}(95-\mathrm{ft})$ depth represents the bottom-screen depth in BSW D, and the $160-\mathrm{m}(300-\mathrm{ft})$ depth represents the depth of the aquifer (CH2M Hill 1982).

The assessment focused on calculating the rate at which benzene would have to be released from the waste site to obtain the MCL concentration of $5 \mu \mathrm{g} / \mathrm{L}$ at BSW $\mathrm{D}, 293 \mathrm{~m}(960 \mathrm{ft})$ downgradient of the source. Based on this release rate, 1) a source concentration, 2) benzene mass at the source, and 3) a time for the entire 
source to be depleted of benzene can be estimated. These values can then be evaluated with respect to their reasonableness.

The results at ST18 associated with the three depths are summarized in Table 8.15. Column 1 identifies the mixing depths that were utilized in the assessment. Column 2 presents the rate of release of benzene that would have to continuously emanate from the site to produce a concentration of $5 \mu \mathrm{g} / \mathrm{L}$ at BSW $D$, the concentration which is presented in column 3.

The dissolved and particulate-soil benzene concentrations at the source, which are presented in columns 4 and 5 , can be estimated utilizing Equations (2) through (4). Based on the calculated particulate-soil concentration for benzene in column 5, a corresponding TPH particulate-soil concentration can be estimated assuming that $0.22 \%$ of the TPH is benzene; these results are presented in column 6 [e.g., $45=(0.1) /(0.0022)]$.

The $82 \mathrm{~kg}$ of benzene mass, which was initially estimated at site ST18 using TPH isopleths (see Table 8.13), is recorded in column 7 of Table 8.15. Based on the dissolved and particulate-soil concentrations in columns 4 and 5, respectively, a corresponding benzene mass can be calculated at the source (see column 8), assuming a bulk density of $1.5 \mathrm{~g} /$ cubic $\mathrm{cm}$, moisture content of $16 \%$, soil density of $2.65 \mathrm{~g} /$ cubic $\mathrm{cm}$, porosity of $43.7 \%$, and a $\mathrm{K}_{\mathrm{d}}$ for benzene of $0.1 \mathrm{ml} / \mathrm{g}$ (see Table 8.5).

The time to deplete the source of its contamination is presented in column 9 and is calculated by dividing the current benzene mass at the source (i.e., column 7) by the benzene flux rate from the source (i.e., column 2). Using a depth of $91.4 \mathrm{~m}$ $(300 \mathrm{ft})$ as an example, the source will be totally depleted of its contamination after 4 years, if it has a total mass of $82 \mathrm{~kg}$ with an exiting flux rate of $22,000 \mathrm{~g} / \mathrm{yr}$.

The 91.4-m ( $300 \mathrm{ft}$ ) mixing-depth scenario appears to be impossible. This scenario estimates a source mass that is larger than what is actually present (i.e., 222 versus $82 \mathrm{~kg}$ ). This scenario indicates that the source would have been totally depleted of its contamination in 4 years, but in fact contamination still exists at the source of the site at levels that require an assessment.

The $29 \mathrm{~m}(95 \mathrm{ft})$ assessment scenario also appears to be impossible; this scenario suggests that the source would have been devoid of all contamination by 1987 (i.e., after 12 years), which is untrue. The third scenario [i.e., $3.05 \mathrm{~m}$ (10 $\mathrm{ft}$ ) depth] is improbable because the conservative benzene assessment presented in Table 8.14 (row 4) suggests that the benzene concentrations at BSW D are unlikely to reach the MCL value of $5 \mu \mathrm{g} / \mathrm{L}$. Because the benzene travel time to BSW D is 1.7 years, contaminant levels that are consistently higher than the MCL should have already been monitored in BSW D. 


\subsection{TOXICITY ASSESSMENT}

The values and references for all toxicity data used in this risk assessment are given in Table 9.1. Much of the toxicity data listed were not used in the final risk assessment process, because the chemicals were not of potential concern, as calculated in the scheme described in Section 7.0.

There are many sources of toxicity data for the compounds analyzed at the Operable Unit 2 source areas. Following EPA Region $X$ guidance (EPA 1991a), a hierarchy of toxicity sources was used. The primary reference was the EPA's Integrated Risk Information System (IRIS; EPA 1992b); the secondary reference was the EPA's Health Effects Assessment Summary Tables (HEAST; EPA 1991d, 1992d). The toxicity data was initially compiled with 1991 HEAST data; the 1992 data was checked and any changes in toxicity values were incorporated in the table. If neither IRIS nor HEAST had toxicity data, then toxicity reference values from the EPA Superfund Technical Support Center were used. The footnotes in Table 9.1 list the sources of all toxicity data used.

There are two ingestion RfDs for manganese in IRIS (EPA 1993). $5 \times 10^{-3}$ is listed for groundwater ingestion and $1.4 \times 10^{-3}$ for ingestion of food. The risk-based screening levels cited in Table 7.4 were calculated with the different ingestion RfDs. The food ingestion value was used for the soil ingestion pathway. However, all risk calculations in the site specific calculations used the more conservative food ingestion value, even for the groundwater ingestion pathway. The effect of this is discussed in the Magnitude of Effect of Uncertainties tables for each site.

Some toxic compounds had toxicity data for ingestion but not for inhalation. This risk assessment did not assign the ingestion value for inhalation. Instead, the compound was assumed to have no inhalation toxicity value and no value was substituted. Every compound that contributed to the risk at any site in a significant manner (cancer risk $>10^{-7}$ or Hazard Quotient $>10^{-2}$ ) had both ingestion and inhalation toxicity data (Tables K.1 through K.60).

There are no IRIS, HEAST, or EPA Superfund Technical Support Center toxicity data for two of the principal contaminants at Operable Unit 2 sites: total petroleum hydrocarbons (TPH) and lead. These compounds were not included in the primary risk calculations. However, toxicity values detailed below were used to calculate their potential contribution to risk in the Site Uncertainty sections of this assessment.

In addition, there were no data for all polynuclear aromatic hydrocarbons (PAHs) except for benzo(a)pyrene. In order to assign a toxicity to the other PAHs, toxicity equivalency factors from a non-EPA source were used.

Greater detail regarding the toxicity data used for these three classes of compounds are detailed below.

\subsection{TOXICITY INFORMATION FOR NONCARCINOGENIC EFFECTS}

\subsubsection{Total Petroleum Hydrocarbons}

Total petroleum hydrocarbons (TPH) were found at some of the Operable Unit 2 sites in high concentrations. These contaminants are a mixture of hydrocarbon compounds commonly found in fuels. The TPH at Eielson Air Force Base originated 
from spills of either diesel fuel or jet fuel. Source areas ST11 and ST18 were spills of diesel fuel, ST19 was a surface spill of JP-4, and ST10/SS14 plus ST13/DP26 were spills of all fuel types, principally JP-4.

The remnants of these spills, the TPH, have been in the subsurface from 30 plus years (e.g., ST19) to five years (e.g., ST13/DP26). While in the subsurface, considerable weathering and degradation of the fuels is believed to have occurred.

Available data suggest that practically all volatile and semi-volatile organic compounds have either dissolved into the groundwater or volatilized into the atmosphere. For example, chemical analyses of fuel floating atop the aquifer at sites ST10/SS14 and ST13/DP26 indicate that greater than $95 \%$ of its benzene is no longer present (U.S. Air Force 1993C) based on the composition of JP-4 (Table 8.1).

The soil borings at each site with the maximum TPH contamination were also analyzed for volatile and semi-volatile organic compounds using EPA Methods 3240 and 3270 . Any detections from these analyses were included in the risk assessment. The much higher concentrations of remaining, non-mobile hydrocarbons are detected with the TPH analysis. The remaining TPH at the Operable Unit 2 sites is probably not a uniform material. It is probably highly variable in composition and toxicity due to variations in site conditions, parent material, and subsurface residence time.

If one compounds this variability with the multiple hydrocarbon spill sites in the United States, it is understandable that there is no single toxicity value for TPH. Neither IRIS nor HEAST lists a cancer potency factor (CP) nor a reference dose (RfD) for TPH. Therefore, based on discussions with representatives of EPA Region X, no risk calculation was performed for this compound in the primary parts of this assessment. Alternate risk calculations are discussed in the specific site uncertainty sections of this assessment. The toxicity values for these alternative calculations are based on the data presented below.

There two methods of determining the toxicity of TPH: 1) substitute the toxicity of the parent product, JP-4 or diesel, or 2) calculate TPH toxicity by removing toxins that were analyzed separately (e.g., benzene) from the parent material. The former method is conservative since the volatile and semi-volatile organic toxic compounds are double counted in the risk assessment. The second method will result in conjectural toxicity values because non-standard and non-approved calculation methods are utilized. Thus, TPH toxicity estimates are calculated using data from both sources in the site-specific uncertainty sections of this assessment. The source or derivation of TPH toxicity data using both methods is outlined below.

EPA (1992C) proposed oral toxicity reference doses for JP-4 and diesel fuel of $8 \times 10^{-}$ $2 \mathrm{mg} / \mathrm{kg}$-day and $8 \times 10^{-3} \mathrm{mg} / \mathrm{kg}$-day, respectively. This study derived oral toxicity values by route-to-route extrapolation of inhalation data. Confidence in the data and the methods used was not high and an uncertainty factor of 10,000 was used to calculate these values. To put these numbers in perspective, this calculated toxicity of diesel fuel is 25 times greater than pure toluene.

PRC Environmental Management (1992) has presented a derivation of chronic reference dose values for diesel fuel, following the same procedure as used by EPA for deriving reference doses. Using experimental data on rats that had been reported in the literature, they have derived an RfD for the oral ingestion of coal-derived fuel oil. The oral RfD given was $7 \times 10^{-2} \mathrm{mg} / \mathrm{kg}$-day. The observed toxic effect was an increased liver weight. The coal-derived fuel oil used in the experiments contained a 
higher percentage of aromatics than would virgin diesel fuel or the site-specific weathered fuel oil, and therefore this value is conservative.

On the basis of these values, an oral reference dose of $8 \times 10^{-2}$ was used for TPH at sites with JP-4 spills (ST10/SS14, ST13/DP26, and ST19) and an oral reference dose of $8 \times 10-3$ was used at sites with diesel spills (ST11 and ST18).

An inhalation toxicity value was not determined. The low concentration of TPH in groundwater and the depths to TPH in subsurface soils, 5 to 15 feet below the ground surface, limit the effectiveness of exposure pathways.

\subsubsection{Lead}

Lead is present as a contaminant at several of the Operable Unit 2 sites. Its chemical form (inorganic or organic) and oxidation state is unknown, all of which affect its toxicity. IRIS has an oral RfD value for tetraethyl lead of $1 \times 10^{-7} \mathrm{mg} / \mathrm{kg}$-day. There are no toxicity data for lead (inorganic) in either IRIS or HEAST. An oral reference dose of $3 \times 10^{-4} \mathrm{mg} / \mathrm{kg}$-day is defensible from the current toxicological literature (Personal Communication M.F. Jarvis and T.T. Jarvis, March 23, 1993).

Both IRIS and HEAST defer to the Clean Air Act's National Ambient Air Quality Standard (primary standard) for lead and lead compounds of 1.5 microgram per cubic meter of air (EPA 1991c). This value can be converted to an inhalation reference dose of $4.3 \times 10^{-4} \mathrm{mg} / \mathrm{kg}$-day by assuming an inhalation rate of $20 \mathrm{~m}^{3}$ per day and a body weight of $70 \mathrm{~kg}$.

The uncertainty sections for the Operable Unit 2 sites (Tables 2.9, 3.8, 4.8, 5.8, and 6.8) present an order of magnitude estimate of the increase in total pathway Hazard Indexes that would result with the inclusion of these RfDs.

\subsection{TOXICITY INFORMATION FOR CARCINOGENIC EFFECTS}

\subsubsection{Polycyclic Aromatic Hydrocarbons}

Benzo(a)pyrene is the only polycyclic aromatic hydrocarbon (PAH) with a toxicity value in IRIS (EPA 1992b). There are three ways to address the lack of toxicity data for the other PAHs: 1) assign no toxicity values to them; 2) assign them the toxicity of benzo(a)pyrene; and 3) assign weighted toxicity values based upon their toxicity relative to benzo(a)pyrene. The third option has been followed in this assessment. Clement Associates (1988) calculated relative potency factors of PAHs based on the toxicity of benzo(a)pyrene (Table 9.2). The toxicity values for the PAHs in Table 9.1 are the products of these factors and the toxicity of benzo(a)pyrene.

It is recognized that the values calculate herein are not as conservative as those listed in the EPA Region X guidance (EPA 1991) for risk-based screening concentration levels. The PAH concentrations in the EPA guidance were calculated with the assumption that all PAHs had toxicity equivalent to benzo(a)pyrene. In order to maintain consistency and conservatism, the contaminant of concern screening for this risk assessment (Section 7.0) used the more conservative EPA risk-based cutoff concentrations. 
IABLE 9.1 Toxicity Data

\begin{tabular}{|c|c|c|c|c|c|c|c|c|c|}
\hline \multirow[b]{2}{*}{ ANALYTE } & \multicolumn{4}{|c|}{$\begin{array}{l}\text { CANCER POTENTCY FACTOR } \\
(\mathrm{mg} / \mathrm{kg} \cdot \mathrm{d})-1\end{array}$} & \multicolumn{3}{|c|}{$\begin{array}{c}\text { RID } \\
\text { (mg/kg.d) }\end{array}$} & \multirow[b]{2}{*}{ Inhalation } & \multirow[b]{2}{*}{ Reference } \\
\hline & CAS & Oral & Reference & Inhalation & Reference & Oral & Reference & & \\
\hline VOLATILES & & & & & & & & & \\
\hline 1,1,1-TRICHLOROETHANE & 71556 & $5.73 E-02$ & 5 & & & $9.00 \mathrm{E}-02$ & 11 & & \\
\hline 1,1,2,2-TETRACHLOROETHANE & 79345 & 2.00E-01 & 11 & 2.00E-01 & 11 & $3.00 E-02$ & 11 & & \\
\hline 1,1,2-TRICHLOROETHANE & 79005 & 5.73E-02 & 11 & $5.73 E-02$ & 11 & 4.00E-03 & 11 & & \\
\hline 1,1-DICHLOROETHANE & 75343 & & & & & $1.00 E-01$ & 10 & $1.00 \mathrm{E}-01$ & 10 \\
\hline 1,1-DICHLOROETHENE & 75354 & $6.00 E-01$ & 11 & $1.80 \mathrm{E}-01$ & 11 & $9.00 \mathrm{E}-03$ & 11 & & \\
\hline 1,2-DICHLOROETHANE & 107062 & $9.10 E-02$ & 11 & $9.10 \mathrm{E}-02$ & 11 & $1.00 E-02$ & 11 & & \\
\hline 1,2-DICHLOROETHENE (TOTAL) & 156605 & & & & & $2.00 \mathrm{E}-02$ & 11 & & \\
\hline 1,2-DICHLOROPROPANE & 78875 & $6.80 \mathrm{E}-02$ & 10 & $6.80 \mathrm{E}-02$ & 10 & & & 4.00E-03 & 11 \\
\hline 2-BUTANONE & 78933 & & & & & $9.00 E-02$ & 9 & 2.90E-01 & 11 \\
\hline 2-HEXANONE & 591786 & & & & & & & & \\
\hline 4-METHYL-2-PENTANONE & & & & & & & & & \\
\hline ACETONE & 67641 & & & & & $1.00 E-01$ & 11 & & \\
\hline $\begin{array}{l}\text { BENZENE } \\
\text { BENZYL ALCOHOL }\end{array}$ & 71432 & $2.90 E-02$ & 11 & $2.90 E-02$ & 11 & & & & \\
\hline BROMODICHLOROMETHANE & 75274 & $1.30 E-01$ & 11 & & & $2.00 E-02$ & 11 & & \\
\hline BROMOFORM & 75252 & $7.90 E-03$ & 11 & $3.90 E-03$ & 11 & $2.00 \mathrm{E}-02$ & 11 & & \\
\hline BROMOMETHANE & 74839 & & & & & $1.40 \mathrm{E}-03$ & 11 & $5.00 \mathrm{E}-03$ & 11 \\
\hline CARBON DISULFIDE & 75150 & & & & & $1.00 E-01$ & 11 & $2.80 \mathrm{E}-03$ & 9 \\
\hline CARBON TETRACHLORIDE & 56235 & $1.30 E-01$ & 11 & $5.30 E-02$ & 11 & $7.00 E-04$ & 11 & & \\
\hline CHLOROBENZENE & 108907 & & & & & $2.00 E-02$ & 11 & $5.70 \mathrm{E}-03$ & $\mathbf{9}$ \\
\hline CHLOROETHANE & 75003 & & & & & $1.00 E+01$ & 18 & $1.00 E+01$ & 11 \\
\hline CHLOROFORM & 67663 & $6.10 \mathrm{E}-03$ & 11 & $8.10 E-02$ & 11 & $1.00 E-02$ & 11 & & \\
\hline CHLOROMETHANE & 74873 & $1.30 E-02$ & 9 & $6.30 E-03$ & 9 & $5.40 \mathrm{E}-01$ & 6 & & \\
\hline CIS-1,3-DICHLOROPROPENE & 542756 & $1.80 E-01$ & 10 & $1.30 \mathrm{E}-01$ & 10 & $3.00 E-04$ & 11 & 2.00E-02 & 11 \\
\hline DIBROMOCHLOROMETHANE & 124481 & $8.40 E-02$ & 11 & & & $2.00 E-02$ & 11 & & \\
\hline ETHYLBENZENE & 100414 & & & & & $1.00 E-01$ & 11 & 2.86E-01 & 11 \\
\hline METHYLENE CHLORIDE & 75092 & $7.50 E-03$ & 11 & $1.60 E-03$ & 11 & $6.00 E-02$ & 11 & & \\
\hline STYRENE & 100425 & $3.00 E-02$ & 9 & $2.00 E-03$ & 9 & $2.00 E-01$ & 11 & 2.40E-01 & 11 \\
\hline TETRACHLOROETHENE & 127184 & $5.10 E-02$ & 4 & $1.80 E-03$ & 9 & $1.00 E-02$ & 11 & & \\
\hline TOLUENE & 108883 & & & & & $2.00 E-01$ & 11 & $5.70 \mathrm{E}-01$ & 11 \\
\hline TRANS-1,3-DICHLOROPROPENE & 10061026 & & & & & $3.00 E-04$ & 8 & & \\
\hline TRICHLOROETHENE & 79016 & $1.10 E-02$ & 14 & $1.70 E-02$ & 9 & & & & \\
\hline VINYL ACETATE & 108054 & & & & & & & $2.00 \mathrm{E}-01$ & 11 \\
\hline VINYL CHLORIDE & 75014 & $1.90 E+00$ & 10 & $2.90 E-01$ & $\mathbf{9}$ & & & & \\
\hline XYLENES (TOTAL) & 1330207 & & & & & $2.00 \mathrm{E}+00$ & 11 & $8.60 \mathrm{E}-02$ & 9 \\
\hline SEMI-VOLATILES & & & & & & & & & \\
\hline 1,2,4-TRICHLOROBENZENE & 120821 & & & & & $1.00 \mathrm{E}-02$ & 11 & & \\
\hline 1,2-DICHLOROBENZENE & 95501 & & & & & $9.00 E-02$ & 11 & $4.00 E-02$ & 9 \\
\hline 1,2-DIPHENYLHYDRAZINE & 122667 & $8.00 \mathrm{E}-01$ & 11 & $8.00 E-01$ & 11 & & & & \\
\hline
\end{tabular}


IABLE 91 Toxicity Data

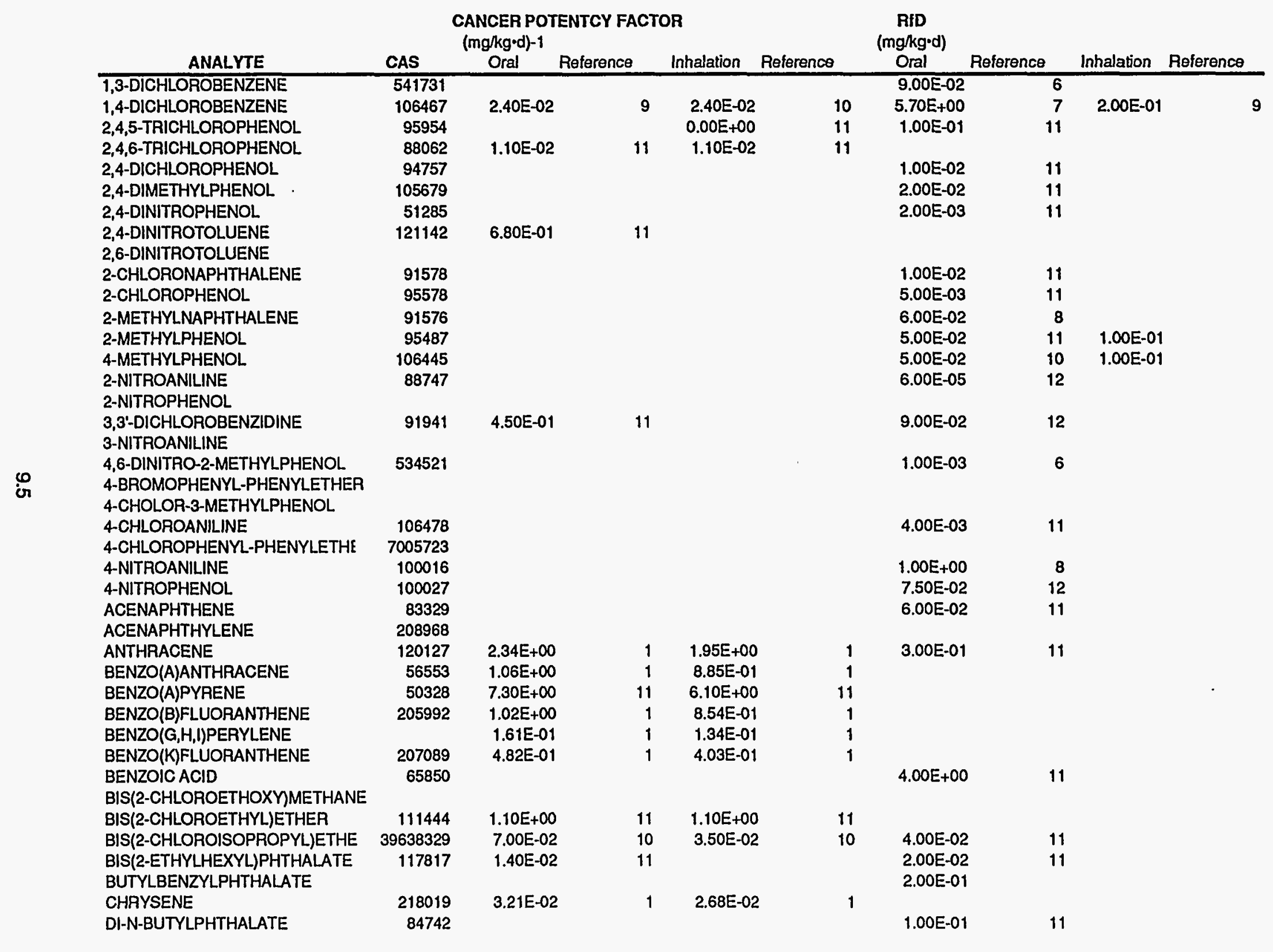


IABLE 9.1. Toxicity Data

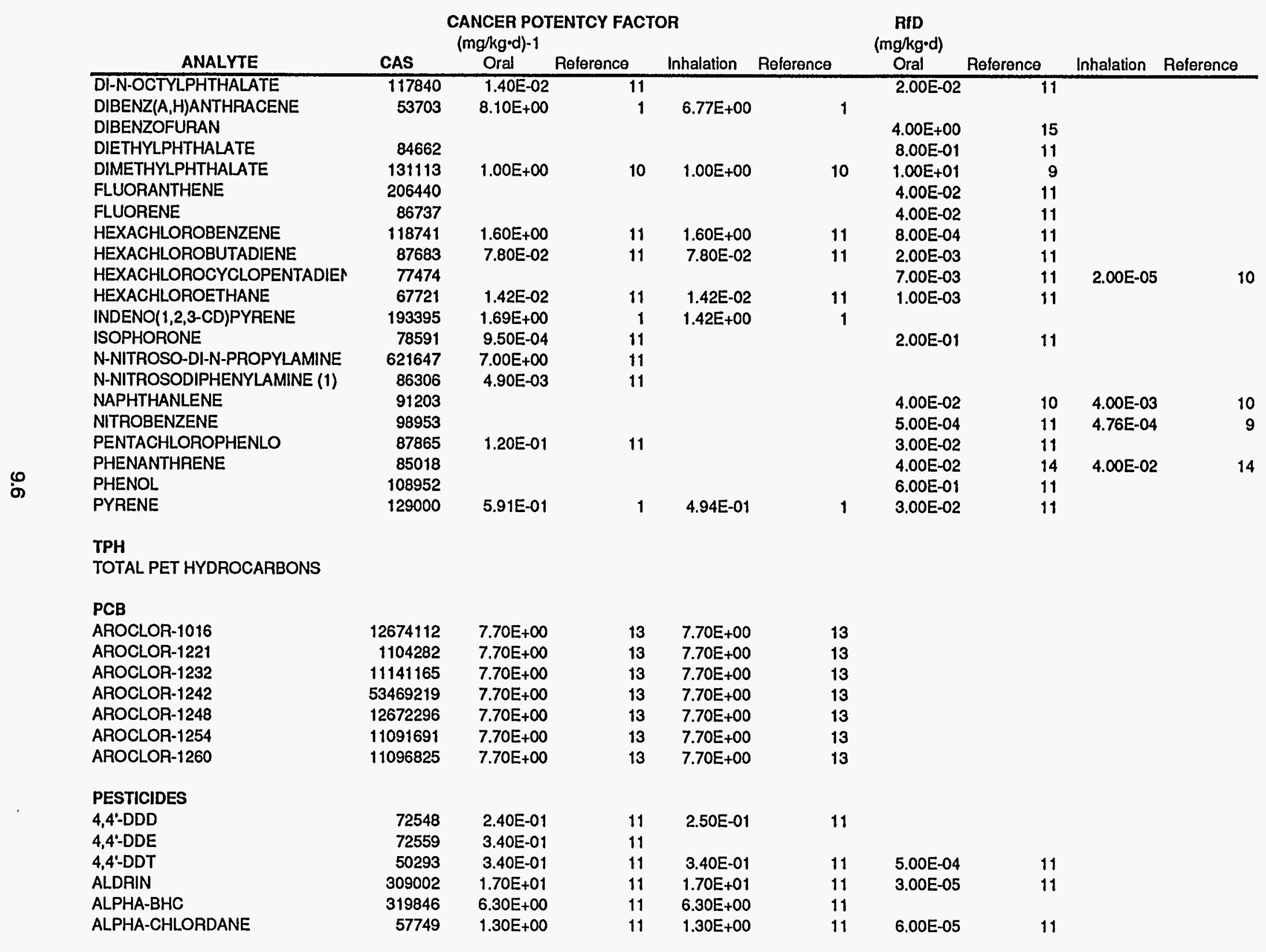


IABLE 9.1, Toxicity Data

\begin{tabular}{|c|c|c|c|c|c|c|c|c|c|}
\hline ANALYTE & CAS & $\begin{array}{l}\text { NCER POTE } \\
\text { ng/kg.d)-1 } \\
\text { Oral }\end{array}$ & $\begin{array}{l}\text { ENTCY FACT } \\
\text { Reference }\end{array}$ & Inhalation & Reference & $\begin{array}{c}\text { RID } \\
\text { (mg/kg·d) } \\
\text { Oral }\end{array}$ & Reference & Inhalation & Reference \\
\hline BETA-BHC & 319857 & $1.80 \mathrm{E}+00$ & 11 & $1.80 E+00$ & 11 & $3.00 E-04$ & 9 & & \\
\hline DELTA-BHC & 319868 & & & & & 2.00E-03 & 8 & & \\
\hline DIELDRIN & 60571 & $1.60 E+01$ & 11 & $1.60 E+01$ & 11 & $5.00 E-05$ & 11 & & \\
\hline $\begin{array}{l}\text { ENDOSULFAN I } \\
\text { ENDOSULFAN II }\end{array}$ & & & & & & $5.00 E-05$ & 11 & & \\
\hline $\begin{array}{l}\text { ENDOSULFAN II } \\
\text { ENDOSULFAN SULFATE }\end{array}$ & & & & & & & & & \\
\hline $\begin{array}{l}\text { ENDRIN } \\
\text { ENDRIN KETONE }\end{array}$ & 72208 & & & & & $3.00 \mathrm{E}-04$ & 11 & & \\
\hline GAMMA-BHC (LINDANE) & & & & & & $3.00 E-04$ & 11 & & \\
\hline GAMMA-CHLORDANE & $\begin{array}{l}58899 \\
57749\end{array}$ & $1.30 E+\infty$ & 9 & & & $3.00 E-04$ & 11 & & \\
\hline HEPTACHLOR & $\begin{array}{l}57749 \\
76448\end{array}$ & $1.30 E+\infty$ & 11 & $1.30 E+00$ & 11 & $6.00 \mathrm{E}-05$ & 11 & & \\
\hline HEPTACHLOR EPOXIDE & $\begin{array}{r}76448 \\
1024573\end{array}$ & $4.50 E+\infty 0$ & 11 & $4.50 \mathrm{E}+00$ & 11 & $5.00 E-04$ & 11 & & \\
\hline METHOXYCHLOR & $\begin{array}{r}1024573 \\
72435\end{array}$ & $9.10 E+\infty 0$ & 11 & $9.10 E+00$ & 11 & $1.00 E-05$ & 11 & & \\
\hline TOXAPHENE & $\begin{array}{r}72435 \\
8001352\end{array}$ & & & & & $5.00 E-03$ & 11 & & \\
\hline METALS & & $1.10 E+00$ & 11 & $1.10 \mathrm{E}+00$ & 11 & & & & \\
\hline ALUMINUM & & & & $3.00 E-04$ & & & & & \\
\hline ANTIMONY & 7429905 & & & & & & & & \\
\hline ARSENIC & 7440360 & & & & & $4.00 E-04$ & 11 & & \\
\hline BARIUM & $\begin{array}{l}7440382 \\
7440393\end{array}$ & $1.75 E+\infty$ & 10 & $1.20 E+01$ & 11 & $3.00 E-04$ & 11 & & \\
\hline BERYYLIUM & 7440393 & & & & & $7.00 \mathrm{E}-02$ & 11 & $1.00 E-04$ & \\
\hline CADMIUM & 7440417 & $4.30 E+\infty 0$ & 11 & $8.40 E+00$ & 11 & $5.00 E-03$ & 11 & & \\
\hline CALCIUM & 7440439 & & & $6.10 E+00$ & 11 & $5.00 E-04$ & 11 & & \\
\hline CHROMIUM VI & 7440473 & & & & & $1.00 E+00$ & 11 & $5.70 \mathrm{E}-07$ & \\
\hline COBALT & 7440484 & & & & & $1.00 E+00$ & 11 & $0 . / U E-0 /$ & 1 \\
\hline COPPER & 7440508 & & & & & $3.70 \mathrm{E}-02$ & 9 & $1.00 E-02$ & \\
\hline IRON & 15438310 & & & & & & & & \\
\hline LEAD & 7439921 & & & & & & & & \\
\hline MAGNESIUM & 7786303 & & & & & & & & \\
\hline MANGANESE & 7439965 & & & & & $1.40 E-03$ & $11 a$ & 1.10E-04 & 1 \\
\hline MERCURY & 7439976 & & & & & $2.00 E-02$ & 11 & & \\
\hline NICKEL & 7440020 & & & $8.40 E-01$ & 11 & $2.00 E-02$ & 11 & & \\
\hline POTASSIUMION & 7447407 & & & & & & & & \\
\hline SELENIUM & 7782492 & & & & & $5.00 E-03$ & 11 & $1.00 E-03$ & 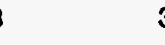 \\
\hline SILVER & 7440224 & & & & & $8.00 E-03$ & 11 & & \\
\hline SODIUM & 7647145 & & & & & $3.00 E+02$ & & & \\
\hline THALLIUM & 7440280 & & & & & $8.00 E-05$ & 11 & & \\
\hline VANADIUM & 7440622 & & & & & $9.00 E-03$ & 11 & & \\
\hline ZINC COMPOUNDS & 7646857 & & & & & $2.00 E-01$ & 11 & & \\
\hline
\end{tabular}


\#\#\#1

Clement Associates. 1988.

Comparative Potency Approach for Estimating the Cancer Risk Associated with Exposure to Mixtures of Polycyclic Aromatic Hydrocarbons. Interim Final Report, Fairfax, Virginia.

\#\#2

EPA (1984a)

U.S. Environmental Protection Agency (EPA). 1984n. Health Effects Assessment for Copper. EPA540/1-86-025, Environmental Criteria and Assessment Office, Clncinnati, Ohio.

\#\#\#3

EPA (1984b)

U.S. Environmental Protection Agency (EPA). 1984an. Health Effects Assessment for Selenium and Compounds. EPA/540/1-86-058, Environmental Criteria and Assessment Office, Cincinnati, Ohio.

\section{\#\#\#}

EPA (1984c)

U.S. Environmental Protection Agency (EPA). 1984aq. Health Effects Assessment for Tetrachloroethylene. EPA/540/1-86-009,

Environmental Criterla and Assessment Office, Cincinnati, Ohio.

\#\#\#

EPA (1984d)

U.S. Environmental Protection Agency (EPA). 1984as. Health Effects Assessment for 1,1,1-Trichloroethane. EPA/540/1-86-005,

Environmental Criteria and Assessment Office, Cincinnati, Ohio.

\#\# 6

EPA (19840)

U.S. Environmental Protection Agency (EPA). 1984az. Summary of Current Acceptable Daily Intakes (ADIS) for Oral Exposure.

Environmental Criteria and Assessment Office, Cincinnati, Ohio. Data provided by S. Sager of ICF-Clement Associates, Inc., in mem

\#\#\# 7

EPA (1985)

U.S. Environmental Protection Agency (EPA). 1985c. "National Primary Drinking Water Regulations; Synthetic Organic Chemicals, Inorganic Chemicals, and Microorganisms; Proposed Rule." Fed. Reg. 50:46936-47025. 


\section{TABLE 9.1. Toxicity Data}

\#\#8

EPA (1986)

U.S. Environmental Protection Agency (EPA). 1986b. Verified Reference Doses (RFDs) of the USEPA. ECAO-CIN-475, Office of Health and Environmental Assessment, Washington, D.C.

\section{\#\#\#}

EPA (1991)

U.S. Environmental Protection Agency (EPA). 1991. Health Effects Assessment Summary Tables.

\section{\#\#\#10}

EPA (1992)

U.S. Environmental Protection Agency (EPA). 1992. Health Effects Assessment Summary Tables. NTIG/PB92-921199. D Swer, Washington, D.C.

\section{\#\#11}

EPA (1992b)

IRIS Update, October 31, 1992 (table of slope factors and RfD's)

(1) \#\#11a

EPA (1993)

IRIS Update, August 5, 1993

Note: Value of 5.00E-03 was used for water ingestion RfD. The more conservative value in table is for soil ingestion.

\section{\#\#\#12}

Saleo (1984)

Salee, M. A. 1984. Revised Health and Environmental Effects Data for Appendix VII Constituents. Memo to Kenneth A. Shuster, Chief, Land Disposal Branch, U.S. Environmental Protection Agency. October 24, 1984. Data provided by S.Sager, ICF-Clement Assoc

\section{\#\#\#13}

Cancer Potency Factors set equal to values for PCBs, general

\section{\#\#14}

Reference Values set equal to values for fluoranthene

\section{\#\#\#15}

Reference Values set equal to values for benzoic acid 


\begin{tabular}{|c|c|}
\hline \multicolumn{2}{|c|}{$\begin{array}{l}\text { IABLE 9.2. Relative Cancer Potency Estimates for Polycyclic } \\
\text { Aromatic Hydrocarbons, from Clement Associates (1988) }\end{array}$} \\
\hline PAH & TRelative Potency Estimate \\
\hline Anthracene & 0.32 \\
\hline Benzo(a)pyrene & 1.0 \\
\hline Benzo(e)pyrene & 0.004 \\
\hline Benz(a)anthracene & 0.145 \\
\hline Benzo(b)fluoranthene & 0.14 \\
\hline Benzo(j)fluoranthene & 0.061 \\
\hline Benzo(k)fluoranthene & 0.066 \\
\hline Benzo(ghi)perylene & 0.022 \\
\hline Chrysene & 0.0044 \\
\hline Cyclopentadieno(dc)pyrene & 0.023 \\
\hline Dibenz(ah)anthracene & 1.11 \\
\hline Indeno(1,2,3-cd)pyrene & 0.232 \\
\hline Pyrene & 0.081 \\
\hline
\end{tabular}




\subsection{UNCERTAINTIES}

The Baseline Risk Assessments presented here are for the "No Action" alternative. The risks predicted are estimates only, based on currently accepted EPA methodologies. Certain assumptions have been made to present a quantifiable characterization of risk. The assumptions are specified throughout the document in the applicable text and tables.

Health risk assessment methodology has uncertainty associated with how accurately the calculated risk estimates represent the actual risk. The assumptions and the uncertainty factors may cause the actual risk to be over-estimated. Sometimes their effect on the representation of the "true" risk is not known. Usually, the effect is difficult to quantify numerically (e.g., in terms of an error bar). As a result, the effect is discussed herein qualitatively.

Some of the assumptions and uncertainty factors associated with the Baseline Risk Assessment specifically, and the health risk assessment process generally (and their likely effect on a representative risk estimate), include

- Use of the aquifer for lifetime of exposure as the sole source of domestic supply. (May over-estimate risk.)

- The contaminant concentrations in tap water are assumed to be the concentrations in the groundwater (no reduction factors for escape of volatiles are taken into account). (May over-estimate risk.)

- $\quad$ This assessment used EPA Region $X$ default exposure parameters for most calculations. Some of this parameters are not realistic for a sub-arctic climate. (May over-estimate risk.)

- The risks quantified (based on EPA cancer potency factors (CPFs) or $\mathrm{q}^{*}$ are statistically at the $95 \%$ upperbound estimate of the risk using a linear, low-dose extrapolation. (May over-estimate risk.)

- The toxicity of TPH and lead is inconclusive. Neither were included in the primary calculations in this assessment. (May under-estimate risk.)

- $\quad$ Existing concentrations are assumed to be the concentrations or exposure source terms in the future. No reduction from natural degradation and attenuation over time is taken into account except where fate and transport modeling has been performed (ST19). No increase due to additional contamination is assumed (except where fate and transport modeling was performed) nor are potential degradation products of existing organic contaminants accounted for. (May over-estimate or under-estimate risk.)

- The groundwater detection limits for some organic and inorganic contaminants, especially PAHs, are higher than risk-based screen concentrations. (May underestimate risk.)

- Most sampling at the Operable Unit 2 sites were conducted during the late summer. Seasonal changes may impact soils and groundwater contamination. (May over-estimate or under-estimate risk.) 
- $\quad$ Surface soil samples were composited from three to five locations. They may have missed hot spots of surface contamination. (May under-estimate risk.)

- $\quad$ Primary risk calculations were based on data collected during the 1991 field season. This data set presents only a brief snapshot of site contamination. (May over-estimate or under-estimate risk.)

- Historical data (1986 to 1989) was used in some of the risk calculations and fate and transport modeling. This data may not have as high a Quality Assurance as the 1991 and 1992 data. (May over-estimate or under-estimate risk.) 


\subsection{POTENTIAL ECOLOGICAL RISK}

This assessment primarily addresses the risks that the Operable Unit 2 sites present to human health. An ecological risk assessment is presently under way as part of the Eielson AFB sitewide study. A draft version of this assessment will be available in fourth quarter 1993. This section of the report, nevertheless, will address briefly address ecological impacts primarily in regards to the two surface water bodies adjacent to Operable Unit 2 sites: Hardfill Lake at ST10/SS14 and Garrison Slough at ST11.

The highest concentrations of several metals in soils or sediments occur in the sediments at the bottom of Hardfill Lake (Table 11.1). These metals include: antimony, arsenic, iron, manganese, and vanadium. Appendix E of this assessment presents evidence that their elevated concentrations may be the result of the natural redox (oxidation-reduction) state of the groundwaters at Eielson. The waters may be oxidized when they migrate to the surface and come in contact with the atmosphere. When iron oxidizes it forms amorphous hydroxides that settle out of the water column into the underlying sediments. Other metals in the water strongly adsorb onto the these hydroxides and also are deposited into the lake sediments. The low concentrations of these metals in the waters at Hardfill lake in contrast to their elevated concentrations in the adjacent, upgradient groundwater at ST10/SS14 support this contention (Table 11.2).

\begin{tabular}{|c|c|c|c|c|c|c|}
\hline SAMPLE ID & ANTIMONY & ARSENIC & BARIUM & $\overline{\mathrm{IRON}}$ & MANGANESE & VANADIUM \\
\hline S10SD01-21.5 & $8.2 \mathrm{~B}$ & 31 & 663 & 36500 & 739 & 75 \\
\hline S10SD02-10.0 & $9.3 \mathrm{~B}$ & $\overline{45}$ & 250 & 40800 & 2350 & 59 \\
\hline S10SD03-15.0 & $6.2 \mathrm{U}$ & 67 & 189 & 39400 & 807 & 48 \\
\hline
\end{tabular}

The sediments and waters of Garrison Slough were analyzed for contaminants in 1992 (U.S. Air Force 1992). Low levels of arsenic and barium were detected in the soils adjacent to the slough at six of the seven sampling sites, which includes one adjacent to ST11.

DDT is present in the surface soils of ST10, ST11, and ST13. The probable source is pesticide spraying atop surface water bodies and along roadways. The ecological risk will be evaluated in the sitewide risk assessment. 


\begin{tabular}{|c|c|}
\hline \multicolumn{2}{|c|}{$\begin{array}{c}\text { TABLE 11.2 Arsenic Surface Water } \\
\text { and Groundwater Concentrations } \\
\text { from ST10/SS14 } \\
\text { (SW is surface water; } \\
\text { GW is groundwater) }\end{array}$} \\
\hline Sample ID & $\begin{array}{l}\text { Arsenic } \\
(\mu g / L)\end{array}$ \\
\hline SW10SW01-0.0 & $4.0 \mathrm{~B}$ \\
\hline S10SW01-12.0 & $4.3 \mathrm{~B}$ \\
\hline SW10SW02-0.0 & $4.8 \mathrm{~B}$ \\
\hline S10SW02-14.0 & $8.9 \mathrm{~B}$ \\
\hline SW10SW03-0.0 & $4.4 \mathrm{~B}$ \\
\hline SW10SW03-8.0 & $3.8 \mathrm{~B}$ \\
\hline GW-10MW01 & 28.0 \\
\hline GW-10MW02A & 37.3 \\
\hline GW-10MW03 & 38.8 \\
\hline GW-10MW04 & 32.8 \\
\hline GW-10MW05 & 22.5 \\
\hline GW-10MW06 & 11.4 \\
\hline GW-10MW08 & 18.4 \\
\hline GW-10MW08I & 14.0 \\
\hline GW-10MW09 & 28.0 \\
\hline GW-10MW10 & $10 \mathrm{U}$ \\
\hline GW-10MW11 & 22.0 \\
\hline
\end{tabular}




\subsection{REFERENCES}

Andelman. J.B. 1990. Total Exposure to Volatile Organic Chemicals in Potable Water. N.M. Ram, R.F. Christman, K.P. Cantor (eds.). Lewis Publishers.

Battelle. 1991. Remedial Investigation/Feasibility Study -- Operable Unit 2 Management Plan, Eielson Air Force Base, Alaska. Prepared by Battelle, Environmental Management Operations, Richland, Washington. (Final).

Battelle. 1992a. Field Sampling Plan, Eielson Air Force Base, Remedial Investigation/Feasibility Study. Prepared by Battelle, Environmental Management Operations, Richland, Washington.

Battelle. 1992b. Remedial Investigation/Feasibility Study -- Operable Units 3, 4, and 5 Management Plan. Ejelson Air Force Base, Alaska. Prepared by Battelle, Environmental Management Operations, Richland, Washington. (Final).

CH2M Hill. 1982. Installation Restoration Program Records Search for Eielson Air Force Base, Alaska. $\mathrm{CH} 2 \mathrm{M}$ Hill, Gainesville, Florida.

Clement Associates. 1988. Comparative Potency Approach for Estimating the Cancer Risk Associated with Exposure to Mixtures of Polycyclic Aromatic Hydrocarbons. Interim Final Report, Clement Associates, Fairfax, Virginia.

Droppo, J. G., D. L. Strenge, J. W. Buck, B. L. Hoopes, R. D. Brockhaus, M. B. Walter, and G. Whelan. 1989. Multimedia Environmental Pollutant Assessment System (MEPAS) Application Guidance: Volume 2 -- Guidelines for Evaluating MEPAS Input Parameters. PNL-7216. Pacific Northwest Laboratory, Richland, Washington.

Eielson Air Force Base. 1992. Eielson Air Force Base Comprehensive Landuse Plan. Eielson Air Force Base, Fairbanks, Alaska.

EPA. 1985. Water Quality Assessment: A Screening Procedure for Toxic and Conventional Pollutants in Surface and Groundwater -- Part II (Revised 1985). EPA/600/6-85/002b. U.S. Environmental Protection Agency, Environmental Research Laboratory, Athens, Georgia.

EPA. 1989a. Risk Assessment Guidance for Superfund: Human Health Evaluation Manual Part A. U.S. Environmental Protection Agency, Office of Solid Waste and Emergency Response. (Interim Final).

EPA. 1989b. "Interim Guidance on Establishing Soil Lead Cleanup levels at Superfund Sites." OSWER Directive 9355.4-02, U.S. Environmental Protection Agency. September 7, 1989.

EPA. 1991a. "Supplemental Guidance for Superfund Risk Assessments in Region 10." U.S. Environmental Protection Agency, Seattle, Washington.

EPA. 1991b. Risk Assessment Guidance for Superfund: Volume 1 - Human Health Evaluation Manual (Part B. Development of Risk-Based Preliminary Remediation Goals). 
U.S. Environmental Protection Agency, Office of Emergency and Remedial Response. (Interim Final).

EPA. 1991c. National Primary and Secondary Ambient Air Quality Standards: Subchapter C-Air Programs. Part 50-CFR 50:693-697. U.S. Environmental Protection Agency, Revised July 1, 1991.

EPA. 1991d. Health Effects Assessment Summary Tables. PB91-921199, U.S. Environmental Protection Agency, National Technical Information Service, Springfield, Virginia.

EPA. 1991e. "Human Health Evaluation Manual, Supplemental Guidance: Standard Default Exposure Factors." OSWER Directive 9285.6-03, U.S. Environmental Protection Agency, Office of Solid Waste and Emergency Response.

EPA. 1991f. US. Environmental Protection Agency Contract Laboratery Program National Functional Guidelines for Organic Data Review. Multi-Media. Multi-Contamination. OLMO1.1 and Low Concentration Water OLCOL.l. U.S. Environmental Protection Agency, Revised June 1991.

EPA. 1992a. Dermal Exposure Assessment: Principles and Applications. U.S. Environmental Protection Agency, Office of Research and Development. (Interim Report).

EPA. 1992b. Integrated Bisk Information System (IRIS) (Online). U.S. Environmental Protection Agency, Office of Health and Environmental Assessment, Environmental Criteria and Assessment Office, U.S. Environmental Protection Agency, Cincinnati, Ohio.

EPA. 1992c. "Toxicity of Fuels." Memorandum from Carol Sweeney. U.S. Environmental Protection Agency, Health and Environmental Assessment Section. April 9, 1992.

EPA. 1992d. "Drinking Water Regulations and Health Advisories." U.S. Environmental Protection Agency, Office of Drinking Water. April 1992.

EPA. 1993. Intearated Bisk Information System (IRIS) (Online). U.S. Environmental Protection Agency, Office of Health and Environmental Assessment, Environmental Criteria and Assessment Office, U.S. Environmental Protection Agency, Cincinnati, Ohio.

Gelhar, L.W., A. Mantoglou, C. Welty, and K.R. Rehfeldt. 1985. A Review of Field Scale Subsurface Solute Transport Processes under Saturated and Unsaturated Conditions. Electric Power Research Institute, Palo Alto, Califomia.

HLA. 1991. Installation Restoration Program Remedial Investigation/Feasibility Study Stage 4. Draft Remedial Investigation/Feasibility Study. Prepared by Harding Lawson Associates.

Hwang , S.T., and J.W. Falco. 1986. "Estimation of Multimedia Exposures Related to Hazardous Waste Facilities." In Pollutants in a Multimedia Environment, pp. 229-264. Plenum Publishing Corporation, New York. 
Layton, D. W., B. J. Mallon, D. H. Rosenblatt, and M. J. Small. 1987. "Deriving Allowable Daily Intakes for System Toxicants Lacking Chronic Toxicity Data." Regulatory Toxicology and Pharmacology 7(1):96-112.

Little, A. D., Inc. 1987. The Installation Bestoration Program Toxicology Guide. Harry G. Armstrong Aerospace Medical Research Laboratory, Wright-Patterson Air Force Base, Ohio, v.3.

Millner, G.C., R.C. James, and A.C. Nye. 1992. "Human Health-Based Soil Cleanup Guidelines for Diesel Fuel No. 2." Joumal of Soil Contamination, v.1, p. 103-157.

Neff, J.M. 1979. Polycyclic Aromatic Hydrocarbons in the Aquatic Environment Applied Science Publishers, London.

PRC Environmental Management. 1992. Underground Storage Tank Characterization at the U.S. Army Resene Center Site. Fort Shafter Falts. Hawaii. Preliminary Risk Assessment, Volume II of III. U.S. Army Corps of Engineers.

SAIC. 1988. Draft Informal Sampling and Analysis Plan for Completing Remedial Investigation and Feasibility Study Activities. Prepared by Science Applications Intemational Corporation (Draft).

SAIC. 1989. U.S. Air Force Installation Restoration Program Remedial Investigation/Feasibility Study of the Fuel Saturated Area at Eielson Air Force Base. Alaska: Draft Remedial Investigation Report. Volumes I, II, III Prepared by Science Applications International Corporation (Draft).

Strenge, D.L., and S.R. Peterson. 1989. Chemical Data Bases for the Multimedia Environmental Pollutant Assessment System (MEPAS): Version 1. PNL-7145, Pacific Northwest Laboratory, Richland, Washington.

U.S. Air Force. 1992. "Summary of Garrison Slough Results (July 1992)." Letter report of Major R.L. Gross, Bioenvironmental Engineering Services.

U.S. Air Force. 1993a. Background Soil Quality. Eielson Air Force Base. Alaska. Prepared by Battelle Environmental Management Operations, Richland, Washington (Final):

U.S. Air Force. 1993b. Backoround Groundwater Quality. Eielson Air Force Base. Alaska. Prepared by Battelle Environmental Management Operations, Richland, Washington (Final).

U.S. Air Force. 1993c. Eielson Air Force Base OU-2 Remedial Investigation/Feasibility Study: Remedial Investigation Report. Prepared by Battelle, Environmental Management Operations, Richland, Washington (Final).

U.S. Air Force. 1993d. Eielson Air Force Base QU-2 Remedial Investigation/Feasibility Study: Remedial Investigation Appendixes. Prepared by Battelle, Environmental Management Operations, Richland, Washington (Final). 
Whelan, G., D. L. Strenge, J. G. Droppo, Jr., B. L. Steelman, and J. W. Buck. 1987. The Bemedial Action Priority System (RAPS): Mathematical Formulations. DOE/RL/87-09. PNL-6200. Pacific Northwest Laboratory, Richland, Washington. 


\title{
Eielson Air Force Base
}

\section{Baseline Risk Assessment}

\author{
Appendix A \\ Risk And Exposure Calculations
}




\section{APPENDIX A--RISK AND EXPOSURE CALCULATIONS}

\section{A.1 RISK AND HAZARD QUOTIENT DEFINED}

The general form of the risk equation for carcinogens is:

risk $_{\mathrm{ij}}$ (unitless) $=\mathrm{CPF}_{\mathrm{ij}}(\mathrm{mg} / \mathrm{kg} \text {-day })^{-1} \times$ exposure $_{\mathrm{ij}}(\mathrm{mg} / \mathrm{kg}$-day)

where risk ${ }_{i j}$ is the upper-bound lifetime excess probability of cancer caused by exposure to contaminant $i$ in exposure route $j, C_{i j}$ is the cancer potency factor or "slope factor," for contaminant $i$ and exposure route $j$, and exposure ${ }_{i j}$ denotes the daily intake rate of contaminant i from exposure route j estimated using site-specific or EPA-recommended default exposure assumptions.

The general form of the risk equation for noncarcinogens is:

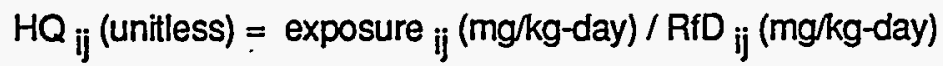

where $H Q_{\mathrm{jj}}$ is a hazard quotient that compares the relative hazard of exposure to contaminant $i$ in exposure route $j$ to RfD. RfD is an estimate (with uncertainty spanning perhaps an order of magnitude) of the daily exposure to the human population (including sensitive subgroups) likely to be without an appreciable risk of deleterious effects during a portion of their lifetime (EPA 1989). The hazard quotients summed across chemicals are defined as Hazard Index (HI) by EPA.

\section{A.2 EXPOSURE CALCULATIONS}

This appendix lists all equations used to calculate the risk for each type of possible exposure pathway. All equations are based on the following general form for estimating exposure:

Exposure $=$

Conc. in Media of Concern $\times$ Contact Rate $\times$ Exposure Period

Averaging Time $\times$ Body Weight

where Conc. is the concentration of contaminant $i$ in a medium of concern. Contact Rate is daily rate of contact with the contaminated medium, and Body Weight is body weight of the exposed individual.

A.2.1 Sources of Data Input into Calculations. This risk assessment includes all values input to each of these calculations. Table 9.1 lists all of the toxicity data as cancer slope factors and chronic reference doses. Media-specific chemical concentrations are listed in Appendix F (Tables F.1 through F.5). Future exposure scenarios for inhalation of resuspended particulates and volatile substances from soils used the maximum soil contamination concentration, be it surface soil, subsurface soil, or sediment. All exposure factors are cited in the appropriate tables in Appendix B. 
The following specific exposure equations were used in this baseline risk assessment (EPA 1989). Sources for data specific to different calculations are listed in parentheses in the descriptions of the equations below.

\section{A.2.2 Water Ingestion}

Carcinogenic Effects

$$
R i s k=\frac{S F_{o} \times C \times I R \times E F \times E D \times C V}{B W \times A T \times 365^{\text {days } / \text { year }}}
$$

Noncarcinogenic Effects

$$
\text { Risk }=\frac{C \times I R \times E F \times E D \times C V}{B W \times A T \times R f D_{o} \times 365^{d a y s} / \text { year }}
$$

Ingestion rate in liters/day

Where

$$
\begin{aligned}
& S F_{o}=\text { oral cancer slope factor }\left((\mathrm{mg} / \mathrm{kg}-\text { day })^{-1}\right) \\
& R f D_{o}=\text { oral chronic reference dose }(\mathrm{mg} / \mathrm{kg} \text {-day) } \\
& C=\text { chemical concentration in water }(\mu \mathrm{g} / \mathrm{L}) \\
& I R=\text { ingestion rate (Lday) } \\
& E F=\text { exposure frequency (days/year) } \\
& E D=\text { exposure duration (years) } \\
& C V=\text { conversion factor }(\mathrm{mg} / 1000 \mu \mathrm{g}) \\
& B W=\text { body weight }(\mathrm{kg}) \\
& A T=\text { averaging time (years) }
\end{aligned}
$$

\section{A.2.3 Dermal Contact with Water}

Carcinogenic Effects

$$
R i s k=\frac{S F_{o} \times D A_{\text {event }} \times S A \times E F \times E D \times C V}{B W \times A T \times 365^{\text {days }} / \text { year }}
$$

Noncarcinogenic Effects

$$
R i s k=\frac{D A_{\text {event }} \times S A \times E F \times E D \times C V}{B W \times A T \times R f D_{0} \times 365^{\text {days }} / \text { year }}
$$


Where

$S F_{o}=$ oral cancer slope factor ((mg/kg-day $\left.)^{-1}\right)$

$R f D_{o}=$ oral chronic reference dose ( $\mathrm{mg} / \mathrm{kg}$-day)

$D A_{\text {event }}=$ absorbed dose/unit area/event $\left(\mathrm{mg} / \mathrm{cm}^{2}\right.$-day) (Appendixes $\mathrm{I}$ and $\mathrm{J}$ )

$S A=$ skin surface area available for contact $\left(\mathrm{cm}^{2}\right)$

$E F=$ exposure frequency (days/year)

$E D=$ exposure duration (years)

$C V=$ conversion factor $\left(\mathrm{mg} / 10^{3} \mu \mathrm{g} \times \mathrm{L} / 10^{3} \mathrm{~cm}\right)$

$B W=$ body weight $(\mathrm{kg})$

$A T=$ averaging time (years)

\section{A.2.4 Inhalation of Volatiles during Water Use}

Carcinogenic Effects

$$
R i s k=\frac{S F i \times C \times I R \times K \times E F \times E D \times C V}{B W \times A T \times 365^{d a y s} / \text { year }}
$$

Noncarcinogenic Effects

$$
R i s k=\frac{C \times I R \times K \times E F \times E D \times C V}{B W \times A T \times R f D_{i} \times 365^{\text {days }} / \text { year }}
$$

Where

$S F i$ = inhalation cancer slope factor $\left((\mathrm{mg} / \mathrm{kg}-\mathrm{day})^{-1}\right)$

$R f D_{i}=$ inhalation chronic reference dose $(\mathrm{mg} / \mathrm{kg}$-day)

$C=$ chemical concentration in water $(\mu \mathrm{g} / \mathrm{L})$

$I R=$ inhalation rate $\left(\mathrm{m}^{3} /\right.$ day $)$

$K=$ volatilization factor (unitless) 0.0005 (Andelman 1990)

$E F=$ exposure frequency (days/year)

$E D=$ exposure duration (years)

$C V=$ conversion factor $\left(\mathrm{mg} / 1000 \mu \mathrm{g} \times 1000 \mathrm{~L} / \mathrm{m}^{3}\right)$

$B W=$ body weight $(\mathrm{kg})$

$A T=$ averaging time (years)

\section{A.2.5 Ingestion of Fish}

Carcinogenic Effects

$$
R i s k=\frac{S F_{o} \times C \times I t R \times B_{i f} \times E F \times E D \times C V}{B W \times A T \times 365^{\text {days }} / \text { year }}
$$


Noncarcinogenic Effects

$$
R i s k=\frac{C \times I t R \times B_{i f} \times E F \times E D \times C V}{B W \times A T \times R f D_{o} \times 365^{d a y s} / \text { year }}
$$

Where

$$
\left.\left.S F_{o}=\text { oral cancer slope factor ((mg/kg-day }\right)^{-1}\right)
$$

$R f D_{o}=$ oral chronic reference dose (mg/kg-day)

$C=$ chemical concentration in water $(\mu \mathrm{g} / \mathrm{L})$

$I t R=$ fish intake rate ( $\mathrm{g}$-fish/day)

$B_{\text {if }}=$ bioaccumulation factor for finfish (L/kg) (Appendix $\mathrm{H}$ )

$E F=$ exposure frequency (days/year)

$E D=$ exposure duration (years)

$C V=$ conversion factor $\left(\mathrm{mg} / 10^{3} \mu \mathrm{g} \times \mathrm{kg} / 10^{3} \mathrm{~g}\right)$

$B W=$ body weight $(\mathrm{kg})$

$A T=$ averaging time (years)

\section{A.2.6 Ingestion of Solls and Sediments}

Carcinogenic Effects

$$
R i s k=\frac{S F_{o} \times C \times I R \times E F \times E D \times C V}{B W \times A T \times 365^{d a y s} / \text { year }}
$$

Noncarcinogenic Effects

$$
R i s k=\frac{C \times I R \times E F \times E D \times C V}{B W \times A T \times R f D_{0} \times 365^{\text {days } / \text { year }}}
$$

Where

$$
\begin{aligned}
& S F_{o}=\text { oral cancer slope factor }\left((\mathrm{mg} / \mathrm{kg} \text {-day })^{-1}\right) \\
& R f D_{o}=\text { oral chronic reference dose }(\mathrm{mg} / \mathrm{kg} \text {-day) } \\
& C=\text { chemical concentration in soil }(\mu \mathrm{g} / \mathrm{kg}) \\
& I R=\text { intake rate }(\mathrm{mg} / \text { day) } \\
& E F=\text { exposure frequency (days } / \text { year) } \\
& E D=\text { exposure duration (years) } \\
& C V=\text { conversion factor }\left(\mathrm{kg} / 10^{9} \mu \mathrm{g}\right) \\
& B W=\text { body weight (kg) } \\
& A T=\text { averaging time (years) }
\end{aligned}
$$

Note: fraction ingested from contaminated source is assumed to be $100 \%$ in this assessment. 
Future exposure scenarios utilize an age-adjusted ingestion factor (IF) that compensates for the greater rate of soil ingestion for small children. Below is the example for the cancer risk calculation.

$$
\text { Risk }=\frac{S F_{o} \times C \times I F \times E F \times C V}{A T \times 365^{d a y s} / \text { year }}
$$

Where

$$
I F=\frac{I R_{c} \times E D_{c}}{B W_{c}}+\frac{I R_{a} \times E D_{a}}{B W_{a}}
$$

$I R_{C}=$ intake rate (child) (mg/day)

$E D_{c}=$ exposure duration (child) (years)

$B W_{c}=$ body weight (child) $(\mathrm{kg})$

$I R_{a}=$ intake rate (adult) (mg/day)

$E D_{a}=$ exposure duration (adult) (years)

$B W_{a}=$ body weight (adult) $(\mathrm{kg})$

\section{A.2.7 Dermal Contact with Solls and Sediments}

Carcinogenic Effects

$$
R i s k=\frac{S F_{o} \times C \times C R \times S A \times S A F \times E F \times E D \times C V}{B W \times A T \times 365^{d a y s} / \text { year }}
$$

Noncarcinogenic Effects

$$
R i s k=\frac{C \times C R \times S A \times S A F \times E F \times E D \times C V}{B W \times A T \times R f D_{0} \times 365^{d a y s} / \text { year }}
$$

Where

$$
\begin{aligned}
& S F_{o}=\text { oral cancer slope factor }\left((\mathrm{mg} / \mathrm{kg} \text {-day })^{-1}\right) \\
& R f D_{o}=\text { oral chronic reference dose }(\mathrm{mg} / \mathrm{kg} \text {-day) } \\
& C=\text { chemical concentration in soil }(\mu \mathrm{g} / \mathrm{kg}) \\
& C R=\text { contact rate or adherence factor }\left(\mathrm{mg} / \mathrm{cm}^{2}\right) \\
& S A=\text { skin surface area available for contact (cm } 2 / \text { event) } \\
& S A F=\text { skin absorption factor (unitless) (Appendix J) } \\
& E F=\text { exposure frequency (events/year) }
\end{aligned}
$$




$$
\begin{aligned}
& E D=\text { exposure duration (years) } \\
& C V=\text { conversion factor }\left(\mathrm{kg} / 10^{9} \mu \mathrm{g}\right) \\
& B W=\text { body weight }(\mathrm{kg}) \\
& A T=\text { averaging time (years) }
\end{aligned}
$$

Future exposure scenarios utilize an age-adjusted ingestion factor (IF) that compensates for the greater rate of soil dermal contact for small children. The compensation is similar in form to that shown for the soil ingestion equation.

Future exposure scenarios utilize an age-adjusted surface area factor (SUF) that compensates for the greater skin surface area for adults. Below is the example for the cancer risk calculation.

$$
R i s k=\frac{S F_{o} \times C \times S A F \times C R \times C V \times E F \times S U F}{A T \times 365^{\text {days }} / \text { year }}
$$

Where

$$
S U F=\frac{S A_{c} \times E D_{c}}{B W_{c}}+\frac{S A_{a} \times E D_{a}}{B W_{a}}
$$

$S A_{C}=$ skin surface area available for contact (child) ( $\mathrm{cm}^{2} /$ event)

$E D_{C}=$ exposure duration (child) (years)

$B W_{C}=$ body weight (child) $(\mathrm{kg})$

$S A_{a}=$ skin surface area available for contact (adult) (cm²/event)

$E D_{a}=$ exposure duration (adult) (years)

$B W_{a}=$ body weight (adult) $(\mathrm{kg})$

\section{A.2.8 Ingestion of Plants}

Carcinogenic Effects

$$
R i s k=\frac{S F_{o} \times C \times I t R \times B_{v i} \times E F \times E D \times C V}{B W \times A T \times 365^{d a y s} / \text { year }}
$$

Noncarcinogenic Effects

$$
R i s k=\frac{C \times I t R \times B_{v i} \times E F \times E D \times C V}{B W \times A T \times R f D_{o} \times 365^{d a y s} / \text { year }}
$$


Where

$S F_{o}=$ oral cancer slope factor $\left((\mathrm{mg} / \mathrm{kg}-\text { day })^{-1}\right)$

$R f D_{o}=$ oral chronic reference dose (mg/kg-day)

$C=$ chemical concentration in soil $(\mu \mathrm{g} / \mathrm{kg})$

$I t R=$ vegetable intake rate ( $g$-vegetable/day)

$B_{v i}=$ soil-to-edible plant transfer ratio (unitless) (Appendix $\mathrm{H}$ )

$E F=$ exposure frequency (days/year)

$E D=$ exposure duration (years)

$C V=$ conversion factor $\left(\mathrm{g} / 10^{6} \mu \mathrm{g}\right)$

$B W=$ body weight $(\mathrm{kg})$

$A T$ = averaging time (years)

\section{A.2.9 Inhalation of Volatiles from Solls}

Carcinogenic Effects

$$
R i s k=\frac{S F i \times C \times 1 / V F \times I R \times E F \times E D \times C V}{B W \times A T \times 365^{\text {days }} / \text { year }}
$$

Noncarcinogenic Effects

$$
R i s k=\frac{C \times 1 / V F \times I R \times E F \times E D \times C V}{B W \times A T \times R f D_{i} \times 365^{d a y s} / \text { year }}
$$

Where

$S F i=$ inhalation cancer slope factor $\left((\mathrm{mg} / \mathrm{kg}-\mathrm{day})^{-1}\right)$

$R f D_{i}=$ inhalation chronic reference dose ( $\mathrm{mg} / \mathrm{kg}$-day)

$C=$ chemical concentration in soil $(\mu \mathrm{g} / \mathrm{kg})$

$I R=$ inhalation rate $\left(\mathrm{m}^{3} /\right.$ day $)$

$V F=$ soil-to-air volatilization factor $\left(\mathrm{m}^{3} / \mathrm{kg}\right)$ (Appendix M)

$E F=$ exposure frequency (days/year)

$E D=$ exposure duration (years)

$C V=$ conversion factor $(\mathrm{mg} / 1000 \mu \mathrm{g})$

$B W=$ body weight $(\mathrm{kg})$

$A T=$ averaging time (years) 


\section{A.2.10 Inhalation of Resuspended Sediments}

Carcinogenic Effects

$$
R i s k=\frac{S F i \times C \times 1 / P E F^{\times} \times I R \times E F \times E D \times C V}{B W \times A T \times 365^{\text {days }} / \text { year }}
$$

Noncarcinogenic Effects

$$
R i s k=\frac{C \times 1 / P E F \times I R \times E F \times E D \times C V}{B W \times A T \times R f D_{i} \times 365^{\text {days }} / \text { year }}
$$

Where

$$
\begin{aligned}
& S F i=\text { inhalation cancer slope factor }\left((\mathrm{mg} / \mathrm{kg} \text {-day })^{-1}\right) \\
& R f D_{i}=\text { inhalation chronic reference dose }(\mathrm{mg} / \mathrm{kg} \text {-day) } \\
& C=\text { chemical concentration in soil }(\mu \mathrm{g} / \mathrm{kg}) \\
& I R=\text { inhalation rate }\left(\mathrm{m}^{3} /\right. \text { day) } \\
& \left.P E F=\text { particulate emission factor }\left(\mathrm{m}^{3} / \mathrm{kg}\right) \quad \text { (Appendix } \mathrm{M}\right) \\
& E F=\text { exposure frequency (days/year) } \\
& E D=\text { exposure duration (years) } \\
& C V=\text { conversion factor }(\mathrm{mg} / 1000 \mu \mathrm{g}) \\
& B W=\text { body weight }(\mathrm{kg}) \\
& A T=\text { averaging time (years) }
\end{aligned}
$$

Note: this assessment assumes that $100 \%$ of particulates are respirable

\section{A.3 REFERENCES}

Andelman. J.B. 1990. Total Exposure to Volatile Organic Chemicals in Potable Water. N.M. Ram, R.F. Christman, K.P. Cantor (eds.). Lewis Publishers.

EPA. 1989. Risk Assessment Guidance for Superfund: Human Health Evaluation Manual Part A. U.S. Environmental Protection Agency, Office of Solid Waste and Emergency Response. (Interim Final). 


\section{Eielson Air Force Base \\ Baseline Risk Assessment}

Appendix B

Exposure Factors 


\section{APPENDIX B--EXPOSURE FACTORS}

The following tables list the exposure factors that are not chemical-specific, and are not already given in their respective descriptions in Appendix A. The majority of factors listed are from EPA Region $X$ guidance (EPA 1991). Those exposure factors that do not adhere to guidance have footnotes.

The exposure duration for the average exposure scenario for industrial land is 9 years. This assessment assumed that this value should be equivalent to the average residence in a home (EPA 1991).

Exposure duration for soils and sediments, both ingestion and dermal contact, and particulate inhalation do not adhere to guidance. The values were adjusted to compensate for the sub-arctic climate at Eielson. The values used (146 days for industrial and 180 days for residential) were adjusted based on the number of days in Fairbanks without snow cover. The mean number of days without snow cover at Fairbanks is 146 days; 180 days is presented as a reasonable maximum value. These values were initially advanced in Appendix A of the Management Plan for Operable Units 3,4, and 5 of Eielson (Battelle 1992). The effect of adjustment is discussed in the uncertainty sections for each site.

There are no known subsistence or sport fisheries at Eielson Air Force Base, and the exposure factors for the fish ingestion pathway reflect this. The limited size and depth of the surface water bodies (Hardfill Lake and Garrison Slough) should preclude these subgroups in the future.

Demographic information for Eielson Air Force Base is in Appendix L. Based on present land use, the risk assessment for all Operable Unit 2 sites used a current industrial land use exposure scenario. Projected land use for all Operable Unit 2 sites is industrial (U.S. Air Force 1992). Therefore, a future industrial land use exposure scenario was calculated for each site. In addition, a future residential land use exposure scenario was calculated for each site.

\section{REFERENCES}

Battelle. 1992. Remedial Investigation/Feasibility Study - Operable Units 3. 4. and 5 Management Plan. Eielson Air Force Base, Alaska. Prepared by Battelle, Environmental Management Operations, Richland, Washington. (Final).

Eielson Air Force Base. 1992. Eielson Air Force Base Comprehensive Landuse Plan. Eielson Air Force Base, Fairbanks, Alaska.

EPA. 1991. "Supplemental Guidance for Superfund Risk Assessments in Region 10." U.S. Environmental Protection Agency, Seattle, Washington. 


\begin{tabular}{|c|c|c|c|c|}
\hline \multicolumn{5}{|c|}{ TABLE B.1. EXPOSURE FACTORS FOR INGESTION OF GROUNDWATER; INDUSTRIAL LAND USE } \\
\hline Exposure Parameter & \multicolumn{2}{|c|}{ Average Exposure } & \multicolumn{2}{|c|}{ Reasonable Maximum Exposure } \\
\hline & Non-Carcinogen & Carcinogen & Non-Carcinogen & Carcinogen \\
\hline Exposed Individual & worker & worker & worker & worker \\
\hline Body Weight $(\mathrm{kg})$ & 70 & 70 & 70 & 70 \\
\hline Exposure Duration (years) & 9 (b) & $9(\mathrm{~b})$ & 25 & 25 \\
\hline Exposure Frequency (days/year) & 250 & 250 & 250 & 250 \\
\hline Intake Rate (liters $\mathrm{H}_{2} \mathrm{O} /$ day) & 1 & 1 & 1 & 1 \\
\hline Averaging Time (years) & $9(\mathrm{~b})$ & 70 & 25 & 70 \\
\hline \multicolumn{5}{|c|}{$\begin{array}{l}\text { NOTE: All factors were obtained from reference (a), unless otherwise noted. } \\
\text { (a) EPA. 1991. "Supplemental Guidance for Superfund Risk Assessments in Region 10." U.S. Environmental Protection } \\
\text { Agency, Seattle, Washington. [Table III-1 b]. } \\
\text { (b) Factor for average residence in a home [reference (a), Table III-1 a]. }\end{array}$} \\
\hline
\end{tabular}




\begin{tabular}{|c|c|c|c|c|}
\hline \multicolumn{5}{|c|}{ TABLE B.2. EXPOSURE FACTORS FOR INGESTION OF GROUNDWATER; RESIDENTIAL LAND USE } \\
\hline \multirow[t]{2}{*}{ Exposure Parameter } & \multicolumn{2}{|c|}{ Average Exposure } & \multicolumn{2}{|c|}{ Reasonable Maximum Exposure } \\
\hline & Non-Carcinogen & Carcinogen & Non-Carcinogen & Carcinogen \\
\hline Exposed Individual & adult & adult & adult & adult \\
\hline Body Weight $(\mathrm{kg})$ & 70 & 70 & 70 & 70 \\
\hline Exposure Duration (years) & 9 & 9 & 30 & 30 \\
\hline Exposure Frequency (days/year) & 275 & 275 & 350 & 350 \\
\hline Intake Rate (liters $\mathrm{H}_{2} \mathrm{O}$ /day) & 1.4 & 1.4 & 2 & 2 \\
\hline Averaging Time (years) & 9 & 70 & 30 & 70 \\
\hline
\end{tabular}




\begin{tabular}{|c|c|c|c|c|}
\hline TABLE B.3. EXPOSURE & $\begin{array}{l}\text { CTORS FOR DE } \\
\text { OUNDWATER }\end{array}$ & $\begin{array}{l}\text { L CONTAC } \\
\text { INDUSTRIA }\end{array}$ & $\begin{array}{l}\text { CONTAMINA } \\
\text { ID USE }\end{array}$ & \\
\hline Exposure Parameter & Average & osure & Reasonable $\mathrm{A}$ & Exposure \\
\hline & Non-Carcinogen & Carcinogen & Non-Carcinogen & Carcinogen \\
\hline Exposed Individual & worker & worker & worker & worker \\
\hline Body Weight (kg) & 70 & 70 & 70 & 70 \\
\hline Exposure Duration (years) & 9 (b) & 9 (b) & 25 & 25 \\
\hline Exposure Frequency (days/year) & 250 & 250 & 250 & 250 \\
\hline Contact Rate (hours/day) & $0.12(c)$ & $0.12(c)$ & $0.17(c)$ & $0.17(c)$ \\
\hline Skin Surface Area Exposed $\left(\mathrm{cm}^{2}\right)$ & $20,000(c)$ & $20,000(c)$ & $20,000(c)$ & $20,000(c)$ \\
\hline Averaging Time (years) & 9 (b) & 70 & 25 & 70 \\
\hline $\begin{array}{l}\text { NOTE: All factors were obtained fro } \\
\text { (a) EPA. 1991. "Supplemental G } \\
\text { Agency, Seattle, Washington. [Tab } \\
\text { (b) Factor for average residence in } \\
\text { (c) EPA. 1991. "Supplemental G } \\
\text { Agency, Seattle, Washington. [Tab }\end{array}$ & $\begin{array}{l}\text { ference (a), unles } \\
\text { ce for Superfund } \\
-1 \text { b]. } \\
\text { me [reference (a), } \\
\text { ice for Superfund } \\
1 \text { a]. }\end{array}$ & $\begin{array}{l}\text { iswise noted. } \\
\text { Issessments i } \\
\text { III-1 a]. } \\
\text { issessments i }\end{array}$ & $\begin{array}{l}\text { 10." U.S. Enviro } \\
\text { 10." U.S. Enviro }\end{array}$ & rotection \\
\hline
\end{tabular}




\begin{tabular}{|c|c|c|c|c|}
\hline \multicolumn{5}{|c|}{$\begin{array}{c}\text { TABLE B.4. EXPOSURE FACTORS FOR DERMAL CONTACT WITH CONTAMINANTS DURING } \\
\text { GROUNDWATER USE; RESIDENTIAL LAND USE }\end{array}$} \\
\hline Exposure Parameter & \multicolumn{2}{|c|}{ Average Exposure } & \multicolumn{2}{|c|}{ Reasonable Maximum Exposure } \\
\hline & Non-Carcinogen & Carcinogen & Non-Carcinogen & Carcinogen \\
\hline Exposed Individual & adult & adult & adult & adult \\
\hline Body Weight (kg) & 70 & 70 & 70 & 70 \\
\hline Exposure Duration (years) & 9 & 9 & 30 & 30 \\
\hline Exposure Frequency (days/year) & 275 & 275 & 350 & 350 \\
\hline Contact Rate (hours) & 0.12 & 0.12 & 0.17 & 0.17 \\
\hline Skin Surface Area Exposed $\left(\mathrm{cm}^{2}\right)$ & 20,000 & 20,000 & 20,000 & 20,000 \\
\hline Averaging Time (years) & $9(\mathrm{~b})$ & 70 & 30 & 70 \\
\hline
\end{tabular}




\section{TABLE B.5, EXPOSURE FACTORS FOR INHALATION OF VOLATILE CONTAMINANTS DURING}

GROUNDWATER USE; INDUSTRIAL LAND USE

\begin{tabular}{||l|c|c|c|c|}
\hline \hline Exposure Parameter & \multicolumn{2}{|c|}{ Average Exposure } & \multicolumn{2}{c|}{ Reasonable Maximum Exposure } \\
\hline & Non-Carcinogen & Carcinogen & Non-Carcinogen & Carcinogen \\
\hline Exposed Individual & worker & worker & worker & worker \\
\hline Body Weight (kg) & 70 & 70 & 70 & 70 \\
\hline Exposure Duration (years) & $9(\mathrm{~b})$ & $9(\mathrm{~b})$ & 25 & 25 \\
\hline Exposure Frequency (days/year) & 250 & 250 & 250 & 250 \\
\hline Intake Rate (cubic meters/day) & $15(\mathrm{c})$ & $15(\mathrm{c})$ & $15(\mathrm{c})$ & $15(\mathrm{c})$ \\
\hline Averaging Time (years) & 9 & 70 & 25 & 70 \\
\hline \hline
\end{tabular}

NOTE: All factors were obtained from reference (a), unless otherwise noted.

(a) EPA. 1991. "Supplemental Guidance for Superfund Risk Assessments in Region 10." U.S. Environmental Protection Agency, Seattle, Washington. [Table III-1 b].

(b) Factor for average residence in a home [reference (a), Table III-1 a].

(c) Factor for daily indoor inhalation rate from OSWER Directive 9285.6-03, Human Health Evaluation Manual, Supplemental

Guidance: "Standard Default Exposure Factors," U.S. Environmental Protection Agency, Office of Solid Waste and Emergency

Response, March 1991. 


\begin{tabular}{|c|c|c|c|c|}
\hline \multicolumn{5}{|c|}{$\begin{array}{c}\text { TABLE B.6. } \\
\text { EXPOSURE FACTORS FOR INHALATION OF VOLATILE CONTAMINANTS DURING } \\
\text { GROUNDWATER USE; RESIDENTIAL LAND USE }\end{array}$} \\
\hline \multirow[t]{2}{*}{ Exposure Parameter } & \multicolumn{2}{|c|}{$\overline{\text { Average Exposure }}$} & \multicolumn{2}{|c|}{ Reasonable Maximum Exposure } \\
\hline & Non-Carcinogen & Carcinogen & Non-Carcinogen & Carcinogen \\
\hline Exposed Individual & adult & adult & adult & adult \\
\hline Body Weight (kg) & 70 & 70 & 70 & 70 \\
\hline Exposure Duration (years) & 9 & 9 & 30 & 30 \\
\hline Exposure Frequency (days/year) & 275 & 275 & 350 & 350 \\
\hline Intake Rate (cubic meters/day) & $15(\mathrm{~b})$ & $15(\mathrm{~b})$ & $15(b)$ & $15(b)$ \\
\hline Averaging Time (years) & 9 & 70 & 30 & 70 \\
\hline \multicolumn{5}{|c|}{$\begin{array}{l}\text { NOTE: All factors were obtained from reference (a), unless otherwise noted. } \\
\text { (a) EPA. 1991. "Supplemental Guidance for Superfund Risk Assessments in Region 10." U.S. Environmental Protection } \\
\text { Agency, Seattle, Washington. [Table lll-1 a]. }\end{array}$} \\
\hline
\end{tabular}




\begin{tabular}{|c|c|c|c|c|}
\hline \multicolumn{5}{|c|}{$\begin{array}{l}\text { TABLE B.7. EXPOSURE FACTORS FOR INCIDENTAL INGESTION OF SURFACE WATER; } \\
\text { INDUSTRIAL LAND USE }\end{array}$} \\
\hline \multirow[t]{2}{*}{ Exposure Parameter } & \multicolumn{2}{|c|}{ Average Exposure } & \multicolumn{2}{|c|}{ Reasonable Maximum Exposure } \\
\hline & Non-Carcinogen & Carcinogen & Non-Carcinogen & Carcinogen \\
\hline Exposed Individual & worker & worker & worker & worker \\
\hline Body Weight (kg) & 70 & 70 & 70 & 70 \\
\hline Exposure Duration (years) & 9 (b) & 9 (b) & 25 & 25 \\
\hline Exposure Frequency (days/year) & $10(c)$ & $10(c)$ & $10(c)$ & $10(c)$ \\
\hline Intake Rate (Liters $\mathrm{H}_{2} \mathrm{O} /$ day) & $0.1(\mathrm{~d})$ & $0.1(d)$ & $0.2(e)$ & $0.2(e)$ \\
\hline Averaging Time (years) & $9(\mathrm{~b})$ & 70 & 25 & 70 \\
\hline \multicolumn{5}{|c|}{$\begin{array}{l}\text { NOTE: All factors were obtained from reference (a), unless otherwise noted. } \\
\text { (a) EPA. 1991. "Supplemental Guidance for Superfund Risk Assessments in Region 10." U.S. Environmental Protection } \\
\text { Agency, Seattle, Washington. [Table III-1 b]. } \\
\text { (b) Factor for average residence in a home [reference (a), Table III-1 a]. } \\
\text { (c) Assumes two } 5 \text { day pond maintenance projects per year. } \\
\text { (d) } 10 \text { percent of industrial water intake rate [reference (a)]. } \\
\text { (e) } 20 \text { percent of industrial water intake rate [reference (a)]. }\end{array}$} \\
\hline
\end{tabular}




\begin{tabular}{|c|c|c|c|c|}
\hline \multicolumn{5}{|c|}{$\begin{array}{c}\text { TABLE B.8. EXPOSURE FACTORS FOR INCIDENTAL INGESTION OF SURFACE WATER; } \\
\text { RESIDENTIAL LAND USE }\end{array}$} \\
\hline \multirow[t]{2}{*}{ Exposure Parameter } & \multicolumn{2}{|c|}{ Average Exposure } & \multicolumn{2}{|c|}{ Reasonable Maximum Exposure } \\
\hline & Non-Carcinogen & Carcinogen & Non-Carcinogen & Carcinogen \\
\hline Exposed Individual & adult & adult & adult & adult \\
\hline Body Weight (kg) & 70 & 70 & 70 & 70 \\
\hline Exposure Duration (years) & 9 & 9 & 30 & 30 \\
\hline Exposure Frequency (days/year) & $7(b)$ & $7(\mathrm{~b})$ & 7 (b) & 7 (b) \\
\hline Intake Rate (liters $\mathrm{H}_{2} \mathrm{O} /$ day) & $0.2(\mathrm{c})$ & $0.2(c)$ & 0.4 (d) & $0.4(d)$ \\
\hline Averaging Time (years) & 9 & 70 & 30 & 70 \\
\hline \multicolumn{5}{|c|}{$\begin{array}{l}\text { NOTE: All factors were obtained from reference (a), unless otherwise noted. } \\
\text { (a) EPA. 1991. "Supplemental Guidance for Superfund Risk Assessments in Region 10." U.S. Environmental } \\
\text { Protection Agency, Seattle, Washington. [Table Ill-1 a]. } \\
\text { (b) Assumes same frequency for non-swimming water sports (e.g., fishing, boating, picnicking) as suggested for } \\
\text { "swimming" in reference (a). } \\
\text { (c) } 10 \text { percent of residential water intake rate [reference (a)]. } \\
\text { (d) } 20 \text { percent of residential water intake rate [reference (a)]. }\end{array}$} \\
\hline
\end{tabular}




\begin{tabular}{|c|c|c|c|c|}
\hline \multicolumn{5}{|c|}{ TABLE B.9, EXPOSURE FACTORS FOR INGESTION OF FISH; INDUSTRIAL LAND USE } \\
\hline Exposure Parameter & \multicolumn{2}{|c|}{ Average Exposure } & \multicolumn{2}{|c|}{ Reasonable Maximum Exposure } \\
\hline & Non-Carcinogen & Carcinogen & Non-Carcinogen & Carcinogen \\
\hline Exposed Individual & worker & worker & worker & worker \\
\hline Body Weight (kg) & 70 & 70 & 70 & 70 \\
\hline Exposure Duration (years) & 9 (b) & 9 (b) & 25 & 25 \\
\hline Exposure Frequency (days/year) & $365(c)$ & $365(c)$ & $365\langle c\rangle$ & 365 (c) \\
\hline Intake Rate (grams of fish/day) & $6.5(c)$ & $6.5(\mathrm{c})$ & $6.5(c)$ & 6.5 (c) \\
\hline Averaging Time (years) & $9(\mathrm{~b})$ & 70 & 25 & 70 \\
\hline \multicolumn{5}{|c|}{$\begin{array}{l}\text { NOTE: All factors were obtained from reference (a), unless otherwise noted. } \\
\text { (a) EPA. 1991. "Supplemental Guidance for Superfund Risk Assessments in Region 10." U.S. Environmental Protection } \\
\text { Agency, Seattle, Washington. [Table III-1 b]. } \\
\text { (b) Factor for average residence in a home [reference (a), Table III-1 a]. } \\
\text { (c) EPA. 1989. Bisk Assessment Guidance for Superfund: Human Health Evaluation Manual Part A. U.S. Environmental } \\
\text { Protection Agency, Office of Solid Waste and Emergency Response. (Interim Final). }\end{array}$} \\
\hline
\end{tabular}




\begin{tabular}{|c|c|c|c|c|}
\hline \multirow[t]{2}{*}{ Exposure Parameter } & \multicolumn{2}{|c|}{ Average Exposure } & \multicolumn{2}{|c|}{ Reasonable Maximum Exposure } \\
\hline & Non-Carcinogen & Carcinogen & Non-Carcinogen & Carcinogen \\
\hline Exposed Individual & worker & worker & worker & worker \\
\hline Body Weight $(\mathrm{kg})$ & 70 & 70 & 70 & 70 \\
\hline Exposure Duration (years) & 9 & 9 & 30 & 30 \\
\hline Exposure Frequency (days/year) & $365(\mathrm{~b})$ & 365 (b) & 365 (b) & $365(b)$ \\
\hline Intake Rate (grams of fish/day) & $6.5(\mathrm{~b})$ & 6.5 (b) & $6.5(\mathrm{~b})$ & $6.5(\mathrm{~b})$ \\
\hline Averaging Time (years) & 9 & 70 & 30 & 70 \\
\hline \multicolumn{5}{|c|}{$\begin{array}{l}\text { NOTE: All factors were obtained from reference (a), unless otherwise noted. } \\
\text { (a) EPA. 1991. "Supplemental Guidance for Superfund Risk Assessments in Region 10." U.S. Environmental Protection } \\
\text { Agency, Seattle, Washington. [Table III-1 a]. } \\
\text { (b) EPA. 1989. Bisk Assessment Guidance for Superfund: Human Health Evaluation ManualPart A. U.S. Environmental } \\
\text { Protection Agency, Office of Solid Waste and Emergency Response. (Interim Final). }\end{array}$} \\
\hline
\end{tabular}




\begin{tabular}{|c|c|c|c|c|}
\hline Exposure Parameter & Average & ssure & Reasonable M & Exposure \\
\hline & Non-Carcinogèn & Carcinogen & Non-Carcinogen & Carcinogen \\
\hline Exposed Individual & worker & worker & worker & worker \\
\hline Body Weight (kg) & 70 & 70 & 70 & 70 \\
\hline Exposure Duration (years) & $9(\mathrm{~b})$ & 9 (b) & 25 & 25 \\
\hline Exposure Frequency (days/year) & $146(c)$ & $146(c)$ & $146(c)$ & $146(c)$ \\
\hline Intake Rate (mg soil/day) & 50 & 50 & 50 & 50 \\
\hline Averaging Time (years) & $9(\mathrm{~b})$ & 70 & 25 & 70 \\
\hline \multicolumn{5}{|c|}{$\begin{array}{l}\text { NOTE: All factors were obtained from reference (a), unless otherwise noted. } \\
\text { (a) EPA. 1991. "Supplemental Guidance for Superfund Risk Assessments in Region 10." U.S. Environmental Protection } \\
\text { Agency, Seattle, Washington. [Table III-1 b]. } \\
\text { (b) Factor for average residence in a home [reference (a), Table III-1 a]. } \\
\text { (c) Average number of days without snow cover, see Pacific Northwest Laboratory. 1992. Bemedial Investigation/Feasibility } \\
\text { Study - Operable Units 3.4. and } 5 \text { ManagementPlan. Eielson Air Force Base. Alaska. Prepared by Pacific Northwest Laboratory, } \\
\text { Environmental Management Operations, Richland, Washington. (Final). }\end{array}$} \\
\hline
\end{tabular}




\begin{tabular}{|c|c|c|c|c|}
\hline \multicolumn{5}{|c|}{$\begin{array}{c}\text { TABLE B.12. EXPOSURE FACTORS FOR INCIDENTAL INGESTION OF SURFACE AND } \\
\text { SUBSURFACE SOILS AND SEDIMENTS; RESIDENTIAL LAND USE }\end{array}$} \\
\hline \multirow[t]{2}{*}{ Exposure Parameter } & \multicolumn{2}{|c|}{ Average Exposure } & \multicolumn{2}{|c|}{ Reasonable Maximum Exposure } \\
\hline & Non-Carcinogen & Carcinogen & Non-Carcinogen & Carcinogen \\
\hline Exposed Individual & adult & adult & child / adult & child / adult \\
\hline Body Weight (kg) & 70 & 70 & $15 / 70$ & $15 / 70$ \\
\hline Exposure Duration (years) & 9 & 9 & $6 / 24$ & $6 / 24$ \\
\hline Exposure Frequency (days/year) & $180(\mathrm{~b})$ & $180(\mathrm{~b})$ & $180 / 180(b)$ & $180 / 180(b)$ \\
\hline Intake Rate (mg soil/day) & 100 & 100 & $200 / 100$ & $200 / 100$ \\
\hline Averaging Time (years) & 9 & 70 & $30 / 30$ & $70 / 70$ \\
\hline \multicolumn{5}{|c|}{$\begin{array}{l}\text { NOTE: All factors were obtained from reference (a), unless otherwise noted. } \\
\text { (a) EPA. 1991. "Supplemental Guidance for Superfund Risk Assessments in Region 10." U.S. Environmental Protection } \\
\text { Agency, Seattle, Washington. [Table III-1 a]. } \\
\text { (b) Pacific Northwest Laboratory. 1992. Bemedial Investigation/Feasibility Study -- Operable Units 3.4. and 5 ManagementPlan } \\
\text { Eielson Air Force Base. Alaska. Prepared by Pacific Northwest Laboratory, Environmental Management Operations, Richland, } \\
\text { Washington. (Final). }\end{array}$} \\
\hline
\end{tabular}




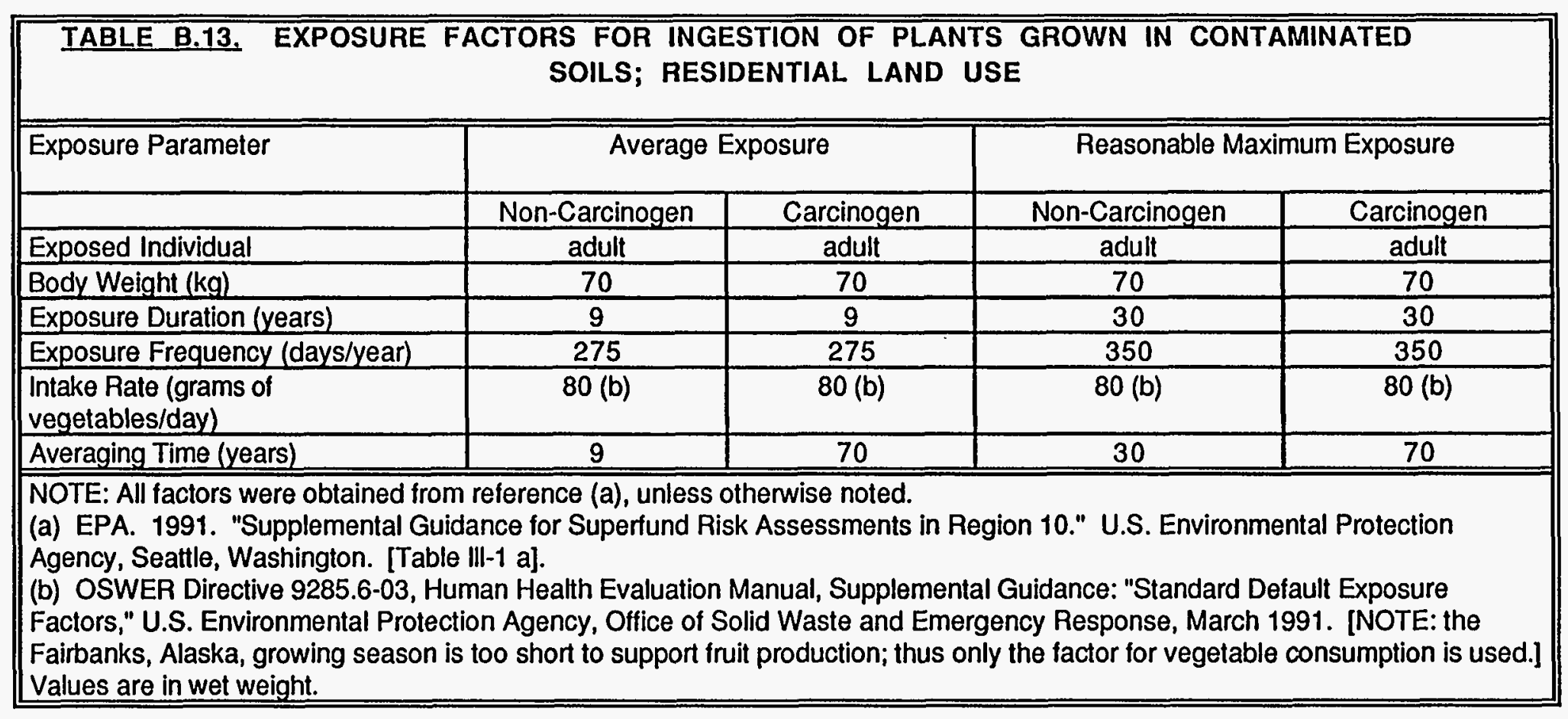




\begin{tabular}{|c|c|c|c|c|}
\hline \multicolumn{5}{|c|}{$\begin{array}{c}\text { TABLE B.14, EXPOSURE FACTORS FOR INHALATION OF VOLATILE CONTAMINANTS RELEASED } \\
\text { FROM SOIL INTO AMBIENT AIR; INDUSTRIAL LAND USE }\end{array}$} \\
\hline \multirow[t]{2}{*}{ Exposure Parameter } & \multicolumn{2}{|c|}{ Average Exposure } & \multicolumn{2}{|c|}{ Reasonable Maximum Exposure } \\
\hline & Non-Carcinogen & Carcinogen & Non-Carcinogen & Carcinogen \\
\hline Exposed Individual & worker & worker & worker & worker \\
\hline Body Weight (kg) & 70 & 70 & 70 & 70 \\
\hline Exposure Duration (years) & $9(\mathrm{~b})$ & $9(\mathrm{~b})$ & 25 & 25 \\
\hline Exposure Frequency (days/year) & 250 & 250 & 250 & 250 \\
\hline Intake Rate (cubic meters/day) & $5(c)$ & $5(c)$ & $5(c)$ & $5(c)$ \\
\hline Averaging Time (years) & 9 & 70 & 25 & 70 \\
\hline \multicolumn{5}{|c|}{$\begin{array}{l}\text { NOTE: All factors were obtained from reference (a), unless otherwise noted. } \\
\text { (a) EPA. 1991. "Supplemental Guidance for Superfund Risk Assessments in Region 10." U.S. Environmental Protection } \\
\text { Agency, Seattle, Washington. [Table IIl-1 b]. } \\
\text { (b) Factor for average residence in a home [reference (a), Table Ill-1 a]. } \\
\text { (c) Total intake rate of } 20 \mathrm{~m}^{3} / \text { day is assumed. } 25 \% \text { is from inhalation of volatiles released from soil (outdoor). If there is no } \\
\text { groundwater source for volatiles (indoor), } 100 \% \text { of intake rate is from inhalation of volatiles released from soil. The rates are based } \\
\text { on OSWER Directive } 9285.6-03 \text {, Human Health Evaluation Manual, Supplemental Guidance: "Standard Default Exposure } \\
\text { Factors," U.S. Environmental Protection Agency, Office of Solid Waste and Emergency Response, March 1991. }\end{array}$} \\
\hline
\end{tabular}




\section{TABLE B.15. EXPOSURE FACTORS FOR INHALATION OF VOLATILE CONTAMINANTS RELEASED FROM SOIL INTO AMBIENT AIR; RESIDENTIAL LAND USE}

\begin{tabular}{|c|c|c|c|c|}
\hline \multirow[t]{2}{*}{ Exposure Parameter } & \multicolumn{2}{|c|}{ Average Exposure } & \multicolumn{2}{|c|}{ Reasonable Maximum Exposure } \\
\hline & Non-Carcinogen & Carcinogen & Non-Carcinogen & Carcinogen \\
\hline Exposed Individual & worker & worker & worker & worker \\
\hline Body Weight (kg) & 70 & 70 & 70 & 70 \\
\hline Exposure Duration (years) & 9 & 9 & 30 & 30 \\
\hline Exposure Frequency (days/year) & 275 & 275 & 350 & 350 \\
\hline Intake Rate (cubic meters/day) & $5(b)$ & 5 (b) & $5(b)$ & $5(b)$ \\
\hline Averaging Time (years) & 9 & 70 & 30 & 70 \\
\hline
\end{tabular}

NOTE: All factors were oblained from reference (a), unless othenwise noted.

(a) EPA. 1991. "Supplemental Guidance for Superfund Risk Assessments in Region 10." U.S. Environmental Protection Agency, Seattle, Washington. [Table III-1 a].

(b) Total intake rate of $20 \mathrm{~m}^{3} /$ day is assumed. $25 \%$ is from inhalation of volatiles released from soil (outdoor). If there is no groundwater source for volatiles (indoor), $100 \%$ of intake rate is from inhalation of volatiles released from soil. The rates are based On OSWER Directive 9285.6-03, Human Health Evaluation Manual, Supplemental Guidance: "Standard Default Exposure Factors," U.S. Environmental Protection Agency, Office of Solid Waste and Emergency Response, March 1991. 


\begin{tabular}{|c|c|c|c|c|}
\hline TABLE B.16. EXPOSURE & $\begin{array}{l}\text { ACTORS FOR } \\
\text { SEDIMENTS; }\end{array}$ & $\begin{array}{l}\overline{\overline{M A L} \text { CONTA }} \\
\text { USTRIAL LA }\end{array}$ & $\begin{array}{l}\text { TH SURFACE S } \\
\text { SE }\end{array}$ & \\
\hline Exposure Parameter & Average & osure & Reasonable $\mathrm{M}$ & Exposure \\
\hline & Non-Carcinogen & Carcinogen & Non-Carcinogen & Carcinogen \\
\hline Exposed Individual & worker & worker & worker & worker \\
\hline Body Weight $(\mathrm{kg})$ & 70 & 70 & 70 & 70 \\
\hline Exposure Duration (years) & $9(\mathrm{~b})$ & $9(\mathrm{~b})$ & 25 & 25 \\
\hline Exposure Frequency (events/year) & $146(c)$ & $146(c)$ & $146(c)$ & $146(c)$ \\
\hline Contact Rate $\left(\mathrm{mg} / \mathrm{cm}^{2}\right)$ & $0.6(d)$ & $0.6(d)$ & $1.0(\mathrm{~d})$ & $1.0(d)$ \\
\hline Surface Area (cm²/event) & $1900(d)$ & 1900 (d) & 5000 (d) & 5000 (d) \\
\hline Averaging Time (years) & $9(\mathrm{~b})$ & 70 & 25 & 70 \\
\hline $\begin{array}{l}\text { NOTE: All factors were obtained fror } \\
\text { (a) EPA. 1991. "Supplemental Gui } \\
\text { Agency, Seattle, Washington. [Tabl } \\
\text { (b) Factor for average residence in a } \\
\text { (c) Pacific Northwest Laboratory. } 19 \\
\text { Eielson Air Force Base, Alaska. Pre } \\
\text { Washington. (Final). } \\
\text { (d) EPA. 1991. "Supplemental Gui } \\
\text { Agency, Seattle, Washington. [Tabl }\end{array}$ & $\begin{array}{l}\text { eference (a), unles } \\
\text { ince for Superfund } \\
\text { II-1 b]. } \\
\text { ome [reference (a), } \\
\text { 2. Bemedial Investi } \\
\text { ired by Pacific North } \\
\text { ance for Superfund }\end{array}$ & $\begin{array}{l}\text { erwise noted. } \\
\text { Assessments i } \\
\text { III-1 a]. } \\
\text { n/Feasibility St } \\
\text { Laboratory, E } \\
\text { Assessments }\end{array}$ & $\begin{array}{l}\text { n 10." U.S. Enviro } \\
\text { perable Units } 3.4 \\
\text { iental Management } \\
\text { n 10." U.S. Enviro }\end{array}$ & $\begin{array}{l}\text { Protection } \\
\text { anagement Plan } \\
\text { ons, Richland, } \\
\text { Protection }\end{array}$ \\
\hline
\end{tabular}




\begin{tabular}{|c|c|c|c|c|}
\hline TABLE B.17, EXPOSUR & $\begin{array}{l}\text { ACTORS FOR } \\
\text { DIMENTS; RE }\end{array}$ & $\begin{array}{l}\text { MAL CONTA } \\
\text { UTIAL LAND }\end{array}$ & TH SURFACE & \\
\hline Exposure Parameter & Average & osure & Reasonable N & Exposure \\
\hline & Non-Carcinogen & Carcinogen & Non-Carcinogen & Carcinogen \\
\hline Exposed Individual & adult & adult & child / adult & child / adult \\
\hline Body Weight (kg) & 70 & 70 & $15 / 70$ & $15 / 70$ \\
\hline Exposure Duration (years) & 9 & 9 & $6 / 24$ & $6 / 24$ \\
\hline Exposure Frequency (events/year) & $180(\mathrm{~b})$ & $180(\mathrm{~b})$ & $180 / 180(b)$ & $180 / 180(\mathrm{~b})$ \\
\hline Contact Rate $\left(\mathrm{mg} / \mathrm{cm}^{2}\right)$ & 0.6 & 0.6 & 1.0 & 1.0 \\
\hline Surface Area (cm²/event) & 1900 & 1900 & $3900 / 5000$ & $3900 / 5000$ \\
\hline Averaging Time (years) & 9 & 70 & $30 / 30$ & $70 / 70$ \\
\hline $\begin{array}{l}\text { NOTE: All factors were obtained frol } \\
\text { (a) EPA. 1991. "Supplemental Gu } \\
\text { Protection Agency, Seattle, Washin } \\
\text { (b) Pacific Northwest Laboratory. } 1 \\
\text { Eielson Air Force Base. Alaska. Pre } \\
\text { Washington. (Final). }\end{array}$ & $\begin{array}{l}\text { ference (a), unles } \\
\text { ce for Superfund } \\
\text { [Table lil-1 a]. } \\
\text { Remedial Investi } \\
\text { ed by Pacific North }\end{array}$ & $\begin{array}{l}\text { invise noted. } \\
\text { ssessments in } \\
\text { Labeasibility St } \\
\text { Laboratory, Er }\end{array}$ & $\begin{array}{l}\text { 10." U.S. Enviro } \\
\text { erable Units } 3.4\end{array}$ & $\begin{array}{l}\text { anagement Plar } \\
\text { ans, Richland, }\end{array}$ \\
\hline
\end{tabular}




\begin{tabular}{|c|c|c|c|c|}
\hline TABLE B.18, EXPOSURE & $\begin{array}{l}\text { ACTORS FOR } \\
\text { INDUSTRI }\end{array}$ & $\begin{array}{l}\text { MAL CONT } \\
\text { AND USE }\end{array}$ & TH SUBSURF & \\
\hline Exposure Parameter & Average & osure & Reasonable $\mathrm{N}$ & Exposure \\
\hline & Non-Carcinogen & Carcinogen & Non-Carcinogen & Carcinogen \\
\hline Exposed Individual & worker & worker & worker & worker \\
\hline Body Weight (kg) & 70 & 70 & 70 & 70 \\
\hline Exposure Duration (years) & $9(\mathrm{~b})$ & $9(\mathrm{~b})$ & 25 & 25 \\
\hline Exposure Frequency (events/year) & $146(c)$ & $146(c)$ & $146(c)$ & $146(c)$ \\
\hline Contact Rate $\left(\mathrm{mg} / \mathrm{cm}^{2}\right)$ & $0.6(d)$ & $0.6(\mathrm{~d})$ & $1.0(\mathrm{~d})$ & $1.0(\mathrm{~d})$ \\
\hline Surface Area (cm²/event) & $1900(d)$ & 1900 (d) & 5000 (d) & $5000(d)$ \\
\hline Averaging Time (years) & $9(\mathrm{~b})$ & 70 & 25 & 70 \\
\hline $\begin{array}{l}\text { NOTE: All factors were obtained fro } \\
\text { (a) EPA. 1991. "Supplemental Gu } \\
\text { Agency, Seattle, Washington. [Tabl } \\
\text { (b) Factor for average residence in a } \\
\text { (c) Pacific Northwest Laboratory. 15 } \\
\text { Eielson Air Force Base. Alaska. Pre } \\
\text { Washington. (Final). } \\
\text { (d) EPA. 1991. "Supplemental Gu } \\
\text { Agency, Seattle, Washington. [Tabl }\end{array}$ & $\begin{array}{l}\text { eference (a), unless } \\
\text { nce for Superfund } F \\
\|-1 \text { b]. } \\
\text { ome [reference (a), } \\
\text {.. Bemedial Investis } \\
\text { red by Pacific North } \\
\text { ince for Superfund } \mathrm{F} \\
\mid-1 \text { a]. }\end{array}$ & $\begin{array}{l}\text { Aswise noted. } \\
\text { Assments it } \\
\text { III-1 a]. } \\
\text { /Feasibility Stl } \\
\text { Laboratory, E } \\
\text { Assessments i }\end{array}$ & $\begin{array}{l}\text { n 10." U.S. Enviro } \\
\text { perable Units } 3.4 . \\
\text { ental Management } \\
\text { 10." U.S. Enviro }\end{array}$ & $\begin{array}{l}\text { Protection } \\
\text { anagement Plan } \\
\text { ons, Richland, } \\
\text { Protection }\end{array}$ \\
\hline
\end{tabular}




\begin{tabular}{|c|c|c|c|c|}
\hline TABLE B.19, EXPOSUR & $\begin{array}{l}\text { ACTORS FOR } \\
\text { RESIDENTI }\end{array}$ & $\begin{array}{l}\text { MAL CONTA } \\
\text { LAND USE }\end{array}$ & ITH SUBSURF & \\
\hline Exposure Parameter & Average & osure & Reasonable $\mathrm{A}$ & Exposure \\
\hline & Non-Carcinogen & Carcinogen & Non-Carcinogen & Carcinogen \\
\hline Exposed Individual & adult & adult & child/adult & child / adull \\
\hline Body Weight $(\mathrm{kg})$ & 70 & 70 & $15 / 70$ & $15 / 70$ \\
\hline Exposure Duration (years) & 9 & 9 & $6 / 24$ & $6 / 24$ \\
\hline Exposure Frequency (events/year) & 180 (b) & 180 (b) & $180 / 180(b)$ & $180 / 180(\mathrm{~b})$ \\
\hline Contact Rate $\left(\mathrm{mg} / \mathrm{cm}^{2}\right)$ & 0.6 & 0.6 & 1.0 & 1.0 \\
\hline Surface Area (cm²/event) & 1900 & 1900 & $3900 / 5000$ & $3900 / 5000$ \\
\hline Averaging Time (years) & 9 & 70 & $30 / 30$ & $70 / 70$ \\
\hline $\begin{array}{l}\text { NOTE: All factors were obtained fro } \\
\text { (a) EPA. 1991. "Supplemental Gui } \\
\text { Protection Agency, Seattle, Washin } \\
\text { (b) Pacific Northwest Laboratory. } 1 \\
\text { Management Plan. Eielson Air Force } \\
\text { Management Operations, Richland, }\end{array}$ & $\begin{array}{l}\text { eference (a), unles } \\
\text { nce for Superfund } \mathrm{F} \\
\text { n. [Table IIl-1 a]. } \\
\text { Bemedial lnvesti } \\
\text { ase. Alaska. Prepa } \\
\text { ashington. (Final). }\end{array}$ & $\begin{array}{l}\text { envise noted. } \\
\text { Assessments ir } \\
\text { alFeasibility St } \\
\text { y Pacific North }\end{array}$ & $\begin{array}{l}\text { 10." U.S. Envirc } \\
\text { perable Units } 3.4 \\
\text { boratory, Environ }\end{array}$ & \\
\hline
\end{tabular}




\begin{tabular}{|c|c|c|c|c|}
\hline \multicolumn{5}{|c|}{$\begin{array}{c}\text { TABLE B.20. EXPOSURE FACTORS FOR INHALATION OF RESUSPENDED PARTICULATES; INDUSTRIAL } \\
\text { LAND USE }\end{array}$} \\
\hline Exposure Parameter & \multicolumn{2}{|c|}{ Average Exposure } & \multicolumn{2}{|c|}{ Reasonable Maximum Exposure } \\
\hline & Non-Carcinogen & Carcinogen & Non-Carcinogen & Carcinogen \\
\hline Exposed Individual & worker & worker & worker & worker \\
\hline Body Weight (kg) & 70 & 70 & 70 & 70 \\
\hline Exposure Duration (years) & 9 (b) & $9(\mathrm{~b})$ & 25 & 25 \\
\hline Exposure Frequency (days/year) & $146(c)$ & $146(c)$ & $146(\mathrm{c})$ & $146(c)$ \\
\hline Intake Rate (cubic meters/day) & 20 & 20 & 20 & 20 \\
\hline Averaging Time (years) & $9(\mathrm{~b})$ & 70 & 25 & 70 \\
\hline
\end{tabular}

NOTE: All factors were obtained from reference (a), unless otherwise noted.

(a) EPA. 1991. "Supplemental Guidance for Superfund Risk Assessments in Region 10." U.S. Environmental Protection Agency, Seattle, Washington. [Table IIl-1 b].

(b) Factor for average residence in a home [reference (a), Table III-1 a].

(c) Pacific Northwest Laboratory, 1992, Pacific Northwest Laboratory. 1992. Remedial Investigation/Feasibility Study -- Operable Units 3. 4. and 5 Management Plan. Eielson Air Force Base. Alaska. Prepared by Pacific Northwest Laboratory, Environmental Management Operations, Richland, Washington. (Final). 


\begin{tabular}{||l|c|c|c||}
\hline \multicolumn{1}{|c|}{ TABLE B.21. EXPOSURE FACTORS FOR INHALATION OF RESUSPENDED PARTICULATES; } \\
RESIDENTIAL LAND USE
\end{tabular}




\begin{tabular}{|c|c|c|c|c|}
\hline \multicolumn{5}{|c|}{$\begin{array}{c}\text { TABLE B.22, EXPOSURE FACTORS FOR DERMAL CONTACT WITH CONTAMINANTS DURING } \\
\text { SURFACE WATER USE; RESIDENTIAL LAND USE }\end{array}$} \\
\hline \multirow[t]{2}{*}{ Exposure Parameter } & \multicolumn{2}{|c|}{ Average Exposure } & \multicolumn{2}{|c|}{ Reasonable Maximum Exposure } \\
\hline & Non-Carcinogen & Carcinogen & Non-Carcinogen & Carcinogen \\
\hline Exposed Individual & adult & adult & adult & adult \\
\hline Body Weight $(\mathrm{kg})$ & 70 & 70 & 70 & 70 \\
\hline Exposure Duration (years) & 9 & 9 & 30 & 30 \\
\hline Exposure Frequency (days/year) & 7 & 7 & 7 & 7 \\
\hline Contact Rate (hours) & 2.6 & 2.6 & 2.6 & 2.6 \\
\hline Skin Surface Area Exposed $\left(\mathrm{cm}^{2}\right)$ & 20,000 & 20,000 & 20,000 & 20,000 \\
\hline Averaging Time (years) & $9(\mathrm{~b})$ & 70 & 30 & 70 \\
\hline \multicolumn{5}{|c|}{$\begin{array}{l}\text { NOTE: All factors were obtained from: } \\
\text { EPA. 1991. "Supplemental Guidance for Superfund Risk Assessments in Region 10." U.S. Environmental Protection Agency, } \\
\text { Seattle, Washington. Table IIl-1 a]. }\end{array}$} \\
\hline
\end{tabular}




\section{Eielson Air Force Base \\ Baseline Risk Assessment}

Appendix C

Fate And Transport Model 


\section{APPENDIX C--FATE AND TRANSPORT MODEL}

\section{C.1 DESCRIPTION OF MEPAS}

The Multimedia Environmental Pollutant Assessment System (MEPAS) is a physicsbased computation code that integrates source-term, transport, and exposure models into a single framework. MEPAS is designed as a preliminary or initial tool for assessing environmental problems; it is designed for site-specific assessments using readily available information to estimate the release of contaminants from waste sites, their transport and fate in the environment, and the potential health impacts associated with exposures to surrounding sensitive receptors.

The MEPAS methodology is based on standard transport models that have been used by industry and government, including the U.S. Environmental Protection Agency. The groundwater model, which was employed in this assessment, is based on the onedimensional advective, three-dimensional dispersive equation for solute movement through a porous medium with a unidirectional, constant flow velocity and degradation/decay (Clapp and Hornberger 1977; Codell et al. 1982; EPA 1988a; Hillel 1980).

$$
\frac{\partial C}{\partial t}+\left(\frac{u}{R_{f}}\right)\left(\frac{\partial C}{\partial x}\right)=\left(\frac{D_{x}}{R_{f}}\right)\left(\frac{\partial^{2} C}{\partial x^{2}}\right)+\left(\frac{D_{y}}{R_{f}}\right)\left(\frac{\partial^{2} C}{\partial y^{2}}\right)+\left(\frac{D_{z}}{R_{f}}\right)\left(\frac{\partial^{2} C}{\partial z^{2}}\right)+\lambda C
$$

in which

$$
\begin{aligned}
& R_{f}=1+B K_{d} / n_{e} \text { (saturated zone) } \\
& R_{f}=1+B K_{d} / T \text { (vadose zone) } \\
& T=n\left[K(T) / K_{s}\right]^{b} \quad \text { (vadose zone) }
\end{aligned}
$$

where $C$ is the dissolved concentration ( $\mathrm{g} / \mathrm{mL}$ or $\mathrm{Ci} / \mathrm{mL}$ ), $\mathrm{u}$ is the pore-water velocity $(\mathrm{cm} / \mathrm{s}), R_{f}$ is the retardation factor (dimensionless); Dx, Dy, Dz are the dispersion coefficients in the $x, y$, and $z$ directions, respectively $\left(\mathrm{cm}^{2} / \mathrm{s}\right), R_{f}$ is the degradation/decay rate $(1 / \mathrm{sec}), B$ is the bulk density $\left(\mathrm{g} / \mathrm{cm}^{3}\right), K_{d}$ is the distribution coefficient $(\mathrm{mL} / \mathrm{g}), n_{e}$ and $\mathrm{n}$ are the effective and total porosities, respectively (fraction), $\mathrm{T}$ is the moisture content (fraction), $K(T)$ is the hydraulic conductivity $(\mathrm{cm} / \mathrm{s}), K_{S}$ is the saturated hydraulic conductivity $(\mathrm{cm} / \mathrm{s})$, and $\mathrm{b}$ is an empirically based parameter that is a function of soil properties.

By solving Equation (1) with appropriate initial and boundary conditions, a set of analytical expressions is obtained that characterizes contaminant transport through the vadose and saturated zones (Whelan et al. 1987b). The solutions are based on Green's functions (Codell 1982, Selim and Mansell 1976; Yeh 1981; Yeh and Tsai 1976). Using this type of approach allows the subsurface pathway to easily consider multiple layers in the vadose zone. For vadose zone modeling, Equation (1) is reduced to one-dimensional ( $z$ direction) solutions of the advective-dispersive equation. Saturated-zone modeling is 
based on two dimensional ( $x$ and $y$ directions), vertically averaged solutions to Equation (1). The vertically averaged depth is defined as the vertical distance over which the contaminant is considered fully mixed. MEPAS calculates the fully mixed region based on hydrodynamic (e.g., dispersion coefficient) and geometric (e.g., aquifer depth) considerations using a Gaussian-distribution analysis (Whelan et al. 1987b). Contaminant transport between vadose-zone layers or vadose and saturated zones are linked through contaminant-flux boundary conditions. The groundwater component also allows the analyst to assess degradation/decay at the source of contamination only, in the environment only following release from the source, or both sequentially.

MEPAS was initially developed for the U.S. Department of Energy (DOE) to assess a suite of environmental concerns at each of its 35 facilities across the country, including its 16 defense production installations. The DOE application involved over 400 waste sites called ranking units (DOE 1988). Previous applications included the evaluation of a variety of waste sites at different DOE facilities during the testing phase of the methodology (Whelan et al. 1988, 1989b). At DOE's Hanford Site in Richland, Washington, MEPAS has been used on the Single-Shell Tank (SST) wastecharacterization project (Buck et al. 1991, Droppo et al. 1991). MEPAS was also used to develop data quality objectives (DQOs) for the SST waste-characterization project by defining risk-based detection limit goals for the analytical laboratory effort (Droppo et al. 1989c).

Whelan et al. (1987) performed similar assessments using MEPAS at 20 EPA CERCLA sites. Two additional applications (Codell et al. 1982) under seven different site conditions evaluated the migration, fate, and effects of mixed wastes associated with creosote, pentachlorophenol, ammoniacal copper arsenate, ammoniacal copper zinc arsenate, copper chromate arsenical, coal-tar asbestos, newly coated asphalt asbestos, old-coated asphalt asbestos, and coal-tar epoxy. Three of these analyses were compared to actual sites; the results of which were confirmed by site monitoring.

The MEPAS methodology is currently associated with the Remedial Action Assessment System (RAAS), which is being developed by DOE's Office of Environmental Restoration; RAAS is a computer tool to help in the selection of a representative list of remediation alternatives in the feasibility stage of EPA's guidance for remediation at CERCLA sites. RAAS will first screen possible remediation technologies to obtain a candidate list for appropriate treatment technologies and then will provide attribute information on that list of candidates. The attributes will be based on a subset of EPA's ten attribute criteria (EPA 1988b). To help in this process, MEPAS will be provided as a tool for computing the transport, fate, and risk for alternative remedies.

Although MEPAS is an extremely versatile methodology, it does have its limitations, as does every model or methodology. The current version of MEPAS does not

- provide spatially varying concentration isopleths, although the code is currently being modified to address this constraint.

- consider complex geochemical interactions between constituents and soil, including kinetics, complexation, functional group interactions, waste mixtures, etc. Chemical interactions with soil are described in MEPAS through a distribution coefficient $\left(K_{d}\right)$.

- consider density differences from that of water, as illustrated by light or dense nonaqueous phase liquids (i.e., LNAPL or DNAPL, respectively). The model does allow the user to limit the vertical region over which the LNAPL might be distributed.

- consider time or spatial variations in pore-water flow velocities. As such, the hydraulic gradient is considered constant over any given reach of the saturated zone. Time 
and spatial variations in pore-water velocity due to boundary conditions or pumpage are not addressed.

Many other documents, including peer-reviewed joumal manuscripts, are available on the MEPAS methodology (Buck et al. 1989; Droppo et al. 1989a, 1989b, 1989d; Hoopes et al. 1988; Whelan et al. 1986, 1989a).

\section{C.2 REFERENCES}

Buck, J. W., B. L. Hoopes, and D. R. Friedrichs. 1989. Multimedia Environmental Pollutant Assessment System (MEPAS): Getting Started with MEPAS. PNL-7126. Pacific Northwest Laboratory, Richland, Washington.

Buck, J. W., M. S. Peffers, and S. T. Hwang. 1991. Preliminary Recommendations on the Decisions of the Characterization Program for the Single Shell Tanks - A System Analysis: Volume 2: Closure-Belated Analyte Priorities, Concentration Thresholds. and Detection Limit Goals Based on Public Health Concerns. PNL-7573. Pacific Northwest Laboratory, Richland, Washington.

Clapp, R. B., and G. M. Hornberger. 1977. "Empirical Equations for Some Soil Hydraulic Properties." Water Resour. Res. 14(4):601-604.

Codell, R. B., K. T. Key, and G. Whelan. 1982. A Collection of Mathematical Models for Dispersion in Surface Water and Groundwater. NUREG-0868. U.S. Nuclear Regulatory Commission, Office of Nuclear Reactor Regulation, Washington, DC.

DOE. 1988. Environmental Survey Preliminary Summary Report of the Defense Production Facilities. DOEJEH-0072. U.S. Department of Energy, Office of Environment, Safety, and Health, Washington, DC.

Droppo, J. G., G. Whelan, J. W. Buck, D. L. Strenge, B. L. Hoopes, and M. B. Walter. 1989a. Supplemental Formulations: The Multimedia Environmental Pollutant Assessment System (MEPAS). PNL-7201. Pacific Northwest Laboratory, Richland, Washington.

Droppo, J. G., D. L. Strenge, J. W. Buck, B. L. Hoopes, R. D. Brockhaus, M. B. Walter, and G. Whelan. 1989b. Multimedia Environmental Pollutant Assessment System (MEPAS) Application Guidance: Volume 1 - User's Guide. PNL-7216. Pacific Northwest Laboratory, Richland, Washington.

Droppo, J. G., D. L. Strenge, J. W. Buck, B. L. Hoopes, R. D. Brockhaus, M. B. Walter, and G. Whelan. 1989c. Multimedia Environmental Pollutant Assessment System (MEPAS) Application Guidance: Volume 2 - Guidelines for Evaluating MEPAS Input Parameters. PNL-7216. Pacific Northwest Laboratory, Richland, Washington.

Droppo, J. G. and B. L. Hoopes. 1989d. "Remedial Action Priority/Multimedia Environmental Pollutant Assessment System." Presented at the Annual Meeting of the American Chemical Society, Miami, Florida, September 12, 1989. 
Droppo, J. G., J. W. Buck, J. S. Wilbur, D. L. Strenge, and M. D. Freshley. 1991. SingleShell Tank Constituent Rankings for Use in Preparing Waste Characterization Plans. PNL-7572. Pacific Northwest Laboratory, Richland, Washington.

EPA. 1988a. Superfund Exposure Assessment Manual. EPA540/1-88/001. U.S. Environmental Protection Agency, Office of Solid Waste and Emergency Response, Washington, DC.

EPA. 1988b. "Hazard Ranking System (HRS) for Uncontrolled Hazardous Substance Releases; Appendix A of the National Oil and Hazardous Substance Contingency Plan." Proposed Rule in 40 CFR Part 300 . Code of Federal Regulations, U.S. Environmental Protection Agency, Washington, DC (February 24, 1988).

Hillel, D. 1980. Eundamentals of Soil Physics. Academic Press, New York.

Hoopes, B. L., J. W. Buck, D. L. Friedrichs, and R. J. Aiken. 1988. "The Multimedia Environmental Pollutant Assessment System (MEPAS): User-Friendly Shell." Presented at the DOE Modeling Conference, Oak Ridge National Laboratory, Oak Ridge, Tennessee, October 3-7.

Selim, H. M., and R. S. Mansell. 1976. "Analytical Solution of the Equation for Transport of Reactive Solutes Through Soils." Water Resour. Res. 12(3):528-532.

Whelan, G., B. L. Steelman, D. L. Strenge, and J. G. Droppo, Jr. 1986. "Overview of the Remedial Action Priority System (RAPS)." Pollutants in a Multimedia Environment.

Cohen, Y., (Ed.), Plenum Press, New York, pp. 191-227.

Whelan, G., R. D. Brockhaus, D. L. Strenge, D. L.,J. G. Droppo, Jr., M. B. Walter, and J. W. Buck. 1987a. "Application of the Remedial Action Priority System to Hazardous Waste Sites on the National Priorities List." SUPERFUND '87: Proceedings of the 8th National Conference. Hazardous Materials Control Research Institute. Washington, DC, November 16-18, 1987; pp. 409-413.

Whelan, G., D. L. Strenge, J. G. Droppo, Jr., B. L. Steelman, and J. W. Buck. 1987b. The Remedial Action Priority System (RAPS): Mathematical Formulations. DOE/RL/87-09. PNL-6200. Pacific Northwest Laboratory, Richland, Washington.

Whelan, G., D. L. Strenge, and J. G. Droppo, Jr. 1988. "The Remedial Action Priority System (RAPS): Comparison Between Simulated and Observed Environmental Contaminant Levels." SUPERFUND "88: Proceedings of the 9th National Conference. Hazardous Materials Control Research Institute. Washington, DC, November 28-30, pp. $539-545$.

Whelan, G., J. W. Buck, D. L. Strenge, J. G. Droppo, Jr., B. L. Hoopes, and R. J. Aiken. 1989a. "Overview of the Multimedia Environmental Pollutant Assessment System (MEPAS)." Haz. Waste Haz. Mat. 9:(2)191-208.

Whelan, G., J. G. Droppo, Jr., D. L. Strenge, M. B. Walter, and J. W. Buck. 1989b. A Demonstration of the Applicability of Implementing the Enhanced Remedial Action Priority System (RAPS) for Environmental Releases. PNL-7102. Pacific Northwest Laboratory, Richland, Washington. 
Yeh, G. T. 1981. AT123D: Analytical Transient One-. Two and Three-Dimensional Simulation of Waste Transport in the Aquifer System. ORNL-5602. Oak Ridge National Laboratory, Oak Ridge, Tennessee.

Yeh, G. T., and Y. Tsai. 1976. "Analytical Three-Dimensional Transient Modeling of Effluent Discharge." Water Resour. Res, 12(3):533-540. 


\section{Eielson Air Force Base \\ Baseline Risk Assessment}

Appendix D

Chemical Concentrations And Monitoring Data 


\section{APPENDIX D--CHEMICAL CONCENTRATIONS AND MONITORING DATA}

Tables D.1 through D.5 list the maximum concentrations for each analyte in each medium. The data are primarily from the 1991 sampling effort. A complete list of that data is in Appendix A of the Operable Unit 2 Remedial Investigation (U.S. Air Force 1993c) However, surface water and sediment data for ST11 are from the Air Force Bioenvironmental Services sampling effort in July 1992 (U.S. Air Force 1992) and additional subsurface soils data for ST10, ST19, and DP26 are from 1992 data (U.S. Air Force 1992, Appendix H).

If a chemical was not detected, then Tables D. 1 through $D .5$ list the maximum contract required quantitation limit (CRQL) reported for that chemical at the site. That is, all analyses for this chemical at the site had an EPA "U" qualifier (the compound was analyzed for, but not detected [EPA 1989]).

If the only detections of a chemical had an EPA "B" qualifier (the analyte was found in the blank as well as in the sample [EPA 1989]), then the maximum detection is listed with a $B$ suffix. If the chemical was detected both with and without a " $\mathrm{B}$ " qualifier, then the maximum non- $B$ value is listed in the tables.

There were samples at several sites where a high concentration of an organic compound, typically xylene, caused the concentrations of several analyses to exceed the calibration of the lab instrumentation. That is, the analyte had an EPA "E" qualifier. In all cases, the sample was rerun with a secondary dilution (EPA "D" qualifier) and this value was preferentially inserted into Tables D.1 through D.5.

The soils at DP26 were not sampled during the 1991 effort because the site was still assigned to Operable Unit 4. The DP26 soil data in Table D.3 is derived from 1992 sampling plus 1986, 1987, and 1988 sampling by Science Applications International Corporation (SAIC 1989). However, all values listed are from the 1991 sampling effort because ST13 had higher concentrations of soil contamination. Table D.6 lists the volatiles and metals SAIC analyzed for in soils.

Several of the monitoring wells at DP26 were resampled in 1992. All values measured were at least half those measured in 1991. However, the well with the maximum groundwater contamination (monitoring well 26-8) was not resampled, so the maximum 1991 value still stands.

The 1991 data collected by $\mathrm{CH} 2 \mathrm{M}$ Hill was validated, and a validation report is in Appendix $\mathrm{G}$ of the Operable Unit 2 RI (U.S. Air Force 1993). Data collected during 1992 was validated and the validation report is also included in Appendix G. SAIC has a Quality Assurance/Quality Control Evaluation discussion of its data in Appendix I of its RI (SAIC 1989).

Tables D.7 through D.11 list the sample that were used as a sample to pick the maximum site-specific contaminant concentrations (Tables D.1 through D.5). All data collected by $\mathrm{CH} 2 \mathrm{M}$ Hill and listed in these tables is EPA Level III as required by EPA (1989) for quantitative risk assessments. SAIC and Air Force Bioenvironmental Services data is not Level III. It was evaluated for the risk assessment; however, none was entered into the risk calculations either because the maximum concentrations did not exceed the riskbased screening concentrations or there were other, Level III, analyses that had higher contaminant concentrations. 
CH2M Hill also collected EPA Level II data from a Close Support Laboratory (CSL) during the 1991 field season. The CSL analyzed for BTEX, TPH, and chlorinated solvents in subsurface soils and groundwater. None of the concentrations measured at the CSL was greater than a comparable Level III analysis from the same site. This was expected because the results of the CSL were used to guide the placement of the soils probes that collected Level III data.

\section{REFERENCES}

EPA. 1989. Bisk Assessment Guidance for Superfund: Human Health Evaluation Manual Part A. U.S. Environmental Protection Agency, Office of Solid Waste and Emergency Response. (Interim Final).

SAIC. 1989. U.S. Air Force Installation Restoration Program Remedial Investigation/Feasibility Study of the Fuel Saturated Area at Eielson Air Force Base. Alaska: Draft Remedial Investigation Report. Volumes I, II, III Prepared by Science Applications International Corporation (Draft).

U.S. Air Force. 1992. "Summary of Garrison Slough Results (July 1992)." Letter report of Major R.L. Gross, Bioenvironmental Engineering Services.

U.S. Air Force. 1993. Eielson Air Force Base OU-2 Remedial Investigation/Feasibility Studv: Remedial Investigation Appendixes. Prepared by Battelle, Environmental Management Operations, Richland, Washington (Revised Draft). 


\begin{tabular}{|c|c|c|c|c|c|c|}
\hline ANALYTES & CAS & $\begin{array}{c}\text { SURFACE } \\
\text { SOILS } \\
(\mu \mathrm{g} / \mathrm{kg})\end{array}$ & $\begin{array}{c}\text { SUBSURFACE } \\
\text { SOILS } \\
\text { ( } \mu g / k g)\end{array}$ & $\begin{array}{c}\text { SEDIMENTS } \\
(\mu \mathrm{g} / \mathrm{kg})\end{array}$ & $\begin{array}{c}\text { GROUND } \\
\text { WATER } \\
(\mu \mathrm{g} / \mathrm{L})\end{array}$ & $\begin{array}{c}\text { SURFACE } \\
\text { WATERS } \\
(\mu \mathrm{g} / \mathrm{L})\end{array}$ \\
\hline \multicolumn{7}{|l|}{ VOLATILES } \\
\hline 1,1,1-TRICHLOROETHANE & 71556 & & $<980$ & $<69$ & $<50$ & $<5$ \\
\hline 1,1,2,2-TETRACHLOROETHANE & 79345 & & $<980$ & $<69$ & $<50$ & $<5$ \\
\hline 1,1,2-TRICHLOROETHANE & 79005 & & $<980$ & $<69$ & $<50$ & $<5$ \\
\hline 1,1-DICHLOROETHANE & 75343 & & $<980$ & $<69$ & $<50$ & $<5$ \\
\hline 1,1-DICHLOROETHENE & 75354 & & $<980$ & $<69$ & $<50$ & $<5$ \\
\hline 1,2-DICHLOROETHANE & 107062 & & $<980$ & $<69$ & $<50$ & $<5$ \\
\hline 1,2-DICHLOROETHENE (TOTAL) & 156605 & & $<980$ & $<69$ & $<50$ & $<5$ \\
\hline 1,2-DICHLOROPROPANE & 78875 & & $<980$ & $<69$ & $<50$ & $<5$ \\
\hline 2-BUTANONE & 78933 & & 4.30E+01 & $1.30 E+02$ & $1.20 E+01$ & $<10$ \\
\hline 2-HEXANONE & 591786 & & $<2000$ & $<140$ & $<100$ & $<10$ \\
\hline 4-METHYL-2-PENTANONE & & & $<2000$ & $<140$ & $<100$ & $<10$ \\
\hline ACETONE & 67641 & & $100000 \mathrm{D}$ & $360 \mathrm{~B}$ & $1400 \mathrm{~B}$ & 33B \\
\hline BENZENE & 71432 & & $9.20 E+03$ & $1.60 E+01$ & $1.30 E+03$ & $2.00 E+00$ \\
\hline BENZYL ALCOHOL & & & $<3600$ & $<13000$ & $<10$ & $<10$ \\
\hline BROMODICHLOROMETHANE & 75274 & & $<980$ & $<69$ & $<50$ & $<5$ \\
\hline BROMOFORM & 75252 & & $<980$ & $<69$ & $<50$ & $<5$ \\
\hline BROMOMETHANE & 74839 & & $<2000$ & $<140$ & $<100$ & $<10$ \\
\hline CARBON DISULFIDE & 75150 & & $<980$ & $<69$ & $<50$ & $<5$ \\
\hline CARBON TETRACHLORIDE & 56235 & & $<980$ & $<69$ & $<50$ & $<5$ \\
\hline CHLOROBENZENE & 108907 & & $<980$ & $<69$ & $<50$ & $<5$ \\
\hline CHLOROETHANE & 75003 & & $<2000$ & $<140$ & $<100$ & $<10$ \\
\hline CHLOROFORM & 67663 & & $1.40 E+02$ & $<69$ & $<50$ & $<5$ \\
\hline CHLOROMETHANE & 74873 & & $<2000$ & $<140$ & $<100$ & $<10$ \\
\hline CIS-1,3-DICHLOROPROPENE & 542756 & & $<980$ & $<69$ & $<50$ & $<5$ \\
\hline DIBROMOCHLOROMETHANE & 124481 & & $<980$ & $<69$ & $<50$ & $<5$ \\
\hline ETHYLBENZENE & 100414 & & $5.40 E+04$ & $<69$ & $2.90 E+02$ & $<5$ \\
\hline METHYLENE CHLORIDE & 75092 & & $2.50 E+02$ & $150 \mathrm{~B}$ & $170 \mathrm{~B}$ & $11 \mathrm{~B}$ \\
\hline STYRENE & 100425 & & $<980$ & $<69$ & $<50$ & $<5$ \\
\hline TETRACHLOROETHENE & 127184 & & $<980$ & $<69$ & $<50$ & $<5$ \\
\hline TOLUENE & 108883 & & $3.30 E+04$ & $7.00 E+00$ & $9.50 E+03$ & $<5$ \\
\hline TRANS-1,3-DICHLOROPROPENE & 10061026 & & $<980$ & $<69$ & $<50$ & $<5$ \\
\hline TRICHLOROETHENE & 79016 & & $<980$ & $<69$ & $<50$ & $<5$ \\
\hline VINYL ACETATE & 108054 & & $<2000$ & $<140$ & $<100$ & $<10$ \\
\hline VINYL CHLORIDE & 75014 & & $<2000$ & $<140$ & $<100$ & $<10$ \\
\hline XYLENES (TOTAL) & 1330207 & & $5.30 E+05$ & $6.50 E+01$ & $2.80 E+03$ & $<5$ \\
\hline \multicolumn{7}{|l|}{ SEMI-VOLATILES } \\
\hline 1,2,4-TRICHLOROBENZENE & 120821 & $<840$ & $<3600$ & $<13000$ & $<1000$ & $<10$ \\
\hline 1,2-DICHLOROBENZENE & 95501 & $<840$ & $<3600$ & $<13000$ & $<1000$ & $<10$ \\
\hline 1,2-DIPHENYLHYDRAZINE & 122667 & & $<3600$ & & & \\
\hline 1,3-DICHLOROBENZENE & 541731 & $<840$ & $<3600$ & $<13000$ & $<1000$ & $<10$ \\
\hline 1,4-DICHLOROBENZENE & 106467 & $<840$ & $<3600$ & $<13000$ & $<1000$ & $<10$ \\
\hline 2,4,5-TRICHLOROPHENOL & 95954 & $<4100$ & $<17000$ & $<64000$ & $<5000$ & \\
\hline 2,4,6-TRICHLOROPHENOL & 88062 & $<840$ & $<3600$ & $<13000$ & $<1000$ & $<10$ \\
\hline 2,4-DICHLOROPHENOL & 94757 & $<840$ & $<3600$ & $<13000$ & $<1000$ & $<10$ \\
\hline 2,4-DIMETHYLPHENOL & 105679 & $<840$ & $<3600$ & $<13000$ & $1.20 \mathrm{E}+01$ & $<10$ \\
\hline 2,4-DINTROPHENOL & 51285 & $<4100$ & $<17000$ & $<64000$ & $<5000$ & $<50$ \\
\hline 2,4-DINITROTOLUENE & 121142 & $<840$ & $<3600$ & $<13000$ & $<1000$ & $<10$ \\
\hline 2,6-DINITROTOLUENE & & $<840$ & $<3600$ & $<13000$ & $<1000$ & $<10$ \\
\hline 2-CHLORONAPHTHALENE & 91578 & $<840$ & $<3600$ & $<13000$ & $<1000$ & $<10$ \\
\hline 2-CHLOROPHENOL & 95578 & $<840$ & $<3600$ & $<13000$ & $<1000$ & $<10$ \\
\hline 2-METHYLNAPHTHALENE & 91576 & $3.60 E+03$ & 8.30E+03 & $2.00 E+03$ & $6.20 E+02$ & $<10$ \\
\hline 2-METHYLPHENOL & 95487 & $<840$ & $<3600$ & $<13000$ & $5.10 E+01$ & $<10$ \\
\hline 4-METHYLPHENOL & 106445 & $<840$ & $<3600$ & $<13000$ & $5.00 E+00$ & $<10$ \\
\hline
\end{tabular}


TABLE D.1. Maximum Contaminant Concentrations in Source Areas ST10 and SS14

\begin{tabular}{|c|c|c|c|c|c|c|}
\hline ANALYTES & CAS & $\begin{array}{c}\text { SURFACE } \\
\text { SOILS } \\
\text { ( } \mu \mathrm{g} / \mathrm{kg}) \\
\end{array}$ & $\begin{array}{c}\text { SUBSURFACE } \\
\text { SOILS } \\
(\mu \mathrm{g} / \mathrm{kg})\end{array}$ & $\begin{array}{c}\text { SEDIMENTS } \\
\text { ( } \mu \mathrm{g} / \mathrm{kg})\end{array}$ & $\begin{array}{c}\text { GROUND } \\
\text { WATER } \\
(\mu \mathrm{g} / \mathrm{L})\end{array}$ & $\begin{array}{c}\text { SURFACE } \\
\text { WATERS } \\
(\mu \mathrm{g} / L)\end{array}$ \\
\hline 2-NITROANILINE & 88747 & $<4100$ & $<17000$ & $<64000$ & $<5000$ & $<50$ \\
\hline 2-NITROPHENOL & & $<840$ & $<3600$ & $<13000$ & $<1000$ & $<10$ \\
\hline 3,3'-DICHLOROBENZIDINE & 91941 & $<1700$ & $<7200$ & $<26000$ & $<2000$ & $<20$ \\
\hline 3-NITROANILINE & & $<4100$ & $<17000$ & $<64000$ & $<5000$ & $<50$ \\
\hline 4,6-DINITRO-2-METHYLPHENOL & 534521 & $<4100$ & $<17000$ & $<64000$ & $<5000$ & $<50$ \\
\hline 4-BROMOPHENYL-PHENYLETHER & & $<840$ & $<3600$ & $<13000$ & $<1000$ & $<10$ \\
\hline 4-CHOLOR-3-METHYLPHENOL & & $<840$ & $<3600$ & $<13000$ & $<1000$ & $<10$ \\
\hline 4-CHLOROANILINE & 106478 & $<840$ & $<3600$ & $<13000$ & $<1000$ & $<10$ \\
\hline 4-CHLOROPHENYL-PHENYLETHER & 7005723 & $<840$ & $<3600$ & $<13000$ & $<1000$ & $<10$ \\
\hline 4-NITROANILINE & 100016 & $<4100$ & $<17000$ & $<64000$ & $<5000$ & $<50$ \\
\hline 4-NITROPHENOL & 100027 & $<4100$ & $<17000$ & $<64000$ & $<5000$ & $<50$ \\
\hline ACENAPHTHENE & 83329 & $<840$ & $5.40 E+01$ & $<13000$ & $<1000$ & $<10$ \\
\hline ACENAPHTHYLENE & 208968 & $<840$ & $<3600$ & $<13000$ & $<1000$ & $<10$ \\
\hline ANTHRACENE & 120127 & $2.30 E+02$ & $<3600$ & $7.80 E+01$ & $9.00 E+00$ & $<10$ \\
\hline BENZO(A)ANTHRACENE & 56553 & $2.60 E+02$ & $5.30 E+01$ & $4.00 E+02$ & $<10$ & $<10$ \\
\hline BENZO(A)PYRENE & 50328 & $2.90 E+02$ & $<3600$ & $8.60 E+01$ & $<10$ & $<10$ \\
\hline BENZO(B)FLUORANTHENE & 205992 & $3.80 E+02$ & $<3600$ & $3.20 E+02$ & $<10$ & $<10$ \\
\hline BENZO(G,H,I)PERYLENE & & $2.20 E+02$ & $<3600$ & $1.00 E+02$ & $<10$ & $<10$ \\
\hline BENZO(K)FLUORANTHENE & 207089 & $2.90 E+02$ & $5.50 E+01$ & $2.40 E+02$ & $<10$ & $<10$ \\
\hline BENZOIC ACID & 65850 & $<4100$ & $<17000$ & $<64000$ & $8.40 E+01$ & $<50$ \\
\hline BIS(2-CHLOROETHOXY)METHANE & & $<840$ & $<3600$ & $<13000$ & $<10$ & $<10$ \\
\hline BIS(2-CHLOROETHYL)ETHER & 111444 & $<840$ & $<3600$ & $<13000$ & $<10$ & \\
\hline BIS(2-CHLOROISOPROPYL)ETHER & 39638329 & $<840$ & $<3600$ & $<13000$ & $<10$ & $<10$ \\
\hline BIS(2-ETHYLHEXYL)PHTHALATE & 117817 & $3.20 \mathrm{E}+02$ & $1.20 E+02$ & $1400 \mathrm{BJ}$ & $1.10 E+04$ & $<10$ \\
\hline BUTYLBENZYLPHTHALATE & & $9.80 \mathrm{E}+02$ & $<3600$ & $4.30 E+02$ & $8.00 E+00$ & $<10$ \\
\hline CHRYSENE & 218019 & $3.30 E+02$ & $8.10 E+01$ & $6.00 E+02$ & $<1000$ & $<10$ \\
\hline DI-N-BUTYLPHTHALATE & 84742 & $<840$ & $170 \mathrm{~B}$ & $<13000$ & $3 B$ & $<10$ \\
\hline DI-N-OCTYLPHTHALATE & 117840 & $3.20 E+02$ & $<3600$ & $<13000$ & $<10$ & $<10$ \\
\hline DIBENZ(A,H)ANTHRACENE & 53703 & $9.40 E+01$ & $<3600$ & $<13000$ & $<10$ & $<10$ \\
\hline DIBENZOFURAN & & $<840$ & $7.40 E+01$ & $<13000$ & $<10$ & $<10$ \\
\hline DIETHYLPHTHALATE & 84662 & $<840$ & $110 \mathrm{~B}$ & $<13000$ & $<10$ & $<10$ \\
\hline DIMETHYLPHTHALATE & 131113 & $<840$ & $<3600$ & $<13000$ & $<10$ & $<10$ \\
\hline FLUORANTHENE & 206440 & $6.50 E+02$ & $5.70 E+02$ & $2.10 \mathrm{E}+03$ & $1.40 E+01$ & $<10$ \\
\hline FLUORENE & 86737 & $<840$ & $1.10 E+03$ & $<13000$ & $5.20 E+01$ & $<10$ \\
\hline HEXACHLOROBENZENE & 118741 & $<840$ & $<3600$ & $<13000$ & $<10$ & $<10$ \\
\hline HEXACHLOROBUTADIENE & 87683 & $<840$ & $<3600$ & $<13000$ & $<10$ & $<10$ \\
\hline HEXACHLOROCYCLOPENTADIENE & 77474 & $<840$ & $<3600$ & $<13000$ & $<10$ & $<10$ \\
\hline HEXACHLOROETHANE & 67721 & $<840$ & $<3600$ & $<13000$ & $<10$ & $<10$ \\
\hline INDENO(1,2,3-CD)PYRENE & 193395 & $2.00 E+02$ & $<3600$ & $1.10 E+02$ & $<10$ & $<10$ \\
\hline ISOPHORONE & 78591 & $<840$ & $<3600$ & $<13000$ & $<10$ & $<10$ \\
\hline N-NITROSO-DI-N-PROPYLAMINE & 621647 & $<840$ & $<3600$ & $<13000$ & $<10$ & $<10$ \\
\hline N-NITROSODIPHENYLAMINE (1) & 86306 & $9.90 E+01$ & $<3600$ & $2.50 E+03$ & $1.10 E+02$ & $<10$ \\
\hline NAPHTHALENE & 91203 & $<840$ & $4.60 \mathrm{E}+03$ & $<13000$ & $5.00 E+02$ & $<10$ \\
\hline NITROBENZENE & 98953 & $<840$ & $<3600$ & $<13000$ & $<10$ & $<10$ \\
\hline PENTACHLOROPHENOL & 87865 & $<4100$ & $<17000$ & $<64000$ & $<50$ & $<50$ \\
\hline PHENANTHRENE & 85018 & $4.80 E+02$ & $6.90 E+02$ & $9.00 E+02$ & $3.50 E+01$ & $<10$ \\
\hline PHENOL & 108952 & $<840$ & $<3600$ & $<13000$ & $8.60 E+01$ & $<10$ \\
\hline PYRENE & 129000 & $5.20 E+02$ & $3.90 E+02$ & $1.70 E+03$ & $1.00 E+01$ & $<10$ \\
\hline \multicolumn{7}{|l|}{$\mathrm{TPH}$} \\
\hline TOTAL PETROLEUM HYDROCARBONS & & $8.09 E+06$ & $1.56 \mathrm{E}+07$ & $1.39 E+07$ & $5.32 E+05$ & $<50$ \\
\hline \multicolumn{7}{|l|}{ PCB } \\
\hline AROCLOR-1016 & 12674112 & $<340$ & $<167$ & $<560$ & $<5$ & $<0.5$ \\
\hline AROCLOR-1221 & 1104282 & $<840$ & $<333$ & $<1400$ & $<12$ & $<1.2$ \\
\hline
\end{tabular}




\begin{tabular}{|c|c|c|c|c|c|c|}
\hline ANALYTES & CAS & $\begin{array}{c}\text { SURFACE } \\
\text { SOILS } \\
(\mu \mathrm{g} / \mathrm{kg})\end{array}$ & $\begin{array}{c}\text { SUBSURFACE } \\
\text { SOILS } \\
(\mu \mathrm{g} / \mathrm{kg})\end{array}$ & SEDIMENTS & $\begin{array}{c}\text { GROUND } \\
\text { WATER } \\
(\mu \mathrm{g} / \mathrm{L})\end{array}$ & $\begin{array}{c}\text { SURFACE } \\
\text { WATERS } \\
(\mu \mathrm{g} / \mathrm{L})\end{array}$ \\
\hline AROCLOR-1232 & 11141165 & $<840$ & $<333$ & $<1400$ & $<12$ & $<1.2$ \\
\hline AROCLOR-1242 & 53469219 & $<340$ & $<167$ & $<560$ & $<5$ & $<0.5$ \\
\hline AROCLOR-1248 & 12672296 & $<340$ & $<34$ & $<560$ & $<2$ & $<0.2$ \\
\hline AROCLOR-1254 & 11091691 & $<170$ & $<34$ & $<280$ & $<2$ & $<0.2$ \\
\hline AROCLOR-1260 & 11096825 & $<170$ & $<34$ & $2.60 \mathrm{E}+02$ & $<2$ & $<0.2$ \\
\hline \multicolumn{7}{|l|}{ PESTICIDES } \\
\hline $4,4^{\prime}-\mathrm{DDD}$ & 72548 & $7.30 E+01$ & $1.00 E+01$ & $3.20 E+02$ & $<1$ & $<0.1$ \\
\hline 4,4'-DDE & 72559 & $1.20 E+01$ & $8.50 E+00$ & $6.30 E+01$ & $<0.4$ & $<0.04$ \\
\hline $4,4^{\prime}-$-DDT & 50293 & $4.40 E+02$ & $5.80 E+01$ & $1.50 E+02$ & $<1$ & $<0.1$ \\
\hline ALDRIN & 309002 & $1.50 E+01$ & $<5.8$ & $<47$ & $<0.4$ & $<0.04$ \\
\hline ALPHA-BHC & 319846 & $<21$ & $<4.3$ & $<35$ & $<0.3$ & $<0.03$ \\
\hline ALPHA-CHLORDANE & 57749 & $<35$ & $<7.1$ & $<57$ & $<0.5$ & $<0.05$ \\
\hline BETA-BHC & 319857 & $<42$ & $<8.6$ & $<70$ & $<0.5$ & $<0.05$ \\
\hline DELTA-BHC & 319868 & $<42$ & $<8.6$ & $<70$ & $<0.5$ & $<0.05$ \\
\hline DIELDRIN & 60571 & $<14$ & $<2.8$ & $<23$ & $<0.2$ & $<0.02$ \\
\hline ENDOSULFAN I & & $<42$ & $<8.6$ & $<70$ & $<0.5$ & $<0.05$ \\
\hline ENDOSULFAN \|I & & $<28$ & $<5.8$ & $<47$ & $<0.4$ & $<0.04$ \\
\hline ENDOSULFAN SULFATE & & $<84$ & $<17$ & $<140$ & $<1$ & $<0.1$ \\
\hline ENDRIN & 72208 & $<42$ & $<8.6$ & $<70$ & $<0.6$ & $<0.06$ \\
\hline ENDRIN KETONE & & $<84$ & $<17$ & $<140$ & $<1$ & $<0.1$ \\
\hline GAMMA-BHC (LINDANE) & 58899 & $<28$ & $<5.8$ & $<47$ & $<0.4$ & $<0.04$ \\
\hline GAMMA-CHLORDANE & 57749 & $<35$ & $<7.1$ & $<57$ & $<0.5$ & 5.00E-02 \\
\hline HEPTACHLOR & 76448 & $<21$ & $<4.3$ & $<35$ & $<0.3$ & $<0.03$ \\
\hline HEPTACHLOR EPOXIDE & 1024573 & $<42$ & $<8.6$ & $<70$ & $<0.5$ & $<0.05$ \\
\hline METHOXYCHLOR & 72435 & $<170$ & $<34$ & $<280$ & $<5$ & $<0.5$ \\
\hline TOXAPHENE & 8001352 & $<690$ & $<140$ & $<1200$ & $<10$ & $<1$ \\
\hline \multicolumn{7}{|l|}{ METALS } \\
\hline ALUMINUM & 7429905 & $1.90 E+07$ & $7.40 E+06$ & $2.14 E+07$ & $4.19 E+03$ & $7.26 \mathrm{E}+01$ \\
\hline ANTIMONY & 7440360 & $1.08 E+04$ & $<14000$ & $9.30 E+03$ & $1.34 E+01$ & $<11.3$ \\
\hline ARSENIC & 7440382 & $2.32 E+04$ & $7.70 E+03$ & $6.72 E+04$ & $5.14 \mathrm{E}+01$ & $8.90 \mathrm{E}+00$ \\
\hline BARIUM & 7440393 & $4.73 E \div 05$ & $9.00 E+04$ & $6.63 E+05$ & $2.43 E+02$ & $1.37 E+02$ \\
\hline BERYLLIUM & 7440417 & $2.50 E+02$ & $<1200$ & $3.00 E+02$ & $4.60 \mathrm{E}-01$ & $<0.2$ \\
\hline CADMIUM & 7440439 & $1.50 E+03$ & $5.50 E+03$ & $2.40 E+03$ & $4.30 E+00$ & 1.00 E-01 \\
\hline CALCIUM & & $9.01 E+06$ & $3.50 E+06$ & $5.01 E+07$ & $6.02 E+04$ & $6.10 E+04$ \\
\hline CHROMIUM & 7440473 & $3.54 E+04$ & $1.70 E+04$ & $3.99 E+04$ & $7.70 \mathrm{E}+00$ & $<1.9$ \\
\hline COBALT & 7440484 & $2.16 E+04$ & $<12000$ & $1.85 E+04$ & $5.50 E_{+00}$ & $<2.9$ \\
\hline COPPER & 7440508 & $7.08 E+04$ & $2.00 E+04$ & $1.01 E+05$ & $2.39 E+01$ & $<1.7$ \\
\hline IRON & 15438310 & $4.07 E+07$ & $1.60 E+07$ & $4.08 E+07$ & $2.11 E+04$ & $1.50 E_{+} 02$ \\
\hline LEAD & 7439921 & $1.74 E+05$ & $3.82 E+04$ & $8.90 E+04$ & $4.57 E_{+} 01$ & $1.70 E+00$ \\
\hline MAGNESIUM & 7786303 & $1.08 E+07$ & $4.40 E+06$ & $1.03 E+07$ & $1.23 E+04$ & $1.07 E+04$ \\
\hline MANGANESE & 7439965 & $7.75 E+05$ & $2.90 E+05$ & $2.35 E+06$ & $3.72 E+03$ & $1.81 E+03$ \\
\hline MERCURY & 7439976 & $4.40 E+01$ & $<80$ & $1.00 E+03$ & $<0.2$ & $<0.1$ \\
\hline NICKEL & 7440020 & $4.51 E+04$ & $1.80 E+04$ & $4.28 E+04$ & $2.03 E+01$ & $9.40 E+00$ \\
\hline POTASSIUM & 7447407 & $1.37 E+06$ & $<1200000$ & $1.89 E+06$ & $3.72 E+03$ & 4.16E+03 \\
\hline SELENIUM & 7782492 & $2.20 E+02$ & $<1100$ & $8.00 E+02$ & 5.1OE-01 & 5.40E-01 \\
\hline SILVER & 7440224 & $7.00 E+02$ & $<2300$ & $<1400$ & $<10$ & $<1.8$ \\
\hline SODIUM & 7647145 & $8.79 E+05$ & $<1200000$ & $9.90 E+05$ & $5.70 \mathrm{E}+03$ & $5.00 E+03$ \\
\hline THALLIUM & 7440280 & $2.70 E+02$ & $<2300$ & $<640$ & $9.00 E-01$ & $<0.8$ \\
\hline VANADIUM & 7440622 & $8.14 E+04$ & $2.80 E+04$ & $7.45 E+04$ & $1.99 E+01$ & $<1.3$ \\
\hline ZINC & 7646857 & $9.07 E+04$ & $3.90 E+04$ & $3.85 E+05$ & $3.86 E+01$ & $5.07 E+01$ \\
\hline
\end{tabular}




\begin{tabular}{|c|c|c|c|c|c|c|}
\hline ANALYTES & CAS & $\begin{array}{l}\text { SURFACE } \\
\text { SOILS } \\
(\mu \mathrm{g} / \mathrm{kg})\end{array}$ & $\begin{array}{c}\text { SUBSURFACE } \\
\text { SOILS } \\
\text { ( } \mu \mathrm{g} / \mathrm{kg})\end{array}$ & $\begin{array}{c}\text { SEDIMENTS } \\
\text { ( } \mu \mathrm{g} / \mathrm{kg})\end{array}$ & $\begin{array}{c}\text { GROUND } \\
\text { WATER } \\
(\mu \mathrm{g} / \mathrm{L})\end{array}$ & $\begin{array}{c}\text { SURFACE } \\
\text { WATERS } \\
(\mu \mathrm{g} / \mathrm{L})\end{array}$ \\
\hline \multicolumn{7}{|l|}{ VOLATILES } \\
\hline 1,1,1-TRICHLOROETHANE & 71556 & & $<650$ & $<1$ & $<5$ & $<1$ \\
\hline 1,1,2,2-TETRACHLOROETHANE & 79345 & & $<650$ & $<1$ & $<5$ & $<1$ \\
\hline 1,1,2-TRICHLOROETHANE & 79005 & & $<650$ & $<1$ & $<5$ & $<1$ \\
\hline 1,1-DICHLOROETHANE & 75343 & & $<650$ & $<1$ & $<5$ & $<1$ \\
\hline 1,1-DICHLOROETHENE & 75354 & & $<650$ & $<1$ & $<5$ & $<1$ \\
\hline 1,2-DICHLOROETHANE & 107062 & & $<650$ & $<1$ & $<5$ & $<1$ \\
\hline 1,2-DICHLOROETHENE (TOTAL) & 156605 & & $<650$ & $<1$ & $1.00 E+00$ & \\
\hline 1,2-DICHLOROPROPANE & 78875 & & $<650$ & $<1$ & $<5$ & $<1$ \\
\hline 2-BUTANONE & 78933 & & $<1300$ & & $<10$ & \\
\hline 2-HEXANONE & 591786 & & $<1300$ & & $<10$ & \\
\hline 4-METHYL-2-PENTANONE & & & $<1300$ & & $<10$ & \\
\hline ACETONE & 67641 & & $2.00 E+01$ & & $12 B$ & \\
\hline BENZENE & 71432 & & $<650$ & $<1$ & $1.00 E+00$ & $<1$ \\
\hline BENZYL ALCOHOL & & $<780$ & $<410$ & & $<10$ & $<10$ \\
\hline BROMODICHLOROMETHANE & 75274 & & $<650$ & $<1$ & $<5$ & $<1$ \\
\hline BROMOFORM & 75252 & & $<650$ & $<1$ & $<5$ & $<1$ \\
\hline BROMOMETHANE & 74839 & & $<1300$ & $<1$ & $<10$ & $<1$ \\
\hline CARBON DISULFIDE & 75150 & & $<650$ & & $<5$ & \\
\hline CARBON TETRACHLORIDE & 56235 & & $<650$ & $<1$ & $<5$ & $<1$ \\
\hline CHLOROBENZENE & 108907 & & $<650$ & $<1$ & $<5$ & $<1$ \\
\hline CHLOROETHANE & 75003 & & $<1300$ & $<1$ & $<10$ & $<1$ \\
\hline CHLOROFORM & 67663 & & $1.00 \mathrm{E}+\infty 0$ & $<1$ & $<5$ & $<1$ \\
\hline CHLOROMETHANE & 74873 & & $<1300$ & $<1$ & $<10$ & $<1$ \\
\hline CIS-1,3-DICHLOROPROPENE & 542756 & & $<650$ & $<1$ & $<5$ & $<1$ \\
\hline DIBROMOCHLOROMETHANE & 124481 & & $<650$ & $<1$ & $<5$ & $<1$ \\
\hline ETHYLBENZENE & 100414 & & $<650$ & $<1$ & $<5$ & $<1$ \\
\hline METHYLENE CHLORIDE & 75092 & & $910 \mathrm{~B}$ & & $12 B$ & \\
\hline STYRENE & 100425 & & $<650$ & $<1$ & $<5$ & $<1$ \\
\hline TETRACHLOROETHENE & 127184 & & $4.00 E+00$ & $<1$ & $<5$ & $<1$ \\
\hline TOLUENE & 108883 & & $2.20 E+02$ & $<1$ & $<5$ & $<1$ \\
\hline TRANS-1,3-DICHLOROPROPENE & 10061026 & & $<650$ & & $<5$ & \\
\hline TRICHLOROETHENE & 79016 & & $<650$ & $<1$ & $<5$ & $<1$ \\
\hline VINYL ACETATE & 108054 & & $<1300$ & & $<10$ & \\
\hline VINYL CHLORIDE & 75014 & & $<1300$ & $<1$ & $<10$ & $<1$ \\
\hline XYLENES (TOTAL) & 1330207 & & $3.30 E+03$ & $<1$ & $<5$ & $<1$ \\
\hline \multicolumn{7}{|l|}{ SEMI-VOLATILES } \\
\hline 1,2,4-TRICHLOROBENZENE & 120821 & $<780$ & $<410$ & $<200$ & $<10$ & $<10$ \\
\hline 1,2-DICHLOROBENZENE & 95501 & $<780$ & $<410$ & $<200$ & $<10$ & $<10$ \\
\hline 1,2-DIPHENYLHYDRAZINE & 122667 & & $<390$ & & & \\
\hline 1,3-DICHLOROBENZENE & 541731 & $<780$ & $<410$ & $<200$ & $<10$ & $<10$ \\
\hline 1,4-DICHLOROBENZENE & 106467 & $<780$ & $<410$ & $<200$ & $<10$ & $<10$ \\
\hline 2,4,5-TRICHLOROPHENOL & 95954 & $<3800$ & $<2000$ & $<200$ & & $<10$ \\
\hline 2,4,6-TRICHLOROPHENOL & 88062 & $<780$ & $<410$ & $<200$ & $<10$ & $<10$ \\
\hline 2,4-DICHLOROPHENOL & 94757 & $<780$ & $<410$ & $<200$ & $<10$ & $<10$ \\
\hline 2,4-DIMETHYLPHENOL & 105679 & $<780$ & $<410$ & $<200$ & $<10$ & $<10$ \\
\hline 2,4-DINITROPHENOL & 51285 & $<3800$ & $<2000$ & $<200$ & $<50$ & $<10$ \\
\hline 2,4-DINITROTOLUENE & 121142 & $<780$ & $<410$ & $<200$ & $<10$ & $<10$ \\
\hline 2,6-DINITROTOLUENE & & $<780$ & $<410$ & $<200$ & $<10$ & $<10$ \\
\hline 2-CHLORONAPHTHALENE & 91578 & $<780$ & $<410$ & $<200$ & $<10$ & $<10$ \\
\hline 2-CHLOROPHENOL & 95578 & $<780$ & $<410$ & $<200$ & $<10$ & $<10$ \\
\hline 2-METHYLNAPHTHALENE & 91576 & $<780$ & $<410$ & $<200$ & $<10$ & $<10$ \\
\hline 2-METHYLPHENOL & 95487 & $<780$ & $<410$ & $<200$ & $<10$ & $<10$ \\
\hline 4-METHYLPHENOL & 106445 & $<780$ & $<410$ & $<200$ & $<10$ & $<10$ \\
\hline
\end{tabular}




\begin{tabular}{|c|c|c|c|c|c|c|}
\hline ANALYTES & CAS & $\begin{array}{c}\text { SURFACE } \\
\text { SOILS } \\
(\mu \mathrm{g} / \mathrm{kg}\rangle\end{array}$ & $\begin{array}{c}\text { SUBSURFACE } \\
\text { SOILS } \\
(\mu \mathrm{g} / \mathrm{kg})\end{array}$ & $\begin{array}{c}\text { SEDIMENTS } \\
(\mu \mathrm{g} / \mathrm{kg})\end{array}$ & $\begin{array}{c}\text { GROUND } \\
\text { WATER } \\
(\mu g / L)\end{array}$ & $\begin{array}{c}\text { SURFACE } \\
\text { WATERS } \\
(\mu \mathrm{g} / \mathrm{L})\end{array}$ \\
\hline 2-NITROANILINE & 88747 & $<3800$ & $<2000$ & $<200$ & $<50$ & $<10$ \\
\hline 2-NITROPHENOL & & $<780$ & $<410$ & $<200$ & $<10$ & $<10$ \\
\hline 3,3'-DICHLOROBENZIDINE & 91941 & $<1600$ & $<820$ & $<200$ & $<20$ & $<10$ \\
\hline 3-NITROANILINE & & $<3800$ & $<2000$ & $<200$ & $<50$ & $<10$ \\
\hline 4,6-DINITRO-2-METHYLPHENOL & 534521 & $<3800$ & $<2000$ & $<200$ & $<50$ & $<10$ \\
\hline 4-BROMOPHENYL-PHENYLETHER & & $<780$ & $<410$ & $<200$ & $<10$ & $<10$ \\
\hline 4-CHOLOR-3-METHYLPHENOL & & $<780$ & $<410$ & $<200$ & $<10$ & $<10$ \\
\hline 4-CHLOROANILINE & 106478 & $<780$ & $<410$ & $<200$ & $<10$ & $<10$ \\
\hline 4-CHLOROPHENYL-PHENYLETHER & 7005723 & $<780$ & $<410$ & $<200$ & $<10$ & $<10$ \\
\hline 4-NITROANILINE & 100016 & $<3800$ & $<2000$ & $<200$ & $<50$ & $<10$ \\
\hline 4-NITROPHENOL & 100027 & $<3800$ & $<2000$ & $<200$ & $<50$ & $<10$ \\
\hline ACENAPHTHENE & 83329 & $<780$ & $<410$ & $<200$ & $<10$ & $<10$ \\
\hline ACENAPHTHYLENE & 208968 & $<780$ & $<410$ & $<200$ & $<10$ & $<10$ \\
\hline ANTHRACENE & 120127 & $<780$ & $<410$ & $<200$ & $<10$ & $<10$ \\
\hline BENZO(A)ANTHRACENE & 56553 & $<780$ & $<410$ & $<200$ & $<10$ & $<10$ \\
\hline BENZO(A)PYRENE & 50328 & $<780$ & $<410$ & $<200$ & $<10$ & $<10$ \\
\hline BENZO(B)FLUORANTHENE & 205992 & $<780$ & $<410$ & $<200$ & $<10$ & $<10$ \\
\hline BENZO(G,H,I)PERYLENE & & $<780$ & $<410$ & $<200$ & $<10$ & $<10$ \\
\hline BENZO(K)FLUORANTHENE & 207089 & $<780$ & $<410$ & $<200$ & $<10$ & $<10$ \\
\hline BENZOIC ACID & 65850 & $<3800$ & $<2000$ & $<200$ & $<50$ & $<10$ \\
\hline BIS(2-CHLOROETHOXY)METHANE & & $<780$ & $<410$ & $<200$ & $<10$ & $<10$ \\
\hline BIS(2-CHLOROETHYL)ETHER & 111444 & $<780$ & $<410$ & $<200$ & & $<10$ \\
\hline BIS(2-CHLOROISOPROPYL)ETHER & 39638329 & $<780$ & $<410$ & $<200$ & $<10$ & $<10$ \\
\hline BIS(2-ETHYLHEXYL)PHTHALATE & 117817 & $1.50 E+02$ & $9.90 E+02$ & $<200$ & $4.00 E+00$ & $<10$ \\
\hline BUTYLBENZYLPHTHALATE & & $<780$ & $<410$ & $<200$ & $<10$ & $<10$ \\
\hline CHRYSENE & 218019 & $<780$ & $<410$ & $<200$ & $<10$ & $<10$ \\
\hline DI-N-BUTYLPHTHALATE & 84742 & $<780$ & 86BJ & $5.01 E+02$ & $<10$ & $<10$ \\
\hline DI-N-OCTYLPHTHALATE & 117840 & $<780$ & $<410$ & $<200$ & $<10$ & $<10$ \\
\hline DIBENZ(A,H)ANTHRACENE & 53703 & $<780$ & $<410$ & $<200$ & $<10$ & $<10$ \\
\hline DIBENZOFURAN & & $<780$ & $<410$ & $<200$ & $<10$ & $<10$ \\
\hline DIETHYLPHTHALATE & 84662 & $<780$ & $<410$ & $<200$ & $<10$ & $<10$ \\
\hline DIMETHYLPHTHALATE & 131113 & $<780$ & $<410$ & $<200$ & $<10$ & $<10$ \\
\hline FLUORANTHENE & 206440 & $1.10 E+02$ & $<410$ & $5.21 E+02$ & $<10$ & $<10$ \\
\hline FLUORENE & 86737 & $<780$ & $<410$ & $<200$ & $<10$ & $<10$ \\
\hline HEXACHLOROBENZENE & 118741 & $<780$ & $<410$ & $<200$ & $<10$ & $<10$ \\
\hline HEXACHLOROBUTADIENE & 87683 & $<780$ & $<410$ & $<200$ & $<10$ & $<10$ \\
\hline HEXACHLOROCYCLOPENTADIENE & 77474 & $<780$ & $<410$ & $<200$ & $<10$ & $<10$ \\
\hline HEXACHLOROETHANE & 67721 & $<780$ & $<410$ & $<200$ & $<10$ & $<10$ \\
\hline INDENO(1,2,3-CD)PYRENE & 193395 & $<780$ & $<410$ & $<200$ & $<10$ & $<10$ \\
\hline ISOPHORONE & 78591 & $<780$ & $<410$ & $<200$ & $<10$ & $<10$ \\
\hline N-NITROSO-DI-N-PROPYLAMINE & 621647 & $<780$ & $<410$ & $<200$ & $<10$ & $<10$ \\
\hline N-NITROSODIPHENYLAMINE (1) & 86306 & $<780$ & $<410$ & $<200$ & $<10$ & $<10$ \\
\hline NAPHTHALENE & 91203 & $<780$ & $<410$ & $<200$ & $<10$ & $<10$ \\
\hline NITROBENZENE & 98953 & $<780$ & $<410$ & $<200$ & $<10$ & $<10$ \\
\hline PENTACHLQROPHENOL & 87865 & $<3800$ & $<2000$ & $<200$ & $<50$ & $<10$ \\
\hline PHENANTHHIRENE & 85018 & $<780$ & $<410$ & $<200$ & $<10$ & $<10$ \\
\hline PHENOL & 108952 & $<780$ & $<410$ & $<200$ & $<10$ & $<10$ \\
\hline PYRENE & 129000 & $9.10 E+01$ & $<410$ & $<200$ & $<10$ & $<10$ \\
\hline \multicolumn{7}{|l|}{ TPH } \\
\hline TOTAL PETROLEUM HYDROCARBONS & & $2.00 \mathrm{E}+05$ & $2.35 E+07$ & & $9.00 E+01$ & \\
\hline \multicolumn{7}{|l|}{ PCB } \\
\hline AROCLOR-1016 & 12674112 & $<370$ & $<150$ & & $<0.5$ & \\
\hline AROCLOR-1221 & 1104282 & $<920$ & $<370$ & & $<1.2$ & \\
\hline
\end{tabular}


IABLE D.2. Maximum Contaminant Concentrations in Source Area ST11

\begin{tabular}{|c|c|c|c|c|c|}
\hline ANALYTES & CAS & $\begin{array}{c}\text { SURFACE } \\
\text { SOILS } \\
(\mu \mathrm{g} / \mathrm{kg})\end{array}$ & 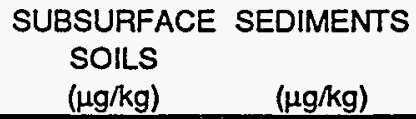 & $\begin{array}{l}\text { GROUND } \\
\text { WATER } \\
(\mu \mathrm{g} / \mathrm{L})\end{array}$ & $\begin{array}{c}\text { SURFACE } \\
\text { WATERS } \\
(\mu \mathrm{g} / L)\end{array}$ \\
\hline AROCLOR-1232 & 11141165 & $<920$ & $<370$ & $<1.2$ & \\
\hline AROCLOR-1242 & 53469219 & $<370$ & $<150$ & $<0.5$ & \\
\hline AROCLOR-1248 & 12672296 & $<370$ & $<74$ & $<0.2$ & \\
\hline AROCLOR-1254 & 11091691 & $<180$ & $<74$ & $<0.2$ & \\
\hline AROCLOR-1260 & 11096825 & $<180$ & $<74$ & $<0.2$ & \\
\hline \multicolumn{6}{|l|}{ PESTICIDES } \\
\hline $4,4^{\prime}-D D D$ & 72548 & $3.10 \mathrm{E}+01$ & $<34$ & $<0.1$ & \\
\hline 4,4'-DDE & 72559 & $7.20 \mathrm{E}+01$ & $<12$ & $<0.04$ & \\
\hline 4,4'-DDT & 50293 & $3.50 E+02$ & $8.90 \mathrm{E}+01$ & $<0.1$ & \\
\hline ALDRIN & 309002 & $<31$ & $<12$ & $<0.04$ & \\
\hline ALPHA-BHC & 319846 & $<23$ & $<9.2$ & $<0.03$ & \\
\hline ALPHA-CHLORDANE & 57749 & $<38$ & $<15$ & $<0.05$ & \\
\hline BETA-BHC & 319857 & $<46$ & $<18$ & $<0.05$ & \\
\hline DELTA-BHC & 319868 & $<46$ & $<18$ & $<0.05$ & \\
\hline DIELDRIN & 60571 & $<15$ & $<6$ & $<0.02$ & \\
\hline ENDOSULFAN I & & $<46$ & $<18$ & $<0.05$ & \\
\hline ENDOSULFAN II & & $<31$ & $<12$ & $<0.04$ & \\
\hline ENDOSULFAN SULFATE & & $<92$ & $<37$ & $<0.1$ & \\
\hline ENDRIN & 72208 & $<46$ & $<18$ & $<0.06$ & \\
\hline ENDRIN KETONE & & $<92$ & $<37$ & $<0.1$ & \\
\hline GAMMA-BHC (LINDANE) & 58899 & $<31$ & $<12$ & $<0.04$ & \\
\hline GAMMA-CHLORDANE & 57749 & $<38$ & $<15$ & $<0.05$ & \\
\hline HEPTACHLOR & 76448 & $<23$ & $<9.2$ & $<0.03$ & \\
\hline HEPTACHLOR EPOXIDE & 1024573 & $<46$ & $<18$ & $<0.05$ & \\
\hline METHOXYCHLOR & 72435 & $<180$ & $<74$ & $<0.5$ & \\
\hline TOXAPHENE & 8001352 & $<770$ & $<310$ & $<1$ & \\
\hline \multicolumn{6}{|l|}{ METALS } \\
\hline ALUMINUM & 7429905 & $2.48 E+07$ & $1.30 E+07$ & $2.57 E+03$ & \\
\hline ANTIMONY & 7440360 & $7.10 E+03$ & $<15000$ & $<11.3$ & \\
\hline ARSENIC & 7440382 & $2.19 E+04$ & $1.22 E+04$ & $6.00 E+01$ & \\
\hline BARIUM & 7440393 & $2.75 E+05$ & $1.30 E+05$ & $2.33 E+02$ & \\
\hline BERYLLIUM & 7440417 & $5.20 E+02$ & $<1300$ & $<0.2$ & \\
\hline CADMIUM & 7440439 & $1.60 \mathrm{E}+03$ & $<1300$ & 3.30E-01 & \\
\hline CALCIUM & & $8.61 E_{+06}$ & $5.50 E+06$ & $6.50 E+04$ & \\
\hline CHROMIUM & 7440473 & $5.46 E+04$ & $2.40 E+04$ & $4.20 E_{+} 00$ & \\
\hline COBALT & 7440484 & $2.09 E+04$ & $1.30 E+04$ & $4.80 \mathrm{E}+00$ & \\
\hline COPPER & 7440508 & $6.20 E+04$ & $3.90 E+04$ & $1.74 E+01$ & \\
\hline IRON & 15438310 & $4.19 E+07$ & $2.70 E+07$ & $1.17 E_{+} 04$ & \\
\hline LEAD & 7439921 & $9.50 E+04$ & $1.20 E+04$ & $4.50 E+00$ & \\
\hline MAGNESIUM & 7786303 & $9.90 E+06$ & $7.10 E+06$ & $1.48 \mathrm{E}+04$ & \\
\hline MANGANESE & 7439965 & $7.09 E+05$ & $5.30 E+05$ & $2.10 E+03$ & \\
\hline MERCURY & 7439976 & $<33$ & $<90$ & $<0.1$ & \\
\hline NICKEL & 7440020 & $5.65 E+04$ & $3.80 E+04$ & $1.20 E+01$ & \\
\hline POTASSIUM & 7447407 & $1.39 E+06$ & $<1300000$ & $4.30 E+03$ & \\
\hline SELENIUM & 7782492 & $3.00 E+02$ & $<1300$ & 4.10E-01 & \\
\hline SILVER & 7440224 & $5.20 E+02$ & $<2500$ & $<1.8$ & \\
\hline SODIUM & 7647145 & $5.64 E+05$ & $<1300000$ & $6.38 E+03$ & \\
\hline THALLIUM & 7440280 & $2.60 E+02$ & $<2500$ & $9.00 E-01$ & \\
\hline VANADIUM & 7440622 & $8.78 E+04$ & $4.30 \mathrm{E}+04$ & $9.00 E+00$ & \\
\hline ZINC & 7646857 & $9.27 E+04$ & $6.70 E+04$ & $2.76 E+01$ & \\
\hline
\end{tabular}




\begin{tabular}{|c|c|c|c|c|}
\hline ANALYTES & CAS & $\begin{array}{c}\text { SURFACE } \\
\text { SOILS } \\
(\mu \mathrm{g} / \mathrm{kg})\end{array}$ & $\begin{array}{c}\text { SUBSURFACE } \\
\text { SOILS } \\
(\mu \mathrm{g} / \mathrm{kg})\end{array}$ & $\begin{array}{c}\text { GROUND } \\
\text { WATER } \\
(\mu \mathrm{g} / \mathrm{L})\end{array}$ \\
\hline \multicolumn{5}{|l|}{ VOLATILES } \\
\hline 1,1,1-TRICHLOROETHANE & 71556 & & $<5500$ & $<200$ \\
\hline $1,1,2,2-$ TETRACHLOROETHANE & 79345 & & $<5500$ & $<200$ \\
\hline $1,1,2$-TRICHLOROETHANE & 79005 & & $<5500$ & $<200$ \\
\hline 1,1-DICHLOROETHANE & 75343 & & $<5500$ & $<200$ \\
\hline 1,1-DICHLOROETHENE & 75354 & & $<5500$ & $<200$ \\
\hline 1,2-DICHLOROETHANE & 107062 & & $<5500$ & $14 B$ \\
\hline 1,2-DICHLOROETHENE (TOTAL) & 156605 & & $<5500$ & $<200$ \\
\hline 1,2-DICHLOROPROPANE & 78875 & & $<5500$ & $<200$ \\
\hline 2-BUTANONE & 78933 & & $1.50 E+04$ & $<400$ \\
\hline 2-HEXANONE & 591786 & & $<11000$ & $<400$ \\
\hline 4METHYL-2-PENTANONE & & & $<11000$ & $5 \mathrm{~B}$ \\
\hline ACETONE & 67641 & & $2.00 E+01$ & $580 \mathrm{~B}$ \\
\hline BENZENE & 71432 & & $2.00 E+04$ & $1.40 E+03$ \\
\hline BENZYL ALCOHOL & & $<790$ & $<9900$ & $<40$ \\
\hline BROMODICHLOROMETHANE & 75274 & & $<5500$ & $<200$ \\
\hline BROMOFORM & 75252 & & $<5500$ & $<200$ \\
\hline BROMOMETHANE & 74839 & & $<11000$ & $<400$ \\
\hline CARBON DISULFIDE & 75150 & & $<5500$ & $2.00 E+00$ \\
\hline CARBON TETRACHLORIDE & 56235 & & $<5500$ & $<200$ \\
\hline CHLOROBENZENE & 108907 & & $<5500$ & $<200$ \\
\hline CHLOROETHANE & 75003 & & $<11000$ & $<400$ \\
\hline CHLOROFORM & 67663 & & $1.00 E+00$ & $1.00 E+00$ \\
\hline CHLOROMETHANE & 74873 & & $<11000$ & $3.00 E+00$ \\
\hline CIS-1,3-DICHLOROPROPENE & 542756 & & $<5500$ & $<200$ \\
\hline DIBROMOCHLOROMETHANE & 124481 & & $<5500$ & $<200$ \\
\hline ETHYLBENZENE & 100414 & & $5.40 E+04$ & $1.10 E+03$ \\
\hline METHYLENE CHLORIDE & 75092 & & $1700 \mathrm{~B}$ & $5.70 E+01$ \\
\hline STYRENE & 100425 & & $<5500$ & $<200$ \\
\hline TETRACHLOROETHENE & 127184 & & $<5500$ & $<200$ \\
\hline TOLUENE & 108883 & & $2.20 E+05$ & $4.20 E+03$ \\
\hline TRANS-1,3-DICHLOROPROPENE & 10061026 & & $<5500$ & $<200$ \\
\hline TRICHLOROETHENE & 79016 & & $<5500$ & $<200$ \\
\hline VINYL ACETATE & 108054 & & $<11000$ & $<400$ \\
\hline VINYL CHLORIDE & 75014 & & $<11000$ & $<400$ \\
\hline XYLENES (TOTAL) & 1330207 & & $2.60 E+05$ & $6.30 E+03$ \\
\hline \multicolumn{5}{|l|}{ SEMI-VOLATILES } \\
\hline 1,2,4-TRICHLOROBENZENE & 120821 & $<790$ & $<9900$ & $<100$ \\
\hline 1,2-DICHLOROBENZENE & 95501 & $<790$ & $<9900$ & $<100$ \\
\hline 1,2-DIPHENYLHYDRAZINE & 122667 & & $<9900$ & \\
\hline 1,3-DICHLOROBENZENE & 541731 & $<790$ & $<9900$ & $<100$ \\
\hline 1,4-DICHLOROBENZENE & 106467 & $<790$ & $<9900$ & $<100$ \\
\hline 2,4,5-TRICHLOROPHENOL & 95954 & $<3800$ & $<48000$ & $<50$ \\
\hline 2,4,6-TRICHLOROPHENOL & 88062 & $<790$ & $<9900$ & $<100$ \\
\hline 2,4-DICHLOROPHENOL & 94757 & $<790$ & $<9900$ & $<100$ \\
\hline 2,4-DIMETHYLPHENOL & 105679 & $<790$ & $<9900$ & $<100$ \\
\hline 2,4-DINITROPHENOL & 51285 & $<3800$ & $<48000$ & $<500$ \\
\hline 2,4-DINITROTOLUENE & 121142 & $<790$ & $<9900$ & $<100$ \\
\hline 2,6-DINITROTOLUENE & & $<790$ & $<9900$ & $<100$ \\
\hline 2-CHLORONAPHTHALENE & 91578 & $<790$ & $<9900$ & $<100$ \\
\hline 2-CHLOROPHENOL & 95578 & $<790$ & $<9900$ & $<100$ \\
\hline 2-METHYLNAPHTHALENE & 91576 & $<790$ & $1.80 E+04$ & $4.90 E+02$ \\
\hline 2-METHYLPHENOL & 95487 & $<790$ & $<9900$ & $1.10 E+01$ \\
\hline 4-METHYLPHENOL & 106445 & $<790$ & $<9900$ & $1.30 E+01$ \\
\hline
\end{tabular}




\begin{tabular}{|c|c|c|c|c|}
\hline ANALYTES & CAS & $\begin{array}{c}\text { SURFACE } \\
\text { SOILS } \\
(\mu \mathrm{g} / \mathrm{kg})\end{array}$ & $\begin{array}{c}\text { SUBSURFACE } \\
\text { SOILS } \\
(\mu g / \mathrm{kg})\end{array}$ & $\begin{array}{c}\text { GROUND } \\
\text { WATER } \\
(\mu \mathrm{g} / \mathrm{L})\end{array}$ \\
\hline 2-NITROANILINE & 88747 & $<3800$ & $<48000$ & $<500$ \\
\hline 2-NITROPHENOL & & $<790$ & $<9900$ & $<100$ \\
\hline 3,3'-DICHLOROBENZIDINE & 91941 & $<1600$ & $<20000$ & $<200$ \\
\hline 3-NITROANILINE & & $<3800$ & $<48000$ & $<500$ \\
\hline 4,6-DINITRO-2-METHYLPHENOL & 534521 & $<3800$ & $<48000$ & $<500$ \\
\hline 4-BFIOMOPHENYL-PHENYLETHER & & $<790$ & $<9900$ & $<100$ \\
\hline 4-CHOLOR-3-METHYLPHENOL. & & $<790$ & $<9900$ & $<100$ \\
\hline 4-CHLOROANILINE & 106478 & $<790$ & $<9900$ & $<100$ \\
\hline 4-CHLOROPHENYL-PHENYLETHER & 7005723 & $<790$ & $<9900$ & $<100$ \\
\hline 4-NITROANILINE & 100016 & $<3800$ & $<48000$ & $<500$ \\
\hline 4-NITROPHENOL & 100027 & $<3800$ & $<48000$ & $<500$ \\
\hline ACENAPHTHENE & 83329 & $1.90 \mathrm{E}+02$ & $9.60 E+01$ & $<100$ \\
\hline ACENAPHTHYLENE & 208968 & $<790$ & $<9900$ & $<100$ \\
\hline ANTHRACENE & 120127 & $3.70 E+02$ & $1.40 E+02$ & $<100$ \\
\hline BENZO(A)ANTHRACENE & 56553 & $1.50 E+03$ & $1.60 E+02$ & $<100$ \\
\hline BENZO(A)PYRENE & 50328 & $1.70 E+03$ & $8.80 E+01$ & $<100$ \\
\hline BENZO(B)FLUORANTHENE & 205992 & $1.90 E+03$ & $1.20 E+02$ & $<100$ \\
\hline BENZO(G,H,I)PERYLENE & & $1.00 E+03$ & $4.30 E+01$ & $<100$ \\
\hline BENZO(K)FLUORANTHENE & 207089 & $2.00 E+03$ & $1.00 E+02$ & $<100$ \\
\hline BENZOIC ACID & 65850 & $<3800$ & $<48000$ & $<500$ \\
\hline BIS(2-CHLOROETHOXY)METHANE & & $<790$ & $<9900$ & $<100$ \\
\hline BIS/2-CHLOROETHYL)ETHER & 111444 & $<790$ & $<9900$ & $<10$ \\
\hline BIS(2-CHLOROISOPROPYL)ETHER & 39638329 & $<790$ & $<9900$ & $<100$ \\
\hline BIS(2-ETHYLHEXYL)PHTHALATE & 117817 & $5.80 E+02$ & $1.80 E+02$ & $3.20 E+03$ \\
\hline BUTYLBENZYLPHTHALATE & & $<790$ & $<9900$ & $<100$ \\
\hline CHRYSENE & 218019 & $2.00 E+03$ & $1.80 E+02$ & $<100$ \\
\hline DI-N-BUTYLPHTHALATE & 84742 & $<790$ & $7.10 E+01$ & $4.00 E+00$ \\
\hline DI-N-OCTYLPHTHALATE & 117840 & $<790$ & $<9900$ & $<100$ \\
\hline DIBENZ(A,H)ANTHRACENE & 53703 & $4.60 E+02$ & $<9900$ & $<100$ \\
\hline DIBENZOFURAN & & $1.20 E+02$ & $1.20 E+02$ & $<100$ \\
\hline DIETHYLPHTHALATE & 84662 & $<790$ & $<9900$ & $<100$ \\
\hline DIMETHYLPHTHALATE & 131113 & $<790$ & $<9900$ & $<100$ \\
\hline FLUORANTHENE & 206440 & $4.20 E+03$ & $1.60 E+03$ & $<100$ \\
\hline FLUORENE & 86737 & $2.40 E+02$ & $2.20 E+02$ & $5.00 E+00$ \\
\hline HEXACHLOROBENZENE & 118741 & $<790$ & $<9900$ & $<100$ \\
\hline HEXACHLOROBUTADIENE & 87683 & $<790$ & $<9900$ & $<100$ \\
\hline HEXACHLOROCYCLOPENTADIENE & 77474 & $<790$ & $<9900$ & $<100$ \\
\hline HEXACHLOROETHANE & 67721 & $<790$ & $<9900$ & $<100$ \\
\hline INDENO(1,2,3-CD)PYRENE & 193395 & $1.10 E+03$ & $4.70 E+01$ & $<100$ \\
\hline ISOPHORONE & 78591 & $<790$ & $<9900$ & $<100$ \\
\hline N-NITROSO-DI-N-PROPYLAMINE & 621647 & $<790$ & $<9900$ & $<100$ \\
\hline N-NITROSODIPHENYLAMINE (1) & 86306 & $<790$ & $<9900$ & $<100$ \\
\hline NAPHTHALENE & 91203 & $<790$ & $1.10 E+04$ & $3.70 E+02$ \\
\hline NITROBENZENE & 98953 & $<790$ & $<9900$ & $<100$ \\
\hline PENTACHLOROPHENOL & 87865 & $<3800$ & $<48000$ & $<500$ \\
\hline PHENANTHRENE & 85018 & $3.00 E+03$ & $2.20 E+03$ & $3.00 E+00$ \\
\hline PHENOL & 108952 & $<790$ & $<9900$ & $9.00 E+00$ \\
\hline PYRENE & 129000 & $3.10 E+03$ & $1.40 E+03$ & $<100$ \\
\hline \multicolumn{5}{|l|}{ TPH } \\
\hline TOTAL PETROLEUM HYDROCARBONS & & $8.14 E+05$ & $3.14 E+07$ & $1.01 E_{+05}$ \\
\hline \multicolumn{5}{|l|}{ PCB } \\
\hline AROCLOR-1016 & 12674112 & $<3400$ & $<180$ & $<2$ \\
\hline AROCLOR-1221 & 1104282 & $<8600$ & $<450$ & $<4.8$ \\
\hline
\end{tabular}


IABLED.3. Maximum Contaminant Concentrations in Source Areas ST13 and DP26

\begin{tabular}{|c|c|c|c|c|}
\hline ANALYTES & CAS & $\begin{array}{c}\text { SURFACE } \\
\text { SOILS } \\
(\mu \mathrm{g} / \mathrm{kg})\end{array}$ & $\begin{array}{c}\text { SUBSURFACE } \\
\text { SOILS } \\
(\mu \mathrm{g} / \mathrm{kg})\end{array}$ & $\begin{array}{c}\text { GROUND } \\
\text { WATER } \\
(\mu \mathrm{g} / \mathrm{L}) \\
\end{array}$ \\
\hline AROCLOR-1232 & 11141165 & $<8600$ & $<450$ & $<4.8$ \\
\hline AROCLOR-1242 & 53469219 & $<3400$ & $<180$ & $<2$ \\
\hline AROCLOR-1248 & 12672296 & $<3400$ & $<91$ & $<0.8$ \\
\hline AROCLOR-1254 & 11091691 & $<1700$ & $<91$ & $<0.8$ \\
\hline AROCLOR-1260 & 11096825 & $<1700$ & $<91$ & $<0.8$ \\
\hline \multicolumn{5}{|l|}{ PESTICIDES } \\
\hline $4,4^{\prime}-\mathrm{DDD}$ & 72548 & $1.40 E+03$ & $4.60 E+01$ & $<0.4$ \\
\hline 4,4'-DDE & 72559 & $5.00 E+02$ & $1.80 E+00$ & $<0.16$ \\
\hline $4,4^{\prime}$-DDT & 50293 & $8.10 E+03$ & $1.00 E+02$ & 1.10E-01 \\
\hline ALDRIN & 309002 & $<290$ & $<15$ & $<0.16$ \\
\hline ALPHA-BHC & 319846 & $<220$ & $<11$ & $<0.12$ \\
\hline ALPHA-CHLORDANE & 57749 & $<350$ & $<19$ & $<0.2$ \\
\hline BETA-BHC & 319857 & $<430$ & $<23$ & $<0.2$ \\
\hline DELTA-BHC & 319868 & $<430$ & $<23$ & $<0.2$ \\
\hline DIELDRIN & 60571 & $<140$ & $<7.4$ & $<0.08$ \\
\hline ENDOSULFAN I & & $<430$ & $<23$ & $<0.2$ \\
\hline ENDOSULFAN $\|$ & & $<290$ & $<15$ & $<0.16$ \\
\hline ENDOSULFAN SULFATE & & $<860$ & $<45$ & $<0.4$ \\
\hline ENDRIN & 72208 & $<430$ & $<23$ & $<0.24$ \\
\hline ENDRIN KETONE & & $<860$ & $<45$ & $<0.4$ \\
\hline GAMMA-BHC (LINDANE) & 58899 & $<290$ & $<15$ & $<0.16$ \\
\hline GAMMA-CHLORDANE & 57749 & $<350$ & $<19$ & $<0.2$ \\
\hline HEPTACHLOR & 76448 & $<220$ & $<11$ & $<0.12$ \\
\hline HEPTACHLOR EPOXIDE & 1024573 & $<430$ & $<23$ & $<0.2$ \\
\hline METHOXYCHLOR & 72435 & $2.70 E+01$ & $<91$ & $<2$ \\
\hline TOXAPHENE & 8001352 & $<7100$ & $<380$ & $<4$ \\
\hline \multicolumn{5}{|l|}{ METALS } \\
\hline ALUMINUM & 7429905 & $1.28 E+07$ & $1.30 E+07$ & $4.28 \mathrm{E}+03$ \\
\hline ANTIMONY & 7440360 & $3.10 E+03$ & $<16000$ & $2.02 E+01$ \\
\hline ARSENIC & 7440382 & $1.16 E+04$ & $8.60 E+03$ & $4.14 E+01$ \\
\hline BARIUM & 7440393 & $5.34 E+05$ & $1.40 E+05$ & $5.29 E+02$ \\
\hline BERYLLIUM & 7440417 & $<48$ & $<1300$ & 8.60E-01 \\
\hline CADMIUM & 7440439 & $1.00 E+03$ & $<1300$ & $6.50 E+00$ \\
\hline CALCIUM & & $1.32 E+07$ & $6.40 E+06$ & $6.51 E+04$ \\
\hline CHROMIUM & 7440473 & $2.47 E+04$ & $2.30 E+04$ & $5.70 E+00$ \\
\hline COBALT & 7440484 & $1.03 E+04$ & $<13000$ & $3.08 \mathrm{E}+01$ \\
\hline COPPER & 7440508 & $2.86 E+04$ & $3.90 E+04$ & $4.01 E+01$ \\
\hline IRON & 15438310 & $2.11 E+07$ & $2.10 E+07$ & $3.51 E+04$ \\
\hline LEAD & 7439921 & $8.83 E+04$ & $6.04 E+04$ & $7.95 E+02$ \\
\hline MAGNESIUM & 7786303 & $5.94 E+06$ & $6.70 E+06$ & $1.52 E+04$ \\
\hline MANGANESE & 7439965 & $4.01 E+05$ & $5.00 E+05$ & $1.22 E+04$ \\
\hline MERCURY & 7439976 & $<33$ & $<90$ & $6.80 \mathrm{E}-01$ \\
\hline NICKEL & 7440020 & $2.58 E+04$ & $2.70 E+04$ & $5.57 E+01$ \\
\hline POTASSIUM & 7447407 & $9.13 E+05$ & $<1300000$ & $4.19 E+03$ \\
\hline SELENIUM & 7782492 & $1.30 E+02$ & $<1300$ & 8.10E-01 \\
\hline SILVER & 7440224 & $<430$ & $<2600$ & $<10$ \\
\hline SODIUM & 7647145 & $5.60 E+05$ & $<1300000$ & $5.54 E+03$ \\
\hline THALLIUM & 7440280 & $2.00 E+02$ & $<2600$ & $1.00 E+00$ \\
\hline VANADIUM & 7440622 & $4.09 E+04$ & $4.40 E+04$ & $2.52 E+01$ \\
\hline ZINC & 7646857 & $7.04 E+04$ & $6.30 E+04$ & $6.44 E+01$ \\
\hline
\end{tabular}


IABLE D.4. Maximum Contaminant Concentrations in Source Area ST18

\begin{tabular}{|c|c|c|c|c|}
\hline ANALYTES & CAS & $\begin{array}{c}\text { SURFACE } \\
\text { SOILS } \\
(\mu \mathrm{g} / \mathrm{kg})\end{array}$ & $\begin{array}{c}\text { SUBSURFACE } \\
\text { SOILS } \\
(\mu \mathrm{g} / \mathrm{kg})\end{array}$ & $\begin{array}{c}\text { GROUND } \\
\text { WATER } \\
(\mu \mathrm{g} / \mathrm{L})\end{array}$ \\
\hline \multicolumn{5}{|l|}{ VOLATILES } \\
\hline 1,1,1-TRICHLOROETHANE & 71556 & & $<680$ & $<5$ \\
\hline 1,1,2,2-TETRACHLOROETHANE & 79345 & & $<680$ & $<5$ \\
\hline 1,1,2-TRICHLOROETHANE & 79005 & & $<680$ & $<5$ \\
\hline 1,1-DICHLOROETHANE & 75343 & & $<680$ & $<5$ \\
\hline 1,1-DICHLOROETHENE & 75354 & & $<680$ & $<5$ \\
\hline 1,2-DICHLOROETHANE & 107062 & & $<680$ & $<5$ \\
\hline 1,2-DICHLOROETHENE (TOTAL) & 156605 & & $<680$ & $2.00 E+00$ \\
\hline 1,2-DICHLOROPROPANE & 78875 & & $<680$ & $<5$ \\
\hline 2-BUTANONE & 78933 & & $<1400$ & $<10$ \\
\hline 2-HEXANONE & 591786 & & $<1400$ & $<10$ \\
\hline 4-METHYL-2-PENTANONE & & & $<1400$ & $<10$ \\
\hline ACETONE & 67641 & & $7.00 E+00$ & $100 \mathrm{~B}$ \\
\hline BENZENE & 71432 & & $<680$ & $<5$ \\
\hline BENZYL ALCOHOL & & $<700$ & $<400$ & $<10$ \\
\hline BROMODICHLOROMETHANE & 75274 & & $<680$ & $<5$ \\
\hline BROMOFORM & 75252 & & $<680$ & $<5$ \\
\hline BROMOMETHANE & 74839 & & $<1400$ & $<10$ \\
\hline CARBON DISULFIDE & 75150 & & $<680$ & $<5$ \\
\hline CARBON TETRACHLORIDE & 56235 & & $<680$ & $<5$ \\
\hline CHL.OROBENZENE & 108907 & & $<680$ & $<5$ \\
\hline CHLOROETHANE & 75003 & & $<1400$ & $<10$ \\
\hline CHLOROFORM & 67663 & & $1.50 E+02$ & $2.00 E+00$ \\
\hline CHLOROMETHANE & 74873 & & $<1400$ & $<10$ \\
\hline CIS-1,3-DICHLOROPROPENE & 542756 & & $<680$ & $<5$ \\
\hline DIBROMOCHLOROMETHANE & 124481 & & $<680$ & $<5$ \\
\hline ETHYLBENZENE & 100414 & & $<680$ & $3.00 E+00$ \\
\hline METHYLENE CHLORIDE & 75092 & & $5.00 E+00$ & $10 \mathrm{~B}$ \\
\hline STYRENE & 100425 & & $<680$ & $<5$ \\
\hline TETRACHLOROETHENE & 127184 & & $7.00 E+00$ & $<5$ \\
\hline TOLUENE & 108883 & & $<680$ & $<5$ \\
\hline TRANS-1,3-DICHLOROPROPENE & 10061026 & & $<680$ & $<5$ \\
\hline TRICHLOROETHENE & 79016 & & $<6$ & $2.00 E+00$ \\
\hline VINYL ACETATE & 108054 & & $<1400$ & $<10$ \\
\hline VINYL CHLORIDE & 75014 & & $<1400$ & $<10$ \\
\hline XYLENES (TOTAL) & 1330207 & & $9.60 E+02$ & $8.00 \mathrm{E}+00$ \\
\hline \multicolumn{5}{|l|}{ SEMI-VOLATILES } \\
\hline 1,2,4-TRICHLOROBENZENE & 120821 & $<700$ & $<400$ & $<10$ \\
\hline 1,2-DICHLOROBENZENE & 95501 & $<700$ & $<400$ & $<10$ \\
\hline 1,2-DIPHENYLHYDRAZINE & 122667 & & $<400$ & \\
\hline 1,3-DICHLOROBENZENE & 541731 & $<700$ & $<400$ & $<10$ \\
\hline 1,4-DICHLOROBENZENE & 106467 & $<700$ & $<400$ & $<10$ \\
\hline 2,4,5-TRICHLOROPHENOL & 95954 & $<3400$ & $<1900$ & $<50$ \\
\hline 2,4,6-TRICHLOROPHENOL & 88062 & $<700$ & $<400$ & $<10$ \\
\hline 2,4-DICHLOROPHENOL & 94757 & $<700$ & $<400$ & $<10$ \\
\hline 2,4-DIMETHYLPHENOL & 105679 & $<700$ & $<400$ & $<10$ \\
\hline 2,4-DINITROPHENOL & 51285 & $<3400$ & $<1900$ & $<50$ \\
\hline 2,4-DINITROTOLUENE & 121142 & $<700$ & $<400$ & $<10$ \\
\hline 2,6-DINITROTOLUENE & & $<700$ & $<400$ & $<10$ \\
\hline 2-CHLORONAPHTHALENE & 91578 & $<700$ & $<400$ & $<10$ \\
\hline 2-CHLOROPHENOL & 95578 & $<700$ & $<400$ & $<10$ \\
\hline 2-METHYLNAPHTHALENE & 91576 & $<700$ & $<400$ & $2.00 E+00$ \\
\hline 2-METHYLPHENOL & 95487 & $<700$ & $<400$ & $<10$ \\
\hline 4-METHYLPHENOL & 106445 & $<700$ & $<400$ & $<10$ \\
\hline
\end{tabular}


IABLED.4. Maximum Contaminant Concentrations in Source Area ST18

\begin{tabular}{|c|c|c|c|c|}
\hline ANALYTES & CAS & $\begin{array}{c}\text { SURFACE } \\
\text { SOILS } \\
(\mu \mathrm{g} / \mathrm{kg})\end{array}$ & $\begin{array}{c}\text { SUBSURFACE } \\
\text { SOILS } \\
(\mu \mathrm{g} / \mathrm{kg})\end{array}$ & $\begin{array}{c}\text { GROUND } \\
\text { WATER } \\
\text { ( } \mu \mathrm{g} / \mathrm{L})\end{array}$ \\
\hline 2-NITROANILINE & 88747 & $<3400$ & $<1900$ & $<50$ \\
\hline 2-NITROPHENOL & & $6.90 E+02$ & $<400$ & $<10$ \\
\hline 3,3'-DICHLOROBENZIDINE & 91941 & $<1400$ & $<800$ & $<20$ \\
\hline 3-NITROANILINE & & $<3400$ & $<1900$ & $<50$ \\
\hline 4,6-DINITRO-2-METHYLPHENOL & 534521 & $<3400$ & $<1900$ & $<50$ \\
\hline 4-BROMOPHENYL-PHENYLETHER & & $<700$ & $<400$ & $<10$ \\
\hline 4-CHOLOR-3-METHYLPHENOL & & $<700$ & $<400$ & $<10$ \\
\hline 4-CHLOROANILINE & 106478 & $<700$ & $<400$ & $<10$ \\
\hline 4-CHLOROPHENYL-PHENYLETHER & 7005723 & $<700$ & $<400$ & $<10$ \\
\hline 4-NITROANILINE & 100016 & $<3400$ & $<1900$ & $<50$ \\
\hline 4-NITROPHENOL. & 100027 & $<3400$ & $<1900$ & $<50$ \\
\hline ACENAPHTHENE & 83329 & $<700$ & $<400$ & $<10$ \\
\hline ACENAPHTHYLENE & 208968 & $<700$ & $<400$ & $<10$ \\
\hline ANTHRACENE & 120127 & $7.30 E+01$ & $<400$ & $<10$ \\
\hline BENZO(A)ANTHRACENE & 56553 & $4.30 E+02$ & $<400$ & $<10$ \\
\hline BENZO(A)PYRENE & 50328 & $5.50 E+02$ & $<400$ & $<10$ \\
\hline BENZO(B)FLUORANTHENE & 205992 & $4.60 E+02$ & $<400$ & $<10$ \\
\hline BENZO(G,H,I)PERYLENE & & $7.50 E+02$ & $<400$ & $<10$ \\
\hline BENZO(K)FLUORANTHENE & 207089 & $4.80 E+02$ & $<400$ & $<10$ \\
\hline BENZOIC ACID & 65850 & $2.30 E+03$ & $<1900$ & $<50$ \\
\hline BIS(2-CHLOROETHOXY)METHANE & & $<700$ & $<400$ & $<10$ \\
\hline BIS(2-CHLOROETHYL)ETHER & 111444 & $<700$ & $<400$ & \\
\hline BIS(2-CHLOROISOPROPYL)ETHER & 39638329 & $<700$ & $<400$ & $<10$ \\
\hline BIS(2-ETHYLHEXYL)PHTHALATE & 117817 & $1.70 E+02$ & $1300 \mathrm{~B}$ & $7.00 E+00$ \\
\hline BUTYLBENZYLPHTHALATE & & $1.30 E+02$ & $<400$ & $<10$ \\
\hline CHRYSENE & 218019 & $5.50 E+02$ & $<400$ & $<10$ \\
\hline DI-N-BUTYLPHTHALATE & 84742 & $<700$ & $87 B$ & $3.00 E+00$ \\
\hline DI-N-OCTYLPHTHALATE & 117840 & $<700$ & $<400$ & $<10$ \\
\hline DIBENZ(A,H)ANTHRACENE & 53703 & $2.50 E+02$ & $<400$ & $<10$ \\
\hline DIBENZOFURAN & & $<700$ & $<400$ & $<10$ \\
\hline DIETHYLPHTHALATE & 84662 & $<700$ & $110 \mathrm{~B}$ & $<10$ \\
\hline DIMETHYLPHTHALATE & 131113 & $<700$ & $<400$ & $<10$ \\
\hline FLUORANTHENE & 206440 & $6.40 E+02$ & $<400$ & $<10$ \\
\hline FLUORENE & 86737 & $<700$ & $<400$ & $<10$ \\
\hline HEXACHLOROBENZENE & 118741 & $<700$ & $<400$ & $<10$ \\
\hline HEXACHLOROBUTADIENE & 87683 & $<700$ & $<400$ & $<10$ \\
\hline HEXACHLOROCYCLOPENTADIENE & 77474 & $<700$ & $<400$ & $<10$ \\
\hline HEXACHLOROETHANE & 67721 & $<700$ & $<400$ & $<10$ \\
\hline INDENO(1,2,3-CD)PYRENE & 193395 & $6.20 E+02$ & $<400$ & $<10$ \\
\hline ISOPHORONE & 78591 & $<700$ & $<400$ & $<10$ \\
\hline N-NITROSO-DI-N-PROPYLAMINE & 621647 & $<700$ & $<400$ & $<10$ \\
\hline N-NITROSODIPHENYLAMINE (1) & 86306 & $7.80 \mathrm{E}+01$ & $<400$ & $3.00 E+00$ \\
\hline NAPHTHALENE & 91203 & $<700$ & $<400$ & $<10$ \\
\hline NITROBENZENE & 98953 & $<700$ & $<400$ & $<10$ \\
\hline PENTACHLOROPHENOL & 87865 & $<3400$ & $<1900$ & $<50$ \\
\hline PHENANTHRENE & 85018 & $2.10 E+02$ & $<400$ & $<10$ \\
\hline PHENOL & 108952 & $<700$ & $<400$ & $<10$ \\
\hline PYRENE & 129000 & $5.80 E+02$ & $<400$ & $<10$ \\
\hline \multicolumn{5}{|l|}{ TPH } \\
\hline TOTAL PETROLEUM HYDROCARBONS & & $9.76 \mathrm{E}+05$ & $1.10 \mathrm{E}+07$ & $2.02 E+03$ \\
\hline \multicolumn{5}{|l|}{ PCB } \\
\hline AROCLOR-1016 & 12674112 & $<360$ & $<39$ & $<2.5$ \\
\hline AROCLOR-1221 & 1104282 & $<890$ & $<96$ & $<6$ \\
\hline
\end{tabular}


IABLE D.4. Maximum Contaminant Concentrations in Source Area ST18

\begin{tabular}{|c|c|c|c|c|}
\hline ANALYTES & CAS & $\begin{array}{c}\text { SURFACE } \\
\text { SOILS } \\
(\mu g / \mathrm{kg})\end{array}$ & $\begin{array}{c}\text { SUBSURFACE } \\
\text { SOILS } \\
(\mu \mathrm{g} / \mathrm{kg})\end{array}$ & $\begin{array}{c}\text { GROUND } \\
\text { WATER } \\
(\mu g / L)\end{array}$ \\
\hline AROCLOR-1232 & 11141165 & $<890$ & $<96$ & $<6$ \\
\hline AROCLOR-1242 & 53469219 & $<360$ & $<39$ & $<2.5$ \\
\hline AROCLOR-1248 & 12672296 & $<360$ & $<19$ & $<1$ \\
\hline AROCLOR-1254 & 11091691 & $<180$ & $<19$ & $<1$ \\
\hline AROCLOR-1260 & 11096825 & $<180$ & $<19$ & $<1$ \\
\hline \multicolumn{5}{|l|}{ PESTICIDES } \\
\hline $4,4^{\prime}-\mathrm{DDD}$ & 72548 & $<82$ & $<8.9$ & $<0.5$ \\
\hline 4,4'-DDE & 72559 & $1.80 E+01$ & $<3.3$ & $<0.2$ \\
\hline 4,4'-DDT & 50293 & $1.40 E+02$ & $<9.6$ & $<0.5$ \\
\hline ALDRIN & 309002 & $\cdot<30$ & $<3.3$ & $<0.2$ \\
\hline ALPHA-BHC & 319846 & $<22$ & $<2.4$ & $<0.15$ \\
\hline ALPHA-CHLORDANE & 57749 & $<37$ & $<4$ & $<0.25$ \\
\hline BETA-BHC & 319857 & $<44$ & $<4.8$ & $<0.25$ \\
\hline DELTA-BHC & 319868 & $<44$ & $<4.8$ & $<0.25$ \\
\hline DIELDRIN & 60571 & $<14$ & $<1.6$ & $<0.1$ \\
\hline ENDOSULFAN I & & $<44$ & $<4.8$ & $<0.25$ \\
\hline ENDOSULFAN \| & & $<30$ & $<3.3$ & $<0.2$ \\
\hline ENDOSULFAN SULFATE & & $<89$ & $<9.6$ & $<0.5$ \\
\hline ENDRIN & 72208 & $<44$ & $<4.8$ & $<0.3$ \\
\hline ENDRIN KETONE & & $<89$ & $<9.6$ & $<0.5$ \\
\hline GAMMA-BHC (LINDANE) & 58899 & $<30$ & $<3.3$ & $<0.2$ \\
\hline GAMMA-CHLORDANE & 57749 & $<37$ & $<4$ & $<0.25$ \\
\hline HEPTACHLOR & 76448 & $<22$ & $<2.4$ & $<0.15$ \\
\hline HEPTACHLOR EPOXIDE & 1024573 & $<44$ & $<4.8$ & $<0.25$ \\
\hline METHOXYCHLOR & 72435 & $<180$ & $<19$ & $<2.5$ \\
\hline TOXAPHENE & 8001352 & $<740$ & $<81$ & $<5$ \\
\hline \multicolumn{5}{|l|}{ METALS } \\
\hline ALUMINUM & 7429905 & $1.96 E+07$ & $5.60 E+06$ & $2.24 E+03$ \\
\hline ANTIMONY & 7440360 & $5.80 E+03$ & $<15000$ & $<60$ \\
\hline ARSENIC & 7440382 & $1.33 E+04$ & $3.70 \mathrm{E}+03$ & $7.34 E+01$ \\
\hline BARIUM & 7440393 & $.9 .01 E+05$ & $6.20 E+04$ & $2.27 E+02$ \\
\hline BERYLLIUM & 7440417 & $5.50 E+02$ & $<1200$ & $<5$ \\
\hline CADMIUM & 7440439 & $1.30 E+03$ & $<1200$ & $1.50 E+01$ \\
\hline CALCIUM & & $2.24 \mathrm{E}+07$ & $3.70 E+06$ & $1.09 E+05$ \\
\hline CHROMIUM & 7440473 & $3.13 E+04$ & $1.10 E+04$ & $3.60 E+00$ \\
\hline COBALT & 7440484 & $1.40 E+04$ & $<12000$ & $<50$ \\
\hline COPPER & 7440508 & $6.55 E+04$ & $1.90 E+04$ & 1.35E+01 \\
\hline IRON & 15438310 & $2.78 E+07$ & $1.10 E+07$ & $1.25 E+04$ \\
\hline LEAD & 7439921 & $9.49 E+04$ & $1.72 E+04$ & $5.00 E+00$ \\
\hline MAGNESIUM & 7786303 & $8.68 E+06$ & $3.60 E+06$ & $1.72 E+04$ \\
\hline MANGANESE & 7439965 & $5.17 E+05$ & $3.40 E+05$ & $2.05 E+03$ \\
\hline MERCURY & 7439976 & $3.30 E+01$ & $<80$ & $2.50 E-01$ \\
\hline NICKEL & 7440020 & $3.54 E+04$ & $1.50 E+04$ & $1.54 E+01$ \\
\hline POTASSIUM & 7447407 & $1.34 E+06$ & $<1200000$ & $5.21 E+03$ \\
\hline SELENIUM & 7782492 & $1.40 E+02$ & $<1300$ & $2.00 E+00$ \\
\hline SILVER & 7440224 & $5.20 E+02$ & $<2500$ & $<10$ \\
\hline SODIUM & 7647145 & $6.87 E+05$ & $<1200000$ & $6.05 E+03$ \\
\hline THALLIUM & 7440280 & $<170$ & $<2500$ & $1.20 E+00$ \\
\hline VANADIUM & 7440622 & $7.19 E+04$ & $2.00 E+04$ & $1.00 E+01$ \\
\hline ZINC & 7646857 & $1.43 E+05$ & $3.10 E+04$ & $1.92 E+01$ \\
\hline
\end{tabular}




\begin{tabular}{|c|c|c|c|c|}
\hline ANALYTES & CAS & $\begin{array}{l}\text { SURFACE } \\
\text { SOILS } \\
(\mu \mathrm{g} / \mathrm{kg})\end{array}$ & $\begin{array}{c}\text { SUBSURFACE } \\
\text { SOILS } \\
(\mu \mathrm{g} / \mathrm{kg})\end{array}$ & $\begin{array}{c}\text { GROUND } \\
\text { WATER } \\
(\mu \mathrm{g} / \mathrm{L})\end{array}$ \\
\hline \multicolumn{5}{|l|}{ VOLATILES } \\
\hline $1,1,1-$ TRICHLOROETHANE & 71556 & & $<33000$ & $<25$ \\
\hline 1,1,2,2-TETRACHLOROETHANE & 79345 & & $<33000$ & $<25$ \\
\hline 1,1,2-TRICHLOROETHANE & 79005 & & $<33000$ & $<25$ \\
\hline 1,1-DICHLOROETHANE & 75343 & & $<33000$ & $<25$ \\
\hline 1,1-DICHLOROETHENE & 75354 & & $<33000$ & $<25$ \\
\hline 1,2-DICHLOROETHANE & 107062 & & $<33000$ & $<25$ \\
\hline 1,2-DICHLOROETHENE (TOTAL) & 156605 & & $<33000$ & $<25$ \\
\hline 1,2-DICHLOROPROPANE & 78875 & & $<33000$ & $<25$ \\
\hline 2-BUTANONE & 78933 & & $<65000$ & $4.80 E+01$ \\
\hline 2-HEXANONE & 591786 & & $<65000$ & $<50$ \\
\hline 4-METHYL-2-PENTANONE & & & $<65000$ & $<50$ \\
\hline ACETONE & 67641 & & $46000 B$ & $16 \mathrm{~A}$ \\
\hline BENZENE & 71432 & & $2.80 \mathrm{E}+02$ & $2.00 E+01$ \\
\hline BENZYL ALCOHOL & & $<900$ & $<2200$ & $<10$ \\
\hline BROMODICHLOROMETHANE & 75274 & & $<33000$ & $<25$ \\
\hline RROMOFORM & 75252 & & $<33000$ & $<25$ \\
\hline BROMOMETHANE & 74839 & & $<65000$ & $<50$ \\
\hline CAFBON DISULFIDE & 75150 & & $<33000$ & $2.00 E+00$ \\
\hline CARBON TETRACHLORIDE & 56235 & & $<33000$ & $<25$ \\
\hline CHLOROBENZENE & 108907 & & $<33000$ & $<25$ \\
\hline CHLOROETHANE & 75003 & & $<65000$ & $<50$ \\
\hline CHLOROFORM & 67663 & & $9000 \mathrm{~B}$ & $<25$ \\
\hline CHLOROMETHANE & 74873 & & $<65000$ & $<50$ \\
\hline CIS-1,3-DICHLOROPROPENE & 542756 & & $<33000$ & $<25$ \\
\hline DIBROMOCHLOROMETHANE & 124481 & & $<33000$ & $<25$ \\
\hline ETHYLBENZENE & 100414 & & $9.90 E+04$ & $3.90 E+02$ \\
\hline METHYLENE CHLORIDE & 75092 & & $1.10 \mathrm{E}+01$ & $300 \mathrm{~B}$ \\
\hline STYRENE & 100425 & & $<33000$ & $<25$ \\
\hline TETRACHLOROETHENE & 127184 & & $<33000$ & $<25$ \\
\hline TOLUENE & 108883 & & $2.10 E+05$ & $1.50 E+03$ \\
\hline TRANS-1,3-DICHLOROPROPENE & 10061026 & & $<33000$ & $<25$ \\
\hline TRICHLOROETHENE & 79016 & & $<33000$ & $<25$ \\
\hline VINYL ACETATE & 108054 & & $<65000$ & $<50$ \\
\hline VINYL CHLORIDE & 75014 & & $<65000$ & $<50$ \\
\hline XYLENES (TOTAL) & 1330207 & & $8.10 E+05$ & $2.30 E+03$ \\
\hline \multicolumn{5}{|l|}{ SEMI-VOLATILES } \\
\hline 1,2,4-TRICHLOROBENZENE & 120821 & $<900$ & $3.24 E+03$ & $<10$ \\
\hline 1,2-DICHLOROBENZENE & 95501 & $<900$ & $<2200$ & $<10$ \\
\hline 1,2-DIPHENYLHYDRAZINE & 122667 & & $<200000$ & $<10$ \\
\hline 1,3-DICHLOROBENZENE & 541731 & $<900$ & $<2200$ & $<10$ \\
\hline 1,4-DICHLOROBENZENE & 106467 & $<900$ & $1.95 E+03$ & $<10$ \\
\hline 2,4,5-TRICHLOROPHENOL & 95954 & $<4400$ & $<11000$ & $<50$ \\
\hline 2,4,6-TRICHLOROPHENOL & 88062 & $<900$ & $<2200$ & $<10$ \\
\hline 2,4-DICHLOROPHENOL & 94757 & $<900$ & $<2200$ & $<10$ \\
\hline 2,4-DIMETHYLPHENOL & 105679 & $<900$ & $<2200$ & $<10$ \\
\hline 2,4-DINITROPHENOL & 51285 & $<4400$ & $<11000$ & $<50$ \\
\hline 2,4-DINITROTOLUENE & 121142 & $<900$ & $<2200$ & $<10$ \\
\hline 2,6-DINITROTOLUENE & & $<900$ & $<2200$ & $<10$ \\
\hline 2-CHLORONAPHTHALENE & 91578 & $<900$ & $<2200$ & $<10$ \\
\hline 2-CHLOROPHENOL & 95578 & $<900$ & $<2200$ & $<10$ \\
\hline 2-METHYLNAPHTHALENE & 91576 & $<900$ & $1.80 E+04$ & $7.30 E+01$ \\
\hline 2-METHYLPHENOL & 95487 & $<900$ & $<2200$ & $2.60 E+01$ \\
\hline 4-METHYLPHENOL & 106445 & $<900$ & $<2200$ & $5.40 E+01$ \\
\hline
\end{tabular}


IABLE D.5. Maximum Contaminant Concentrations in Source Area ST19

\begin{tabular}{|c|c|c|c|c|}
\hline ANALYTES & CAS & $\begin{array}{l}\text { SURFACE } \\
\text { SOILS } \\
(\mu \mathrm{g} / \mathrm{kg})\end{array}$ & $\begin{array}{c}\text { SUBSURFACE } \\
\text { SOILS } \\
(\mu \mathrm{g} / \mathrm{kg})\end{array}$ & $\begin{array}{c}\text { GROUND } \\
\text { WATER } \\
(\mu g / L)\end{array}$ \\
\hline 2.NITROANILINE & 88747 & $<4400$ & $<11000$ & $<50$ \\
\hline 2.NTROPHENOL & & $<900$ & $<2200$ & $<10$ \\
\hline 3,3'-DICHLOROBENZIDINE & 91941 & $<1800$ & $<4400$ & $<20$ \\
\hline 3-NITROANILINE & & $<4400$ & $<11000$ & $<50$ \\
\hline 4,6-DINITRO-2-METHYLPHENOL & 534521 & $<4400$ & $<11000$ & $<50$ \\
\hline 4-BROMOPHENYL-PHENYLETHER & & $<900$ & $<2200$ & $<10$ \\
\hline 4-CHOLOR-3-METHYLPHENOL & & $<900$ & $<2200$ & $<10$ \\
\hline 4-CHLOROANILINE & 106478 & $<900$ & $<2200$ & $<10$ \\
\hline 4-CHLOROPHENYL-PHENYLETHER & 7005723 & $<900$ & $<2200$ & $<10$ \\
\hline 4-NITROANILINE & 100016 & $<4400$ & $<11000$ & $<50$ \\
\hline 4-NITROPHENOL & 100027 & $<4400$ & $<11000$ & $<50$ \\
\hline ACENAPHTHENE & 83329 & $<900$ & $1.70 E+02$ & $<10$ \\
\hline ACENAPHTHYLENE & 208968 & $<900$ & $<2200$ & $<10$ \\
\hline ANTHRACENE & 120127 & $<900$ & $<2200$ & $<10$ \\
\hline BENZO(A)ANTHRACENE & 56553 & $<900$ & $5.20 E+01$ & $<10$ \\
\hline BENZO(A)PYRENE & 50328 & $<900$ & $<2200$ & $<10$ \\
\hline BENZO(B)FLUORANTHENE & 205992 & $<900$ & $<2200$ & $<10$ \\
\hline BENZO(G,H,I)PERYLENE & & $<900$ & $<2200$ & $<10$ \\
\hline BENZO(K)FLUORANTHENE & 207089 & $<900$ & $<2200$ & $<10$ \\
\hline BENZOIC ACID & 65850 & $<4400$ & $<11000$ & $4.00 E+01$ \\
\hline BIS(2-CHLOROETHOXY)METHANE & & $<900$ & $<2200$ & $<10$ \\
\hline BIS(2-CHLOROETHYL)ETHER & 111444 & $<900$ & $<2200$ & $<10$ \\
\hline BIS(2-CHLOROISOPROPYL)ETHER & 39638329 & $<900$ & $<2200$ & $<10$ \\
\hline BIS(2-ETHYLHEXYL)PHTHALATE & 117817 & $1.20 \mathrm{E}+02$ & $1100 \mathrm{~B}$ & $1.50 E+01$ \\
\hline BUTYLBENZYLPHTHALATE & & $<900$ & $<2200$ & $<10$ \\
\hline CHRYSENE & 218019 & $<900$ & $1.67 E+02$ & $<10$ \\
\hline DI-N-BUTYLPHTHALATE & 84742 & $<900$ & $7.70 E+01$ & $<10$ \\
\hline DI-N-OCTYLPHTHALATE & 117840 & $<900$ & $<2200$ & $<10$ \\
\hline DIBENZ(A,H)ANTHRACENE & 53703 & $<900$ & $<2200$ & $<10$ \\
\hline DIBENZOFURAN & & $<900$ & $<2200$ & $<10$ \\
\hline DIETHYLPHTHALATE & 84662 & $<900$ & $<2200$ & $<10$ \\
\hline DIMETHYLPHTHALATE & 131113 & $<900$ & $<2200$ & $<10$ \\
\hline FLUORANTHENE & 206440 & $<900$ & $4.70 E+02$ & $<10$ \\
\hline FLUORENE & 86737 & $<900$ & $3.40 \mathrm{E}+02$ & $<10$ \\
\hline HEXACHLOROBENZENE & 118741 & $<900$ & $<2200$ & $<10$ \\
\hline HEXACHLOROBUTADIENE & 87683 & $<900$ & $<2200$ & $<10$ \\
\hline HEXACHLOROCYCLOPENTADIENE & 77474 & $<900$ & $<2200$ & $<10$ \\
\hline HEXACHLOROETHANE & 67721 & $<900$ & $<2200$ & $<10$ \\
\hline INDENO(1,2,3-CD)PYRENE & 193395 & $<900$ & $<2200$ & $<10$ \\
\hline ISOPHORONE & 78591 & $<900$ & $<2200$ & $<10$ \\
\hline N-NITROSO-DI-N-PROPYLAMINE & 621647 & $<900$ & $<2200$ & $<10$ \\
\hline N-NITROSODIPHENYLAMINE (1) & 86306 & $<900$ & $<2200$ & $<10$ \\
\hline NAPHTHALENE & 91203 & $<900$ & $1.20 \mathrm{E}+04$ & $1.40 E+02$ \\
\hline NITROBENZENE & 98953 & $<900$ & $<2200$ & $<10$ \\
\hline PENTACHLOROPHENOL & 87865 & $<4400$ & $<11000$ & $<50$ \\
\hline PHENANTHRENE & 85018 & $<900$ & $5.60 E+02$ & $<10$ \\
\hline PHENOL & 108952 & $<900$ & $<2200$ & $<10$ \\
\hline PYRENE & 129000 & $<900$ & $4.50 E+02$ & $<10$ \\
\hline \multicolumn{5}{|l|}{ TPH } \\
\hline TOTAL PETROLEUM HYDROCARBONS & & $2.84 E+04$ & $4.00 E+06$ & $5.19 E+03$ \\
\hline \multicolumn{5}{|l|}{ PCB } \\
\hline AROCLOR-1016 & 12674112 & $<43$ & $<36$ & $<2.5$ \\
\hline AROCLOR-1221 & 1104282 & $<110$ & $<89$ & $<6$ \\
\hline
\end{tabular}


TABLE D.5. Maximum Contaminant Concentrations in Source Area ST19

\begin{tabular}{|c|c|c|c|c|}
\hline ANALYTES & CAS & $\begin{array}{c}\text { SURFACE } \\
\text { SOILS } \\
(\mu \mathrm{g} / \mathrm{kg})\end{array}$ & $\begin{array}{c}\text { SUBSURFACE } \\
\text { SOILS } \\
(\mu \mathrm{g} / \mathrm{kg})\end{array}$ & $\begin{array}{c}\text { GROUND } \\
\text { WATER } \\
(\mu g / L)\end{array}$ \\
\hline AROCLOR-1232 & 11141165 & $<110$ & $<89$ & $<6$ \\
\hline AROCLOR-1242 & 53469219 & $<43$ & $<36$ & $<2.5$ \\
\hline AROCLOR-1248 & 12672296 & $<43$ & $<18$ & $<1$ \\
\hline AROCLOR-1254 & 11091691 & $<22$ & $<18$ & $<1$ \\
\hline AROCLOR-1260 & 11096825 & $<22$ & $<18$ & $<1$ \\
\hline \multicolumn{5}{|l|}{ PESTICIDES } \\
\hline $4,4^{\circ}-\mathrm{DDD}$ & 72548 & $<10$ & $<8.2$ & $<0.5$ \\
\hline $4,4^{\prime}-\mathrm{DDE}$ & 72559 & $<3.6$ & $<3$ & $<0.2$ \\
\hline $4,4^{\prime} \cdot \mathrm{DDT}$ & 50293 & $9.30 E+00$ & $<8.9$ & $<0.5$ \\
\hline ALDRIN & 309002 & $<3.6$ & $<3$ & $<0.2$ \\
\hline ALPHA-BHC & 319846 & $<2.7$ & $<2.2$ & $<0.15$ \\
\hline ALPHA-CHLORDANE & 57749 & $<4.5$ & $<3.7$ & $<0.25$ \\
\hline BETA-BHC & 319857 & $<5.4$ & $<4.4$ & $<0.25$ \\
\hline DELTA-BHC & 319868 & $<5.4$ & $<4.4$ & $<0.25$ \\
\hline DIELDRIN & 60571 & $<1.8$ & $<1.4$ & $<0.1$ \\
\hline ENDOSULFAN I & & $<5.4$ & $<4.4$ & $<0.25$ \\
\hline ENDOSULFAN ॥ & & $<3.6$ & $<3$ & $<0.2$ \\
\hline ENDOSULFAN SULFATE & & $<11$ & $<8.9$ & $<0.5$ \\
\hline ENDRIN & 72208 & $<5.4$ & $<4.4$ & $<0.3$ \\
\hline ENDRIN KETONE & & $<11$ & $<8.9$ & $<0.5$ \\
\hline GAMMA-BHC (LINDANE) & 58899 & $<3.6$ & $<3$ & $<0.2$ \\
\hline GAMMA-CHLORDANE & 57749 & $<4.5$ & $<3.7$ & $<0.25$ \\
\hline HEPTACHLOR & 76448 & $<2.7$ & $<2.2$ & $<0.15$ \\
\hline HEPTACHLOR EPOXIDE & 1024573 & $<5.4$ & $<4.4$ & $<0.25$ \\
\hline METHOXYCHLOR & 72435 & $<22$ & $<18$ & $<2.5$ \\
\hline TOXAPHENE & 8001352 & $<91$ & $<74$ & $<5$ \\
\hline \multicolumn{5}{|l|}{ METALS } \\
\hline ALUMINUM & 7429905 & $2.09 E+07$ & $6.10 E+06$ & $3.93 \mathrm{E}+03$ \\
\hline ANTIMONY & 7440360 & $7.30 E+03$ & $<14000$ & $2.59 E+01$ \\
\hline ARSENIC & 7440382 & $1.95 E+04$ & $4.10 E+03$ & $4.30 E+01$ \\
\hline BARIUM & 7440393 & $2.09 \mathrm{E}+05$ & $6.10 E+04$ & $2.64 E+02$ \\
\hline BERYLLIUM & 7440417 & $3.50 \mathrm{E}+02$ & $<1100$ & 3.70E-01 \\
\hline CADMIUM & 7440439 & $1.70 E+03$ & $<1100$ & $3.20 E+00$ \\
\hline CALCIUM & & $8.64 E+06$ & $3.40 E+06$ & $5.45 \mathrm{E}+04$ \\
\hline CHROMIUM & 7440473 & $3.60 \mathrm{E}+04$ & $1.90 E+04$ & $8.70 E+00$ \\
\hline COBALT & 7440484 & $1.91 E+04$ & $<11000$ & $1.40 E+01$ \\
\hline COPPER & 7440508 & $6.27 E+04$ & $1.90 E+04$ & 2.17E+01 \\
\hline IRON & 15438310 & $3.87 E+07$ & $1.40 E+07$ & $6.45 E+04$ \\
\hline LEAD & 7439921 & $1.73 E+04$ & $8.40 E+03$ & $5.60 E+00$ \\
\hline MAGNESIUM & 7786303 & $1.01 E+07$ & $4.10 E+06$ & $1.30 E+04$ \\
\hline MANGANESE & 7439965 & $6.59 E+05$ & $1.70 E+05$ & $8.58 \mathrm{E}+03$ \\
\hline MERCURY & 7439976 & $3.80 E+01$ & $<80$ & $<0.2$ \\
\hline NICKEL & 7440020 & $4.25 E+04$ & $2.00 E+04$ & $1.87 E_{+} 01$ \\
\hline POTASSIUM & 7447407 & $1.14 E+06$ & $<1100000$ & $3.12 E+03$ \\
\hline SELENIUM & 7782492 & $4.00 E+02$ & $<1100$ & $7.40 E-01$ \\
\hline SILVER & 7440224 & $<490$ & $<2300$ & $<10$ \\
\hline SODIUM & 7647145 & $7.72 E+05$ & $<1100000$ & $4.79 E+03$ \\
\hline THALLIUM & 7440280 & $2.90 E+02$ & $<2200$ & $8.00 E-01$ \\
\hline VANADIUM & 7440622 & $7.08 E+04$ & $3.60 E+04$ & $2.97 E+01$ \\
\hline ZINC & 7646857 & $1.16 E+05$ & $3.60 E+04$ & $2.47 E+01$ \\
\hline
\end{tabular}




\begin{tabular}{|c|}
\hline $\begin{array}{l}\text { IABLE D.6. Volatile Organic Compounds and Metals } \\
\text { Analytes Measured in DP26 Soil Samples by SAIC (1989) }\end{array}$ \\
\hline $\begin{array}{l}\text { VOLATILES } \\
\end{array}$ \\
\hline 1,1,1-TRICHLOROETHANE \\
\hline 1,1,2-TRICHLOROETHANE \\
\hline 2-BUTANONE \\
\hline 2-HEXANONE \\
\hline 4-METHYL-2-PENTANONE \\
\hline ACETONE \\
\hline BENZENE \\
\hline CARBON TETRACHLORIDE \\
\hline CHLOROFORM \\
\hline CIS-1,2-DICHLOROETHENE \\
\hline ETHYLBENZENE \\
\hline METHYLENE CHLORIDE \\
\hline P-DICHLOROBENZENE \\
\hline TETRACHLOROETHENE \\
\hline TETRAHYDROFURAN \\
\hline TOLUENE \\
\hline TRANS-1,2-DICHLOROETHENE \\
\hline TRICHLOROETHENE \\
\hline VINYL CHLORIDE \\
\hline XYLENES (TOTAL) \\
\hline METALS \\
\hline LEAD \\
\hline
\end{tabular}




\begin{tabular}{|c|c|c|c|c|c|c|}
\hline Sample & Medium & Year Collected & Volatiles & $\begin{array}{l}\text { Metals, SemiVolatiles } \\
\text { PCBs, Pesticides }\end{array}$ & TPH & Collected by \\
\hline S10SD01-21.5 & Sediment & 1991 & $x$ & $\mathrm{x}$ & $x$ & $\mathrm{CH} 2 \mathrm{M}$ Hill \\
\hline S10SD02-10.0 & Sediment & 1991 & $x$ & $x$ & $x$ & CH2M Hill \\
\hline S10SD03-15.0 & Sediment & 1991 & $x$ & $\mathrm{x}$ & $x$ & CH2M Hill \\
\hline SD10SD04-0.0 & Sediment & 1991 & $x$ & $x$ & $x$ & CH2M Hill \\
\hline SD10SD04-0.0 & Sediment & 1991 & $x$ & $x$ & $\mathrm{x}$ & CH2M Hill \\
\hline SD10SD05-0.0 & Sediment & 1991 & $x$ & $x$ & $x$ & CH2M Hill \\
\hline SD10SD06-0.0 & Sediment & 1991 & $x$ & $x$ & $x$ & CH2M Hill \\
\hline SD10SD07-0.0 & Sediment & 1991 & $\mathrm{x}$ & $x$ & $x$ & CH2M Hill \\
\hline SD10SD08-0.0 & Sediment & 1991 & $x$ & $x$ & $x$ & CH2M Hill \\
\hline SL-10-CMP-01 & Surface Soil & 1991 & $x$ & $x$ & $x$ & $\mathrm{CH} 2 \mathrm{M}$ Hill \\
\hline SL-10-CMP-02 & Surface Soil & 1991 & $x$ & $x$ & $x$ & CH2M Hill \\
\hline SL-10-CMP-03 & Surface Soil & 1991 & $x$ & $x$ & $x$ & CH2M Hill \\
\hline SL-10-CMP-04 & Surface Soil & 1991 & $x$ & $x$ & $x$ & CH2M Hill \\
\hline SL-10-CMP-04 & Surface Soil & 1991 & $x$ & $x$ & $x$ & CH2M Hill \\
\hline SL-10-CMP-05 & Surface Soil & 1991 & $x$ & $x$ & $\mathrm{x}$ & $\mathrm{CH} 2 \mathrm{M}$ Hill \\
\hline SL-10-DIR-01 & Surface Soil & 1991 & $x$ & $x$ & $x$ & CH2M Hill \\
\hline SL-10-DIR-02 & Surface Soil & 1991 & $x$ & $x$ & $x$ & CH2M Hill \\
\hline SL-10-DIR-03 & Surface Soil & 1991 & $x$ & $x$ & $x$ & $\mathrm{CH} 2 \mathrm{M}$ Hill \\
\hline SL-10-DIR-04 & Surface Soil & 1991 & $x$ & $x$ & $x$ & CH2M Hill \\
\hline SL-10-DIR-05 & Surface Soil & 1991 & $x$ & $x$ & $x$ & CH2M Hill \\
\hline SL-14-CMP-01 & Surface Soil & 1991 & $x$ & $x$ & $x$ & CH2M Hill \\
\hline SL-14-CMP-02 & Surface Soil & 1991 & $x$ & $x$ & $x$ & CH2M Hill \\
\hline SL-14-CMP-03 & Surface Soil & 1991 & $x$ & $x$ & $x$ & $\mathrm{CH} 2 \mathrm{M}$ Hill \\
\hline SL-14-CMP-04 & Surface Soil & 1991 & $x$ & $x$ & $x$ & CH2M Hill \\
\hline SL-14-CMP-05 & Surface Soil & 1991 & $x$ & $x$ & $x$ & CH2M Hill \\
\hline S10SB03-05.5 & Subsurface Soil & 1991 & $x$ & & $\mathrm{x}$ & CH2M Hill \\
\hline S1OSBO6-05.5 & Subsurface Soil & 1991 & $x$ & & $x$ & CH2M Hill \\
\hline S10SB09-05.5 & Subsurface Soil & 1991 & $x$ & & $x$ & CH2M Hill \\
\hline S10SB14-07.0 & Subsurface Soil & 1991 & $x$ & & $x$ & CH2M Hill \\
\hline S10SB16-03.0 & Subsurface Soil & 1991 & $x$ & & $x$ & CH2M Hill \\
\hline S10SB19-05.5 & Subsurface Soil & 1991 & $x$ & & $x$ & CH2M Hill \\
\hline S10SB22-03.0 & Subsurface Soil & 1991 & $x$ & & $x$ & CH2M Hill \\
\hline SL10SBC-04.5 & Subsurface Soil & 1991 & $x$ & $x$ & $x$ & $\mathrm{CH} 2 \mathrm{M}$ Hill \\
\hline SL10SBC-07.5 & Subsurface Soil & 1991 & $x$ & $\mathrm{x}$ & $x$ & $\mathrm{CH} 2 \mathrm{M}$ Hill \\
\hline SL10SBC-10.5 & Subsurface Soil & 1991 & $x$ & $x$ & $x$ & CH2M Hill \\
\hline SL1OSBC-14.0 & Subsurface Soil & 1991 & $x$ & $x$ & $x$ & $\mathrm{CH} 2 \mathrm{M}$ Hill \\
\hline S14SB01-03.0 & Subsurface Soil & 1991 & $x$ & & $x$ & CH2M Hill \\
\hline S14SB06-05.5 & Subsurface Soil & 1991 & $x$ & & $x$ & CH2M Hill \\
\hline S14SB08-08.0 & Subsurface Soil & 1991 & $x$ & & $x$ & $\mathrm{CH} 2 \mathrm{M}$ Hill \\
\hline S14SB09-05.5 & Subsurface Soil & 1991 & $x$ & & $x$ & CH2M Hill \\
\hline S14SB15-08.0 & Subsurface Soil & 1991 & $x$ & & $x$ & CH2M Hill \\
\hline SL14SB19-1.7 & Subsurface Soil & 1991 & $x$ & & $x$ & $\mathrm{CH} 2 \mathrm{M}$ Hill \\
\hline S14SB21-05.5 & Subsurface Soil & 1991 & $x$ & & $x$ & $\mathrm{CH} 2 \mathrm{M}$ Hill \\
\hline SL14SBC-4.5 & Subsurface Soil & 1991 & $x$ & $x$ & $x$ & CH2M Hill \\
\hline SL14SBC-7.5 & Subsurface Soil & 1991 & $x$ & $x$ & $x$ & CH2M Hill \\
\hline SL14SBC-10.5 & Subsurface Soil & 1991 & $x$ & $x$ & $x$ & $\mathrm{CH} 2 \mathrm{M}$ Hill \\
\hline 10TP01-A & Subsurface Soil & 1992 & $x$ & $\mathrm{~Pb}$ & & CH2M Hill \\
\hline 10TP01-8 & Subsurface Soil & 1992 & $x$ & $\mathrm{~Pb}$ & & CH2M Hill \\
\hline 10TP02-A & Subsurface Soil & 1992 & $x$ & $\mathrm{~Pb}$ & & CH2M Hill \\
\hline 10TP02-B & Subsurface Soil & 1992 & $x$ & $\mathrm{~Pb}$ & & $\mathrm{CH} 2 \mathrm{M}$ Hill \\
\hline GW-10MW01 & Groundwater & 1991 & $x$ & $x$ & & $\mathrm{CH} 2 \mathrm{M}$ Hill \\
\hline GW-10MW02A & Groundwater & 1991 & $x$ & $x$ & & CH2M Hill \\
\hline GW-10MW03 & Groundwater & 1991 & $x$ & $x$ & & CH2M Hill \\
\hline GW-10MWO4 & Groundwater & 1991 & $x$ & $x$ & & CH2M Hill \\
\hline GW-10MWO5 & Groundwater & 1991 & $x$ & $x$ & & CH2M Hill \\
\hline GW-10MWOS & Groundwater & 1991 & $x$ & $x$ & & $\mathrm{CH} 2 \mathrm{M}$ Hill \\
\hline GW-10MWO8 & Groundwater & 1991 & $x$ & $x$ & & CH2M Hill \\
\hline
\end{tabular}


IABLED.7, ST10/SS14 Samples Used for Risk Assessment

\begin{tabular}{llccccc}
\multicolumn{1}{c}{ Sample } & Medium & Year Collected & Volatiles & $\begin{array}{c}\text { Metals, SemiVolatiles } \\
\text { PCBs, Pesticides }\end{array}$ & TPH & Collected by \\
\hline GW-10MW08 & Groundwater & 1991 & $\mathrm{X}$ & $\mathrm{X}$ & CH2M Hill \\
10MW081 & Groundwater & 1991 & $\mathrm{X}$ & $\mathrm{X}$ & CH2M Hill \\
10MW09 & Groundwater & 1991 & $\mathrm{X}$ & $\mathrm{X}$ & CH2M Hill \\
10MW10 & Groundwater & 1991 & $\mathrm{X}$ & $\mathrm{X}$ & CH2M Hill \\
10MW11 & Groundwater & 1991 & $\mathrm{X}$ & $\mathrm{X}$ & CH2M Hill \\
GW-W-1 & Groundwater & 1991 & $\mathrm{X}$ & $\mathrm{X}$ & CH2M Hill \\
GW-W-1 & Groundwater & 1991 & $\mathrm{X}$ & $\mathrm{X}$ & CH2M Hill \\
GW-14MW02 & Groundwater & 1991 & $\mathrm{X}$ & $\mathrm{X}$ & CH2M Hill \\
GW-14MW03 & Groundwater & 1991 & $\mathrm{X}$ & $\mathrm{X}$ & CH2M Hill \\
& & & & $\mathrm{X}$ & \\
SW10SW01-0.0 & Surface Water & 1991 & $\mathrm{X}$ & $\mathrm{X}$ & CH2M Hill \\
SW10SW01-12.0 & Surface Water & 1991 & $\mathrm{X}$ & $\mathrm{X}$ & CH2M Hill \\
SW10SW02-0.0 & Surface Water & 1991 & $\mathrm{X}$ & $\mathrm{X}$ & CH2M Hill \\
SW10SW02-14.0 & Surface Water & 1991 & $\mathrm{X}$ & $\mathrm{X}$ & CH2M Hill \\
SW10SW03-0.0 & Surface Water & 1991 & $\mathrm{X}$ & $\mathrm{X}$ & CH2M Hill \\
SW10SW03-8.0 & Surface Water & 1991 & $\mathrm{X}$ & $\mathrm{X}$ & CH2M Hill
\end{tabular}


IABLE D.8. ST11 Samples Used for Risk Assessment

\begin{tabular}{|c|c|c|c|c|c|c|}
\hline Sample & Medium & Year Collected & Volatiles & $\begin{array}{l}\text { Metals, SemiVolatiles } \\
\text { PCBs, Pesticides }\end{array}$ & TPH & Collected by \\
\hline GS-4 & Sediments & 1992 & $x$ & SemiVolatiles & & U.S.A.F \\
\hline SL-11-CMP-01 & Surface Soil & 1991 & & $x$ & & CH2M Hill \\
\hline SL-11-CMP-02 & Surface Soil & 1991 & & $x$ & & CH2M Hill \\
\hline SL-11-CMP-03 & Surface Soil & 1991 & & $x$ & & CH2M Hill \\
\hline SL-11-CMP-04 & Surface Soil & 1991 & & $x$ & & CH2M Hill \\
\hline SL-11-CMP-05 & Surface Soil & 1991 & & $x$ & & CH2M Hill \\
\hline S11SBO6-08.0 & Subsurface Soil & 1991 & $x$ & & $x$ & CH2M Hill \\
\hline SL11SB08.1.5 & Subsurface Soil & 1991 & $x$ & & $x$ & CH2M Hill \\
\hline S11SB12-08.0 & Subsurface Soil & 1991 & $x$ & & $x$ & CH2M Hill \\
\hline S11SB19-05.5 & Subsurface Soil & 1991 & $x$ & & $x$ & CH2M Hill \\
\hline S11SB20-05.5 & Subsurface Soil & 1991 & $x$ & & $x$ & CH2M Hill \\
\hline S11SB23-08.0 & Subsurface Soil & 1991 & $x$ & & $x$ & CH2M Hill \\
\hline S11SB25-10.5 & Subsurface Soil & 1991 & $x$ & & $x$ & CH2M Hill \\
\hline SL11SBC-04.5 & Subsurface Soil & 1991 & $x$ & $x$ & $x$ & CH2M Hill \\
\hline SL11SBC-07.5 & Subsurface Soil & 1991 & $x$ & $x$ & $x$ & CH2M Hill \\
\hline SL11SBC-12.0 & Subsurface Soil & 1991 & $x$ & $x$ & $x$ & CH2M Hill \\
\hline GW-11MW01 & Groundwater & 1991 & $x$ & $x$ & $x$ & CH2M Hill \\
\hline GW-11MW02 & Groundwater & 1991 & $x$ & $x$ & $x$ & CH2M Hill \\
\hline GW-11MW03 & Groundwater & 1991 & $x$ & $x$ & $x$ & CH2M Hill \\
\hline GW-11MW04 & Groundwater & 1991 & $x$ & $x$ & $x$ & CH2M Hill \\
\hline GW-11MW05 & Groundwater & 1991 & $x$ & $x$ & $x$ & CH2M Hill \\
\hline GW-11MW06 & Groundwater & 1991 & $x$ & $x$ & $x$ & CH2M Hill \\
\hline GW-11MW07 & Groundwater & 1991 & $x$ & $x$ & $x$ & CH2M Hill \\
\hline GS-4 & Surface Water & 1992 & $x$ & SemiVolatiles & & U.S.A.F \\
\hline
\end{tabular}


IABLE D.9. ST13/DP26 Samples Used for Risk Assessment

\begin{tabular}{|c|c|c|c|c|c|c|}
\hline Sample & Medium & Year Collected & Volatiles & $\begin{array}{l}\text { Metals, SemiVolatiles } \\
\text { PCBs, Pesticides }\end{array}$ & TPH & Collected by \\
\hline SL-13-CMP-01 & Surface Soil & 1991 & $\mathrm{x}$ & $x$ & $\bar{x}$ & $\mathrm{CH} 2 \mathrm{M} \mathrm{Hill}$ \\
\hline SL-13-CMP-02 & Surface Soil & 1991 & $x$ & $x$ & $x$ & $\mathrm{CH} 2 \mathrm{M}$ Hill \\
\hline SL-13-CMP-03 & Surface Soil & 1991 & $x$ & $x$ & $x$ & $\mathrm{CH} 2 \mathrm{M}$ Hill \\
\hline SL-13-CMP-04 & Surface Soil & 1991 & $x$ & $x$ & $\mathrm{x}$ & $\mathrm{CH} 2 \mathrm{M}$ Hill \\
\hline SL-13-CMP-05 & Surface Soil & 1991 & $\mathrm{x}$ & $x$ & $x$ & $\mathrm{CH} 2 \mathrm{M}$ Hill \\
\hline $13-04(0)$ & Subsurface Soil & 1987 & $\mathrm{x}$ & $\mathrm{Pb}$ & & SAIC \\
\hline $.13-04(5)$ & Subsurface Soil & 1987 & $x$ & $\mathrm{~Pb}$ & & SAIC \\
\hline $13-04(10)$ & Subsurface Soil & 1987 & $x$ & $\mathrm{~Pb}$ & & SAIC \\
\hline $13-04(15)$ & Subsurface Soil & 1987 & $x$ & $\mathrm{~Pb}$ & & SAIC \\
\hline $13-04(20)$ & Subsurface Soil & 1987 & $x$ & $\mathrm{~Pb}$ & & SAIC \\
\hline $13-04(25)$ & Subsurface Soil & 1987 & $x$ & $\mathrm{~Pb}$ & & SAIC \\
\hline $13-04(30)$ & Subsurface Soil & 1987 & $\mathrm{x}$ & $\mathrm{Pb}$ & & SAIC \\
\hline $13-04(35)$ & Subsurface Soil & 1987 & $x$ & $\mathrm{~Pb}$ & & SAIC \\
\hline $13-04(35)$ & Subsurface Soil & 1987 & $x$ & $\mathrm{~Pb}$ & & SAIC \\
\hline $13-04(40)$ & Subsurface Soil & 1987 & $x$ & $\mathrm{~Pb}$ & & SAIC \\
\hline $13 A B-01(0)$ & Subsurface Soil & 1987 & $x$ & $\mathrm{~Pb}$ & & SAIC \\
\hline $13 A B-01(5)$ & Subsurface Soil & 1987 & $x$ & $\mathrm{~Pb}$ & & SAIC \\
\hline $13 A B-01(10)$ & Subsurface Soil & 1987 & $x$ & $\mathrm{~Pb}$ & & SAIC \\
\hline $13 A B-01(15)$ & Subsurface Soil & 1987 & $x$ & $\mathrm{~Pb}$ & & SAIC \\
\hline $26-01(0)$ & Subsurface Soil & 1986 & $x$ & $\mathrm{~Pb}$ & & SAIC \\
\hline $26-01(0)$ & Subsurface Soil & 1986 & $x$ & $\mathrm{~Pb}$ & & SAIC \\
\hline $26-01(5)$ & Subsurface Soil & 1986 & $x$ & $\mathrm{~Pb}$ & & SAIC \\
\hline $26-01(5)$ & Subsurface Soil & 1986 & $x$ & $\mathrm{~Pb}$ & & SAIC \\
\hline $26-01(10)$ & Subsurface Soil & 1986 & $x$ & $\mathrm{~Pb}$ & & SAIC \\
\hline $26-01(10)$ & Subsurface Soil & 1986 & $x$ & $\mathrm{~Pb}$ & & SAIC \\
\hline $26-01(15)$ & Subsurface Soil & 1986 & $x$ & $\mathrm{~Pb}$ & & SAIC \\
\hline $26-01(15)$ & Subsurface Soil & 1986 & $x$ & $\mathrm{~Pb}$ & & SAIC \\
\hline $26-01(20)$ & Subsurface Soil & 1986 & $x$ & $\mathrm{~Pb}$ & & SAIC \\
\hline $26-01(20)$ & Subsurface Soil & 1986 & $x$ & $\mathrm{~Pb}$ & & SAIC \\
\hline $26-01(25)$ & Subsurface Soil & 1986 & $x$ & $\mathrm{~Pb}$ & & SAIC \\
\hline $26-01(25)$ & Subsurface Soil & 1986 & $x$ & $\mathrm{~Pb}$ & & SAIC \\
\hline $26-01(30)$ & Subsurface Soil & 1986 & $x$ & $\mathrm{~Pb}$ & & SAIC \\
\hline $26-01(30)$ & Subsurface Soil & 1986 & $x$ & $\mathrm{~Pb}$ & & SAIC \\
\hline $26-03(0)$ & Subsurface Soil & 1986 & $x$ & $\mathrm{~Pb}$ & & SAIC \\
\hline $26-03(5)$ & Subsurface Soil & 1986 & $x$ & $\mathrm{~Pb}$ & & SAIC \\
\hline $26-03(10)$ & Subsurface Soil & 1986 & $x$ & $\mathrm{~Pb}$ & & SAIC \\
\hline $26-03(15)$ & Subsurface Soil & 1986 & $x$ & $\mathrm{~Pb}$ & & SAIC \\
\hline $26-03(20)$ & Subsurfaco Soil & 1986 & $x$ & $\mathrm{~Pb}$ & & SAIC \\
\hline $26-03(25)$ & Subsurface Soil & 1986 & $x$ & $\mathrm{~Pb}$ & & SAIC \\
\hline $26-03(25)$ & Subsurface Soil & 1986 & $x$ & $\mathrm{~Pb}$ & & SAIC \\
\hline $26-03(30)$ & Subsurface Soil & 1986 & $x$ & $\mathrm{~Pb}$ & & SAIC \\
\hline $26-04(0)$ & Subsurface Soil & 1987 & $x$ & $\mathrm{~Pb}$ & & SAIC \\
\hline $26-04(0)$ & Subsurface Soil & 1987 & $x$ & $\mathrm{~Pb}$ & & SAIC \\
\hline $26-04(5)$ & Subsurface Soil & 1987 & $x$ & $\mathrm{~Pb}$ & & SAIC \\
\hline $26-04(10)$ & Subsurface Soil & 1987 & $x$ & $\mathrm{~Pb}$ & & SAIC \\
\hline $26-04(15)$ & Subsurface Soil & 1987 & $x$ & $\mathrm{~Pb}$ & & SAIC \\
\hline $26-04(20)$ & Subsurface Soil & 1987 & $x$ & $\mathrm{~Pb}$ & & SAIC \\
\hline $26-04(25)$ & Subsurface Soil & 1987 & $x$ & $\mathrm{~Pb}$ & & SAIC \\
\hline $26-04(30)$ & Subsurface Soil & 1987 & $x$ & $\mathrm{~Pb}$ & & SAIC \\
\hline $26-04(35)$ & Subsurface Soil & 1987 & $x$ & $\mathrm{~Pb}$ & & SAIC \\
\hline $26-04(40)$ & Subsurface Soil & 1987 & $x$ & $\mathrm{~Pb}$ & & SAIC \\
\hline $26-05(0)$ & Subsurface Soil & 1987 & $x$ & $\mathrm{~Pb}$ & & SAIC \\
\hline $26-05(5)$ & Subsurface Soil & 1987 & $x$ & $\mathrm{~Pb}$ & & SAIC \\
\hline $26-05(5)$ & Subsurface Soil & 1987 & $x$ & $\mathrm{~Pb}$ & & SAIC \\
\hline $26-05(10)$ & Subsurface Soil & 1987 & $x$ & $\mathrm{~Pb}$ & & SAIC \\
\hline $26-05(15)$ & Subsurface Soil & 1987 & $x$ & $\mathrm{~Pb}$ & & SAIC \\
\hline $26-05(20)$ & Subsurface Soil & 1987 & $x$ & $\mathrm{~Pb}$ & & SAIC \\
\hline $26-05(25)$ & Subsurface Soil & 1987 & $x$ & $\mathrm{~Pb}$ & & SAIC \\
\hline
\end{tabular}




\begin{tabular}{|c|c|c|c|c|c|c|}
\hline Sample & Medium & Year Collected & Volatiles & $\begin{array}{l}\text { Metals, SemiVolatiles } \\
\text { PCBs, Pesticides }\end{array}$ & TPH & Collected by \\
\hline $26-05(30)$ & Subsurface Soil & 1987 & $x$ & $\mathrm{~Pb}$ & & SAIC \\
\hline $26-05(35)$ & Subsurface Soil & 1987 & $x$ & $\mathrm{~Pb}$ & & SAIC \\
\hline $26-05(40)$ & Subsurface Soil & 1987 & $x$ & $\mathrm{~Pb}$ & & SAIC \\
\hline $26-06(0)$ & Subsurface Soil & 1987 & $\mathrm{x}$ & $\mathrm{Pb}$ & & SAIC \\
\hline $26-06(5)$ & Subsurface Soil & 1987 & $x$ & $\mathrm{~Pb}$ & & SAIC \\
\hline $26-06(10)$ & Subsurface Soil & 1987 & $x$ & $\mathrm{~Pb}$ & & SAIC \\
\hline $26-06(10)$ & Subsurface Soil & 1987 & $x$ & $\mathrm{~Pb}$ & & SAIC \\
\hline $26-06(15)$ & Subsurface Soil & 1987 & $x$ & $\mathrm{~Pb}$ & & SAIC \\
\hline $26-06(20)$ & Subsurface Soil & 1987 & $x$ & $\mathrm{~Pb}$ & & SAIC \\
\hline $26-06(30)$ & Subsurface Soil & 1987 & $x$ & $\mathrm{~Pb}$ & & SAIC \\
\hline $26-06(35)$ & Subsurface Soil & 1987 & $x$ & $\mathrm{~Pb}$ & & SAIC \\
\hline $26-06(40)$ & Subsurface Soil & 1987 & $x$ & $\mathrm{~Pb}$ & & SAIC \\
\hline $26-07(0)$ & Subsurface Soil & 1987 & $x$ & $\mathrm{~Pb}$ & & SAIC \\
\hline $26-07(5)$ & Subsurface Soil & 1987 & $x$ & $\mathrm{~Pb}$ & & SAIC \\
\hline $26-07(10)$ & Subsurface Soil & 1987 & $x$ & $\mathrm{~Pb}$ & & SAIC \\
\hline $26-07(15)$ & Subsurface Soil & 1987 & $x$ & $\mathrm{~Pb}$ & & SAIC \\
\hline $26-07(15)$ & Subsurface Soil & 1987 & $x$ & $\mathrm{~Pb}$ & & SAIC \\
\hline $26-07(20)$ & Subsurface Soil & 1987 & $x$ & $\mathrm{~Pb}$ & & SAIC \\
\hline 26-07(25) & Subsurface Soil & 1987 & $x$ & $\mathrm{~Pb}$ & & SAIC \\
\hline $26-07(30)$ & Subsurface Soil & 1987 & $x$ & $\mathrm{~Pb}$ & & SAIC \\
\hline $26-07(35)$ & Subsurface Soil & 1987 & $x$ & $\mathrm{~Pb}$ & & SAIC \\
\hline $26-07(40)$ & Subsurface Soil & 1987 & $x$ & $\mathrm{~Pb}$ & & SAIC \\
\hline $26-08(0)$ & Subsurface Soil & 1987 & $x$ & $\mathrm{~Pb}$ & & SAIC \\
\hline $26-08(5)$ & Subsurface Soil & 1987 & $x$ & $\mathrm{~Pb}$ & & SAIC \\
\hline $26-08(10)$ & Subsurface Soil & 1987 & $x$ & $\mathrm{~Pb}$ & & SAIC \\
\hline $26-08(15)$ & Subsurface Soil & 1987 & $x$ & $\mathrm{~Pb}$ & & SAIC \\
\hline $26-08(20)$ & Subsurface Soil & 1987 & $x$ & $\mathrm{~Pb}$ & & SAIC \\
\hline $26-08(25)$ & Subsurface Soil & 1987 & $x$ & $\mathrm{~Pb}$ & & SAIC \\
\hline $26-08(25)$ & Subsurface Soil & 1987 & $x$ & $\mathrm{~Pb}$ & & SAIC \\
\hline $26-08(30)$ & Subsurface Soil & 1987 & $x$ & $\mathrm{~Pb}$ & & SAIC \\
\hline $26-08(35)$ & Subsurface Soil & 1987 & $x$ & $\mathrm{~Pb}$ & & SAIC \\
\hline $26-08(40)$ & Subsurface Soil & 1987 & $x$ & $\mathrm{~Pb}$ & & SAIC \\
\hline $26-08(40)$ & Subsurfaco Soil & 1987 & $x$ & $\mathrm{~Pb}$ & & SAIC \\
\hline $26-08(45)$ & Subsurface Soil & 1987 & $x$ & $\mathrm{~Pb}$ & & SAIC \\
\hline $26-08(50)$ & Subsurface Soil & 1987 & $x$ & $\mathrm{~Pb}$ & & SAIC \\
\hline $26-08(55)$ & Subsurface Soil & 1987 & $x$ & $\mathrm{~Pb}$ & & SAIC \\
\hline $26-08(60)$ & Subsurface Soil & 1987 & $x$ & $\mathrm{~Pb}$ & & SAIC \\
\hline $26-09(0)$ & Subsurface Soil & 1987 & $x$ & $\mathrm{~Pb}$ & & SAIC \\
\hline $26-09(5)$ & Subsurface Soil & 1987 & $x$ & $\mathrm{~Pb}$ & & SAIC \\
\hline $26-09(10)$ & Subsurface Soil & 1987 & $x$ & $\mathrm{~Pb}$ & & SAIC \\
\hline $26-09(15)$ & Subsurface Soil & 1987 & $x$ & $\mathrm{~Pb}$ & & SAIC \\
\hline $26-09(20)$ & Subsurface Soil & 1987 & $x$ & $\mathrm{~Pb}$ & & SAIC \\
\hline $26-09(25)$ & Subsurface Soil & 1987 & $x$ & $\mathrm{~Pb}$ & & SAIC \\
\hline $26-09(30)$ & Subsurface Soil & 1987 & $x$ & $\mathrm{~Pb}$ & & SAIC \\
\hline 26-09(35) & Subsurface Soil & 1987 & $x$ & $\mathrm{~Pb}$ & & SAIC \\
\hline $26-09(40)$ & Subsurface Soil & 1987 & $x$ & $\mathrm{~Pb}$ & & SAIC \\
\hline $26-09(40)$ & Subsurface Soil & 1987 & $x$ & $\mathrm{~Pb}$ & & SAIC \\
\hline $26-10(0)$ & Subsurface Soil & 1987 & $x$ & $\mathrm{~Pb}$ & & SAIC \\
\hline $26-10(0)$ & Subsurface Soil & 1987 & $x$ & $\mathrm{~Pb}$ & & SAIC \\
\hline $26-10(5)$ & Subsurface Soil & 1987 & $x$ & $\mathrm{~Pb}$ & & SAIC \\
\hline $26-10(10)$ & Subsurface Soil & 1987 & $x$ & $\mathrm{~Pb}$ & & SAIC \\
\hline $26-10(15)$ & Subsurface Soil & 1987 & $x$ & $\mathrm{~Pb}$ & & SAIC \\
\hline $26-10(20)$ & Subsurface Soil & 1987 & $x$ & $\mathrm{~Pb}$ & & SAIC \\
\hline $26-10(25)$ & Subsurfaco Soil & 1987 & $x$ & $\mathrm{~Pb}$ & & SAIC \\
\hline $26-10(30)$ & Subsurface Soil & 1987 & $x$ & $\mathrm{~Pb}$ & & SAIC \\
\hline $26-10(35)$ & Subsurfaco Soil & 1987 & $x$ & $\mathrm{~Pb}$ & & SAIC \\
\hline $26-10(40)$ & Subsurface Soil & 1987 & $x$ & $\mathrm{~Pb}$ & & SAIC \\
\hline $26-11(0)$ & Subsurface Soil & 1987 & $x$ & $\mathrm{~Pb}$ & & SAIC \\
\hline $26-11(5)$ & Subsurface Soil & 1987 & $x$ & $\mathrm{~Pb}$ & & SAIC \\
\hline $26-11(5)$ & Subsurface Soil & 1987 & $x$ & $\mathrm{~Pb}$ & & SAIC \\
\hline
\end{tabular}




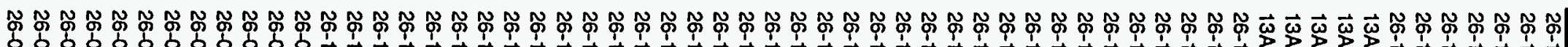

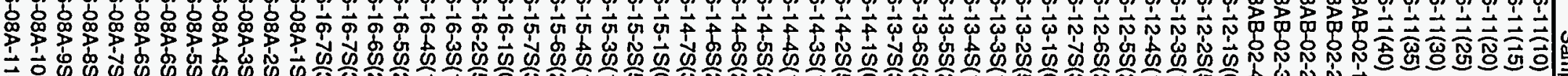

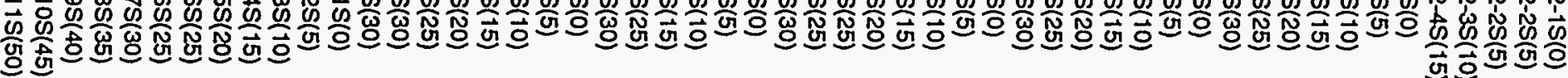

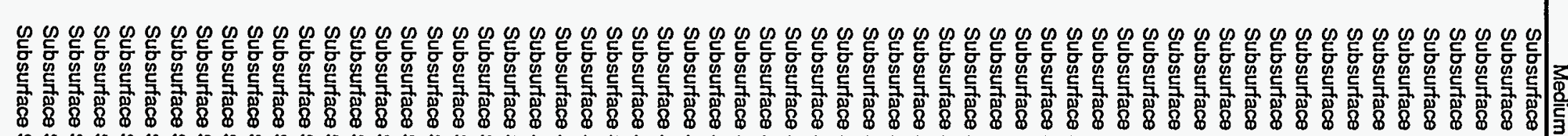

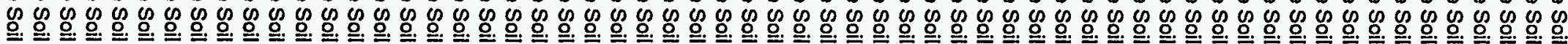

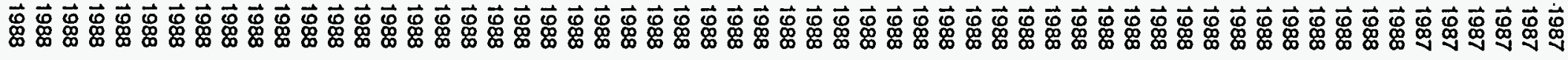

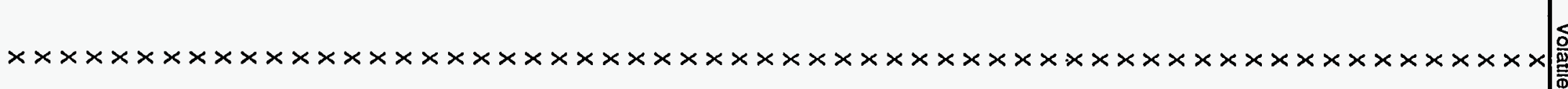

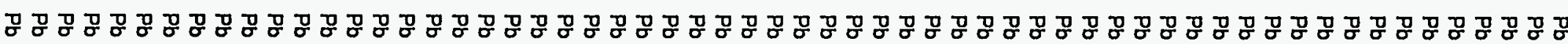

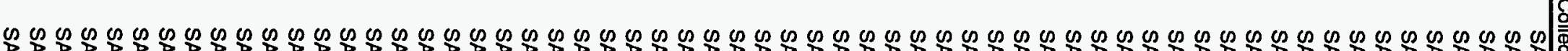

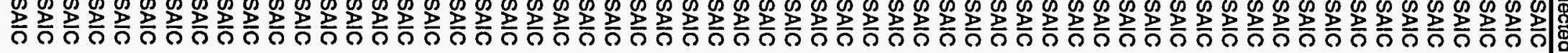


IABLED.9. ST13/DP26 Samples Used for Risk Assessment

\begin{tabular}{|c|c|c|c|c|c|c|}
\hline Sample & Medium & Year Collected & Volatiles & $\begin{array}{l}\text { Metals, SemiVolatiles } \\
\text { PCBs, Pesticides }\end{array}$ & TPH & Collected by \\
\hline $26-08 A-12 S(55)$ & Subsurface Soil & 1988 & $x$ & $\mathrm{~Pb}$ & & SAIC \\
\hline $26-08 A-12 S(55)$ & Subsurface Soil & 1988 & $x$ & $\mathrm{~Pb}$ & & SAIC \\
\hline $26-08 A-13 S(60)$ & Subsurface Soil & 1988 & $\ddot{x}$ & $\mathrm{~Pb}$ & & SAIC \\
\hline$S 13 S B 01-05.5$ & Subsurface Soil & 1991 & $x$ & $x$ & & CH2M Hill \\
\hline S13SBO5-03.0 & Subsurface Soil & 1991 & $x$ & $x$ & & CH2M Hill \\
\hline S13SBOB-03.0 & Subsurface Soil & 1991 & $x$ & $x$ & & CH2M Hill \\
\hline S13SB11-03.0 & Subsurface Soil & 1991 & $x$ & $x$ & & CH2M Hill \\
\hline SL13SBC-04.5 & Subsurface Soil & 1991 & & $x$ & & CH2M Hill \\
\hline SL13SBC-07.5 & Subsurface Soil & 1991 & & $\mathrm{x}$ & & CH2M Hill \\
\hline SL13SBC-12.7 & Subsurface Soil & 1991 & & $x$ & & CH2M Hill \\
\hline 26MW02D-A & Subsurface Soil & 1992 & $x$ & SemiVolatiles & & CH2M Hill \\
\hline 26MWO2D-B & Subsurface Soil & 1992 & $\mathrm{x}$ & SemiVolatiles & & CH2M Hill \\
\hline 26MW02D-C & Subsurface Soil & 1992 & $x$ & SemiVolatiles & & CH2M Hill \\
\hline GW-13MW01 & Groundwater & 1991 & $x$ & $x$ & & CH2M Hill \\
\hline GW-13MW02 & Groundwater & 1991 & $x$ & $x$ & & CH2M Hill \\
\hline GW-13MW03 & Groundwater & 1991 & $\mathbf{x}$ & $x$ & & CH2M Hill \\
\hline GW-13MW04 & Groundwater & 1991 & $\mathrm{x}$ & $\mathrm{x}$ & & CH2M Hill \\
\hline 13MWO5 & Groundwater & 1991 & $\mathbf{x}$ & $x$ & & CH2M Hill \\
\hline GW-26MW01 & Groundwater & 1991 & $x$ & $x$ & & CH2M Hill \\
\hline GW-26MW02 & Groundwater & 1991 & $x$ & $x$ & & CH2M Hill \\
\hline GW-26MW03 & Groundwater & 1991 & $x$ & $x$ & & CH2M Hill \\
\hline GW-26MW04 & Groundwater & 1991 & $\mathrm{x}$ & $x$ & & CH2M Hill \\
\hline GW-26MW05 & Groundwater & 1991 & $x$ & $\mathrm{x}$ & & CH2M Hill \\
\hline GW-26MW06 & Groundwater & 1991 & $x$ & $x$ & & CH2M Hill \\
\hline GW-26MW07 & Groundwater & 1991 & $x$ & $x$ & & CH2M Hill \\
\hline GW-26MW08 & Groundwater & 1991 & $x$ & $x$ & & $\mathrm{CH} 2 \mathrm{M}$ Hill \\
\hline GW-26MWO8A & Groundwater & 1991 & $x$ & $x$ & & CH2M Hill \\
\hline GW-26MW10 & Groundwater & 1991 & $x$ & $x$ & & CH2M Hill \\
\hline GW-26MW11 & Groundwater & 1991 & $x$ & $x$ & & CH2M Hill \\
\hline GW-26MW12 & Groundwater & 1991 & $x$ & $x$ & & CH2M Hill \\
\hline GW-26MW13 & Groundwater & 1991 & $x$ & $x$ & & CH2M Hill \\
\hline GW-26MW14 & Groundwater & 1991 & $\mathrm{x}$ & & & CH2M Hill \\
\hline GW-26MW15 & Groundwater & 1991 & $x$ & $x$ & & CH2M Hill \\
\hline 26MW02I & Groundwater & 1991 & $x$ & $x$ & & CH2M Hill \\
\hline 26MWO2D & Groundwater & 1992 & $x$ & & & CH2M Hill \\
\hline
\end{tabular}


IABLE D.10. ST18 Samples Used for Risk Assessment

\begin{tabular}{|c|c|c|c|c|c|c|}
\hline & & & & Metals, SemiVolatiles & & \\
\hline Sample & Medium & Year Collected & Volatiles & PCBs, Pesticides & TPH & Collected by \\
\hline SL-18-CMP-01 & Surface Soil & 1991 & & $x$ & & CH2M Hill \\
\hline SL-18-CMP-02 & Surface Soil & 1991 & & $\mathrm{x}$ & & CH2M Hill \\
\hline SL-18-CMP-03 & Surface Soil & 1991 & & $x$ & & $\mathrm{CH} 2 \mathrm{M}$ Hill \\
\hline SL-18-CMP-04 & Surface Soil & 1991 & & $x$ & & CH2M Hill \\
\hline SL-18-CMP-05 & Surface Soil & 1991 & & $x$ & & CH2M Hill \\
\hline S18SB01-08.0 & Subsurface Soil & 1991 & $x$ & & $x$ & CH2M Hill \\
\hline S18SBO3-03.0 & Subsurface Soil & 1991 & $x$ & & $x$ & CH2M Hill \\
\hline S18SB11-03.0 & Subsurface Soil & 1991 & $x$ & & $x$ & CH2M Hill \\
\hline S18SB13-03.0 & Subsurface Soil & 1991 & $x$ & & $x$ & CH2M Hill \\
\hline S18SB14-05.5 & Subsurface Soil & 1991 & $x$ & & $x$ & CH2M Hill \\
\hline S18SB16-10.5 & Subsurface Soil & 1991 & $x$ & & $x$ & CH2M Hill \\
\hline S18SB18-8.0 & Subsurface Soil & 1991 & $\mathrm{x}$ & & $x$ & CH2M Hill \\
\hline SL18SBC-12.5 & Subsurface Soil & 1991 & $x$ & $\mathrm{x}$ & $x$ & CH2M Hill \\
\hline SL18SBC- 18.5 & Subsurface Soil & 1991 & $x$ & $x$ & $\mathrm{x}$ & CH2M Hill \\
\hline GW-18MW01 & Groundwater & 1991 & $x$ & $x$ & $x$ & CH2M Hill \\
\hline GW-18MW02 & Groundwater & 1991 & $x$ & $\mathrm{x}$ & $\mathrm{x}$ & CH2M Hill \\
\hline GW-18MW03 & Groundwater & 1991 & $x$ & $\mathrm{x}$ & $x$ & CH2M Hill \\
\hline GW-18MW05 & Groundwater & 1991 & $x$ & $x$ & $x$ & CH2M Hill \\
\hline GW-18MW06 & Groundwater & 1991 & $x$ & $x$ & $x$ & CH2M Hill \\
\hline GW-18MW07 & Groundwater & 1991 & $x$ & $x$ & $x$ & CH2M Hill \\
\hline GW-18MW08 & Groundwater & 1991 & $x$ & $x$ & $x$ & CH2M Hill \\
\hline 18MW05I & Groundwater & 1991 & $x$ & $\mathrm{x}$ & $x$ & CH2M Hill \\
\hline
\end{tabular}


IABLED.11 ST19 Samples Used for Risk Assessment

\begin{tabular}{|c|c|c|c|c|c|c|}
\hline Sample & Medium & Year Collected & Volatiles & $\begin{array}{l}\text { Metals, SemiVolatiles } \\
\text { PCBs, Pesticides }\end{array}$ & TPH & Collected by \\
\hline$\overline{S L-19-C M P-01}$ & Surface Soil & 1991 & & $x$ & & CH2M Hill \\
\hline SL-19-CMP-02 & Surface Soil & 1991 & & $x$ & & CH2M Hill \\
\hline SL-19-CMP-03 & Surface Soil & 1991 & & $x$ & & CH2M Hill \\
\hline SL-19-CMP-04 & Surface Soil & 1991 & & $x$ & & CH2M Hill \\
\hline SL-19-CMP-05 & Surface Soil & 1991 & & $x$ & & CH2M Hill \\
\hline S19SB03-1.6 & Subsurface Soil & 1991 & $x$ & & $x$ & CH2M Hill \\
\hline S19SBO9-1.8 & Subsurface Soil & 1991 & $x$ & & $x$ & CH2M Hill \\
\hline S19SB12-5.5 & Subsurface Soil & 1991 & $x$ & & $\mathrm{x}$ & CH2M Hill \\
\hline S19SB15-3.0 & Subsurface Soil & 1991 & $x$ & & $x$ & CH2M Hill \\
\hline S19SB18-1.7 & Subsurface Soil & 1991 & $\mathrm{x}$ & & $x$ & CH2M Hill \\
\hline S19SB22-2.1 & Subsurface Soil & 1991 & $x$ & & $x$ & CH2M Hill \\
\hline S19SB25-4.3 & Subsurface Soil & 1991 & $x$ & & $x$ & CH2M Hill \\
\hline S19SB28-03.0 & Subsurface Soil & 1991 & $x$ & & $x$ & CH2M Hill \\
\hline S19SB32-05.5 & Subsurface Soil & 1991 & $x$ & & $x$ & CH2M Hill \\
\hline SL19SBC-4.5 & Subsurface Soil & 1991 & $x$ & $x$ & $x$ & CH2M Hill \\
\hline SL19SBC-07.5 & Subsurface Soil & 1991 & $x$ & $\ddot{x}$ & $x$ & CH2M Hill \\
\hline 19SB39 & Subsurface Soil & 1992 & $x$ & SemiVolatiles & & CH2M Hill \\
\hline GW-19MW01 & Groundwater & 1991 & $x$ & $x$ & $x$ & CH2M Hill \\
\hline GW-19MWO2A & Groundwater & 1991 & $x$ & $x$ & $x$ & CH2M Hill \\
\hline GW-19MWO2A & Groundwater & 1991 & $x$ & $x$ & 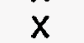 & CH2M Hill \\
\hline GW-19MWO3 & Groundwater & 1991 & $x$ & $x$ & $x$ & CH2M Hill \\
\hline GW-19MWO4 & Groundwater & 1991 & $x$ & $x$ & $x$ & CH2M Hill \\
\hline 19MWO6 & Groundwater & 1991 & $x$ & $x$ & $x$ & CH2M Hill \\
\hline
\end{tabular}




\title{
Eielson Air Force Base \\ Baseline Risk Assessment
}

\author{
Appendix $\mathbf{E}$ \\ Determination Of Background Metal Concentrations
}




\section{APPENDIX E-.DETERMINATION OF BACKGROUND METAL CONCENTRATIONS}

The Fairbanks area of Alaska is noted for elevated concentrations of metals, in particular high levels of iron and manganese in the groundwater (Cederstrom 1963) and high levels of arsenic in groundwater (Nelson 1978; Krumhart 1982; Weddleton et al. 1989). These metals and several others were found to occur at elevated concentrations at Operable Unit 2. Many of these metals exceed risk-based screening concentrations (Section 7.0), and background samples for both soil and groundwater were collected to help identify which metals could be considered equivalent to site background and not the result of base activities. U.S. Air Force (1993a, b) documents the results of the Eielson sitewide background sampling efforts.

The metals at Operable Unit 2 sites were statistically compared to site background in section E.1. Those metals that could not be considered statistically equivalent to background were compared to concentrations of metals believed to be background (i.e., iron) in section E.2. This additional step was necessary, in part, because the background groundwater samples were collected in June when groundwater is diluted with snow melt. Operable Unit 2 groundwater samples were collected during August and September when dilution is minimal. There are no background data for several metals. One of these, thallium, occurs in concentrations that exceed risk-based screening concentrations (Section 7.0). Section E.3 discusses metals that have no groundwater background data. There are no background data for surface waters.

The risks reported for all sites in this assessment are reported both with and without the contribution of those metals deemed equivalent to site background in this appendix. Except for lead, the concentrations of all metals in all media were not considered the result of base activities. Except for lead, there are no known anthropogenic sources for metals at Operable Unit 2.

\section{E.1 COMPARISON TO BACKGROUND}

Results for metal analyses listed in Tables 7.5 through 7.9 were statistically compared to background values measured during the 1991 and 1992 field sampling events. The mean for each set of values for an individual analyte was compared to the background mean through a one-tailed t-test (equation 1).

$$
t=\frac{\left(\bar{x}-\bar{x}_{b}\right)}{\sqrt{\frac{\left((N-1) \times s^{2}\right)+\left(\left(N_{b}-1\right) \times s_{b}^{2}\right)}{\left(N+N_{b}-2\right)} \times \frac{N+N_{b}}{N \times N_{b}}}}
$$

\footnotetext{
Where

$\bar{x}=$ sample mean

$\bar{x}_{b}=$ background mean

$s=$ sample standard deviation

$s_{b}=$ background standard deviation

$N=$ number of site measurements
} 
$N_{b}=$ number of background measurements

The null hypothesis tested was that the mean of the site metal concentrations (metalspecific) was less than or equal to the mean of the background metal concentration. If the calculated t-value is less than the t-value calculated for a one-tailed test with $\left(N+N_{b}-2\right)$ degrees of freedom with 5-percent level of significance $(\alpha)$, (e.g., the null hypothesis can not be rejected) then one can conclude that there is no evidence to suggest that the sample and background came from populations having different means. The cells of analytes where the null hypothesis could not be rejected were highlighted with a neutral gray pattern in Tables 7.2 through 7.6. They were considered not related to base activities and were considered equivalent to site background in the risk assessment.

Sampling constraints diminish the power of the of the t-test. The t-test assumes that the samples are from a normally distributed population. Even if the concentrations of metals are normally distributed, it is unlikely that this condition can be satisfied for certain metals. For example, metals with contract required quantitation limits (CRQLs) that are elevated relative to their mean concentration can positively skew the distribution. Another factor to consider is the size of the samples compared. A t-test is most effective when comparing samples of similar size (EPA 1989). This condition is reasonably satisfied with groundwater samples where the number of background analyses is 14 and the number of analyses per site ranges from 5 to 21 . In contrast, there are 60 background metal analyses from alluvium and most sites have 3 subsurface soil analyses and 5 surface soil analyses. These uncertainties are discussed in the uncertainty sections for each site.

Within each population, if the contaminant was not detected, then one-half the was substituted for that analysis. The majority of the following metals sampled in soils at Operable Unite 2 sites had non-detects: beryllium, cadmium, and thallium. The majority of the following metals sampled in groundwater at Operable Unite 2 sites had nondetects: antimony, beryllium, cadmium, chromium, cobalt, mercury, nickel, silver, selenium, and thallium.

E.1.1 Soils--CH2M Hill collected background samples from a variety of soil types: alluvium, fill, and loess (U.S. Air Force 1993a). The various soil types were used in order to ensure proper comparison between site analyses and background. All subsurface soils and sediments were compared to background samples collected in alluvium. All surface soils, except source areas ST10/SS14, were also compared to alluvium. Surface soils at ST10/SS14 are fill, so they were compared to background samples collected in fill borrow pits. There is no loess at Operable Unit 2 sites.

E.1.2 Water--All groundwater and surface water analyses were compared to samples collected from background wells during the June 1992 sampling event (U.S. Air Force 1993b). Background surface water data are not currently available.

Several of the metals analyzed in the background wells were not detected at CRQLs that exceeded risk-based screening concentrations: antimony, beryllium, and cadmium. If the maximum groundwater concentration for one of these three metals exceeded the appropriate risk-based screening concentrations, the corresponding cell was highlighted in Tables 7.2 through 7.6. These metals were considered not related to base activities because there are no known sources at Eielson.

There are no background groundwater data for three metals analyzed at the Operable Unit 2 sites: mercury, selenium, and thallium. Neither mercury nor selenium occurs in concentrations great than risk-based screening concentrations (Section 7.0). However, 
maximum groundwater concentrations of thallium did exceed risk-based screening concentrations at all Operable Unit 2 sites. The criteria used to identify thallium in groundwater as not related to base activities are detailed below.

\section{E.2 TREND ANALYSIS OF METAL CONCENTRATIONS}

Except for lead, all metal concentrations measured at the Operable Unit 2 sites were considered equivalent to background and not related to base activities. The mean concentrations for some metals were not statistically equivalent to measured background. However, the relationships delineated below suggest that elevated concentrations result from elevated concentrations of naturally occurring metals, principally iron.

E.2.1 Arsenic in Groundwater--The mean arsenic concentration in groundwater exceeded mean measured background at most of the Operable Unit 2 source areas: ST10/SS14, ST11, ST13/DP26, and ST18.

Background groundwater data for metals have been collected (U.S. Air Force 1993b). Table E.1 lists the measured background arsenic analyses.

\begin{tabular}{|c|c|c|}
\hline \multicolumn{3}{|c|}{$\begin{array}{c}\text { TABLEE.1, Arsenic Groundwater } \\
\text { Concentrations (Total) from June } 1992 \\
\text { Background Samples (U.S. Air Force 1993b) }\end{array}$} \\
\hline $\begin{array}{c}\text { WELL } \\
\text { ID }\end{array}$ & $\begin{array}{c}\text { ARSENIC } \\
(\mu g / L)\end{array}$ & \\
\hline $1-1$ & 5 & $\bar{U}$ \\
\hline $1-2$ & 5 & $\mathrm{U}$ \\
\hline $5-3$ & 5 & U \\
\hline $17-2$ & 5 & U \\
\hline $20-1 B$ & 5 & U \\
\hline $20-17$ & 22 & \\
\hline $20-18$ & 5 & $\bar{U}$ \\
\hline $20-21$ & 8.1 & \\
\hline $27-1$ & 10 & \\
\hline $38-3$ & 5 & $\mathrm{U}$ \\
\hline $46-1$ & 5 & $\mathrm{U}$ \\
\hline $46-3$ & 5 & $\mathrm{U}$ \\
\hline $53-2$ & 5 & $\bar{U}$ \\
\hline $54-2$ & 5 & $\bar{U}$ \\
\hline $54-4$ & 5 & $\mathrm{U}$ \\
\hline $54-5$ & 56 & \\
\hline $54-8$ & 19 & \\
\hline \multicolumn{3}{|c|}{ U Compound was analyzed for, but not detectec } \\
\hline
\end{tabular}

Most of the measured background arsenic concentrations are below the detection limit. One is greater than the maximum contamination limit (MCL). However, the background samples were collected in June, when the groundwater table is elevated due to snow 
melt. The elevation of the groundwater table may dilute the groundwater concentrations of metals. Therefore, these values are probably lower than those that would be measured in August, when the Operable Unit 2 samples were collected. For comparison, Table E.2 lists arsenic background values measured during October 1988. They are consistently higher than the values measured during the June 1992 event. This relationship is true for all metals measured.

\begin{tabular}{|c|c|}
\hline \multicolumn{2}{|c|}{$\begin{array}{c}\text { IABLEE.2, Arsenic Groundwater } \\
\text { Concentrations (Total) from October 1988 } \\
\text { Background Samples }\end{array}$} \\
\hline \hline $\begin{array}{c}\text { WELL } \\
D\end{array}$ & $\begin{array}{c}\text { ARSENIC } \\
(\mu \mathrm{g} / \mathrm{L})\end{array}$ \\
\hline $1-1$ & 8.9 \\
\hline $1-2$ & 11.7 \\
\hline $5-3$ & 8.9 \\
\hline $53-2$ & 9.6 \\
\hline
\end{tabular}

Regional data suggest that elevated arsenic concentrations may be equivalent to site background and not the result of base activities. Weber (1986) reported very high arsenic levels ( $>50 \mathrm{mg} / \mathrm{L}$ ) north of Fairbanks where water wells tap fractured reservoirs in mineralized bedrock. Fluvial sands and gravels, not mineralized crystalline rocks, form the aquifer at Eielson. However, Weber (1986) recognized that elevated arsenic groundwater concentrations do occur along valley bottoms and ascribed this enrichment to concentration by fluvial processes (i.e., placer deposits). This point, however, should be tempered by recognizing that the alluvial aquifer of the Tanana Basin, which would include Eielson AFB as well as the community of North Pole, is generally noted for shallow groundwater, high levels of iron and manganese, but typically low levels of arsenic.

Figures E.1 to E.4 plot the arsenic groundwater concentration versus iron concentration for the Operable Unit 2 sites. The plots suggest the concentrations of the two metals are linearly related. The square of the correlation coefficient $\left(r^{2}\right)$ of the linear regression for each plot is included in the figures. The square of the correlation coefficient is the fraction of variance in the dependent variable (arsenic), which is explained by variance in the independent variable (iron). The correlation coefficient is defined below.

$r_{j k}=\frac{S P_{j k} /(n-1)}{s_{j} s_{k}}$

Where

$S P_{j k}=$ sum of the products

$s_{j}=$ standard deviation for variable $j$

$s_{k}=$ standard deviation for variable $k$

$n=$ number of paired measurements 
Dissolved arsenic has no solubility control; it can not precipitate and its aqueous concentration is controlled solely by sorption (Crecelius et al. 1986). Arsenic preferentially adsorbs onto iron-rich amorphic oxides, and it has been shown elsewhere that when iron was removed from soils, arsenic sorption was eliminated or reduced appreciably (Jacobs et al. 1970). Therefore, less iron in the soil (the more iron in the groundwater) leads to more arsenic in the groundwater. This plots described in the preceding paragraph are consistent with this relationship.

Dissolved arsenic has no solubility control; it can not precipitate and its aqueous concentration is controlled solely by sorption (Crecelius et al. 1986). Arsenic preferentially adsorbs onto iron-rich amorphic oxides, and it has been shown elsewhere that when iron was removed from soils, arsenic sorption was eliminated or reduced appreciably (Jacobs et al. 1970). Therefore, reduction of the iron concentration in soil (the more iron in the groundwater) leads to more arsenic in the groundwater. This plots described in the preceding paragraph are consistent with this relationship.

Groundwater iron concentration is a reliable measure of the oxidation state of the waters; the greater the iron concentration, the more reducing the waters. The elevated arsenic concentration, therefore, may be due to local redox conditions.

There are no known sources for arsenic contamination at Eielson. Arsenic contamination is typically associated with wood treatment, fungicides, and animal poisons.

There is no evidence to suggest that the elevated groundwater arsenic at Operable Unit 2 is caused by contamination. Therefore, a reasonable case can be made for high groundwater metals levels caused by variations in the natural redox conditions, not due to site contamination.

E.2.2 Antimony, Arsenic, and Vanadium in Surface Soils--The mean concentrations of antimony, arsenic, and vanadium in Operable Unit 2 surface soils were not statistically equivalent to or less than mean background values. Antimony and arsenic were not equivalent to measured background at sites ST10/SS14 nor was vanadium at site ST19. Figures E.5, E.6, and E.7 plot the concentrations of antimony, arsenic, and vanadium, respectively, versus iron in surface soils for all Operable Unit 2 analyses and Eielson soil background analyses. Very strong linear relationships with respect to iron are apparent for all metals $\left(0 / 76 \leq r^{2} \leq 0.90\right)$.

Sedimentary iron in the form of ferric hydroxide $(\mathrm{FeOH})$ is common in reducing sedimentary environments. The adsorptive power of ferric hydroxide is very great for anions (Mason 1966), and antimony, arsenic, and vanadium have been reported in notable concentrations in sedimentary iron rich deposits. Thus, it is probable that elevated antimony, arsenic and vanadium in surface soils are due solely to elevated iron concentrations in the same soils.

The relationship between arsenic and iron is consistent for both groundwater and surface soils. In both media, arsenic concentrations preferentially mimics iron's due to the strong affinity of arsenic to sorb onto iron hydroxides in the mineral matrix. Lower concentrations of these hydroxides, perhaps due to variability in the fill that covers the base, provides fewer molecules for the arsenic to sorb onto, thus leading to diminished arsenic soils concentrations.

If the concentrations of iron hydroxides within the mineral matrix of the saturated zone were to decrease, perhaps due to a change in the redox potential, then the iron would 
preferentially dissolve into the water. Any arsenic that had been sorbed onto the dissolved iron would then also dissolve into the water, thus increasing the groundwater concentration of both metals.

When comparing the two media, soils and groundwater, one must realize that the concentrations of iron and arsenic are much greater in soils than groundwater. At Operable Unit 2, the average arsenic concentrations are $9,800 \mu \mathrm{g} / \mathrm{kg}$ for soils and $24 \mu \mathrm{g} / \mathrm{L}$ for groundwater. The average iron concentrations are $19,600,000 \mu \mathrm{g} / \mathrm{kg}$ for soils and $9,800 \mu \mathrm{g} / \mathrm{L}$ for groundwater. Thus, even where arsenic and iron have preferentially dissolved into groundwater, their concentrations in the remaining soils are not "low"; there is still a large reservoir of both remaining in the soils.

There are no known contaminants at Eielson that would have led to elevated antimony, arsenic, iron, or vanadium levels in surface soil.

E.2.3 Manganese--Manganese occurs in elevated concentrations in the groundwaters at all Operable Unit 2 sites. The maximum concentrations at all sites exceed risk-based screening concentrations (Section 7.0). The mean groundwater concentration at sites ST13/DP26 were not statistically equivalent to site background; groundwater manganese at the other Operable Unit 2 sites were statistically equivalent to site background.

Figure E.8 plots manganese versus iron for Operable Unit 2 groundwaters. A linear relationship between the concentrations of the two metals is apparent $\left(r^{2}=0.51\right)$. This should be expected because manganese is often present in solid solution in minerals containing iron since their ions are mutually replaceable (Mason 1966). Therefore, minerals that contain ferrous iron should also have manganese.

E.2.4 Barium-Mean concentrations of groundwater barium exceed mean site background values for all Operable Unit 2 sites except ST19. The maximum concentrations at ST10/SS14 and ST13/DP26 exceed risk cutoff values defined in section 7.0 of this assessment.

Figure E.9 plots barium versus manganese for Operable Unit 2 groundwaters. There is a linear relationship between the two metals $\left(r^{2}=0.53\right)$. Manganese commonly occurs in sedimentary rocks as a form of hydrated manganese dioxide, which has very great adsorptive powers (Mason 1966). Hydrated manganese dioxide is a negatively charged colloid and adsorbs cations, and barium has been reported in notable concentrations in sedimentary deposits. It is proposed that elevated groundwater concentrations of barium are caused by dissolution of these manganese hydrates and adsorbed barium cations in the reducing groundwaters at Eielson.

Barium is a common byproduct in coal ash. Eielson AFB has a coal-fired power plant, and ash disposal has occurred on base. Although there are no known disposal sites near or directly upgradient of the Operable Unit 2 sites, one can not dismiss this source entirely.

\section{E.3 METALS WITH NO BACKGROUND DATA}

Maximum groundwater concentrations of thallium exceeded risk-based screening concentrations (Section 7.0) at all sites in Operable Unit 2. No background data were collected for thallium. There are no known sources for thallium, it has been used in the past for rodenticides and herbicides, but its use was discontinued in the United States 
prior to the development of Eielson. This assessment will assume that thallium is not related to base activities.

There are no background metal data for surface waters at Eielson. Six surface water samples were collected from Hardfill Lake at ST10 and analyzed for metals (U.S. Air Force 1993c). The mean concentration of metals in the waters of Hardfill Lake was less than the means for groundwater at all Operable Unit 2 sites for all metals except: calcium, magnesium, potassium, and sodium. Only one of these four metals, sodium, has a toxicity value (Table 9.1). The following metals were not detected at Hardfill Lake: antimony, beryllium, chromium, cobalt, copper, mercury, silver, thallium, vanadium, and zinc. Cadmium and nickel were only detected in one sample.

Since surface waters have lower concentrations for almost all metals, especially the more toxic ones, and all metals except lead are considered background in groundwaters, as delineated above, this assessment will consider all metals in surface waters equivalent to site background and not related to base activities.

\section{E.4 REFERENCES}

Battelle. 1992. Remedial Investigation/Feasibility Study - Operable Unit 2 Baseline Risk Assessment Report. Eielson Air Force Base. Alaska. Prepared by Battelle, Environmental Management Operations, Richland, Washington. (Draft).

Cederstrom, D.J. 1963. Ground-Water Resources of the Fairbanks Area. Alaska. U.S. Geological Survey Water-Supply Paper 1590.

Crecelius, E.A., N.S. Bloom, C.E. Cowan, and E.A. Jenne. 1986. Speciation of Selenium and Arsenic in Natural Waters and Sediments. Volume 2: Arsenic Speciation. Electric Power Research institute EA-4641, v. 2, 73 p.

EPA. 1989. Bisk Assessment Guidance for Superfund: Human Health Evaluation Manual Part A. U.S. Environmental Protection Agency, Office of Solid Waste and Emergency Response. (Interim Final).

HLA. 1991. Installation Restoration Program Remedial Investigation/Feasibility Study. Stage 4. Draft Remedial Investigation/Feasibility Study. Prepared by Harding Lawson Associates.

Jacobs, L.W., J.K. Syers, and D.R. Keeney. 1970. "Arsenic Sorption by Soils." Soil Science Society of America. Proceedings, v. 34, p. 750-754.

Krumhart, A. P. 1982. Hydrologic Information for Land-Use Planning. Badger Road Area. Eairbanks. Alaska. Water-Resources Investigation 82-4097. U.S. Geological Survey.

Mason, Brian. 1966. Principles of Geochemistry. John Wiley \& Sons, New York, New York.

Nelson, G. 1978. "Hydrologic Information for Land-Use Planning, Fairbanks Vicinity, Alaska." U.S. Geological Survey. 
U.S. Air Force. 1993a. Background Soil Quality, Eielson Air Force Base. Alaska. Prepared by Battelle Environmental Management Operations, Richland, Washington (Final).

U.S. Air Force. 1993b. Background Groundwater Quality, Eielson Air Force Base Alaska. Prepared by Battelle Environmental Management Operations, Richland, Washington (Final).

U.S. Air Force. 1993c. Eielson Air Force Base OU-2 Remedial Investigation/Feasibility Study: Remedial Investigation Report, Prepared by Battelle, Environmental Management Operations, Richland, Washington (Draft Final).

Weber, E.F. 1986. A Stochastic Model and Risk Analysis of Arsenic. Well Depth, and Well Yield in the Faimbanks Area. Alaska. Master's Thesis, University of Alaska, Fairbanks.

Weddleton, J., H. Richards, and R. Seifert. 1989. Building in Alaska. A Guide for Assessing Risks and Costs of Water Well Drilling in the Fairbanks Area. Cooperative Extension Service University of Alaska Fairbanks, Fairbanks, Alaska. 


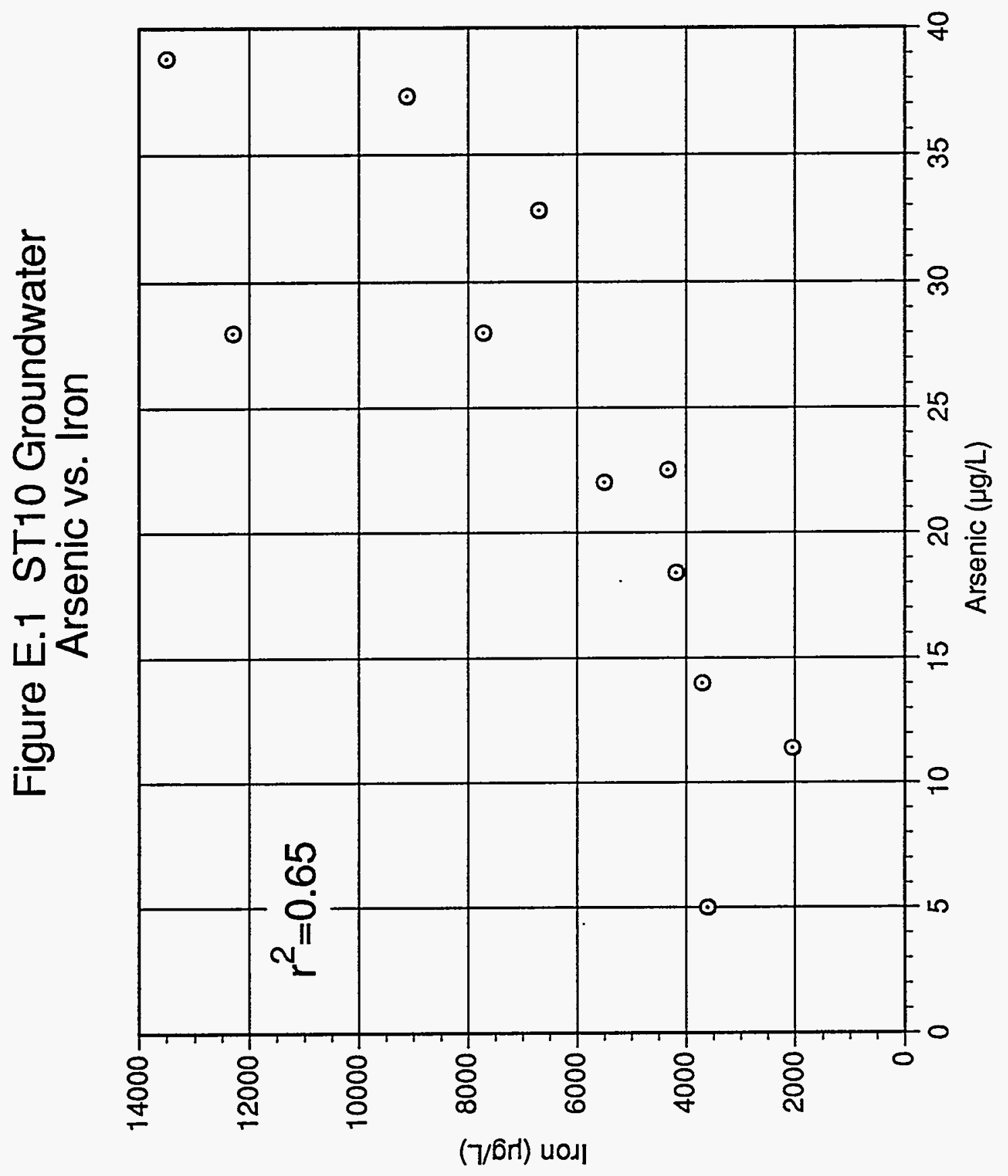




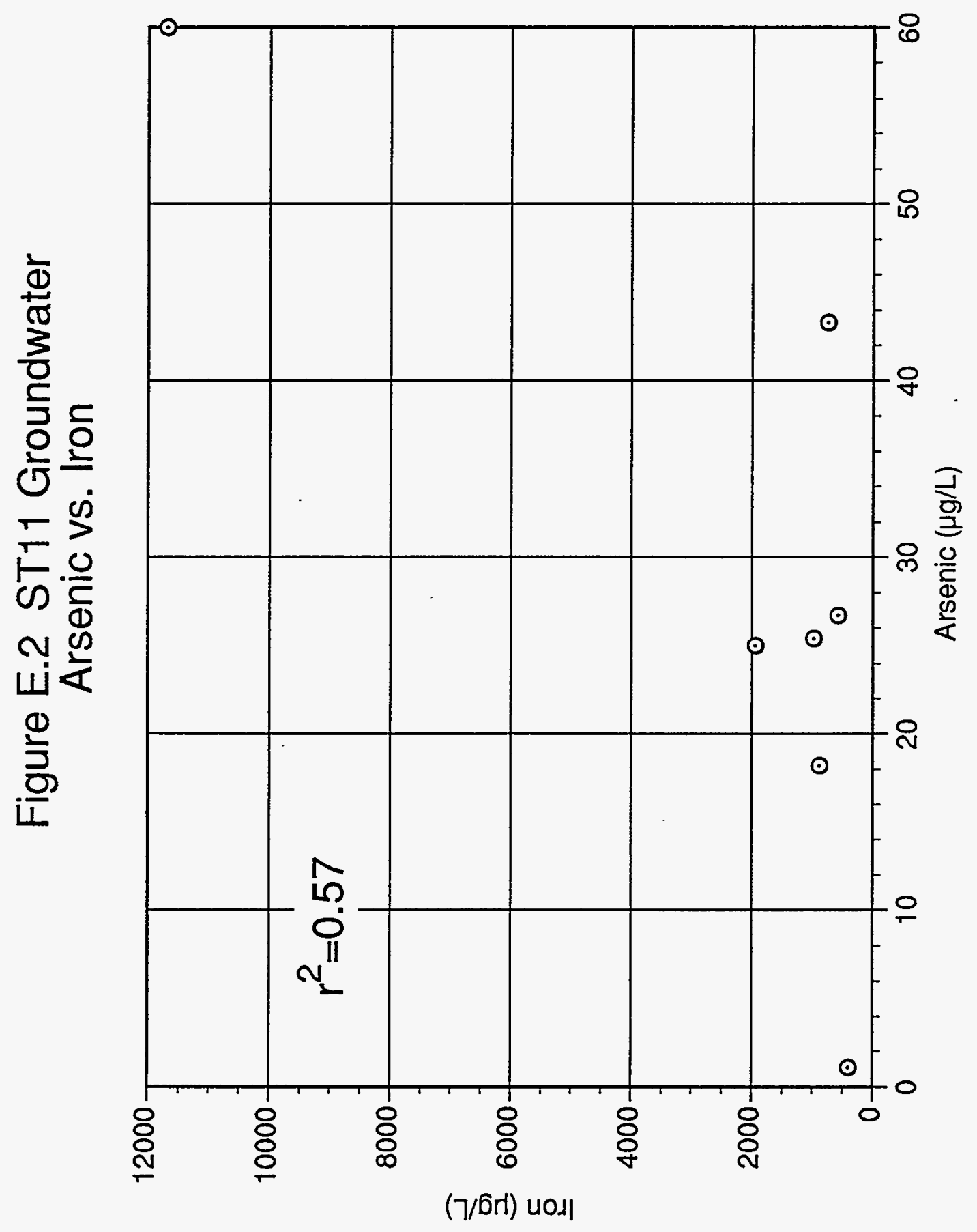




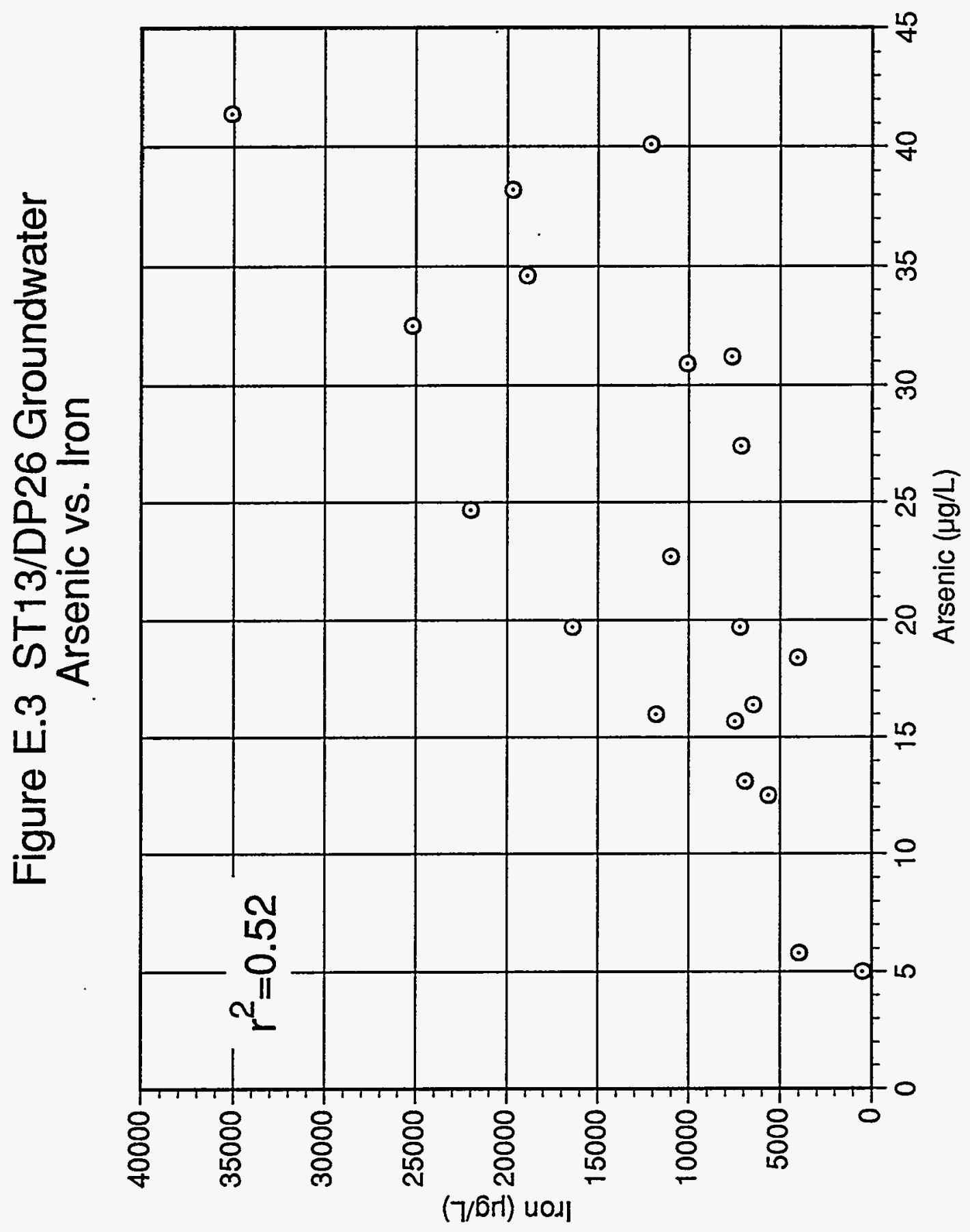




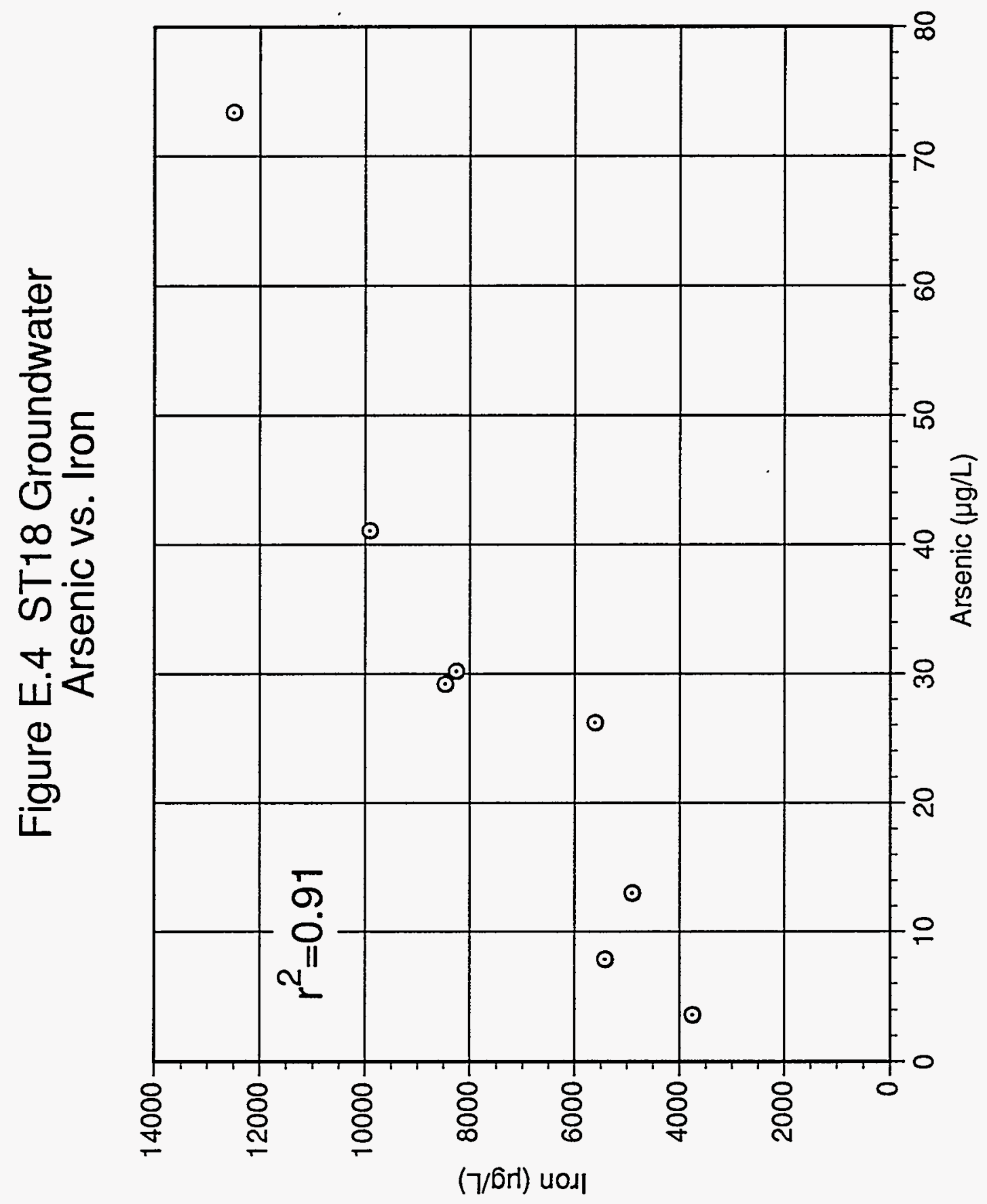




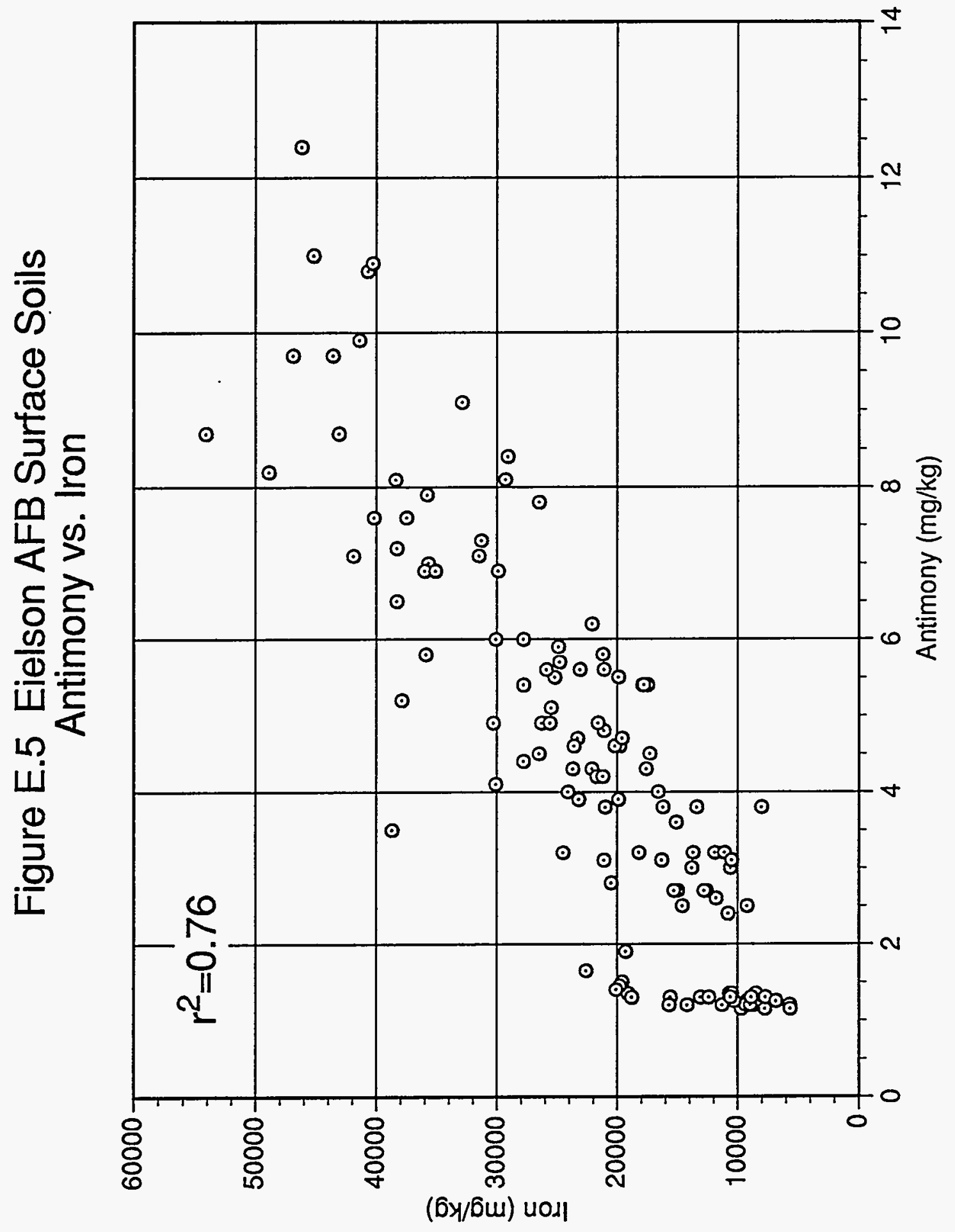




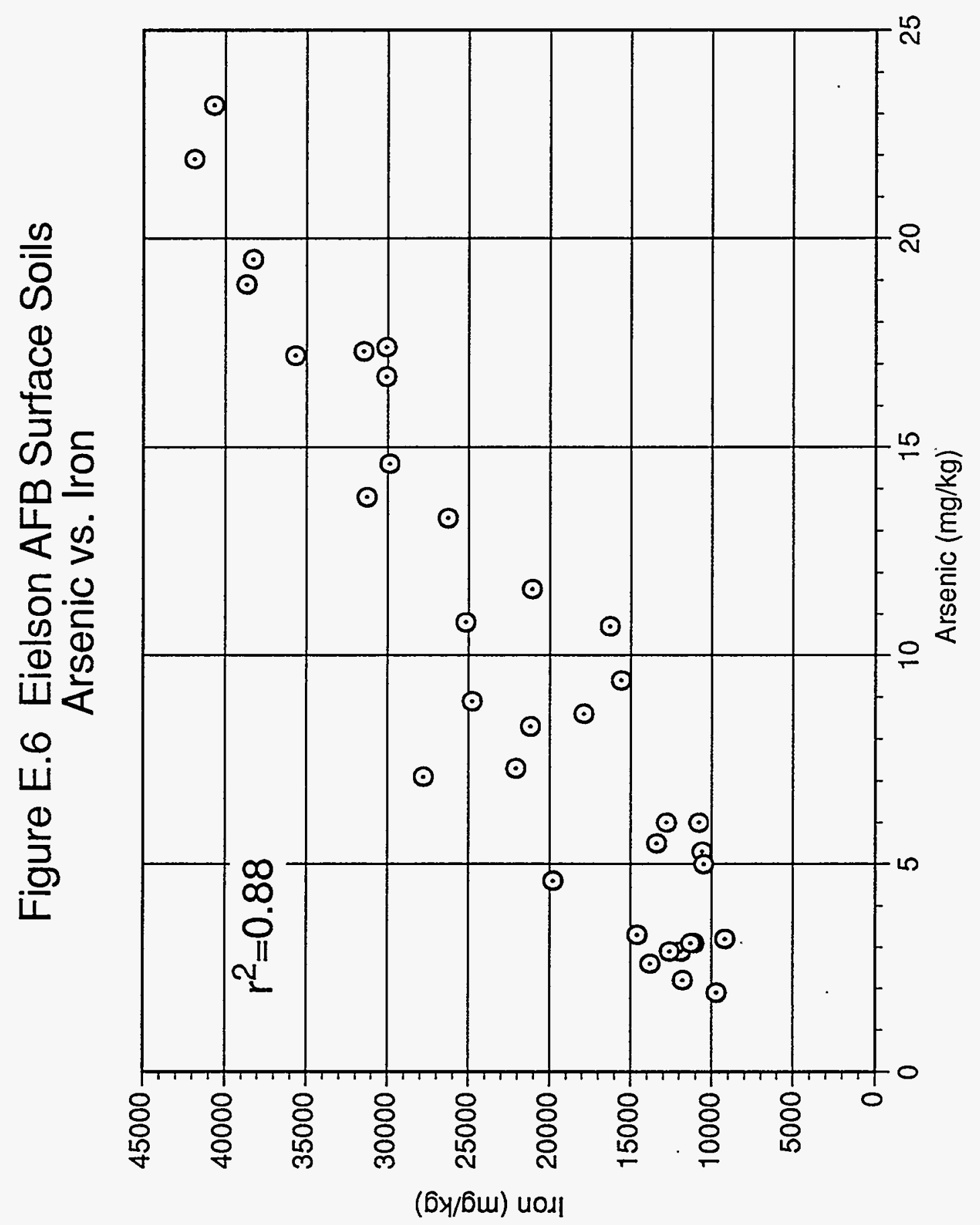




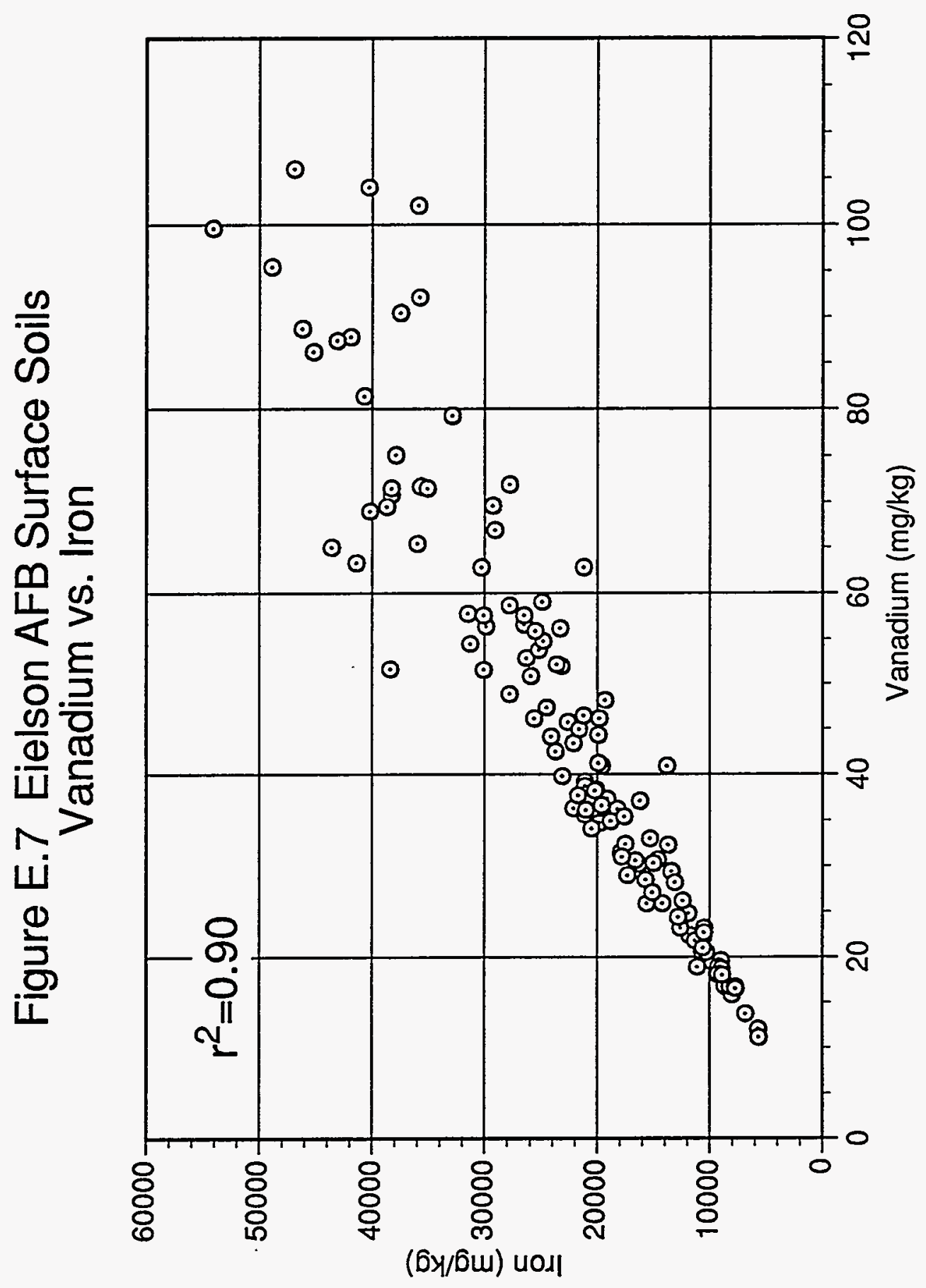




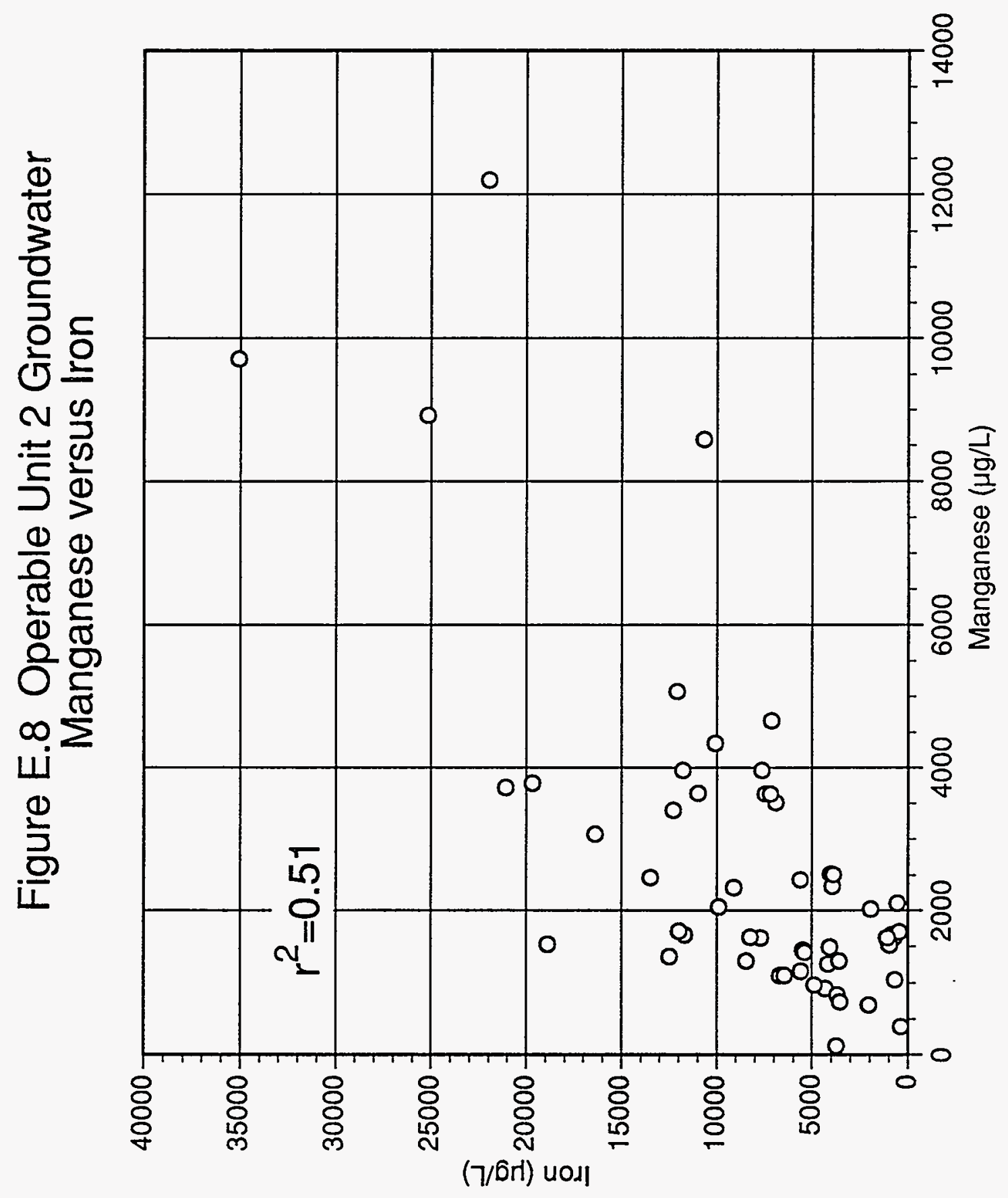


Figure E.9 Operable Unit 2 Groundwaters Barium vs. Manganese

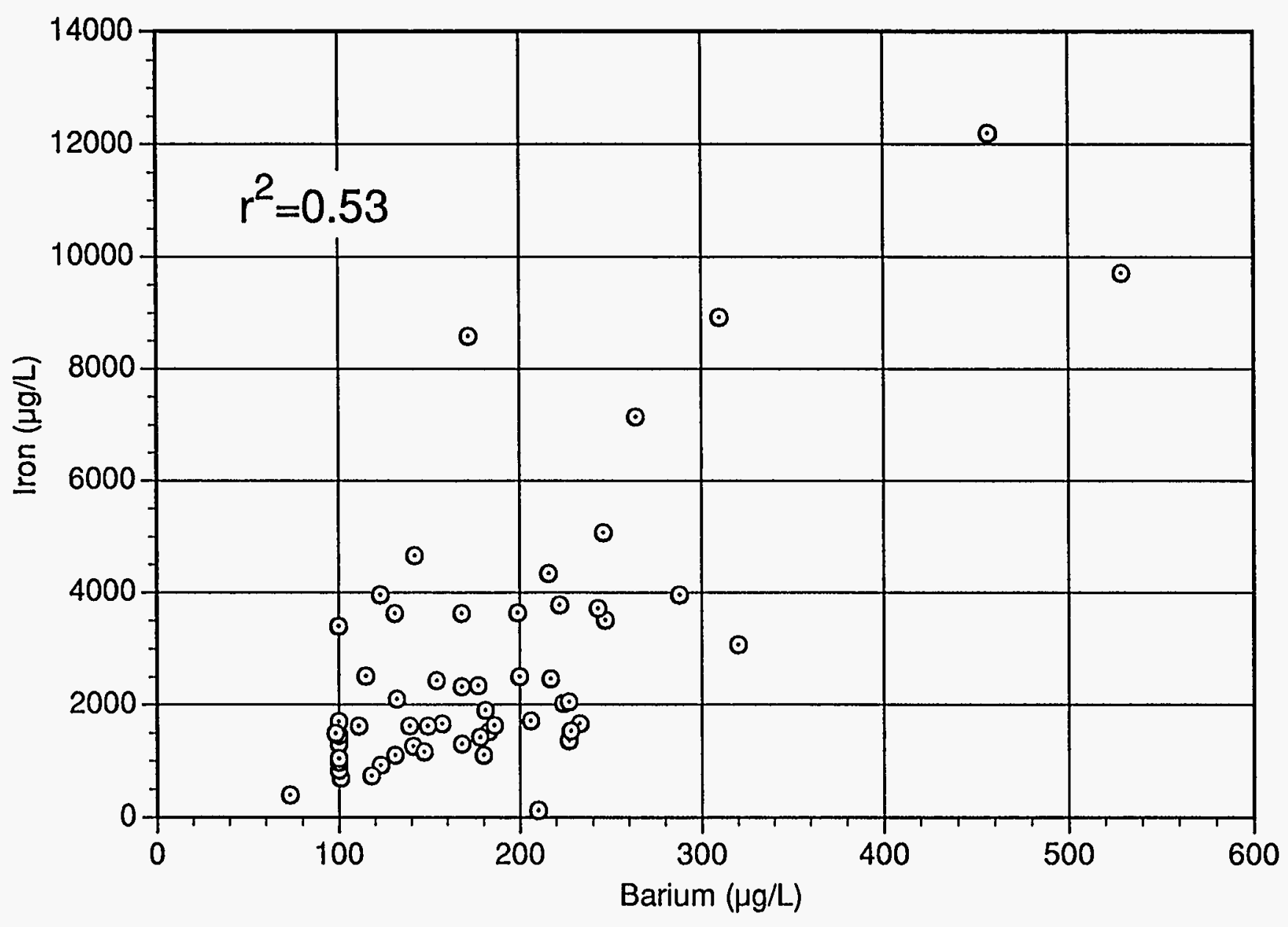




\section{Eielson Air Force Base \\ Baseline Risk Assessment}

Appendix F

Chemical Concentrations Input Into Risk Calculations 


\section{APPENDIX F--CHEMICAL CONCENTRATIONS INPUT INTO RISK CALCULATIONS}

Tables F.1 through F.5 list the contaminant concentrations for each media that were input into the risk calculations. The tables include either the maximum value or the 95-percent upper confidence on the mean concentration, whichever is smaller, for each contaminant whose maximum value at a site exceeds its risk-based screening concentrations (Section 7.0).

A t-statistic was used to calculate the 95-percent upper confidence limit on the arithmetic mean concentration using the following formula:

$$
U C L=\bar{x}+t\left(\frac{s}{\sqrt{n}}\right)
$$

where $U C L=$ upper confidence limit on the sample mean

$\bar{x}=$ sample mean

$t=\mathrm{t}$-value at an uncertainty of 5 percent and $(n-1)$ degrees of freedom

$s=$ sample standard deviation

$n=$ number of samples.

Sampling constraints diminish the validity of the of the 95-percent upper confidence limit. The upper confidence limit uses a t-value, and $t$-values assume a normally distributed population. This uncertainty is discussed in the uncertainty sections for each site.

Tables D.7 to D.11 list the sampling locations from each site whose concentrations were input into the calculation of the upper confidence limit. 1992 groundwater data for organic contaminants were obtained for six wells at ST13/DP26, five had been sampled in 1991 (Table 5.21 of U.S. Air Force 1993). The contaminant concentrations measured in these wells in 1992 was less than those measured in 1991. In order to be conservative and consistent, 1992 data was not used for these five wells.

All available Level III soil analyses, those listed in Tables D.7 to D.11, were input into the calculation of the 95-percent upper confidence limit. EPA guidance (1991) suggests that surface soil data should be used to represent the 95-percent upper confidence limit for an area the size of a yard for residential use scenarios. If ones assumes that a residential lot is 100 by 100 feet, then the concentration of surface soil samples at sites ST11, ST18, and ST19 is tight enough to meet this "hot spot" criterion, and none were detected at these sites. The concentration of surface soil samples at sites ST10/SS14 and ST13/DP26 do not meet this criterion, because both sets of sites cover a much larger area. In order to correct for this, the surface soil analyses at ST10/SS14 were biased or directed to look for potential "hot spots" that had been identified in previous sampling by SAIC (1989).

Exceptlons-The input data includes all metals whose maximum concentration exceeds its risk-based screening concentrations, even if the metal is believed to be natural background (Appendix E). All metals, except lead, are believed to be natural background. The risks for each site were calculated both with and without the background metals data, and both values are reported in all risk summary tables.

The input data does not include any contaminants believed to be laboratory derived. A discussion of the criteria used for this exclusion is in Section 7.1 of this assessment. 
No concentrations were input for undetected analytes, regardless of their respective contract required quantitation limit (CRQL). Many undetected analytes had $\mathrm{CRQL}$ values that were greater than twice the risk threshold, and they are labeled with an " $A$ " in Tables 7.5 to 7.9. There are no known sources for any of these analytes. The problem was recognized prior to the 1991 sampling event, and it was discussed in Section 4.2 of the Quality Assurance Project Plan in the Operable Unit 2 Management Plan (Battelle 1991). This issue is discussed in Section 7 and in the site uncertainty sections.

The input values for groundwater benzene, toluene, ethylbenzene, and xylenes for future scenarios at site ST19 are derived from fate and transport modeling. A description of the models used are in Section 8.3 and Appendix C. Section 8.3 also outlines the criteria for the selection of these input values.

One groundwater sample of bis (2-ethylhexyl) phthalate from monitoring well 26-MW08A exceeded the risk-based screening concentrations in Table 7.4, and it did not pass the 10 times the maximum blank concentration guidance in EPA (1989) for known laboratory contaminants. The sample had a 10:1 dilution and a concentration of $3200 \mu \mathrm{g} / \mathrm{L}$. There is no known source for bis (2-ethylhexyl) phthalate at Eielson AFB; it is most likely a laboratory contaminant. Therefore, the risk assessment will not carry it through the primary risk calculations. However, an altemative risk value with the addition of this contaminant was calculated and reported upon in Section 4.4.2 of this report. The concentration of bis (2-ethylhexyi) phthalate input into this secondary calculation is 46 $\mu \mathrm{g} / \mathrm{L}$. This is the 95-percent upper confidence limit on the arithmetic mean concentration for all ST13/DP26 groundwater analyses. The value for well 26-MW08A was reduced by the dilution ratio to account for the dilution water input. All other analyses were adjusted to the one-half the CRQL of $10 \mu \mathrm{g} / \mathrm{L}$ because they passed the $10 \times$ rule for known laboratory contaminants(EPA 1991).

\section{REFERENCES}

Battelle. 1991. Bemedial Investigation/Feasibility Study -- Operable Unit 2 Management Plan. Eielson Air Force Base. Alaska. Prepared by Battelle, Environmental Management Operations, Richland, Washington. (Final).

EPA. 1989. Bisk Assessment Guidance for Superfund: Human Health Evaluation Manual Part A. U.S. Environmental Protection Agency, Office of Solid Waste and Emergency Response. (Interim Final).

EPA. 1991. U.S. Environmental Protection Agency Contract Laboratony Program National Functional Guidelines for Organic Data Review. Multi-Media. Multi-Contamination. OLMO1. 1 and Low Concentration Water OLCOl. U.S. Environmental Protection Agency, Revised June 1991.

SAIC. 1989. U.S. Air Force Installation Restoration Program Remedial Investigation/Feasibility Study of the Fuel Saturated Area at Eielson Air Force Base. Alaska: Draft Remedial Investigation Repent. Volumes I, II, III Prepared by Science Applications International Corporation (Draft).

U.S. Air Force. 1993. Eielson Air Force Base OU-2 Remedial Investigation/Feasibility Study: Remedial Investigation Repont, Prepared by Battelle, Environmental Management Operations, Richland, Washington (Final). 


\begin{tabular}{|c|c|c|c|c|c|}
\hline \multicolumn{6}{|c|}{ TABLE F.1. Input Data for Source Areas ST10/SS14 Risk Assessment } \\
\hline $\begin{array}{l}\text { CONTAMINANT } \\
\text { OF CONCERN }\end{array}$ & $\begin{array}{c}\text { SURFACE } \\
\text { SOILS } \\
(\mu \mathrm{g} / \mathrm{kg}) \\
\end{array}$ & $\begin{array}{c}\text { SUBSURFACE } \\
\text { SOILS } \\
(\mu \mathrm{g} / \mathrm{kg}) \\
\end{array}$ & $\begin{array}{c}\text { SEDIMENTS } \\
(\mu \mathrm{g} / \mathrm{kg})\end{array}$ & $\begin{array}{c}\text { GROUND } \\
\text { WATER } \\
(\mu \mathrm{g} / \mathrm{L})\end{array}$ & $\begin{array}{l}\text { SURFACE } \\
\text { WATERS } \\
(\mu \mathrm{g} / \mathrm{L}) \\
\end{array}$ \\
\hline \multicolumn{6}{|l|}{ VOLATILES } \\
\hline BENZENE & & $1.30 \mathrm{E}+03$ & & $3.84 E+02$ & $1.00 E+00$ \\
\hline ETHYLBENZENE & & & & $8.33 E+01$ & \\
\hline TOLUENE & & & & $2.03 E+03$ & \\
\hline XYLENES (TOTAL) & & & & $6.90 \mathrm{E}+02$ & \\
\hline \multicolumn{6}{|l|}{ SEMI-VOLATILES } \\
\hline ANTHRACENE & & & & $9.00 E+00$ & \\
\hline BENZO(A)ANTHRACENE & $2.60 \mathrm{E}+02$ & $5.30 \mathrm{E}+01$ & $4.00 \mathrm{E}+02$ & & \\
\hline BENZO(A)PYRENE & $2.90 E+02$ & & $8.60 \mathrm{E}+01$ & & \\
\hline BENZO(B)FLUORANTHENE & $3.80 E+02$ & & $3.20 \mathrm{E}+02$ & & \\
\hline BENZO(K)FLUORANTHENE & $2.90 E+02$ & $5.50 \mathrm{E}+01$ & $2.40 \mathrm{E}+02$ & & \\
\hline CHRYSENE & $3.30 E+02$ & $8.10 E+01$ & $6.00 \mathrm{E}+02$ & & \\
\hline DIBENZ(A,H)ANTHRACENE & $9.40 \mathrm{E}+01$ & & & & \\
\hline INDENO $(1,2,3-C D)$ PYRENE & $2.00 E+02$ & & $1.10 \mathrm{E}+02$ & & \\
\hline NAPHTHALENE & & & & $1.26 E+02$ & \\
\hline PYRENE & $4.05 E+02$ & $3.90 \mathrm{E}+02$ & $1.70 E+03$ & $1.00 \mathrm{E}+01$ & \\
\hline \multicolumn{6}{|l|}{ PCB } \\
\hline AROCLOR-1260 & & & $1.30 \mathrm{E}+02$ & & \\
\hline & & & & & \\
\hline \multicolumn{6}{|l|}{ PESTICIDES } \\
\hline $4,4^{\prime}-$ DDD & & & $1.50 \mathrm{E}+02$ & & \\
\hline $4,4^{\prime}-\mathrm{DDT}$ & $1.58 \mathrm{E}+02$ & & & & \\
\hline ALDRIN & $7.40 \mathrm{E}+00$ & & & & \\
\hline & & & & & \\
\hline \multicolumn{6}{|l|}{ METALS } \\
\hline ANTIMONY & & & & $1.34 \mathrm{E}+01$ & \\
\hline ARSENIC & $1.02 E+04$ & $5.86 \mathrm{E}+03$ & $3.73 E+04$ & $3.38 \mathrm{E}+01$ & $6.60 \mathrm{E}+00$ \\
\hline BARIUM & & & $3.81 \mathrm{E}+05$ & $1.68 E+02$ & \\
\hline BERYLLIUM & $1.02 E+02$ & & $1.61 E+02$ & $4.60 \mathrm{E}-01$ & \\
\hline CADMIUM & & & & $1.59 \mathrm{E}+00$ & \\
\hline MANGANESE & $3.93 E+05$ & $2.42 E+05$ & $1.15 E+06$ & $2.20 E+03$ & $1.15 E+03$ \\
\hline THALLIUM & & & & $9.00 \mathrm{E}-01$ & \\
\hline
\end{tabular}




\begin{tabular}{|l|l|l|l|l|l|l||}
\hline \multicolumn{6}{|c|}{ TABLE F.2. Input Data for Source Area ST11 Risk Assessment } \\
\hline \hline $\begin{array}{l}\text { CONTAMINANT } \\
\text { OF CONCERN }\end{array}$ & $\begin{array}{c}\text { SURFACE } \\
\text { SOILS } \\
(\mu \mathrm{g} / \mathrm{kg})\end{array}$ & $\begin{array}{c}\text { SUBSURFACE } \\
\text { SOILS } \\
(\mu \mathrm{g} / \mathrm{kg})\end{array}$ & $\begin{array}{c}\text { SEDIMENTS } \\
(\mu \mathrm{g} / \mathrm{kg})\end{array}$ & $\begin{array}{c}\text { GROUND } \\
\text { WATER } \\
(\mu \mathrm{g} / \mathrm{L})\end{array}$ & $\begin{array}{c}\text { SURFACE } \\
\text { WATERS } \\
(\mu \mathrm{g} / \mathrm{L})\end{array}$ \\
\hline VOLATILES & & & & & \\
\hline BENZENE & & & & $1.00 \mathrm{E}+00$ & \\
\hline PESTICIDES & & & & & & \\
\hline 4,4'-DDT & $2.72 \mathrm{E}+02$ & & & & & \\
\hline METALS & & & & & & \\
\hline ARSENIC & $1.92 \mathrm{E}+04$ & $1.46 \mathrm{E}+04$ & & $4.22 \mathrm{E}+01$ & \\
\hline BARIUM & & & & $2.05 \mathrm{E}+02$ & \\
\hline BERYLLIUM & $4.80 \mathrm{E}+02$ & & & & \\
\hline MANGANESE & $6.51 \mathrm{E}+05$ & $5.3 \mathrm{E}+05$ & & $1.98 \mathrm{E}+03$ & \\
\hline THALLIUM & & & & $6.10 \mathrm{E}-01$ & \\
\hline
\end{tabular}




\begin{tabular}{|c|c|c|c|}
\hline \multicolumn{4}{|c|}{ TABLE F.3. Input Data for Source Areas ST13/DP26 Risk Assessment } \\
\hline $\begin{array}{l}\text { CONTAMINANT } \\
\text { OF CONCERN }\end{array}$ & $\begin{array}{c}\text { SURFACE } \\
\text { SOILS } \\
(\mu \mathrm{g} / \mathrm{kg}) \\
\end{array}$ & $\begin{array}{c}\text { SUBSURFACE } \\
\text { SOILS } \\
(\mu \mathrm{g} / \mathrm{kg}) \\
\end{array}$ & $\begin{array}{c}\text { GROUND } \\
\text { WATER } \\
(\mu \mathrm{g} / \mathrm{L}) \\
\end{array}$ \\
\hline \multicolumn{4}{|l|}{ VOLATILES } \\
\hline BENZENE & & $4.05 E+03$ & $2.78 E+02$ \\
\hline CHLOROFORM & & & $1.00 E+00$ \\
\hline CHLOROMETHANE & & & $3.00 \mathrm{E}+00$ \\
\hline ETHYLBENZENE & & $1.09 E+04$ & $2.18 E+02$ \\
\hline TOLUENE & & $1.96 E+04$ & $8.66 \mathrm{E}+02$ \\
\hline XYLENES (TOTAL) & & & $1.42 E+03$ \\
\hline \multicolumn{4}{|l|}{ SEMI-VOLATILES } \\
\hline BENZO(A)ANTHRACENE & $1.08 \mathrm{E}+03$ & $1.60 \mathrm{E}+02$ & \\
\hline BENZO(A)PYRENE & $1.25 \mathrm{E}+03$ & $8.80 \mathrm{E}+01$ & \\
\hline BENZO(B)FLUORANTHENE & $1.42 \mathrm{E}+03$ & $1.20 \mathrm{E}+02$ & \\
\hline BENZO(G,H,I)PERYLENE & $7.60 E+02$ & & \\
\hline BENZO(K)FLUORANTHENE & $1.49 \mathrm{E}+03$ & $1.00 \mathrm{E}+02$ & \\
\hline CHRYSENE & $1.42 E+03$ & $1.80 E+02$ & \\
\hline DIBENZ(A,H)ANTHRACENE & $4.70 E+02$ & & \\
\hline INDENO $(1,2,3-C D) P Y R E N E$ & $8.22 E+02$ & $4.70 \mathrm{E}+01$ & \\
\hline NAPHTHALENE & & & $7.04 \mathrm{E}+01$ \\
\hline PYRENE & $2.14 E+03$ & $1.40 \mathrm{E}+03$ & \\
\hline \multicolumn{4}{|l|}{$\overline{\text { PESTICIDES }}$} \\
\hline $4,4^{\prime}-\mathrm{DDD}$ & $9.36 \mathrm{E}+02$ & & \\
\hline $4,4^{\prime}-\mathrm{DDE}$ & $3.24 \mathrm{E}+02$ & & \\
\hline 4,4'-DDT & $5.31 E+03$ & & \\
\hline \multicolumn{4}{|l|}{ METALS } \\
\hline ANTIMONY & & & $1.28 \mathrm{E}+01$ \\
\hline ARSENIC & $1.01 E+04$ & $9.71 E+03$ & $2.67 E+01$ \\
\hline BARIUM & & & $2.64 \mathrm{E}+02$ \\
\hline BERYLLIUM & & & $8.60 \mathrm{E}-01$ \\
\hline CADMIUM & & & $1.20 E+00$ \\
\hline MANGANESE & $3.46 \mathrm{E}+05$ & $5.00 \mathrm{E}+05$ & $5.25 E+03$ \\
\hline THALLIUM & & & $1.00 \mathrm{E}+00$ \\
\hline
\end{tabular}




\begin{tabular}{|c|c|c|c|}
\hline \multicolumn{4}{|c|}{ TABLE F.4. Input Data for Source Area ST18 Risk Assessment } \\
\hline $\begin{array}{l}\text { CONTAMINANT } \\
\text { OF CONCERN }\end{array}$ & $\begin{array}{c}\text { SURFACE } \\
\text { SOILS } \\
(\mu \mathrm{g} / \mathrm{kg}) \\
\end{array}$ & $\begin{array}{c}\text { SUBSURFACE } \\
\text { SOILS } \\
(\mu \mathrm{g} / \mathrm{kg}) \\
\end{array}$ & $\begin{array}{c}\text { GROUND } \\
\text { WATER } \\
(\mu \mathrm{g} / \mathrm{L}) \\
\end{array}$ \\
\hline \multicolumn{4}{|l|}{ VOLATILES } \\
\hline CHLOROFORM & & & $2.00 E+00$ \\
\hline TRICHLOROETHENE & & & $2.00 \mathrm{E}+00$ \\
\hline \multicolumn{4}{|l|}{ SEMI-VOLATILES } \\
\hline BENZO(A)ANTHRACENE & $4.00 E+02$ & & \\
\hline BENZO(A)PYRENE & $4.82 E+02$ & & \\
\hline BENZO(B)FLUORANTHENE & $4.48 \mathrm{E}+02$ & & \\
\hline BENZO(G,H,I)PERYLENE & $6.10 \mathrm{E}+02$ & & \\
\hline BENZO(K)FLUORANTHENE & $4.49 \mathrm{E}+02$ & & \\
\hline CHRYSENE & $4.91 E+02$ & & \\
\hline DIBENZ(A,H)ANTHRACENE & $9.40 \mathrm{E}+01$ & & \\
\hline INDENO(1,2,3-CD)PYRENE & $5.23 E+02$ & & \\
\hline N-NITROSODIPHENYLAMINE (1) & & & $3.00 \mathrm{E}+00$ \\
\hline PYRENE & $5.80 \mathrm{E}+02$ & & \\
\hline \multicolumn{4}{|l|}{ METALS } \\
\hline ARSENIC & $1.20 \mathrm{E}+04$ & $3.70 \mathrm{E}+03$ & $4.30 \mathrm{E}+01$ \\
\hline BERYLLIUM & $4.66 \mathrm{E}+02$ & & \\
\hline CADMIUM & & & $5.52 E+00$ \\
\hline MANGANESE & $5.11 E+05$ & $3.40 E+05$ & $1.63 E+03$ \\
\hline THALLIUM & & & $1.20 \mathrm{E}+00$ \\
\hline
\end{tabular}




\begin{tabular}{||l|c|c|c||}
\hline \multicolumn{1}{|c|}{ TABLE F.5. Input Data for Source Area ST19 Risk Assessment } \\
OF CONCERN & $\begin{array}{c}\text { SURFACE } \\
\text { SOILS } \\
(\mu \mathrm{g} / \mathrm{kg})\end{array}$ & $\begin{array}{c}\text { SUBSURFACE } \\
\text { SOILS } \\
(\mu \mathrm{g} / \mathrm{kg})\end{array}$ & $\begin{array}{c}\text { GROUND } \\
\text { WATER } \\
(\mu \mathrm{g} / \mathrm{L})\end{array}$ \\
\hline \hline VOLATILES & & & \\
\hline BENZENE & & & $8.50 \mathrm{E}+00$ \\
\hline ETHYLBENZENE & & & $2.50 \mathrm{E}+02$ \\
\hline TOLUENE & & & $9.40 \mathrm{E}+02$ \\
\hline XYLENES (TOTAL) & & & $1.46 \mathrm{E}+03$ \\
\hline SEMI-VOLATILES & & & \\
\hline BENZO(A)ANTHRACENE & & $5.20 \mathrm{E}+01$ & \\
\hline CHRYSENE & & $1.67 \mathrm{E}+02$ & \\
\hline PYRENE & & $4.50 \mathrm{E}+02$ & \\
\hline & & & \\
\hline METALS & & & $2.59 \mathrm{E}+01$ \\
\hline ANTIMONY & & & $4.00 \mathrm{E}+01$ \\
\hline ARSENIC & $1.94 \mathrm{E}+04$ & $4.10 \mathrm{E}+03$ & $2.20 \mathrm{E}+02$ \\
\hline BARIUM & & & $3.10 \mathrm{E}-01$ \\
\hline BERYLLIUM & $3.40 \mathrm{E}+02$ & & $2.10 \mathrm{E}+00$ \\
\hline CADMIUM & $6.57 \mathrm{E}+05$ & $1.7 \mathrm{E}+05$ & $7.40 \mathrm{E}+03$ \\
\hline MANGANESE & & & $8.00 \mathrm{E}-01$ \\
\hline THALLIUM & & & \\
\hline
\end{tabular}




\title{
Eielson Air Force Base \\ Baseline Risk Assessment
}

\author{
Appendix $\mathbf{G}$ \\ Chemical Parameters Used In Risk Assessments
}




\section{APPENDIX G--CHEMICAL PARAMETERS USED IN RISK ASSESSMENTS}

Table G.1 presents the chemical parameters used in this risk assessment. The parameters include molecular weight, Henry's Law constant, carbon-matter partition coefficient $\left(\mathrm{K}_{\mathrm{OC}}\right)$, octonal-water partition coefficient $\left(\mathrm{K}_{\mathrm{O}}\right)$, and molecular diffusivity. All but the last set of values were taken from the Multimedia Environmental Pollutant Assessment System (MEPAS) database compiled by Strenge and Peterson (1989). References for each parameter are provided in this compilation.

The values for gas diffusivity were calculated from the following equation presented in Thibodeaux (1979)

$$
\left(\frac{D_{A}}{D_{B}}\right)=\sqrt{\frac{M_{B}}{M_{A}}}
$$

where $D_{A}=$ Gas Diffusivity

$$
M A=\text { Molecular Weight }
$$

The input values were for ethyl ether that has a molecular weight of $74.14 \mathrm{grams} / \mathrm{mole}$ and gas diffusivity of $0.089 \mathrm{mg} / \mathrm{cm}^{3}$ at $20^{\circ} \mathrm{C}$. The molecular weight is from Strenge and Peterson (1989) and the gas diffusivity is from Weast et al. (1986). Temperature affects gas diffusivity. It is a function of the molecular speed of a gas, that, in turn is a function of its average kinetic energy that is determined solely by temperature. Thus, the diffusivity reported is probably larger, more conservative, than the average value at Eielson because of the sub-arctic climate. This may lead to an overestimation of the risk of volatile contaminants released from soil.

All chemical parameters for total petroleum hydrocarbons (TPH) are set to those for 2 methyl naphthalene, a common constituent of JP-4.

Several of the compounds listed do not have chemical parameters. The MEPAS database did not include these compounds, and since they were not detected at the Operable Unit 2 sites, no additional effort was expended in reporting these values.

\section{REFERENCES}

Strenge, D. L., and S. R. Peterson. 1989. Chemical Data Bases for the Multimedia Environmental Pollutant Assessment System (MEPAS): Version 1. PNL-7145, Pacific Northwest Laboratory, Richland, Washington.

Thibodeaux, L.J. 1979. Chemodynamics. John Wiley and Sons, New York.

Weast, R. C., M. J. Astle, and W. H. Beyer. 1986. CRC Handbook of Chemistry and Physics. CRC Press, Inc., Boca Raton, Florida. 
TABLE G1. Chemical Parameters Used in Risk Assessements

\begin{tabular}{|c|c|c|c|c|c|c|}
\hline ANALYTES & CAS & $\begin{array}{c}\text { Molecular Weight } \\
(\mathrm{g} / \mathrm{mole})\end{array}$ & $\begin{array}{c}\text { Henry's Law } \\
\text { Constant } \\
\text { (atm m3/mole) }\end{array}$ & $\begin{array}{c}\text { Carbon-matter } \\
\text { Partition } \\
\mathrm{m} / \mathrm{g}\end{array}$ & $\begin{array}{c}\text { Octanol-water } \\
\text { Partition } \\
\mathrm{ml} / \mathrm{g}\end{array}$ & $\begin{array}{c}\text { Gas } \\
\text { Diffusivity } \\
\text { (g/cm3) }\end{array}$ \\
\hline \multicolumn{7}{|l|}{ VOLATILES } \\
\hline 1,1,1-TRICHLOROETHANE & 71556 & 133.41 & 4.92E-03 & $1.52 E+02$ & $3.16 E+02$ & 6.63E-02 \\
\hline 1,1,2,2-TETRACHLOROETHANE & 79345 & 167.85 & $3.81 E-04$ & $1.18 E+02$ & $2.45 E+02$ & $5.92 E-02$ \\
\hline 1,1,2-TRICHLOROETHANE & 79005 & 133.41 & 1.17E-03 & $5.60 E+01$ & $2.95 E+02$ & $6.63 E-02$ \\
\hline 1,1-DICHLOROETHANE & 75343 & 98.96 & $5.43 E-03$ & $3.00 E+01$ & $6.17 E+01$ & 7.70E-02 \\
\hline 1,1-DICHLOROETHENE & 75354 & 96.94 & $1.60 E-01$ & $6.50 \mathrm{E}+01$ & $6.92 E+01$ & $7.78 E-02$ \\
\hline 1,2-DICHLOROETHANE & 107062 & 98.96 & $9.78 E-04$ & $1.40 E+01$ & $3.02 E+01$ & $7.70 E-02$ \\
\hline 1,2-DICHLOROETHENE (TOTAL) & 156605 & 96.94 & $6.90 E-02$ & $9.60 E+00$ & $3.02 E+00$ & $7.78 E-02$ \\
\hline 1,2-DICHLOROPROPANE & 78875 & 112.99 & 2.31E-03 & $5.10 E+01$ & $1.00 E+02$ & 7.21E-02 \\
\hline 2-BUTANONE & 78933 & 72.12 & 2.70E-05 & $4.50 \mathrm{E}+00$ & $1.88 \mathrm{E}+00$ & $9.02 E-02$ \\
\hline 2-HEXANONE & 591786 & 100.16 & 1.10E-05 & $1.48 E+01$ & $2.40 E+01$ & $7.66 \mathrm{E}-02$ \\
\hline \multicolumn{7}{|l|}{ 4-METHYL-2-PENTANONE } \\
\hline ACETONE & 67641 & 58 & 2.10E-O5 & $2.20 E+00$ & 5.80E-01 & 1.01E-01 \\
\hline BENZENE & 71432 & 78 & $5.59 E-03$ & $8.30 E+01$ & $1.32 E+02$ & 8.68E-02 \\
\hline \multicolumn{7}{|l|}{ BENZYL ALCOHOL } \\
\hline BROMODICHLOROMETHANE & 75274 & 163.8 & $2.12 E-03$ & $1.07 E+02$ & $1.74 E+02$ & $5.99 E-02$ \\
\hline BROMOFORM & 75252 & 252.75 & 5.52E-04 & $1.16 E+02$ & $2.51 E+02$ & 4.82E-02 \\
\hline BROMOMETHANE & 74839 & 94.94 & $1.16 E-01$ & $9.55 E+00$ & $1.55 E+01$ & 7.86E-02 \\
\hline CARBON DISULFIDE & 75150 & 76.14 & $1.23 E-02$ & $5.40 E+01$ & $1.00 E+02$ & 8.78E-02 \\
\hline CARBON TETRACHLORIDE & 56235 & 154 & 3.02E-02 & $5.02 E+02$ & $4.36 E+02$ & $6.18 E-02$ \\
\hline CHLOROBENZENE & 108907 & 112.56 & $3.72 E-03$ & $3.30 E+02$ & $6.92 E+02$ & $7.22 E-02$ \\
\hline CHLOROETHANE & 75003 & 64.52 & $1.48 E-02$ & $1.66 E+01$ & $2.69 E+01$ & 9.54E-02 \\
\hline CHLOROFORM & 67663 & 119 & 2.87E-03 & $5.00 E+01$ & $9.33 E+01$ & 7.02E-02 \\
\hline CHLOROMETHANE & 74873 & 50.49 & 4.42E-02 & $3.50 E+01$ & $8.91 E+00$ & $1.08 E-01$ \\
\hline CIS-1,3-DICHLOROPROPENE & 542756 & 110.97 & $1.30 E-03$ & $2.47 E+01$ & $1.00 E+02$ & 7.27E-02 \\
\hline DIBROMOCHLOROMETHANE & 124481 & 208.29 & $9.95 E-04$ & $7.59 E+01$ & $1.23 E+02$ & 5.31E-02 \\
\hline ETHYLBENZENE & 100414 & 106.17 & $6.43 E-03$ & $1.10 E+03$ & $1.41 \mathrm{E}+03$ & $7.44 E-02$ \\
\hline METHYLENE CHLORIDE & 75092 & 84.93 & 2.03E-03 & $8.80 E+00$ & $2.00 E+01$ & 8.32E-02 \\
\hline STYRENE & 100425 & 104.16 & 4.71E-03 & $5.49 E+02$ & $8.91 E+02$ & 7.51E-02 \\
\hline TETRACHLOROETHENE & 127184 & 165.85 & $2.59 E-02$ & $3.64 E+02$ & $3.98 E+02$ & 5.95E-02 \\
\hline TOLUENE & 108883 & 92.15 & $6.37 E-03$ & $3.00 E+02$ & $5.37 E+02$ & 7.98E-02 \\
\hline TRANS-1,3-DICHLOROPROPENE & 10061026 & 110.97 & $1.30 E-03$ & $2.47 E+01$ & $1.00 E+02$ & 7.27E-02 \\
\hline TRICHLOROETHENE & 79016 & 131.29 & $9.10 E-03$ & $1.26 \mathrm{E}+02$ & $2.40 E+02$ & $6.69 E-02$ \\
\hline VINYL ACETATE & 108054 & 86.1 & $3.76 E-04$ & $1.66 \mathrm{E}+01$ & $2.95 E+00$ & 8.26E-02 \\
\hline VINYL CHLORIDE & 75014 & 62.5 & 8.19E-02 & $5.70 E+01$ & $2.40 E+01$ & $9.69 E-02$ \\
\hline XYLENES (TOTAL) & 1330207 & 106.17 & $7.04 \mathrm{E}-03$ & $2.40 E+02$ & $1.82 E+03$ & 7.44E-02 \\
\hline \multicolumn{7}{|l|}{ SEMI-VOLATILES } \\
\hline 1,2,4-TRICHLOROBENZENE & 120821 & 181.45 & 2.31E-03 & $9.20 E+03$ & $2.00 E+04$ & 5.69E-02 \\
\hline 1,2-DICHLOROBENZENE & 95501 & 147.01 & $1.93 E-03$ & $1.70 E+03$ & $4.00 E+03$ & $6.32 E-02$ \\
\hline 1,2-DIPHENYLHYDRAZINE & 122667 & 184.24 & $3.42 E-09$ & $4.18 E+02$ & $7.94 \mathrm{E}+02$ & $5.65 E-02$ \\
\hline 1,3-DICHLOROBENZENE & 541731 & 147.01 & $2.63 E-03$ & $1.70 E+03$ & $3.98 E+03$ & $6.32 E-02$ \\
\hline 1,4-DICHLOROBENZENE & 106467 & 147.01 & $2.89 E-03$ & $1.70 E+03$ & $3.98 E+03$ & $6.32 E-02$ \\
\hline 2,4,5-TRICHLOROPHENOL & 95954 & 197.44 & $2.18 E-04$ & $8.90 E+01$ & $5.25 E+03$ & 5.45E-02 \\
\hline $2,4,6$-TRICHLOROPHENOL & 88062 & 197.44 & $4.00 E-06$ & $2.00 E+03$ & $7.41 E+03$ & 5.45E-02 \\
\hline 2,4-DICHLOROPHENOL & 94757 & 221 & $1.88 E-04$ & $2.00 E+01$ & $6.46 E+02$ & 5.15E-02 \\
\hline 2,4-DIMETHYLPHENOL & 105679 & 122.16 & $1.80 E-05$ & $9.60 E+01$ & $6.46 \mathrm{E}+02$ & $6.93 E-02$ \\
\hline 2,4-DINITROPHENOL & 51285 & 184.11 & $6.50 E-10$ & $1.66 \mathrm{E}+01$ & $3.16 \mathrm{E}+01$ & 5.65E-02 \\
\hline 2,4-DINITROTOLUENE & 121142 & 182.14 & 5.00E-06 & $4.50 E+01$ & $1.00 E+02$ & 5.68E-02 \\
\hline \multicolumn{7}{|l|}{ 2,6-DINITROTOLUENE } \\
\hline 2-CHLORONAPHTHALENE & 91578 & 162.2 & 5.40E-04 & $4.80 E+03$ & $1.00 E+04$ & 6.02E-02 \\
\hline 2-CHLOROPHENOL & 95578 & 128.56 & $1.00 E-05$ & $7.30 \mathrm{E}+01$ & $1.51 E+02$ & $6.76 \mathrm{E}-02$ \\
\hline 2-METHYLNAPHTHALENE & 91576 & 142.2 & $3.10 E-04$ & $4.47 E+03$ & $7.24 E+03$ & $6.43 E-02$ \\
\hline 2-METHYLPHENOL & 95487 & 108.15 & $1.00 E-06$ & $1.48 E+01$ & $9.33 E+01$ & 7.37E-02 \\
\hline 4-METHYLPHENOL & 106445 & 138.12 & $2.20 E-05$ & 4.36E+01 & $6.17 E+01$ & 6.52E-02 \\
\hline 2-NITROANILINE & 88747 & 108.15 & 2.38E-07 & $1.70 E+01$ & $8.51 E+01$ & 7.37E-02 \\
\hline \multicolumn{7}{|l|}{ 2-NITROPHENOL } \\
\hline 3,3'-DICHLOROBENZIDINE & 91941 & 253.13 & $1.00 E-06$ & 4.35E+00 & $3.16 E+03$ & $4.82 E-02$ \\
\hline
\end{tabular}


IABLE G.1. Chemical Parameters Used in Risk Assessements

\begin{tabular}{|c|c|c|c|c|c|c|}
\hline ANALYTES & CAS & $\begin{array}{c}\text { Molecular Weight } \\
\text { (g/mole) }\end{array}$ & $\begin{array}{l}\text { Henry's Law } \\
\text { Constant } \\
\text { (atm m3/mole) }\end{array}$ & $\begin{array}{c}\text { Carbon-matter } \\
\text { Partition } \\
\mathrm{ml} / \mathrm{g} \\
\end{array}$ & $\begin{array}{l}\text { Octanol-water } \\
\text { Partition } \\
\mathrm{ml} / \mathrm{g}\end{array}$ & $\begin{array}{l}\text { Gas } \\
\text { Diffusivity } \\
\text { (g/cm3) }\end{array}$ \\
\hline $\begin{array}{l}\text { 4,6-DINITRO-2-METHYLPHENOL } \\
\text { 4-BROMOPHENYL-PHENYLETHER } \\
\text { 4-CHOLOR-3-METHYLPHENOL }\end{array}$ & 534521 & 198.03 & $1.00 \mathrm{E}-06$ & $2.41 E+00$ & $5.01 E+02$ & 5.45E-02 \\
\hline 4-CHLOROANILINE & 106478 & 127.57 & $1.00 E-06$ & 4.17E+01 & $6.76 \mathrm{E}+01$ & $6.78 E-02$ \\
\hline 4-CHLOROPHENYL-PHENYLETHER & 7005723 & 204.66 & 2.67E-04 & $7.41 E+03$ & $1.20 E+04$ & $5.36 \mathrm{E}-02$ \\
\hline 4-NITROANILINE & 100016 & 138.12 & 3.75E-07 & $1.51 E+01$ & $2.45 E+01$ & 6.52E-02 \\
\hline 4-NITROPHENOL & 100027 & 139.11 & 2.95E-04 & $2.37 E+00$ & $8.13 E+01$ & $6.50 E-02$ \\
\hline ACENAPHTHENE & 83329 & 154 & 2.41E-04 & 4.60E+03 & $1.00 E+04$ & 6.18E-02 \\
\hline ACENAPHTHYLENE & 208968 & 152 & $1.14 E-04$ & $2.50 E+03$ & $5.01 E+03$ & $6.22 E-02$ \\
\hline ANTHRACENE & 120127 & 178 & $1.90 E-05$ & $1.40 E+04$ & $2.82 E+04$ & $5.74 E-02$ \\
\hline BENZO(A)ANTHRACENE & 56553 & 228 & $1.00 E-06$ & $1.38 E+06$ & $3.98 E+05$ & 5.08E-02 \\
\hline BENZO(A)PYRENE & 50328 & 252 & 2.00E-06 & $5.50 E+06$ & $1.15 E+06$ & $4.83 E-02$ \\
\hline BENZO(B)FLUORANTHENE & 205992 & 252 & $1.20 \mathrm{E}-05$ & $5.50 \mathrm{E}+05$ & $1.15 E+06$ & 4.83E-02 \\
\hline BENZO(G,H,I)PERYLENE & & & & & & \\
\hline BENZO(K)FLUORANTHENE & 207089 & 252 & 3.90E-05 & $5.50 E+05$ & $1.15 E+06$ & 4.83E-02 \\
\hline BENZOIC ACID & 65850 & 122.13 & $1.30 \mathrm{E}-07$ & $1.50 E+00$ & $7.41 E+01$ & $6.93 E-02$ \\
\hline BIS(2-CHLOROETHOXY)METHANE & & & & & & \\
\hline BIS(2-CHLOROETHYL)ETHER & 111444 & 143.02 & $1.30 \mathrm{E}-05$ & $1.39 E+01$ & $3.16 E+01$ & $6.41 E-02$ \\
\hline BIS(2-CHLOROISOPROPYL)ETHER & 39638329 & 171 & $1.13 E-04$ & $6.10 E+01$ & $1.26 \mathrm{E}+02$ & 5.86E-02 \\
\hline $\begin{array}{l}\text { BIS(2-ETHYLHEXYL)PHTHALATE } \\
\text { BUTYLBENZYLPHTHALATE }\end{array}$ & 117817 & 391 & 4.40E-07 & 8.71E+04 & 4.10E+00 & $3.88 E-02$ \\
\hline CHRYSENE & 218019 & 228.3 & $1.00 E-06$ & $2.00 E+05$ & 4.07E+05 & 5.07E-02 \\
\hline DI-N-BUTYLPHTHALATE & 84742 & 278 & 2.82E-07 & $1.70 E+05$ & $4.00 E+05$ & 4.60E-02 \\
\hline DI-N-OCTYLPHTHALATE & 117840 & 391 & $6.00 E-06$ & $3.60 E+09$ & $7.41 E+09$ & $3.88 E-02$ \\
\hline $\begin{array}{l}\text { DIBENZ(A,H)ANTHRACENE } \\
\text { DIBENZOFURAN }\end{array}$ & 53703 & 278 & 2.61E-09 & $3.30 E+06$ & 4.07E+05 & 4.60E-02 \\
\hline DIETHYLPHTHALATE & 84662 & 222.2 & 2.00E-08 & $6.90 E+01$ & $2.88 E+02$ & $5.14 E-02$ \\
\hline DIMETHYLPHTHALATE & 131113 & 194.18 & $1.00 E-06$ & $1.74 E+01$ & $3.63 E+01$ & 5.50E-02 \\
\hline FLUORANTHENE & 206440 & 202.26 & $1.00 E-05$ & $3.80 E+04$ & $7.94 E+04$ & 5.39E-02 \\
\hline FLUORENE & 86737 & 166 & 1.17E-04 & $7.30 E+03$ & $1.58 E+04$ & 5.95E-02 \\
\hline HEXACHLOROBENZENE & 118741 & 284.79 & $6.81 E-04$ & $3.90 \mathrm{E}+03$ & $1.70 E+05$ & 4.54E-02 \\
\hline HEXACHLOROBUTADIENE & 87683 & 260.76 & $1.00 E-02$ & $2.90 E+04$ & $6.03 E+04$ & 4.75E-02 \\
\hline HEXACHLOROCYCLOPENTADIENE & 77474 & 272.8 & 2.75E-02 & $3.60 E+03$ & $1.00 E+04$ & 4.64E-02 \\
\hline HEXACHLOROETHANE & 67721 & 236.74 & $9.85 E-03$ & $2.00 E+04$ & $3.98 E+04$ & 4.98E-02 \\
\hline INDENO(1,2,3-CD)PYAENE & 193395 & 276 & $6.86 \mathrm{E}-08$ & $1.60 \mathrm{E}+06$ & $3.16 E+06$ & 4.61E-02 \\
\hline ISOPHORONE & 78591 & 138.2 & $6.00 \mathrm{E}-06$ & $8.70 E+01$ & $1.82 E+02$ & $6.52 E-02$ \\
\hline N-NITROSO-DI-N-PROPYLAMINE & 621647 & 130.2 & $6.00 \mathrm{E}-06$ & $1.50 \mathrm{E}+01$ & $3.09 E+01$ & $6.72 E-02$ \\
\hline N-NITROSODIPHENYLAMINE (1) & 86306 & 198.2 & $6.60 \mathrm{E}-04$ & $6.48 E+02$ & $1.35 E+03$ & $5.44 E-02$ \\
\hline NAPHTHALENE & 91203 & 128.16 & $7.20 E-04$ & $9.40 E+02$ & $1.70 E+03$ & 6.77E-02 \\
\hline NITROBENZENE & 98953 & 123.11 & 2.40E-05 & $3.60 E+01$ & $7.08 E+01$ & $6.91 E-02$ \\
\hline PENTACHLOROPHENOL & 87865 & 266 & 3.00E-06 & $5.30 E+04$ & $1.00 E+05$ & $4.70 E-02$ \\
\hline PHENANTHRENE & 85018 & 178 & 2.30E-05 & $1.40 E+04$ & $2.88 E+04$ & 5.74E-02 \\
\hline PHENOL & 108952 & 94.11 & $1.00 E-06$ & $1.42 E \div 01$ & $2.88 E+01$ & 7.90E-02 \\
\hline PYRENE & 129000 & 202.26 & $5.00 E-06$ & $3.80 E+04$ & $2.09 E+05$ & 5.39E-02 \\
\hline \multicolumn{7}{|l|}{ TPH } \\
\hline TOTAL PETROLEUM HYDROCARBONS (1) & & 142.2 & $2.90 E-04$ & $4.50 E+03$ & $7.20 E+03$ & $6.43 E-02$ \\
\hline \multicolumn{7}{|l|}{ PCB } \\
\hline AROCLOR-1016 & 12674112 & 257.9 & 3.30E-04 & $1.80 E+05$ & $3.80 E+05$ & 4.77E-02 \\
\hline AROCLOR-1221 & 1104282 & 200.7 & 1.70E-04 & $5.80 E+03$ & $1.20 E+04$ & 5.41E-02 \\
\hline AROCLOR-1232 & 11141165 & 232.2 & $1.10 \mathrm{E}-05$ & 7.71E+02 & $1.59 E+03$ & 5.03E-02 \\
\hline AROCLOR-1242 & 53469219 & 266.5 & $1.98 E-03$ & $6.30 \mathrm{E}+03$ & $1.29 E+04$ & 4.69E-02 \\
\hline AROCLOR-1248 & 12672296 & 299.5 & 3.6OE-03 & 2.77E+05 & $5.75 E+05$ & 4.43E-02 \\
\hline AROCLOR-1254 & 11091691 & 328.4 & 8.30E-03 & $5.30 E+05$ & $1.10 E+06$ & $4.23 \mathrm{E}-02$ \\
\hline AROCLOR-1260 & 11096825 & 375.7 & $1.70 E-04$ & $6.70 E+06$ & $1.41 E+07$ & 3.95E-02 \\
\hline
\end{tabular}


TABLE G.1. Chemical Parameters Used in Risk Assessements

\begin{tabular}{|c|c|c|c|c|c|c|}
\hline ANALYTES & CAS & $\begin{array}{c}\text { Molecular Weight } \\
\text { (g/mole) }\end{array}$ & $\begin{array}{l}\text { Henry's Law } \\
\text { Constant } \\
\text { (atm } \mathrm{m} 3 / \text { mole) }\end{array}$ & $\begin{array}{c}\text { Carbon-matter } \\
\text { Partition } \\
\mathrm{ml} / \mathrm{g}\end{array}$ & $\begin{array}{c}\text { Octanol-water } \\
\text { Partition } \\
\mathrm{ml} / \mathrm{g}\end{array}$ & $\begin{array}{c}\text { Gas } \\
\text { Diffusivity } \\
\text { (g/cm3) }\end{array}$ \\
\hline \multicolumn{7}{|l|}{ PESTICIDES } \\
\hline $4,4^{\circ}-\mathrm{DDD}$ & 72548 & 320 & 8.00E-06 & $7.70 E+05$ & $1.58 \mathrm{E}+06$ & 4.28E-02 \\
\hline 4,4'-DDE & 72559 & 318 & $6.80 E-05$ & $4.40 E+06$ & $1.00 \mathrm{E}+07$ & 4.30E-02 \\
\hline $4,4^{\prime}-\mathrm{DDT}$ & 50293 & 354.49 & 5.13E-04 & $2.43 E+05$ & $1.55 E+06$ & 4.07E-02 \\
\hline \multicolumn{7}{|l|}{ 4,4'-METHOXYCHLOR } \\
\hline ALDRIN & 309002 & 365 & $5.00 E-04$ & $9.60 E+04$ & $2.00 E+05$ & 4.01E-02 \\
\hline ALPHA-BHC & 319846 & 290.83 & $6.00 E-06$ & $3.80 E+03$ & $7.94 E+03$ & 4.49E-02 \\
\hline ALPHA-CHLORDANE & 57749 & 409.8 & 5.00E-05 & $9.50 E+03$ & $6.03 E+04$ & $3.79 E-02$ \\
\hline BETA-BHC & 319857 & 290.93 & 4.47E-07 & $3.80 E+03$ & $7.94 E+03$ & 4.49E-02 \\
\hline DELTA-BHC & 319868 & 290.83 & 2.07E-07 & $6.60 E+03$ & $1.26 \mathrm{E}+04$ & 4.49E-02 \\
\hline DIELDRIN & 60571 & 380.95 & $5.80 E-05$ & $4.10 E+00$ & $3.16 \mathrm{E}+03$ & $3.93 E-02$ \\
\hline ENDOSULFAN I & & 406.9 & $1.00 E-05$ & $9.60 E-03$ & $3.55 E+03$ & $3.80 E-02$ \\
\hline ENDOSULFAN \| & & 406.9 & $1.90 E-05$ & $9.60 E-03$ & $4.17 E+03$ & $3.80 \mathrm{E}-02$ \\
\hline \multicolumn{7}{|l|}{ ENDOSULFAN SULFATE } \\
\hline ENDRIN & 72208 & 380.9 & 1.00E-06 & $1.06 \mathrm{E}+04$ & $3.98 E+05$ & $3.93 E-02$ \\
\hline \multicolumn{7}{|l|}{ ENDRIN KETONE } \\
\hline GAMMA-BHC (LINDANE) & 58899 & 290.83 & 8.00E-06 & $1.08 E+03$ & $7.94 E+03$ & 4.49E-02 \\
\hline GAMMA-CHLORDANE & 57749 & 409.8 & 5.00E-05 & $9.50 E+03$ & $6.03 E+04$ & 3.79E-02 \\
\hline HEPTACHLOR & 76448 & 373.5 & 2.90E-03 & $6.00 E+03$ & $2.51 E+04$ & 3.97E-02 \\
\hline HEPTACHLOR EPOXIDE & 1024573 & 389.2 & 4.39E-04 & $2.20 \mathrm{E}+02$ & $5.10 E+02$ & $3.88 E-02$ \\
\hline METHOXYCHLOR & 72435 & 345.65 & $2.48 E-08$ & $4.90 \mathrm{E}+00$ & $2.00 E+04$ & 4.12E-02 \\
\hline TOXAPHENE & 8001352 & 414 & $4.90 E-03$ & $9.64 \mathrm{E}+02$ & $2.00 E+03$ & 3.77E-02 \\
\hline \multicolumn{7}{|l|}{ METALS } \\
\hline ALUMINUM & 7429905 & 26.98 & $0.00 E_{+} 00$ & $0.00 E+00$ & $0.00 E+00$ & \\
\hline ANTIMONY & 7440360 & 122 & $0.00 E+00$ & $0.00 E+00$ & $0.00 E+00$ & \\
\hline ARSENIC & 7440382 & 75 & $0.00 E+00$ & $0.00 E+00$ & $0.00 E+00$ & \\
\hline BARIUM & 7440393 & 137 & $0.00 E+00$ & $0.00 E+00$ & $0.00 E+00$ & \\
\hline BERYLLIUM & 7440417 & 9 & $0.00 E+00$ & $0.00 E+00$ & $0.00 E+00$ & \\
\hline CADMIUM & 7440439 & 112 & $0.00 E+00$ & $0.00 E+00$ & $0.00 E+00$ & \\
\hline \multicolumn{7}{|l|}{ CALCIUM } \\
\hline CHROMIUM & 7440473 & 52 & $0.00 E+00$ & $0.00 E+00$ & $0.00 E+00$ & \\
\hline COBALT & 7440484 & 58.93 & $0.00 E+00$ & $0.00 E+00$ & $0.00 E+00$ & \\
\hline COPPEA & 7440508 & 63.55 & $0.00 E+00$ & $0.00 E+00$ & $0.00 E+00$ & \\
\hline IRON & 15438310 & 56 & $0.00 E+00$ & $0.00 E+00$ & $0.00 E+00$ & \\
\hline LEAD & 7439921 & 207 & $0.00 E+00$ & $0.00 E+00$ & $0.00 E+00$ & \\
\hline MAGNESIUM & 7786303 & 24.3 & $0.00 E+00$ & $0.00 E+00$ & $0.00 E+00$ & \\
\hline MANGANESE & 7439965 & 55 & $0.00 \mathrm{E}+00$ & $0.00 E+00$ & $0.00 E+00$ & \\
\hline MERCURY & 7439976 & 201 & $1.14 E-03$ & $0.00 E+00$ & $0.00 E+00$ & \\
\hline NICKEL & 7440020 & 59 & $0.00 E+00$ & $0.00 E+00$ & $0.00 E+00$ & \\
\hline POTASSIUM & 7447407 & & & & & \\
\hline SELENIUM & 7782492 & 79 & $0.00 \mathrm{E}+00$ & $0.00 E+00$ & $0.00 E+00$ & \\
\hline SILVER & 7440224 & 108 & $0.00 E+00$ & $0.00 E+00$ & $0.00 E+00$ & \\
\hline SODIUM & 7647145 & & & & & \\
\hline THALLIUM & 7440280 & 204 & $0.00 \mathrm{E}+00$ & $0.00 E+00$ & $0.00 E+00$ & \\
\hline VANADIUM & 7440622 & 50.94 & $0.00 E+00$ & $0.00 E+00$ & $0.00 E+00$ & \\
\hline ZINC & 7646857 & 65.38 & $0.00 E+00$ & $0.00 E+00$ & $0.00 E+00$ & \\
\hline
\end{tabular}




\section{Eielson Air Force Base \\ Baseline Risk Assessment}

Appendix $H$

Biotransfer Parameters Used In Risk Assessments 


\section{APPENDIX H--BIOTRANSFER PARAMETERS USED IN RISK ASSESSMENTS}

Table H.1 presents the biotranster parameters used in this risk assessment for the fish and vegetable ingestion pathways. The parameters include bioconcentration factors for finfish and soil-to-edible plant transfer ratios. All non-italicized values were taken from the Multimedia Environmental Pollutant Assessment System (MEPAS) database compiled by Strenge and Peterson (1989). References for each parameter are provided in this compilation.

Italicized values were calculated from the chemical parameters provided in Table G.1. The calculated values for the bioconcentration factors for finfish are based on the equation from Veith et al. (1980)

$$
\log \left(B_{i f}\right)=\left[0.76 \bullet \log \left(K_{o w i}\right)\right]-0.23
$$

where $\quad B_{\mathrm{if}}=$ bioconcentration factor for finfish for compound $\mathrm{i}(\mathrm{L} / \mathrm{Kg})$

$\mathrm{K}_{\text {owi }}=$ the octanol-water partition coefficient for compound $\mathrm{i}$

The calculate values for the soil-to-edible plant transfer ratios are based on the equation from Travis and Arms (1988)

$$
\log \left(B_{v i}\right)=0.986-\left[0.578 \cdot \log \left(K_{o w i}\right)\right]
$$

where $\quad B_{v i}=$ soil-to-edible plant transfer ratio for compound $\mathrm{i}$ (unitless; $\mathrm{mg} / \mathrm{kg}$ wet plant per $\mathrm{mg} / \mathrm{kg}$ dry soil)

$K_{\text {owi }}=$ the octanol-water partition coefficient for compound $\mathrm{i}$

Note that the original correlation presented by Travis and Arms (1988) was based on plant concentration expressed as dry weight. The above correlation was obtained by assuming that the dry weight concentration is four times the wet weight concentration (i.e., the plant is $75 \%$ water). The conversion is necessary because the intake rate of vegetables in Table B.13 is in wet weight.

The parameters listed in Table $\mathrm{H} .1$ should be viewed as a first approximation of the true, site-specific values. As such, the risks calculated for the ingestion of vegetables and fish are approximate. This subject is discussed in the uncertainty sections of this assessment.

Several of the compounds listed do not have biotransfer parameters. The MEPAS database did not include the appropriate chemical parameters for these compounds, and because they were not detected at the Operable Unit 2 sites, no additional effort was expended in calculating the biotransfer parameters.

\section{REFERENCES}

Strenge, D.L., and S.R. Peterson. 1989. Chemical Data Bases for the Multimedia Envirenmental Pollutant Assessment System (MEPAS): Version 1. PNL-7145, Pacific Northwest Laboratory, Richland, Washington.

Travis, C.C. and A.D. Arms. 1988. "Bioconcentration of Organics in Beef, Milk, and Vegetation." Environ. Sci. Tech 22(3):271-274. 
Veith, G.D., K.J. Macek, R. Petrocelli, and J. Carroll. 1980. "An Evaluation of Using Partition Coefficients and Water Solubility to Estimate Bioconcentration Factors of Organic Chemicals in Fish." L.Fish. Res. Board Can. (Prepublication Copy). 
TABLE H.1. Biotransfer Parameters Used in Risk Assessments

ANALYTES

CAS Bioaccumulation Factor Soil-to-Edible Plant for Finfish

Concentration Ratio $(\mathrm{L} / \mathrm{kg})$ (Unitless)

\begin{tabular}{|c|c|c|c|}
\hline \multicolumn{4}{|l|}{ VOLATILES } \\
\hline 1,1,1-TRICHLOROETHANE & 71556 & 52 & $3.48 E-01$ \\
\hline 1,1,2,2-TETRACHLOROETHANE & 79345 & 39 & $4.03 E-01$ \\
\hline 1,1,2-TRICHLOROETHANE & 79005 & 39 & $3.62 E-01$ \\
\hline 1,1-DICHLOROETHANE & 75343 & 14 & $8.94 E-01$ \\
\hline 1,1-DICHLOROETHENE & 75354 & 15 & $8.36 E-01$ \\
\hline 1,2-DICHLOROETHANE & 107062 & 2 & $1.35 E+00$ \\
\hline 1,2-DICHLOROETHENE (TOTAL) & 156605 & 2.9 & $5.11 E+00$ \\
\hline 1,2-DICHLOROPROPANE & 78875 & 19 & $6.76 E-01$ \\
\hline 2-BUTANONE & 78933 & 1 & $6.72 E+00$ \\
\hline 2-HEXANONE & 591786 & 7 & $1.54 E+00$ \\
\hline \multicolumn{4}{|l|}{ 4-METHYL-2-PENTANONE } \\
\hline ACETONE & 67641 & 0 & $1.33 E+01$ \\
\hline BENZENE & 71432 & 24 & $5.76 E-01$ \\
\hline \multicolumn{4}{|l|}{ BENZYL ALCOHOL } \\
\hline BROMODICHLOROMETHANE & 75274 & 30 & $4.91 E-01$ \\
\hline BROMOFORM & 75252 & 39 & $3.97 E-01$ \\
\hline BROMOMETHANE & 74839 & 5 & $1.99 E+00$ \\
\hline CARBON DISULFIDE & 75150 & 19 & $6.76 E-01$ \\
\hline CARBON TETRACHLORIDE & 56235 & 150 & $2.89 E-01$ \\
\hline CHLOROBENZENE & 108907 & 645 & $2.21 E-01$ \\
\hline CHLOROETHANE & 75003 & 7 & $1.44 E+00$ \\
\hline CHLOROFORM & 67663 & 18 & $7.04 E-01$ \\
\hline CHLOROMETHANE & 74873 & 3 & $2.74 E+00$ \\
\hline CIS-1,3-DICHLOROPROPENE & 542756 & 19 & $6.76 E-01$ \\
\hline DIBROMOCHLOROMETHANE & 124481 & 23 & $6.00 E-01$ \\
\hline ETHYLBENZENE & 100414 & 146 & $1.46 E-01$ \\
\hline METHYLENE CHLORIDE & 75092 & 5.74 & $1.71 E+00$ \\
\hline STYRENE & 100425 & 103 & $1.91 E-01$ \\
\hline TETRACHLOROETHENE & 127184 & 100 & $3.04 E-01$ \\
\hline TOLUENE & 108883 & 70 & $2.56 E-01$ \\
\hline TRANS-1,3-DICHLOROPROPENE & 10061026 & 19 & $6.76 E-01$ \\
\hline TRICHLOROETHENE & 79016 & 11 & $4.08 E-01$ \\
\hline VINYL ACETATE & 108054 & 1 & $5.18 E+00$ \\
\hline VINYL CHLORIDE & 75014 & 7 & $1.54 E+00$ \\
\hline XYLENES (TOTAL) & 1330207 & 177 & $1.26 E-01$ \\
\hline \multicolumn{4}{|l|}{ SEMI-VOLATILES } \\
\hline 1,2,4-TRICHLOROBENZENE & 120821 & 1093 & $3.16 E-02$ \\
\hline 1,2-DICHLOROBENZENE & 95501 & 89 & $8.02 E-02$ \\
\hline 1,2-DIPHENYLHYDRAZINE & 122667 & 94 & $2.04 E-01$ \\
\hline 1,3-DICHLOROBENZENE & 541731 & 66 & $8.04 E-02$ \\
\hline 1,4-DICHLOROBENZENE & 106467 & 60 & $8.04 E-02$ \\
\hline 2,4,5-TRICHLOROPHENOL & 95954 & 1900 & $6.85 E-02$ \\
\hline 2,4,6-TRICHLOROPHENOL & 88062 & 20 & 5.61E-02 \\
\hline 2,4-DICHLOROPHENOL & 94757 & 80 & $2.30 E-01$ \\
\hline 2,4-DIMETHYLPHENOL & 105679 & 150 & $2.30 E-01$ \\
\hline 2,4-DINITROPHENOL & 51285 & 8 & $1.32 E+00$ \\
\hline 2,4-DINITROTOLUENE & 121142 & 19 & $6.76 E-01$ \\
\hline \multicolumn{4}{|l|}{ 2,6-DINITROTOLUENE } \\
\hline 2-CHLORONAPHTHALENE & 91578 & 646 & $4.72 E-02$ \\
\hline 2-CHLOROPHENOL & 95578 & 6.4 & $5.33 E-01$ \\
\hline
\end{tabular}


TABLE H.1. Biotransfer Parameters Used in Risk Assessments

ANALYTES

CAS Bioaccumulation Factor Soil-to-Edible Plant for Finfish

Concentration Ratio

\begin{tabular}{|c|c|c|c|}
\hline & & $\begin{array}{l}\text { for Finfish } \\
\text { ( }(/ \mathrm{kg})\end{array}$ & $\begin{array}{c}\text { Concentration Ratio } \\
\text { (Unitless) }\end{array}$ \\
\hline 2-METHYLNAPHTHALENE & 91576 & 505 & $5.69 E-02$ \\
\hline 2-METHYLPHENOL & 95487 & 18 & $7.04 E-01$ \\
\hline 4-METHYLPHENOL & 106445 & 14 & $8.94 E-01$ \\
\hline 2-NITROANILINE & 88747 & 17 & $7.42 E-01$ \\
\hline \multicolumn{4}{|l|}{ 2-NITROPHENOL } \\
\hline 3,3'-DICHLOROBENZIDINE & 91941 & 269 & $9.19 E-02$ \\
\hline \multicolumn{4}{|l|}{ 3-NITROANILINE } \\
\hline \multicolumn{3}{|l|}{ 4-BROMOPHENYL-PHENYLETHER } & $2.66 E-01$ \\
\hline \multicolumn{4}{|l|}{ 4-CHOLOR-3-METHYLPHENOL } \\
\hline 4-CHLOROANILINE & 106478 & 14 & $8.48 E-01$ \\
\hline 4-CHLOROPHENYL-PHENYLETHER & 7005723 & 742 & $4.25 E-02$ \\
\hline 4-NITROANILINE & 100016 & 7 & $1.52 E+00$ \\
\hline 4-NITROPHENOL & 100027 & 126 & $7.62 E-01$ \\
\hline ACENAPHTHENE & 83329 & 646 & 4.72E-02 \\
\hline ACENAPHTHYLENE & 208968 & 301 & $7.04 E-02$ \\
\hline ANTHRACENE & 120127 & 1420 & $2.59 E-02$ \\
\hline BENZO(A)ANTHRACENE & 56553 & 11700 & $5.61 E-03$ \\
\hline BENZO(A)PYRENE & 50328 & 23776 & $3.04 E-03$ \\
\hline BENZO(B)FLUORANTHENE & 205992 & 23776 & $3.04 E-03$ \\
\hline \multicolumn{4}{|l|}{ BENZO(G,H,I)PERYLENE } \\
\hline BENZO(K)FLUORANTHENE & 207089 & 23776 & $3.04 E-03$ \\
\hline BENZOIC ACID & 65850 & 16 & $8.04 E-01$ \\
\hline \multicolumn{4}{|l|}{ BIS(2-CHLOROETHOXY)METHANE } \\
\hline BIS(2-CHLOROETHYL)ETHER & 111444 & 11 & $1.32 E+00$ \\
\hline BIS(2-CHLOROISOPROPYL)ETHER & 39638329 & 23 & $5.92 E-01$ \\
\hline BIS(2-ETHYLHEXYL)PHTHALATE & 117817 & 2 & $4.28 E+00$ \\
\hline \multicolumn{4}{|l|}{ BUTYLBENZYLPHTHALATE } \\
\hline CHRYSENE & 218019 & 10797 & $5.54 E-03$ \\
\hline DI-N-BUTYLPHTHALATE & 84742 & 10655 & $5.60 E-03$ \\
\hline DI-N-OCTYLPHTHALATE & 117840 & 18666455 & 1.91E-05 \\
\hline DIBENZ(A,H)ANTHRACENE & 53703 & 113000 & $5.54 E-03$ \\
\hline \multicolumn{4}{|l|}{ DIBENZOFURAN } \\
\hline DIETHYLPHTHALATE & 84662 & 44 & 3.67E-01 \\
\hline DIMETHYLPHTHALATE & 131113 & 57 & $1.21 E+00$ \\
\hline FLUORANTHENE & 206440 & 3118 & 1.43E-02 \\
\hline FLUORENE & 86737 & 713 & $3.62 E-02$ \\
\hline HEXACHLOROBENZENE & 118741 & 5561 & $9.18 E-03$ \\
\hline HEXACHLOROBUTADIENE & 87683 & 2530 & 1.67E-02 \\
\hline HEXACHLOROCYCLOPENTADIENE & 77474 & 29 & $4.72 E-02$ \\
\hline HEXACHLOROETHANE & 67721 & 1845 & $2.12 E-02$ \\
\hline INDENO(1,2,3-CD)PYRENE & 193395 & 51258 & $1.70 E-03$ \\
\hline ISOPHORONE & 78591 & 31 & $4.78 E-01$ \\
\hline N-NITROSO-DI-N-PROPYLAMINE & 621647 & 8 & $1.33 E+00$ \\
\hline N-NITROSODIPHENYLAMINE (1) & 86306 & 141 & $1.50 E-01$ \\
\hline NAPHTHALENE & 91203 & 168 & $1.31 E-01$ \\
\hline NITROBENZENE & 98953 & 15 & $8.25 E-01$ \\
\hline PENTACHLOROPHENOL & 87865 & 3715 & $1.25 E-02$ \\
\hline PHENANTHRENE & 85018 & 1443 & $2.56 E-02$ \\
\hline PHENOL & 108952 & 8 & $1.39 E+00$ \\
\hline PYRENE & 129000 & 2800 & $8.15 E-03$ \\
\hline
\end{tabular}


TABLE H.1. Biotransfer Parameters Used in Risk Assessments

ANALYTES

CAS Bioaccumulation Factor Soil-to-Edible Plant for Finfish

Concentration Ratio $(\mathrm{L} / \mathrm{kg})$ (Unitless)

\begin{tabular}{|c|c|c|c|}
\hline $\begin{array}{l}\text { TPH } \\
\text { TOTAL PETROLEUM HYD }\end{array}$ & & 0 & 4.00E-02 \\
\hline \multicolumn{4}{|l|}{ РСB } \\
\hline AROCLOR-1016 & 12674112 & 17000 & 5.77E-03 \\
\hline AROCLOR-1221 & 1104282 & 742 & $4.25 E-02$ \\
\hline AROCLOR-1232 & 11141165 & 160 & $1.37 E-01$ \\
\hline AROCLOR-1242 & 53469219 & 784 & 4.07E-02 \\
\hline AROCLOR-1248 & 12672296 & 14039 & $4.54 E-03$ \\
\hline AROCLOR-1254 & 11091691 & 22986 & $3.12 E-03$ \\
\hline AROCLOR-1260 & 11096825 & 159737 & $7.14 E-04$ \\
\hline \multicolumn{4}{|l|}{ PESTICIDES } \\
\hline $4,4^{\prime}-\mathrm{DDD}$ & 72548 & 2710 & $2.53 E-03$ \\
\hline $4,4^{\prime}-\mathrm{DDE}$ & 72559 & 8450 & $8.71 E-04$ \\
\hline $4,4^{3}-\mathrm{DDT}$ & 50293 & 29830 & $2.56 E-03$ \\
\hline \multicolumn{4}{|l|}{ 4,4'-METHOXYCHLOR } \\
\hline ALDRIN & 309002 & 3140 & 8.36E-03 \\
\hline ALPHA-BHC & 319846 & 500 & 5.39E-02 \\
\hline ALPHA-CHLORDANE & 57749 & 322 & $1.67 E-02$ \\
\hline BETA-BHC & 319857 & 542 & 5.39E-02 \\
\hline DELTA-BHC & 319868 & 770 & $4.13 E-02$ \\
\hline DIELDRIN & 60571 & 4870 & 9.19E-02 \\
\hline ENDOSULFAN I & & 294 & $8.59 E-02$ \\
\hline ENDOSULFAN II & & 332 & 7.83E-02 \\
\hline \multicolumn{4}{|l|}{ ENDOSULFAN SULFATE } \\
\hline ENDRIN & 72208 & 1480 & $5.61 E-03$ \\
\hline \multicolumn{4}{|l|}{ ENDRIN KETONE } \\
\hline GAMMA-BHC (LINDANE) & 58899 & 180 & $5.39 E-02$ \\
\hline GAMMA-CHLORDANE & 57749 & 322 & $1.67 E-02$ \\
\hline HEPTACHLOR & 76448 & 1299 & 2.77E-02 \\
\hline HEPTACHLOR EPOXIDE & 1024573 & 67 & $2.64 E-01$ \\
\hline METHOXYCHLOR & 72435 & 8300 & $3.16 E-02$ \\
\hline TOXAPHENE & 8001352 & 190 & $1.20 E-01$ \\
\hline \multicolumn{4}{|l|}{ METALS } \\
\hline ALUMINUM & 7429905 & 10 & $1.80 E-04$ \\
\hline ANTIMONY & 7440360 & 200 & $1.40 E-04$ \\
\hline ARSENIC & 7440382 & 100 & $1.50 E-03$ \\
\hline BARIUM & 7440393 & 200 & $3.75 E-03$ \\
\hline BERYLLIUM & 7440417 & 19 & 4.70E-04 \\
\hline CADMIUM & 7440439 & 200 & 3.75E-02 \\
\hline \multicolumn{4}{|l|}{ CALCIUM } \\
\hline CHROMIUM & 7440473 & 200 & $1.13 \mathrm{E}-03$ \\
\hline COBALT & 7440484 & 50 & $9.40 \mathrm{E}-03$ \\
\hline COPPER & 7440508 & 50 & $6.25 E-02$ \\
\hline IRON & 15438310 & 2000 & $2.50 E-04$ \\
\hline LEAD & 7439921 & 100 & $8.00 E-04$ \\
\hline MAGNESIUM & 7786303 & 50 & $1.38 E-01$ \\
\hline MANGANESE & 7439965 & 400 & $3.75 E-02$ \\
\hline MERCURY & 7439976 & 1000 & $5.00 E-02$ \\
\hline NICKEL & 7440020 & 100 & $1.50 E-02$ \\
\hline
\end{tabular}


TABLE H.1. Biotransfer Parameters Used in Risk Assessments

\begin{tabular}{|c|c|c|c|}
\hline ANALYTES & CAS & $\begin{array}{c}\text { Bioaccumulation Factor } \\
\text { for Finfish } \\
(\mathrm{L} / \mathrm{kg})\end{array}$ & $\begin{array}{c}\text { Soil-to-Edible Plant } \\
\text { Concentration Ratio } \\
\text { (Unitless) }\end{array}$ \\
\hline POTASSIUM & 7447407 & & \\
\hline SELENIUM & 7782492 & 170 & $6.25 E-03$ \\
\hline SILVER & 7440224 & 2.3 & 3.25E-04 \\
\hline SODIUM & 7647145 & & \\
\hline THALLIUM & 7440280 & 10000 & $1.00 \mathrm{E}-04$ \\
\hline VANADIUM & 7440622 & 10 & $1.30 E-03$ \\
\hline ZINC & 7646857 & 2500 & $1.48 \mathrm{E}-01$ \\
\hline
\end{tabular}




\title{
Eielson Air Force Base \\ Baseline Risk Assessment
}

\author{
Appendix I \\ Method For Estimation of Contaminant Exposure in Aqueous \\ Phase Due to Dermal Contact
}




\section{APPENDIX I--METHOD FOR ESTIMATION OF CONTAMINANT EXPOSURE IN AQUEOUS PHASE DUE TO DERMAL CONTACT}

Dermal absorption will occur from contact with groundwater or surface water during showering. Dermal absorption can also occur while swimming; however, swimming was not considered a viable pathway in this assessment due to the sub-arctic climate at Eielson. The dermal absorption procedure described below is the model defined in EPA (1992).

The total daily absomtion rate, corrected by the gastrointestinal tract absorption fraction, is given by

$$
\text { Dose }=\frac{\left(D_{\text {event }}\right)(A)(F)(f)}{(B W)}
$$

where Dose = daily intake via dermal absorption equivalent to oral intake (mg/kg-day)

$D_{\text {event }}=$ dose absorbed per unit area per event (mg/ $\mathrm{cm}^{2}$-event)

$A=$ area of skin exposed to contaminated water $\left(\mathrm{cm}^{2}\right)$ (Appendix $B$ )

$F=$ frequency of events (events/day) (Appendix $B$ )

$\mathrm{BW}=$ body weight of exposed individual $(\mathrm{kg})$ (Appendix $\mathrm{B}$ )

$\mathrm{f}=$ fraction of material absorbed in passing through the $\mathrm{Gl}$ tract (assumed to be 1

in this risk assessment)

The dose estimated by Equation (1) is equivalent to oral exposure because the Gl correction has been applied. This adjustment for absorption in the $\mathrm{Gl}$ tract and through the skin is needed as described in the EPA (1989) because EPA's toxicity data are based on the oral or inhalation routes and on the administered dose of chemicals. Specific equations provided by EPA (1992) for evaluation of the dose absorbed per event are described below:

\section{I.1 EXPOSURE TO INORGANIC COMPOUNDS}

The absorbed dose per unit area per event for inorganic compounds is evaluated as follows:

$$
D A_{\text {event }}=\left(K_{p}{ }^{W}\right)\left(C_{w}\right)\left(t_{\text {event }}\right)
$$

where $K_{p}{ }^{W}=$ permeability coefficient from water $(\mathrm{cm} / \mathrm{hr}$ ) provided in Appendix $\mathrm{J}$ $C_{w}=$ concentration of chemical in water $\left(\mathrm{mg} / \mathrm{cm}^{3}\right)$ provided in Appendix $F$ $t_{\text {event }}=$ duration of event (hr/day) provided in Appendix B (Assume one event per day). 


\section{I.2 EXPOSURE TO ORGANIC COMPOUNDS}

The dose absorbed per unit area per event was evaluated for organic chemicals using the steps outlined below:

Step 1: Calculate the value for B (dimensionless), given by:

$$
B=\frac{K_{a w}}{10^{4}}
$$

Step 2: Determine the diffusion coefficient for skin, Dsc $\left(\mathrm{cm}^{2} / \mathrm{hr}\right)$, given by:

$$
\log \frac{D_{s C}}{E_{s c}}=-2.72-0.0061(M W)
$$

where $M W=$ molecular weight of the organic compound and $E_{S C}$ is set to $10^{-3} \mathrm{~cm}$.

Step 3: Calculate the delay time, $\tau(\mathrm{hr})$ from the following equation:

$$
\tau=\frac{E_{s c}^{2}}{6 D_{s c}}
$$

Step 4: Calculate the time to reach steady state, $t^{\star}(\mathrm{hr})$ from the following procedure dependent on the value calculated for $B$.

For $B \leq 0.1$, then $t^{*}=2.4 \tau$

For $0.1 \leq B \leq 1.17$, then $t^{*}=(8.4+6 \log B) \tau$

For $B \geq 1.17$, then

$$
t^{*}=6\left(b-\sqrt{b^{2}-c^{2}}\right) \tau
$$

where the constants $b$ and $c$ are given as

$$
\mathrm{b}=\frac{2}{\pi}(1+\mathrm{B})^{2}-\mathrm{c}
$$

and 


$$
c=\frac{1+3 B}{3}
$$

Step 5: Calculate $D A_{\text {event }}$ using the following equations depending on the value calculated for $t$ relative to the vent duration, $t$ event

$$
\begin{aligned}
& \text { For } t_{\text {event }}<t^{*} \text {, } \\
& \qquad \mathrm{DA}_{\text {event }}=2 \mathrm{~K}_{\mathrm{p}} \mathrm{C}_{\mathrm{w}} \sqrt{\frac{6 \pi \mathrm{event}}{\pi}} \\
& \text { and for } t_{\text {event }}>t^{*}, \\
& \mathrm{DA}_{\text {event }}=\mathrm{K}_{\mathrm{p}} \mathrm{C}_{\mathrm{w}}\left[\frac{t_{\text {event }}}{1+B}+2 \tau\left\{\frac{1+3 B}{1+B}\right\}\right]
\end{aligned}
$$

\section{I.3 REFERENCES}

EPA. 1989. Bisk Assessment Guidance for Superfund: Human Health Evaluation Manual Part A. U.S. Environmental Protection Agency, Office of Solid Waste and Emergency Response. (Interim Final).

EPA. 1992. Dermal Exposure Assessment: Principles and Applications. U.S. Environmental Protection Agency, Office of Research and Development. (Interim Report).

Strenge, D.L., and S.R. Peterson. 1989. Chemical Data Bases for the Multimedia Environmental Pollutant Assessment System (MEPAS): Version 1. PNL-7145, Pacific Northwest Laboratory, Richland, Washington. 


\title{
Eielson Air Force Base Baseline Risk Assessment
}

\author{
Appendix J
}

Dermal Parameters Used in Risk Assessments 


\section{APPENDIX J--DERMAL PARAMETERS USED IN RISK ASSESSMENTS}

The parameters are the skin permeability constant for aqueous solutions and the skin absorption fraction for soil exposure are in Table J.1. The former parameter is used for the water dermal contact pathway; the later is used for the soil dermal contact pathway.

All non-italicized values for the skin permeability constant were taken from the Multimedia Environmental Pollutant Assessment System (MEPAS) database compiled by Strenge and Peterson (1989). All of his values were taken from tables in EPA (1992a); this includes laboratory measurements and theoretical calculations. Italicized values were calculated from octanol-water partition coefficients using the algorithms presented on page 5-20 of EPA (1992a).

The skin absorption fractions for soil exposure are from EPA (1992b).

Several of the compounds listed do not have dermal parameters. The MEPAS database did not include chemical parameters for these compounds, and since they were not detected at the Operable Unit 2 sites, no additional effort was expended in calculating the dermal parameters.

\section{REFERENCES}

EPA. 1992a. Dermal Exposure Assessment: Principles and Applications. U.S. Environmental Protection Agency, Office of Research and Development. (Interim Report).

EPA. 1992b. "New Interim Region IV Guidance." U.S. Environmental Protection Agency, Region X (Carol Sweeney).

Strenge, D.L., and S.R. Peterson. 1989. Chemical Data Bases for the Multimedia Environmental Pollutant Assessment System (MEPAS): Version 1. PNL-7145, Pacific Northwest Laboratory, Richland, Washington. 
IABLEJ.1. Dermal Parameters Used in Risk Assessments

ANALYTES CAS Skin Permeability Constant Skin Absorption Fraction for Aqueous Solutions for Soil Exposure $(\mathrm{cm} / \mathrm{hr})$ (Unitless)

\begin{tabular}{|c|c|c|c|}
\hline \multicolumn{4}{|l|}{ VOLATILES } \\
\hline 1,1,1-TRICHLOROETHANE & 71556 & $1.70 E-02$ & 0.01 \\
\hline 1,1,2,2-TETRACHLOROETHANE & 79345 & $9.00 E-03$ & 0.01 \\
\hline 1,1,2-TRICHLOROETHANE & 79005 & 8.40E-03 & 0.01 \\
\hline 1,1-DICHLOROETHANE & 75343 & 8.90E-03 & 0.01 \\
\hline 1,1-DICHLOROETHENE & 75354 & 1.60E-02 & 0.01 \\
\hline 1,2-DICHLOROETHANE & 107062 & $5.30 E-03$ & 0.01 \\
\hline 1,2-DICHLOROETHENE (TOTAL) & 156605 & $1.00 E-02$ & 0.01 \\
\hline 1,2-DICHLOROPROPANE & 78875 & $1.00 E-02$ & 0.01 \\
\hline 2-BUTANONE & 78933 & $5.00 E-03$ & 0.01 \\
\hline 2-HEXANONE & 591786 & & 0.01 \\
\hline \multicolumn{4}{|l|}{ 4-METHYL-2-PENTANONE } \\
\hline ACETONE & 67641 & $1.00 E-03$ & 0.01 \\
\hline BENZENE & 71432 & 1.10E-01 & 0.01 \\
\hline \multicolumn{4}{|l|}{ BENZYL ALCOHOL } \\
\hline BROMODICHLOROMETHANE & 75274 & $5.80 \mathrm{E}-03$ & 0.01 \\
\hline BROMOFORM & 75252 & 2.60E-03 & 0.01 \\
\hline BROMOMETHANE & 74839 & $3.50 E-03$ & 0.01 \\
\hline CARBON DISULFIDE & 75150 & 5.00E-01 & 0.01 \\
\hline CARBON TETRACHLORIDE & 56235 & 2.20E-02 & 0.01 \\
\hline CHLOROBENZENE & 108907 & 4.10E-02 & 0.01 \\
\hline CHLOROETHANE & 75003 & 8.00E-03 & 0.01 \\
\hline CHLOROFORM & 67663 & $1.30 E-01$ & 0.01 \\
\hline CHLOROMETHANE & 74873 & 4.20E-03 & 0.01 \\
\hline CIS-1,3-DICHLOROPROPENE & 542756 & $0.00 E+00$ & 0.01 \\
\hline DIBROMOCHLOROMETHANE & 124481 & $3.90 E-03$ & 0.01 \\
\hline ETHYLBENZENE & 100414 & $1.00 E+00$ & 0.01 \\
\hline METHYLENE CHLORIDE & 75092 & $4.50 E-03$ & 0.01 \\
\hline STYRENE & 100425 & $6.70 \mathrm{E}-01$ & 0.01 \\
\hline TETRACHLOROETHENE & 127184 & $3.70 E-01$ & 0.01 \\
\hline TOLUENE & 108883 & $1.00 E+00$ & 0.01 \\
\hline TRANS-1,3-DICHLOROPROPENE & 10061026 & & 0.01 \\
\hline TRICHLOROETHENE & 79016 & 2.30E-01 & 0.01 \\
\hline VINYL ACETATE & 108054 & & 0.01 \\
\hline VINYL CHLORIDE & 75014 & 7.30E-03 & 0.01 \\
\hline XYLENES (TOTAL) & 1330207 & 8.00E-02 & 0.01 \\
\hline \multicolumn{4}{|l|}{ SEMI-VOLATILES } \\
\hline 1,2,4-TRICHLOROBENZENE & 120821 & $1.00 \mathrm{E}-01$ & 0.01 \\
\hline 1,2-DICHLOROBENZENE & 95501 & $6.10 \mathrm{E}-02$ & 0.01 \\
\hline 1,2-DIPHENYLHYDRAZINE & 122667 & $1.80 E-02$ & 0.01 \\
\hline 1,3-DICHLOROBENZENE & 541731 & 8.70E-02 & 0.01 \\
\hline 1,4-DICHLOROBENZENE & 106467 & $6.20 \mathrm{E}-02$ & 0.01 \\
\hline 2,4,5-TRICHLOROPHENOL & 95954 & & 0.01 \\
\hline 2,4,6-TRICHLOROPHENOL & 88062 & 5.90E-02 & 0.01 \\
\hline 2,4-DICHLOROPHENOL & 94757 & & 0.01 \\
\hline 2,4-DIMETHYLPHENOL & 105679 & $1.10 \mathrm{E}-01$ & 0.01 \\
\hline 2,4-DINITROPHENOL & 51285 & $3.20 E-03$ & 0.01 \\
\hline
\end{tabular}


TABLE J1. Dermal Parameters Used in Risk Assessments

ANALYTES CAS Skin Permeability Constant Skin Absorption Fraction for Aqueous Solutions for Soil Exposure $(\mathrm{cm} / \mathrm{hr})$

\begin{tabular}{|c|c|c|c|}
\hline 2,4-DINITROTOLUENE & 121142 & $3.80 \mathrm{E}-03$ & 0.01 \\
\hline \multicolumn{4}{|l|}{ 2,6-DINITROTOLUENE } \\
\hline 2-CHLORONAPHTHALENE & 91578 & $0.00 E+00$ & 0.01 \\
\hline 2-CHLOROPHENOL & 95578 & 3.30E-02 & 0.01 \\
\hline 2-METHYLNAPHTHALENE & 91576 & $3.16 E-01$ & 0.01 \\
\hline 2-METHYLPHENOL & 95487 & $1.60 \mathrm{E}-02$ & 0.01 \\
\hline 4-METHYLPHENOL & 106445 & & 0.01 \\
\hline 2-NITROANILINE & 88747 & $1.80 \mathrm{E}-02$ & 0.01 \\
\hline \multicolumn{4}{|l|}{ 2-NITROPHENOL } \\
\hline 3,3'-DICHLOROBENZIDINE & 91941 & $1.70 \mathrm{E}-02$ & 0.01 \\
\hline \multicolumn{4}{|l|}{ 3-NITROANILINE } \\
\hline 4,6-DINITRO-2-METHYLPHENOL & 534521 & $3.80 \mathrm{E}-03$ & 0.01 \\
\hline \multicolumn{4}{|l|}{ 4-BROMOPHENYL-PHENYLETHER } \\
\hline \multicolumn{4}{|l|}{ 4-CHOLOR-3-METHYLPHENOL } \\
\hline 4-CHLOROANILINE & 106478 & & 0.01 \\
\hline 4-CHLOROPHENYL-PHENYLETHER & 7005723 & & 0.01 \\
\hline 4-NITROANILINE & 100016 & & 0.01 \\
\hline 4-NITROPHENOL & 100027 & $5.60 E-03$ & 0.01 \\
\hline ACENAPHTHENE & 83329 & & 0.01 \\
\hline ACENAPHTHYLENE & 208968 & & 0.01 \\
\hline ANTHRACENE & 120127 & $3.16 E-02$ & 0.01 \\
\hline BENZO(A)ANTHRACENE & 56553 & $8.10 \mathrm{E}-01$ & 0.01 \\
\hline BENZO(A)PYRENE & 50328 & $1.20 E+00$ & 0.01 \\
\hline BENZO(B)FLUORANTHENE & 205992 & $1.20 E+00$ & 0.01 \\
\hline BENZO(G,H,I)PERYLENE & & & 0.01 \\
\hline BENZO(K)FLUORANTHENE & 207089 & $3.16 E-02$ & 0.01 \\
\hline BENZOIC ACID & 65850 & 7.30E-03 & 0.01 \\
\hline BIS(2-CHLOROETHOXY)METHANE & & & 0.01 \\
\hline BIS(2-CHLOROETHYL)ETHER & 111444 & $2.10 \mathrm{E}-03$ & 0.01 \\
\hline BIS(2-CHLOROISOPROPYL)ETHER & 39638329 & & 0.01 \\
\hline BIS(2-ETHYLHEXYL)PHTHALATE & 117817 & $3.30 E+00$ & 0.01 \\
\hline BUTYLBENZYLPHTHALATE & & & 0.01 \\
\hline CHRYSENE & 218019 & 8.10E-01 & 0.01 \\
\hline DI-N-BUTYLPHTHALATE & 84742 & 3.30E-02 & 0.01 \\
\hline DI-N-OCTYLPHTHALATE & 117840 & $3.16 E-02$ & 0.01 \\
\hline DIBENZ(A,H)ANTHRACENE & 53703 & $2.70 E+00$ & 0.01 \\
\hline DIBENZOFURAN & & & 0.01 \\
\hline DIETHYLPHTHALATE & 84662 & 4.80E-03 & 0.01 \\
\hline DIMETHYLPHTHALATE & 131113 & $1.60 E-03$ & 0.01 \\
\hline FLUORANTHENE & 206440 & $3.60 E-01$ & 0.01 \\
\hline FLUORENE & 86737 & $3.16 E-02$ & 0.01 \\
\hline HEXACHLOROBENZENE & 118741 & $2.10 \mathrm{E}-01$ & 0.01 \\
\hline HEXACHLOROBUTADIENE & 87683 & $1.20 E-01$ & 0.01 \\
\hline HEXACHLOROCYCLOPENTADIENE & 77474 & & 0.01 \\
\hline HEXACHLOROETHANE & 67721 & 4.20E-02 & 0.01 \\
\hline INDENO(1,2,3-CD)PYRENE & 193395 & $1.90 E+00$ & 0.01 \\
\hline ISOPHORONE & 78591 & 4.20E-03 & 0.01 \\
\hline N-NITROSO-DI-N-PROPYLAMINE & 621647 & & 0.01 \\
\hline
\end{tabular}


IABLE J.1. Dermal Parameters Used in Risk Assessments

\begin{tabular}{|c|c|c|c|}
\hline ANALYTES & CAS & $\begin{array}{l}\text { Skin Permeability Constant } \\
\text { for Aqueous Solutions } \\
(\mathrm{cm} / \mathrm{hr})\end{array}$ & $\begin{array}{l}\text { Skin Absorption Fraction } \\
\text { for Soil Exposure } \\
\text { (Unitless) }\end{array}$ \\
\hline N-NITROSODIPHENYLAMINE (1) & 86306 & $2.00 \mathrm{E}-02$ & 0.01 \\
\hline NAPHTHALENE & 91203 & $6.90 \mathrm{E}-02$ & 0.01 \\
\hline NITROBENZENE & 98953 & $2.23 E-02$ & 0.01 \\
\hline PENTACHLOROPHENOL & 87865 & $6.50 E-01$ & 0.01 \\
\hline PHENANTHRENE & 85018 & $2.30 \mathrm{E}-01$ & 0.01 \\
\hline PHENOL & 108952 & 8.20E-03 & 0.01 \\
\hline PYRENE & 129000 & $3.16 E-02$ & 0.01 \\
\hline \multicolumn{4}{|l|}{ TPH } \\
\hline TOTAL PETROLEUM HYDROCARE & & & 0.01 \\
\hline \multicolumn{4}{|l|}{ РCB } \\
\hline AROCLOR-1016 & 12674112 & $3.16 E-02$ & 0.01 \\
\hline AROCLOR-1221 & 1104282 & $3.16 E-02$ & 0.01 \\
\hline AROCLOR-1232 & 11141165 & $5.02 E-03$ & 0.01 \\
\hline AROCLOR-1242 & 53469219 & $3.16 E-02$ & 0.01 \\
\hline AROCLOR-1248 & 12672296 & $3.16 E-02$ & 0.01 \\
\hline AROCLOR-1254 & 11091691 & $3.16 E-02$ & 0.01 \\
\hline AROCLOR-1260 & 11096825 & $3.16 E-02$ & 0.01 \\
\hline \multicolumn{4}{|l|}{ PESTICIDES } \\
\hline $4,4^{\prime}-$ DDD & 72548 & $2.80 \mathrm{E}-01$ & 0.01 \\
\hline $4,4^{\prime}-\mathrm{DDE}$ & 72559 & $2.40 E-01$ & 0.01 \\
\hline 4,4'-DDT & 50293 & 4.30E-01 & 0.01 \\
\hline \multicolumn{4}{|l|}{ 4,4'-METHOXYCHLOR } \\
\hline ALDRIN & 309002 & 1.60E-03 & 0.01 \\
\hline ALPHA-BHC & 319846 & $3.16 E-02$ & 0.01 \\
\hline ALPHA-CHLORDANE & 57749 & $5.20 E-02$ & 0.01 \\
\hline BETA-BHC & 319857 & & 0.01 \\
\hline DELTA-BHC & 319868 & & 0.01 \\
\hline DIELDRIN & 60571 & $1.60 \mathrm{E}-02$ & 0.01 \\
\hline ENDOSULFAN I & & & 0.01 \\
\hline ENDOSULFAN ॥ & & & 0.01 \\
\hline \multicolumn{4}{|l|}{ ENDOSULFAN SULFATE } \\
\hline ENDRIN & 72208 & $1.60 \mathrm{E}-02$ & 0.01 \\
\hline \multicolumn{4}{|l|}{ ENDRIN KETONE } \\
\hline GAMMA-BHC (LINDANE) & 58899 & $1.40 E-02$ & 0.01 \\
\hline GAMMA-CHLORDANE & 57749 & $5.20 \mathrm{E}-02$ & 0.01 \\
\hline HEPTACHLOR & 76448 & $1.10 \mathrm{E}-02$ & 0.01 \\
\hline HEPTACHLOR EPOXIDE & 1024573 & & 0.01 \\
\hline METHOXYCHLOR & 72435 & & 0.01 \\
\hline TOXAPHENE & 8001352 & $1.50 E-02$ & 0.01 \\
\hline \multicolumn{4}{|l|}{ METALS } \\
\hline ALUMINUM & 7429905 & $1.00 E-05$ & 0.001 \\
\hline ANTIMONY & 7440360 & $1.00 \mathrm{E}-03$ & 0.001 \\
\hline ARSENIC & 7440382 & $1.00 \mathrm{E}-03$ & 0.001 \\
\hline BARIUM & 7440393 & $1.00 E-03$ & 0.001 \\
\hline
\end{tabular}


IABLE J1. Dermal Parameters Used in Risk Assessments

\begin{tabular}{lccr} 
& ANALYTES & \multicolumn{2}{c}{$\begin{array}{c}\text { Skin Permeability Constant } \\
\text { for Aqueous Solutions } \\
\text { (cm/hr) }\end{array}$} \\
\hline BERYLLIUM & 7440417 & $1.00 \mathrm{E}-03$ & $\begin{array}{c}\text { Skin Absorption Fraction } \\
\text { for Soil Exposure } \\
\text { (Unitless) }\end{array}$ \\
CADMIUM & 7440439 & $1.00 \mathrm{E}-03$ & 0.001 \\
CALCIUM & & & 0.01 \\
CHROMIUM & 7440473 & $2.00 \mathrm{E}-03$ & 0.001 \\
COBALT & 7440484 & $4.00 \mathrm{E}-04$ & 0.001 \\
COPPER & 7440508 & $1.00 \mathrm{E}-03$ & 0.001 \\
IRON & 15438310 & $1.00 \mathrm{E}-03$ & 0.001 \\
LEAD & 7439921 & $4.00 \mathrm{E}-06$ & 0.001 \\
MAGNESIUM & 7786303 & $1.00 \mathrm{E}-03$ & 0.001 \\
MANGANESE & 7439965 & $1.00 \mathrm{E}-03$ & 0.001 \\
MERCURY & 7439976 & $1.00 \mathrm{E}-03$ & 0.001 \\
NICKEL & 7440020 & $1.00 \mathrm{E}-04$ & 0.001 \\
POTASSIUM & 7447407 & & \\
SELENIUM & 7782492 & $1.00 \mathrm{E}-03$ & 0.001 \\
SILVER & 7440224 & $6.00 \mathrm{E}-04$ & 0.001 \\
SODIUM & 7647145 & & \\
THALLIUM & 7440280 & $1.00 \mathrm{E}-03$ & 0.001 \\
VANADIUM & 7440622 & $1.00 \mathrm{E}-03$ & 0.001 \\
ZINC & 7646857 & $6.00 \mathrm{E}-04$ & 0.001 \\
\hline
\end{tabular}




\title{
Eielson Air Force Base \\ Baseline Risk Assessment
}

\author{
Appendix $\mathbf{K}$ \\ Risk Output Tables
}




\section{APPENDIX K--RISK OUTPUT TABLES}

This appendix contains the detail risk output tables for all Operable Unit 2 sites; 60 tables total. The tables follow, in general, EPA (1989) guidance. However, in order to condense the large number of tables, several redundant columns were not included. Toxicity data for each chemical are in Table 9.1 of this assessment. The chronic daily intake (CDI) for carcinogenic chemicals can be calculated by dividing the chemical-specific risk by the slope factor. The CDI for non-carcinogenic chemicals is the product of the reference (RfD) and the hazard quotient.

Each site or combination of sites includes 12 tables. A general list of the tables available for each is below.

1) STXX Cancer Risk Estimate

Current Industrial Land Use

Average Exposure Scenario

2) STXX Cancer Risk Estimate

Current Industrial Land Use

Reasonable Maximum Exposure Scenario

3) STXX Hazard Index Estimate

Current Industrial Land Use

Average Exposure Scenario

4) STXX Hazard Index Estimate

Current Industrial Land Use

Reasonable Maximum Exposure Scenario

5) STXX Cancer Risk Estimate

Future Industrial Land Use

Average Exposure Scenario

6) STXX Cancer Risk Estimate

Future industrial Land Use

Reasonable Maximum Exposure Scenario

7) STXX Hazard Index Estimate

Future Industrial Land Use

Average Exposure Scenario

8) STXX Hazard Index Estimate

Future Industrial Land Use

Reasonable Maximum Exposure Scenario

9) STXX Cancer Risk Estimate

Future Residential Land Use

Average Exposure Scenario

10) STXX Cancer Risk Estimate

Future Residential Land Use

Reasonable Maximum Exposure Scenario 


$$
\begin{aligned}
& \text { STXX Hazard Index Estimate } \\
& \text { Future Residential Land Use } \\
& \text { Average Exposure Scenario }
\end{aligned}
$$

12)

\author{
STXX Hazard Index Estimate \\ Future Residential Land Use \\ Reasonable Maximum Exposure Scenario
}

All data necessary to perform these calculations are provided in this assessment. Appendix A contains the equations used for risk calculation, Appendix $B$ details the parameters for the individual exposure scenarios, and Appendix $F$ lists the chemical concentrations input into the equations. The appropriate toxicity data is in Table 9.1

A lower level cutoff was used to determine which chemicals were listed in the tables. The cutoff for carcinogenic chemicals is $1 \times 10^{-7}$; the cutoff for non-carcinogenic chemicals is $1 \times 10^{-2}$. If the total pathway cancer risk or pathway hazard index was below these values, then a value of 0 was entered into the appropriate row of the risk output table.

The summation of all risk values and Hazard Quotients are listed in the total exposure risk and exposure Hazard Index columns, respectively. In addition, this column also includes this summation minus the contribution from metals believed to be site background. A discussion of the determination of site background metals is in Appendix E. All metals analyzed, except lead in surface soils and groundwater (no Hazard Quotient was calculated for lead), are considered site background. They were subtracted from the total pathway risk and listed separately.

\title{
REFERENCES
}

EPA. 1989. Bisk Assessment Guidance for Superfund: Human Health Evaluation Manual Part A. U.S. Environmental Protection Agency, Office of Solid Waste and Emergency Response. (Interim Final). 
Table K.1. ST10/SS14 Cancer Risk Estimates Current Industrial Land Use Average Exposure Scenario

\begin{tabular}{lccc} 
Chemical- & $\begin{array}{c}\text { Chemal } \\
\text { Specific } \\
\text { Risk }\end{array}$ & $\begin{array}{c}\text { Total } \\
\text { Pathway } \\
\text { Risk }\end{array}$ & $\begin{array}{c}\text { Total } \\
\text { Exposure } \\
\text { Risk }\end{array}$ \\
\hline Exposure Pathway: Ingestion of Groundwater & & \\
\hline
\end{tabular}

$\begin{array}{ll}\text { BENRENE } & 1 E-05 \\ \text { ANTHRACENE } & 1 E-06 \\ \text { PYRENE } & 7 E-06 \\ \text { ARSENIC } & 7 E-05 \\ \text { BERYUUM } & 2 E-06\end{array}$

$1 E-04$

Exposure Pathway: Inhalation of Volatiles from Groundwater

$\begin{array}{ll}\text { BENRZENE } & 9 \mathrm{E}-05 \\ \text { ANTHRACENE } & 2 \mathrm{E}-04 \\ \text { PYPENE } & 5 \mathrm{E}-05\end{array}$

3E-04

Exposure Pathway: Dermal Contact with Groundwater

$\begin{array}{ll}\text { BENZENE } & 1 \mathrm{E}-05 \\ \text { ANTHRACENE } & 7 \mathrm{E}-07 \\ \text { PYPEE } & 6 \mathrm{E}-06 \\ \text { ARSENIC } & 2 \mathrm{E}-07\end{array}$

$2 \mathrm{E}-05$

Exposure Pathway: Incidental Ingestion of Surface Water

$$
<1 E-07
$$

Exposure Pathway: Dermal Contact with Surface Water

$$
<1 E-07
$$

Exposure Pathway: Ingestion of Fish from Hardfill Lake

ARSENIC

1E-05 
Table K.1. ST10/SS14 Cancer Risk Estimates

Current Industrial Land Use

Average Exposure Scenario

\begin{tabular}{|c|c|c|c|}
\hline Chemical & $\begin{array}{c}\text { Chemical- } \\
\text { Specific } \\
\text { Risk }\end{array}$ & $\begin{array}{c}\text { Total } \\
\text { Pathway } \\
\text { Risk }\end{array}$ & $\begin{array}{l}\text { Total } \\
\text { Exposure } \\
\text { Risk }\end{array}$ \\
\hline Exposure & estion of & & \\
\hline
\end{tabular}

ARSENIC

7E-07

$8 E-07$

Exposure Pathway: Dermal Contact with Surface Soils

$<1 E-07$

Exposure Pathway: Incidental Ingestion of Sediments

ARSENIC

$2 E-06$

3E-06

Exposure Pathway: Dermal Contact with Sediments

$<1 E-07$

Exposure Pathway: Incidental Ingestion of Subsurface Soils

ARSENIC

4E-07

$4 \mathrm{E}-07$

Exposure Pathway: Dermal Contact with Subsurface Soils

$<1 E-07$

Exposure Pathway: Inhalation of Volatile Contaminants Released from the Soil

BENRENE

4E-07

4E-07

Exposure Pathway: Inhalation of Resuspended Sediments

$\begin{array}{ll}\text { ARSENIC } & 4 \mathrm{E}-07 \\ \text { CHROMUM } & 7 \mathrm{E}-07\end{array}$

1E-06 
Table K.2. ST10/SS14 Cancer Risk Estimates

Current Industrial Land Use

Reasonable Maximum Exposure Scenario

\begin{tabular}{cccc} 
& Chemical- & Total & Total \\
& Specific & Pathway & Exposure \\
Chemical & Risk & Risk & Risk \\
\hline
\end{tabular}

Exposure Pathway: Ingestion of Groundwater

$\begin{array}{ll}\text { BENZENE } & 4 \mathrm{E}-05 \\ \text { ANTHRACENE } & 3 \mathrm{E}-06 \\ \text { PYRENE } & 2 \mathrm{E}-05 \\ \text { ARSENIC } & 2 \mathrm{E}-04 \\ \text { BERYUUM } & 7 \mathrm{E}-06\end{array}$

3E-04

Exposure Pathway: Inhalation of Volatiles from Groundwater

$\begin{array}{ll}\text { BENZENE } & 3 E-04 \\ \text { ANTHRACENE } & 5 E-04 \\ \text { PYRENE } & 1 E-04\end{array}$

8E-04

Exposure Pathway: Dermal Contact with Groundwater

$\begin{array}{ll}\text { BENEENE } & 4 E-05 \\ \text { ANTHRACENE } & 2 E-06 \\ \text { PYRENE } & 2 E-05 \\ \text { ARSENIC } & 7 E-07\end{array}$

7E-05

Exposure Pathway: Incidental Ingestion of Surface Water

$\begin{array}{ll}\text { ARSENIC } & 3 E-07\end{array}$

3E-07

Exposure Pathway: Dermal Contact with Surface Water

$<1 E-07$

Exposure Pathway: Ingestion of Fish from Hardfill Lake

ARSENIC $\quad 4 E-05$

4E-05

Exposure Pathway: Incidental Ingestion of Surface Soils

BENZO(A)PYRENE 3E-07 
Table K.2. ST10/SS14 Cancer Risk Estimates Current Industrial Land Use Reasonable Maximum Exposure Scenario

\begin{tabular}{lccc} 
Chemical & $\begin{array}{c}\text { Chemical- } \\
\text { Specific } \\
\text { Risk }\end{array}$ & $\begin{array}{c}\text { Total } \\
\text { Pathway } \\
\text { Risk }\end{array}$ & $\begin{array}{c}\text { Total } \\
\text { Exposure } \\
\text { Risk }\end{array}$ \\
\hline DIBENZ(A,H)ANTHRACENE & $8 \mathrm{E}-08$ & & \\
ARSENIC & $2 \mathrm{E}-06$ & &
\end{tabular}

2E-06

Exposure Pathway: Dermal Contact with Surface Soils

$\begin{array}{ll}\text { BENZO(A)PYRENE } & 2 \mathrm{E}-07 \\ \text { ARSENIC } & 2 \mathrm{E}-07\end{array}$

6E-07

Exposure Pathway: Incidental Ingestion of Sediments

$\begin{array}{ll}\text { PYPENE } & 1 E-07 \\ \text { AROCLOR-1260 } & 1 E-07 \\ \text { ARSENIC } & 7 E-06\end{array}$

7E-06

Exposure Pathway: Dermal Contact with Sediments

$\begin{array}{ll}\text { PYPENE } & 1 \mathrm{E}-07 \\ \text { AROCLOR-1260 } & 1 \mathrm{E}-07 \\ \text { ARSENIC } & 7 \mathrm{E}-07\end{array}$

$1 E-06$

Exposure Pathway: Incidental Ingestion of Subsurface Soils

ARSENIC 1E-06

1E-06

Exposure Pathway: Dermal Contact with Subsurface Soils

ARSENIC 1E-07

$1 E-07$

Exposure Pathway: Inhalation of Volatile Contaminants Released from the Soil

BENENE $\quad 1 E-06$

$1 E-06$

Exposure Pathway: Inhalation of Resuspended Sediments 
Table K.2. ST10/SS14 Cancer Risk Estimates

Current Industrial Land Use

Reasonable Maximum Exposure Scenario

\begin{tabular}{lccc} 
Chemical & $\begin{array}{c}\text { Chemical- } \\
\text { Specific } \\
\text { Risk }\end{array}$ & $\begin{array}{c}\text { Total } \\
\text { Pathway } \\
\text { Risk }\end{array}$ & $\begin{array}{c}\text { Total } \\
\text { Exposure } \\
\text { Risk }\end{array}$ \\
\hline ARSENIC & $1 E-06$ & & \\
CHROMUM & $2 E-06$ & &
\end{tabular}

3E-06

Total Cancer Risk

$1 \mathrm{E}-03$

Total Cancer Risk - Site Background Metals

$1 \mathrm{E}-03$ 
Table K.3. ST10/SS14 Hazard Index Estimates

Current Industrial Land Use

Average Exposure Scenario

\begin{tabular}{lcc} 
Hazard & Pathway & Exposure \\
Chemical & Hazard & Hazard \\
Index \\
\hline
\end{tabular}

Exposure Pathway: Ingestion of Groundwater

$\begin{array}{lc}\text { TOLUENE } & 1 \mathrm{E}-01 \\ \text { NAPHTHALENE } & 3 \mathrm{E}-02 \\ \text { ANTIMONY } & 3 \mathrm{E}-01 \\ \text { ARSENIC } & 1 \mathrm{E}+00 \\ \text { BARIUM } & 2 \mathrm{E}-02 \\ \text { CADMIUM } & 3 \mathrm{E}-02 \\ \text { MANGANESE } & 2 \mathrm{E}+01 \\ \text { THALLIUM } & 1 \mathrm{E}-01\end{array}$

$2 E+01$

Exposure Pathway: Inhalation of Volatiles from Groundwater

$\begin{array}{ll}\text { ETHMBENTENE } & 2 \mathrm{E}-02 \\ \text { TOLUENE } & 3 \mathrm{E}-01 \\ \text { XYLENES (TOTAL) } & 6 \mathrm{E}-01\end{array}$

9E-01

Exposure Pathway: Dermal Contact with Groundwater

$\begin{array}{lc}\text { ETHMBENLENE } & 1 \mathrm{E}-01 \\ \text { TOLUENE } & 1 \mathrm{E}+00 \\ \text { NAPHTHALENE } & 3 \mathrm{E}-02 \\ \text { MANGANESE } & 4 \mathrm{E}-02\end{array}$

$1 E+00$

Exposure Pathway: Incidental Ingestion of Surface Water

MANGANESE 3E-02

$3 E-02$

Exposure Pathway: Dermal Contact with Surface Water

$<1 \mathrm{E}-02$

Exposure Pathway: Ingestion of Fish from Hardfill Lake

ARSENIC

MANGANESE
2E-01

$3 E+01$

$3 E+01$ 
Table K.3. ST10/SS14 Hazard Index Estimates Current Industrial Land Use

Average Exposure Scenario

\begin{tabular}{ccc} 
Hazard & Pathway & Exposure \\
Chemical & Hazard & Hazard \\
Quotient & Index & Index \\
\hline
\end{tabular}

Exposure Pathway: Incidental Ingestion of Surface Soils

ARSENIC $1 E-02$

MANGANESE 8E-02

9E-02

Exposure Pathway: Dermal Contact with Surface Soils

$<1 E-02$

Exposure Pathway: Incidental Ingestion of Sediments

$\begin{array}{ll}\text { ARSENIC } & 4 \mathrm{E}-02 \\ \text { MANGANESE } & 2 \mathrm{E}-01\end{array}$

3E-01

Exposure Pathway: Dermal Contact with Sediments

$<1 \mathrm{E}-02$

Exposure Pathway: Incidental Ingestion of Subsurface Soils

$\begin{array}{ll}\text { MANGANESE } & 5 \mathrm{E}-02\end{array}$

$5 E-02$

Exposure Pathway: Dermal Contact with Subsurface Soils

$<1 E-02$

Exposure Pathway: Inhalation of Volatile Contaminants Released from the Soil

$<1 \mathrm{E}-02$

Exposure Pathway: Inhalation of Resuspended Sediments

$\begin{array}{ll}\text { BARIUM } & 2 E-02 \\ \text { CHFOMILM } & 2 E-01 \\ \text { MANGANESE } & 5 E-02\end{array}$

3E-01

Total Exposure Hazard Index

$5 E+01$

Total Exposure Hazard Index-Site Background Metals

$2 E+00$ 
Table K.4. ST10/SS14 Hazard Risk Estimates Current Industrial Land Use

Reasonable Maximum Exposure Scenario

Total

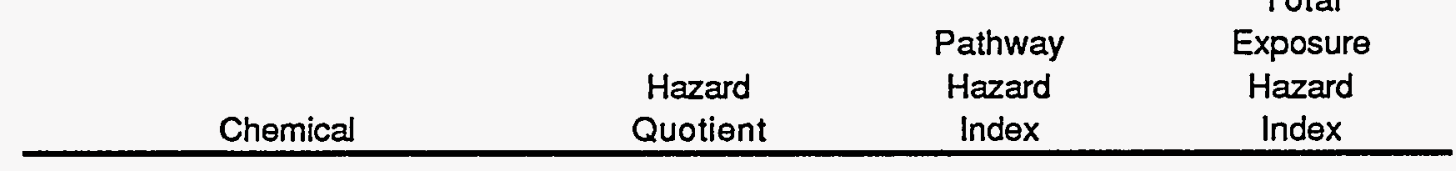

Exposure Pathway: Ingestion of Groundwater

$\begin{array}{ll}\text { TOLUENE } & 1 \mathrm{E}-01 \\ \text { NAPHTHALENE } & 3 \mathrm{E}-02 \\ \text { ANTIMONY } & 3 \mathrm{E}-01 \\ \text { ARSENIC } & 1 \mathrm{E}+00 \\ \text { BAPIUM } & 2 \mathrm{E}-02 \\ \text { CADMIUM } & 3 \mathrm{E}-02 \\ \text { MANGANESE } & 2 \mathrm{E}+01 \\ \text { THALLIUM } & 1 \mathrm{E}-01\end{array}$

$2 E+01$

Exposure Pathway: Inhalation of Volatiles from Groundwater

$\begin{array}{ll}\text { ETHYBENZENE } & 2 E-02 \\ \text { TOLUENE } & 3 E-01 \\ \text { XYLENES (TOTAL) } & 6 E-01\end{array}$

9E-01

Exposure Pathway: Dermal Contact with Groundwater

$\begin{array}{lr}\text { ETHMBENRENE } & 1 \mathrm{E}-01 \\ \text { TOLUENE } & 1 \mathrm{E}+00 \\ \text { NAPHTHALENE } & 4 \mathrm{E}-02 \\ \text { MANGANESE } & 5 \mathrm{E}-02\end{array}$

$1 E+00$

Exposure Pathway: Incidental Ingestion of Surface Water

$\begin{array}{ll}\text { MANGANESE } & 6 E-02\end{array}$

7E-02

Exposure Pathway: Dermal Contact with Surface Water

$$
<1 E-02
$$


Table K.4. ST10/SS14 Hazard Risk Estimates Current Industrial Land Use

Reasonable Maximum Exposure Scenario

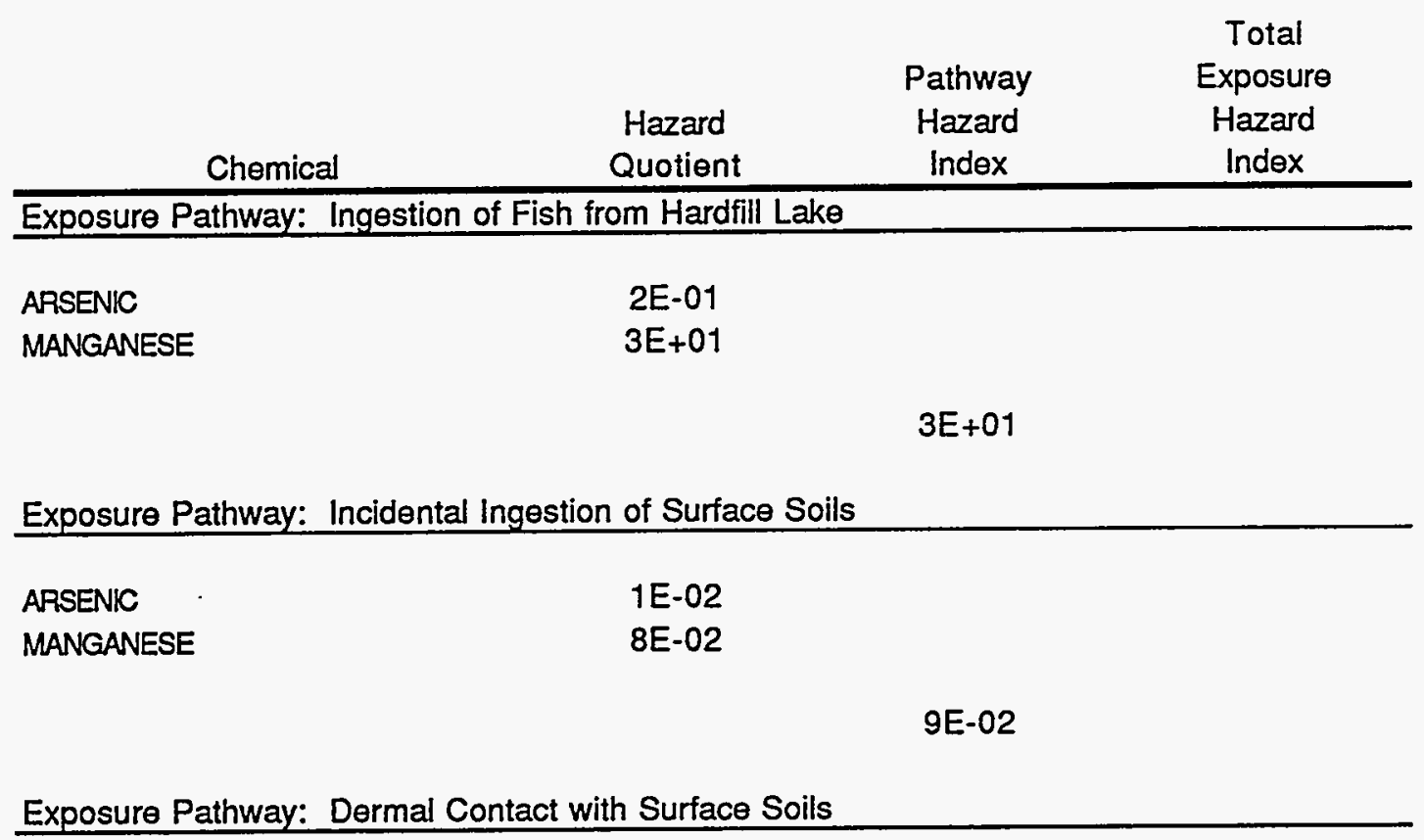

$2 \mathrm{E}-03$

Exposure Pathway: Incidental Ingestion of Sediments

$\begin{array}{ll}\text { ARSENIC } & 4 \mathrm{E}-02 \\ \text { MANGANESE } & 2 \mathrm{E}-01\end{array}$

3E-01

Exposure Pathway: Dermal Contact with Sediments

MANGANESE

$2 \mathrm{E}-02$

3E-02

Exposure Pathway: Incidental Ingestion of Subsurface Soils

MANGANESE

$5 E-02$

$5 \mathrm{E}-02$

Exposure Pathway: Dermal Contact with Subsurface Soils

$<1 \mathrm{E}-02$

Exposure Pathway: Inhalation of Volatile Contaminants Released from the Soil

<1E-02

K.11 
Table K.4. ST10/SS14 Hazard Risk Estimates

Current Industrial Land Use

Reasonable Maximum Exposure Scenario

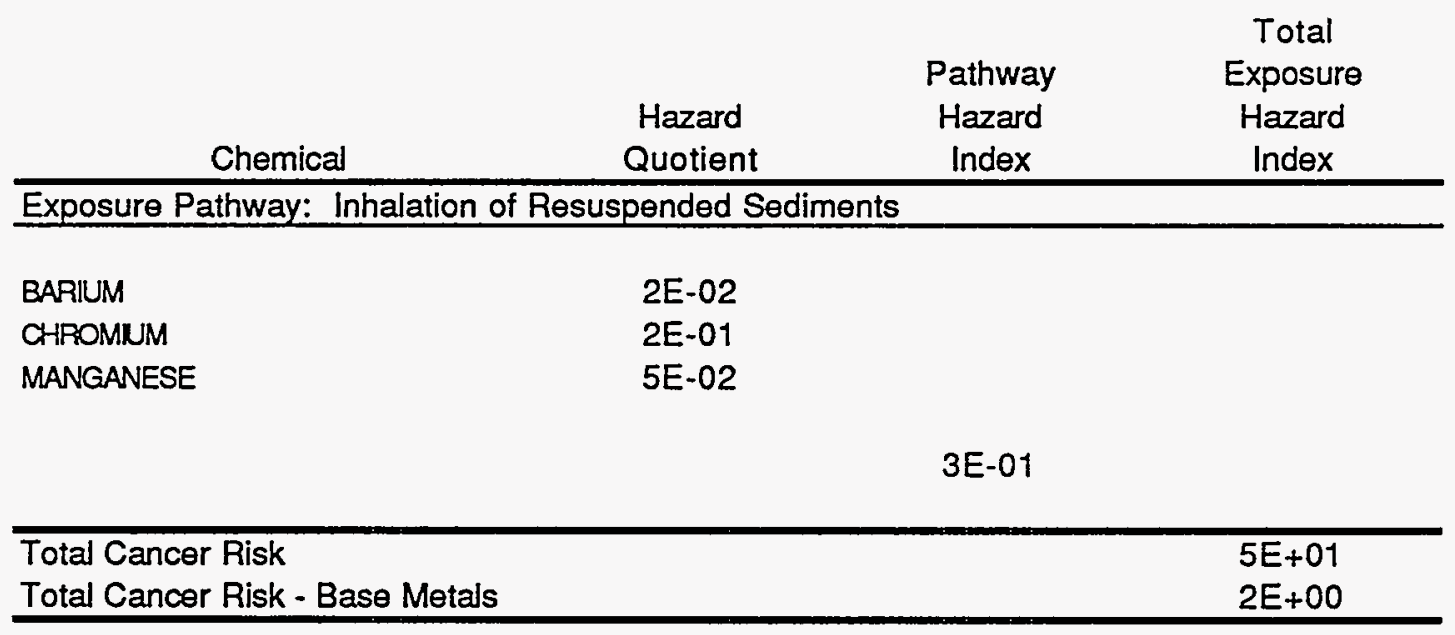


Table K.5. ST10/SS14 Cancer Risk Estimates

Future Industrial Land Use

Average Exposure Scenario

\begin{tabular}{cccc} 
& Chemical- & Total & Total \\
& Specific & Pathway & Exposure \\
Chemical & Risk & Risk & Risk \\
\hline
\end{tabular}

Exposure Pathway: Ingestion of Groundwater

$\begin{array}{ll}\text { BENVENE } & 1 \mathrm{E}-05 \\ \text { ANTHRACENE } & 1 \mathrm{E}-06 \\ \text { ARSENIC } & 7 \mathrm{E}-05 \\ \text { PYPENE } & 7 \mathrm{E}-06 \\ \text { BERYUUM } & 2 \mathrm{E}-06\end{array}$

1E-04

Exposure Pathway: Inhalation of Volatiles from Groundwater

$\begin{array}{ll}\text { BENZENE } & 9 \mathrm{E}-05 \\ \text { ANTHRACENE } & 2 \mathrm{E}-04 \\ \text { PYRENE } & 5 \mathrm{E}-05\end{array}$

Exposure Pathway: Dermal Contact with Groundwater

3E-04

$\begin{array}{ll}\text { BENZENE } & 1 E-05 \\ \text { ANTHRACENE } & 7 E-07 \\ \text { PYRENE } & 6 E-06 \\ \text { ARSENIC } & 2 E-07\end{array}$

2E-05

Exposure Pathway: Incidental Ingestion of Surface Water

$<1 E-07$

Exposure Pathway: Dermal Contact with Surface Water

$<1 E-07$

Exposure Pathway: Ingestion of Fish from Hardfill Lake

ARSENIC

1E-05

1E-05 
Table K.5. ST10/SS14 Cancer Risk Estimates Future Industrial Land Use

Average Exposure Scenario

\begin{tabular}{lccc} 
Chemical & $\begin{array}{c}\text { Chemical- } \\
\text { Specific } \\
\text { Risk }\end{array}$ & $\begin{array}{c}\text { Total } \\
\text { Pathway } \\
\text { Risk }\end{array}$ & $\begin{array}{c}\text { Total } \\
\text { Exposure } \\
\text { Risk }\end{array}$ \\
\hline Exposure Pathway: incidental Ingestion of Surface Soils & \\
\hline
\end{tabular}

8E-07

Exposure Pathway: Dermal Contact with Surface Soils

$<1 E-07$

Exposure Pathway: Incidental Ingestion of Sediments

$\begin{array}{ll}\text { ARSENIC 2E-06 } & \end{array}$

3E-06

Exposure Pathway: Dermal Contact with Sediments

$<1 E-07$

Exposure Pathway: Incidental Ingestion of Subsurface Soils

ARSENIC 4E-07

4E-07

Exposure Pathway: Dermal Contact with Subsurface Soils

$<1 E-07$

Exposure Pathway: Inhalation of Volatile Contaminants Released from the Soil

BENZENE 4E-07

4E-07

Exposure Pathway: Inhalation of Resuspended Sediments

$\begin{array}{ll}\text { ARSENIC } & 4 \mathrm{E}-07 \\ \text { CHROMUM } & 7 \mathrm{E}-07\end{array}$

$1 E-06$

\begin{tabular}{lc}
\hline Total Cancer Risk & $4 E-04$ \\
Total Cancer Risk - Base Metals & $3 E-04$ \\
\hline
\end{tabular}


Table K.6. ST10/SS14 Cancer Risk Estimates

Future Industrial Land Use

Reasonable Maximum Exposure Scenario

\begin{tabular}{cccc} 
& Chemical- & Total & Total \\
& Specific & Pathway & Exposure \\
Chemical & Risk & Risk & Risk \\
\hline
\end{tabular}

Exposure Pathway: Ingestion of Groundwater

$\begin{array}{ll}\text { BENZENE } & 3 E-05 \\ \text { ANTHRACENE } & 3 E-06 \\ \text { PYRENE } & 2 E-05 \\ \text { ARSENIC } & 2 E-04 \\ \text { BERYUUM } & 7 E-06\end{array}$

3E-04

Exposure Pathway: Inhalation of Volatiles from Groundwater

$\begin{array}{ll}\text { BENTENE } & 3 E-04 \\ \text { ANTHRACENE } & 5 E-04 \\ \text { PYREE } & 1 E-04\end{array}$

$8 E-04$

Exposure Pathway: Dermal Contact with Groundwater

$\begin{array}{ll}\text { BENLENE } & 4 \mathrm{E}-05 \\ \text { ANTHRACENE } & 2 \mathrm{E}-06 \\ \text { PYPENE } & 2 \mathrm{E}-05 \\ \text { ARSENIC } & 7 \mathrm{E}-07\end{array}$

7E-05

Exposure Pathway: Incidental Ingestion of Surface Water

$\begin{array}{ll}\text { ARSENIC } & 3 E-07\end{array}$

3E-07

Exposure Pathway: Dermal Contact with Surface Water

$<1 \mathrm{E}-07$

Exposure Pathway: Ingestion of Fish from Hardfill Lake

ARSENIC

4E-05

4E-05

K. 15 
Table K.6. ST10/SS14 Cancer Risk Estimates

Future Industrial Land Use

Reasonable Maximum Exposure Scenario

\begin{tabular}{lccc} 
Chemical & $\begin{array}{c}\text { Chemical- } \\
\text { Specific } \\
\text { Risk }\end{array}$ & $\begin{array}{c}\text { Total } \\
\text { Pathway } \\
\text { Risk }\end{array}$ & $\begin{array}{c}\text { Total } \\
\text { Exposure } \\
\text { Risk }\end{array}$ \\
\hline Exposure Pathway: Incidental Ingestion of Surface Soils & & \\
\hline & & & \\
BENZO(A)PYRENE & $3 E-07$ & & \\
DIBENZ(A,H)ANTHRACENE & $8 \mathrm{E}-08$ & & \\
ARSENIC & $2 \mathrm{E}-06$ &
\end{tabular}

2E-06

Exposure Pathway: Dermal Contact with Surface Soils

BENZO(A)PYRENE 2E-07

ARSENIC 2E-07

6E-07

Exposure Pathway: Incidental Ingestion of Sediments

PYPENE 1E-07

AROCLOR-1260 1E-07

ARSENIC 7E-06

7E-06

Exposure Pathway: Dermal Contact with Sediments

$\begin{array}{ll}\text { PYPENE } & 1 \mathrm{E}-07 \\ \text { AROCLOR-1260 } & 1 \mathrm{E}-07 \\ \text { ARSENIC } & 7 \mathrm{E}-07\end{array}$

1E-06

Exposure Pathway: Incidental Ingestion of Subsurface Soils

ARSENIC 1E-06

1E-06

Exposure Pathway: Dermal Contact with Subsurface Soils

$\begin{array}{ll}\text { ARSENIC } & 1 E-07\end{array}$

$1 E-07$ 
Table K.6. ST10/SS14 Cancer Risk Estimates

Future Industrial Land Use

Reasonable Maximum Exposure Scenario

\begin{tabular}{lccc} 
& Chemical- & Total & Total \\
& Specific & Pathway & Exposure \\
Chemical & Risk & Risk & Risk \\
\hline Exposure Pathway: Inhalation of Volatile Contaminants Released from the Soil & \\
\hline
\end{tabular}

BENTENE

1E-06

1E-06

Exposure Pathway: Inhalation of Resuspended Sediments

$\begin{array}{ll}\text { ARSENIC } & 1 E-06 \\ \text { CHROMIUM } & 2 E-06\end{array}$

3E-06

Total Cancer Risk

$1 \mathrm{E}-03$

Total Cancer Risk - Base Metals

$1 \mathrm{E}-03$

K.17 
Table K.7. ST10/SS14 Hazard Index Estimates Future Industrial Land Use

Average Exposure Scenario

Total Exposure

$\begin{array}{cc}\text { Pathway } & \text { Exposure } \\ \text { Hazard } & \text { Hazard }\end{array}$

Chemical

Hazard

Index

Index

Exposure Pathway: Ingestion of Groundwater

$\begin{array}{lc}\text { TOLUENE } & 1 \mathrm{E}-01 \\ \text { NAPHTHALENE } & 3 \mathrm{E}-02 \\ \text { ANTIMONY } & 3 \mathrm{E}-01 \\ \text { ARSENIC } & 1 \mathrm{E}+00 \\ \text { BARIUM } & 2 \mathrm{E}-02 \\ \text { CADMIUM } & 3 \mathrm{E}-02 \\ \text { MANGANESE } & 2 \mathrm{E}+01 \\ \text { THALIUM } & 1 \mathrm{E}-01\end{array}$

$2 E+01$

Exposure Pathway: Inhalation of Volatiles from Groundwater

$\begin{array}{ll}\text { ETHMBENZENE } & 2 E-02 \\ \text { TOLUENE } & 3 E-01 \\ \text { XYLENES (TOTAL) } & 6 E-01\end{array}$

9E-01

Exposure Pathway: Dermal Contact with Groundwater

$\begin{array}{lr}\text { ETHYLBENENE } & 1 \mathrm{E}-01 \\ \text { TOLUENE } & 1 \mathrm{E}+00 \\ \text { NAPHTHALENE } & 3 \mathrm{E}-02 \\ \text { MANGANESE } & 4 \mathrm{E}-02\end{array}$

$1 E+00$

Exposure Pathway: Incidental Ingestion of Surface Water

MANGANESE 3E-02

3E-02

Exposure Pathway: Dermal Contact with Surface Water

$<1 E-02$ 
Table K.7. ST10/SS14 Hazard Index Estimates Future Industrial Land Use

Average Exposure Scenario

\begin{tabular}{|c|c|c|c|}
\hline Chemical & $\begin{array}{l}\text { Hazard } \\
\text { Quotient }\end{array}$ & $\begin{array}{l}\text { Pathway } \\
\text { Hazard } \\
\text { Index }\end{array}$ & $\begin{array}{l}\text { Total } \\
\text { Exposure } \\
\text { Hazard } \\
\text { Index }\end{array}$ \\
\hline
\end{tabular}

ARSENIC 2E-01

MANGANESE $3 E+01$

$3 E+01$

Exposure Pathway: Incidental Ingestion of Surface Soils

ARSENIC $1 E-02$

MANGANESE 8E-02

9E-02

Exposure Pathway: Dermal Contact with Surface Soils

$<1 E-02$

Exposure Pathway: Incidental Ingestion of Sediments

ARSENIC 4E-02

MANGANESE 2E-01

3E-01

Exposure Pathway: Dermal Contact with Sediments

$\begin{array}{ll}\text { MANGANESE } & 2 \mathrm{E}-02\end{array}$

3E-02

Exposure Pathway: Incidental Ingestion of Subsurface Soils

$\begin{array}{ll}\text { MANGANESE } & 5 \mathrm{E}-02\end{array}$

$5 E-02$

Exposure Pathway: Dermal Contact with Subsurface Soils

$<1 \mathrm{E}-02$

Exposure Pathway: Inhalation of Volatile Contaminants Released from the Soil

$<1 E-02$ 
Table K.7. ST10/SS14 Hazard Index Estimates

Future Industrial Land Use

Average Exposure Scenario

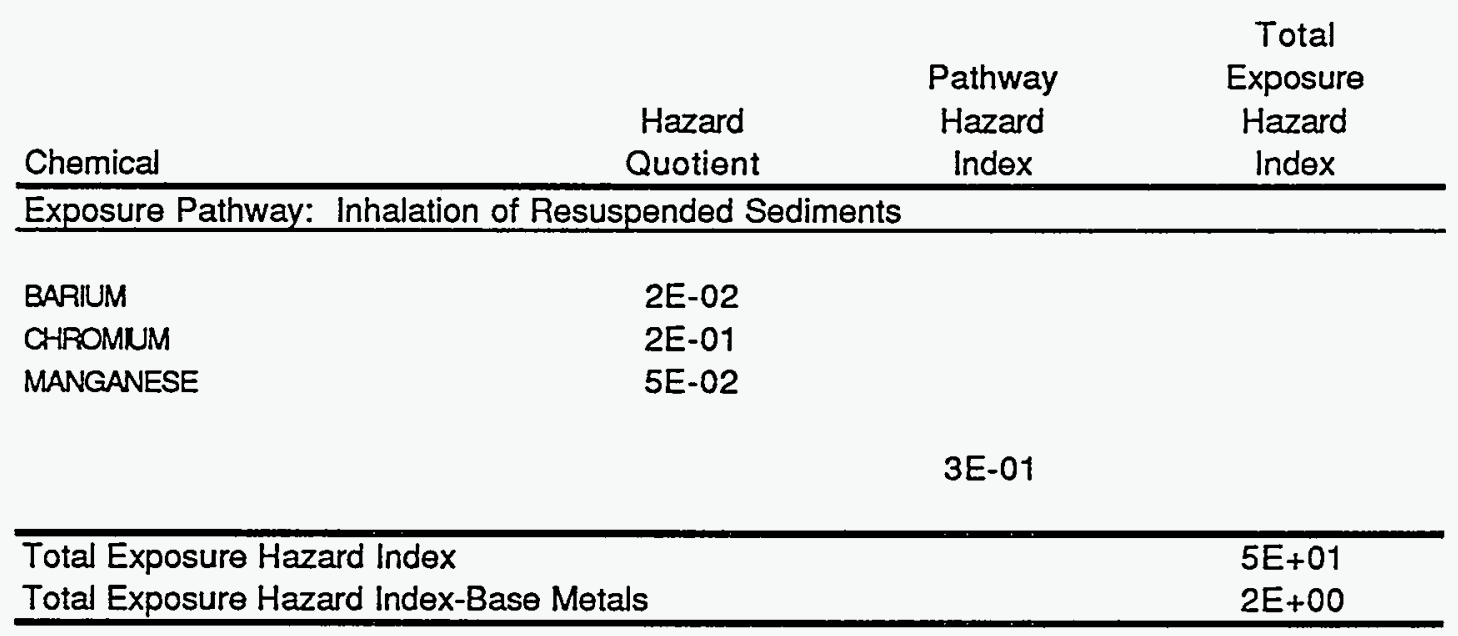


Table K.8. ST10/SS14 Hazard Index Estimates Future Industrial Land Use Reasonable Maximum Exposure Scenario

Chemical

$\begin{array}{ccc}\text { Pathway } & \text { Total } \\ \text { Hazard } & \text { Exposure } \\ \text { Quotient } & \text { Index } & \text { Hazard } \\ \text { Index }\end{array}$

Exposure Pathway: Ingestion of Groundwater

$\begin{array}{ll}\text { TOLUENE } & 1 \mathrm{E}-01 \\ \text { NAPHTHALENE } & 3 \mathrm{E}-02 \\ \text { ANTIMONY } & 3 \mathrm{E}-01 \\ \text { ARSENIC } & 1 \mathrm{E}+00 \\ \text { BARIUM } & 2 \mathrm{E}-02 \\ \text { CADMIUM } & 3 \mathrm{E}-02 \\ \text { MANGANESE } & 2 \mathrm{E}+01 \\ \text { THALIUM } & 1 \mathrm{E}-01\end{array}$

$2 E+01$

Exposure Pathway: Inhalation of Volatiles from Groundwater

$\begin{array}{ll}\text { ETHMBENZENE } & 2 E-02 \\ \text { TOLUENE } & 3 E-01 \\ \text { XYLENES (TOTAL) } & 6 E-01\end{array}$

9E-01

Exposure Pathway: Dermal Contact with Groundwater

$\begin{array}{ll}\text { ETHMBENZENE } & 1 \mathrm{E}-01 \\ \text { TOLUENE } & 1 \mathrm{E}+00 \\ \text { NAPHTHALIENE } & 4 \mathrm{E}-02 \\ \text { MANGANESE } & 5 \mathrm{E}-02\end{array}$

$1 E+00$

Exposure Pathway: Incidental Ingestion of Surface Water

MANGANESE 6E-02

7E-02

Exposure Pathway: Dermal Contact with Surface Water

$<1 E-02$ 
Table K.8. ST10/SS14 Hazard Index Estimates

Future Industrial Land Use

Reasonable Maximum Exposure Scenario

\begin{tabular}{lccc} 
Chemical & $\begin{array}{c}\text { Hazard } \\
\text { Quotient }\end{array}$ & $\begin{array}{c}\text { Pathway } \\
\text { Hazard } \\
\text { Index }\end{array}$ & $\begin{array}{c}\text { Total } \\
\text { Exposure } \\
\text { Hazard } \\
\text { Index }\end{array}$ \\
\hline Exposure Pathway: Ingestion of Fish from Hardfill Lake & \\
\hline ARSENIC & $2 \mathrm{E}-01$ & & \\
MANGANESE & $3 \mathrm{E}+01$ &
\end{tabular}

$3 E+01$

Exposure Pathway: Incidental Ingestion of Surface Soils

ARSENIC $1 E-02$

MANGANESE $\quad 8 \mathrm{E}-02$

9E-02

Exposure Pathway: Dermal Contact with Surface Soils

$2 \mathrm{E}-03$

Exposure Pathway: Incidental Ingestion of Sediments

ARSENIC 4E-02

MANGANESE 2E-01

3E-01

Exposure Pathway: Dermal Contact with Sediments

MANGANESE 2E-02

3E-02

Exposure Pathway: Incidental Ingestion of Subsurface Soils

MANGANESE $\quad 5 E-02$

$5 E-02$

Exposure Pathway: Dermal Contact with Subsurface Soils

$<1 E-02$

Exposure Pathway: Inhalation of Volatile Contaminants Released from the Soil

$<1 E-02$ 
Table K.8. ST10/SS14 Hazard Index Estimates

Future Industrial Land Use

Reasonable Maximum Exposure Scenario

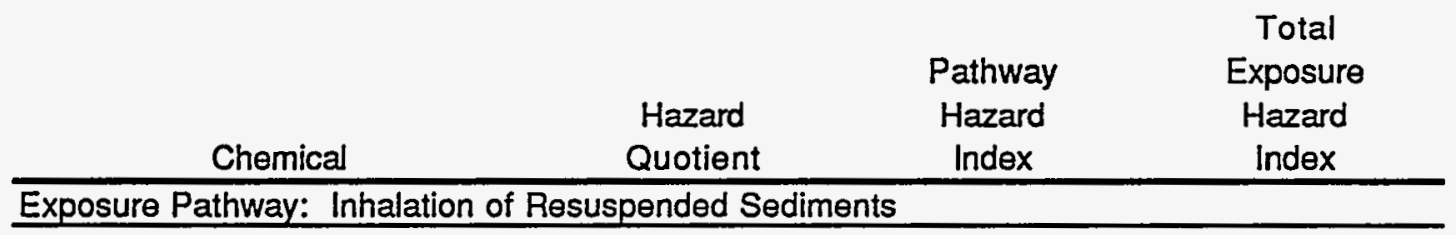

BARIUM

CHROMIUM

MANGANESE
2E-02

2E-01

$5 \mathrm{E}-02$

3E-01 
Table K.9. ST10/SS14 Cancer Risk Estimates

Future Residential Land Use

Average Exposure Scenario

\begin{tabular}{lccc} 
Chemical & $\begin{array}{c}\text { Chemical- } \\
\text { Specific } \\
\text { Risk }\end{array}$ & $\begin{array}{c}\text { Total } \\
\text { Pathway } \\
\text { Risk }\end{array}$ & $\begin{array}{c}\text { Total } \\
\text { Exposure } \\
\text { Risk }\end{array}$ \\
\hline Exposure Pathway: Ingestion of Groundwater & & \\
\hline & & & \\
BENENE & $2 E-05$ & \\
ANTHRACENE & $2 \mathrm{E}-06$ & \\
PYRENE & $1 \mathrm{E}-05$ & \\
ARSENIC & $1 \mathrm{E}-04$ & \\
BERYUUM & $4 \mathrm{E}-06$ &
\end{tabular}

2E-04

Exposure Pathway: Inhalation of Volatiles from Groundwater

$\begin{array}{ll}\text { BENTENE } & 1 \mathrm{E}-04 \\ \text { ANTHRACENE } & 2 \mathrm{E}-04 \\ \text { PYPENE } & 5 \mathrm{E}-05\end{array}$

3E-04

Exposure Pathway: Dermal Contact with Groundwater

$\begin{array}{ll}\text { BENLENE } & 1 \mathrm{E}-05 \\ \text { ANTHRACENE } & 8 \mathrm{E}-07 \\ \text { PYPENE } & 6 \mathrm{E}-06 \\ \text { ARSENIC } & 2 \mathrm{E}-07\end{array}$

2E-05

Exposure Pathway: Incidental Ingestion of Surface Water

$$
<1 \mathrm{E}-07
$$

Exposure Pathway: Dermal Contact with Surface Water

$$
<1 E-07
$$

Exposure Pathway: Ingestion of Fish from Hardfill Lake

ARSENIC 1E-05

1E-05 
Table K.9. ST10/SS14 Cancer Risk Estimates

Future Residential Land Use

Average Exposure Scenario

\begin{tabular}{cccc} 
& $\begin{array}{c}\text { Chemical- } \\
\text { Specific }\end{array}$ & $\begin{array}{c}\text { Total } \\
\text { Cathway }\end{array}$ & $\begin{array}{c}\text { Total } \\
\text { Exposure } \\
\text { Chemical }\end{array}$ \\
Risk & Risk & Risk \\
\hline Exposure Pathway: Incidental Ingestion of Surface Soils & \\
\hline
\end{tabular}

BENZO(A)PYRENE

$2 \mathrm{E}-07$

ARSENIC

$2 E-06$

2E-06

Exposure Pathway: Dermal Contact with Surface Soils

6E-08

Exposure Pathway: Ingestion of Plants Grown in Contaminated Soils

$\begin{array}{ll}\text { BENZO(A)ANTHRACENE } & 2 E-07 \\ \text { BENZO(A)PYRENE } & 7 E-07 \\ \text { BENZO(B)FLUORANTHENE } & 1 \mathrm{E}-07 \\ \text { DIBENZ(A,H)ANTHRACENE } & 5 \mathrm{E}-07 \\ \text { PYRENE } & 2 \mathrm{E}-07 \\ \text { ALDRIN } & 1 \mathrm{E}-07 \\ \text { ARSENIC } & 3 \mathrm{E}-06\end{array}$

$5 E-06$

Exposure Pathway: Incidental Ingestion of Sediments

ARSENIC 6E-06

6E-06

Exposure Pathway: Dermal Contact with Sediments

1E-07

Exposure Pathway: Incidental Ingestion of Subsurface Soils

ARSENIC 9E-07

1E-06

Exposure Pathway: Dermal Contact with Subsurface Soils

$<1 \mathrm{E}-07$ 
Table K.9. ST10/SS14 Cancer Risk Estimates Future Residential Land Use

Average Exposure Scenario

\begin{tabular}{|c|c|c|c|}
\hline Chemical & $\begin{array}{c}\text { Chemical- } \\
\text { Specific } \\
\text { Risk }\end{array}$ & $\begin{array}{c}\text { Total } \\
\text { Pathway } \\
\text { Risk }\end{array}$ & $\begin{array}{c}\text { Total } \\
\text { Exposure } \\
\text { Risk }\end{array}$ \\
\hline \multicolumn{4}{|c|}{ Exposure Pathway: Inhalation of Volatile Contaminants Released from the Soil } \\
\hline \multirow[t]{2}{*}{ BENZENE } & $4 E-07$ & & \\
\hline & & $4 E-07$ & \\
\hline \multicolumn{4}{|c|}{ Exposure Pathway: Inhalation of Resuspended Sediments } \\
\hline ARSENIC & $4 \mathrm{E}-07$ & & \\
\hline \multirow[t]{2}{*}{ CHROMUM } & $8 \mathrm{E}-07$ & & \\
\hline & & $1 E-06$ & \\
\hline Total Cancer Risk & & & 5E-04 \\
\hline Total Cancer Risk - Base Metals & & & $4 E-04$ \\
\hline
\end{tabular}


Table K.10. ST10/SS14 Cancer Risk Estimates

Future Residential Land Use

Reasonable Maximum Exposure Scenario

\begin{tabular}{cccc} 
Chemical & $\begin{array}{c}\text { Chemical- } \\
\text { Specific } \\
\text { Risk }\end{array}$ & $\begin{array}{c}\text { Total } \\
\text { Pathway } \\
\text { Risk }\end{array}$ & $\begin{array}{c}\text { Total } \\
\text { Exposure } \\
\text { Risk }\end{array}$ \\
\hline Exposure Pathway: Ingestion of Groundwater & & \\
\hline
\end{tabular}

$\begin{array}{ll}\text { BENTENE } & 1 \mathrm{E}-04 \\ \text { ANTHRACENE } & 1 \mathrm{E}-05 \\ \text { PYPENE } & 7 \mathrm{E}-05 \\ \text { ARSENIC } & 7 \mathrm{E}-04 \\ \text { BERYUUM } & 2 \mathrm{E}-05\end{array}$

9E-04

Exposure Pathway: Inhalation of Volatiles from Groundwater

$\begin{array}{lr}\text { BENZIENE } & 4 E-04 \\ \text { ANTHRACENE } & 8 E-04 \\ \text { PYPEE } & 2 E-04\end{array}$

$1 \mathrm{E}-03$

Exposure Pathway: Dermal Contact with Groundwater

$\begin{array}{ll}\text { BENIENE } & 7 E-05 \\ \text { ANTHRACENE } & 4 \mathrm{E}-06 \\ \text { PYPENE } & 3 \mathrm{E}-05 \\ \text { ARSENIC } & 1 \mathrm{E}-06\end{array}$

1E-04

Exposure Pathway: Incidental Ingestion of Surface Water

ARSENIC $\quad 5 \mathrm{E}-07$

$5 E-07$

Exposure Pathway: Dermal Contact with Surface Water

$$
<1 E-07
$$

Exposure Pathway: Ingestion of Fish from Hardfill Lake

ARSENIC

$5 \mathrm{E}-05$

$5 E-05$ 
Table K.10. ST10/SS14 Cancer Risk Estimates

Future Residential Land Use

Reasonable Maximum Exposure Scenario

\begin{tabular}{|c|c|c|c|}
\hline Chemical & $\begin{array}{c}\text { Chemical- } \\
\text { Specific } \\
\text { Risk }\end{array}$ & $\begin{array}{c}\text { Total } \\
\text { Pathway } \\
\text { Risk }\end{array}$ & $\begin{array}{c}\text { Total } \\
\text { Exposure } \\
\text { Risk }\end{array}$ \\
\hline \multicolumn{4}{|c|}{ Exposure Pathway: Incidental Ingestion of Surface Soils } \\
\hline BENZO(A)ANTHRACENE & $2 E-07$ & & \\
\hline BENZO(A)PYRENE & 2E-06 & & \\
\hline BENZO(B)FLUORANTHENE & $3 E-07$ & & \\
\hline BENZO(K)FLUORANTHENE & $1 E-07$ & & \\
\hline DIBENZ(A,H)ANTHRACENE & $6 E-07$ & & \\
\hline INDENO(1,2,3-CD)PYRENE & $3 E-07$ & & \\
\hline PYFEE & $2 E-07$ & & \\
\hline ALDRIN & $1 \mathrm{E}-07$ & & \\
\hline ARSENIC & $1 E-05$ & & \\
\hline BERYUUM & $4 E-07$ & & \\
\hline
\end{tabular}

2E-05

Exposure Pathway: Dermal Contact with Surface Soils

$\begin{array}{ll}\text { BENZO(A)ANTHRACENE } & 1 \mathrm{E}-07 \\ \text { BENZO(A)PYRENE } & 5 \mathrm{E}-07 \\ \text { DIBENZ(A,H)ANTHRACENE } & 2 \mathrm{E}-07 \\ \text { ARSENIC } & 4 \mathrm{E}-07\end{array}$

1E-06

Exposure Pathway: Ingestion of Plants Grown in Contaminated Soils

$\begin{array}{ll}\text { BENZO(A)ANTHRACENE } & \text { 7E-07 } \\ \text { BENZO(A)PYRENE } & 3 \mathrm{E}-06 \\ \text { BENZO(B)FLUORANTHENE } & 6 \mathrm{E}-07 \\ \text { BENZO(K)FLUORANTHENE } & 2 \mathrm{E}-07 \\ \text { DIBENZ(A,H)ANTHRACENE } & 2 \mathrm{E}-06 \\ \text { INDENO(1,2,3-CD)PYRENE } & 3 \mathrm{E}-07 \\ \text { PYPENE } & 9 \mathrm{E}-07 \\ \text { ALDRIN } & 5 \mathrm{E}-07 \\ \text { ARSENIC } & 1 \mathrm{E}-05\end{array}$

2E-05

Exposure Pathway: Incidental Ingestion of Sediments

$\begin{array}{ll}\text { BENZO(A)ANTHRACENE } & 3 E-07 \\ \text { BENZO(A)PYRENE } & 5 E-07 \\ \text { BENZO(B)FLUORANTHENE } & 3 E-07 \\ \text { PYPENE } & 8 E-07 \\ \text { AROCLOR-1260 } & 8 E-07 \\ \text { ARSENIC } & 5 E-05\end{array}$


Table K.10. ST10/SS14 Cancer Risk Estimates

Future Residential Land Use

Reasonable Maximum Exposure Scenario

\begin{tabular}{lccc} 
Chemical & $\begin{array}{c}\text { Chemical- } \\
\text { Specific } \\
\text { Risk }\end{array}$ & $\begin{array}{c}\text { Total } \\
\text { Pathway } \\
\text { Risk }\end{array}$ & $\begin{array}{c}\text { Total } \\
\text { Exposure } \\
\text { Risk }\end{array}$ \\
\hline BERYUUM & $6 \mathrm{E}-07$ & & \\
& & $6 \mathrm{G}-05$ &
\end{tabular}

Exposure Pathway: Dermal Contact with Sediments

$\begin{array}{ll}\text { BENZO(A)PYRENE } & 1 \mathrm{E}-07 \\ \text { PYRENE } & 2 \mathrm{E}-07 \\ \text { AROCLOR-1260 } & 2 \mathrm{E}-07 \\ \text { ARSENIC } & 2 \mathrm{E}-06\end{array}$

2E-06

Exposure Pathway: Incidental Ingestion of Subsurface Soils

ARSENIC 8E-06

9E-06

Exposure Pathway: Dermal Contact with Subsurface Soils

ARSENIC 2E-07

3E-07

Exposure Pathway: Inhalation of Volatile Contaminants Released from the Soil

BENTENE

1E-06

1E-06

Exposure Pathway: Inhalation of Resuspended Sediments

$\begin{array}{ll}\text { ARSENIC } & 1 E-06 \\ \text { CHROMUM } & 2 E-06\end{array}$

3E-06

Total Cancer Risk

3E-03

Total Cancer Risk - Background Metals

$2 \mathrm{E}-03$ 
Table K.11. ST10/SS14 Hazard Index Estimates

Future Residential Land Use

Average Exposure Scenario

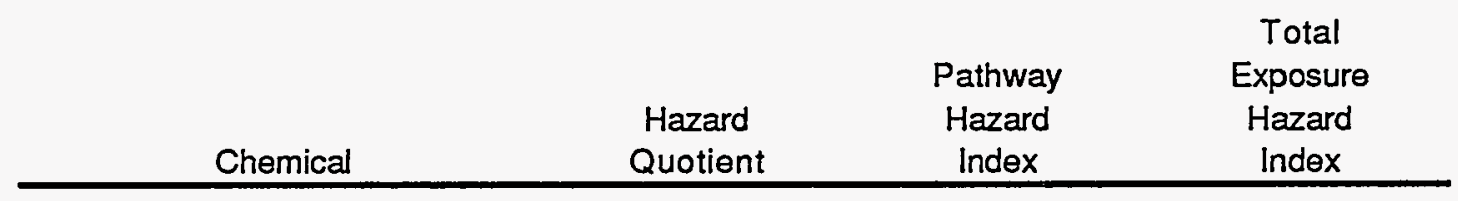

Exposure Pathway: Ingestion of Groundwater

\begin{tabular}{lc}
\hline ETHMBENZENE & $1 \mathrm{E}-02$ \\
TOLUENE & $2 \mathrm{E}-01$ \\
NAPHTHALENE & $5 \mathrm{E}-02$ \\
ANTIMONY & $5 \mathrm{E}-01$ \\
ARSENIC & $2 \mathrm{E}+00$ \\
BARIUM & $4 \mathrm{E}-02$ \\
CADMIUM & $5 \mathrm{E}-02$ \\
MANGANESE & $2 \mathrm{E}+01$ \\
THALLIUM & $2 \mathrm{E}-01$
\end{tabular}

$3 E+01$

Exposure Pathway: Inhalation of Volatiles from Groundwater

$\begin{array}{ll}\text { ETHMBENZENE } & 2 \mathrm{E}-02 \\ \text { TOLUENE } & 3 \mathrm{E}-01 \\ \text { XYLENES (TOTAL) } & 6 \mathrm{E}-01\end{array}$

$1 E+00$

Exposure Pathway: Dermal Contact with Groundwater

$\begin{array}{lc}\text { ETHMBENZENE } & 1 \mathrm{E}-01 \\ \text { TOLUENE } & 1 \mathrm{E}+00 \\ \text { NAPHTHALENE } & 3 \mathrm{E}-02 \\ \text { MANGANESE } & 4 \mathrm{E}-02\end{array}$

$1 E+00$

Exposure Pathway: Incidental Ingestion of Surface Water

MANGANESE

$5 \mathrm{E}-02$

$5 E-02$

Exposure Pathway: Dermal Contact with Surface Water

$$
<1 E-02
$$

Exposure Pathway: Ingestion of Fish from Hardfill Lake

ARSENIC

2E-01 
Table K.11. ST10/SS14 Hazard Index Estimates Future Residential Land Use

Average Exposure Scenario

\begin{tabular}{llc} 
Chemical & $\begin{array}{c}\text { Pathway } \\
\text { Hazard } \\
\text { Index }\end{array}$ & $\begin{array}{c}\text { Total } \\
\text { Exposure } \\
\text { Hazard } \\
\text { Index }\end{array}$ \\
\hline MANGANESE & $3 \mathrm{E}+01$ &
\end{tabular}

$3 E+01$

Exposure Pathway: Incidental Ingestion of Surface Soils

ARSENIC 1E-02

MANGANESE 1E-01

1E-01

Exposure Pathway: Dermal Contact with Surface Soils

$<1 \mathrm{E}-02$

Exposure Pathway: Ingestion of Plants Grown in Contaminated Soils

ARSENIC 4E-02

MANGANESE $\quad 9 E+00$

$9 E+00$

Exposure Pathway: Incidental Ingestion of Sediments

$\begin{array}{ll}\text { ARSENIC } & 4 \mathrm{E}-02 \\ \text { MANGANESE } & 3 \mathrm{E}-01\end{array}$

3E-01

Exposure Pathway: Dermal Contact with Sediments

$<1 \mathrm{E}-02$

Exposure Pathway: Incidental Ingestion of Subsurface Soils

ARSENIC

MANGANESE

1E-02

1E-01

1E-01

Exposure Pathway: Dermal Contact with Subsurface Soils

$<1 E-02$ 
Table K.11. ST10/SS14 Hazard Index Estimates

Future Residential Land Use

Average Exposure Scenario

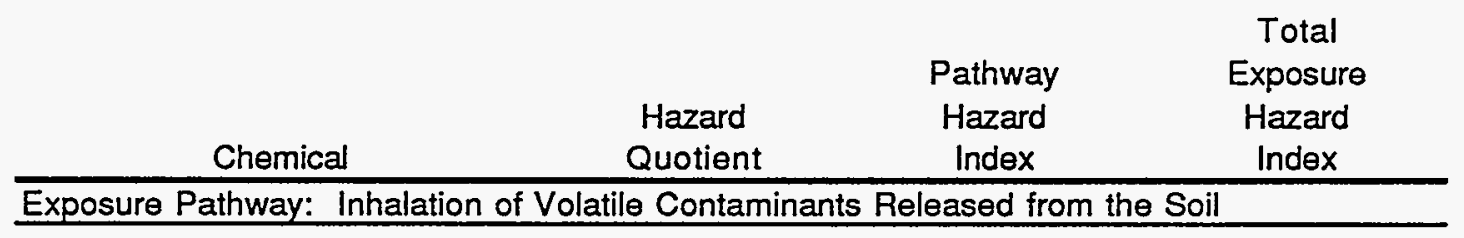

$<1 E-02$

Exposure Pathway: Inhalation of Resuspended Sediments

$\begin{array}{ll}\text { BARIUM } & 2 \mathrm{E}-02 \\ \text { CHPOMIUM } & 3 \mathrm{E}-01 \\ \text { MANGANESE } & 6 \mathrm{E}-02\end{array}$

$4 E-01$

Total Exposure Hazard Index

$7 \mathrm{E}+01$

Total Exposure Hazard Index-Base Metals

$3 \mathrm{E}+00$ 
Table K.12. ST10/SS14 Hazard Index Estimates

Future Residential Scenario

Reasonable Maximum Exposure Scenario

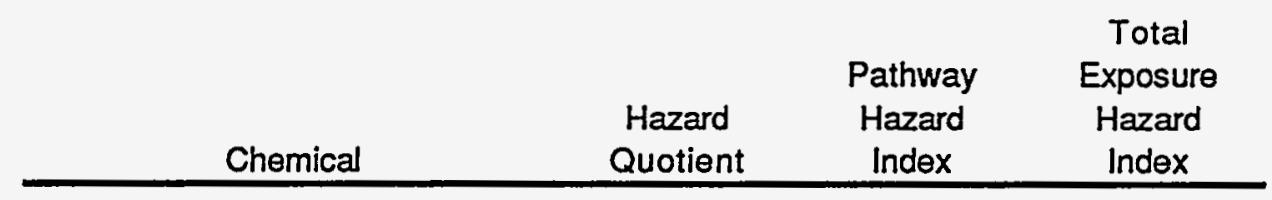

Exposure Pathway: Ingestion of Groundwater

$\begin{array}{lc}\text { ETHMBENZENE } & 2 \mathrm{E}-02 \\ \text { TOLUENE } & 3 \mathrm{E}-01 \\ \text { NAPHTHALENE } & 9 \mathrm{E}-02 \\ \text { ANTIMONY } & 9 \mathrm{E}-01 \\ \text { ARSENIC } & 3 \mathrm{E}+00 \\ \text { BARIUM } & 7 \mathrm{E}-02 \\ \text { CADMIUM } & 9 \mathrm{E}-02 \\ \text { MANGANESE } & 4 \mathrm{E}+01 \\ \text { THALLIUM } & 3 \mathrm{E}-01\end{array}$

$5 E+01$

Exposure Pathway: Inhalation of Volatiles from Groundwater

$\begin{array}{ll}\text { ETHMBENZENE } & 3 E-02 \\ \text { TOLUENE } & 4 \mathrm{E}-01 \\ \text { XYLENES (TOTAL) } & 8 \mathrm{E}-01\end{array}$

$1 E+00$

Exposure Pathway: Dermal Contact with Groundwater

ETHMBENZENE

TOLUENE

NAPHTHALENE

MANGANESE
2E-01

$2 \mathrm{E}+00$

$5 \mathrm{E}-02$

$7 \mathrm{E}-02$

$$
2 \mathrm{E}+00
$$

Exposure Pathway: Incidental Ingestion of Surface Water

MANGANESE

9E-02

9E-02

Exposure Pathway: Dermal Contact with Surface Water

$$
<1 E-02
$$

Exposure Pathway: Ingestion of Fish from Hardfill Lake

ARSENIC 2E-01


Table K.12. ST10/SS14 Hazard Index Estimates

Future Residential Scenario

Reasonable Maximum Exposure Scenario

\begin{tabular}{lccc} 
Chemical & $\begin{array}{c}\text { Hazard } \\
\text { Quotient }\end{array}$ & $\begin{array}{c}\text { Pathway } \\
\text { Hazard } \\
\text { Index }\end{array}$ & $\begin{array}{c}\text { Total } \\
\text { Exposure } \\
\text { Hazard } \\
\text { Index }\end{array}$ \\
\hline MANGANESE & $3 E+01$ & & \\
& & $3 E+01$ &
\end{tabular}

Exposure Pathway: Incidental Ingestion of Surface Soils

$\begin{array}{ll}\text { ARSENIC } & 6 \mathrm{E}-02 \\ \text { MANGANESE } & 5 \mathrm{E}-01\end{array}$

6E-01

Exposure Pathway: Dermal Contact with Surface Soils

MANGANESE 2E-02

2E-02

Exposure Pathway: Ingestion of Plants Grown in Contaminated Soils

ARSENIC 6E-02

MANGANESE $1 E+01$

$1 E+01$

Exposure Pathway: Incidental Ingestion of Sediments

$\begin{array}{lr}\text { ARSENIC } & 2 E-01 \\ \text { BARIUM } & 1 E-02 \\ \text { CHROMUM } & 1 E-02 \\ \text { MANGANESE } & 2 E+00\end{array}$

$2 E+00$

Exposure Pathway: Dermal Contact with Sediments

MANGANESE

4E-02

$5 E-02$

Exposure Pathway: Incidental Ingestion of Subsurface Soils

ARSENK

MANGANESE
4E-02

$3 E-01$ 
Table K.12. ST10/SS14 Hazard Index Estimates Future Residential Scenario

Reasonable Maximum Exposure Scenario

\begin{tabular}{ccc} 
& Potal \\
Chemical & $\begin{array}{c}\text { Pathway } \\
\text { Hazard } \\
\text { Quotient }\end{array}$ & $\begin{array}{c}\text { Exposure } \\
\text { Hazard } \\
\text { Index }\end{array}$ \\
\hline Exposure Pathway: Dermal Contact with Subsurface Soils & \\
\hline
\end{tabular}

$1 \mathrm{E}-02$

Exposure Pathway: Inhalation of Volatile Contaminants Released from the Soil

$$
<1 \mathrm{E}-02
$$

Exposure Pathway: Inhalation of Resuspended Sediments

$\begin{array}{ll}\text { BARIUM } & 2 \mathrm{E}-02 \\ \text { CHROMUM } & 2 \mathrm{E}-01 \\ \text { MANGANESE } & 5 \mathrm{E}-02\end{array}$

3E-01

Total Exposure Hazard Index

$1 E+02$

Total Exposure Hazard Index-Site Background Metals

$4 \mathrm{E}+00$ 
Table K.13. ST11 Cancer Risk Estimates

Current Industrial Land Use

Average Exposure Scenario

Chemical-

Specific

Total

Risk

Pathway

Total

Exposure

Exposure Pathway: Incidental Ingestion of Surface Water

$$
<1 \mathrm{E}-07
$$

Exposure Pathway: Ingestion of Fish from Garrison Slough

$$
<1 E-07
$$

Exposure Pathway: Incidental Ingestion of Surface Soils
ARSENIC
1E-06

1E-06

Exposure Pathway: Dermal Contact with Surface Soils

$<1 E-07$

Exposure Pathway: Incidental Ingestion of Subsurface Soils

$<1 \mathrm{E}-07$

Exposure Pathway: Dermal Contact with Subsurface Soils

$<1 \mathrm{E}-07$

Exposure Pathway: Inhalation of Volatile Contaminants Released from the Soil

$<1 E-07$

Exposure Pathway: Inhalation of Resuspended Sediments

$<1 \mathrm{E}-07$

Total Cancer Risk

2E-06

Total Cancer Risk - Site Background Metals

$4 \mathrm{E}-09$ 
Table K.14. ST11 Cancer Risk Estimates

Current Industrial Land Use

Reasonable Maximum Exposure Scenario

\begin{tabular}{cccc} 
& Chemical- & Total & Total \\
& Specific & Pathway & Exposure \\
Chemical & Risk & Risk & Risk \\
\hline
\end{tabular}

Exposure Pathway: Incidental Ingestion of Surface Water

$<1 E-07$

Exposure Pathway: Ingestion of Fish from Garrison Slough

$<1 E-07$

Exposure Pathway: Incidental ingestion of Surface Soils

$\begin{array}{ll}\text { ARSENIC } & 4 E-06 \\ \text { BERYUUM } & 3 E-07\end{array}$

$4 \mathrm{E}-06$

Exposure Pathway: Dermal Contact with Surface Soils

ARSENIC $3 E-07$

4E-07

Exposure Pathway: Incidental Ingestion of Subsurface Soils

ARSENIC 3E-06

$$
\text { 3E-06 }
$$

Exposure Pathway: Dermal Contact with Subsurface Soils

$<1 \mathrm{E}-07$

Exposure Pathway: Inhalation of Volatile Contaminants Released from the Soil

$<1 E-07$

Exposure Pathway: Inhalation of Resuspended Sediments

$<1 E-07$

Total Cancer Risk

7E-06

Total Cancer Risk - Site Background Metals

$2 E-08$ 
Table K.15. ST11 Hazard Index Estimates Current Industrial Land Use Average Exposure Scenario

\begin{tabular}{|c|c|c|c|}
\hline Chemical & $\begin{array}{l}\text { Hazard } \\
\text { Quotient }\end{array}$ & $\begin{array}{c}\text { Pathway } \\
\text { Hazard } \\
\text { Index }\end{array}$ & $\begin{array}{c}\text { Exposure } \\
\text { Hazard } \\
\text { Index }\end{array}$ \\
\hline
\end{tabular}

Exposure Pathway: Incidental Ingestion of Surface Water

$<1 E-02$

Exposure Pathway: Ingestion of Fish from Garrison Slough

$<1 E-02$

Exposure Pathway: Incidental Ingestion of Surface Soils

ARSENIC 2E-02

MANGANESE 1E-01

2E-01

Exposure Pathway: Dermal Contact with Surface Soils

$<1 E-02$

Exposure Pathway: Incidental Ingestion of Subsurface Soils

ARSENIC 1E-02

MANGANESE $\quad 1 E-01$

1E-01

Exposure Pathway: Dermal Contact with Subsurface Soils

$<1 E-02$

Exposure Pathway: Inhalation of Volatile Contaminants Released from the Soil

$<1 E-02$

Exposure Pathway: Inhalation of Resuspended Sediments

$$
<1 E-02
$$


Table K.16. ST11 Hazard Risk Estimates

Current Industrial Land Use

Reasonable Maximum Exposure Scenario

Total

$\begin{array}{cc}\text { Pathway } & \text { Exposure } \\ \text { Hazard } & \text { Hazard }\end{array}$

Hazard

Quotient

Index

Index

Exposure Pathway: Incidental Ingestion of Surface Water

$<1 \mathrm{E}-02$

Exposure Pathway: Ingestion of Fish from Garrison Slough

$<1 \mathrm{E}-02$

Exposure Pathway: Incidental Ingestion of Surface Soils

$\begin{array}{ll}\text { ARSENIC } & 2 E-02 \\ \text { MANGANESE } & 1 E-01\end{array}$

Exposure Pathway: Dermal Contact with Surface Soils

MANGANESE $\quad 1 E-02$

2E-02

Exposure Pathway: Incidental Ingestion of Subsurface Soils

$\begin{array}{ll}\text { ARSENIC } & 1 \mathrm{E}-02 \\ \text { MANGANESE } & 1 \mathrm{E}-01\end{array}$

1E-01

Exposure Pathway: Dermal Contact with Subsurface Soils

MANGANESE 1E-02

1E-02

Exposure Pathway: Inhalation of Volatile Contaminants Released from the Soil

$<1 E-02$

Exposure Pathway: Inhalation of Resuspended Sediments

$<1 E-02$

Total Cancer Risk - Site Background Metals

2E-04 
Table K.17. ST11 Cancer Risk Estimates

Future Industrial Land Use

Average Exposure Scenario

\begin{tabular}{cccc} 
& Chemical- & Total & Total \\
& Specific & Pathway & Exposure \\
Chemical & Risk & Risk & Risk \\
\hline
\end{tabular}

Exposure Pathway: Ingestion of Groundwater

ARSENIC $\quad 9 E-05$

9E-05

Exposure Pathway: Inhalation of Volatiles from Groundwater

BENZENE 3E-07

3E-07

Exposure Pathway: Dermal Contact with Groundwater

$\begin{array}{ll}\text { ARSENIC } & 2 \mathrm{E}-07\end{array}$

3E-07

Exposure Pathway: Incidental Ingestion of Surface Water

$<1 \mathrm{E}-07$

Exposure Pathway: Ingestion of Fish from Garrison Slough

$<1 \mathrm{E}-07$

Exposure Pathway: Incidental Ingestion of Surface Soils

ARSENIC $\quad 1 E-06$

1E-06

Exposure Pathway: Dermal Contact with Surface Soils

$<1 E-07$

Exposure Pathway: Incidental Ingestion of Subsurface Soils

ARSENIC $9 E-07$

9E-07 
Table K.17. ST11 Cancer Risk Estimates

Future Industrial Land Use

Average Exposure Scenario

\begin{tabular}{|c|c|c|c|}
\hline Chemical & $\begin{array}{l}\text { Chemical- } \\
\text { Specific } \\
\text { Risk }\end{array}$ & $\begin{array}{c}\text { Total } \\
\text { Pathway } \\
\text { Risk }\end{array}$ & $\begin{array}{c}\text { Total } \\
\text { Exposure } \\
\text { Risk } \\
\end{array}$ \\
\hline Exposure & nal Contact & surface Sol & \\
\hline
\end{tabular}

Exposure Pathway: Inhalation of Volatile Contaminants Released from the Soil

$<1 E-07$

Exposure Pathway: Inhalation of Resuspended Sediments

$<1 \mathrm{E}-07$

Total Cancer Risk

Total Cancer Risk - Site Background Metals
1E-04

4E-07 
Table K.18. ST11 Cancer Risk Estimates

Future Industrial Land Use

Reasonable Maximum Exposure Scenario

\begin{tabular}{cccc} 
& Chemical- & Total & Total \\
& Specific & Pathway & Exposure \\
Chemical & Risk & Risk & Risk \\
\hline
\end{tabular}

Exposure Pathway: Ingestion of Groundwater

ARSENIC 3E-04

3E-04

Exposure Pathway: Inhalation of Volatiles from Groundwater

BENZENE $\quad 8 \mathrm{E}-07$

8E-07

Exposure Pathway: Dermal Contact with Groundwater

BENEENE 1E-07

ARSENIC $9 E-07$

1E-06

Exposure Pathway: Incidental Ingestion of Surface Water

$<1 \mathrm{E}-07$

Exposure Pathway: Ingestion of Fish from Garrison Slough

$<1 \mathrm{E}-07$

Exposure Pathway: Incidental Ingestion of Surface Soils

$\begin{array}{ll}\text { ARSENIC } & 3 E-06 \\ \text { BERYLUUM } & 2 E-07\end{array}$

4E-06

Exposure Pathway: Dermal Contact with Surface Soils

$\begin{array}{ll}\text { ARSENIC } & 3 E-07\end{array}$

4E-07 
Table K.18. ST11 Cancer Risk Estimates

- Future Industrial Land Use

Reasonable Maximum Exposure Scenario

\begin{tabular}{lccc} 
& Chemical- & Total & Total \\
& Specific & Pathway & Exposure \\
Chemical & Risk & Risk & Risk \\
\hline Exposure Pathway: & Incidental lngestion of Subsurface Soils & \\
\hline
\end{tabular}

ARSENIC 3E-06

3E-06

Exposure Pathway: Dermal Contact with Subsurface Soils

$<1 \mathrm{E}-07$

Exposure Pathway: Inhalation of Volatile Contaminants Released from the Soil

$<1 E-07$

Exposure Pathway: Inhalation of Resuspended Sediments

$<1 \mathrm{E}-07$

Total Cancer Risk - Site Background Metals

$1 \mathrm{E}-06$ 
Table K.19. ST11 Hazard Index Estimates

Future Industrial Land Use

Average Exposure Scenario

\begin{tabular}{|c|c|c|c|}
\hline Chemical & $\begin{array}{l}\text { Hazard } \\
\text { Quotient }\end{array}$ & $\begin{array}{l}\text { Pathway } \\
\text { Hazard } \\
\text { Index }\end{array}$ & $\begin{array}{l}\text { Total } \\
\text { Exposure } \\
\text { Hazard } \\
\text { Index }\end{array}$ \\
\hline
\end{tabular}

Exposure Pathway: Ingestion of Groundwater

$\begin{array}{ll}\text { ARSENIC } & 2 E+01 \\ \text { BARIUM } & 3 E-02 \\ \text { MANGANESE } & 1 E+01 \\ \text { THALIUM } & 7 E-02\end{array}$

\section{$2 E+01$}

Exposure Pathway: Inhalation of Volatiles from Groundwater

$<1 \mathrm{E}-02$

Exposure Pathway: Dermal Contact with Groundwater

MANGANESE 3E-02

4E-02

Exposure Pathway: Incidental Ingestion of Surface Water

$<1 E-02$

Exposure Pathway: Ingestion of Fish from Garrison Slough

$<1 E-02$

Exposure Pathway: Incidental Ingestion of Surface Soils

ARSENIC

$2 \mathrm{E}-02$

MANGANESE

$1 E-01$

2E-01

Exposure Pathway: Dermal Contact with Surface Soils

$<1 E-02$

Exposure Pathway: Incidental Ingestion of Subsurface Soils

ARSENIC

MANGANESE
$1 E-02$

$1 E-01$ 
Table K.19. ST11 Hazard Index Estimates

Future Industrial Land Use

Average Exposure Scenario

Total

Pathway

Exposure

Hazard

Hazard

Hazard

Chemical

Quotient

Index

Index

Exposure Pathway: Dermal Contact with Subsurface Soils

$<1 E-02$

Exposure Pathway: Inhalation of Volatile Contaminants Released from the Soil

$<1 E-02$

Exposure Pathway: Inhalation of Resuspended Sediments

$<1 E-02$

Total Exposure Hazard Index

$2 \mathrm{E}+01$

Total Exposure Hazard Index-Background Metals

$2 \mathrm{E}-04$ 
Table K.20. ST11 Hazard Index Estimates

Future Industrial Land Use

Reasonable Maximum Exposure Scenario

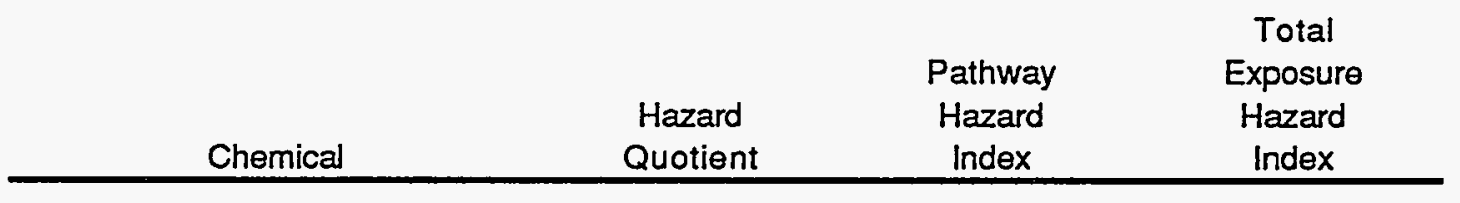

Exposure Pathway: Ingestion of Groundwater

$\begin{array}{ll}\text { ARSENIC } & 2 E+01 \\ \text { BARIUM } & 3 E-02 \\ \text { MANGANESE } & 1 E+01 \\ \text { THALIUM } & 7 E-02\end{array}$

$2 E+01$

Exposure Pathway: Inhalation of Volatiles from Groundwater

$$
<1 E-02
$$

Exposure Pathway: Dermal Contact with Groundwater

MANGANESE 5E-02

$5 E-02$

Exposure Pathway: Incidental Ingestion of Surface Water

$$
<1 E-02
$$

Exposure Pathway: Ingestion of Fish from Garrison Slough

$$
<1 E-02
$$

Exposure Pathway: Incidental Ingestion of Surface Soils

$\begin{array}{ll}\text { ARSENIC } & 2 \mathrm{E}-02 \\ \text { MANGANESE } & 1 \mathrm{E}-01\end{array}$

2E-01

Exposure Pathway: Dermal Contact with Surface Soils

MANGANESE $1 \mathrm{E}-02$

$2 E-02$

Exposure Pathway: Incidental Ingestion of Subsurface Soils

ARSENIC $1 E-02$ 
Table K.20. ST11 Hazard Index Estimates

Future Industrial Land Use

Reasonable Maximum Exposure Scenario

\begin{tabular}{|c|c|c|c|}
\hline Chemical & $\begin{array}{l}\text { Hazard } \\
\text { Quotient }\end{array}$ & $\begin{array}{l}\text { Pathway } \\
\text { Hazard } \\
\text { Index }\end{array}$ & $\begin{array}{c}\text { Total } \\
\text { Exposure } \\
\text { Hazard } \\
\text { Index }\end{array}$ \\
\hline MANGANESE & $1 E-01$ & & \\
\hline
\end{tabular}

$1 E-01$

Exposure Pathway: Dermal Contact with Subsurface Soils

MANGANESE $1 E-02$

$$
1 \mathrm{E}-02
$$

Exposure Pathway: Inhalation of Volatile Contaminants Released from the Soil

$$
<1 E-02
$$

Exposure Pathway: Inhalation of Resuspended Sediments

$$
<1 E-02
$$


Table K.21. ST11 Cancer Risk Estimates

Future Residential Land Use

Average Exposure Scenario

\begin{tabular}{cccc} 
Chemical & $\begin{array}{c}\text { Chemical- } \\
\text { Specific } \\
\text { Risk }\end{array}$ & $\begin{array}{c}\text { Total } \\
\text { Pathway } \\
\text { Risk }\end{array}$ & $\begin{array}{c}\text { Total } \\
\text { Exposure } \\
\text { Risk }\end{array}$ \\
\hline Exposure Pathway: Ingestion of Groundwater & \\
\hline
\end{tabular}

ARSENIC $1 E-04$

$1 E-04$

Exposure Pathway: Inhalation of Volatiles from Groundwater

BENEENE $\quad 3 E-07$

3E-07

Exposure Pathway: Dermal Contact with Groundwater

$\begin{array}{ll}\text { ARSENIC } & 2 \mathrm{E}-07\end{array}$

3E-07

Exposure Pathway: Incidental Ingestion of Surface Water

$<1 \mathrm{E}-07$

Exposure Pathway: Ingestion of Fish from Garrison Slough

$<1 E-07$

Exposure Pathway: Incidental Ingestion of Surface Soils

ARSENIC 3E-06

BERYUUM $2 E-07$

3E-06

Exposure Pathway: Dermal Contact with Surface Soils

$<1 \mathrm{E}-07$

Exposure Pathway: Ingestion of Plants Grown in Contaminated Soils

ARSENIC 6E-06

BERYUUM $\quad 1 E-07$

$6 \mathrm{E}-06$ 
Table K.21. ST11 Cancer Risk Estimates

Future Residential Land Use

Average Exposure Scenario

\begin{tabular}{lccc} 
& $\begin{array}{c}\text { Chemical- } \\
\text { Specific } \\
\text { Risk }\end{array}$ & $\begin{array}{c}\text { Total } \\
\text { Pathway } \\
\text { Risk }\end{array}$ & $\begin{array}{c}\text { Total } \\
\text { Exposure } \\
\text { Risk }\end{array}$ \\
\hline Exposure Pathway: & Incidental Ingestion of Subsurface Soils & \\
ARSENIC & $2 \mathrm{E}-06$
\end{tabular}

$2 \mathrm{E}-06$

Exposure Pathway: Dermal Contact with Subsurface Soils

$<1 E-07$

Exposure Pathway: Inhalation of Volatile Contaminants Released from the Soil

$<1 E-07$

Exposure Pathway: Inhalation of Resuspended Sediments

$<1 E-07$

Total Cancer Risk

2E-04

Total Cancer Risk - Background Metals

$4 \mathrm{E}-07$ 
Table K.22. ST11 Cancer Risk Estimates

Future Residential Land Use

Reasonable Maximum Exposure Scenario

\begin{tabular}{lccc} 
Chemical & $\begin{array}{c}\text { Chemical- } \\
\text { Specific } \\
\text { Risk }\end{array}$ & $\begin{array}{c}\text { Total } \\
\text { Pathway } \\
\text { Risk }\end{array}$ & $\begin{array}{c}\text { Total } \\
\text { Exposure } \\
\text { Risk }\end{array}$ \\
\hline Exposure Pathway: Ingestion of Groundwater & \\
ARSENIC & $9 \mathrm{k}-04$
\end{tabular}

$9 \mathrm{E}-04$

Exposure Pathway: Inhalation of Volatiles from Groundwater

BENZENE 1E-06

1E-06

Exposure Pathway: Dermal Contact with Groundwater

BENEENE 2E-07

ARSENIC 1E-06

2E-06

Exposure Pathway: Incidental Ingestion of Surface Water

$<1 E-07$

Exposure Pathway: Ingestion of Fish from Garrison Slough

$$
<1 E-07
$$

Exposure Pathway: Incidental Ingestion of Surface Soils

$\begin{array}{ll}\text { ARSENIC } & 3 E-05 \\ \text { BERYLUM } & 2 E-06\end{array}$

3E-05

Exposure Pathway: Dermal Contact with Surface Soils

$\begin{array}{ll}\text { ARSENIC } & 8 \mathrm{E}-07\end{array}$

8E-07 
Table K.22. ST11 Cancer Risk Estimates

Future Residential Land Use

Reasonable Maximum Exposure Scenario

\begin{tabular}{|c|c|c|c|}
\hline Chemical & $\begin{array}{c}\text { Chemical- } \\
\text { Specific } \\
\text { Risk }\end{array}$ & $\begin{array}{c}\text { Total } \\
\text { Pathway } \\
\text { Risk }\end{array}$ & $\begin{array}{c}\text { Total } \\
\text { Exposure } \\
\text { Risk }\end{array}$ \\
\hline \multicolumn{4}{|c|}{ Exposure Pathway: Ingestion of Plants Grown in Contaminated Soils } \\
\hline $\begin{array}{l}4,4 '-D D T \\
\text { ARSENIC } \\
\text { BERYUUM }\end{array}$ & $\begin{array}{l}1 E-07 \\
2 E-05 \\
5 E-07\end{array}$ & $2 E-05$ & \\
\hline \multicolumn{4}{|c|}{ Exposure Pathway: Incidental Ingestion of Subsurface Soils } \\
\hline ARSENIC & 7E-06 & $7 E-06$ & \\
\hline Exposure Pathn & al Contact & surface $S$ & \\
\hline
\end{tabular}

$\begin{array}{ll}\text { ARSENIC } & 4 \mathrm{E}-07\end{array}$

4E-07

Exposure Pathway: Inhalation of Volatile Contaminants Released from the Soil

$<1 \mathrm{E}-07$

Exposure Pathway: Inhalation of Resuspended Sediments

$<1 \mathrm{E}-07$

Total Cancer Risk

$9 \mathrm{E}-04$

Total Cancer Risk - Background Metals

2E-06 
Table K.23. ST11 Hazard Index Estimates

Future Residential Land Use

Average Exposure Scenario

\begin{tabular}{|c|c|c|c|}
\hline Chemical & $\begin{array}{l}\text { Hazard } \\
\text { Quotient }\end{array}$ & $\begin{array}{l}\text { Pathway } \\
\text { Hazard } \\
\text { Index }\end{array}$ & $\begin{array}{l}\text { Total } \\
\text { Exposure } \\
\text { Hazard } \\
\text { Index }\end{array}$ \\
\hline
\end{tabular}

Exposure Pathway: Ingestion of Groundwater

ARSENIC $2 E+01$

BARIUM 4E-02

MANGANESE $2 E+01$

THALLIUM $1 E-01$

$2 E+01$

Exposure Pathway: Inhalation of Volatiles from Groundwater

$$
<1 E-02
$$

Exposure Pathway: Dermal Contact with Groundwater

$$
<1 \mathrm{E}-02
$$

Exposure Pathway: Incidental Ingestion of Surface Water

$$
<1 E-02
$$

Exposure Pathway: Ingestion of Fish from Garrison Slough

$$
<1 \mathrm{E}-02
$$

Exposure Pathway: Incidental Ingestion of Surface Soils

$\begin{array}{ll}4,4^{\prime}-D D T & 2 E-04 \\ \text { ARSENIC } & 2 \mathrm{E}-02 \\ \text { BERIUUM } & 3 \mathrm{E}-05 \\ \text { MANGANESE } & 2 \mathrm{E}-01\end{array}$

$2 \mathrm{E}-01$

Exposure Pathway: Dermal Contact with Surface Soils

$$
<1 E-02
$$

Exposure Pathway: Ingestion of Plants Grown in Contaminated Soils

$\begin{array}{ll}\text { ARSENIC } & 8 \mathrm{E}-02 \\ \text { MANGANESE } & 2 \mathrm{E}+01\end{array}$

$2 E+01$ 
Table K.23. ST11 Hazard index Estimates

Future Residential Land Use

Average Exposure Scenario

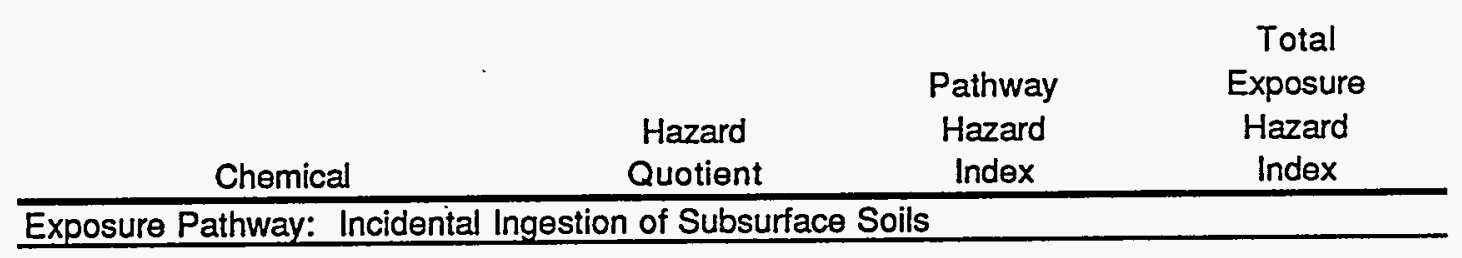

ARSENIC

$3 E-02$

MANGANESE

$3 E-01$

3E-01

Exposure Pathway: Dermal Contact with Subsurface Soils

$$
<1 \mathrm{E}-02
$$

Exposure Pathway: Inhalation of Volatile Contaminants Released from the Soil

$<1 \mathrm{E}-02$

Exposure Pathway: Inhalation of Resuspended Sediments

$$
<1 E-02
$$


Table K.24. ST11 Hazard Index Estimates

Future Residential Scenario

Reasonable Maximum Exposure Scenario

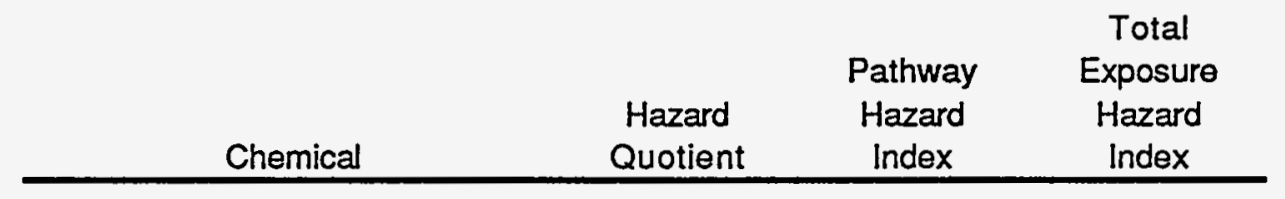

Exposure Pathway: Ingestion of Groundwater

$\begin{array}{ll}\text { ARSENIC } & 4 E+00 \\ \text { BARIUM } & 8 E-02 \\ \text { MANGANESE } & 4 E+01 \\ \text { THALLIUM } & 2 E-01\end{array}$

$4 \mathrm{E}+01$

Exposure Pathway: Inhalation of Volatiles from Groundwater

$<1 \mathrm{E}-02$

Exposure Pathway: Dermal Contact with Groundwater

$<1 \mathrm{E}-02$

Exposure Pathway: Incidental Ingestion of Surface Water

$<1 \mathrm{E}-02$

Exposure Pathway: Ingestion of Fish from Garrison Slough

$<1 \mathrm{E}-02$

Exposure Pathway: Incidental Ingestion of Surface Soils

ARSENIC 1E-01

MANGANESE $\quad 9 E-01$

$1 E+00$

Exposure Pathway: Dermal Contact with Surface Soils

MANGANESE 3E-02

3E-02

Exposure Pathway: Ingestion of Plants Grown in Contaminated Soils

ARSENIC

MANGANESE
$1 E-01$

$2 E+01$

$2 E+01$ 
Table K.24. ST11 Hazard Index Estimates

Future Residential Scenario

Reasonable Maximum Exposure Scenario

Total

$\begin{array}{cc}\text { Pathway } & \text { Exposure } \\ \text { Hazard } & \text { Hazard }\end{array}$

Chemical

Hazard

Index

Index

Exposure Pathway: Incidental Ingestion of Subsurface Soils

ARSENIC

9E-02

MANGANESE

7E-01

8E-01

Exposure Pathway: Dermal Contact with Subsurface Soils

MANGANESE

$2 \mathrm{E}-02$

2E-02

Exposure Pathway: Inhalation of Volatile Contaminants Released from the Soil

$<1 E-02$

Exposure Pathway: Inhalation of Resuspended Sediments

$<1 E-02$

Total Exposure Hazard Index

$6 E+01$

Total Exposure Hazard Index-Background Metals

3E-03 
Table K.25. ST13/DP26 Cancer Risk Estimates

Current Industrial Land Use

Average Exposure Scenario

\begin{tabular}{cccc} 
& Chemical- & Total & Total \\
& Specific & Pathway & Exposure \\
Chemical & Risk & Risk & Risk \\
\hline
\end{tabular}

Exposure Pathway: Incidental Ingestion of Surface Soils

$\begin{array}{ll}\text { BENZO(A)PYRENE } & 3 E-07 \\ \text { DIBENZ(A,H)ANTHRACENE } & 1 E-07 \\ \text { ARSENIC } & 7 E-07\end{array}$

1E-06

Exposure Pathway: Dermal Contact with Surface Soils

2E-07

Exposure Pathway: Incidental Ingestion of Subsurface Soils

ARSENIC 6E-07

7E-07

Exposure Pathway: Dermal Contact with Subsurface Soils

$$
<1 \mathrm{E}-07
$$

Exposure Pathway: Inhalation of Volatile Contaminants Released from the Soil

BENEENE 2E-06

2E-06

Exposure Pathway: Inhalation of Resuspended Sediments

$$
<1 E-07
$$


Table K.26. ST13/DP26 Cancer Risk Estimates Current Industrial Land Use

Reasonable Maximum Exposure Scenario

\begin{tabular}{cccc} 
& Chemical- & Total & Total \\
& Specific & Pathway & Exposure \\
Chemical & Risk & Risk & Risk \\
\hline
\end{tabular}

Exposure Pathway: Incidental Ingestion of Surface Soils

$\begin{array}{ll}\text { BENZO(A)ANTHRACENE } & 1 E-07 \\ \text { BENZO(A)PYRENE } & 9 E-07 \\ \text { BENZO(B)FLUORANTHENE } & 1 E-07 \\ \text { DIBENZ(A,H)ANTHRACENE } & 4 E-07 \\ \text { INDENO(1,2,3-CD)PYRENE } & 1 E-07 \\ 4,4^{\prime}-D D T & 2 E-07 \\ \text { ARSENIC } & 2 E-06\end{array}$

4E-06

Exposure Pathway: Dermal Contact with Surface Soils

$\begin{array}{ll}\text { BENZO(A)ANTHRACENE } & 1 \mathrm{E}-07 \\ \text { BENZO(A)PYRENE } & 9 \mathrm{E}-07 \\ \text { BENZO(B)FLUORANTHENE } & 1 \mathrm{E}-07 \\ \text { DIBENZ(A,H)ANTHRACENE } & 4 \mathrm{E}-07 \\ \text { INDENO(1,2,3-CD)PYRENE } & 1 \mathrm{E}-07 \\ 4,4^{\prime}-\mathrm{DDT} & 2 \mathrm{E}-07 \\ \text { ARSENIC } & 2 \mathrm{E}-07\end{array}$

2E-06

Exposure Pathway: Incidental Ingestion of Subsurface Soils

ARSENIC

$2 \mathrm{E}-06$

2E-06

Exposure Pathway: Dermal Contact with Subsurface Soils

ARSENIC

$2 E-07$

3E-07

Exposure Pathway: Inhalation of Volatile Contaminants Released from the Soil

BENZENE

6E-06

6E-06 
Table K.26. ST13/DP26 Cancer Risk Estimates

Current Industrial Land Use

Reasonable Maximum Exposure Scenario

\begin{tabular}{|c|c|c|c|}
\hline Chemical & $\begin{array}{c}\text { Chemical- } \\
\text { Specific } \\
\text { Risk } \\
\end{array}$ & $\begin{array}{c}\text { Total } \\
\text { Pathway } \\
\text { Risk }\end{array}$ & $\begin{array}{c}\text { Total } \\
\text { Exposure } \\
\text { Risk }\end{array}$ \\
\hline \multicolumn{4}{|c|}{ Exposure Pathway: Inhalation of Resuspended Sediments } \\
\hline \multirow[t]{2}{*}{ ARSENIC } & $1 E-07$ & & \\
\hline & & $1 E-07$ & \\
\hline \multirow{2}{*}{\multicolumn{3}{|c|}{$\begin{array}{l}\text { Total Cancer Risk } \\
\text { Total Cancer Risk - Site Background Metals }\end{array}$}} & $1 \mathrm{E}-05$ \\
\hline & & & $1 E-05$ \\
\hline
\end{tabular}


Table K.27. ST13/DP26 Hazard Index Estimates Current Industrial Land Use

Average Exposure Scenario

Chemical

Hazard

Quotient

Pathway
Hazard
Index

Exposure

Hazard

Index

Exposure Pathway: Incidental Ingestion of Surface Soils

\begin{tabular}{ll}
\hline ARSENIC & $1 \mathrm{E}-02$ \\
MANGANESE & $7 \mathrm{E}-02$
\end{tabular}

8E-02

Exposure Pathway: Dermal Contact with Surface Soils

$<1 E-02$

Exposure Pathway: Incidental Ingestion of Subsurface Soils

MANGANESE

1E-01

1E-01

Exposure Pathway: Dermal Contact with Subsurface Soils

$<1 E-02$

Exposure Pathway: Inhalation of Volatile Contaminants Released from the Soil

$<1 E-02$

Exposure Pathway: Inhalation of Resuspended Sediments

$<1 E-02$

Total Exposure Hazard Index

2E-01

Total Exposure Hazard Index-Site Background Metals

$8 \mathrm{E}-03$ 
Table K.28. ST11/DP26 Hazard Risk Estimates Current Industrial Land Use Reasonable Maximum Exposure Scenario

\begin{tabular}{ccc} 
& Total \\
Hazard & Pathway & Exposure \\
Quotient & Hazard & Hazard \\
Index & Index \\
\hline
\end{tabular}

Exposure Pathway: Incidental Ingestion of Surface Soils

$\begin{array}{ll}\text { ARSENIC } & 1 \mathrm{E}-02 \\ \text { MANGANESE } & 7 \mathrm{E}-02\end{array}$

8E-02

Exposure Pathway: Dermal Contact with Surface Soils

1E-02

Exposure Pathway: Incidental Ingestion of Subsurface Soils

MANGANESE 1E-01

$1 E-01$

Exposure Pathway: Dermal Contact with Subsurface Soils

MANGANESE $1 E-02$

1E-02

Exposure Pathway: Inhalation of Volatile Contaminants Released from the Soil

$<1 E-02$

Exposure Pathway: Inhalation of Resuspended Sediments

1E-02

\begin{tabular}{ll}
\hline Total Cancer Risk & 2E-01
\end{tabular}

Total Cancer Risk - Site Background Metals 1E-02 
Table K.29. ST13/DP26 Cancer Risk Estimates

Future Industrial Land Use

Average Exposure Scenario

\begin{tabular}{cccc} 
& Chemical- & Total & Total \\
& Specific & Pathway & Exposure \\
Chemical & Risk & Risk & Risk \\
\hline
\end{tabular}

Exposure Pathway: Ingestion of Groundwater

$\begin{array}{ll}\text { BENZENE } & 1 \mathrm{E}-05 \\ \text { ARSENIC } & 6 \mathrm{E}-05 \\ \text { BERYUUM } & 5 \mathrm{E}-06\end{array}$

7E-05

Exposure Pathway: Inhalation of Volatiles from Groundwater

$\begin{array}{ll}\text { BENZENE } & 8 \mathrm{E}-05 \\ \text { CHLOROFORM } & 8 \mathrm{E}-07 \\ \text { CHLOROMETHANE } & 2 \mathrm{E}-07\end{array}$

8E-05

Exposure Pathway: Dermal Contact with Groundwater

$\begin{array}{ll}\text { BENTENE } & 1 E-05 \\ \text { ARSENIC } & 1 E-07\end{array}$

1E-05

Exposure Pathway: Incidental Ingestion of Surface Soils

$\begin{array}{ll}\text { BENZO(A)PYRENE } & 3 E-07 \\ \text { BENZO(B)FLUORANTHENE } & 5 E-08 \\ \text { DIBENZ(A,H)ANTHRACENE } & 1 E-07 \\ \text { ARSENIC } & 7 E-07\end{array}$

1E-06

Exposure Pathway: Dermal Contact with Surface Soils

2E-07

Exposure Pathway: Incidental Ingestion of Subsurface Soils

$\begin{array}{ll}\text { ARSENIC 6E-07 } & \end{array}$

7E-07 
Table K.29. ST13/DP26 Cancer Risk Estimates

Future Industrial Land Use

Average Exposure Scenario

\begin{tabular}{|c|c|c|c|}
\hline Chemical & $\begin{array}{c}\text { Chemical- } \\
\text { Specific } \\
\text { Risk }\end{array}$ & $\begin{array}{c}\text { Total } \\
\text { Pathway } \\
\text { Risk }\end{array}$ & $\begin{array}{c}\text { Total } \\
\text { Exposure } \\
\text { Risk }\end{array}$ \\
\hline \multicolumn{4}{|c|}{ Exposure Pathway: Dermal Contact with Subsurface Soils } \\
\hline & & $<1 E-07$ & \\
\hline
\end{tabular}

BENZENE 5E-07

$5 E-07$

Exposure Pathway: Inhalation of Resuspended Sediments

$<1 \mathrm{E}-07$

Total Cancer Risk

2E-04

Total Cancer Risk - Background Metals

$1 E-04$ 
Table K.30. ST13/DP26 Cancer Risk Estimates Future Industrial Land Use

Reasonable Maximum Exposure Scenario

\begin{tabular}{cccc} 
& Chemical- & Total & Total \\
& Specific & Pathway & Exposure \\
Chemical & Risk & Risk & Risk \\
\hline
\end{tabular}

Exposure Pathway: Ingestion of Groundwater

$\begin{array}{ll}\text { BENLENE } & 3 E-05 \\ \text { ARSENIC } & 2 E-04 \\ \text { BERYYUM } & 1 E-05\end{array}$

2E-04

Exposure Pathway: Inhalation of Volatiles from Groundwater

$\begin{array}{ll}\text { BENEENE } & 2 \mathrm{E}-04 \\ \text { CHLOROFORM } & 2 \mathrm{E}-06 \\ \text { CHLOROMETHANE } & 5 \mathrm{E}-07\end{array}$

$2 E-04$

Exposure Pathway: Dermal Contact with Groundwater

$\begin{array}{ll}\text { BENZENE } & 4 \mathrm{E}-05 \\ \text { ARSENIC } & 6 \mathrm{E}-07\end{array}$

4E-05

Exposure Pathway: Incidental Ingestion of Surface Soils

$\begin{array}{ll}\text { BENZO(A)ANTHRACENE } & 1 \mathrm{E}-07 \\ \text { BENZO(A)PYRENE } & 9 \mathrm{E}-07 \\ \text { BENZO(B)FLUORANTHENE } & 1 \mathrm{E}-07 \\ \text { DIBENZ(A,H)ANTHRACENE } & 4 \mathrm{E}-07 \\ \text { INDENO(1,2,3-CD)PYRENE } & 1 \mathrm{E}-07 \\ 4,4^{\prime}-\mathrm{DDT} & 2 \mathrm{E}-07 \\ \text { ARSENIC } & 2 \mathrm{E}-06\end{array}$

4E-06

Exposure Pathway: Dermal Contact with Surface Soils

$\begin{array}{ll}\text { BENZO(A)ANTHRACENE } & 1 \mathrm{E}-07 \\ \text { BENZO(A)PYRENE } & 9 \mathrm{E}-07 \\ \text { BENZO(B)FLUORANTHENE } & 1 \mathrm{E}-07 \\ \text { DIBENZ(A,H)ANTHRACENE } & 4 \mathrm{E}-07 \\ \text { INDENO(1,2,3-CD)PYRENE } & 1 \mathrm{E}-07 \\ 4,4^{\prime}-\text { DDT } & 2 \mathrm{E}-07\end{array}$


Table K.30. ST13/DP26 Cancer Risk Estimates

Future Industrial Land Use

Reasonable Maximum Exposure Scenario

\begin{tabular}{lccc} 
Chemical & $\begin{array}{c}\text { Chemical- } \\
\text { Specific } \\
\text { Risk }\end{array}$ & $\begin{array}{c}\text { Total } \\
\text { Pathway } \\
\text { Risk }\end{array}$ & $\begin{array}{c}\text { Total } \\
\text { Exposure } \\
\text { Risk }\end{array}$ \\
\hline ARSENIC & $2 \mathrm{E}-07$ & & \\
& & $2 \mathrm{E}-06$
\end{tabular}

Exposure Pathway: Incidental Ingestion of Subsurface Soils

ARSENIC 2E-06

2E-06

Exposure Pathway: Dermal Contact with Subsurface Soils

$<1 E-07$

Exposure Pathway: Inhalation of Volatile Contaminants Released from the Soil

BENZENE $\quad 1 E-06$

1E-06

Exposure Pathway: Inhalation of Resuspended Sediments

ARSENIC

$1 \mathrm{E}-07$

$1 \mathrm{E}-07$

Total Cancer Risk

5E-04

Total Cancer Risk - Background Metals

3E-04 
Table K.31. ST13/DP26 Hazard Index Estimates Future Industrial Land Use Average Exposure Scenario

\begin{tabular}{|c|c|c|c|}
\hline Chemical & $\begin{array}{l}\text { Hazard } \\
\text { Quotient }\end{array}$ & $\begin{array}{l}\text { Pathway } \\
\text { Hazard } \\
\text { Index }\end{array}$ & $\begin{array}{l}\text { Total } \\
\text { Exposure } \\
\text { Hazard } \\
\text { Index }\end{array}$ \\
\hline
\end{tabular}

Exposure Pathway: Ingestion of Groundwater

$\begin{array}{ll}\text { ETHMLBENZENE } & 2 \mathrm{E}-02 \\ \text { TOLUENE } & 4 \mathrm{E}-02 \\ \text { NAPHTHALENE } & 2 \mathrm{E}-02 \\ \text { ANTIMONY } & 3 \mathrm{E}-01 \\ \text { ARSENIC } & 9 \mathrm{E}-01 \\ \text { BARIUM } & 4 \mathrm{E}-02 \\ \text { CADMIUM } & 2 \mathrm{E}-02 \\ \text { MANGANESE } & 4 \mathrm{E}+01 \\ \text { THALLIUM } & 1 \mathrm{E}-01\end{array}$

$4 E+01$

Exposure Pathway: Inhalation of Volatiles from Groundwater

$\begin{array}{lc}\text { ETHMBENZENE } & 6 E-02 \\ \text { TOLUENE } & 1 E-01 \\ \text { XYLENES (TOTAL) } & 1 E+00\end{array}$

$1 E+00$

Exposure Pathway: Dermal Contact with Groundwater

$\begin{array}{ll}\text { ETHMBENZENE } & 3 \mathrm{E}-01 \\ \text { TOLUENE } & 5 \mathrm{E}-01 \\ \text { NAPHTHALENE } & 2 \mathrm{E}-02 \\ \text { MANGANESE } & 9 \mathrm{E}-02\end{array}$

8E-01

Exposure Pathway: Incidental Ingestion of Surface Soils

$\begin{array}{ll}\text { ARSENIC } & 1 \mathrm{E}-02 \\ \text { MANGANESE } & 7 \mathrm{E}-02\end{array}$

8E-02

Exposure Pathway: Dermal Contact with Surface Soils

$<1 \mathrm{E}-02$ 
Table K.31. ST13/DP26 Hazard Index Estimates

Future Industrial Land Use

Average Exposure Scenario

\begin{tabular}{|c|c|c|c|}
\hline Chemical & $\begin{array}{l}\text { Hazard } \\
\text { Quotient }\end{array}$ & $\begin{array}{l}\text { Pathway } \\
\text { Hazard } \\
\text { Index }\end{array}$ & $\begin{array}{c}\text { Total } \\
\text { Exposure } \\
\text { Hazard } \\
\text { Index }\end{array}$ \\
\hline Exposure & n of Subsur & & \\
\hline
\end{tabular}

MANGANESE

$1 E-01$

1E-01

Exposure Pathway: Dermal Contact with Subsurface Soils

$<1 \mathrm{E}-02$

Exposure Pathway: Inhalation of Volatile Contaminants Released from the Soil

$<1 E-02$

Exposure Pathway: Inhalation of Resuspended Sediments

$$
<1 E-02
$$


Table K.32. ST13/DP26 Hazard Index Estimates

Future Industrial Land Use

Reasonable Maximum Exposure Scenario

\begin{tabular}{|c|c|c|c|}
\hline Chemical & $\begin{array}{l}\text { Hazard } \\
\text { Quotient }\end{array}$ & $\begin{array}{l}\text { Pathway } \\
\text { Hazard } \\
\text { Index }\end{array}$ & $\begin{array}{l}\text { Total } \\
\text { Exposure } \\
\text { Hazard } \\
\text { Index }\end{array}$ \\
\hline
\end{tabular}

Exposure Pathway: Ingestion of Groundwater

$\begin{array}{ll}\text { ETHMIBENZENE } & 2 \mathrm{E}-02 \\ \text { TOLUENE } & 4 \mathrm{E}-02 \\ \text { NAPHTH-LLLENE } & 2 \mathrm{E}-02 \\ \text { ANTIMONY } & 3 \mathrm{E}-01 \\ \text { ARSENIC } & 9 \mathrm{E}-01 \\ \text { BARIUM } & 4 \mathrm{E}-02 \\ \text { CADMIUM } & 2 \mathrm{E}-02 \\ \text { MANGANESE } & 4 \mathrm{E}+01 \\ \text { THALIUM } & 1 \mathrm{E}-01\end{array}$

$4 E+01$

Exposure Pathway: Inhalation of Volatiles from Groundwater

$\begin{array}{lc}\text { ETHMBENZENE } & 6 \mathrm{E}-02 \\ \text { TOLUENE } & 1 \mathrm{E}-01 \\ \text { XYLENES (TOTAL) } & 1 \mathrm{E}+00\end{array}$

$1 E+00$

Exposure Pathway: Dermal Contact with Groundwater

$\begin{array}{ll}\text { ETHMBENZENE } & 3 \mathrm{E}-01 \\ \text { TOLUENE } & 5 \mathrm{E}-01 \\ \text { NAPHTHALENE } & 2 \mathrm{E}-02 \\ \text { MANGANESE } & 1 \mathrm{E}-01\end{array}$

$1 E+00$

Exposure Pathway: Incidental Ingestion of Surface Soils

$\begin{array}{ll}\text { ARSENIC } & 1 \mathrm{E}-02 \\ \text { MANGANESE } & 7 \mathrm{E}-02\end{array}$

$8 \mathrm{E}-02$

Exposure Pathway: Dermal Contact with Surface Soils

1E-02 
Table K.32. ST13/DP26 Hazard Index Estimates

Future Industrial Land Use

Reasonable Maximum Exposure Scenario

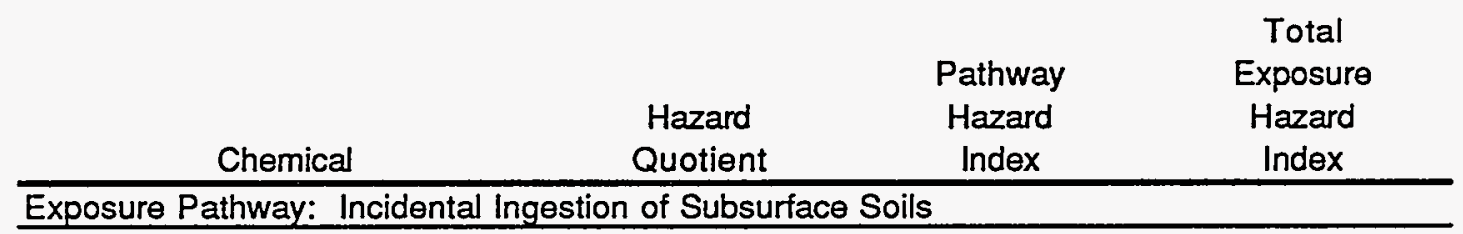

MANGANESE

1E-01

1E-01

Exposure Pathway: Dermal Contact with Subsurface Soils

MANGANESE

$1 E-02$

$1 \mathrm{E}-02$

Exposure Pathway: Inhalation of Volatile Contaminants Released from the Soil

$<1 E-02$

Exposure Pathway: Inhalation of Resuspended Sediments

$<1 E-02$

Total Exposure Hazard Index

$4 \mathrm{E}+01$

Total Exposure Hazard Index-Background Metals

$2 \mathrm{E}+00$ 
Table K.33. ST13/DP26 Cancer Risk Estimates Future Residential Land Use

Average Exposure Scenario

\begin{tabular}{cccc} 
& Chemical- & Total & Total \\
& Specific & Pathway & Exposure \\
Chemical & Risk & Risk & Risk \\
\hline
\end{tabular}

Exposure Pathway: Ingestion of Groundwater

$\begin{array}{ll}\text { BENTENE } & 2 \mathrm{E}-05 \\ \text { ARSENIC } & 9 \mathrm{E}-05 \\ \text { BERYUUM } & 7 \mathrm{E}-06\end{array}$

$1 E-04$

Exposure Pathway: Inhalation of Volatiles from Groundwater

$\begin{array}{ll}\text { BENZENE } & 8 \mathrm{E}-05 \\ \text { CHLOROFORM } & 8 \mathrm{E}-07 \\ \text { CHLOROMETHANE } & 2 \mathrm{E}-07\end{array}$

8E-05

Exposure Pathway: Dermal Contact with Groundwater

$\begin{array}{ll}\text { BENUENE } & 1 \mathrm{E}-05 \\ \text { ARSENIC } & 2 \mathrm{E}-07\end{array}$

$1 E-05$

Exposure Pathway: Incidental Ingestion of Surface Soils

$\begin{array}{ll}\text { BENZO(A)ANTHRACENE } & 1 \mathrm{E}-07 \\ \text { BENZO(A)PYRENE } & 8 \mathrm{E}-07 \\ \text { BENZO(B)FLUORANTHENE } & 1 \mathrm{E}-07 \\ \text { DIBENZ(A,H)ANTHRACENE } & 3 \mathrm{E}-07 \\ \text { INDENO(1,2,3-CD)PYRENE } & 1 \mathrm{E}-07 \\ 4,4^{\prime}-\text { DDT } & 2 \mathrm{E}-07 \\ \text { ARSENIC } & 2 \mathrm{E}-06\end{array}$

3E-06

Exposure Pathway: Dermal Contact with Surface Soils

2E-07

Exposure Pathway: Ingestion of Plants Grown in Contaminated Soils

$\begin{array}{ll}\text { BENZO(A)ANTHRACENE } & 7 E-07 \\ \text { BENZO(A)PYRENE } & 3 E-06 \\ \text { BENZO(B)FLUORANTHENE } & 5 E-07 \\ \text { DIBENZ(A,H)ANTHRACENE } & 2 E-06\end{array}$


Table K.33. ST13/DP26 Cancer Risk Estimates Future Residential Land Use Average Exposure Scenario

\begin{tabular}{lccc} 
Chemical & $\begin{array}{c}\text { Chemical- } \\
\text { Specific } \\
\text { Risk }\end{array}$ & $\begin{array}{c}\text { Total } \\
\text { Pathway } \\
\text { Risk }\end{array}$ & $\begin{array}{c}\text { Total } \\
\text { Exposure } \\
\text { Risk }\end{array}$ \\
\hline $\begin{array}{l}4,4^{\prime}-\text { DDT } \\
\text { ARSENIC }\end{array}$ & $\begin{array}{c}5 E-07 \\
3 E-06\end{array}$ & & \\
& & 1E-05
\end{tabular}

Exposure Pathway: Incidental Ingestion of Subsurface Soils

ARSENIC 2E-06

2E-06

Exposure Pathway: Dermal Contact with Subsurface Soils

$$
<1 E-07
$$

Exposure Pathway: Inhalation of Volatile Contaminants Released from the Soil

BENZENE 5E-07

$5 \mathrm{E}-07$

Exposure Pathway: Inhalation of Resuspended Sediments

$$
<1 E-07
$$

\begin{tabular}{lr}
\hline Total Cancer Risk & $2 E-04$ \\
Total Cancer Risk - Site Background Metals & $1 E-04$ \\
\hline
\end{tabular}


Table K.34. ST13/DP26 Cancer Risk Estimates

Future Residential Land Use

Reasonable Maximum Exposure Scenario

\begin{tabular}{lccc}
\multicolumn{1}{c}{ Chemical } & $\begin{array}{c}\text { Chemical- } \\
\text { Specific } \\
\text { Risk }\end{array}$ & $\begin{array}{c}\text { Total } \\
\text { Pathway } \\
\text { Risk }\end{array}$ & $\begin{array}{c}\text { Total } \\
\text { Exposure } \\
\text { Risk }\end{array}$ \\
\hline Exposure Pathway: Ingestion of Groundwater & \\
\hline BENZENE & $9 \mathrm{E}-05$ & \\
ARSENIC & $5 \mathrm{E}-04$ & \\
BERYUUM & $4 \mathrm{E}-05$ & \\
& & & \\
& & & \\
& & & \\
Exposure Pathway: Inhalation of Volatiles from Groundwater
\end{tabular}

\begin{tabular}{ll}
\hline BENEENE & $4 \mathrm{E}-04$ \\
CHLOROFORM & $4 \mathrm{E}-06$ \\
CHLOROMETHANE & $8 \mathrm{E}-07$
\end{tabular}

4E-04

Exposure Pathway: Dermal Contact with Groundwater

$\begin{array}{ll}\text { BENZENE } & 6 E-05 \\ \text { ARSENIC } & 9 E-07\end{array}$

6E-05

Exposure Pathway: Incidental Ingestion of Surface Soils

$\begin{array}{ll}\text { BENZO(A)ANTHRACENE } & 9 \mathrm{E}-07 \\ \text { BENZO(A)PYRENE } & 7 \mathrm{E}-06 \\ \text { BENZO(B)FLUORANTHENE } & 1 \mathrm{E}-06 \\ \text { BENZO(G,H,I)PERYLENE } & 1 \mathrm{E}-07 \\ \text { BENZO(K)FLUORANTHENE } & 6 \mathrm{E}-07 \\ \text { C-IRYSENE } & 4 \mathrm{E}-08 \\ \text { DIBENZ(A,H)ANTHRACENE } & 3 \mathrm{E}-06 \\ \text { INDENO(1,2,3-CD)PYRENE } & 1 \mathrm{E}-06 \\ 4,4^{\prime}-\text { DDD } & 2 \mathrm{E}-07 \\ 4,4^{\prime}-\mathrm{DDE} & 9 \mathrm{E}-08 \\ 4,4^{\prime}-\mathrm{DDT} & 1 \mathrm{E}-06 \\ \text { ARSENIC } & 1 \mathrm{E}-05\end{array}$

3E-05

Exposure Pathway: Dermal Contact with Surface Soils

$\begin{array}{ll}\text { BENZO(A)ANTHRACENE } & 3 E-07 \\ \text { BENZO(A)PYRENE } & 2 E-06 \\ \text { BENZO(B)FLUORANTHENE } & 3 E-07\end{array}$


Table K.34. ST13/DP26 Cancer Risk Estimates Future Residential Land Use Reasonable Maximum Exposure Scenario

\begin{tabular}{lccc}
\multicolumn{1}{c}{ Chemical } & $\begin{array}{c}\text { Chemical- } \\
\text { Specific } \\
\text { Risk }\end{array}$ & $\begin{array}{c}\text { Total } \\
\text { Pathway } \\
\text { Risk }\end{array}$ & $\begin{array}{c}\text { Total } \\
\text { Exposure } \\
\text { Risk }\end{array}$ \\
\hline BENZO(K)FLUORANTHENE & $2 \mathrm{E}-07$ & & \\
DIBENZ(A,H)ANTHRACENE & $9 \mathrm{E}-07$ & & \\
INDENO(1,2,3-CD)PYRENE & $3 \mathrm{E}-07$ & & \\
4,4'-DDT & $4 \mathrm{E}-07$ & & \\
ARSENIC & $4 \mathrm{E}-07$ & &
\end{tabular}

$5 E-06$

Exposure Pathway: Ingestion of Plants Grown in Contaminated Soils

$\begin{array}{ll}\text { BENZO(A)ANTHRACENE } & 3 E-06 \\ \text { BENZO(A)PYRENE } & 1 E-05 \\ \text { BENZO(B)FLUORANTHENE } & 2 E-06 \\ \text { BENZO(K)FLUORANTHENE } & 1 E-06 \\ \text { CHRYSENE } & 1 E-07 \\ \text { DIBENZ(A,H)ANTHRACENE } & 1 E-05 \\ \text { INDENO\{1,2,3-CD)PYRENE } & 1 E-06 \\ 4,4^{\prime}-\text { DDD } & 3 E-07 \\ 4,4^{\prime}-D D T & 2 E-06 \\ \text { ARSENIC } & 1 E-05\end{array}$

$5 E-05$

Exposure Pathway: Incidental Ingestion of Subsurface Soils

$\begin{array}{ll}\text { BENZO(A)PYRENE } & 2 E-07 \\ \text { ARSENIC } & 1 E-05\end{array}$

1E-05

Exposure Pathway: Dermal Contact with Subsurface Soils

ARSENIC

4E-07

7E-07

Exposure Pathway: Inhalation of Volatile Contaminants Released from the Soil

BENEENE

$1 E-06$

2E-06

Exposure Pathway: Inhalation of Resuspended Sediments

ARSENIC 1E-07

2E-07 
Table K.34. ST13/DP26 Cancer Risk Estimates

Future Residential Land Use

Reasonable Maximum Exposure Scenario

\begin{tabular}{lccc} 
& $\begin{array}{c}\text { Chemical- } \\
\text { Specific } \\
\text { Chemical }\end{array}$ & $\begin{array}{c}\text { Total } \\
\text { Pathway } \\
\text { Risk }\end{array}$ & $\begin{array}{c}\text { Total } \\
\text { Exposure } \\
\text { Risk }\end{array}$ \\
\hline Total Cancer Risk & & $1 \mathrm{E}-03$ \\
Total Cancer Risk - Background Metals & & $6 \mathrm{E}-04$ \\
\hline
\end{tabular}


Table K.35. ST13/DP26 Hazard Index Estimates Future Residential Land Use

Average Exposure Scenario

Total

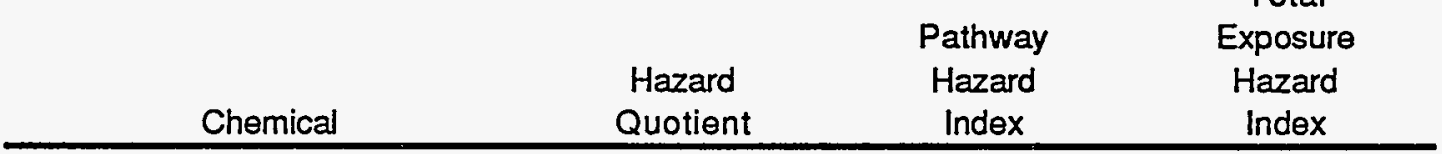

Exposure Pathway: Ingestion of Groundwater

\begin{tabular}{ll}
\hline ETHMBENZENE & $3 \mathrm{E}-02$ \\
TOLUENE & $7 \mathrm{E}-02$ \\
XYLENES (TOTAL) & $1 \mathrm{E}-02$ \\
NAPHTHALENE & $3 \mathrm{E}-02$ \\
ANTIMONY & $5 \mathrm{E}-01$ \\
ARSENIC & $1 \mathrm{E}+00$ \\
BARIUM & $6 \mathrm{E}-02$ \\
CADMIUM & $4 \mathrm{E}-02$ \\
MANGANESE & $6 \mathrm{E}+01$ \\
THALLIUM & $2 \mathrm{E}-01$
\end{tabular}

$6 \mathrm{E}+01$

Exposure Pathway: Inhalation of Volatiles from Groundwater

$\begin{array}{lc}\text { ETHMBENEENE } & 6 \mathrm{E}-02 \\ \text { TOLUENE } & 1 \mathrm{E}-01 \\ \text { XYLENES (TOTAL) } & 1 \mathrm{E}+00\end{array}$

$2 E+00$

Exposure Pathway: Dermal Contact with Groundwater

$\begin{array}{ll}\text { ETHMBENLENE } & 3 \mathrm{E}-01 \\ \text { TOLUENE } & 5 \mathrm{E}-01 \\ \text { NAPHTHALENE } & 2 \mathrm{E}-02 \\ \text { MANGANESE } & 1 \mathrm{E}-01\end{array}$

9E-01

Exposure Pathway: Incidental Ingestion of Surface Soils

ARSENIC

MANGANESE

$1 E-02$

9E-02

1E-01

Exposure Pathway: Dermal Contact with Surface Soils

$<1 \mathrm{E}-02$ 
Table K.35. ST13/DP26 Hazard Index Estimates Future Residential Land Use Average Exposure Scenario

\begin{tabular}{|c|c|c|c|}
\hline Chemical & $\begin{array}{l}\text { Hazard } \\
\text { Quotient }\end{array}$ & $\begin{array}{l}\text { Pathway } \\
\text { Hazard } \\
\text { Index }\end{array}$ & $\begin{array}{c}\text { Total } \\
\text { Exposure } \\
\text { Hazard } \\
\text { Index }\end{array}$ \\
\hline
\end{tabular}

\begin{tabular}{ll}
\hline $4,4^{\prime}-$ DDT & $2 \mathrm{E}-02$ \\
ARSENIC & $4 \mathrm{E}-02$ \\
MANGANESE & $8 \mathrm{E}+00$
\end{tabular}

$8 E+00$

Exposure Pathway: Incidental Ingestion of Subsurface Soils

$\begin{array}{ll}\text { ARSENIC } & 2 \mathrm{E}-02 \\ \text { MANGANESE } & 3 \mathrm{E}-01\end{array}$

3E-01

Exposure Pathway: Dermal Contact with Subsurface Soils

$<1 E-02$

Exposure Pathway: Inhalation of Volatile Contaminants Released from the Soil

$<1 E-02$

Exposure Pathway: Inhalation of Resuspended Sediments

$<1 E-02$

Total Exposure Hazard Index

$7 E+01$

Total Exposure Hazard Index-Background Metals

$2 \mathrm{E}+00$ 
Table K.36. ST13/DP26 Hazard Index Estimates Future Residential Scenario

Reasonable Maximum Exposure Scenario

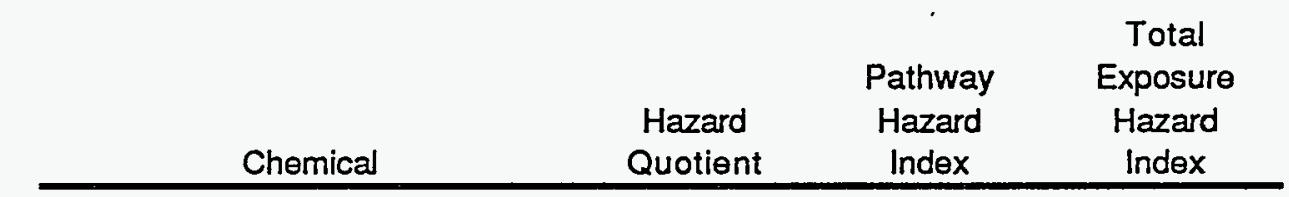

Exposure Pathway: Ingestion of Groundwater

ETHMLBENZENE
TOLUENE
XYLENES (TOTAL)
NAPHTHALENE
ANTIMONY
ARSENIC
BARIUM
CADMIUM
MANGANESE
THALUUM

6E-02

$1 E-01$

$2 \mathrm{E}-02$

$5 E-02$

$9 E-01$

$2 \mathrm{E}+00$

1E-01

7E-02

$1 E+02$

$3 E-01$

$1 E+02$

Exposure Pathway: Inhalation of Volatiles from Groundwater

$\begin{array}{ll}\text { ETHMBENEENE } & 8 \mathrm{E}-02 \\ \text { TOLUENE } & 2 \mathrm{E}-01 \\ \text { XYLENES (TOTAL) } & 2 \mathrm{E}+00\end{array}$

$$
2 E+00
$$

Exposure Pathway: Dermal Contact with Groundwater

$\begin{array}{ll}\text { ETHMBENZENE } & 4 \mathrm{E}-01 \\ \text { TOLUENE } & 8 \mathrm{E}-01 \\ \text { XYLENES (TOTAL) } & 1 \mathrm{E}-02 \\ \text { NAPHTHALLNE } & 3 \mathrm{E}-02 \\ \text { MANGANESE } & 2 \mathrm{E}-01\end{array}$

$$
1 E+00
$$

Exposure Pathway: Incidental Ingestion of Surface Soils

$\begin{array}{ll}4,4^{\prime}-\text { DDT } & 2 \mathrm{E}-02 \\ \text { ARSENIC } & 6 \mathrm{E}-02 \\ \text { MANGANESE } & 5 \mathrm{E}-01\end{array}$

5E-01 
Table K.36. ST13/DP26 Hazard Index Estimates

Future Residential Scenario

Reasonable Maximum Exposure Scenario

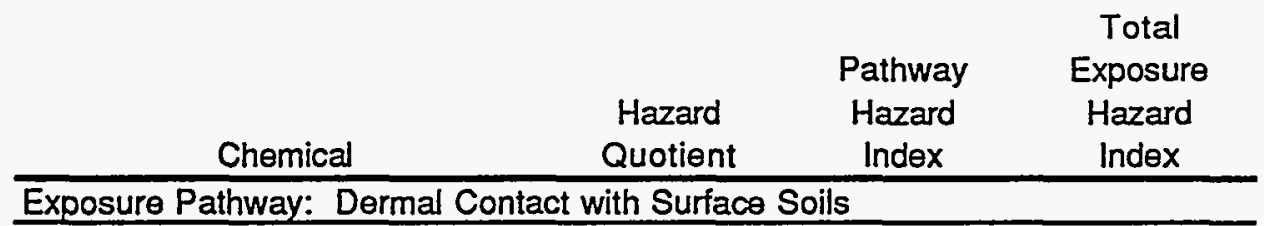

MANGANESE

$1 E-02$

2E-02

Exposure Pathway: Ingestion of Plants Grown in Contaminated Soils

$\begin{array}{ll}4,4^{\prime}-D D T & 3 E-02 \\ \text { ARSENIC } & 6 E-02 \\ \text { MANGANESE } & 1 E+01\end{array}$

$1 E+01$

Exposure Pathway: Incidental Ingestion of Subsurface Soils

ARSENIC 6E-02

MANGANESE 7E-01

$$
\text { 7E-01 }
$$

Exposure Pathway: Dermal Contact with Subsurface Soils

$\begin{array}{ll}\text { MANGANESE } & 2 E-02\end{array}$

2E-02

Exposure Pathway: Inhalation of Volatile Contaminants Released from the Soil

$$
<1 E-02
$$

Exposure Pathway: Inhalation of Resuspended Sediments

$$
<1 E-02
$$

\begin{tabular}{ll}
\hline Total Exposure Hazard Index & $1 \mathrm{E}+02$ \\
Total Exposure Hazard Index-Background Metals & $3 \mathrm{E}+00$ \\
\hline
\end{tabular}


Table K.37

ST18 Cancer Risk Estimate

Current Industrial Land Use

Average Exposure Scenario

Chemical

Chemical- Total

Specific Pathway

Total

Risk

Risk

Exposure

Exposure Pathway: Incidental Ingestion of Surface Soils

BENZO(A)PYRENE

ARSENIC

1E-07

$8 \mathrm{E}-07$

$$
\text { 1E-06 }
$$

Exposure Pathway: Dermal Contact with Surface Soils

$$
<1 E-07
$$

Exposure Pathway: Incidental Ingestion of Subsurface Soils

ARSENIC $2 \mathrm{E}-07$

$$
2 E-07
$$

Exposure Pathway: Dermal Contact with Subsurface Soils

$<1 E-07$

Exposure Pathway: Inhalation of Volatile Contaminants Released from the $S$.

$<1 E-07$

Exposure Pathway: Inhalation of Resuspended Sediments

$$
<1 \mathrm{E}-07
$$


Table 38. ST18 Cancer Risk Estimate

Current Industrial Scenario

Reasonable Maximum Exposure Scenario

Chemical

Chemical-
specific
Risk

Total

Pathway

Risk

Total

Exposure

Risk

Exposure Pathway: Incidental Ingestion of Surface Soils

$\begin{array}{ll}\text { BENZO(A)PYRENE } & 4 E-07 \\ \text { DIBENZ(A,H)ANTHRACENE } & 8 E-08 \\ \text { INDENO(1,2,3-CD)PYRENE } & 9 E-08 \\ \text { ARSENIC } & 2 E-06 \\ \text { BERYUUM } & 2 E-07\end{array}$

3E-06

Exposure Pathway: Dermal Contact with Surface Soils

$\begin{array}{ll}\text { BENZO(A)PYRENE } & 4 E-07 \\ \text { ARSENIC } & 2 E-07\end{array}$

9E-07

Exposure Pathway: Incidental Ingestion of Subsurface Soils

ARSENIC 7E-07

7E-07

Exposure Pathway: Dermal Contact with Subsurface Soils

$<1 E-07$

Exposure Pathway: Inhalation of Volatile Contaminants Released from the Soil

$<1 \mathrm{E}-07$

Exposure Pathway: Inhalation of Resuspended Sediments

ARSENIC $\quad 1 E-07$

1E-07

Total Cancer Risk

5E-06

Total Cancer Risk - Site Background Metals

$1 \mathrm{E}-06$ 
Table K.39. ST18 Hazard Index Estimates

Current Industrial Land Use

Average Exposure Scenario

$\begin{array}{ccc}\text { Hazard } & \text { Pathway } & \text { Exposure } \\ \text { Chemical } & \text { Hazard } & \text { Hazard } \\ \text { Index }\end{array}$

Exposure Pathway: Incidental Ingestion of Surface Soils

ARSENIC $1 E-02$

MANGANESE 1E-01

1E-01

Exposure Pathway: Dermal Contact with Surface Soils

$<1 \mathrm{E}-02$

Exposure Pathway: Incidental Ingestion of Subsurface Soils

MANGANESE 7E-02

7E-02

Exposure Pathway: Dermal Contact with Subsurface Soils

$<1 \mathrm{E}-07$

Exposure Pathway: Inhalation of Volatile Contaminants Released from the Soil

$<1 E-02$

Exposure Pathway: Inhalation of Resuspended Sediments

$<1 E-02$

Total Exposure Hazard Index

2E-01

Total Exposure Hazard Index-Site Background Metals

7E-06 
Table K.40. ST18 Hazard Risk Estimates

Current Industrial Land Use

Reasonable Maximum Exposure Scenario

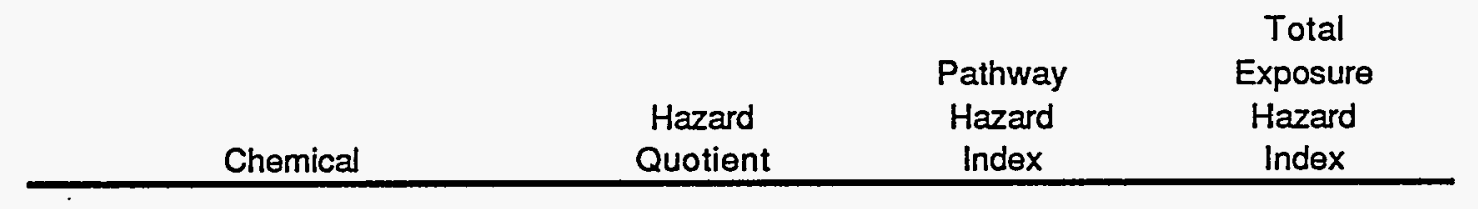

Exposure Pathway: Incidental Ingestion of Surface Soils

ARSENIC $\quad 1 E-02$

MANGANESE 1E-01

$1 E-01$

Exposure Pathway: Dermal Contact with Surface Soils

$<1 E-02$

Exposure Pathway: Incidental Ingestion of Subsurface Soils

MANGANESE $\quad 7 E-02$

7E-02

Exposure Pathway: Dermal Contact with Subsurface Soils

$<1 E-02$

Exposure Pathway: Inhalation of Volatile Contaminants Released from the Soil

$<1 E-02$

Exposure Pathway: Inhalation of Resuspended Sediments

$<1 E-02$

Total Cancer Risk

2E-01

Total Cancer Risk - Site Background Metals

1E-05 
Table K.41. ST18 Cancer Risk Estimates

Future Industrial Land Use

Average Exposure Scenario

\begin{tabular}{cccc} 
& Chemical- & Total & Total \\
& Specific & Pathway & Exposure \\
Chemical & Risk & Risk & Risk \\
\hline
\end{tabular}

Exposure Pathway: Ingestion of Groundwater

$\begin{array}{ll}\text { ARSENIC } & 9 \mathrm{E}-05\end{array}$

9E-05

Exposure Pathway: Inhalation of Volatiles from Groundwater

CHLOROFORM 2E-06

TRICHLOROETHENE 3E-07

2E-06

Exposure Pathway: Dermal Contact with Groundwater

$\begin{array}{ll}\text { ARSENIC } & 2 E-07\end{array}$

4E-07

Exposure Pathway: Incidental Ingestion of Surface Soils

BENZO(A)PYRENE 1E-07

ARSENIC $8 \mathrm{E}-07$

$1 E-06$

Exposure Pathway: Dermal Contact with Surface Soils

$<1 E-07$

Exposure Pathway: Incidental Ingestion of Subsurface Soils

$<1 \mathrm{E}-07$

Exposure Pathway: Dermal Contact with Subsurface Soils

$<1 E-07$

Exposure Pathway: Inhalation of Volatile Contaminants Released from the Soil

$<1 \mathrm{E}-07$ 
Table K.41. ST18 Cancer Risk Estimates

Future Industrial Land Use

Average Exposure Scenario

\begin{tabular}{|c|c|c|}
\hline $\begin{array}{c}\text { Chemical- } \\
\text { Specific } \\
\text { Risk }\end{array}$ & $\begin{array}{c}\text { Total } \\
\text { Pathway } \\
\text { Risk }\end{array}$ & $\begin{array}{c}\text { Total } \\
\text { Exposure } \\
\text { Risk }\end{array}$ \\
\hline \multicolumn{3}{|c|}{ Exposure Pathway: Inhalation of Resuspended Sediments } \\
\hline & $<1 \mathrm{E}-07$ & \\
\hline Total Cancer Risk & & 1E-04 \\
\hline Total Cancer Risk - Site Background Metals & & $2 E-06$ \\
\hline
\end{tabular}


Table K.42. ST18 Cancer Risk Estimates

Future Industrial Land Use

Reasonable Maximum Exposure Scenario

\begin{tabular}{cccc} 
& Chemical- & Total & Total \\
& Specific & Pathway & Exposure \\
Chemical & Risk & Risk & Risk \\
\hline
\end{tabular}

Exposure Pathway: Ingestion of Groundwater

$\begin{array}{ll}\text { ARSENIC 3E-04 } & \end{array}$

$3 E-04$

Exposure Pathway: Inhalation of Volatiles from Groundwater

CHLOROFORM 4E-06

TRICHLOROETHENE 9E-07

5E-06

Exposure Pathway: Dermal Contact with Groundwater

TRICHLOROETHENE 3E-07

ARSENIC 9E-07

$1 E-06$

Exposure Pathway: Incidental Ingestion of Surface Soils

$\begin{array}{ll}\text { BENZO(A)PYRENE } & 4 \mathrm{E}-07 \\ \text { DIBENZ(A,H)ANTHRACENE } & 8 \mathrm{E}-08 \\ \text { INDENO(1,2,3-CD)PYRENE } & 9 \mathrm{E}-08 \\ \text { ARSENIC } & 2 \mathrm{E}-06 \\ \text { BERYUUM } & 2 \mathrm{E}-07\end{array}$

3E-06

Exposure Pathway: Dermal Contact with Surface Soils

BENZO(A)PYRENE 4E-07

ARSENIC 2E-07

9E-07

Exposure Pathway: Incidental Ingestion of Subsurface Soils

$\begin{array}{ll}\text { ARSENIC } & \text { 7E-07 }\end{array}$

7E-07 
Table K.42. ST18 Cancer Risk Estimates

Future Industrial Land Use

Reasonable Maximum Exposure Scenario

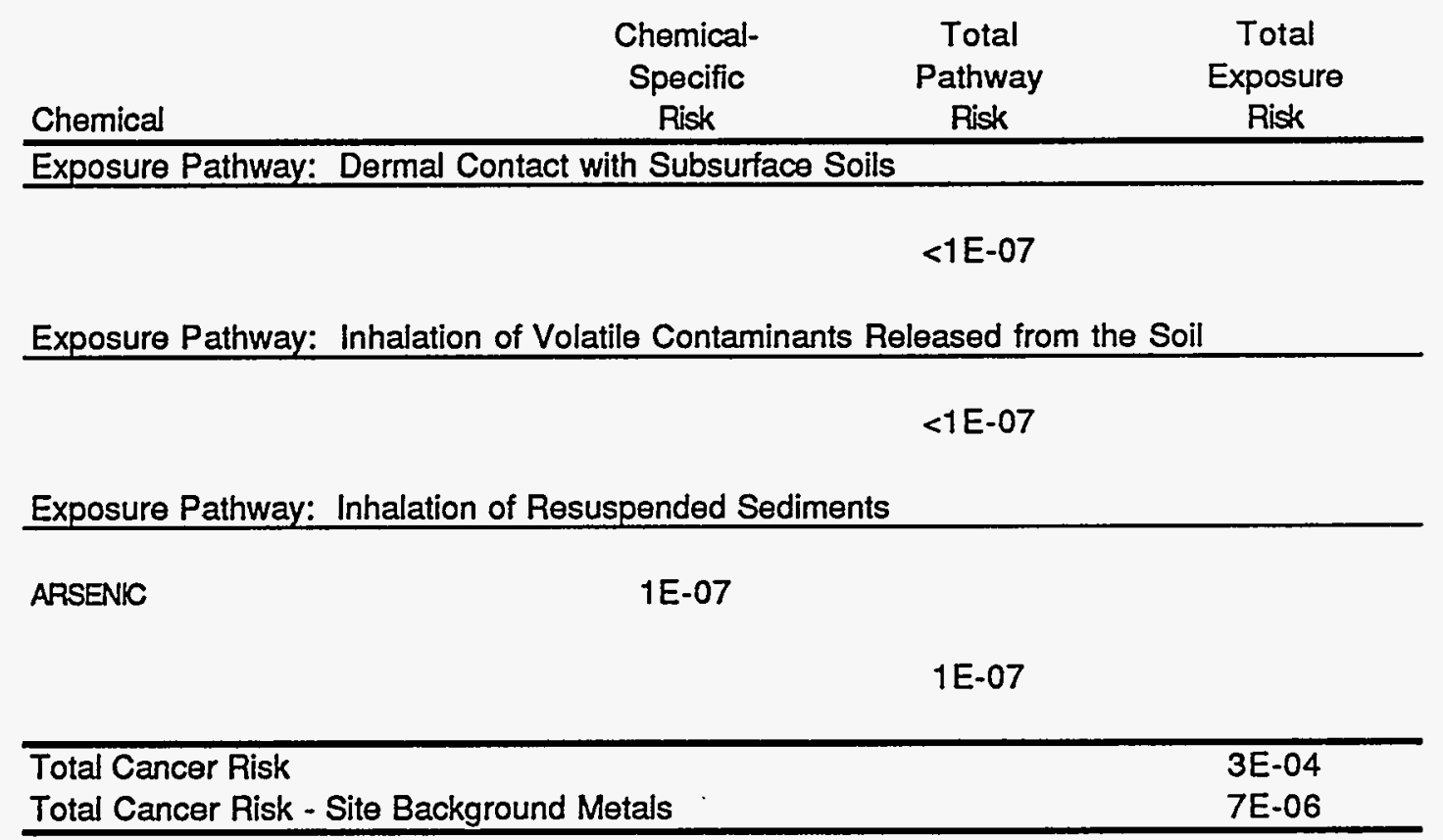


Table K.43. ST18 Hazard Index Estimates

Future Industrial Land Use

Average Exposure Scenario

\begin{tabular}{|c|c|c|c|}
\hline Chemical & $\begin{array}{l}\text { Hazard } \\
\text { Quotient }\end{array}$ & $\begin{array}{l}\text { Pathway } \\
\text { Hazard } \\
\text { Index }\end{array}$ & $\begin{array}{c}\text { Total } \\
\text { Exposure } \\
\text { Hazard } \\
\text { Index }\end{array}$ \\
\hline
\end{tabular}

Exposure Pathway: Ingestion of Groundwater

$\begin{array}{lr}\text { ARSENIC } & 1 \mathrm{E}+00 \\ \text { CADMIUM } & 1 \mathrm{E}-01 \\ \text { MANGANESE } & 1 \mathrm{E}+01 \\ \text { THALIUM } & 1 \mathrm{E}-01\end{array}$

$1 E+01$

Exposure Pathway: Inhalation of Volatiles from Groundwater

$<1 \mathrm{E}-02$

Exposure Pathway: Dermal Contact with Groundwater

$<1 E-02$

Exposure Pathway: Incidental Ingestion of Surface Soils

ARSENIC

$1 E-02$

MANGANESE

$1 \mathrm{E}-01$

$1 E-01$

Exposure Pathway: Dermal Contact with Surface Soils

$<1 E-02$

Exposure Pathway: Incidental Ingestion of Subsurface Soils

MANGANESE 7E-02

7E-02

Exposure Pathway: Dermal Contact with Subsurface Soils

$<1 E-02$

Exposure Pathway: Inhalation of Volatile Contaminants Released from the Soil

$<1 \mathrm{E}-02$ 
Table K.43. ST18 Hazard Index Estimates

Future Industrial Land Use

Average Exposure Scenario

Total

Exposure

Pathway

$\begin{array}{cc}\text { Hazard } & \text { Hazard } \\ \text { Quotient } & \text { Index }\end{array}$

Hazard

Index

Exposure Pathway: Inhalation of Resuspended Sediments

$<1 E-02$

Total Exposure Hazard Index

$1 \mathrm{E}+01$

Total Exposure Hazard Index-Background Metals

5E-03 
Table K.44. ST18 Hazard Index Estimates

Future Industrial Land Use

Reasonable Maximum Exposure Scenario

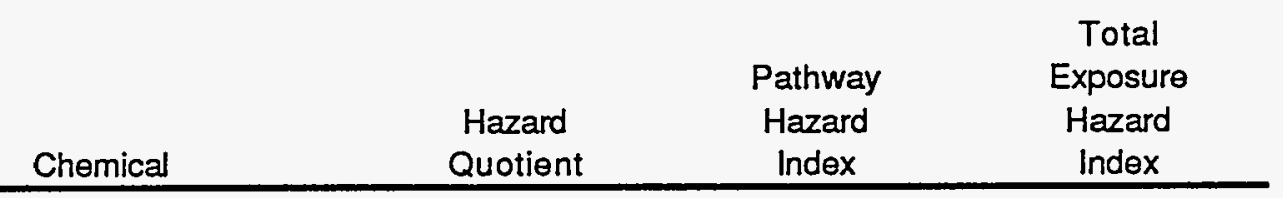

Exposure Pathway: Ingestion of Groundwater

$\begin{array}{lc}\text { ARSENIC } & 1 E+00 \\ \text { CADMIUM } & 1 E-01 \\ \text { MANGANESE } & 1 E+01 \\ \text { THALIUM } & 1 E-01\end{array}$

$1 E+01$

Exposure Pathway: Inhalation of Volatiles from Groundwater

$<1 E-02$

Exposure Pathway: Dermal Contact with Groundwater

$<1 \mathrm{E}-02$

Exposure Pathway: Incidental Ingestion of Surface Soils

ARSENIC

1E-02

MANGANESE 1E-01

1E-01

Exposure Pathway: Dermal Contact with Surface Soils

$<1 E-02$

Exposure Pathway: Incidental Ingestion of Subsurface Soils

MANGANESE 7E-02

7E-02

Exposure Pathway: Dermal Contact with Subsurface Soils

$<1 E-02$

Exposure Pathway: Inhalation of Volatile Contaminants Released from the Soil

$<1 E-02$ 
Table K.44. ST18 Hazard Index Estimates

Future Industrial Land Use

Reasonable Maximum Exposure Scenario

\begin{tabular}{ccc} 
Hazard & Pathway \\
Quotient & $\begin{array}{c}\text { Hazard } \\
\text { Index }\end{array}$ & $\begin{array}{c}\text { Total } \\
\text { Exposure } \\
\text { Hazard } \\
\text { Index }\end{array}$ \\
\hline \multicolumn{3}{l}{ Pathway: Inhalation of Resuspended Sediments } \\
& $<1 \mathrm{E}-02$ & \\
\hline & & $1 \mathrm{E}+01$ \\
\hline & $6 \mathrm{E}-03$ \\
\hline
\end{tabular}

Total Exposure Hazard Index
Total Exposure Hazard Index-Background Metals

$1 E+01$ 
Table K.45. ST18 Cancer Risk Estimates

Future Residential Land Use

Average Exposure Scenario

\begin{tabular}{cccc} 
& Chemical- & Total & Total \\
& Specific & Pathway & Exposure \\
Chemical & Risk & Risk & Risk \\
\hline
\end{tabular}

Exposure Pathway: Ingestion of Groundwater

ARSENIC 1E-04

$1 \mathrm{E}-04$

Exposure Pathway: Inhalation of Volatiles from Groundwater

CHLOROFORM 2E-06

TRICHLOROETHENE 4E-07

2E-06

Exposure Pathway: Dermal Contact with Groundwater

$\begin{array}{ll}\text { TRICHLOROETHENE } & 1 E-07 \\ \text { ARSENIC } & 2 E-07\end{array}$

4E-07

Exposure Pathway: Incidental Ingestion of Surface Soils

$\begin{array}{ll}\text { BENZO(A)PYRENE } & 3 E-07 \\ \text { ARSENIC } & 2 E-06 \\ \text { BERYUUM } & 2 E-07\end{array}$

3E-06

Exposure Pathway: Dermal Contact with Surface Soils

$<1 E-07$

Exposure Pathway: Ingestion of Plants Grown in Contaminated Soils

$\begin{array}{ll}\text { BENZO(A)ANTHRACENE } & 3 E-07 \\ \text { BENZO(A)PYRENE } & 1 E-06 \\ \text { BENZO(B)FLUORANTHENE } & 2 E-07 \\ \text { DIBENZ(A,H)ANTHRACENE } & 5 E-07 \\ \text { PYPENE } & 3 E-07 \\ \text { ARSENIC } & 3 E-06 \\ \text { BERYUUM } & 1 E-07\end{array}$

6E-06 
Table K.45. ST18 Cancer Risk Estimates

Future Residential Land Use

Average Exposure Scenario

\begin{tabular}{lccc} 
& Chemical- & Total & Total \\
& Specific & Pathway & Exposure \\
Chemical & Risk & Risk & Risk \\
\hline Pathway: Incidental Ingestion of Subsurface Soils & \\
\hline
\end{tabular}

ARSENIC

6E-07

$6 \mathrm{E}-07$

Exposure Pathway: Dermal Contact with Subsurface Soils

$$
<1 E-07
$$

Exposure Pathway: Inhalation of Volatile Contaminants Released from the Soil

$$
<1 E-07
$$

Exposure Pathway: Inhalation of Resuspended Sediments

$$
<1 \mathrm{E}-07
$$


Table K.46. ST18 Cancer Risk Estimates

Future Residential Land Use

Reasonable Maximum Exposure Scenario

\begin{tabular}{cccc} 
& Chemical- & Total & Total \\
& Specific & Pathway & Exposure \\
Chemical & Risk & Risk & Risk \\
\hline
\end{tabular}

Exposure Pathway: Ingestion of Groundwater

$\begin{array}{ll}\text { CHLOROFORM } & 1 E-07 \\ \text { TRICHLOROETHENE } & 3 E-07 \\ \text { N-NITROSODIPHENYLAMINE (1) } & 2 E-07 \\ \text { ARSENIC } & 9 E-04\end{array}$

9E-04

Exposure Pathway: Inhalation of Volatiles from Groundwater

CHLOROFORM

TRICHLOROETHENE
7E-06

1E-06

9E-06

Exposure Pathway: Dermal Contact with Groundwater

$\begin{array}{ll}\text { CHLOROFORM } & 1 E-07 \\ \text { TRICHLOROETHENE } & 5 E-07 \\ \text { ARSENIC } & 2 E-06\end{array}$

2E-06

Exposure Pathway: Incidental Ingestion of Surface Soils

\begin{tabular}{ll}
\hline BENZO(A)ANTHRACENE & $3 E-07$ \\
BENZO(A)PYRENE & $3 E-06$ \\
BENZO(B)FLUORANTHENE & $4 E-07$ \\
BENZO(K)FLUORANTHENE & $2 E-07$ \\
DIBENZ(A,H)ANTHRACENE & $6 E-07$ \\
INDENO(1,2,3-CD)PYRENE & $7 E-07$ \\
PYRENE & $3 E-07$ \\
ARSENIC & $2 E-05$ \\
BERYUUM & $2 E-06$
\end{tabular}

$2 \mathrm{E}-05$

Exposure Pathway: Dermal Contact with Surface Soils

$\begin{array}{ll}\text { BENZO(A)ANTHRACENE } & 1 \mathrm{E}-07 \\ \text { BENZO(A)PYRENE } & 8 \mathrm{E}-07 \\ \text { BENZO(B)FLUORANTHENE } & 1 \mathrm{E}-07 \\ \text { DIBENZ(A,H)ANTHRACENE } & 2 \mathrm{E}-07 \\ \text { INDENO(1,2,3-CD)PYRENE } & 2 \mathrm{E}-07\end{array}$


Table K.46. ST18 Cancer Risk Estimates

Future Residential Land Use

Reasonable Maximum Exposure Scenario

\begin{tabular}{|c|c|c|c|}
\hline Chemical & $\begin{array}{c}\text { Chemical- } \\
\text { Specific } \\
\text { Risk }\end{array}$ & $\begin{array}{c}\text { Total } \\
\text { Pathway } \\
\text { Risk }\end{array}$ & $\begin{array}{l}\text { Total } \\
\text { Exposure } \\
\text { Risk }\end{array}$ \\
\hline ARSENIC & $5 E-07$ & & \\
\hline
\end{tabular}

2E-06

Exposure Pathway: Ingestion of Plants Grown in Contaminated Soils

$\begin{array}{ll}\text { BENZO(A)ANTHRACENE } & 1 \mathrm{E}-06 \\ \text { BENZO(A)PYRENE } & 5 \mathrm{E}-06 \\ \text { BENZO(B)FLUORANTHENE } & 7 \mathrm{E}-07 \\ \text { BENZO(K)FLUORANTHENE } & 3 \mathrm{E}-07 \\ \text { DIBENZ(A,H)ANTHRACENE } & 2 \mathrm{E}-06 \\ \text { INDENO(1,2,3-CD)PYRENE } & 7 \mathrm{E}-07 \\ \text { PYPENE } & 1 \mathrm{E}-06 \\ \text { ARSENIC } & 1 \mathrm{E}-05 \\ \text { BERYUUM } & 4 \mathrm{E}-07\end{array}$

3E-05

Exposure Pathway: Incidental Ingestion of Subsurface Soils

ARSENIC 5E-06

$5 E-06$

Exposure Pathway: Dermal Contact with Subsurface Soils

ARSENIC 1E-07

$1 E-07$

Exposure Pathway: Inhalation of Volatile Contaminants Released from the Soil

$<1 E-07$

Exposure Pathway: Inhalation of Resuspended Sediments

ARSENIC $\quad 1 E-07$

1E-07

Total Cancer Risk

$1 E-03$

Total Cancer Risk - Background Metals

$3 E-05$ 
Table K.47. ST18 Hazard Index Estimates

Future Residential Land Use

Average Exposure Scenario

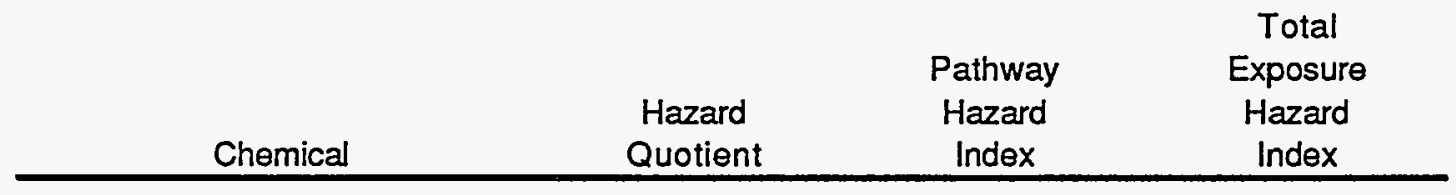

Exposure Pathway: Ingestion of Groundwater

ARSENIC

$2 \mathrm{E}+00$

CADMIUM

2E-01

MANGANESE

2E+01

THALLIUM

2E-01

$$
2 \mathrm{E}+01
$$

Exposure Pathway: Inhalation of Volatiles from Groundwater

$<1 E-02$

Exposure Pathway: Dermal Contact with Groundwater

MANGANESE

3E-02

$4 \mathrm{E}-02$

Exposure Pathway: Incidental Ingestion of Surface Soils

$\begin{array}{ll}\text { ARSENIC } & 1 \mathrm{E}-02 \\ \text { MANGANESE } & 1 \mathrm{E}-01\end{array}$

1E-01

Exposure Pathway: Dermal Contact with Surface Soils

$<1 \mathrm{E}-02$

Exposure Pathway: Ingestion of Plants Grown in Contaminated Soils

$\begin{array}{ll}\text { ARSENIC } & 5 \mathrm{E}-02 \\ \text { MANGANESE } & 1 \mathrm{E}+01\end{array}$

$1 \mathrm{E}+01$

Exposure Pathway: Incidental Ingestion of Subsurface Soils

MANGANESE $\quad 2 E-01$

2E-01

Exposure Pathway: Dermal Contact with Subsurface Soils 
Table K.47. ST18 Hazard Index Estimates

Future Residential Land Use

Average Exposure Scenario

\begin{tabular}{|c|c|c|c|}
\hline Chemical & $\begin{array}{l}\text { Hazard } \\
\text { Quotient }\end{array}$ & $\begin{array}{l}\text { Pathway } \\
\text { Hazard } \\
\text { Index }\end{array}$ & $\begin{array}{l}\text { Total } \\
\text { Exposure } \\
\text { Hazard } \\
\text { Index }\end{array}$ \\
\hline & & $<1 \mathrm{E}-02$ & \\
\hline
\end{tabular}

Exposure Pathway: Inhalation of Volatile Contaminants Released from the Soil

$<1 E-02$

Exposure Pathway: Inhalation of Resuspended Sediments

$<1 E-02$

Total Exposure Hazard Index

$3 E+01$

Total Exposure Hazard Index-Site Background Metals

$7 \mathrm{E}-03$ 
Table K.48. ST18 Hazard Index Estimates

Future Residential Scenario

Reasonable Maximum Exposure Scenario

Total

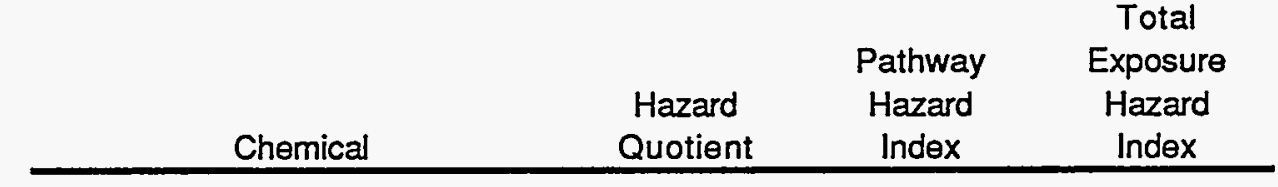

Exposure Pathway: Ingestion of Groundwater

$\begin{array}{ll}\text { ARSENIC } & 4 E+00 \\ \text { CADMUM } & 3 E-01 \\ \text { MANGANESE } & 3 E+01 \\ \text { THALLIUM } & 4 E-01\end{array}$

$4 E+01$

Exposure Pathway: Inhalation of Volatiles from Groundwater

$<1 E-02$

Exposure Pathway: Dermal Contact with Groundwater

$<1 E-02$

Exposure Pathway: Incidental Ingestion of Surface Soils

ARSENIC $\quad 8 E-02$

MANGANESE 7E-01

8E-01

Exposure Pathway: Dermal Contact with Surface Soils

MANGANESE 2E-02

2E-02

Exposure Pathway: Ingestion of Plants Grown in Contaminated Soils

ARSENIC 7E-02

MANGANESE $\quad 2 E+01$

$2 \mathrm{E}+01$

Exposure Pathway: Incidental Ingestion of Subsurface Soils

MANGANESE

5E-01

$5 E-01$ 
Table K.48. ST18 Hazard Index Estimates

Future Residential Scenario

Reasonable Maximum Exposure Scenario

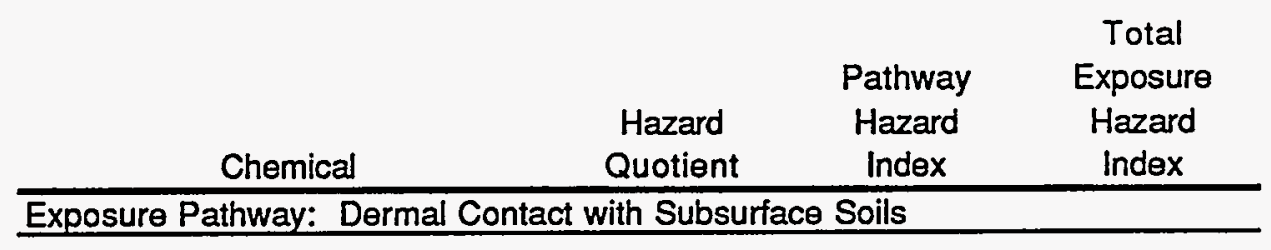

MANGANESE 1E-02

1E-02

Exposure Pathway: Inhalation of Volatile Contaminants Released from the Soil

$<1 \mathrm{E}-02$

Exposure Pathway: Inhalation of Resuspended Sediments

$<1 E-02$

Total Exposure Hazard Index

$5 \mathrm{E}+01$

Total Exposure Hazard Index-Background Metals

$1 \mathrm{E}-02$ 
Table K.49. ST19 Cancer Risk Estimates

Current Industrial Land Use

Average Exposure Scenario

\begin{tabular}{cccc} 
& Chemical- & Total & Total \\
& Specific & Pathway & Exposure \\
Chemical & Risk & Risk & Risk \\
\hline
\end{tabular}

Exposure Pathway: Incidental Ingestion of Surface Soils

ARSENIC $\quad 1 E-06$

1E-06

Exposure Pathway: Dermal Contact with Surface Soils

$<1 \mathrm{E}-07$

Exposure Pathway: Incidental Ingestion of Subsurface Soils

$\begin{array}{ll}\text { ARSENIC } & 3 E-07\end{array}$

3E-07

Exposure Pathway: Dermal Contact with Subsurface Soils

$<1 E-07$

Exposure Pathway: Inhalation of Volatile Contaminants Released from the Soil

$<1 E-07$

Exposure Pathway: Inhalation of Resuspended Sediments

$<1 \mathrm{E}-07$

Total Cancer Risk

2E-06

Total Cancer Risk - Site Background Metals

$2 \mathrm{E}-08$ 
Table K.50. ST19 Cancer Risk Estimates

Current Industrial Land Use

Reasonable Maximum Exposure Scenario

\begin{tabular}{lccc} 
Chemical & $\begin{array}{c}\text { Chemical- } \\
\text { Specific } \\
\text { Risk }\end{array}$ & $\begin{array}{c}\text { Total } \\
\text { Pathway } \\
\text { Risk }\end{array}$ & $\begin{array}{c}\text { Total } \\
\text { Exposure } \\
\text { Risk }\end{array}$ \\
\hline Exposure Pathway: Incidental Ingestion of Surface Soils & \\
\hline ARSENIC & $3 E-06$ & & \\
BERYLUM & $1 E-07$ &
\end{tabular}

4E-06

Exposure Pathway: Dermal Contact with Surface Soils

ARSENIC $\quad 3 E-07$

4E-07

Exposure Pathway: Incidental Ingestion of Subsurface Soils

ARSENIC 7E-07

8E-07

Exposure Pathway: Dermal Contact with Subsurface Soils

1E-07

Exposure Pathway: Inhalation of Volatile Contaminants Released from the Soil

$<1 E-07$

Exposure Pathway: Inhalation of Resuspended Sediments

$\begin{array}{ll}\text { ARSENIC 2E-07 } & \end{array}$

$2 \mathrm{E}-07$

Total Cancer Risk

$5 E-06$

Total Cancer Risk - Site Background Metals

$7 E-08$ 
Table K.51. ST19 Hazard Index Estimates Current Industrial Land Use

Average Exposure Scenario

\begin{tabular}{ccc} 
Hazard & Pathway & Exposure \\
Chemical & Hazard & Hazard \\
Index \\
\hline
\end{tabular}

Exposure Pathway: Incidental Ingestion of Surface Soils

ARSENIC 2E-02

MANGANESE 1E-01

2E-01

Exposure Pathway: Dermal Contact with Surface Soils

$<1 E-02$

Exposure Pathway: Incidental Ingestion of Subsurface Soils

$\begin{array}{ll}\text { MANGANESE } & 3 \mathrm{E}-02\end{array}$

4E-02

Exposure Pathway: Dermal Contact with Subsurface Soils

$<1 E-02$

Exposure Pathway: Inhalation of Volatile Contaminants Released from the Soil

$<1 \mathrm{E}-02$

Exposure Pathway: Inhalation of Resuspended Sediments

$<1 E-02$

\begin{tabular}{ll}
\hline Total Exposure Hazard Index & $2 \mathrm{E}-01$ \\
Total Exposure Hazard Index-Site Background Metals & $5 \mathrm{E}-06$ \\
\hline
\end{tabular}

K.100 
Table K.52. ST19 Hazard Risk Estimates

Current Industrial Land Use

Reasonable Maximum Exposure Scenario

Total

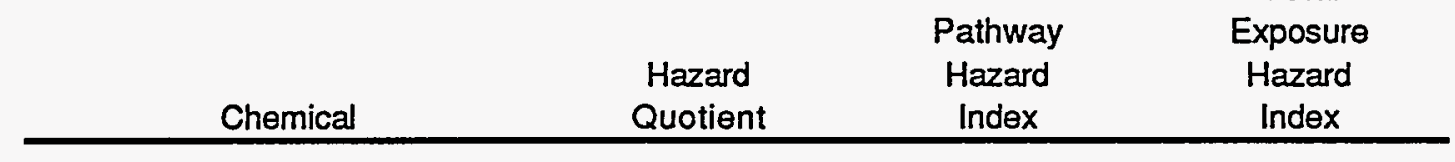

Exposure Pathway: Incidental Ingestion of Surface Soils

$\begin{array}{ll}\text { ARSENIC } & 2 \mathrm{E}-02 \\ \text { MANGANESE } & 1 \mathrm{E}-01\end{array}$

2E-01

Exposure Pathway: Dermal Contact with Surface Soils

MANGANESE

1E-02

2E-02

Exposure Pathway: Incidental Ingestion of Subsurface Soils

MANGANESE $\quad 3 E-02$

4E-02

Exposure Pathway: Dermal Contact with Subsurface Soils

$<1 E-02$

Exposure Pathway: Inhalation of Volatile Contaminants Released from the Soil

$<1 E-02$

Exposure Pathway: Inhalation of Resuspended Sediments

$$
<1 E-02
$$

Total Cancer Risk

2E-01

Total Cancer Risk - Site Background Metals

$9 \mathrm{E}-06$ 
Table K.53. ST19 Cancer Risk Estimates

Future Industrial Land Use

Average Exposure Scenario

\begin{tabular}{cccc} 
& Chemical- & Total & Total \\
& Specific & Pathway & Exposure \\
Chemical & Risk & Risk & Risk \\
\hline
\end{tabular}

Exposure Pathway: Ingestion of Groundwater

$\begin{array}{ll}\text { BENLENE } & 3 E-07 \\ \text { ARSENIC } & 9 E-05 \\ \text { BERYUUM } & 2 E-06\end{array}$

9E-05

Exposure Pathway: Inhalation of Volatiles from Groundwater

BENRENE 2E-06

2E-06

Exposure Pathway: Dermal Contact with Groundwater

$\begin{array}{ll}\text { BENRENE } & 3 \mathrm{E}-07 \\ \text { ARSENIC } & 2 \mathrm{E}-07\end{array}$

$5 \mathrm{E}-07$

Exposure Pathway: Incidental Ingestion of Surface Soils

ARSENIC

1E-06

1E-06

Exposure Pathway: Dermal Contact with Surface Soils

$<1 E-07$

Exposure Pathway: Incidental Ingestion of Subsurface Soils

$<1 E-07$

Exposure Pathway: Dermal Contact with Subsurface Soils

$<1 E-07$

Exposure Pathway: Inhalation of Volatile Contaminants Released from the Soil

$<1 E-07$ 
Table K.53. ST19 Cancer Risk Estimates

Future Industrial Land Use

Average Exposure Scenario

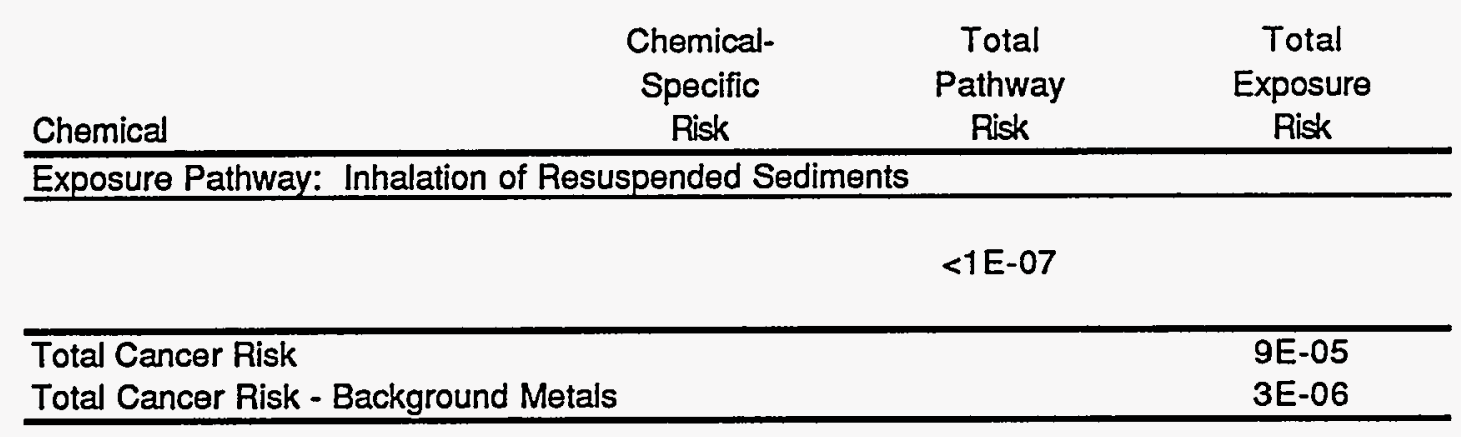


Table K.54. ST19 Cancer Risk Estimates

Future Industrial Land Use

Reasonable Maximum Exposure Scenario

\begin{tabular}{cccc} 
& Chemical- & Total & Total \\
& Specific & Pathway & Exposure \\
Chemical & Risk & Risk & Risk \\
\hline
\end{tabular}

Exposure Pathway: Ingestion of Groundwater

$\begin{array}{ll}\text { BENZENE } & 9 E-07 \\ \text { ARSENIC } & 2 E-04 \\ \text { BERYUUM } & 5 E-06\end{array}$

3E-04

Exposure Pathway: Inhalation of Volatiles from Groundwater

BENTENE 6E-06

$6 E-06$

Exposure Pathway: Dermal Contact with Groundwater

$\begin{array}{ll}\text { BENEENE } & 1 E-06 \\ \text { ARSENIC } & 8 \mathrm{E}-07\end{array}$

2E-06

Exposure Pathway: Incidental Ingestion of Surface Soils

ARSENIC 3E-06

BERYUUM $\quad 1 E-07$

4E-06

Exposure Pathway: Dermal Contact with Surface Soils

$\begin{array}{ll}\text { ARSENIC } & 3 E-07\end{array}$

4E-07

Exposure Pathway: Incidental Ingestion of Subsurface Soils

$\begin{array}{ll}\text { ARSENIC } & 7 E-07\end{array}$

$8 \mathrm{E}-07$

Exposure Pathway: Dermal Contact with Subsurface Soils

$1 \mathrm{E}-07$ 
Table K.54. ST19 Cancer Risk Estimates

Future Industrial Land Use

Reasonable Maximum Exposure Scenario

\begin{tabular}{|c|c|c|c|}
\hline Chemical & $\begin{array}{c}\text { Chemical- } \\
\text { Specific } \\
\text { Risk }\end{array}$ & $\begin{array}{c}\text { Total } \\
\text { Pathway } \\
\text { Risk }\end{array}$ & $\begin{array}{c}\text { Total } \\
\text { Exposure } \\
\text { Risk }\end{array}$ \\
\hline Exposure $\mathrm{F}$ & tile Contam & leased fror & \\
\hline
\end{tabular}

Exposure Pathway: Inhalation of Resuspended Sediments

$\begin{array}{ll}\text { ARSENIC } & 2 \mathrm{E}-07\end{array}$

2E-07

Total Cancer Risk

3E-04

Total Cancer Risk - Site Background Metals

$8 \mathrm{E}-06$ 
Table K.55. ST19 Hazard Index Estimates

Future Industrial Land Use

Average Exposure Scenario

\begin{tabular}{|c|c|c|c|}
\hline Chemical & $\begin{array}{l}\text { Hazard } \\
\text { Quotient }\end{array}$ & $\begin{array}{c}\text { Pathway } \\
\text { Hazard } \\
\text { Index }\end{array}$ & $\begin{array}{c}\text { Total } \\
\text { Exposure } \\
\text { Hazard } \\
\text { Index }\end{array}$ \\
\hline
\end{tabular}

Exposure Pathway: Ingestion of Groundwater

$\begin{array}{lc}\text { ETHMBENRENE } & 7 E-02 \\ \text { TOLUENE } & 9 \mathrm{E}-02 \\ \text { XYLENES (TOTAL) } & 2 \mathrm{E}-02 \\ \text { ANTIMONY } & 6 \mathrm{E}-01 \\ \text { ARSENIC } & 1 \mathrm{E}+00 \\ \text { BARIUM } & 3 \mathrm{E}-02 \\ \text { CADMIUM } & 4 \mathrm{E}-02 \\ \text { MANGANESE } & 5 \mathrm{E}+01 \\ \text { THALLIUM } & 1 \mathrm{E}-01\end{array}$

$5 E+01$

Exposure Pathway: Inhalation of Volatiles from Groundwater

ETHYBENZENE 2E-01

TOLUENE 2E-01

XYLENES (TOTAL) $\quad 3 E+00$

$3 E+00$

Exposure Pathway: Dermal Contact with Groundwater

ETHYBENZENE $\quad 9 E-01$

TOLUENE $\quad 1 E+00$

XYLENES (TOTAL) 2E-02

MANGANESE $1 E-01$

$2 E+00$

Exposure Pathway: Incidental Ingestion of Surface Soils

ARSENIC 2E-02

MANGANESE $1 E-01$

2E-01

Exposure Pathway: Dermal Contact with Surface Soils

$<1 \mathrm{E}-02$ 
Table K.55. ST19 Hazard Index Estimates

Future Industrial Land Use

Average Exposure Scenario

Total

\begin{tabular}{|c|c|c|c|}
\hline Chemical & $\begin{array}{l}\text { Hazard } \\
\text { Quotient }\end{array}$ & $\begin{array}{c}\text { Pathway } \\
\text { Hazard } \\
\text { Index }\end{array}$ & $\begin{array}{l}\text { Total } \\
\text { Exposure } \\
\text { Indexard }\end{array}$ \\
\hline Exposure & th Subsurf & & \\
\hline
\end{tabular}

Exposure Pathway: Inhalation of Volatile Contaminants Released from the Soil

$<1 E-02$

Exposure Pathway: Inhalation of Resuspended Sediments

$$
<1 E-02
$$


Table K.56. ST19 Hazard Index Estimates

Future Industrial Land Use

Reasonable Maximum Exposure Scenario

Total

\begin{tabular}{ccc} 
Hazard & Pathway & Exposure \\
Chemical & Hazard & Hazard \\
Index & Qndex \\
\hline
\end{tabular}

Exposure Pathway: Ingestion of Groundwater

$\begin{array}{lc}\text { ETHMLENRENE } & 7 \mathrm{E}-02 \\ \text { TOLUENE } & 9 \mathrm{E}-02 \\ \text { XYLENES (TOTAL) } & 2 \mathrm{E}-02 \\ \text { ANTIMONY } & 6 \mathrm{E}-01 \\ \text { ARSENIC } & 1 \mathrm{E}+00 \\ \text { BARIUM } & 3 \mathrm{E}-02 \\ \text { CADMIUM } & 4 \mathrm{E}-02 \\ \text { MANGANESE } & 5 \mathrm{E}+01 \\ \text { THALLIUM } & 1 \mathrm{E}-01\end{array}$

$5 E+01$

Exposure Pathway: Inhalation of Volatiles from Groundwater

$\begin{array}{ll}\text { ETHMLENEENE } & 2 \mathrm{E}-01 \\ \text { TOLUENE } & 2 \mathrm{E}-01 \\ \text { XYLENES (TOTAL) } & 5 \mathrm{E}+00\end{array}$

$5 E+00$

Exposure Pathway: Dermal Contact with Groundwater

$\begin{array}{ll}\text { ETHMBENRENE } & 1 E+00 \\ \text { TOLUENE } & 1 E+00 \\ \text { XYLENES (TOTAL) } & 2 E-02 \\ \text { MANGANESE } & 2 E-01\end{array}$

$2 E+00$

Exposure Pathway: Incidental Ingestion of Surface Soils

$\begin{array}{ll}\text { ARSENIC } & 2 \mathrm{E}-02 \\ \text { MANGANESE } & 1 \mathrm{E}-01\end{array}$

2E-01

Exposure Pathway: Dermal Contact with Surface Soils

MANGANESE $\quad 1 E-02$

2E-02 
Table K.56. ST19 Hazard Index Estimates

Future Industrial Land Use

Reasonable Maximum Exposure Scenario

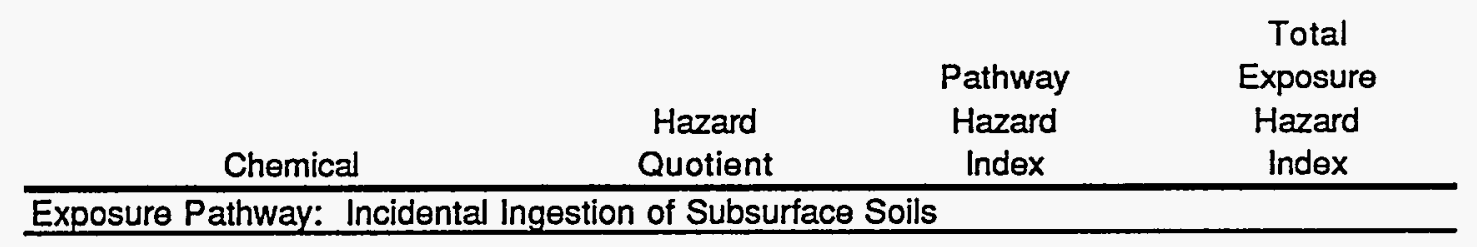

MANGANESE

3E-02

4E-02

Exposure Pathway: Dermal Contact with Subsurface Soils

$<1 E-02$

Exposure Pathway: Inhalation of Volatile Contaminants Released from the Soil

$<1 E-02$

Exposure Pathway: Inhalation of Resuspended Sediments

$<1 E-02$

Total Exposure Hazard Index

$6 E+01$

Total Exposure Hazard Index-Site Background Metals

$7 E+00$ 
Table K.57. ST19 Cancer Risk Estimates

Future Residential Land Use

Average Exposure Scenario

Chemical-

Specific

Total

Total

Chemical

Risk

Pathway

Exposure

Risk

Risk

Exposure Pathway: Ingestion of Groundwater

$\begin{array}{ll}\text { BENEENE } & 5 E-07 \\ \text { ARSENIC } & 1 E-04 \\ \text { BERYUUM } & 3 E-06\end{array}$

$1 E-04$

Exposure Pathway: Inhalation of Volatiles from Groundwater

BENZENE 3E-06

3E-06

Exposure Pathway: Dermal Contact with Groundwater

$\begin{array}{ll}\text { BENLENE } & 4 \mathrm{E}-07 \\ \text { ARSENIC } & 2 \mathrm{E}-07\end{array}$

$6 \mathrm{E}-07$

Exposure Pathway: Incidental Ingestion of Surface Soils

$\begin{array}{ll}\text { ARSENIC } & 3 E-06 \\ \text { BERYLUUM } & 1 E-07\end{array}$

3E-06

Exposure Pathway: Dermal Contact with Surface Soils

$<1 \mathrm{E}-07$

Exposure Pathway: Ingestion of Plants Grown in Contaminated Soils

ARSENIC 6E-06

6E-06 
Table K.57. ST19 Cancer Risk Estimates

Future Residential Land Use

Average Exposure Scenario

\begin{tabular}{cccc} 
& Chemical- & Total & Total \\
& Specific & Pathway & Exposure \\
Chemical & Risk & Risk & Risk \\
\hline Exposure Pathway: Incidental Ingestion of Subsurface Soils & \\
\hline
\end{tabular}

ARSENIC

7E-07

7E-07

Exposure Pathway: Dermal Contact with Subsurface Soils

$<1 E-07$

Exposure Pathway: Inhalation of Volatile Contaminants Released from the Soil

$$
<1 E-07
$$

Exposure Pathway: Inhalation of Resuspended Sediments

$$
<1 E-07
$$

\begin{tabular}{ll}
\hline Total Cancer Risk & $2 \mathrm{E}-04$ \\
Total Cancer Risk - Site Background Metals & $3 \mathrm{E}-06$ \\
\hline
\end{tabular}


Table K.58. ST19 Cancer Risk Estimates

Future Residential Land Use

Reasonable Maximum Exposure Scenario

\begin{tabular}{cccc} 
& Chemical- & Total & Total \\
& Specific & Pathway & Exposure \\
Chemical & Risk & Risk & Risk \\
\hline
\end{tabular}

Exposure Pathway: Ingestion of Groundwater

$\begin{array}{ll}\text { BENZENE } & 3 E-06 \\ \text { ARSENIC } & 8 \mathrm{E}-04 \\ \text { BERYUUUM } & 2 \mathrm{E}-05\end{array}$

$8 \mathrm{E}-04$

Exposure Pathway: Inhalation of Volatiles from Groundwater

BENZENE 1E-05

$1 E-05$

Exposure Pathway: Dermal Contact with Groundwater

$\begin{array}{ll}\text { BENTENE } & 2 E-06 \\ \text { ARSENIC } & 1 E-06\end{array}$

3E-06

Exposure Pathway: Incidental Ingestion of Surface Soils

$\begin{array}{ll}\text { ARSENIC } & 3 E-05 \\ \text { BERYUUM } & 1 E-06\end{array}$

3E-05

Exposure Pathway: Dermal Contact with Surface Soils

ARSENIC

8E-07

$8 E-07$

Exposure Pathway: Ingestion of Plants Grown in Contaminated Soils

ARSENIC

2E-05

BERYUUM

$3 \mathrm{E}-07$

2E-05 
Table K.58. ST19 Cancer Risk Estimates

Future Residential Land Use

Reasonable Maximum Exposure Scenario

$\begin{array}{cccc} & \text { Chemical- } & \text { Total } & \text { Total } \\ & \text { Specific } & \text { Pathway } & \text { Exposure } \\ \text { Chemical } & \text { Risk } & \text { Risk } & \text { Risk }\end{array}$

Exposure Pathway: Incidental Ingestion of Subsurface Soils

ARSENIC 6E-06

6E-06

Exposure Pathway: Dermal Contact with Subsurface Soils

ARSENIC 2E-07

2E-07

Exposure Pathway: Inhalation of Volatile Contaminants Released from the Soil

$<1 E-07$

Exposure Pathway: Inhalation of Resuspended Sediments

ARSENIC 2E-07

$2 E-07$

Total Cancer Risk

9E-04

Total Cancer Risk - Site Background Metals

2E-05 
Table K.59. ST19 Hazard Index Estimates

Future Residential Land Use

Average Exposure Scenario

Total

$\begin{array}{ccc} & \text { Pathway } & \text { Exposure } \\ \text { Chemical } & \text { Hazard } & \text { Hazard } \\ \text { Qndex } & \text { Hazard } \\ \text { Index }\end{array}$

Exposure Pathway: Ingestion of Groundwater

$\begin{array}{lc}\text { ETHMBENIENE } & 1 \mathrm{E}-01 \\ \text { TOLUENE } & 1 \mathrm{E}-01 \\ \text { XYLENES (TOTAL) } & 3 \mathrm{E}-02 \\ \text { ANTIMONY } & 1 \mathrm{E}+00 \\ \text { ARSENIC } & 2 \mathrm{E}+00 \\ \text { BARIUM } & 5 \mathrm{E}-02 \\ \text { CADMIUM } & 6 \mathrm{E}-02 \\ \text { MANGANESE } & 8 \mathrm{E}+01 \\ \text { THALLIUM } & 2 \mathrm{E}-01\end{array}$

$8 \mathrm{E}+01$

Exposure Pathway: Inhalation of Volatiles from Groundwater

$\begin{array}{ll}\text { ETHMBENTENE } & 2 \mathrm{E}-01 \\ \text { TOLUENE } & 3 \mathrm{E}-01 \\ \text { XYLENES (TOTAL) } & 3 \mathrm{E}+00\end{array}$

$4 E+00$

Exposure Pathway: Dermal Contact with Groundwater

$\begin{array}{ll}\text { ETHYBENEENE } & 1 E+00 \\ \text { TOLUENE } & 1 E+00 \\ \text { XYLENES (TOTAL) } & 2 E-02 \\ \text { MANGANESE } & 1 E-01\end{array}$

$2 E+00$

Exposure Pathway: Incidental Ingestion of Surface Soils

ARSENIC 2E-02

MANGANESE 2E-01

2E-01

Exposure Pathway: Dermal Contact with Surface Soils

$<1 E-02$

Exposure Pathway: Ingestion of Plants Grown in Contaminated Soils

$\begin{array}{ll}\text { ARSENIC } & 8 \mathrm{E}-02\end{array}$ 
Table K.59. ST19 Hazard Index Estimates

Future Residential Land Use

Average Exposure Scenario

Total

\begin{tabular}{|c|c|c|c|}
\hline Chemical & $\begin{array}{l}\text { Hazard } \\
\text { Quotient }\end{array}$ & $\begin{array}{l}\text { Pathway } \\
\text { Hazard } \\
\text { Index }\end{array}$ & $\begin{array}{c}\text { Exposure } \\
\text { Hazard } \\
\text { Index }\end{array}$ \\
\hline MANGANESE & $2 E+01$ & & \\
\hline
\end{tabular}

$2 E+01$

Exposure Pathway: Incidental Ingestion of Subsurface Soils

ARSENIC

$1 \mathrm{E}-02$

MANGANESE

9E-02

$1 E-01$

Exposure Pathway: Dermal Contact with Subsurface Soils

$<1 E-02$

Exposure Pathway: Inhalation of Volatile Contaminants Released from the Soil

$<1 E-02$

Exposure Pathway: Inhalation of Resuspended Sediments

$<1 E-02$

Total Exposure Hazard Index

$1 \mathrm{E}+02$

Total Exposure Hazard Index-Site Background Metals

$6 \mathrm{E}+00$

K.115 
Table K.60. ST19 Hazard Index Estimates

Future Residential Scenario

Reasonable Maximum Exposure Scenario

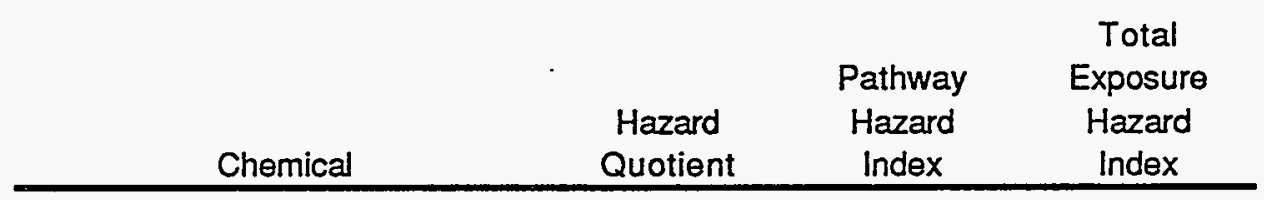

Exposure Pathway: Ingestion of Groundwater

$\begin{array}{ll}\text { ETHMLENZENE } & 2 E-01 \\ \text { TOLUENE } & 2 E-01 \\ \text { XYLENES (TOTAL) } & 5 E-02 \\ \text { ANTIMONY } & 2 E+00 \\ \text { ARSENIC } & 4 E+00 \\ \text { BARIUM } & 9 E-02 \\ \text { CADMIUM } & 1 E-01 \\ \text { MANGANESE } & 1 E+02 \\ \text { THALLUUM } & 3 E-01\end{array}$

$2 E+02$

Exposure Pathway: Inhalation of Volatiles from Groundwater

$\begin{array}{ll}\text { ETHMLBENZENE } & 3 E-01 \\ \text { TOLUENE } & 3 E-01 \\ \text { XYLENES (TOTAL) } & 4 E+00\end{array}$

$5 E+00$

Exposure Pathway: Dermal Contact with Groundwater

$\begin{array}{ll}\text { ETHYLENZENE } & 1 E+00 \\ \text { TOLUENE } & 2 E+00 \\ \text { XYLENES (TOTAL) } & 3 E-02 \\ \text { MANGANESE } & 2 E-01\end{array}$

$$
3 E+00
$$

Exposure Pathway: Incidental Ingestion of Surface Soils

$\begin{array}{ll}\text { ARSENIC } & 1 \mathrm{E}-01 \\ \text { MANGANESE } & 9 \mathrm{E}-01\end{array}$

$1 E+00$

Exposure Pathway: Dermal Contact with Surface Soils

MANGANESE 3E-02

3E-02 
Table K.60. ST19 Hazard Index Estimates

Future Residential Scenario

Reasonable Maximum Exposure Scenario

\begin{tabular}{|c|c|c|c|}
\hline Chemical & $\begin{array}{c}\text { Hazard } \\
\text { Quotient }\end{array}$ & $\begin{array}{c}\text { Pathway } \\
\text { Hazard } \\
\text { Index }\end{array}$ & $\begin{array}{c}\text { Total } \\
\text { Exposure } \\
\text { Hazard } \\
\text { Index }\end{array}$ \\
\hline \multicolumn{4}{|c|}{ Exposure Pathway: Ingestion of Plants Grown in Contaminated Soils } \\
\hline $\begin{array}{l}\text { ARSENIC } \\
\text { MANGANESE }\end{array}$ & $\begin{array}{l}1 E-01 \\
2 E+01\end{array}$ & $2 E+01$ & \\
\hline \multicolumn{4}{|c|}{ Exposure Pathway: Incidental Ingestion of Subsurface Soils } \\
\hline MANGANESE & $\begin{array}{l}3 E-02 \\
2 E-01\end{array}$ & $3 E-01$ & \\
\hline Exposure Pathway: $D e$ & with Subsu & Soils & \\
\hline
\end{tabular}

$$
<1 E-2
$$

Exposure Pathway: Inhalation of Volatile Contaminants Released from the Soil

$$
<1 E-2
$$

Exposure Pathway: Inhalation of Resuspended Sediments

MANGANESE

$1 E-02$

1E-02

\begin{tabular}{ll}
\hline Total Exposure Hazard Index & $2 \mathrm{E}+02$ \\
Total Exposure Hazard Index-Site Background Metals & $8 \mathrm{E}+00$ \\
\hline
\end{tabular}




\section{Eielson Air Force Base \\ Baseline Risk Assessment}

Appendix L

Demographic Information 


\section{APPENDIX L--DEMOGRAPHIC INFORMATION}

Eielson Air Force Base (AFB) covers an area of approximately 19,270 acres, located approximately 25 miles southeast of Fairbanks, Alaska. Military operations have existed at the site almost continuously since 1944. However, a major construction program between 1947 and 1954 greatly expanded operations. The Base is contiguous to Fort Wainwright, an Army Facility much larger than Eielson AFB.

The mission of Eielson AFB is to train and equip personnel for close air support of ground troops in an arctic environment (Eielson AFB Comprehensive Plan Narrative, June 1987). Eielson AFB operations include industrial areas, aircraft maintenance and operations, an active runway and associated facilities, and administrative offices, as well as residential and recreation facilities.

Eielson AFB is a major employer in the Fairbanks area. The Base employs approximately 3,400 military personnel and 500 civilians (Eielson AFB Comprehensive Plan Narrative, June 1987). The total population (living and working on the Base) is approximately 10,000. The total residential population of Eielson AFB is 5,132 (telephone conversation Public Affairs Office, April 1992). Residential and occupational populations are primarily concentrated in the developed portion of the Base.

Demographics information is available on an annual basis from the Economic Resource Impact Statement prepared for Eielson AFB. Long-range demographic and housing/zoning information was not available, and is not compiled as a planning activity, because of the changing nature of military activities and the related Base staffing requirements. Generally, military staffing results in short periods of residence at Eielson AFB, when compared to civilian residential durations.

The area is active with ongoing Base functions, including work, school, and recreational activities. The Base contains two elementary schools, one middle school, and one juniorsenior high school. There is one child care center and one medical and dental clinic.

The Base boundary is fenced and guarded. However most of the Operational Unit 2 source areas are unfenced or partially fenced, and are accessible to onsite personnel.

Several areas of the Base are used for recreation, hunting, fishing, picnicking and camping by onsite personnel and families. The Operable Unit 2 source areas are located within the industrial areas of the Base, and none are used for recreation.

Long-range land-use plans (Eielson Air Force Base 1992) indicate All Operable Unit 2 sites will remain industrial sites for the foreseeable future. Site ST19 is located within a designated wetland; therefore, no development is planned for this site.

Currently, the potentially exposed population at the Operable Unit 2 sites is on duty military personnel, civilian employees of the Air Force, and seasonal contractor personnel. The military personnel typically work at Eielson for 6 years or less (personal communication, Julie Stringer 1992).

There are a limited number of personnel based at all Operable Unit 2 sites except ST19. There are no personnel at ST19. Observations of the work patterns during summer 1992 suggest that personnel assigned to these sites spend little work time ( $<2$ hours per day) outdoors. There are no residences at any of the sites. 
Site ST10/SS14 has a drinking water supply well (Base Supply Well 14) that penetrates the groundwater contamination and is completed at a depth of 95 feet. No contamination was detected in water samples collected from this well in 1991. The water is used for a rest room and an emergency shower. Bottled water is provided for drinking.

It is doubtful that either surface water body adjacent to Operable Unit 2, Hardfill Lake and Garrison Slough, could support subsistence fishing. No fish were found during water sampling at the lake in 1991 (personal communication, Heidi Hoffman 1992), and Garrison Slough is less than one meter deep adjacent to ST11.

\section{REFERENCES}

Eielson Air Force Base. 1992. Eielson Air Force Base Comprehensive Land-Use Plan. Eielson Air Force Base, Fairbanks, Alaska. 


\title{
Eielson Air Force Base Baseline Risk Assessment
}

\author{
Appendix M \\ Models Used for Outdoor Volatilization and Particle \\ Resuspension
}




\section{APPENDIX M--MODELS USED FOR OUTDOOR VOLATILIZATION AND PARTICLE RESUSPENSION}

\section{M.1 VOLATILIZATION}

In accordance with EPA (1991a), a volatile contaminant is defined as a chemical having a unitless Henry's law constant exceeding $10^{-4}$ and molecular weight less than 200 . For volatile compounds in soil, the outdoor ambient air concentrations of the volatiles were computed as $C_{\text {air }}=C_{\text {soil }} / V F$, where $C_{\text {air }}$ and $C_{\text {soil }}$ are concentrations in air $\left(\mathrm{mg} / \mathrm{m}^{3}\right)$ and in soil (mg/kg), respectively, and $V F\left(\mathrm{~m}^{3} / \mathrm{kg}\right)$ is the soil-to-air volatilization factor. This factor was developed in Hwang and Falco (1986) and is given in EPA (1991b) as

$$
V F=\frac{(L S \times V \times D H)}{A} \times \frac{(3.14 \times \alpha \times T)^{1 / 2}}{\left(2 \times D_{e i} \times E \times K_{a s} \times 10^{-3 \mathrm{~kg} / \mathrm{g}}\right)}
$$

where

$$
\alpha=\frac{\left(D_{e i} \times E\right)}{E+\left(p_{s}\right)(1-E) / K_{a s}}
$$

Standard default parameters given in EPA (1991b) were used to calculate this factor.

They are

\begin{tabular}{|c|c|c|}
\hline$L S$ & length of side of contaminated area $(\mathrm{m})$ & Site specific (Table M.1) \\
\hline$V$ & wind speed in mixing zone $(\mathrm{m} / \mathrm{s})$ & $2.25 \mathrm{~m} / \mathrm{s}$ \\
\hline$D H$ & diffusion height $(\mathrm{m})$ & $2 \mathrm{~m}$ \\
\hline $\begin{array}{l}A \\
D_{\rho i}\end{array}$ & $\begin{array}{l}\text { area of contamination }\left(\mathrm{cm}^{2}\right) \\
\text { effective diffusivity }\left(\mathrm{cm}^{2} / \mathrm{s}\right)\end{array}$ & $\begin{array}{l}\text { Site Specific (Table M.1) } \\
D_{i} \times E^{0.33}\end{array}$ \\
\hline$E$ & true soil porosity (unitless) & 0.35 \\
\hline$K_{a s}$ & soil/air partition coefficient (g soil/ $/ \mathrm{cm}^{3}$ air) & $H / K_{d} \times 41$ \\
\hline$p_{s}$ & true soil density $\left(\mathrm{g} / \mathrm{cm}^{3}\right)$ & $2.65 \mathrm{~g} / \mathrm{cm}^{3}$ \\
\hline$T$ & exposure interval (s) & $7.9 \times 10^{8} \mathrm{~s}$ \\
\hline$D_{i}$ & gas diffusivity $\left(\mathrm{cm}^{2} / \mathrm{s}\right)$ & Appendix G \\
\hline $\begin{array}{l}\mathrm{H} \\
\mathrm{K}_{\mathrm{d}}\end{array}$ & $\begin{array}{l}\text { Henry's law constant (atm-m } 3 / \mathrm{mol}) \\
\text { soil water partition coefficient }\left(\mathrm{cm}^{3} / \mathrm{g}\right)\end{array}$ & $\begin{array}{l}\text { Appendix } \mathrm{G} \\
\mathrm{K}_{\mathrm{OC}} \times \mathrm{OC}\end{array}$ \\
\hline $\begin{array}{l}\text { Koc } \\
O C\end{array}$ & $\begin{array}{l}\text { organic carbon partition coefficient }\left(\mathrm{cm}^{3} / \mathrm{g}\right) \\
\text { organic carbon content (fraction) }\end{array}$ & $\begin{array}{l}\text { Appendix G } \\
0.02\end{array}$ \\
\hline
\end{tabular}

Parameter Definition(units) Default

The soil-to-air volatilization factors are listed in Table M.3 


\begin{tabular}{|c|c|c|c|}
\hline \multicolumn{4}{|c|}{$\begin{array}{c}\text { IABLEM.1, SITE SPECIFIC LENGTH AND AREAS FOR } \\
\text { CALUCLATIONS OF VF AND PEF }\end{array}$} \\
\hline \multirow[t]{2}{*}{ Site } & LS & $\bar{A}$ & A \\
\hline & (m) & (cm2) & (m2) \\
\hline ST10/SS14 & 427 & $1.30 E+09$ & $1.30 E+05$ \\
\hline ST11 & 130 & $5.92 E+07$ & $5.92 E+03$ \\
\hline ST13/DP26 & 1097| & $1.51 E+09$ & $1.51 E+05$ \\
\hline ST18 & 101 & $1.07 E+08$ & $1.07 E+04$ \\
\hline ST19 & 457 & $4.18 E+08$ & $4.18 E+04$ \\
\hline \multicolumn{4}{|c|}{$\begin{array}{l}\text { Meteorological data in the Appendix B of the Operable Unit } 2 \\
\text { RI (U.S. Air Force, 1993) indicates that the predominant } \\
\text { wind direction is from the west. Thus, LS was measured along } \\
\text { a north-south axis. }\end{array}$} \\
\hline
\end{tabular}

\section{M.2 RESUSPENSION OF PARTICULATES}

The release of contaminated particulates is calculated as in $\mathrm{C}_{\text {air }}=\mathrm{C}_{\text {Soil }} / \mathrm{PEF}$ where $\mathrm{C}_{\text {air }}$ $\left(\mathrm{mg} / \mathrm{m}^{3}\right)$ and $\mathrm{C}_{\text {soil }}(\mathrm{mg} / \mathrm{kg})$ are respectively air and soil contaminant concentrations. The value for PEF is calculated similarly to EPA (1991b) as :

$$
\operatorname{PEF}\left(\mathrm{m}^{3} / \mathrm{kg}\right)=\frac{\mathrm{LS} \times \mathrm{V} \times \mathrm{DH} \times 3600 \mathrm{~s} / \mathrm{hr}}{\mathrm{A}} \times \frac{1000 \mathrm{~g} / \mathrm{kg}}{0.036 \times(1-\mathrm{G}) \times\left(\mathrm{U}_{\mathrm{m}} / \mathrm{U}_{\mathrm{t}}\right)^{3} \times \mathrm{F}(\mathrm{x})}
$$

Standard default parameters given in EPA (1991b) were used to calculate this factor. They are

\begin{tabular}{|c|c|c|}
\hline Parameter & Definition (units) & Default \\
\hline PEF & particulate emission factor $\left(\mathrm{m}^{3} / \mathrm{kg}\right)$ & $4.63 \times 10^{9} \mathrm{~m}^{3} / \mathrm{kg}$ \\
\hline LS & width of contaminated area $(\mathrm{m})$ & Site specific (Table M.1) \\
\hline V & wind speed in mixing zone (m/s) & $2.25 \mathrm{~m} / \mathrm{s}$ \\
\hline $\mathrm{DH}$ & diffusion height $(\mathrm{m})$ & $2 \mathrm{~m}$ \\
\hline A & area of contamination $\left(\mathrm{m}^{2}\right)$ & Site specific (Table M.1) \\
\hline 0.036 & respirable fraction $\left(g / \mathrm{m}^{2}-\mathrm{hr}\right)$ & $0.036 \mathrm{~g} / \mathrm{m}^{2}-\mathrm{hr}$ \\
\hline & fraction of vegetative cover (unitless) & \\
\hline Um & mean annual wind speed $(\mathrm{m} / \mathrm{s})$ & $4 / 5 \mathrm{~m} / \mathrm{s}$ \\
\hline Ut & $\begin{array}{l}\text { equivalent threshold value of wind speed } \\
\text { at } 10 \mathrm{~m}(\mathrm{~m} / \mathrm{s})\end{array}$ & $12.8 \mathrm{~m} / \mathrm{s}$ \\
\hline$F(x)$ & function dependent on Um/Ut (unitless) & $\begin{array}{c}0.0497 \text { (Cowherd et } \\
\text { al. 1984) }\end{array}$ \\
\hline
\end{tabular}


Ut was calculated using the following equation from Cowherd et al. (1985):

$$
\frac{U_{t}}{U_{*}}=\frac{1}{0.4} \ln \left(z / z_{0}\right)
$$

Where

$\begin{array}{lll}\text { Parameter } & \text { Definition (units) } & \text { Default } \\ U_{*} & \text { Threshold friction velocity }(\mathrm{m} / \mathrm{sec}) & 0.75 \mathrm{~m} / \mathrm{sec} \\ z & \text { Height above surface }(\mathrm{m}) & 10 \mathrm{~m} \\ z_{0} & \text { Roughness height }(\mathrm{m}) & 0.01 \mathrm{~m}\end{array}$

The PEF for each site is listed in Table M.3.

The soil ingestion and particulate inhalation pathways are evaluated (in the risk assessment) for exposure frequencies of 146 and 180 days/year. These exposure frequencies are significantly less than the EPA(1991a) guidance values of 250 and 350 days/year. The discrepancy is caused by the atypical climate of the Fairbanks Alaska region. The average number of days per year without snow cover in this area is 147 days (Battelle 1992). Snow cover would prevent dust generation. Summer rains would further reduce the total number of days per year available for dust generation.

\begin{tabular}{||l|c||}
\hline \multicolumn{2}{|c|}{ TABLEM22. Particulate } \\
\begin{tabular}{|} 
Emission Factors (PEF) for Each \\
Operable Unit 2 Site.
\end{tabular} \\
\hline \hline Site & $\begin{array}{c}\text { PEF } \\
\mathrm{m}^{3} / \mathrm{kg}\end{array}$ \\
\hline ST10/SS14 & $2.35 \mathrm{E}+07$ \\
\hline ST11 & $1.56 \mathrm{E}+08$ \\
\hline ST13/DP26 & $5.22 \mathrm{E}+07$ \\
\hline ST18 & $6.71 \mathrm{E}+07$ \\
\hline ST19 & $7.82 \mathrm{E}+07$ \\
\hline
\end{tabular}

\section{M.3 REFERENCES}

Battelle, 1992. Bemedial Investigation/Feasibility Study -- Operable Units 3, 4. and 5 Management Plan. Eielson Air Force Base. Alaska. Prepared by Battelle, Environmental Management Operations, Richland, Washington. (Final).

Cowherd, C., G.E. Muleski, P.J. Englehart, and D.A. Gillette. 1984. Rapid Assessment of Exposure to Particulate Emissions from Surface Contamination Sites, Final Report EPA Contract 68-030-3116, Project 7972-L, Midwest Research Institute, Kansas City Missouri. 
EPA. 1991a. "Supplemental Guidance for Superfund Risk Assessments in Region 10." U.S. Environmental Protection Agency, Seattle, Washington.

EPA. 1991b. Bisk Assessment Guidance for Superfund: Volume I- Human Health Evaluation Manual (Part B. Development of Risk-Based Preliminary Remediation Goals). U.S. Environmental Protection Agency, Office of Emergency and Remedial Response. (Interim Final).

Hwang , S.T., and J.W. Falco. 1986. "Estimation of Multimedia Exposures Related to Hazardous Waste Facilities." In Pollutants in a Multimedia Environment, pp. 229-264. Plenum Publishing Corporation, New York.

U.S. Air Force. 1993. Eielson Air Force Base OU-2 Remedial Investigation/Feasibility Study: Remedial Investigation Report Prepared by Battelle, Environmental Management Operations, Richland, Washington (Final Draft). 
IABLEM.3, Soil-to-Air Volatilization Factors Used in Risk Assessements

\begin{tabular}{|c|c|c|}
\hline ANALYTES & CAS & $\begin{array}{c}\text { Soll-to-Air } \\
\text { Volatllization Factor } \\
(\mathrm{m} 3 / \mathrm{kg})\end{array}$ \\
\hline \multicolumn{3}{|l|}{ VOLATILES } \\
\hline 1,1,1-TRICHLOROETHANE & 71556 & $1.22 E+03$ \\
\hline 1,1,2,2-TETRACHLOROETHANE & 79345 & $4.10 E+03$ \\
\hline 1,1,2-TRICHLOROETHANE & 79005 & $2.42 E+03$ \\
\hline 1,1-DICHLOROETHANE & 75343 & $4.69 E+02$ \\
\hline 1,1-DICHLOROETHENE & 75354 & $6.62 E+01$ \\
\hline 1,2-DICHLOROETHANE & 107062 & $7.82 E+02$ \\
\hline 1,2-DICHLOROETHENE (TOTAL) & 156605 & $9.09 E+00$ \\
\hline 1,2-DICHLOROPROPANE & 78875 & $9.59 E+02$ \\
\hline 2-BUTANONE & 78933 & $1.09 E+03$ \\
\hline 2-HEXANONE & 591786 & $6.64 E+03$ \\
\hline ACETONE & 67641 & $6.47 E+02$ \\
\hline BENEENE & 71432 & $6.43 E+02$ \\
\hline BROMODICHLOROMETHANE & 75274 & $1.45 E+03$ \\
\hline BROMOMETHANE & 74839 & $2.53 E+01$ \\
\hline CARBONDISULFIDE & 75150 & $3.69 E+02$ \\
\hline CARBON TETRACHLORIDE & 56235 & $5.93 E+02$ \\
\hline CHLOROBENEENE & 108907 & $1.99 E+03$ \\
\hline CHLOROETHANE & 75003 & $1.55 E+02$ \\
\hline CHLOROFORM & 67663 & $8.41 E+02$ \\
\hline CHLOROMETHANE & 74873 & $3.07 E+01$ \\
\hline CIS-1,3-DICHLOROPROPENE & 542756 & $1.28 E+03$ \\
\hline ETHMBENZENE & 100414 & $2.13 E+03$ \\
\hline METHMENE CHLORIDE & 75092 & $4.19 E+02$ \\
\hline STYRENE & 100425 & $1.97 E+03$ \\
\hline TETRACHLOROETHENE & 127184 & $6.24 E+02$ \\
\hline TOLUENE & 108883 & $1.27 E+03$ \\
\hline TRANS-1,3-DICHLOROPROPENE & 10061026 & $1.28 E+03$ \\
\hline TRICHLOROETHENE & 79016 & $7.75 E+02$ \\
\hline VINYL ACETATE & 108054 & $3.74 E+02$ \\
\hline VINYL CHLORIDE & 75014 & $4.39 E+01$ \\
\hline XYLENES (TOTAL) & 1330207 & $2.32 E+03$ \\
\hline \multicolumn{3}{|l|}{ SEMI-VOLATILES } \\
\hline 1,2,4-TRICHLOROBENZENE & 120821 & $1.53 E+04$ \\
\hline 1,2-DICHLOROBENZENE & 95501 & $7.12 E+03$ \\
\hline 1,3-DICHLOROBENZENE & 541731 & $6.08 E+03$ \\
\hline 1,4-DICHLOROBENVENE & 106467 & $5.80 E+03$ \\
\hline 2,4,5-TRICHLOROPHENOL & 95954 & $2.61 E+04$ \\
\hline 2,4,6-TRICHLOROPHENOL & 88062 & $2.29 E+05$ \\
\hline 2,4-DIMETHYLPHENOL & 105679 & $2.83 E+04$ \\
\hline 2,4-DINITROTOLUENE & 121142 & $2.33 E+04$ \\
\hline 2-CHLORONAPHTHALENE & 91578 & $2.18 E+04$ \\
\hline
\end{tabular}


TABLEM.3. Soil-to-Air Volatilization Factors Used in Risk Assessements

\begin{tabular}{lrr}
\multicolumn{1}{c}{ ANALYTES } & \multicolumn{1}{c}{ CAS } & $\begin{array}{c}\text { Soll-to-Air } \\
\text { Volatilization Factor } \\
\text { (m 3/kg) }\end{array}$ \\
\hline 2-CHLOROPHENOL & 95578 & $1.86 \mathrm{E}+04$ \\
2-METHYLNAPHTHALENE & 91576 & $2.37 \mathrm{E}+04$ \\
4-METHYLPHENOL & 106445 & $8.16 \mathrm{E}+03$ \\
4NITROPHENOL & 100027 & $2.56 \mathrm{E}+03$ \\
ACENAPHTHENE & 83329 & $3.22 \mathrm{E}+04$ \\
ACENAPHTHYLENE & 208968 & $3.31 \mathrm{E}+04$ \\
ANTHRACENE & 120127 & $2.00 \mathrm{E}+05$ \\
BIS(2-CHLOROETHYL)ETHER & 111444 & $7.66 \mathrm{E}+03$ \\
BIS(2-CHLOROISOPROPYL)ETHER & 39638329 & $5.42 \mathrm{E}+03$ \\
FLORENE & 86737 & $5.93 \mathrm{E}+04$ \\
ISOPHORONE & 78591 & $2.68 \mathrm{E}+04$ \\
N-NITROSO-DI-N-PROPYLAMINE & 621647 & $1.09 \mathrm{E}+04$ \\
N-NITROSODIPHENYLAMINE (1) & 86306 & $7.62 \mathrm{E}+03$ \\
NAPHTHALENE & 91203 & $7.34 \mathrm{E}+03$ \\
NITROBENUENE & 98953 & $8.13 \mathrm{E}+03$ \\
PHENANTHRENE & 85018 & $1.84 \mathrm{E}+05$ \\
TPH & & \\
TOTAL PETROLEUM HYDROCARBONS (1) & & $3.46 \mathrm{E}+03$
\end{tabular}


PNL-8752

UC-602

\section{DISTRIBUTION}

No. of

Copies

\section{OFFSITE}

12 DOE/Office of Scientific and Technical Information

\section{ONSITE}

\section{Pacific Northwest Laboratory}

J.G. Droppo

J.S. Fruchter

T.J Gilmore

P.M. Irving

M.R. Jarvis

T.T. Jarvis

G.V. Last

R.E. Lewis (5)

T.L. Liikala

P.E. Long

A.D. Maughan

M.T. Murphy

R.M. Smith

G. Whelan

P.J. White

Publishing Coordination

Technical Report Files (5)

\section{Routing}

R.M. Ecker

M.J. Graham

P.M. Irving

S.A. Rawson

P.C. Hays (last)

Distr. 1 